San Jose State University

SJSU ScholarWorks

Master's Theses

Master's Theses and Graduate Research

1997

\title{
Evaluation of petroleum fuel attenuation rates in the western Santa Clara Valley Ground Water Basin
}

Peter Mark Langtry

San Jose State University

Follow this and additional works at: https://scholarworks.sjsu.edu/etd_theses

\section{Recommended Citation}

Langtry, Peter Mark, "Evaluation of petroleum fuel attenuation rates in the western Santa Clara Valley Ground Water Basin" (1997). Master's Theses. 1508.

DOI: https://doi.org/10.31979/etd.muz2-f9c8

https://scholarworks.sjsu.edu/etd_theses/1508

This Thesis is brought to you for free and open access by the Master's Theses and Graduate Research at SJSU ScholarWorks. It has been accepted for inclusion in Master's Theses by an authorized administrator of SJSU ScholarWorks. For more information, please contact scholarworks@sjsu.edu. 


\section{INFORMATION TO USERS}

This manuscript has been reproduced from the microfilm master. UMI films the text directly from the original or copy submitted. Thus, some thesis and dissertation copies are in typewriter face, while others may be from any type of computer printer.

The quality of this reproduction is dependent upon the quality of the copy submitted. Broken or indistinct print, colored or poor quality illustrations and photographs, print bleedthrough, substandard margins, and improper alignment can adversely affect reproduction.

In the unlikely event that the author did not send UMI a complete manuscript and there are missing pages, these will be noted. Also, if unauthorized copyright material had to be removed, a note will indicate the deletion.

Oversize materials (e.g., maps, drawings, charts) are reproduced by sectioning the original, beginning at the upper left-hand corner and continuing from left to right in equal sections with small overlaps. Each original is also photographed in one exposure and is included in reduced form at the back of the book.

Photographs included in the original manuscript have been reproduced xerographically in this copy. Higher quality 6" $x$ 9" black and white photographic prints are available for any photographs or illustrations appearing in this copy for an additional charge. Contact UMI directly to order.

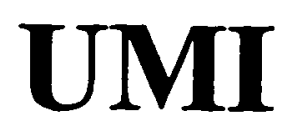

A Bell \& Howell Information Company 300 North Zeeb Road, Ann Arbor MI 48106-1346 USA 

Evaluation of Petroleum Fuel Attenuation Rates in the Western Santa Clara Valley Ground Water Basin

\author{
A Thesis \\ Presented to the Department of Geology \\ San Jose State University \\ In Parrial Fulfillment \\ of the Requirements for the Degree \\ Master of Science
}

by

Peter Mark Langtry

August, 1997 
OMI Number: 1386209

\title{
UMI Microform 1386209
}

Copyright 1997, by UMI Company. All rights reserved.

This microform edition is protected against unauthorized copying under Title 17, United States Code.

\author{
UMI \\ 300 North Zeeb Road \\ Ann Arbor, MI 48103
}


(C) 1997

Peter Mark Langtry

ALL RIGHTS RESERVED 
APPROVED FOR THE DEPARTMENT OF GEOLOGY

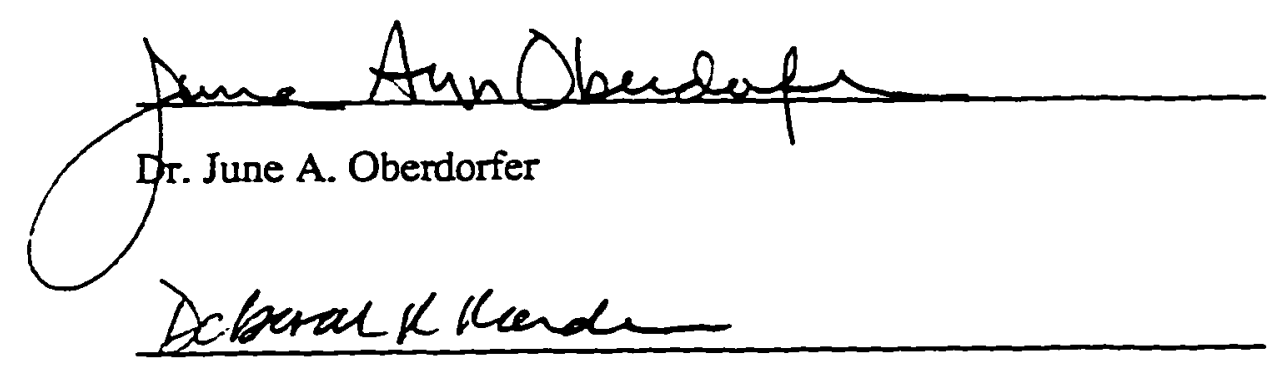

Dr. Deborah R. Harden

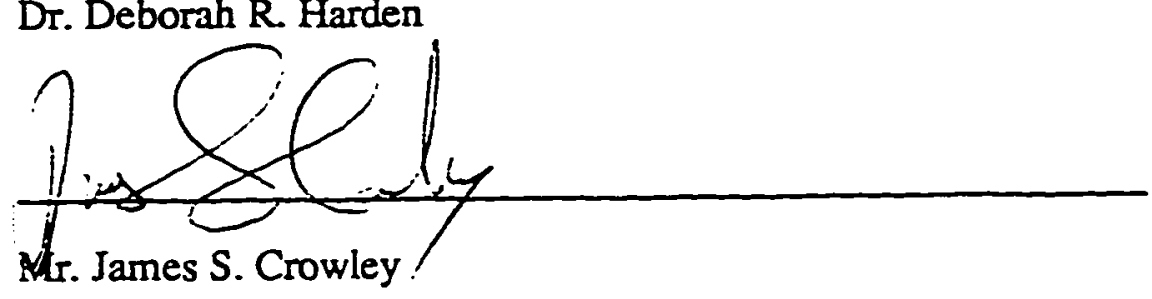

APPROVED FOR THE UNIVERSITY

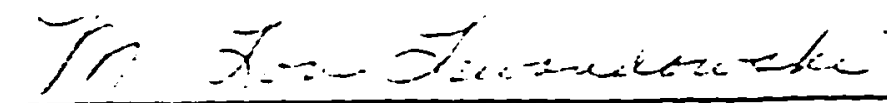




\section{ABSTRACT \\ EVALUATION OF PETROLEUM FUEL ATTENUATION RATES IN THE WESTERN SANTA CLARA VALLEY GROUND WATER BASIN \\ by Peter Mark Langtry}

Reported fuel leak cases were reviewed at the Santa Clara Valley Water District to evaluate the attenuation of petroleum fuels dissolved in ground water in the approximate western half of the Santa Clara Valley ground water basin. Sites with wells that met the criteria of decreasing concentrations of gasoline range petroleum hydrocarbons, including benzene, were included in this study.

The attenuation rate constants for gasoline range hydrocarbons and benzene were found to have a mean of $-0.002 /$ day and fell within a relatively narrow range, indicating that similar attenuation processes are occurring throughout the study area. Sites with attenuation rate constants above the mean were found to be more likely to follow first order degradation, while sites with attenuation rate constants less than the mean were less likely to follow first order degradation. The attenuation rate constants do not appear to be influenced significantly by environmental conditions or site history factors. 


\section{ACKNOWLEDGMENTS}

I would like to thank my thesis advisors, especially Dr. June Oberdorfer, not only for her exceptional instruction in hydrogeology but also for her patience with my slow (glacial) thesis pace. I also thank the staff of the Santa Clara Valley Water District for assistance with my file review efforts and letting me intrude on their already crowded offices. I also thank my family for always supporting me. Finally, I thank my employer, Lowney Associates, for giving me time from work to spend on courses and research. 
TABLE OF CONTENTS

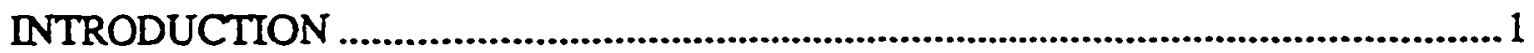

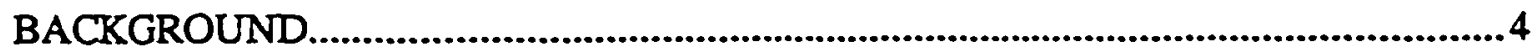

Fate of Petroleum Fuel Contaminants in Ground Water........................................4

Characteristics of the Santa Clara Valley Ground Water Basin ..............................9

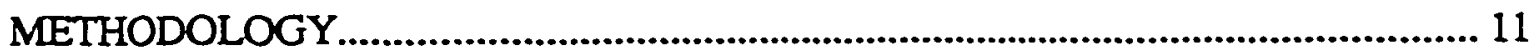

Selection of Study Area .................................................................................. 11

Selection of Target Petroleum Hydrocarbon Contaminants.................................. 11

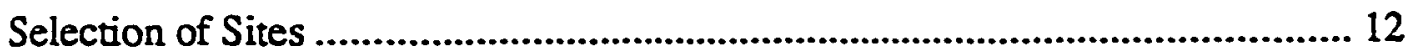

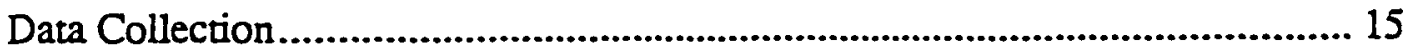

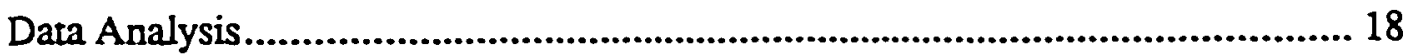

Statistical Evaluation............................................................................................ 20

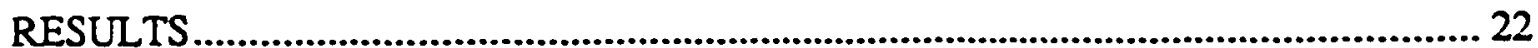

Descriptive Summary of TPH as Gasoline and Benzene Attenuation Rate

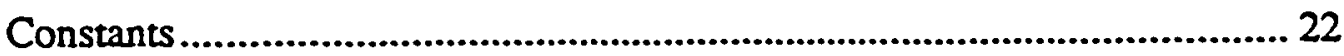

Descriptive Summary of TPH as Gasoline and Benzene Coefficients of

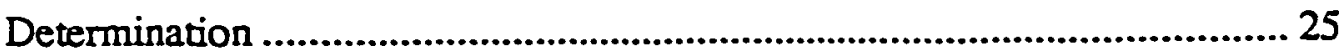

Statistical Analysis of Attenuation Rate Constant and Coefficient of

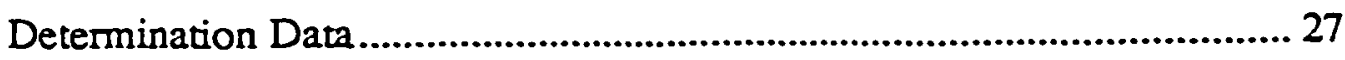


Tests for Normal (Gaussian) Distribution of Attenuation Rate

Constant Data.

Testing for Normal (Gaussian) Distribution of Coefficient of

Determination Data

F-Tests to Compare Benzene Attenuation Rate Constant

Distributions for Confined and Unconfined Conditions. 36

Evaluation of Benzene Attenuation Rate Constant Data Grouped by

Soil Type. 37

Evaluation of Benzene Attenuation Rate Constant Data Grouped by Remedial Activities............................................................................. 40

Attenuation Rate Constants as Function of Parameters....................................... 43

Relationship of Attenuation Rate Constant to Coefficient of Determination $\left(\mathrm{r}^{2}\right)$ 43

Relationship of Attenuation Rates to Ground Water Depth Range and Distance from Source. 44

Effect of Ground Water Elevations on Attenuation Rate Constants and Coefficient of Determination 44

Spatial Distribution of Atrenuation Rate Constant for Benzene 49

DISCUSSION. 50

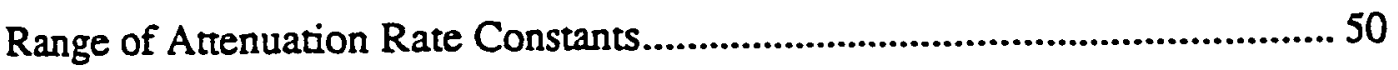

Predicted Behavior of Benzene Attenuation Duration......................................... 50

Relationship of Attenuation Rate Constants to Coefficients of

Determination 52 
Degradation Rate Constants as a Function of Aquifer Conditions and Soil

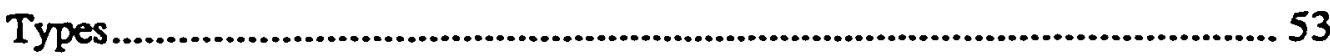

Degradation Rate Constants as a Function of Remedial Activities...................... 54

Degradation Rate Constants as a Function of Ground Water Elevation

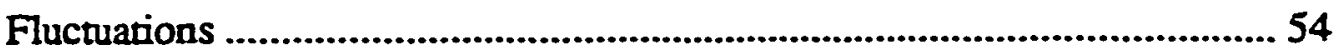

Spatial Distribution of Attenuation Rate Constants............................................. 55

Comparison of Results to Previous Studies ......................................................... 55

Ground Water Gradient ..................................................................................... 56

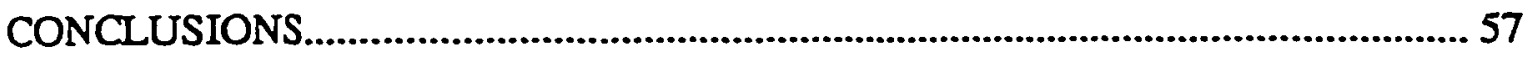

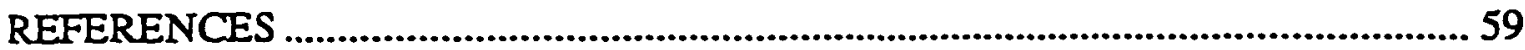

Appendix a. Examples of data collection forms ............................................................... 61

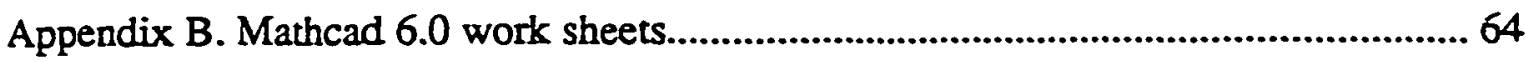

Appendix C. Summary of Site parameters................................................................. 235 


\section{LIST OF ILLUSTRATIONS}

Figure 1. Map of the Santa Clara Valley ground water basin showing study area.......... 2

Figure 2. Hypothetical change in average concentration of dissolved petroleum fuel

hydrocarbons during the life of a plume.......................................................... 8

Figure 3. Flow chart of file review process, western area ....................................... 16

Figure 4. Flow chart of file review process, northeastem area .................................... 17

Figure 5. Histograms of attenuation rate constants, confined and unconfined

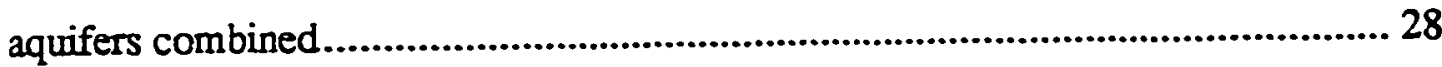

Figure 6. Histograms of attenuation rate constants, confined aquifers.......................... 29

Figure 7. Histograms of attenuation rate constants, unconfined aquifers....................... 30

Figure 8. Histograms of coefficients of determination, confined and unconfined

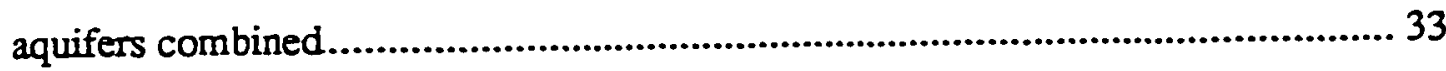

Figure 9. Histograms of coefficients of determination, confined aquifers ...................... 34

Figure 10. Histograms of coefficients of determination, unconfined aquifers................. 35

Figure 11. TPH as gasoline attenuation rate constant versus coefficient of

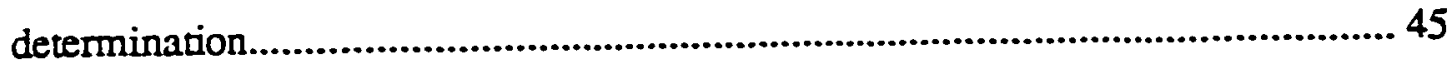

Figure 12. Benzene attenuation rate constant versus coefficient of determination ......... 45

Figure 13. TPH as gasoline attenuation rate constant versus ground water depth

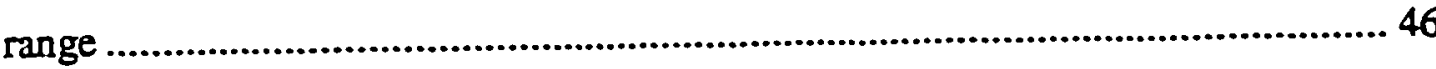

Figure 14. Benzene attenuation rate constant versus ground water depth range............ 46 
Figure 15. TPH as gasoline attenuation rate constant versus distance from source ....... 47

Figure 16. Benzene attenuation rate constant versus distance from source ................... 47

Figure 17. Time required for benzene to decrease from an initial concentration to

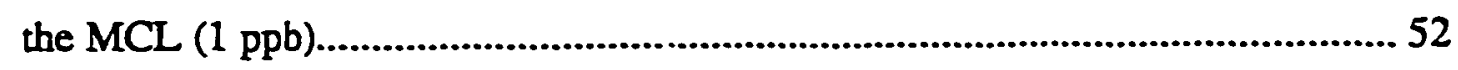




\section{LIST OF TABLES}

Table 1. Summary of fuel leak sites eliminated from study ........................................ 14

Table 2. Summary of numeric and descriptive information gathered............................ 18

Table 3. Summary of attenuation rate constant results by site................................... 23

Table 4. Summary of attenuation rate constant results by well..................................... 24

Table 5. Summary of coefficient of determination of TPH as gasoline and benzene ...... 26

Table 6. Summary of coefficient of determination of TPH as gasoline and benzene ...... 26

Table 7. Results of $\chi^{2}$ tests for normal distribution of attenuation rate constants .......... 32

Table 8. Results of $\chi^{2}$ tests for normal distribution of coefficient of determination........ 36

Table 9. Results of F-tests for confined versus unconfined aquifer.............................. 37

Table 10. Summary of benzene attenuation rate constants between aquifer soil type

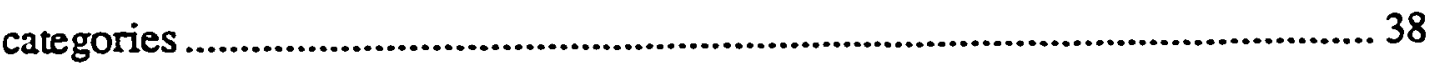

Table 11. Results of F-tests for aquifer soil type categories...................................... 39

Table 12. Summary of TPH as gasoline attenuation rate constants categorized by remedial activity...................................................................................... 40

Table 13. Summary of benzene attenuation rates categorized by remedial activity ........ 41

Table 14. Summary of benzene attenuation rate constants between remedial method categories...................................................................................... 41

Table 15. Results of F-tests for remedial method categories.................................... 42 
Table 16. Summary of sites with relationships between ground water elevation and TPH as gasoline and benzene concentration .......................................................... 48

Table 17. Summary of sites showing increase or decrease in degradation rate constant with distance from source 49 


\section{INTRODUCTION}

Many regions of the United States rely upon ground water to supply water for domestic, agricultural, and industrial uses. This reliance upon ground water has focused attention on the quality of ground water resources, with particular emphasis upon protection of human health. The Santa Clara Valley has historically relied heavily upon ground water. Potential impacts to the quality of ground water in the Santa Clara Valley include salt water intrusion, leakage of chemicals from underground storage tanks (USTs), leaching of wastes from septic systems, migration of leachates from landfills, and leaching of residual pesticides in surficial soils. The extent of the Santa Clara Valley ground water basin is shown on Figure 1.

Over 1,000 sites in the Santa Clara Valley with reported leaking USTs have impacted ground water. The majority of the leaking USTs contained gasoline or diesel. The impacts to ground water are commonly limited to uppermost ground water bearing zones (generally shallow) beneath the fuel leak sites. Shallow ground water in the Santa Clara Valley ranges in depth from approximately 5 feet near the San Francisco Bay to 100 feet or greater in the higher elevations of the valley. Relatively few reported cases of petroleum fuel hydrocarbons have impacted domestic or agricultural wells. The majority of these wells generally draw water from deeper aquifers greater than 100 feet below the surface.

The objective of this thesis is to study the degradaion of petroleum hydrocarbons in ground water at petroleum fuel leak sites in selected areas of the Santa Clara Valley ground water basin to: 1) determine the observed degradation rates of total petroleum 


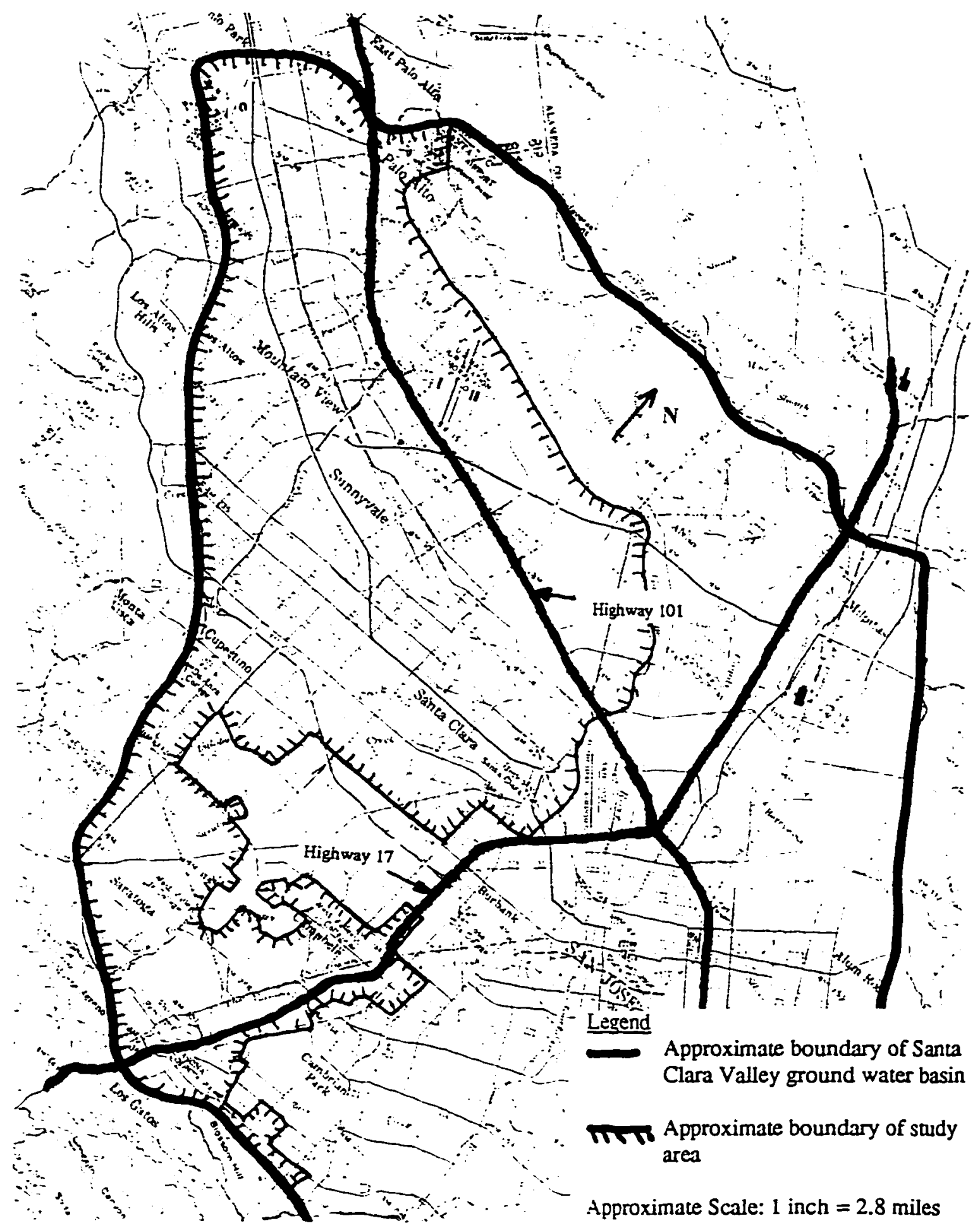

Figure 1. Map of Santa Clara Valley ground water basin showing approximate boundary of study area. 
hydrocarbons (TPH) as gasoline and benzene in the study area, and 2) evaluate whether hydrogeologic and site history factors can be identified that affect the degradation rates. 


\section{BACKGROLND}

\section{Fare of Perroleum Fuel Contaminants in Ground Warer}

Concentrations of dissolved pecroleum hydrocarbons in ground water decrease by natural attenuation mechanisms that involve chemical, physical, and biological processes. Chemical processes include hydrolysis and other chemical reactions, but are not significant with perroleum fuel compounds (McAllister and Chiang, 1994). Physical processes include volatilizarion, sorption, and dispersion. Dispersion is the physical mixing and dilucion of a solute as it travels through a porous medium, and will result in an apparent attenuation of contaminants over time. Volatilization is the process by which dissolved contaminants volatilize from ground water into soil gas of the vadose zone. The sorption of organic compounds onto aquifer soils depends.on the octanol-water partitioning coefficient of the compounds and the organic content of the soils. The physical processes do not reduce the overall mass of the contaminants, although volatilization does result in removal of some contaminants from the ground water. In contrast, degradation does reduce the mass of organic contaminants as a result of biologically mediated and abiotic oxidacion. The generalized metabolism of a petroleum hydrocarbon of the empirical formula $\mathrm{C}_{x} \mathrm{H}_{\mathrm{y}}$ in the presence of oxygen can be represented by:

$$
\mathrm{C}_{\mathrm{x}} \mathrm{H}_{1}+\mathrm{O}_{2} \Rightarrow \mathrm{CO}_{2}+\mathrm{H}_{2} \mathrm{O}
$$

In addition, organic compounds can be urilized as a carbon source under anaerobic condicions, with the electon donor being nirate, nirite, sulfate, or carbon in the organic 
molecule itself. The generalized metabolism of a petroleum hydrocarbon of the empirical formula $\mathrm{C}_{x} \mathrm{H}_{y}$ in the presence of nitrate can be represented by:

$$
\mathrm{C}_{\mathbf{x}} \mathrm{H}_{\mathbf{y}}+\mathrm{NO}_{3}^{-}+\mathrm{H}^{+}=\mathrm{CO}_{2}+\mathrm{N}_{2}+\mathrm{H}_{2} \mathrm{O}
$$

The natural biodegradation of petroleum hydrocarbons in ground water has received considerable attention in the last several years. A study performed by Hadley and Armstrong (1991) concluded that biodegradation of benzene in the ground water was the likely reason for the near absence of benzene in drinking water supply wells in Califomia. In addition, Davis et al. (1994), Klecka et al. (1990), and Hutchins et al. (1991) have performed studies which indicated the imporance of biological processes on the attenuation of petroleum hydrocarbons in ground water.

The study performed by Davis et al. (1994) focused on ground water impacted with benzene. Based on analyses of ground water samples, laboratory biodegradation tests, and computer modeling, the study concluded that aerobic biodegradation was the primary mechanism for the attenuation of benzene beneath the study site. The aquifer beneath the study site was reported to be unconfined and composed primarily of silty sand. The average rate of benzene loss measured in the laboratory was calculated to be 6.7 $\mu \mathrm{g} /$ day and $13 \mu \mathrm{g} /$ day at initial concentrations of $1 \mathrm{mg} / \mathrm{kg}$ and $10 \mathrm{mg} / \mathrm{kg}$, respectively.

A study of natural biodegradation at the Cliffs-Dow superfund site in Michigan was performed by Klecka et al. (1990). The study demonstrated the occurrence of aerobic biodegradation of phenolic and polycyclic aromatic compounds in an unconfined shallow aquifer. Although observed degradation rates of the compounds based on field analycical data were not discussed, laboratory studies indicated that the degradation of the organic compounds was first order. The aerobic biodegradation laboratory microcosms 
reportedly resulted in the mineralization of 60 to 70 percent of the initial mass of the organic substrate after 4 weeks of incubation; the actual rates were not reported.

The study performed by Hutchins et al. (1991) focused on the effects of nitrate addition to ground water contaminated with jet fuel (JP-4). Ground water at the study site was present within a sandy, shallow, unconfined aquifer. The study indicated that aerobic biodegradation and denitrification were the primary factors in observed reductions of petroleum fuels at the study site. Benzene was found to be degraded quickly under aerobic conditions at the site. Toluene, ethylbenzene, and xylene degradation was found to be enhanced under anaerobic, denitrifying conditions.

Most types of petroleum hydrocarbons are biodegradable, including aliphatic, olefinic, and aromatic compounds. However, some types of high molecular weight asphaltines may degrade very slowly (Borden and Bedient, 1986a and 1986b). Limiting factors for the rate of natural biodegradation include the diffusion rate of atmospheric oxygen into the unsaturated soil zone and into the ground water, the availability of necessary inorganic numrients, and the presence of bacterial species that can metabolize the petroleum hydrocarbon contaminants. Inorganic nutrients required for microbial activity include nitrogen, phosphorus, sulfur, and iron.

Buscheck et al. (1993) predicted the first order attenuation rate of petroleum hydrocarbons at several fuel leak sites using ground water quality monitoring data. By assuming a first order degradation rate for a hydrocarbon contaminant, the change in concentration $(C)$ with time can be represented by:

$$
\mathrm{dC} / \mathrm{dt}=\mathrm{kC}
$$


$\mathrm{k}$ is the first order degradation rate constant $\left(\mathrm{T}^{-1}\right)$.

The solution to the above equation can further be represented by the exponential expression:

$$
C(t)=C_{0} e^{k t}
$$

where: $C(t)$ is the concentration as a function of time $t$

$C_{o}$ is the concentration at $t=0$.

The ground water quality data used in the decay rate calculation was obtained from one or more monitoring wells located within a shrinking soluble plume. Busheck et al. (1993) noted that first order decay is appropriate for low concentrations (less than 1 part per million $\{\mathrm{ppm}\}$ ) of dissolved petroleum hydrocarbons.

A study of fuel leak sites in California with petroleum fuel impacted ground water was performed by Rice et al. (1995) to evaluate trends in both plume lengths and dissolved fuel concentrations. The study identified four stages in the life of a plume of dissolved petroleum fuel, shown on Figure 2. The first stage occurs soon after the petroleum fuels reach the ground water and is characterized by increasing concentrations. During the second stage, the petroleum fuel concentrations are relatively stable. The first and second stages were termed the "active source period," because there is a source of fuel, such as free product or fuel absorbed onto soil particles, that continues to contribute to the dissolved fuel concentrations. When the source is no longer present as a result of remediation and/or natural attenuation, the plume enters the third stage, when the 
Source present
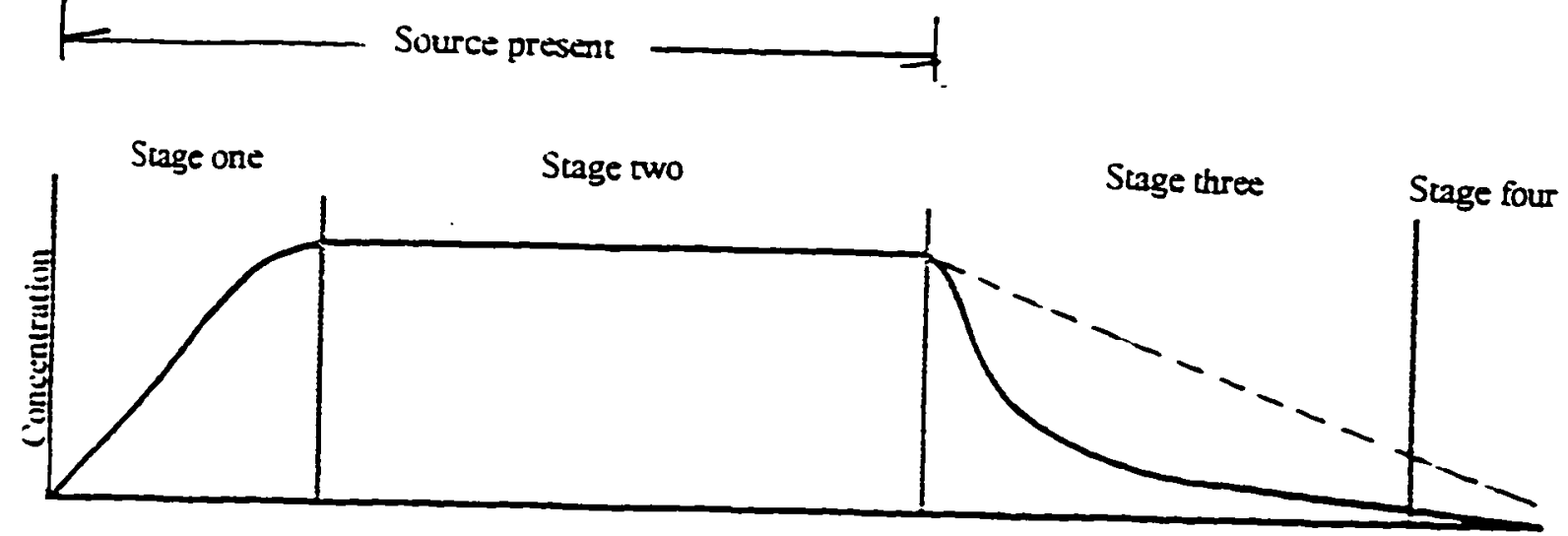

Time

Figure 2. Hypothetical change in average concentration of dissolved petroleum fuel hydrocarbons during the life of a plume (after Rice et al., 1995). The theoretical linear decay as a result of dispersion only is shown as a dashed line.

concentrations begin to decrease logarithmically. Eventually, the plume enters the fourth stage, which Rice et al. termed the "exhausted plume" phase. This stage was generally characterized by low average benzene concentrarions. Of 271 sites in California that met their study criteria (well characterized plumes and sire condirions), 8 percent were in the first stage, 16 percent were in the second stage, 59 percent were in the third stage, and 17 percent were in the fourch stage of concentration trends.

The study by Rice et al. (1995) found that sites wich significant negative trends in concentration showed a range of attenuation rates. The calculated site average artenuation rate constants ranged from a 90 percentile of $-0.002 /$ day ( 90 percent of values less than $-0.002 / \mathrm{day}$ ) to a 10 percentile of -0.000 tiday (:0 percent of values less than - 
$0.0004 /$ day), with a median of $-0.0008 /$ day. Since the concentration trends were loglinear, the inverse of the attenuation rates were interpreted as the amount of ime required for a decrease in concentration to 10 percent of the original value. These times ranged from approximately 500 to 2,500 days (approximately 1.5 to 7 years) with a median of 1,175 days (approximately 3.2 years). The study concluded that the benzene attenuation rate constants were not normally distributed.

Decreases in concentration as a result of dispersion during transportation would likely be linear, as opposed to the logarithmic decay of biodegradation. The theoretical decrease in concentration as a result of dispersion only is shown on Figure 2. Since the contribution of the various attenuation processes may vary from one location to another, the observed attenuation can theoretically range from linear to logarithmic, with the behavior approaching logarithmic as biological processes become more prominent

\section{Characteristics of the Santa Clara Valley Ground Water Basin}

The aquifers in Santa Clara Valley that are used for drinking water sources are generally present at depths of at least 100 feet. These aquifers have been generally grouped into two areas:

- Forebay areas at the perimeter of the ground water basin, where aquifers are primarily unconfined and consist of alluvial fan and alluvial deposits, and

- Confined ground water zone of the valley consisting of fine and course alluvium interbedded with deposits of the San Francisco Bay (State of California Department of Water Resources, 1967). 
The shallow, uppermost ground water bearing zones that are most likely to be impacted with petroleum fuels are present at depths of up to approximately 100 feet near the perimeter of the valley (forebay areas) and are as shallow as 5 feet near the San Francisco Bay. These shallow water bearing zones in the northern confined zone are typically heterogeneous and are generally less than approximately 25 feet thick. Due to the low transmissivities and narurally poor ground water quality, these shallow ground water bearing zones are not currently used as a drinking water source. The shallow ground water bearing zones are generally unconfined in the forebay area and confined closer to the bay, as discussed above. However, due to heterogeneities in the shallow sediments, this relarionship is not as consistent as it is for the deeper aquifers. 


\section{METHODOLOGY}

\section{Selecrion of Studv Area}

The study focused on reported fuel leaks in the ciries of Campbell, Cupertino, Los Altos, Los Gatos, Mountain View, Palo Alto, Santa Clara, Saratoga, and Sunnyvale, which occupy the western portion of the Santa Clara Valley ground warer basin (Figure 1). The srudy area was selected to provide a representative sample of the Santa Clara Valley ground water basin, from the forebay near the base of the foothills to the confined area of the basin closer to the San Francisco Bay.

\section{Selection of Target Petroleum Hydrocarbon Contaminants}

This study focused on TPH as gasoline and benzene. Most studies have focused on benzene rather than TPH as gasoline for two primary reasons: 1) benzene is a known carcinogen and therefore poses a significant threat to human health; and 2) laboratory analysis for TPH as gasoline is non-specific and includes peroleum hydrocarbons generally ranging from $C-6$ to $C-18$ chain compounds. The TPH as gasoline analysis also includes benzene. The original composition of the petroleum fuel will vary, depending on the year produced and the manufacturer. When released into the environment, the fuels undergo modification as a result of natural attenuation, and the residual fuel composition will be dependent on the age of the release, remedial activicies, and narural processes specific to a particular site. As a result of the variability in the composition of the source of the TPH as gasoline, the behavior of TPH as gasoline is more prone to variability benween sites than is the behavior of benzene. However, TPH as gasoline was included in 
this study since it has generally not been evaluated in previous studies and monitoring data is readily available.

\section{Selection of Sites}

This study focused on sites where dissolved hydrocarbon concentrations are decreasing, or in the third phase of the life of a plume as described by Rice et al. (1995). Fuel leak cases within the srudy area on-file at the SCVWD were the source of the chemical concentration and hydrogeologic data. Cases were eliminated from review if dissolved petroleum fuels displayed increasing, stable, or low concentrations (exhausted plumes). Therefore, the initial step was essentially a sorting process to extract the sites with decreasing concentrations. The reason for a site being eliminated from review was recorded, but it was not the intent of this study to analyze the entire population of fuel leak sites in the study area, only those which showed decreasing concentrations to evaluate causes of natural attenuation.

For fuel leak files reviewed, each file was initially screened to evaluate whether it met the following criteria:

- There were at least four sampling events spanning at least one-year in one or more monitoring wells located within a dissolved petroleum fuel plume down-gradient of the former source area.

- There were soil boring logs available to evaluate soil conditions and hydrogeologic conditions at the site. 
- The ground water flow direction beneath the site remained relatively stable. Occasional or seasonal excursions from the predominant ground water flow direction were allowed.

The selection of sites for review was revised part way into the research process. Initially, a database list of the SCVWD sites with ground water impact was compiled. This list consisted of the SCVWD case type "O" sites, which are defined as "other ground water, any other actual or potential use other than drinking water or no beneficial use" (SCVWD, 1995). All fuel leak sites with impacted ground water are listed as "O" case types. Fuel leak cases listed on the database printout in the cities of Campbell, Cupertino, Los Altos, Los Altos Hills, Los Gatos, Mountain View, and Palo Alto were reviewed (total of 173 cases listed on database printout).

Some cases without ground water impact are listed as the "O" case types that were included in the initial database printout. To help reduce research time, a new list was created with the help of Jim Crowley of the SCVWD that listed the initial and current ground water concentrations of TPH. This capability was not available when the research began since the SCVWD had not yet completed expanding their database to include TPH concentrations. For the cities of Santa Clara and Sunnyvale (total of 160 reported fuel leak cases impacting ground water), sites were able to be screened based on the initial and current TPH concentrations. Sites that showed an increase in concentration and those that showed stable concentrations between the initial and current levels were not reviewed. In addition, sites where low concentrations (less than $500 \mu \mathrm{g} / \mathrm{TPH}$ ) were initially detected or where there was no ground water impact were also not reviewed. The selection of the $500 \mu \mathrm{g} / \mathrm{l}$ threshold was based on the results of the first phase of file reviews; sites where 
initial concentrations were less than $500 \mu \mathrm{g} /$ generally did not have sufficient data or meet the selection criteria.

Many files were not available for review at the time of the research visits to the SCVWD file room. Reasons for this included files being checked out by the case managers and the managers not being present, files being sent out to be placed on microfiche, files checked out for update of the SCVWD database, and other reasons. Since the presence or absence of files was a random event, the missing files are not anticipated to have a significant impact on the overall data set.

Flow charts for the two phases of file review, based on the two database lists, are presented in Figures 3 and 4. A breakdown of the sites reviewed and eliminated is presented below in Table 1.

Table 1. Summary of fuel leak sites eliminated from the study.

\section{Campbell, Cupertino, Los Altos, Los Gatos, Mountain View, Palo Alto}

Less than 4 consecutive monitoring events with decreasing

TPH concentrations

No impacted down-gradient wells

Ground water flow direction highly variable

Free product present in down-gradient well

Stable or increasing concentrations

No significant impact down-gradient of source (initial concentration

less than $500 \mathrm{ppb}$ TPH, sporadic detections of TPH) or no ground water data (soil only)

Outside of ground water basin (foothills)

Suspect data (poor report quality, incomplete reporting, well screen intervals suspect, up-gradient source possibly contributing to TPH concentrations detected down-gradient of source)

Non-fuels reported in TPH analysis

Files not available to be located for review 
Table 1. (continued) Summary of fuel leak sites eliminated from study

\section{Santa Clara, Sunnyvale}

\section{Sites Eliminated after Initial Screening}

Increasing or stable concentrations

No ground water impact or initial concentrations less than $500 \mathrm{ppb}$ TPH

\section{Sites Eliminated after Review}

Less than 4 consecutive monitoring events with decreasing

TPH concentrations

No impacted down-gradient wells

Ground water flow direction highly variable

Free product present in down-gradient well 2

Stable or increasing concentrations 6

No significant impact down-gradient of source (initial concentration 11

less than $500 \mathrm{ppb}$ TPH, sporadic detections of TPH) or no ground water data (soil only)

Suspect data (poor report quality, incomplete reporting, well screen

intervals suspect, up-gradient source possibly contributing to

TPH concentrations detected down-gradient of source)

Files nor able to be located for review

\section{Data Collection}

Files that met the above criteria were then reviewed in further detail to gather data on ground water quality and hydrogeologic conditions. The data were gathered for each well at a site that met the selection criteria. Boring logs were reviewed to assess whether the site is under confined or unconfined conditions, and to record the aquifer materials. The aquifer materials were categorized using the United Soil Classification System. A 


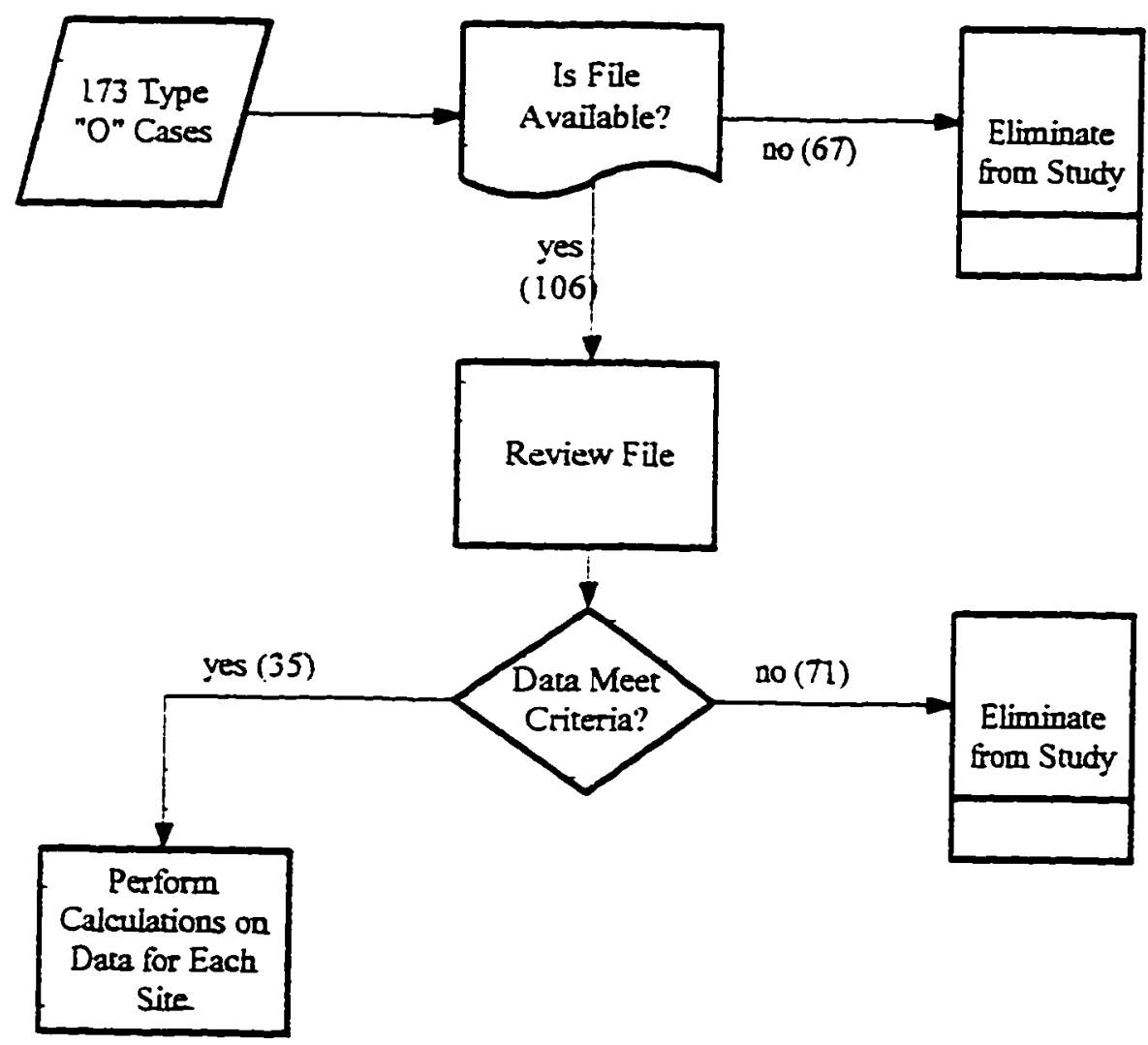

Figure 3. Flow chart of tile review process for cities of Campbell, Cupertino, Los Alos, Los Alos Hills, Los Gatos, Mountain View, and Palo Alto. 


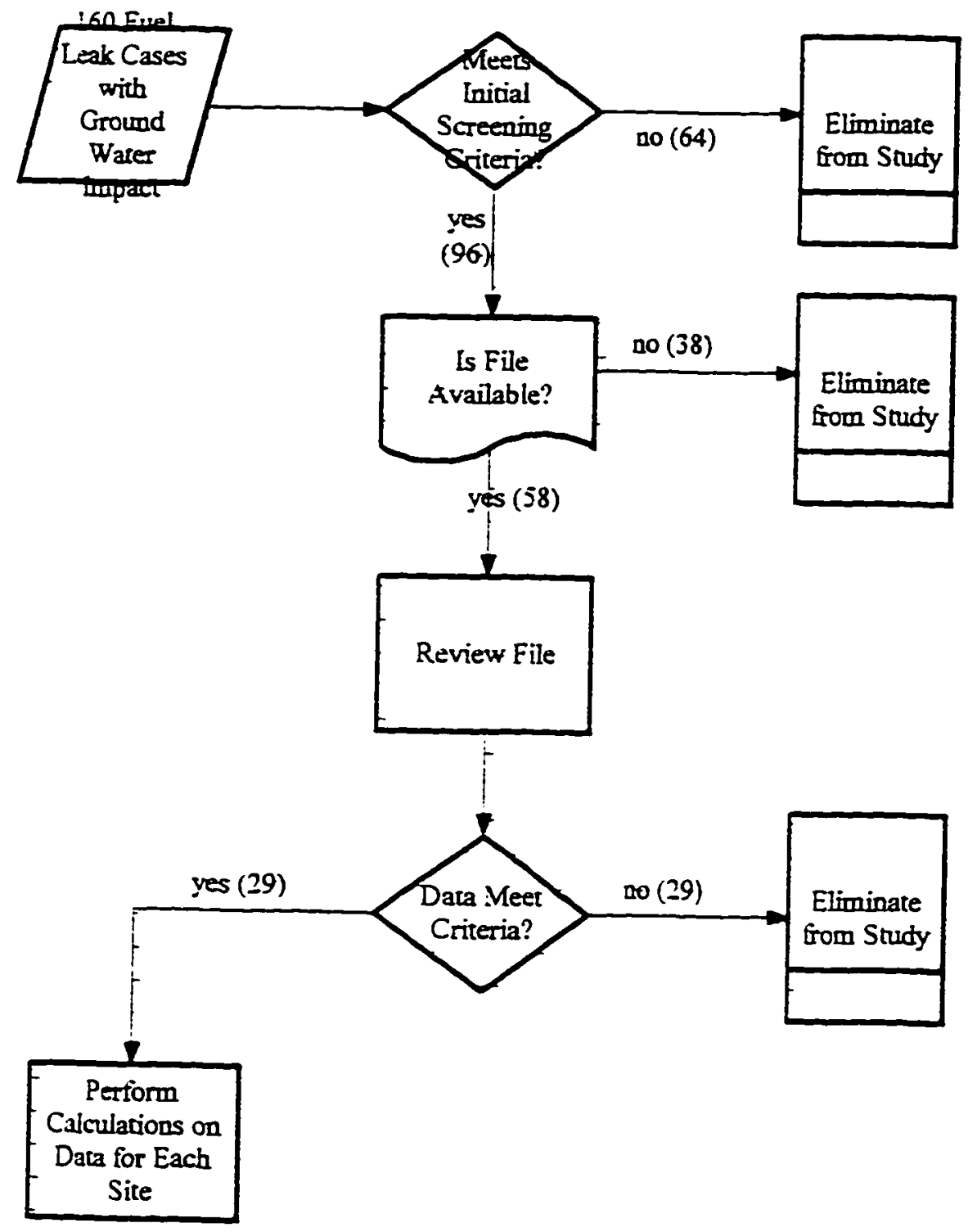

Figure 4. Flow charr of file review process for cicies of Sunnyvale and Santa C.arz 
summary of the numeric and descriprive information gathered is presented in Table 2 below.

Table 2. Summary of numeric and descriptive information gathered

- Remediation Performed (i.e., none, soil vapor extraction, pump and treat, etc.)

- Aquifer Materials (i.e., clayey sand, silty sand, silt, etc.)

- Confined vs. Unconfined

- Ground Water Elevations and Depths

- Distance from Monitoring Well to Source (UST, fuel pump island, etc.)

- Ground Water Gradient

- Ground Water Quality Data (TPH as gasoline and benzene)

- Dates of Monitoring Events

The data were collected on a two-page form, which is presented in Appendix A.

The first page is a summary of site conditions and the second form is for recording contaminant concentration and ground water elevation data. Data were recorded for each monitoring well at a site that met the data screening criteria. When there were tables with historical ground water quality data, a photocopy of the table was used instead of the second page of the data form. Forty-two sites with one well, 18 sites with two wells, and four sites with three wells met the criteria.

\section{Data Analvsis}

For sites where free product has historically been present, only the data since the disappearance of free product in the selected well was evaluated. In addition, some monitoring wells display an increasing concentration trend early in the monitoring history, possibly as a result of the fuel release impacting ground water. Other monitoring wells show initial relatively stable concentrations down-gradient of the source. Most of these 
sites eventually show a decreasing concentration trend, depending on where the data "window" is in relation to the life of the plume. Only the data from the decreasing trend were evaluated, beginning at the highest concentration peak A minimum of four data points were evaluated, which included a minimum of three detected concentrations and one non-detect (ND) value. For sites where concentration data decreases to ND, the data were evaluated until the first ND value. The ND value(s) were evaluated at one half the detection limit

Prior to evaluating the data, a log transformation was performed on the concentration values so that the slope (degradation rate) of the least squares regression could be calculated. Analytical results for duplicate samples were averaged. The transformed data for each well that met the selection criteria were plotted and evaluated using Mathcad 6.0 (MathSoft Inc.). For sites where the data plot approximately on a straight line, the degradation can be described as first order decay. Taking the log of both sides of equation (2) yields:

$$
\log C(t)=\log (C o)+k t
$$

Mathcad 6.0 was used to calculate the attenuation rate constant $(\mathrm{k})$, the correlation coefficient ( $r$ ), and the coefficient of determination $\left(r^{2}\right)$ value. The slope of the line and the correlation parameters are estimated by Mathcad using least squares methods. The value of $r$ lies between -1 and +1 . A negative value of $r$ indicates a negative relationship between concentration and time, with the relationship becoming more linear as $\mathrm{r}$ approaches -1 or +1 . The $\mathrm{r}^{2}$ provides the proportion of the total variability of concentration that can be accounted for by the independent variable time (Ott, 1984). As $\mathrm{I}^{2}$ approaches 1 , the degradation rate approaches first order decay. The ground water 
elevations were also plotted on the Mathcad output to qualitatively evaluate sites where there is a relationship between ground water elevations and concentrations. Ground water elevations were plotted on the graphs to evaluate which sites show a relationship between concentrations and ground water elevation. The Mathcad output and graphs for all of the sites are shown in Appendix B.

\section{Statistical Evaluation}

The distributions of the TPH as gasoline and benzene degradation rate constants were tested for normal distribution using the chi-square $\left(\chi^{2}\right)$ method. The chi-squared tests were performed to back up the histograms of the data, to evaluate whether the observed distributions can be described as normal. The primary purpose of testing for normal distributions is that if a population is nomally distributed, further statistical tests can be performed and inferences can be made about the population distribution. These inferences include predicting the percentage of values that lie within a specified number of standard deviations about the mean.

F-tests were also performed to evaluate whether the variances of groupings of data based on aquifer soil types, confined versus unconfined conditions, and remedial activities were statistically different, and therefore possibly from different parent populations. If a set of values appears to be collected from different populations, then there may be different processes operating under each circumstance (i.e., confined versus unconfined aquifer conditions).

To estimate the degree of interrelation between variables, such as monitoring well distance from source versus degradation rate constant, data were plotted against each other and the correlation coefficients were calculated. These plots were performed to help 
identify relationships that may influence observed degradation rate constants. Details of the statistical evaluation are presented in the following section. 


\section{RESULTS}

The results of the individual site/well calculations are summarized in Table C- 1 in Appendix $C$, along with other numeric and non-numeric site conditions. Table $C-1$ lists values for each well. Average values for sites with two or three wells are shown in bold The spread sheet was used to plot data graphically and to perform statistical analyses. The spreadsheet enabled the data to be sorted for various condirions, such as confined versus unconfined, remedial activities, and aquifer soil type.

\section{Descriptive Summary of TPH as Gasoline and Benzene Arenuation Rate Constants}

The calculated attenuation rates are summarized below in Tables 3 and 4. The data is presented in Tabie 3 based on individual values for each site, which is either the value for one well or the average of two or three wells, depending on the number of wells meeting the selection criteria at a site. The data is presented in Table 4 based on the values for each individual well. The purpose of analyzing the data by the two approaches in Tables 3 and 4 was to evaluate whether there are differences in distribution of attenuation rate constants between the approaches. If the distributions are similar between the two approaches, then results of this study can be applied to sites where only one well is available down-gradient of the source.

To describe the observed attenuation rate constants, the mean, median ( 50 th percentile), minimum, and maximum values are shown on Tables 3 and 4 . In addition, the 5 th percentile, 25 th percentile 75 th percentile, and 95 th percentile are also presented in Tables 3 and 4 . These percentages are the level below which a given percentage of values lie. For example, for the 25 th percentile, 25 percent of the values are less than the stated 


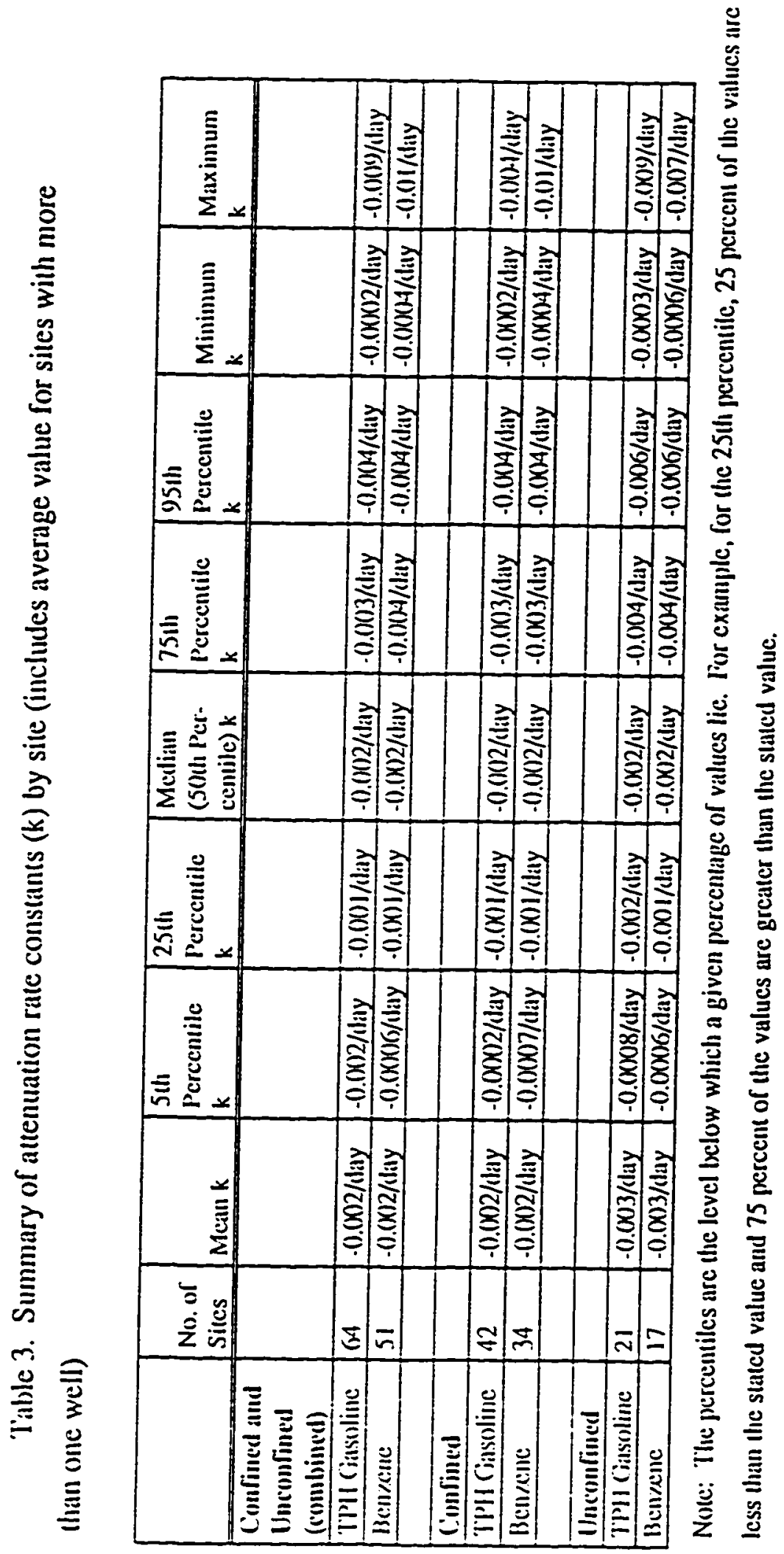




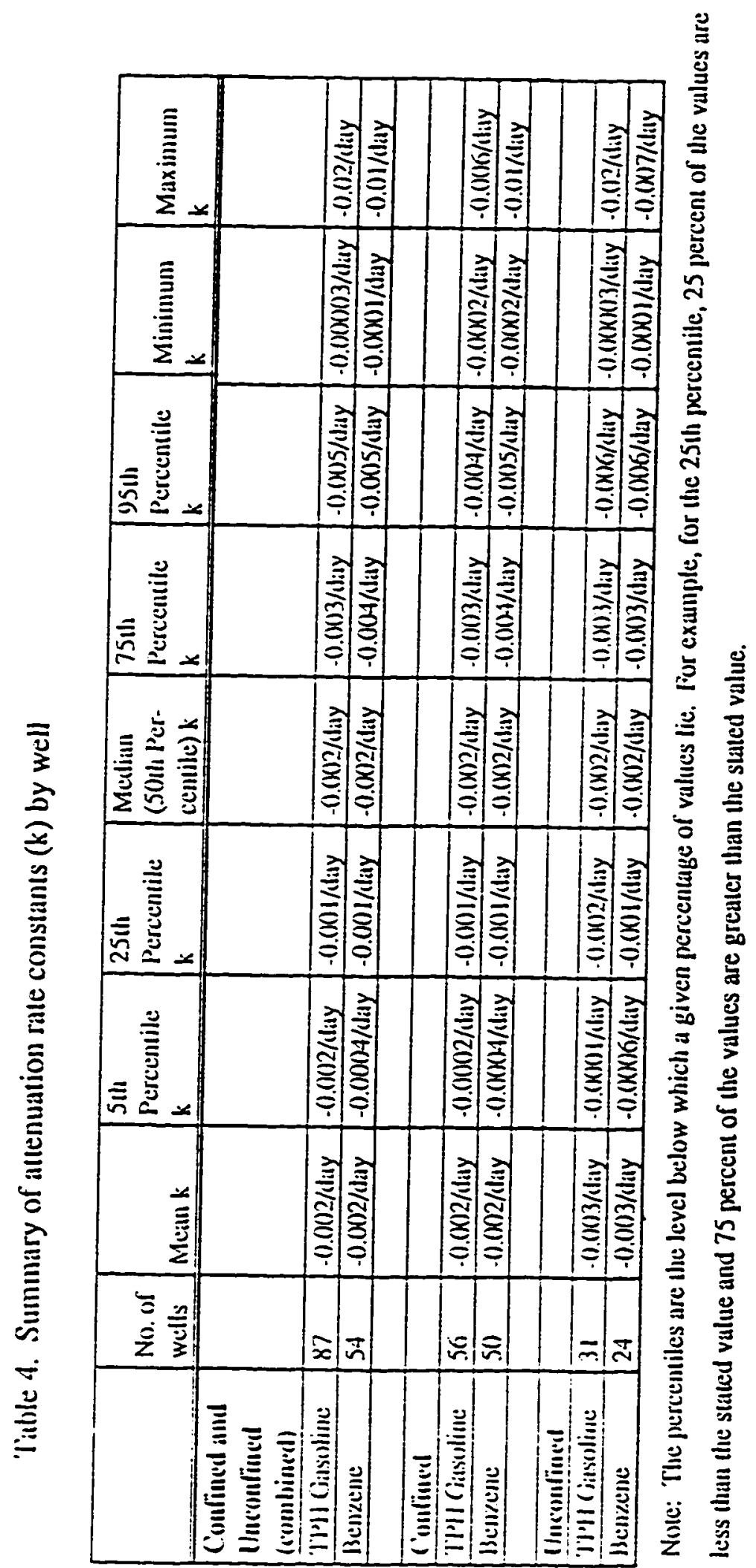


value and 75 percent of the values are greater than the stated value. These percentages were selected to provide a description of the distribution of values around the mean and in the tail regions of the distribution.

The data is categorized in Tables 3 and 4 three ways: 1) confined and unconfined combined, 2) confined, and 3) unconfined. The reason for splitting the data into confined versus unconfined is to evaluate whether there are statistically significant differences in degradation processes between these two hydrogeologic conditions.

Tables 3 and 4 indicate that the attenuation rate constants vary over a relatively narrow range. In addition, there does not appear to be a significant difference in distributions of the attenuation rate data between the data set for individual wells and site averages. An evaluation of the data for confined versus unconfined conditions is discussed below.

\section{Descriptive Summary of TPH as Gasoline and Benzene Coefficients of Determination}

To evaluate whether the attenuation of TPH as gasoline and benzene can be described as first order decay (logarithmic), the coefficient of determination $\left(r^{2}\right)$ values were calculated for each site. As $r^{2}$ approaches 1 , the decay approaches first order. The calculated $r^{2}$ for each site are presented below in Tables 5 and 6 . The data are presented in Table 5 based on individual values for each site, which is either the value for one well or the average of two or three wells, depending on the number of wells at a site meeting the selection criteria. The data is presented in Table 6 based on values for each individual well. To describe the observed correlations, the mean, median (50th percentile), 75th percentile, and 95th percentile, plus minimum and maximum values are shown. 
Table 5. Summary of coefficient of determination $\left(\mathrm{r}^{2}\right)$ of TPH as gasoline and benzene by site (includes average value for sites with more than one well)

\begin{tabular}{|l|l|l|l|l|l|l|l|}
\hline & $\begin{array}{l}\text { Number } \\
\text { of Sites }\end{array}$ & Mean $\mathrm{r}^{2}$ & $\begin{array}{l}\text { Median } \\
\text { (50th Per } \\
\text { centile) } \mathrm{r}^{2}\end{array}$ & $\begin{array}{l}\text { 75th } \\
\text { Percentile } \\
\mathrm{r}^{2}\end{array}$ & $\begin{array}{l}\text { 95th } \\
\text { Percenile } \\
\mathrm{r}^{2}\end{array}$ & $\begin{array}{l}\text { Minimum } \\
\mathrm{r}^{2}\end{array}$ & $\begin{array}{l}\text { Maximum } \\
\mathrm{r}^{2}\end{array}$ \\
\hline Confined & & & & & & & \\
\hline TPH Gasoline & 40 & 0.63 & 0.68 & 0.76 & 0.93 & 0.08 & 0.99 \\
\hline Benzene & 36 & 0.61 & 0.67 & 0.80 & 0.93 & 0.07 & 0.95 \\
\hline & & & & & & & \\
\hline Unconfined & & & & & & & \\
\hline TPH Gasoline & 21 & 0.60 & 0.70 & 0.76 & 0.98 & 0.08 & 0.99 \\
\hline Benzene & 17 & 0.57 & 0.71 & 0.74 & 0.86 & 0.05 & 0.92 \\
\hline
\end{tabular}

Table 6. Summary of coefficient of determination $\left(\mathrm{r}^{2}\right)$ of TPH as gasoline and benzene for individual wells

\begin{tabular}{|l|l|l|l|l|l|l|l|}
\hline & $\begin{array}{l}\text { Number } \\
\text { of Wells }\end{array}$ & Mean $\mathrm{r}^{2}$ & $\begin{array}{l}\text { Median } \\
\text { (50ht Per } \\
\text { centile) } \mathrm{r}^{2}\end{array}$ & $\begin{array}{l}\text { 75th } \\
\text { Percentle } \\
\mathrm{r}^{2}\end{array}$ & $\begin{array}{l}95 \mathrm{ch} \\
\text { Percentile } \\
\mathrm{r}^{2}\end{array}$ & $\begin{array}{l}\text { Minimum } \\
\mathrm{r}^{2}\end{array}$ & $\begin{array}{l}\text { Maximum } \\
\mathrm{r}^{2}\end{array}$ \\
\hline Confined & & & & & & & \\
\hline TPH Gasoline & 56 & 0.63 & 0.68 & 0.81 & 0.93 & 0.05 & 0.99 \\
\hline Benzene & 50 & 0.63 & 0.72 & 0.82 & 0.95 & 0.006 & 0.96 \\
\hline & & & & & & & \\
\hline Unconfined & & & & & & & \\
\hline TPH Gasoline & 31 & 0.58 & 0.72 & 0.78 & 0.95 & 0.002 & 0.99 \\
\hline Benzene & 24 & 0.57 & 0.61 & 0.80 & 0.95 & 0.002 & 0.98 \\
\hline
\end{tabular}

The data are grouped by confined and unconfined ground water conditions. The reason for this grouping is to evaluate whecher there are noticeable differences in degradation processes between these two hydrogeologic conditions.

The data presented in Tables 5 and 6 indicates that the coefficient of determination data varies significantly from site to site. There also does not appear to be a significant 
difference in the distribution of values between the data set for individual wells and site averages.

Statistical Analysis of Attenuation Rate Constant and Coefficient of Determination Data Tests for Normal (Gaussian) Disuribution of Attenuation Rate Constant Data

Histograms of the TPH as gasoline and benzene attenuation rate constant data generally appear to display normal distributions. The distributions are presented in Figures 5,6 , and 7, grouped as combined confined and unconfined aquifers (Figure 5), confined aquifers only (Figure 6), and unconfined aquifers only (Figure 7). To evaluate whether the distributions can be described as normal, chi-square $\left(\chi^{2}\right)$ tests were performed.

The $\chi^{2}$ method tests how well a disuribution of sample values conforms to a normal distribution by using a goodness-of-fit test procedure. A null hypothesis $\left(N_{0}\right)$ is initially stated that the population of the degradation rates from which the sample is drawn is normally discributed with an unknown mean and variance. The alternative hypothesis $\left(\mathrm{N}_{1}\right)$ is that the parent population is not normally distributed. The normal distribution is then divided into equal segments, with each segment having equal area under the curve. The probability that a random observation will fall into each segment will then be equal to the area under each curve. If four segments are selected that have equal areas, then a random observation would have a probability of 0.25 of falling into a particular segment. The limits of the equal sized areas, expressed as standard deviations of a normal curve, are $-\infty$ to $-0.67,-0.67$ to 0,0 to +0.67 , and +0.67 to $+\infty$. The expected frequency of observations falling into each category (one fourth) is then compared to the observed frequency. If the number deviates significantly from expected, the null hypothesis is 


\section{TPH as Gasoline}
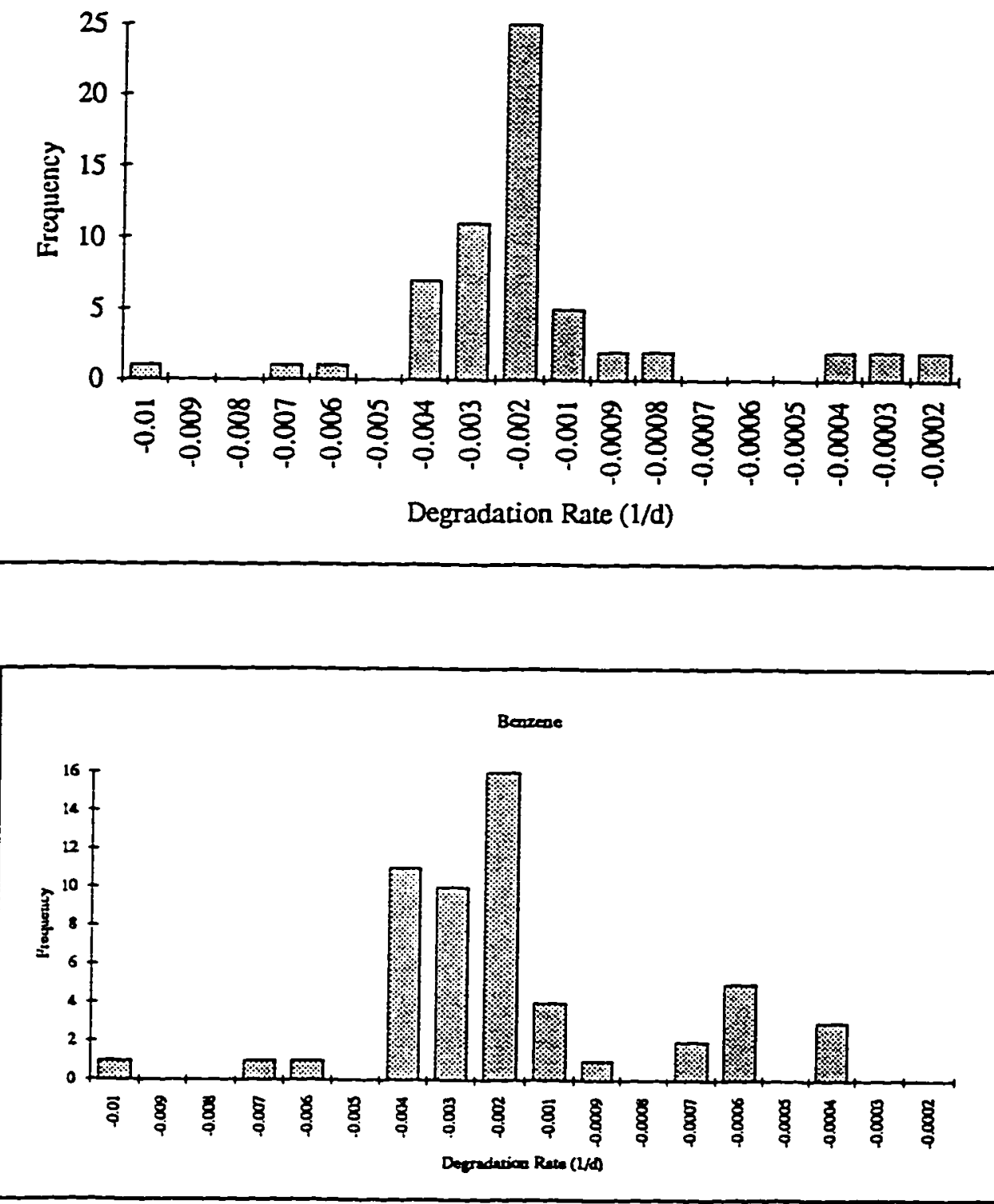

Figure 5. Histograms of attenuation rate constants, confined and unconfined aquifers combined. 


\section{TPH as Gasoline}

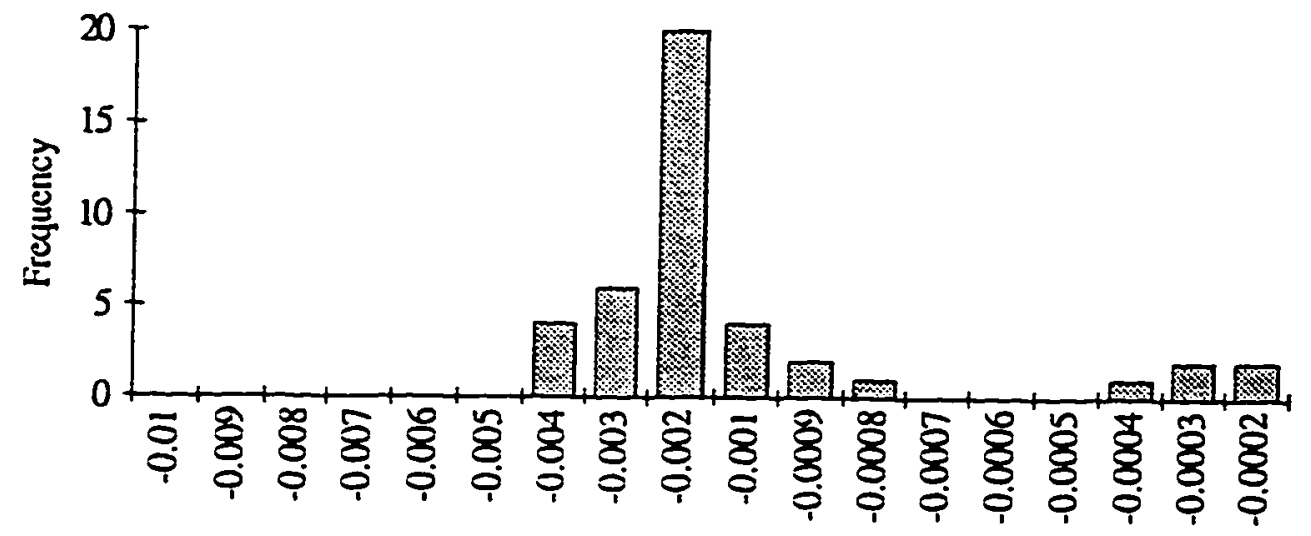

Degradation Rate (1/d)

\section{Benzene}

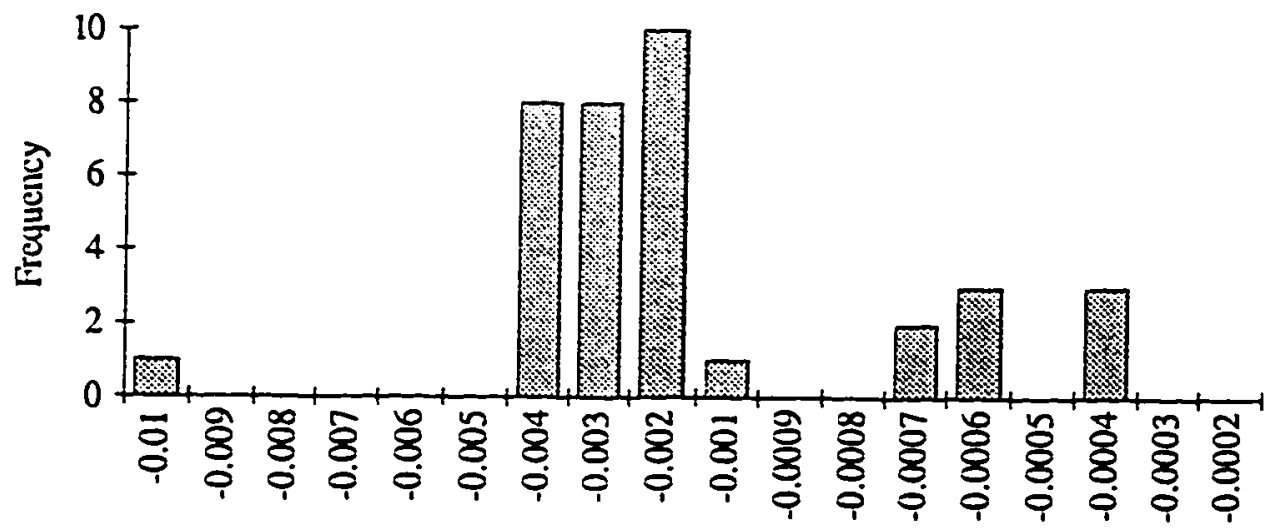

Degradation Rate (1/d)

Figure 6. Histograms of attenuation rate constants, confined aquifers 
TPH as Gasoline

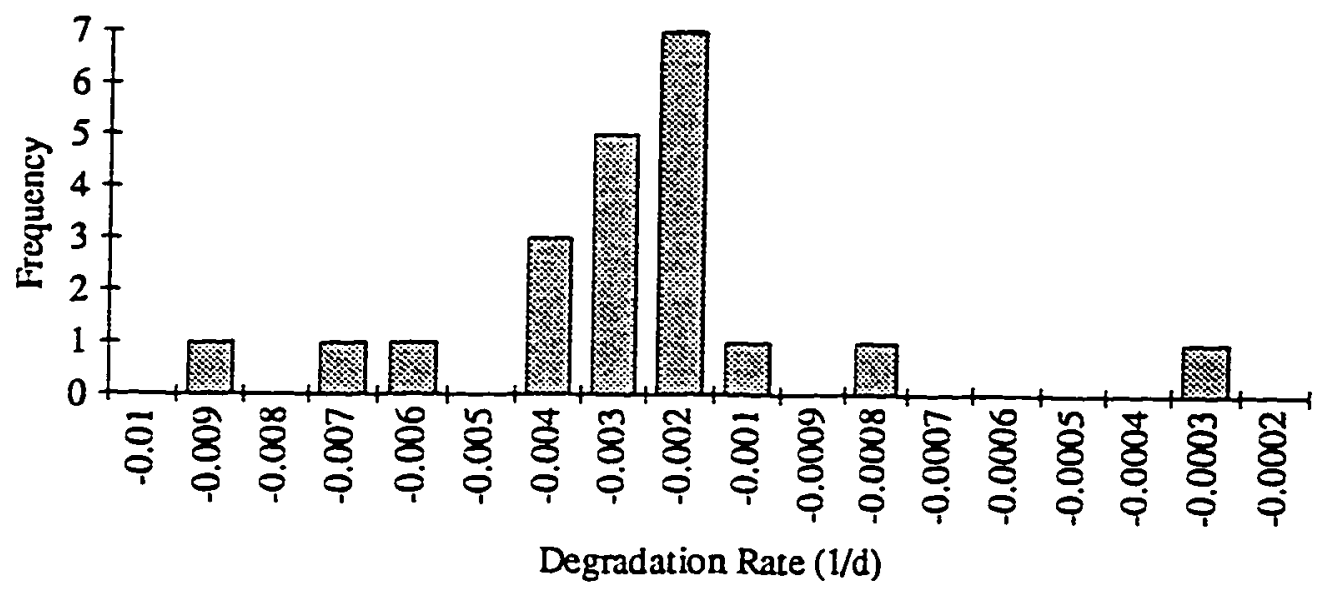

\section{Benzene}

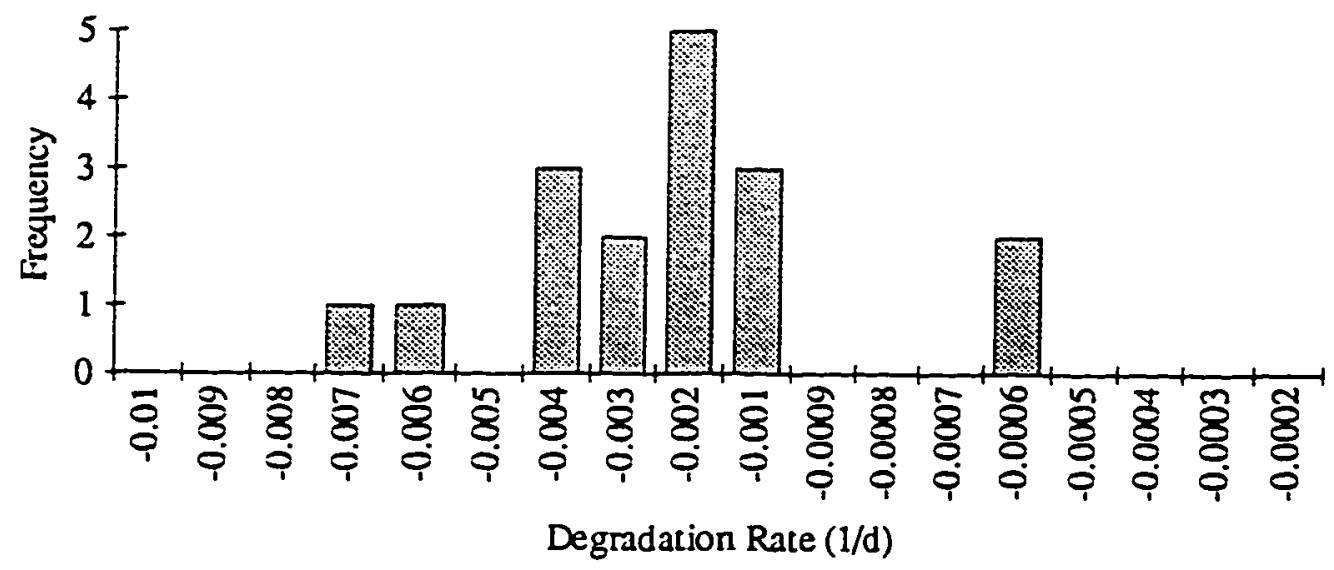

Figure 7. Histograms of attenuation rate constants, unconfined aquifers 
rejected, and the sample distribution is probably not normal (Davis, 1986). A level of significance of 10 percent was selected for the tests, meaning that there is a one in ten chance of rejecting the null hypothesis when it is actually correct.

The first step is to standardize the data using the following equation:

$$
\mathrm{Z}_{\mathrm{i}}=\mathrm{X}_{\mathrm{i}}-\mathrm{X} / \mathrm{s}
$$

where $Z_{i}$ is the standardized ith value, $X_{i}$ is the ith value, $X$ is the sample mean, and $s$ is the sample standard deviation. The number of values within each standard deviation range are then summed. The $\chi^{2}$ is then calculated by the following equation:

$$
\chi^{2}=\Sigma\left(O_{j}-E_{j}\right) / E_{j}
$$

where $O_{j}$ is the number of observations within the jth class and $E_{j}$ is the number of observations expected in that class. The $\chi^{2}$ value is then compared to the critical value at the level of significance (10 percent) and one degree of freedom. If the $\chi^{2}$ value exceeds the crivical value, then the null hypothesis is rejected and the conclusion can be made that the distribution is not normal (Davis, 1986).

The calculations were performed using Excel spreadsheets. The results of the $\chi^{2}$ tests (Table 7) show that the distribution of benzene attenuation rates is normally distributed and that the TPH as gasoline attenuation rates are normally distributed for confined conditions only. The tests were performed for both TPH as gasoline and benzene under three conditions: 1) where the values for confined and unconfined aquifers were combined; 2) unconfined aquifers only; and 3) confined aquifers only. The $\chi^{2}$ tests 
were performed in these combinations to evaluate differences in the distribution between the groups.

Table 7. Results of $\chi^{2}$ tests for normal distribution of degradation rate constants

\begin{tabular}{|c|c|c|c|}
\hline & $\begin{array}{c}\chi^{2} \\
\text { value }\end{array}$ & $\begin{array}{l}\text { Critica } \\
\text { I Value }\end{array}$ & Result \\
\hline \multicolumn{4}{|c|}{ Confined and Unconfined (Combined) } \\
\hline TPH as Gasoline & 10.80 & 2.71 & $\begin{array}{l}\text { Hypothesis rejected, population is } \\
\text { not normal }\end{array}$ \\
\hline Benzene & 1.65 & 2.71 & $\begin{array}{l}\text { Hypothesis accepted, population } \\
\text { is normal }\end{array}$ \\
\hline \multicolumn{4}{|l|}{ Confined } \\
\hline TPH as Gasoline & 1.05 & 2.71 & $\begin{array}{l}\text { Hypothesis accepted, population } \\
\text { is normal }\end{array}$ \\
\hline Benzene & 1.00 & 2.71 & $\begin{array}{l}\text { Hypothesis accepted, populacion } \\
\text { is normal }\end{array}$ \\
\hline \multicolumn{4}{|l|}{ Unconfined } \\
\hline TPH as Gasoline & 3.03 & 2.71 & $\begin{array}{l}\text { Hypothesis rejected, population is } \\
\text { not normal }\end{array}$ \\
\hline Benzene & 1.57 & 2.71 & $\begin{array}{l}\text { Hypothesis accepted, population } \\
\text { is normal }\end{array}$ \\
\hline
\end{tabular}

Testing for Normal (Gaussian) Distribution of Coefficient of Determination Data

Histograms of the TPH as gasoline and benzene coefficient of determination

(Figures 8, 9, and 10) do not appear to display normal distributions. The data are grouped as combined confined and unconfined (Figure 8), confined only (Figure 9), and unconfined only (Figure 10). To evaluate whether the distributions can be described as normal, a chisquare $\left(\chi^{2}\right)$ test was performed on the TPH as gasoline confined aquifer category, since this distribution appeared to be the most "normal" of the graphs (Figure 9). 

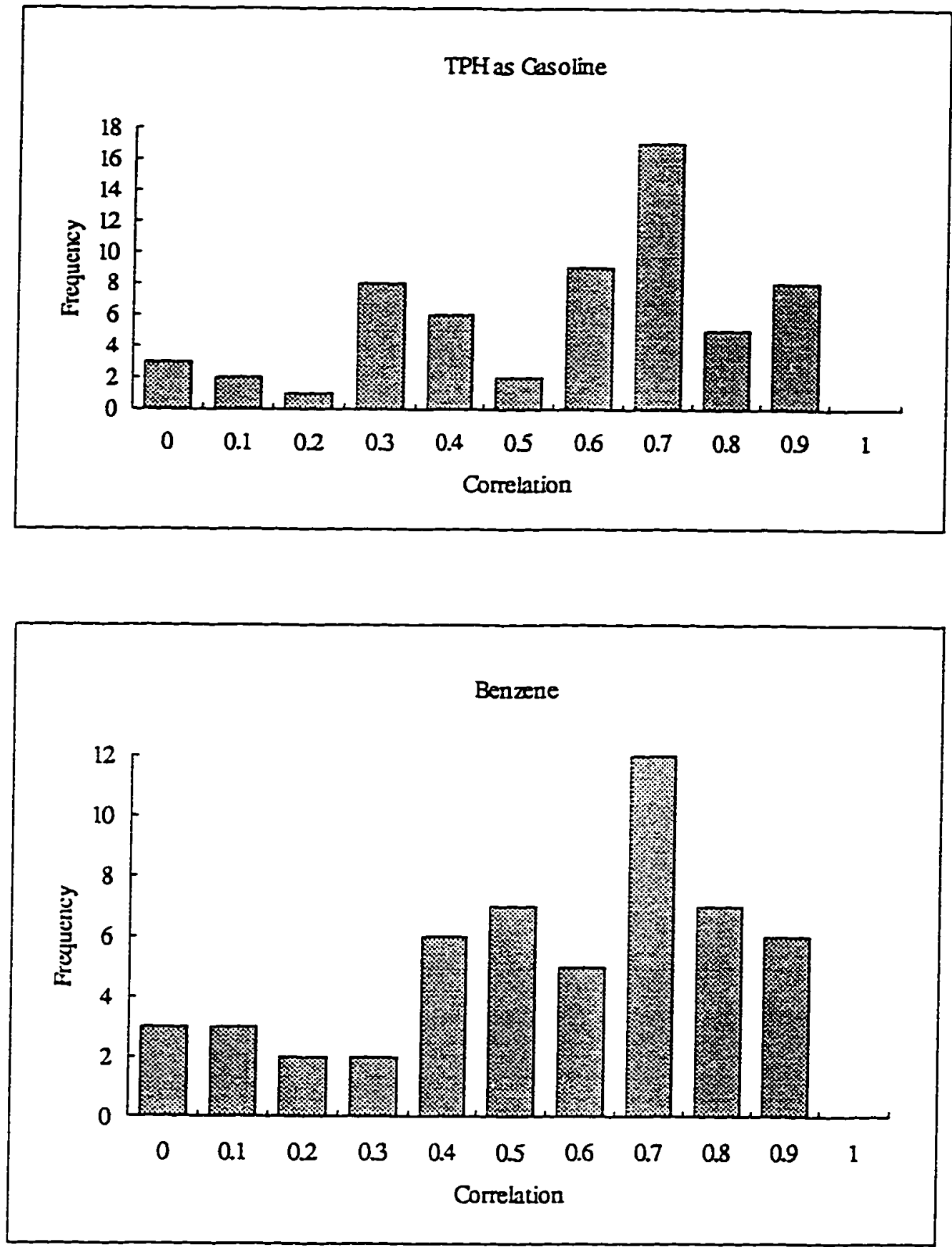

Figure 8. Histograms of coefficients of determination, confined and unconfined aquifers combined. The $x$-axis shows the number of values within each range, starting at 0 to 0.1 at the left (numbers are off-set). 

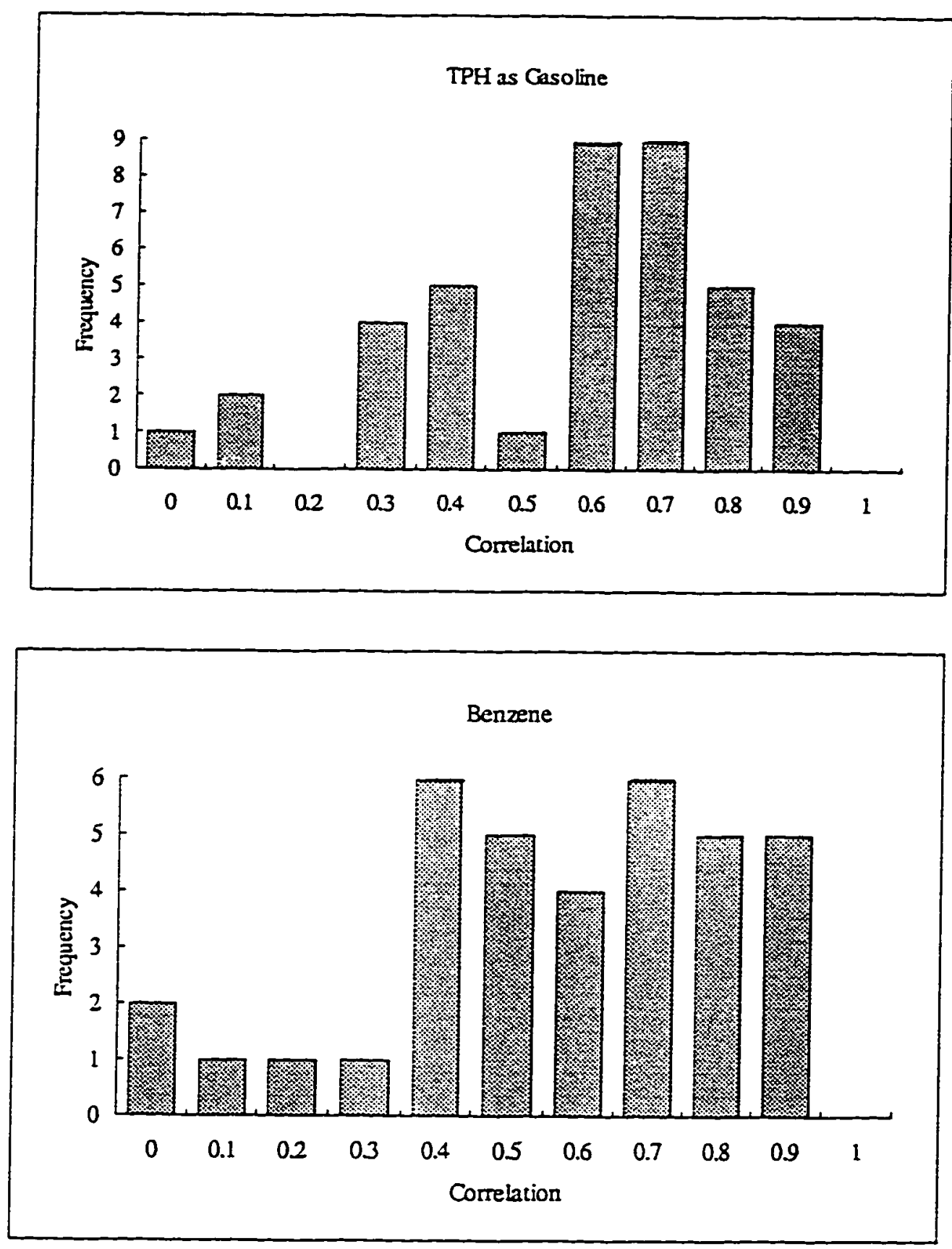

Figure 9. Histograms of coefficients of determination, confined aquifers. The $x$ axis shows the number of values within each range, starting at 0 to 0.1 at the left (numbers are off-set). 

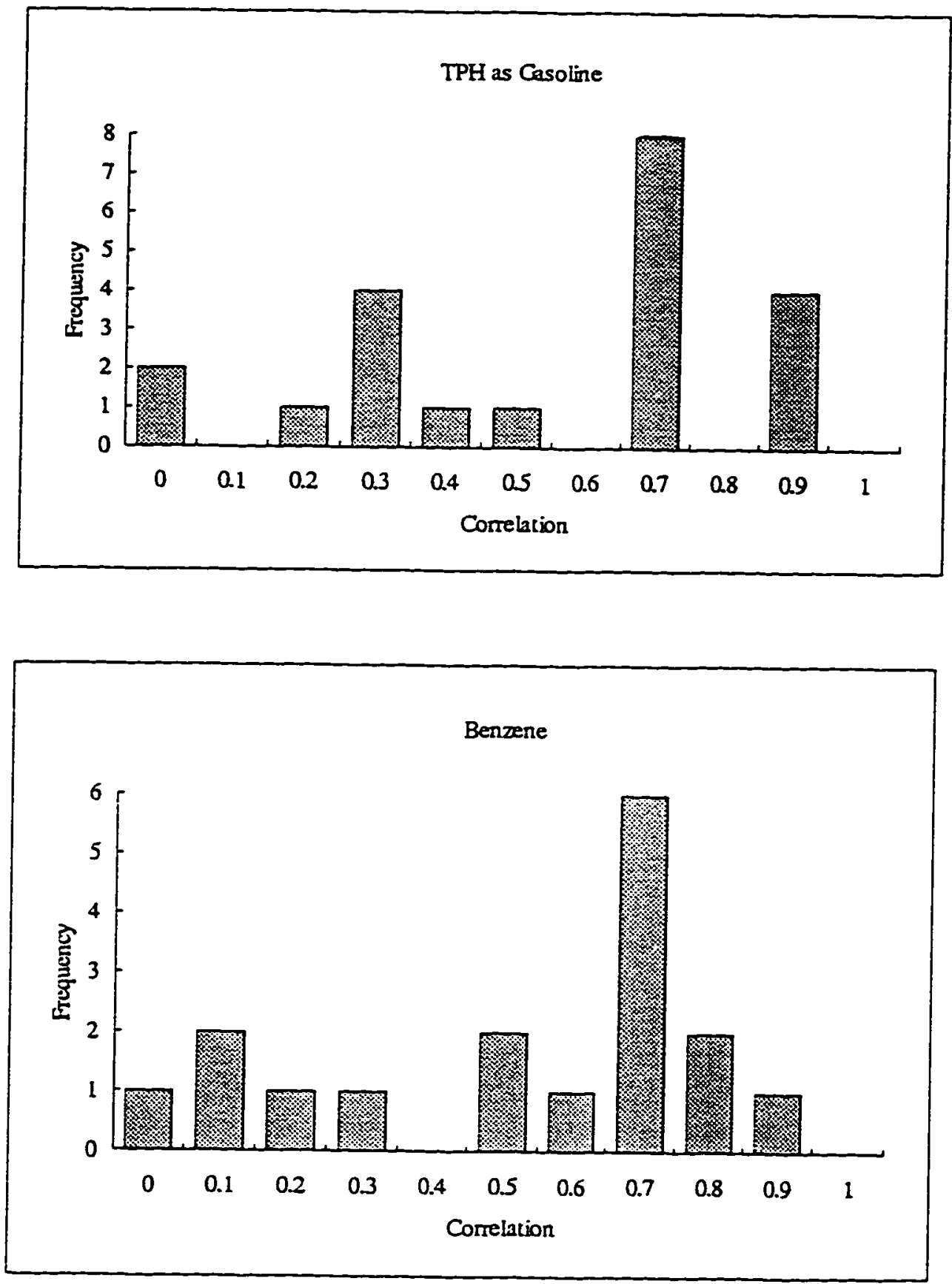

Figure 10. Histograms of coefficients of determination, unconfined aquifers. The $x$-axis shows the number of values within each range, starting at 0 to 0.1 at the left (numbers are off-set). 
The $\chi^{2}$ test was performed using the methodology presented previously. The null hypothesis being tested was that the samples were collected from a normally distributed popularion. The result of the $\chi^{2}$ test, presented below in Table 8 , indicate that the distribution is not normally distributed.

Table 8. Results of $\chi^{2}$ test for normal distribution of coefficient of determination $\left(\mathrm{r}^{2}\right)$ data.

\begin{tabular}{|l|l|l|l|}
\hline & $\begin{array}{c}\chi^{2} \\
\text { Value }\end{array}$ & $\begin{array}{c}\text { Critica } \\
\text { 1 Value }\end{array}$ & Result \\
\hline \hline Confined & & & \\
\hline TPH as Gasoline & 4.20 & 2.71 & $\begin{array}{l}\text { Hypothesis rejected, population is } \\
\text { not normal }\end{array}$ \\
\hline
\end{tabular}

F-Tests to Compare Benzene Attenuation Rate Constant Distributions for Confined and Unconfined Conditions

To evaluate whether the sample distributions of the benzene attenuation rate constants for confined and unconfined aquifer conditions are significantly different, the equality of variances in attenuation rate constant values between the two categories were evaluated using F-tests. The F-tests evaluate differences in the variances of two sample distributions. If the variances are significantly different, the samples (categories) may have been drawn from different parent populations. If the samples appear to have been drawn from different parent populations, then different degradation processes may be operating under each set of conditions. Benzene was selected for this evaluation since the distribution of benzene attenuation rates appears to be nomal.

The F statistic is the ratio of the variances of the two categories that are being compared, with the highest variance in the numerator so that $F$ is always greater than 1 . A null hypothesis is stated that the samples are drawn from populations with equal variances. 
The ratio of the variances is compared to the critical value of $F$ at a specified level of significance, in this case 5 percent. Degrees of freedom (n-1) for both the numerator and denominator are taken into account. If the ratio does not exceed the critical value, the null hypothesis is accepted (that the samples are from populations with equal variances). If $F$ exceeds the critical value, the null hypothesis is rejected, and we conclude that the variance of the degradation rates is not the same for both samples (Davis, 1986). The results of the $F$ tests, presented below in Table 9, indicate that the populations are different.

Table 9. Results of F-tests for confined versus unconfined aquifer conditions.

Confined category variance $=9.8 \times 10^{-7}$

Unconfined category variance $=4.2 \times 10^{-6}$

$F=$ Unconfined variance/Confined variance $=4.3$

Degrees of Freedom Confined Category $=41$

Degrees of Freedom Unconfined Category $=20$

Critical value at 5 percent level of significance $=1.8$

Therefore, null hypothesis is rejected (populations are different)

Evaluation of Benzene Attenuation Rate Constant Data Grouped by Soil Type

Benzene attenuation rate constant data was grouped according to the aquifer soil type, using three broad categories dependent upon the presence or absence of silt and clay. The three categories, A, B, and C, generally included the following soil types:

Category A. Clean sand and gravel

Category B. Silty sand, silty gravel, clayey silt 
Category C. Clayey sand, clayey gravel, and silty clay

The soil type categorization is considered to be weak as a result of inconstancies in soil classifications and heterogeneities in shallow aquifers common in the study area. The soil data was only applicable for the location of the monitoring well. In addition, the shallow aquifer soil type assigned to each site sometime required a judgment as to which strata contributed most to the aquifer transitivity. Averaging of multi-strata aquifers and laterally heterogeneous aquifers was outside the scope of this study. Insignificant differences in the sample means and variances between the categories were observed, as shown in Table 10.

Table 10. Summary of benzene attenuation rate constants between aquifer soil type categories.

\begin{tabular}{|l|l|l|l|l|}
\hline Category & $\begin{array}{l}\text { Number of } \\
\text { observations }\end{array}$ & Mean $\mathrm{k}$ & Median $\mathrm{k}$ & Variance \\
\hline $\begin{array}{l}\mathrm{A}-\text { Clean sand and } \\
\text { gravel }\end{array}$ & 11 & -0.003 & -0.002 & $1 \times 10^{-6}$ \\
\hline $\begin{array}{l}\text { B - Silty sand, silty } \\
\text { gravel, and clayey silt }\end{array}$ & 18 & -0.003 & -0.002 & $6 \times 10^{-6}$ \\
\hline $\begin{array}{l}\text { C - Clayey Sand, clayey } \\
\text { gravel, and silty clay }\end{array}$ & 23 & -0.002 & -0.002 & $2 \times 10^{-6}$ \\
\hline
\end{tabular}

To evaluate whether the three categories can be described as being derived from the same parent population, the equality of variances in attenuation rate values between the three categories was evaluated using F-tests using the methods presented in the previous section. The resuits of the F tests, presented below in Table 11 , indicate that the sample population variances are the same for categories $A$ versus $C$, but different for categories $A$ versus $B$ and $B$ versus $C$. 
Table 11. Results of F-tests for aquifer soil type categories

Categories A vs. B

Category $\mathrm{A}$ variance $=1 \times 10^{-6}$

Category $B$ variance $=6 \times 10^{-6}$

$\mathrm{F}=\mathrm{B}$ variance $/ \mathrm{A}$ variance $=6$

Degrees of Freedom Category $A=10$

Degrees of Freedom Category $B=17$

Critical value at 5 percent level of significance $=2.7$

Therefore, null hypothesis is rejected (popularions are different).

Categories A vs. C

Category $\mathrm{A}$ variance $=1 \times 10^{-6}$

Category $\mathrm{C}$ variance $=2 \times 10^{-6}$

$\mathrm{F}=\mathrm{B}$ variance $/ \mathrm{A}$ variance $=2$

Degrees of Freedom Category $A=10$

Degrees of Freedom Category $C=22$

Critical value at 5 percent level of significance $=2.6$

Therefore, null hypothesis is accepted (populations are same).

Categories B vs. C

Category $B$ variance $=6 \times 10^{-6}$

Category $C$ variance $=2 \times 10^{-6}$

$\mathrm{F}=\mathrm{B}$ variance $/ \mathrm{A}$ variance $=3$

Degrees of Freedom Category $B=17$

Degrees of Freedom Category $C=22$

Critical value at 5 percent level of significance $=2.1$

Therefore, null hypothesis is rejected (populations are different). 
Evaluation of Benzene Attenuation Rate Constant Data Grouped by Remedial Activities

The attenuation rate constants for TPH as gasoline and benzene were sorted based on remedial activities, including no remediation. Combinations of remedial activities were also sorted. The categorized attenuation rates for TPH as gasoline and benzene are summarized below in Tables 12 and 13, respectively, including mean, median, minimum, and maximum values.

To evaluate whether remedial methods at sites affect the benzene attenuation rate constants, $F$ tests were performed between the "no remediation" category and categories of remedial activities. The variances of the remedial method caregories tested are presented below in Table 14. The category of ground water pump and treat (alone) and bioenhancement were not included due to small sample size.

Table 12. Summary of TPH as gasoline attenuation rate constants categorized by remedial activity.

\begin{tabular}{|c|c|c|c|c|c|}
\hline $\begin{array}{l}\text { Remedial } \\
\text { Activities } \\
\end{array}$ & Number & Mean $k$ & Median k & Minimum $\mathbf{k}$ & Maximum $\mathbf{k}$ \\
\hline none & 19 & $-0.002 / \mathrm{day}$ & $-0.002 / d a y$ & $-0.0002 / d a y$ & $-0.006 /$ day \\
\hline sve & 14 & $-0.003 /$ day & $-0.002 /$ day & $-0.0008 /$ day & $-0.009 /$ day \\
\hline ex & 12 & $-0.002 /$ day & $-0.002 /$ day & $-0.0002 /$ day & $-0.004 /$ day \\
\hline $\mathrm{pt}$ & 4 & $-0.002 /$ day & $-0.002 /$ day & $-0.0002 /$ day & $-0.002 /$ day \\
\hline sve and other & 22 & $-0.002 /$ day & $-0.002 /$ day & $-0.0008 /$ day & $-0.009 /$ day \\
\hline ex and other & 16 & $-0.002 /$ day & $-0.002 /$ day & $-0.0002 /$ day & $-0.004 /$ day \\
\hline bio and other & 6 & $-0.002 /$ day & $-0.002 /$ day & $-0.0003 /$ day & $-0.004 /$ day \\
\hline pt and other & 19 & $-0.002 / \mathrm{day}$ & $-0.002 /$ day & $-0.0002 /$ day & $-0.004 /$ day \\
\hline
\end{tabular}


Table 13. Summary of benzene attenuation rates categorized by remedial activity.

\begin{tabular}{l|l|l|l|l|l|}
\hline $\begin{array}{l}\text { Remedial } \\
\text { Activities }\end{array}$ & Number & Mean $\mathbf{k}$ & Median $\mathrm{k}$ & Minimum $\mathbf{k}$ & Maximum $\mathbf{k}$ \\
\hline none & 18 & $-0.002 /$ day & $-0.002 /$ day & $-0.0004 /$ day & $-0.007 /$ day \\
\hline sve & 7 & $-0.003 /$ day & $-0.002 /$ day & $-0.001 /$ day & $-0.004 /$ day \\
\hline ex & 9 & $-0.002 /$ day & $-0.002 /$ day & $-0.0004 /$ day & $-0.004 /$ day \\
\hline $\mathrm{pt}$ & 4 & $-0.002 /$ day & $-0.002 /$ day & $-0.0006 /$ day & $-0.003 /$ day \\
\hline sve and other & 19 & $-0.003 /$ day & $-0.002 /$ day & $-0.0007 /$ day & $-0.01 /$ day \\
\hline ex and other & 11 & $-0.003 /$ day & $-0.003 /$ day & $-0.0004 /$ day & $-0.004 /$ day \\
\hline bio and other & 5 & $-0.002 /$ day & $-0.002 /$ day & $-0.0006 /$ day & $-0.003 /$ day \\
\hline pt and other & 14 & $-0.003 /$ day & $-0.002 /$ day & $-0.0006 /$ day & $-0.001 /$ day \\
\hline
\end{tabular} sve = soil vapor extraction
ex = excavation
pt = ground water pump and treat
bio = bioenhancement (such as the addition of hydrogen peroxide and/or nutrients)

Table 14. Variance of benzene attenuation rate constants between remedial method categories.

\begin{tabular}{|l|c|c|}
\hline Category & $\begin{array}{c}\text { Number of } \\
\text { observations }\end{array}$ & Variance \\
\hline no remediation & 18 & $3 \times 10^{-6}$ \\
\hline sve only & 7 & $1 \times 10^{-6}$ \\
\hline excavation only & 9 & $2 \times 10^{-6}$ \\
\hline sve alone and in combination with other methods & 19 & $4 \times 10^{-6}$ \\
\hline excavation alone and in combination with other methods & 11 & $2 \times 10^{-6}$ \\
\hline $\begin{array}{l}\text { Pump and Treat alone and in combination with other } \\
\text { methods }\end{array}$ & 14 & $5 \times 10^{-6}$ \\
\hline
\end{tabular}

As in the previous section, F-tests were performed to test the null hypothesis that the samples are drawn from populations with equal variances. The results of the F tests, presented below in Table 15, indicate that the samples were drawn from populations with equal variances. 
Table 15. Results of F-tests for remedial method categories.

\section{No remediation vs. SVE only}

No remediation category variance $=3 \times 10^{-6}$

SVE only category variance $=1 \times 10^{-6}$

$F=3 \times 10^{-6} / 1 \times 10^{-6}=3$

Degrees of Freedom, no remediation category $=17$

Degrees of Freedom, SVE category $=6$

Critical value at 5 percent level of significance $=3.91$

Therefore, null hypothesis is accepted (populations are same)

No remediation vs. Excavation only

No remediation category variance $=3 \times 10^{-6}$

Excavation only category variance $=2 \times 10^{-6}$

$F=3 \times 10^{-6} / 2 \times 10^{-6}=1.5$

Degrees of Freedom, no remediation category $=17$

Degrees of Freedom, excavation category $=8$

Critical value at 5 percent level of significance $=3.19$

Therefore, null hypothesis is accepted (populations are same)

No remediation vs. SVE alone and in combination with other methods

No remediation category variance $=3 \times 10^{-6}$

$S V E$ combination category variance $=4 \times 10^{-6}$

$F=4 \times 10^{-6} / 3 \times 10^{-6}=1.3$

Degrees of Freedom, no remediation category $=17$

Degrees of Freedom, SVE combination category $=18$

Critical value at 5 percent level of significance $=2.29$

Therefore, null hypothesis is accepted (populations are same) 
Table 15. (continued) Results of F-tests for remedial method categories.

No remediation vs. Excavation alone and in combination with other methods

No remediation category variance $=3 \times 10^{-6}$

Excavation combination category variance $=2 \times 10^{-6}$

$\mathrm{F}=3 \times 10^{-6} / 2 \times 10^{-6}=1.5$

Degrees of Freedom, no remediation category $=17$

Degrees of Freedom, excavation combination category $=10$

Critical value at 5 percent level of significance $=2.84$

Therefore, null hypothesis is accepted (populations are same)

No remediation vs. ground water pump and treat alone and in combination with other methods

No remediation category variance $=3 \times 10^{-6}$

Pump and treat combination category variance $=5 \times 10^{-6}$

$F=5 \times 10^{-6} / 3 \times 10^{-6}=1.8$

Degrees of Freedom, no remediation category $=17$

Degrees of Freedom, excavation combination category $=13$

Critical value at 5 percent level of significance $=2.5$

Therefore, null hypothesis is accepted (populations are same)

\section{Attenuation Rate Constants as Function of Parameters}

Relationship of Attenuation Rate Constant to Coefficient of Determination $\left(\mathrm{r}^{2}\right)$

To evaluate whether a relationship exists between the attenuation rate constants and $\mathrm{r}^{2}$ for TPH as gasoline and benzene, the two variables were plotred against each other, as shown in Figure 11 and 12. The correlation coefficients for the relationship between the two values are also presented in the figures. According to Davis (1986), the significance of the correlation coefficients can be tested if both variables are normally 
distributed. Therefore, since the $r^{2}$ values are not normally distributed, the level of significance of the correlation values could not be calculated.

Relationship of Attenuarion Rates to Ground Water Depth Range and Distance from Source

Attenuation rate constants for TPH as gasoline and benzene are plotted against ground water depth range in Figures 13 and 14. The ground water depth range is the difference between the maximum and minimum ground water depths during the time period under consideration. The correlation coefficients between TPH as gasoline and benzene to ground water depth range are -0.10 and -0.12 , respectively. A level of significance was not calculated for the correlation coefficients since the distribution of the ground water depth range does not appear to be normal. However, based on the low correlations, the pattems shown on Figures 13 and 14 appear to be random, indicating that the ground water depth range does not play a significant role in attenuation rate.

The attenuation rate constants for TPH as gasoline and benzene are shown plotted against distance from source in Figures 15 and 16. The correlation coefficients between TPH as gasoline and benzene attenuation rate constants to the distance from source are 0.07 and 0.02 , respectively. The low correlation coefficients between the data indicate that there is no relationship between the observed degradation rates and the distance from source.

Effect of Ground Water Elevations on Attenuation Rate Constants and Coefficient of Determination

Ground water elevations were plotted on the Mathcad worksheets to evaluate sites where there was an apparent relationship to concentrations and ground water elevation. 


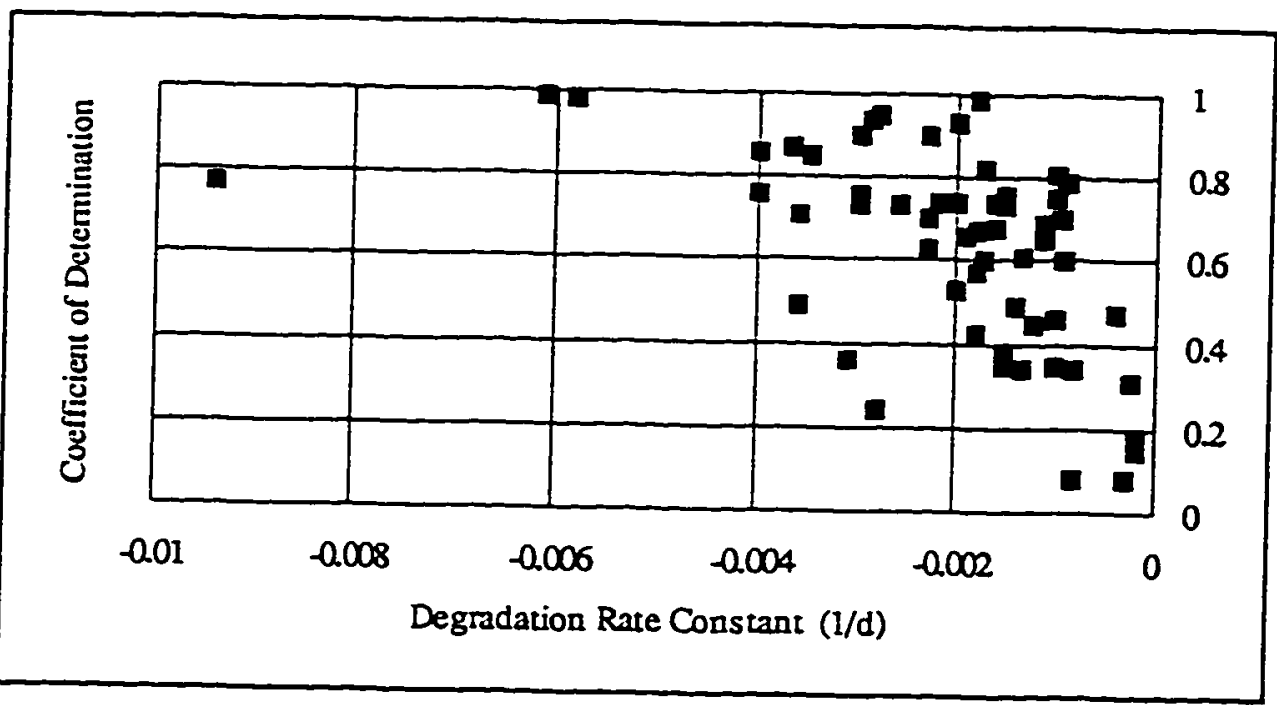

Correlation coefficient $=-0.52$

Figure 11. TPH as gasoline attenuation rate constant versus coefficient of determination (confined and unconfined aquifers combined).

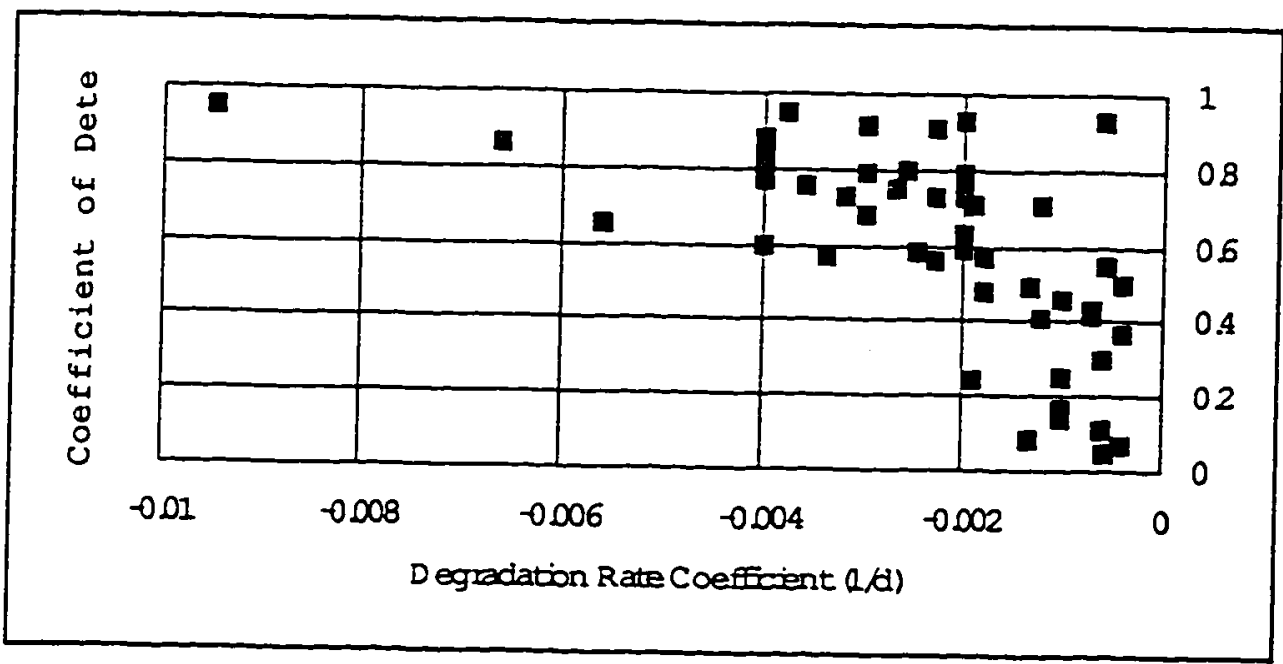

Correlation coefficient $=-0.61$

Figure 12. Benzene attenuation rate constant versus coefficient of determination (confined and unconfined aquifers combined). 


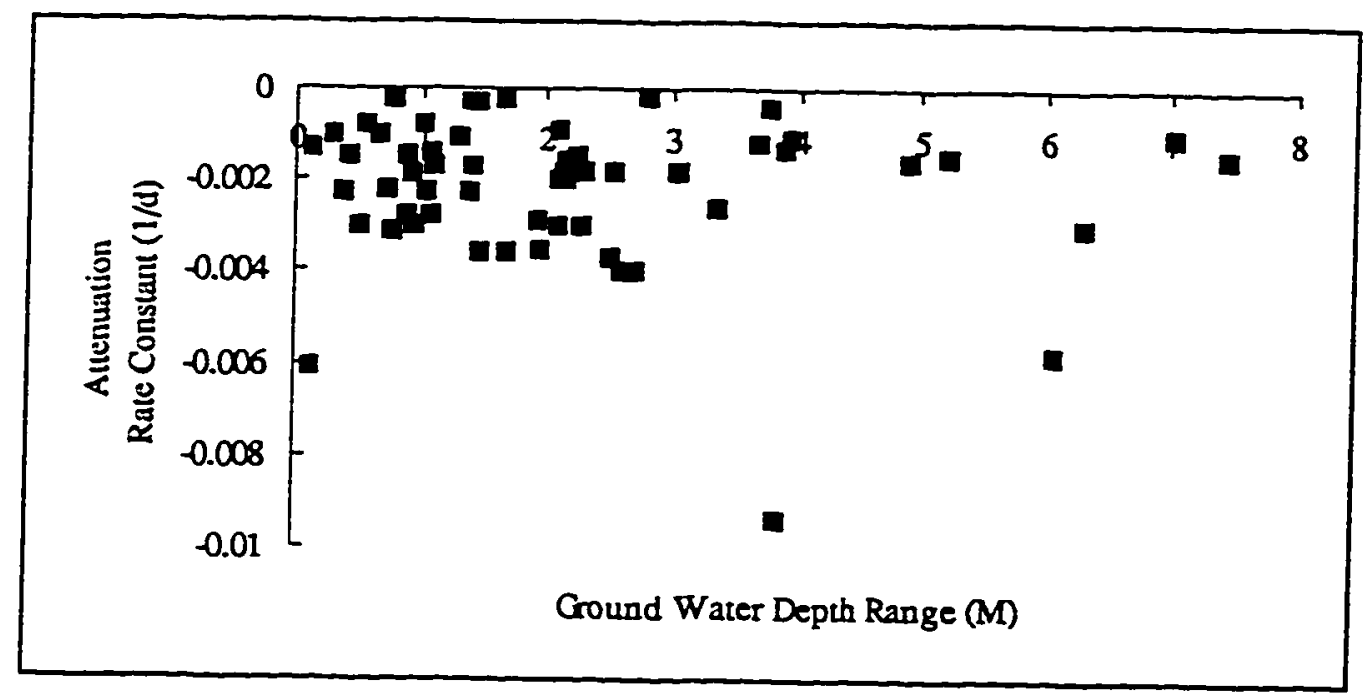

Correlation coefficient $=-0.10$

Figure 13. TPH as gasoline attenuation rate constant versus ground water depth range (maximum minus minimum elevations).

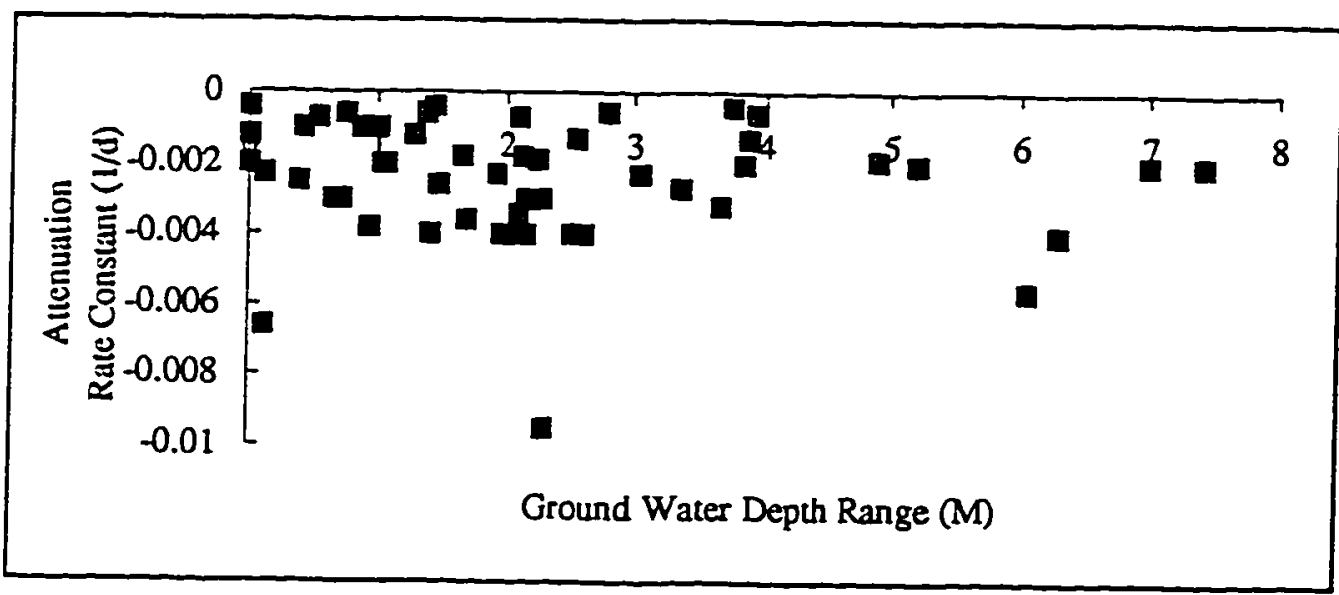

Correlation coefficient $=-0.12$

Figure 14. Benzene attenuation rate constant versus ground water depth range (maximum minus minimum elevations). 


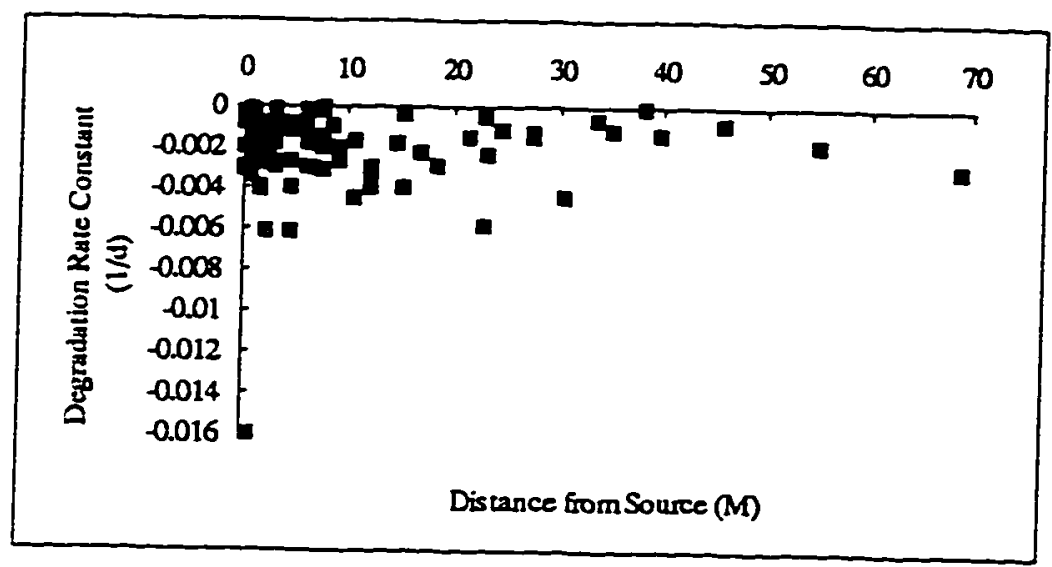

Correlation coefficient $=0.07$

Figure 15. TPH as gasoline attenuation rate constant versus distance from source (confined and unconfined combined).

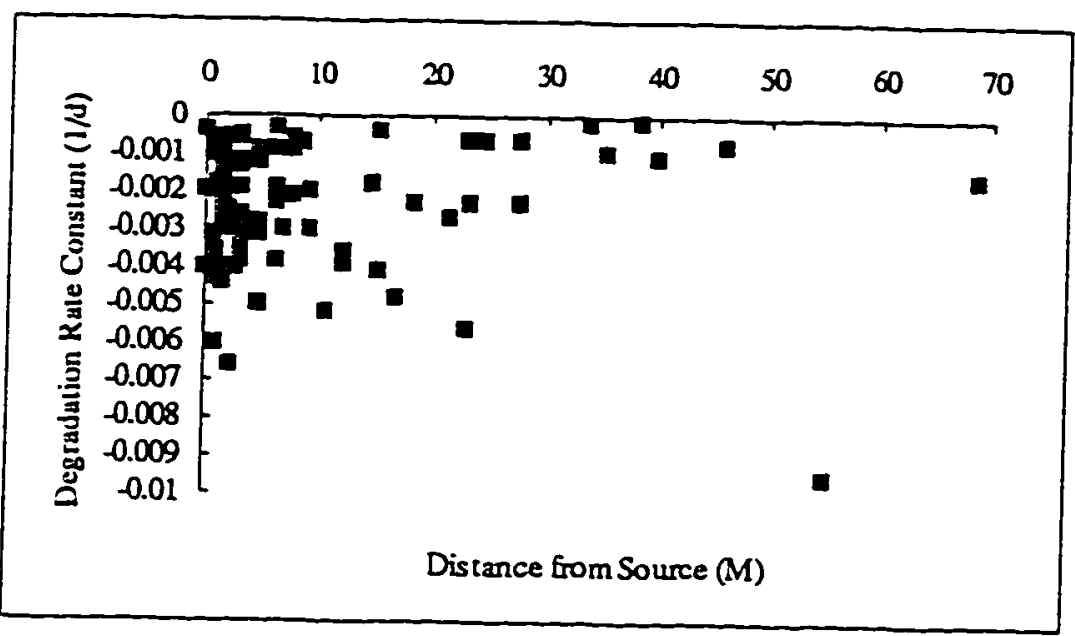

Correlation coefficient $=0.02$

Figure 16. Benzene attenuation rate constant versus distance from source (confined and unconfined combined). 
The Mathcad worksheets are presented in Appendix B. Fluctuating ground water elevations may affect the degradation rates of TPH as gasoline and benzene if residual petroleum hydrocarbons are absorbed onto soil at the source area. When ground water elevations increase during winter, the absorbed hydrocarbons may become mobilized in the ground water, which would increase concentrations.

Ground water elevations were qualitatively compared to TPH as gasoline and benzene concentrations. In general, if both ground water elevations and concentrations showed an increase or decrease during more than half of the sample events, the well was recorded as showing a relationship between the two. The magnitude of the increase or decrease was not taken into consideration. A summary of the correlation and attenuation rate values for TPH as gasoline and benzene for sites with a elevation/concentration relationship are presented below in Table 16. The summary presented in Table 16 indicates that sites where concentrations of TPH as gasoline and benzene appear to be influenced by ground water elevation fluctuations have lower attenuation rate constants and coefficients of determination than sites with no ground water elevation relationship. The evaluation was performed on individual wells instead of average site values for sites with more than one well since some sites had wells with wells that both did and did not display a relationship between elevation and concentration.

Table 16. Summary of sites with relationship between ground water elevation and TPH as gasoline and benzene concentration.

\begin{tabular}{|l|l|l|l|}
\hline & Number of Wells & Mean & Median \\
\hline Degradation Rate (k) & & & \\
\hline TPH Gasoline & 20 & -0.002 & -0.001 \\
\hline Benzene & 12 & -0.001 & -0.001 \\
\hline
\end{tabular}


Table 16 (continued). Summary of sites with relationship between ground water elevation and TPH as gasoline and benzene concentration.

\begin{tabular}{|l|l|l|l|}
\hline & Number of Wells & Mean & Median \\
\hline $\begin{array}{l}\text { Coefficient of } \\
\text { Determination }\left(r^{2}\right)\end{array}$ & & & \\
\hline TPH Gasoline & 20 & 0.40 & 0.41 \\
\hline Benzene & 12 & 0.34 & 0.30 \\
\hline
\end{tabular}

Spatial Distribution of Atrenuation Rate Constant for Benzene

To qualitatively evaluate whether the attenuation rate constant varies with distance down-gradient from the source, the attenuation rate constants were compared to distance from source for sites with benzene data available for two or three monitoring wells. The results of the comparison suggest that the attenuation rate constants generally appear to decrease with increasing distance from the source (Table 17). The magnitude of the change was not taken into consideration, since the degree of change appeared to vary significantly from site to site. Not included in Table 17 are three sites with multiple wells meeting the study criteria but that did not have benzene data and one site with two downgradient wells that were equidistant from the source.

Table 17. Summary of sites showing increase or decrease in attenuation rate constant with distance from source.

Number of sites with benzene data from two or more wells down-gradient of source Sites with decreasing benzene attenuation rate constants with distance from source Sites with increasing benzene attenuation rate constants with distance from source Initial decrease with distance, then increase

No significant change with distance from source

$\frac{18}{12}$




\section{DISCUSSION}

\section{$\underline{\text { Range of Attenuation Rate Constants }}$}

The attenuation rate constants were found to vary over a relatively narrow range. The TPH as gasoline attenuation rate constants (combined confined and unconfined sites) ranged from $-0.0002 /$ day to $-0.009 /$ day, with a mean of $-0.002 /$ day. Benzene attenuation rate constants ranged from $-0.0004 /$ day to $-0.01 /$ day, with a mean of $-0.002 /$ day. The relatively narrow range of the attenuation rate constants suggests that similar degradation processes occur throughout the study area.

There was not a significant difference in the comparison between the data for individual wells versus site averages. This indicates that the atrenuation rate constant observed in one well at a site may behave independendly from attenuation rate constants observed in other wells on the same site. Because the hydrogeologic characteristics are most likely relatively uniform within sites, the variability of artenuarion rate constants within single sites suggests that factors other than hydrogeologic characteristics control the attenuation rate constants.

\section{Predicted Behavior of Benzene Amenuation Duration}

A mean benzene attenuation rate constant for combined confined and unconfined aquifers of $-0.0023 / d a y$ was observed, with a standard deviarion of 0.0017 . Because the distribution was found to be normally distributed, approximately 68 percent of the values can be expected to fall within one standard deviation on either side of the mean value. In aciiticn. approximately 95 percent of the values can be expected to fall within plus or minus two standard deviations (Davis, 1986). Therefore, approximately 68 percent of 
sites with decreasing concentrations of benzene can be expected to have attenuation rates ranging from $-0.004 /$ day to $-0.0006 /$ day. Assuming log linear degradation, the inverse of the attenuation rates provides the duration for the concentrations to decrease to one tenth of an inirial value. Therefore, approximately 68 percent of sites with decreasing concentrations of benzene would be expected to take between 250 and 1,666 days (approximately 0.7 to 4.6 years) to decrease to 10 percent of an initial value. Only 5 percent of sites would be expected to have benzene attenuation rates exceed approximately $-0.006 /$ day, which corresponds to a duration of 166 days (approximately 0.45 year). The lower 5 percent of attenuation rates is not able to be accounted for using standard deviations, because two standard deviations would place the degradation rate greater than 0 . This overlaps the portion of the population of sites where attenuation rates are stable or increasing, which were eliminated from this study.

To provide a tool that can be used to predict length of time for an initial concentration of benzene to reach 1 part per billion (ppb), the attenuation rate constants for the mean $(-0.0023 / \mathrm{day})$, plus one standard deviation $(-0.004 / \mathrm{day})$, and minus one standard deviation (-0.0006/day) of all sites are plotted against time (Figure 17). The concentration of $1 \mathrm{ppb}$ benzene is the maximum contaminant level (MCL) for drinking water established by the California Environmental Protection Agency (EPA). The logarithmic concentrations are plotted along the $y$-axis, and time is presented along the $x$ axis. To predict how long it will take for a particular concentration of benzene to decay to a concentration of $1 \mathrm{ppb}$, the user would read from the $y$ axis the initial concentration to the three diagonal lines, and then down to the corresponding time. For example, using Figure 17, the mean length of time to reach $1 \mathrm{ppb}$ benzene corresponding to an initial concentration of $30 \mathrm{ppb}$ is approximately 2.1 years. In addition, 68 percent of sites would be expected to decrease from a level of $30 \mathrm{ppb}$ to $1 \mathrm{ppb}$ benzene between 


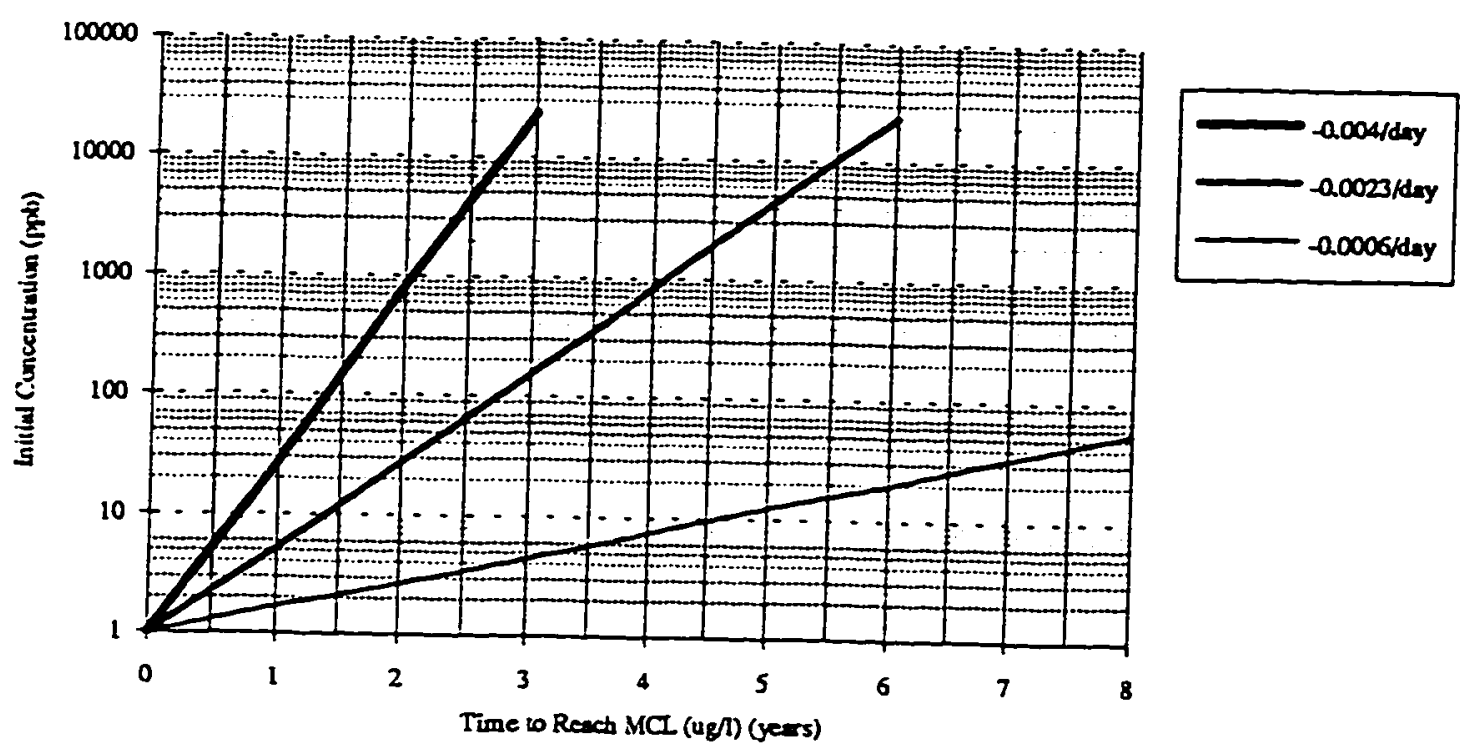

Figure 17. Time required for benzene to decrease from an initial concentration to the $\mathrm{MCL}(1 \mu \mathrm{g} / \mathrm{l})$ for mean $(-0.0023 /$ day $)$, plus one standard deviation $(-0.004 /$ day $)$, and minus one standard deviation $(-0.0006 /$ day).

approximately 1 and 6.7 years (plus and minus one standard deviation of the attenuation rate constants).

\section{Relationship of Attenuation Rate Constants to Coefficients of Determination}

The coefficients of determination show a very wide range and a non-normal distribution. Figures 11 and 12 indicate that sites with attenuation rate constants greater than $-0.002 /$ day generally displayed coefficients of determination greater than 0.5 . This suggests that first order degradation contributes significantly to sites where attenuation rates are generally above the median. This emphasizes the importance of biodegradation at these sites, since biological degradation tends to follow first order kinetics. Sites with degradarion rate constants less than $-0.002 /$ day displayed a wide range of coefficients of 
determination. This indicates that biodegradation may be less significant at some sites, with other degradation mechanisms playing a more significant role.

Although the coefficients of determination are relatively low $(0.5$ to 0.8$)$ by general standards, the amount of variability, or "noise," of the concentration versus time plots shown in Appendix B appears to be consistent for environmental data. Sites with moderate levels of coefficients of determination behave relatively linearly. Some "noise" is typically introduced in environmental data as a result of variability in ground water flow directions, irregular rate of input of contaminants into ground water, variable well sampling procedures, and variable analytical/sample preparation practices at different laboratories, among other reasons.

\section{Degradation Rate Constants as a Function of Aquifer Conditions and Soil Tvpes}

The mean degradation rate constants for TPH as gasoline and benzene were slightly higher for unconfined conditions versus confined conditions $(-0.003 /$ day versus $-0.002 /$ day). However, the differences do not appear to be significant, based on the similarity between the means, range, and distribution of the values (see Tables 3 and 4). This suggests that there are similar degradation processes operating under each of the hydrogeologic conditions. The results of the F-test between the sample variances of the confined and unconfined categories suggested that there was a significant difference in the benzene degradation rate coefficients between unconfined and confined aquifers.

However, the results of the F-test may be influenced by variability in the data, since the populations qualitatively appear to be similar.

The comparison of degradation rate constants categorized by aquifer soil types did not appear to indicate that there is a significant difference between sites with aquifers composed of clean sands/gravel than those with clayey soils. There was a significant 
difference in the sample populations between clean sands/gravels and sites with silty soils and between sites with silty and clayey soils. These results do not correspond with what is intuitively expected. As a result of the differences in clay content and porosity, a difference between clean sands/gravels with clayey soils would be expected. The resuits may reflect inconsistent soil classification practices in the field or may be coincidental. In addition, a more detailed study with larger samples may need to be performed to identify differences in degradation processes between aquifer soil types.

\section{Degradation Rate Constants as a Function of Remedial Activities}

Benzene degradation rate constants categorized by remedial activity did not show significant differences in sample variations between the category of "no remediation" and those with various remedial activities. These results indicate that there is no significant difference between the distribution of values between the categories. However, increases in mean degradation rate constants were observed $(-0.003 /$ day versus $-0.002 /$ day $)$ for sites where soil vapor extraction, excavation, and pump and reat were performed, although the differences may not be significant.

\section{Degradation Rate Constants as a Function of Ground Water Elevation Fluctuations}

Comparison of values between Table 16 to Tables 3,4,5, and 6 indicates that sites where concentrations of TPH as gasoline and benzene appear to be influenced by ground water elevation fluctuations have lower mean degradation rate constants and coefficients of determination than sites with no ground water elevation relationship. The decreased degradation rate constants may be a result of remobilization of residual contaminants. This could occur when an increase in ground water elevation results in ground water coming into contact with residual fuel hydrocarbons absorbed onto soil. 
The cause of the decrease in the mean coefficients of determination may be a result of fluctuating water levels causing greater variability in the concentrations.

\section{Spatial Distribution of Degradation Rate Constants}

The degradation rate constants generally appear to decrease with increasing distance down-gradient from the source. This may be the result of a depletion of oxygen within the plume down-gradient of the source that may reduce biologically mediated degradation rates. The sites showing increases in degradation rate constants may be the result of the placement of monitoring wells off-set from the center line of the petroleum plume. Such off-set monitoring wells, although down-gradient of the source, may not be capturing the most highly contaminated ground water but rather ground water closer to the lateral fringe of the plume where oxygen is available by transverse mixing with uncontaminated ground water. These results appear to be consistent with the findings of a study by Borden (1986a), where high degradation rates were observed near the source of a dissolved petroleum plume as a result of the presence of dissolved oxygen. The degradation rates decreased down-gradient of the source as a result of a zone of oxygen depletion along the centerline of a plume. Dissolved oxygen was found to increase in concentration away from the centerline, with increasing degradation rates associated with the increased dissolved oxygen.

\section{Comparison of Results to Previous Studies}

A previous study by Rice et al. (1995) concluded that benzene attenuation rate constants are not normally distributed while this study found them to be normally distributed. In addition, the mean degradation rate constant value $(-0.0008 /$ day $)$ was also 
different from that found in this study $(-0.0023 /$ day $)$. The previous study included sites from many different ground water basins in Califomia. Therefore, the difference in the results berween this study and the Rice et al. study may be the result of different processes operating in various ground water basins across California. Attenuation processes within a ground water basin may reflect basin characteristics, such as depth to ground water, soil types, ground water chemistry, and hydrogeologic conditions. Therefore, application of the results of this study to sites outside of the study area may be inappropriate. The differences between the studies suggest the need to study the behavior of other ground water basins in detail.

\section{Ground Water Gradient}

The hydraulic gradient information collected for each site was not used to perform any analyses. This is because of the high variability of the gradient observed at many sites over time and also spatially across sites. As a result, it was not possible to assign one meaningful hydraulic gradient value to a particular site. 


\section{CONCLUSIONS .}

The primary conclusions of this study are as follows:

1. The values of the attenuation rate constants fall within a relatively narrow range, indicating that similar attenuation processes are occurring throughout the study area. These attenuation rate constants are greater than those found for California as a whole (Rice et al., 1995) indicating that they may reflect conditions specific to the study area and should not necessarily be applied to other areas.

2. The higher the attenuation rate constants, the more likely the attenuation will be first order. This most likely points to biodegradation, which generally follow first order kinetics, as a major cause of concentration decreases at these sites. The lower degradation rates (less than the median rate) display a higher degree of variation of the coefficient of determination, indicating that attenuation processes other than biodegradation may play a more significant role at some of these sites. Such processes couid include dispersion during contaminant transport, which would result in an apparent degradation as a result of dilution.

3. The attenuarion rate constants do not appear to be influenced significandly by environmental conditions and site history factors, which suggests that the attenuation processes that are occurring tend to be independent of these influences. However, turher study with larger sample populations may be needed in order to more 
confidently determine whether there are significant differences in attenuation rate constants between categories based on soil types and remedial methods. 


\section{REFERENCES}

Borden, R. C., and P. B. Bedient. 1986a. Transport of Dissolved Hydrocarbons Influenced by Oxygen-Limited Biodegradation 1 . Theoretical Development. Water Resources Research. Vol. 22, No. 13. pp. 1973 - 1982.

Borden, R. C., and P. B. Bedient. 1986b. Transport of Dissolved Hydrocarbons Influenced by Oxygen-Limired Biodegradation 2. Field Application. Water Resources Research. Vol. 22, No. 13. pp. 1983 - 1990.

Buscheck. T. E., K. T. Kirk, and S. N. Nelson. 1993. Evaluation of Intrinsic Bioremediation at Field Sires. Proceedings of the Conference on Petroleum Hydrocarbons and Otganic Chemicals in Ground Water, National Ground Water Association/API, Houston, Texas, November 10 - 12.

Davis, J. C. 1986. Statistics and Data Analvsis in Geology Second Edition, John Wiley and Sons, New York, 646p.

Davis, J. W., N. J. Klier, and C. L. Carpenter. 1994. Narural Biological Attenuation of Benzene in Ground Water Beneath a Manufacturing Facility. Ground Water. Vol. 32, o. 2. pp. $215-226$.

Hacley, P. W., and R. Amscrong. 1991. "Where's the Benzene?" - Examining Califomia Ground Water Surveys. Ground Water. Vol. 29, No. 1, pp. 35 - 40. 
Hutchins, S. R., W. C. Downs, J. T. Wilson, G. B. Smith, D. A. Kovacs, D. D. Fine, R. H. Douglas, and D. J. Hendrix. 1991. Effect of Nitrate Addition on Biorestoration of Fuel-Contaminated Aquifer: Field Demonstration. Ground Water. Vol. 29, No. 4, pp. $571-580$

Klecka, G.W., J. W. Davis, D. R. Ray, and S. S. Madson. 1990. Natural Bioremediation of Organic Contaminants in Ground Water: Cliff-Dow Superfund Site. Ground Water. Vol. 28, No. 4, pp. 534 - 543.

McAllister, P.M., C.Y. Chiang. 1994. A Practical Approach to Evaluating Natural Attenuation of Contaminants in Ground Water. Ground Water Monitoring Review. Spring 1994, pp. $161-173$.

Ott, Lyman. 1984. An Introduction to Statistical Methods and Data Analysis, PWS Publishers, Boston, Massachusetts, 775 p.

Rice, D. W., R.D. Randolph, J.C. Michaelsen, B.P. Dooher, D.H. MacQueen, S.J. Cullen, W.E. Kastenberg, L.G. Everet, and M.A. Marino. November 16, 1995. Califomia Leaking Underground Fuel Tank (LUFT) Historical Case Analyses. Prepared for the California State Water Resources Control Board Underground Storage Tank Program and Senate Bill 1764 Leaking Underground Fuel Tank Advisory Commirtee 
State of California Department of Water Resources. 1967 "Bulletin No. 118-1, Evaluation of Ground Water Resources, South Bay, Appendix A: Geology," August. 
APPENDIX A. EXAMPLES OF DATA COLLECTION FORMS 


\section{DATA LOG}

SCVWD Site $=$

Site Address:

Site Name:

Site Location:

Contaminant Released:

TPHg

TPHd

Other:

Source Removed: $Y \mathbb{N}$

Free Product: Y/N

Remediation activities:

Hvdrogeologic Conditions:

Confined/Unconfined

Vadose Zone soil type:

Aquifer thickness:

Aquifer soil type:

Ground water flow direction:

Ground Water Gradienr:

Data Evaluation Results:

Monitoring Well:

Average Ground Water Depth:

Distance/direction from source:

Ground Water Depth Range:

\begin{tabular}{|l|l|l|l|l|}
\hline Pafameter & TPHg & Benzene & TPHd & \\
\hline Deg. Rate & & & & \\
\hline Correlation & & & & \\
\hline $\mathrm{R}=$ & & & & \\
\hline
\end{tabular}

Monitoring Well:

Distance/direction from source:

Average Ground Water Depth:

Ground Water Depth Range:

\begin{tabular}{|l|l|l|l|l|}
\hline Parameter & TPHg & Benzene & TPHd & \\
\hline Deg. Rate & & & & \\
\hline Correlation & & & & \\
\hline $\mathrm{R}^{2}$ & & & & \\
\hline
\end{tabular}


Analutical Data:

SCVWD Site

Site Address:

Monitoring Well:

Distance/direction from source:

(Concenurations in ppb)

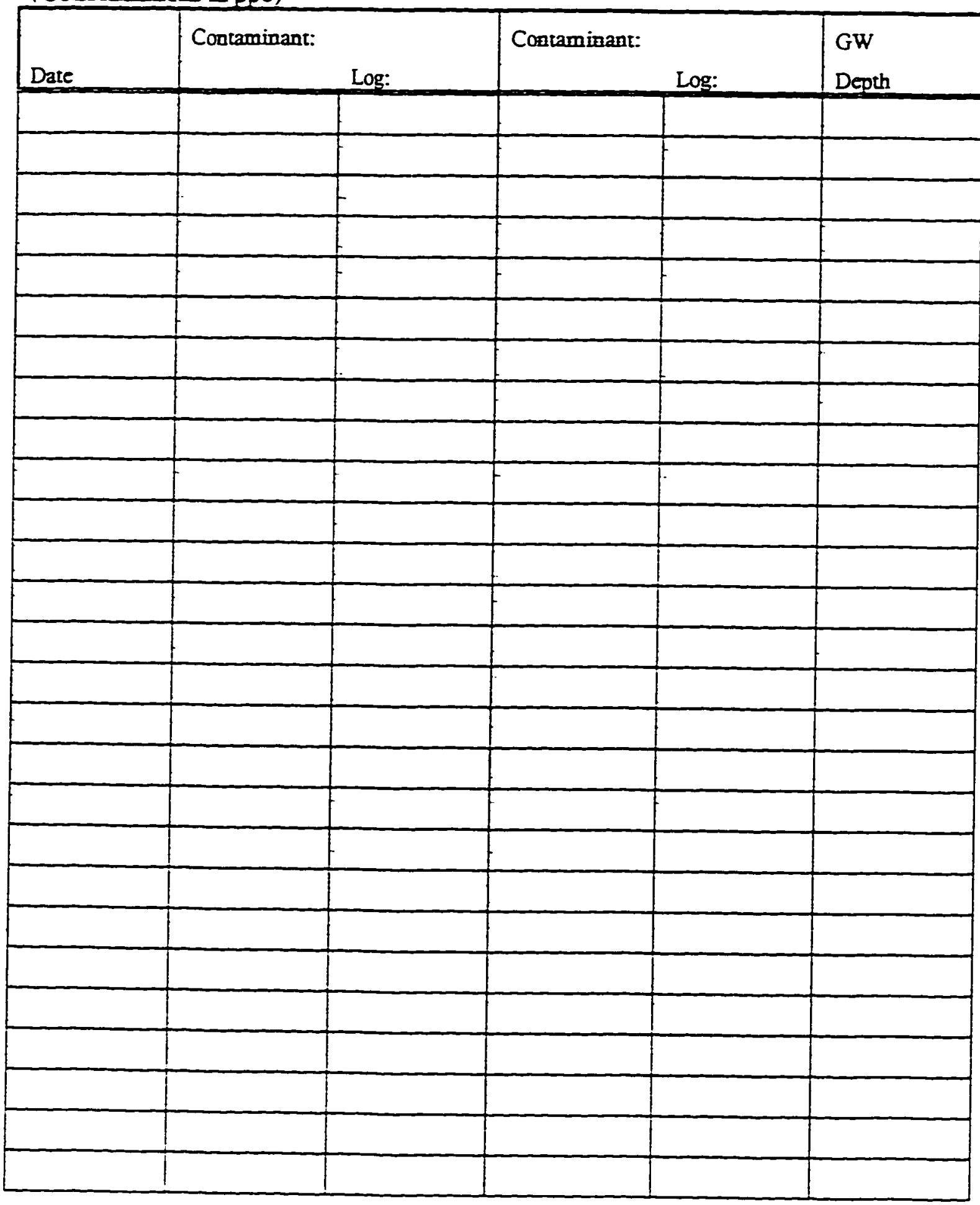


APPENDEX B. MATHCAD 6.0 WORK SHEETS 


\section{LEGEND}

SCWND Site Number:

Site ficdress:

Site Name:

Ciry:

Contaminant: TPH Gasoline

$$
i=0 . .14
$$

This is the number of data points minus one $(n-1)$

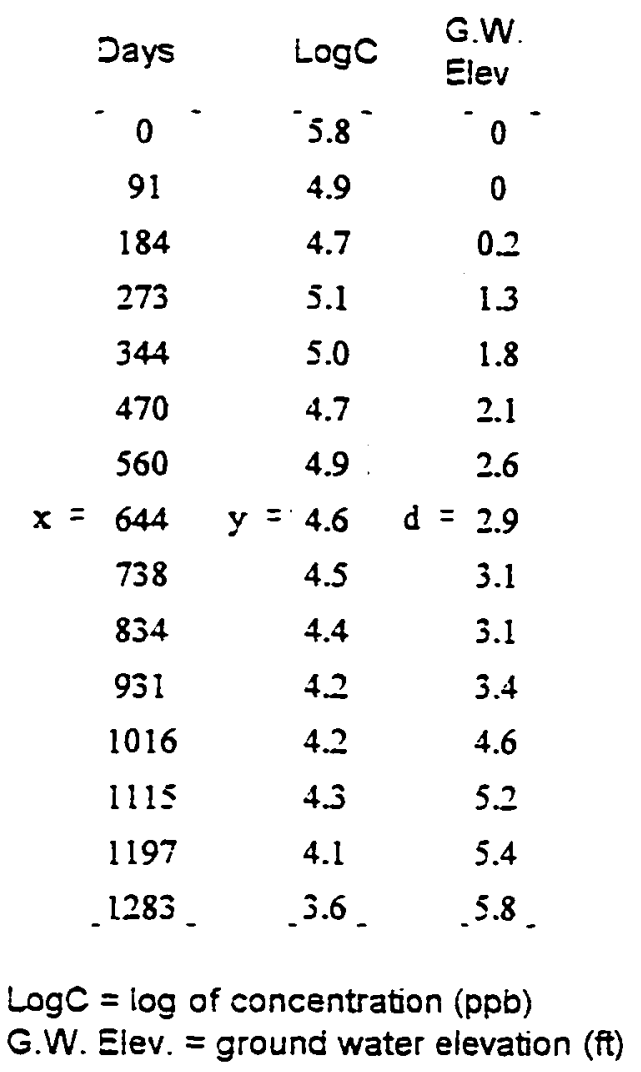

$a=\operatorname{slope}(x, y) \quad a=-0.0011(k)$

$b=$ intercept $(x . y) b=5.3265$

$\operatorname{corr}(x, y)=-0.8992 \quad(r)$

$\operatorname{cotr}(x, y)^{2}=0.8086 \quad\left(r^{3}\right)$

G.W. Elev. = ground water elevation ( $\mathrm{ft}$ )

Squares = concentration data points

Circles $=$ ground water elevation

Dashed line $=$ least aquares regression line

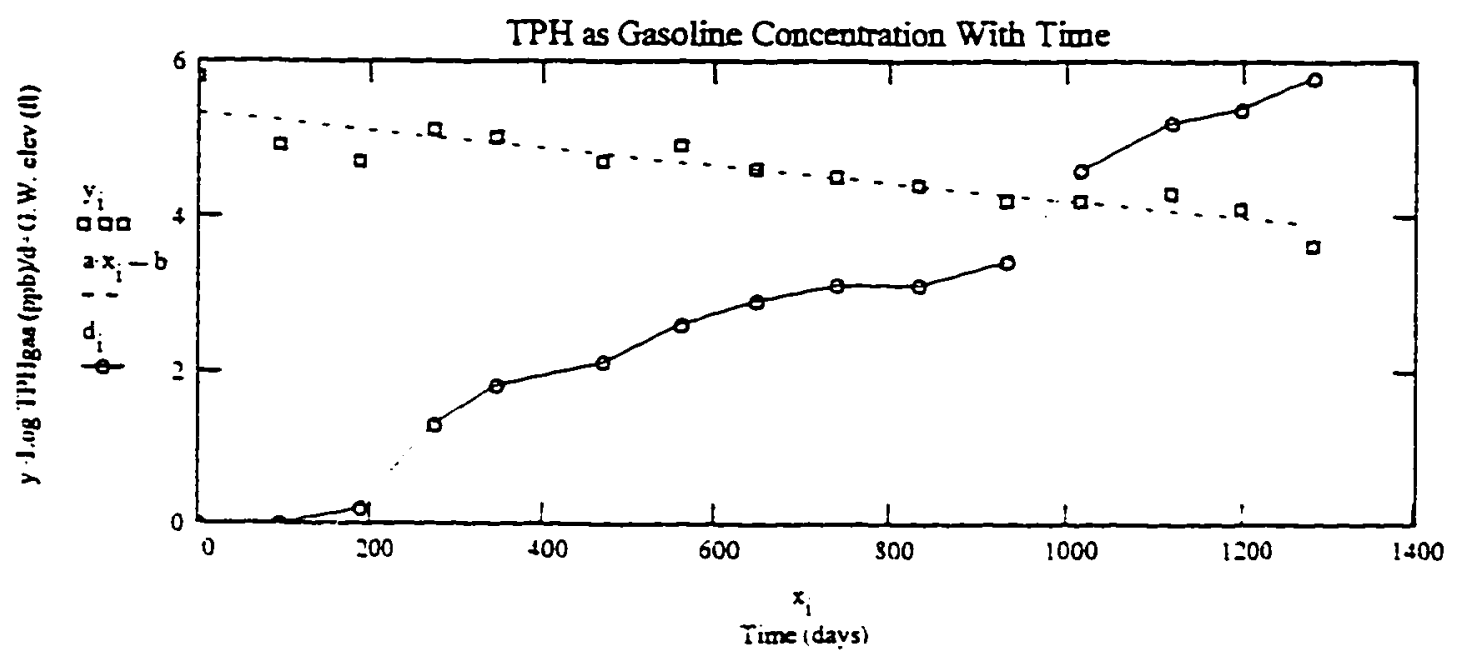


SCWND Site Number : 07S1W27EO1

Site Address: 921 Hamilton Avenue

Site Name: Exxon \#7-7121

City: Campbell

Contaminant: TPHg

$\begin{array}{ccc}\text { Days } & \text { LogC } & \begin{array}{c}\text { GW } \\ \text { Elev }\end{array} \\ 0 & -3.04 & 0 \\ 146 & 2.78 & 2.26 \\ \mathrm{x}=203 & \mathrm{y}=1.4 & \mathrm{~d}=2.15 \\ 327 & 2.69 & 2.45 \\ 389 & -1.4 & 1.46 .\end{array}$

$a=\operatorname{slope}(x . y) \quad a=-0.0031$

$b=$ intercept $(x, y) b=2.9303$

$\operatorname{corr}(x . y)=-0.603$

$\operatorname{com}(x, y)^{2}=0.3637$

Note: This site has two decreasing trends. one beginning in 1990 and the second beginning in 1993. The second trend was used.

Note: Ground water elevations adjusted to it graph. $O$ feet $=124.58$ feet

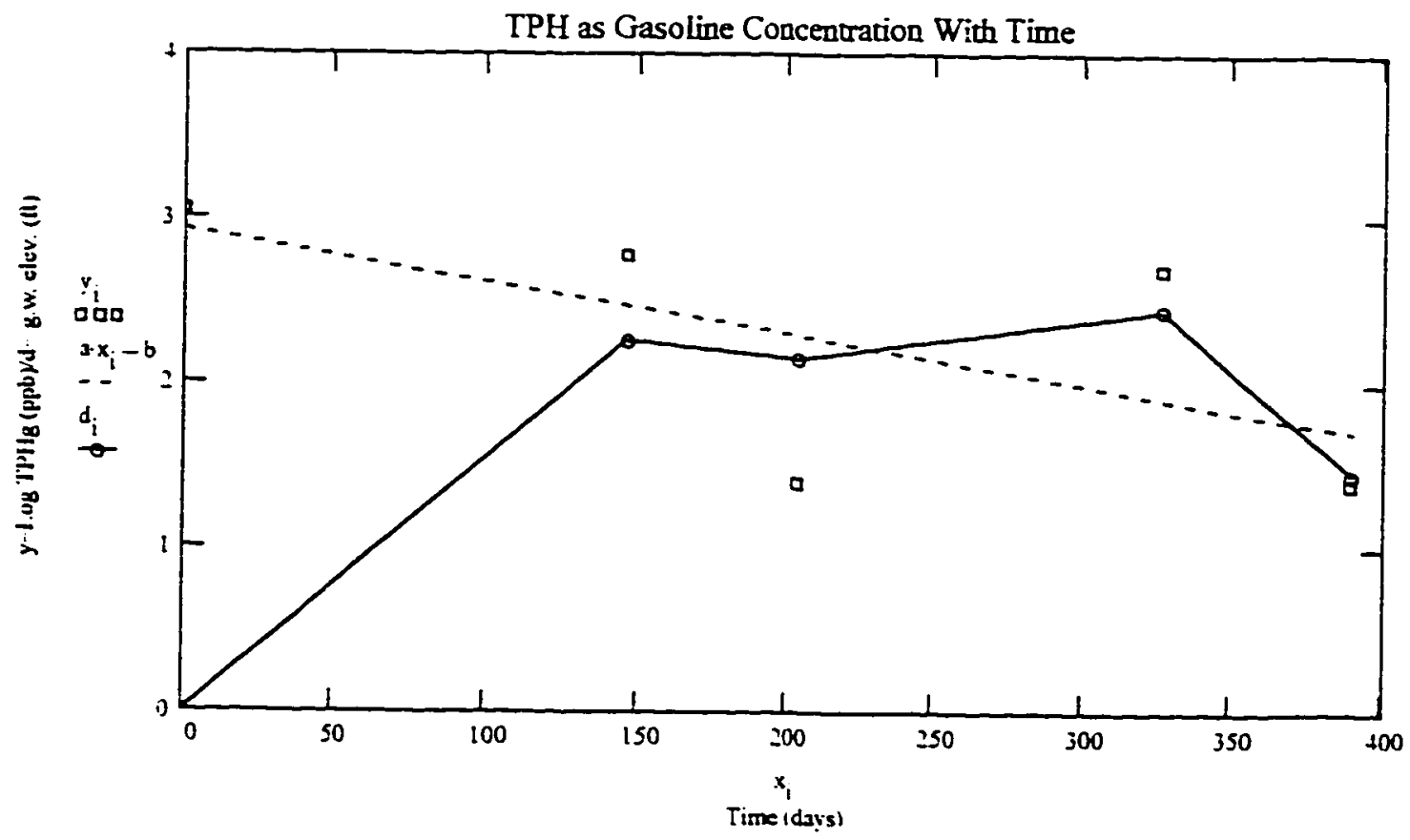


SCWWD Site Number : 07S1W27EO:

Site Address: 921 Hamilton Avenue

Site Name: Exxon \#7-7121

City: Campbell

Contaminant: Benzene

$$
i=0 . .4
$$

$\begin{array}{ccc}\text { Days } & \text { LogC } & \begin{array}{l}\text { GE } \\ \text { Elev }\end{array} \\ 0 & -1.57^{\circ} & - \\ 146 & 1.49 & 2.26 \\ \mathrm{x}= & \mathrm{y}=-0.3 & \mathrm{~d}=2.15 \\ 327 & 1.11 & 2.45 \\ 389 . & -0.3 . & .1 .46\end{array}$

$a=\operatorname{slope}(x . y) \quad a=-0.0038$

$b=$ intercept $(x, y) b=1.5247$

Note: This site has two decreasing trends. one beginning in 1990 and the second beginning in 1993. The second trend was used.

$\operatorname{corr}(x, y)=-0.6193$

$\operatorname{corr}(x . y)^{2}=0.3835$

Note: Ground water elevations adjusted to it graph. $O$ feet $=124.58$ feet

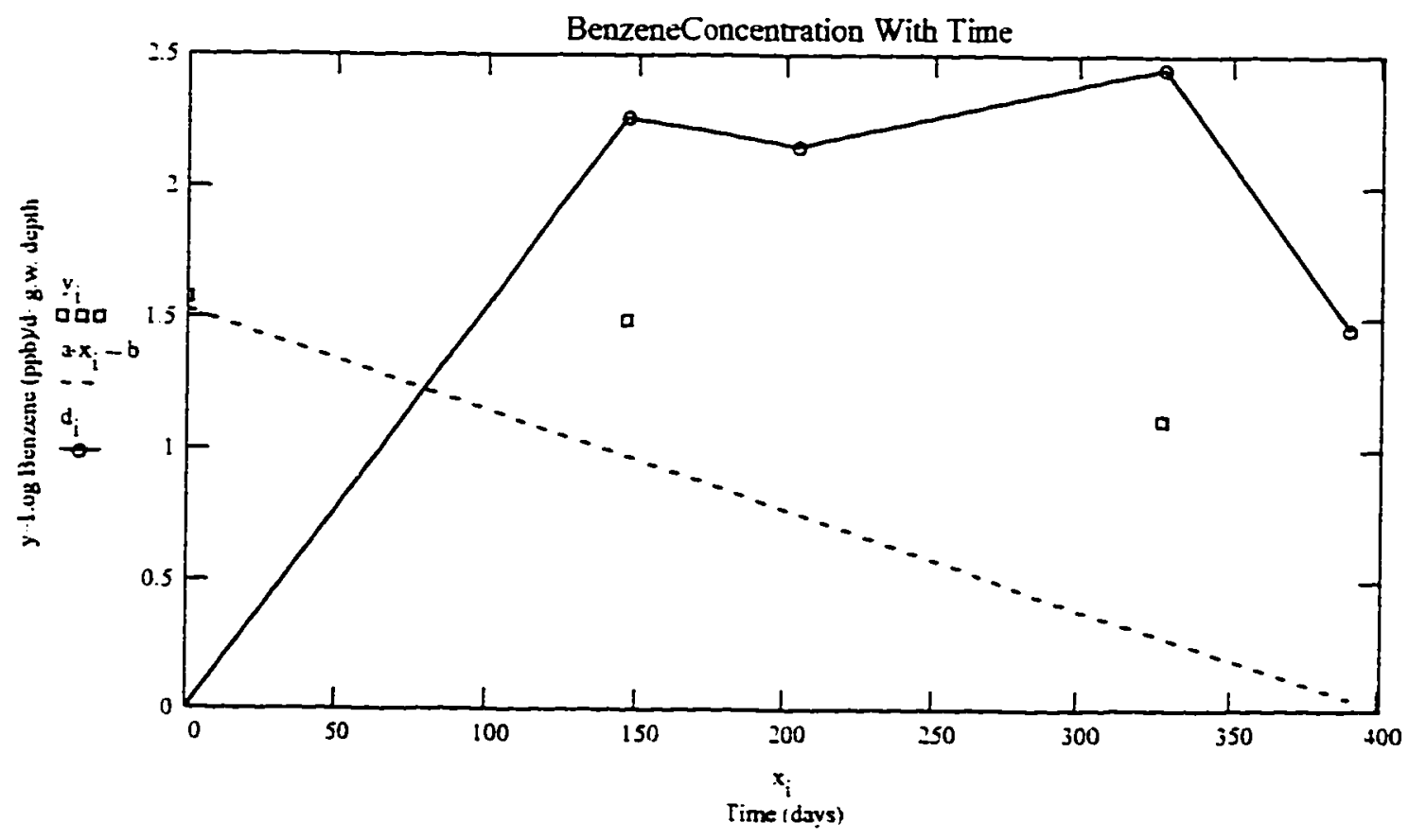


SCWWD Site Number : 07S1W33R01F

Site fiddress: 800 San Thomas Aquino

Site Name: Bartyzel Property

City: Campbell

Contaminant: TPHg

$$
i=0.5
$$

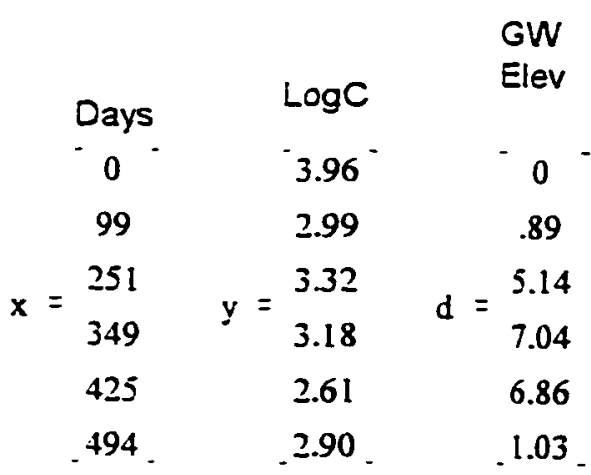

Note: Ground water elevations were adjusted to fit the

$\mathrm{a}=\operatorname{slope}(\mathrm{x} . \mathrm{y}) \quad \mathrm{a}=-0.0018$ graph. Oft $=208.17 \mathrm{ft}$.

b $=$ intercepl(x.y) $b=3.6492$

$\operatorname{corr}(x . y)=-0.7519$

$\operatorname{corr}(x . y)^{2}=0.5653$

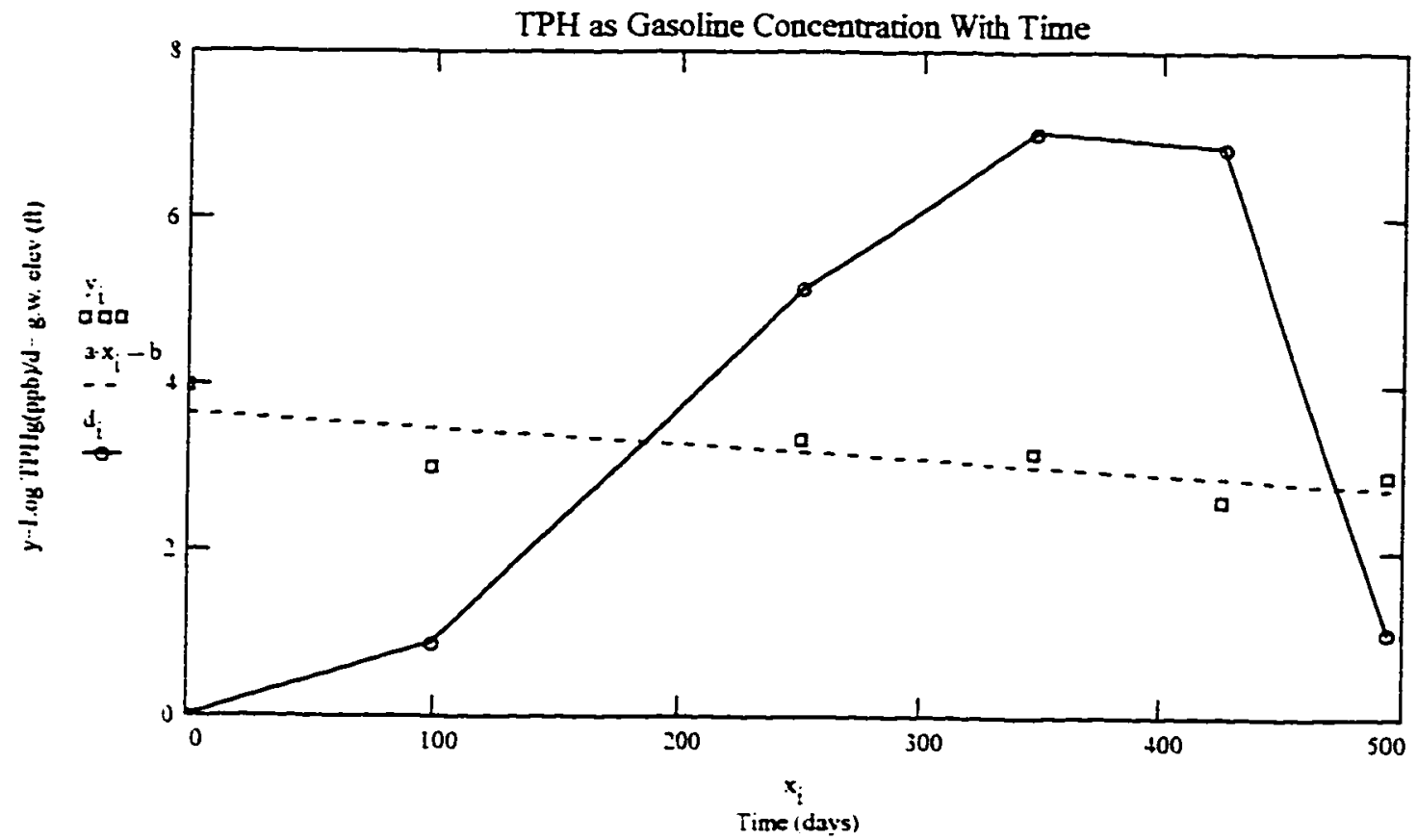


SCWWD Site Number : 07S1W33R01F Site Address: 800 San Thomas Aquino Site Name: Bartyzel Property

City: Campbell

Contaminant: Benzene

$$
i=0 . .5
$$

$a=\operatorname{slope}(x, y) \quad a=-0.0018$

$b=$ intercept(x.y) $b=3.6492$

$\operatorname{com}(x . y)=-0.7519$

$\operatorname{corr}(x . y)^{2}=0.5653$

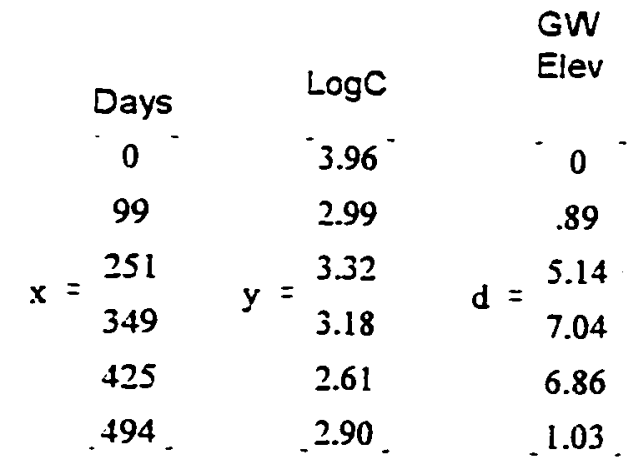

Note: Ground water elevations were adjusted to fit the graph. $0 \mathrm{ft}=208.17 \mathrm{ft}$.

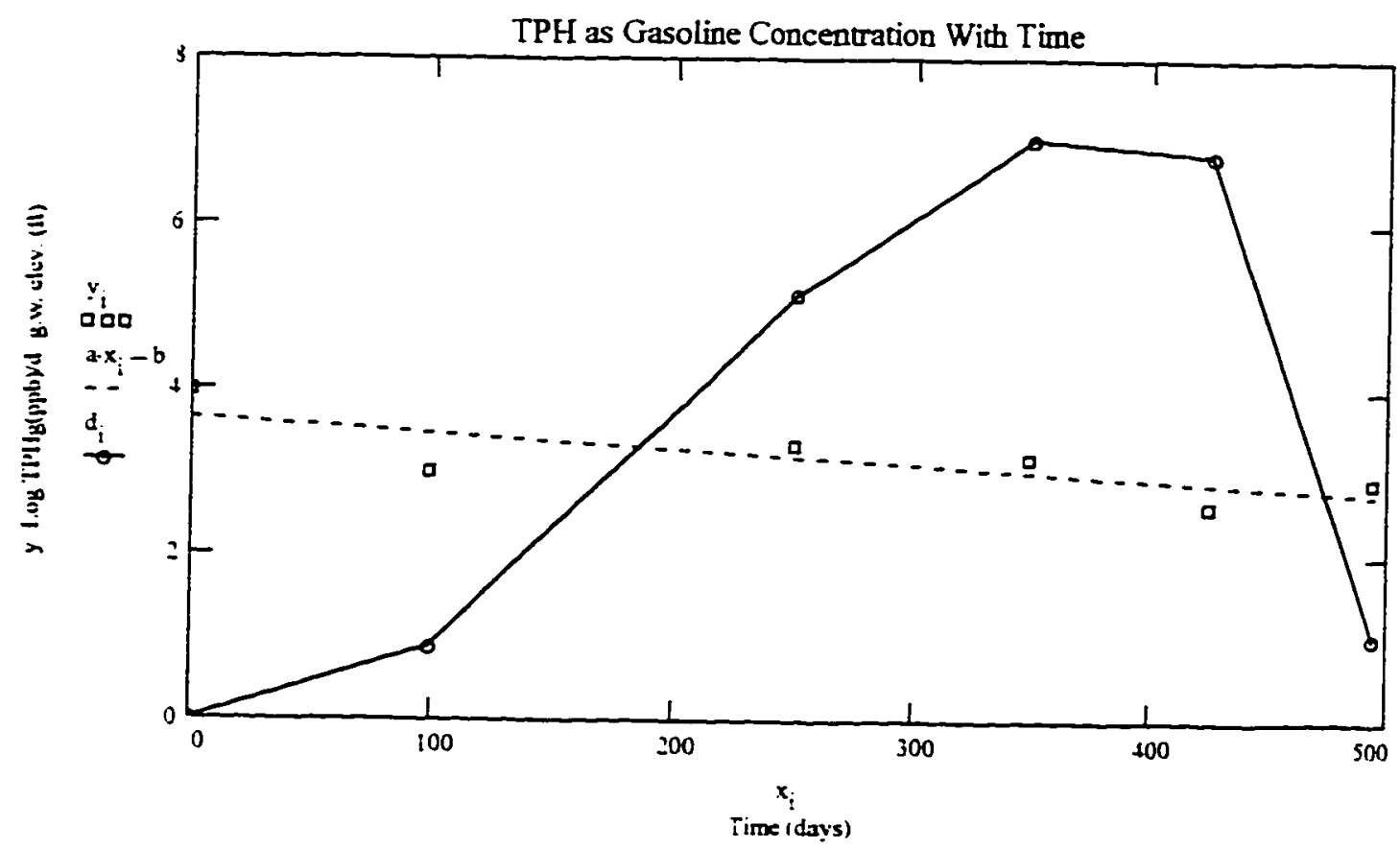


SCWWD Site Number 07s1w27f01: Site Address: 535 W. Hamilton Ave Site Name: Campbell Chevron

City: Campbell

Contaminant: TPH Gasoline (mw-1)

$$
i=0 . .6
$$

$\begin{array}{ccc}\text { Days } & \text { Logc } & \begin{array}{c}\text { G.W. } \\ \text { Elev }\end{array} \\ 0 & 4.2 & -6.83 \\ 29 & 3.9 & .22 \\ 49 & 2.8 & 0 \\ \mathrm{x}= & \mathrm{y}=2.4 & \mathrm{~d}=14 \\ 114 & 2.6 & 0 \\ 128 & 2.5 & 11.69 \\ -151 & -1.4 . & -14.99 .\end{array}$

\footnotetext{
$a=\operatorname{slope}(x, y) \quad a=-0.0155$

$b=$ intercept $(x, y) \quad b=4.0338$

$\operatorname{corr}(x, y)=-0.9041$

$\operatorname{corr}(x . y)^{2}=0.8173$
}

Note: Ground water elevations have been adjusted to fit the graph. O feet $=100.83$ feet. Two elevation data points shown did not have data and were input as 0 .

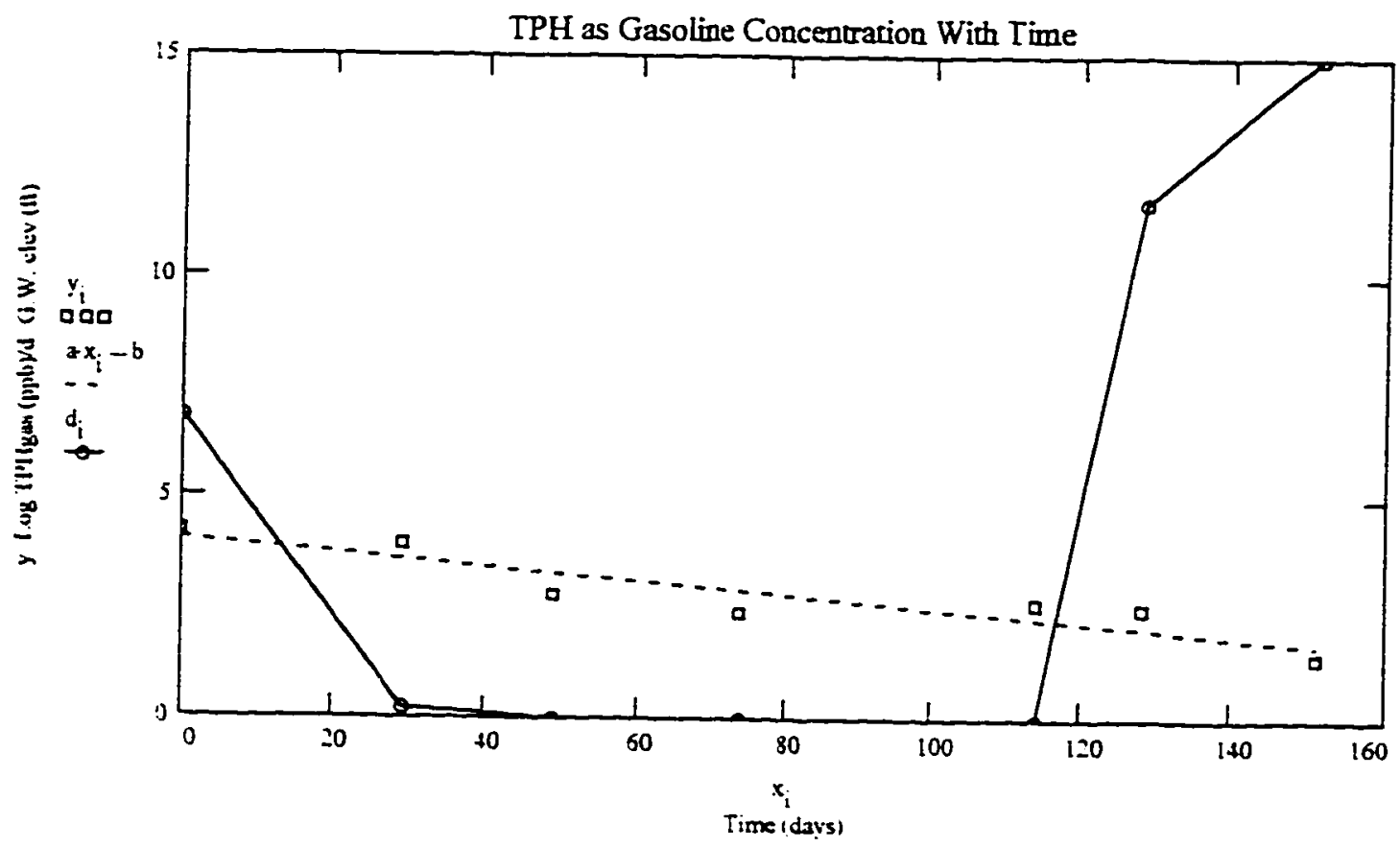


SCVWD Site Number 07s 1 w27f01: Site Address: $535 \mathrm{~W}$. Hamilton Ave Site Name: Campbell Chevron City: Campbell

Contaminant: Benzene (MW-1)

$$
i=0 . .5
$$

$\begin{array}{ccc}\text { Days } & \text { LogC } & \begin{array}{c}\text { G.W. } \\ \text { Elev }\end{array} \\ 0 & 2 & -2.95 \\ 105 & 1.5 & 4.67 \\ 207 & y=1.2 & 8.37 \\ 309 & .4 & 14.22 \\ 352 & .23 & 0 \\ .399 . & -0.6 . & 0\end{array}$

$a=\operatorname{slope}(x, y) \quad a=-0.006$

$b=\operatorname{intercept}(x . y) \quad b=2.1568$

Note: Ground water elevations were adjusted to it the graph. $O \mathrm{ft}=100.25 \mathrm{ft}$.

$\operatorname{corr}(x . y)=-0.9684$

$\operatorname{com}(x . y)^{2}=0.9378$

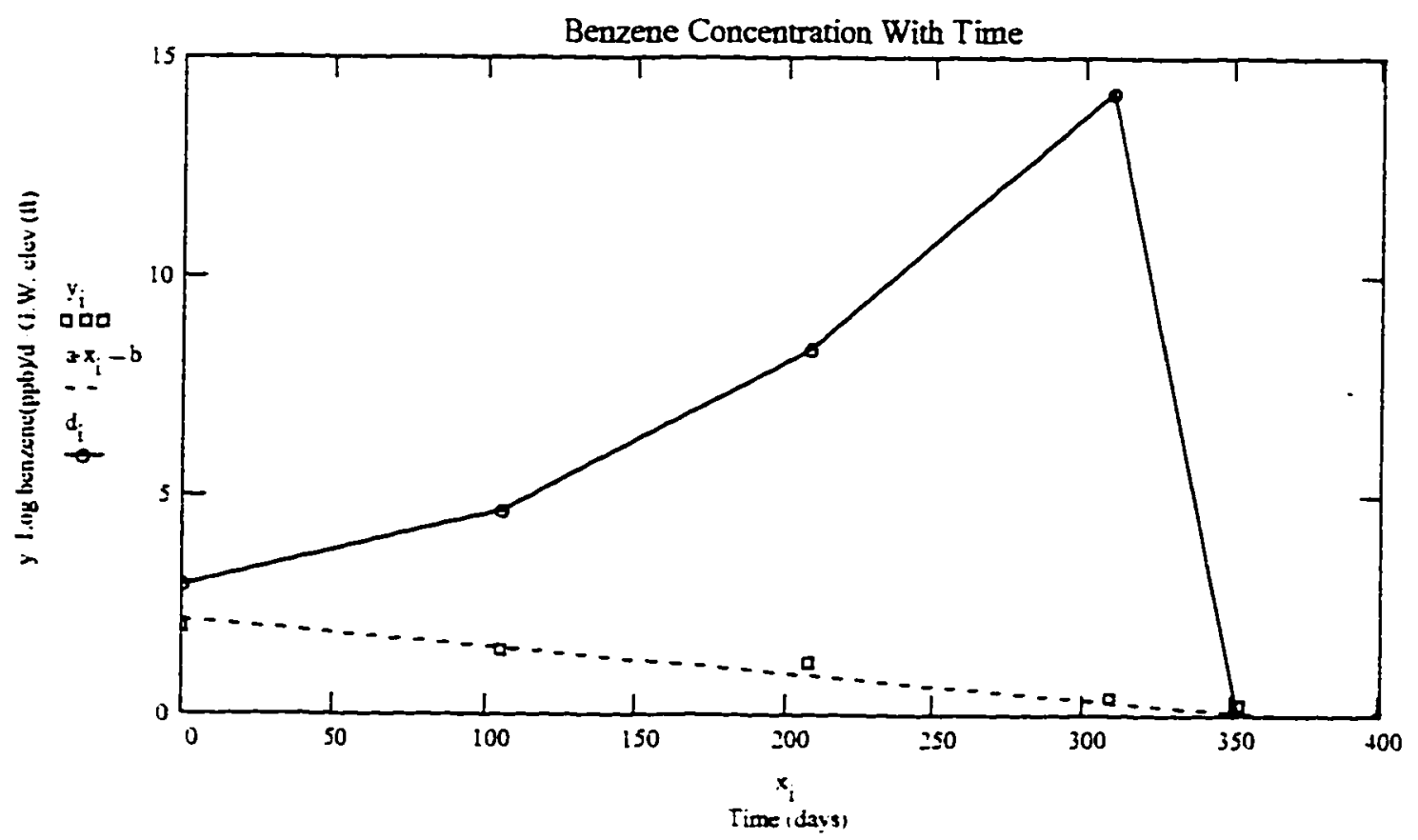


SCVND Site Number 07s1w27f01

Site Address: $535 \mathrm{~W}$. Hamilton Ave

Site Name: Campbell Chevron

City: Campbell

Contaminant: Benzene (mw-3)

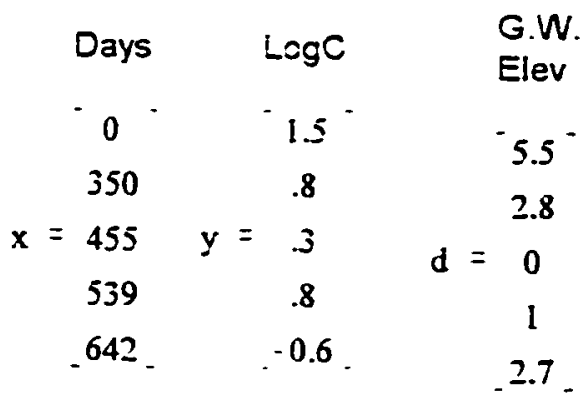

$a=\operatorname{slope}(x . y) \quad a=-0.0027$

b $=$ intercept(x.y) b $=1.6203$

$\operatorname{corr}(x . y)=-0.8479$

Note: Ground water elevations have been adjusted to fit the graph. $O$ feet $=102.25$ feet $/ 2$

$\operatorname{corr}(x . y)^{2}=0.719$

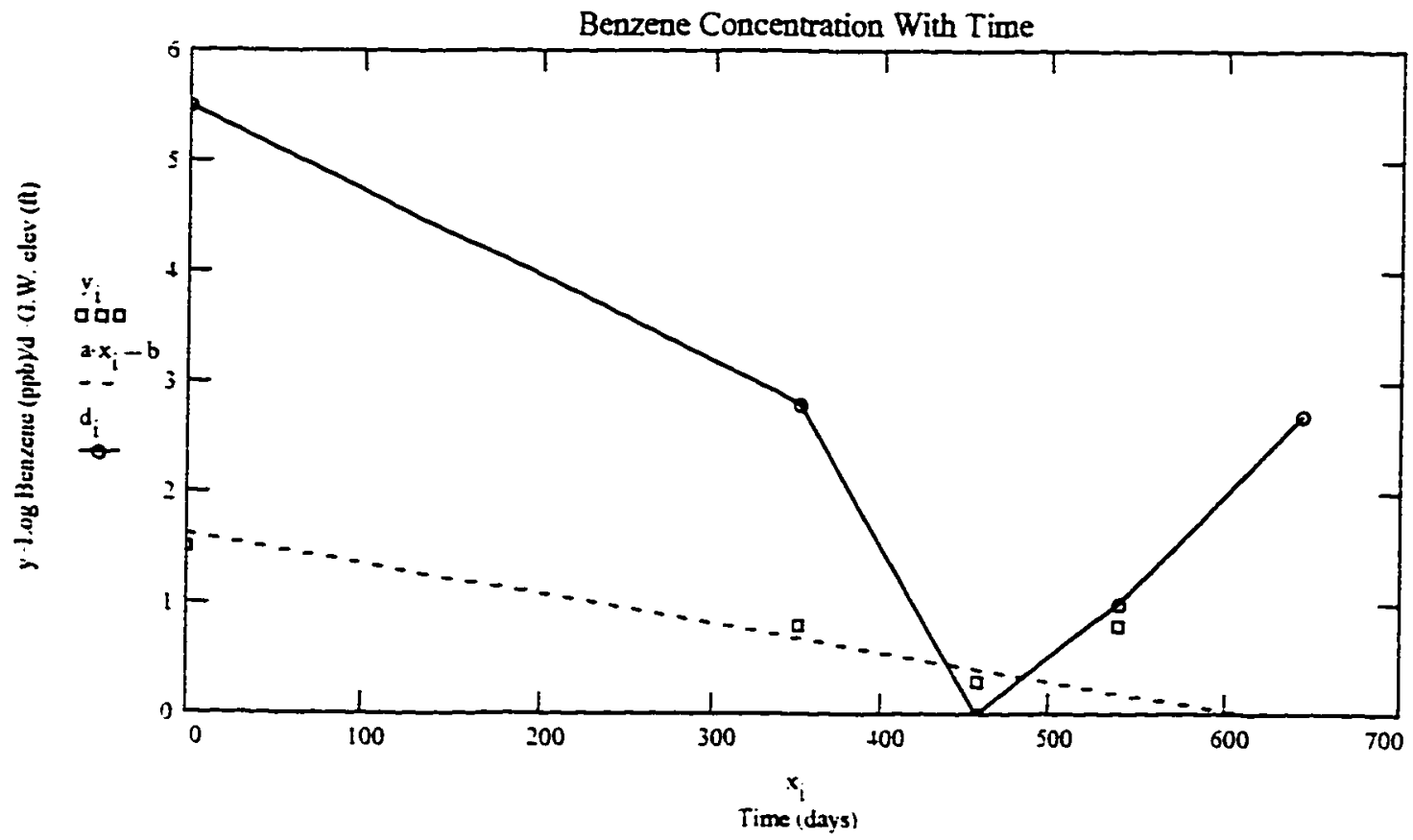


SCWWD Site Number 07s1w27f01: Site Address: $535 \mathrm{~W}$. Hamilton Ave Site Name: Campbell Chevron City: Campbell

$\begin{array}{ccc}\text { Days } & \text { LogC } & \begin{array}{c}\text { G.W. } \\ \text { Elev }\end{array} \\ 0 & -3.8^{-} & - \\ 350 & 3.1 & 2.8 \\ 455 & 3.3 & 0 \\ 539 & 3.1 & 1 \\ 642 & =2.1 & 2.7 \\ 762 & 2.5 & 6 \\ 784 & .4 & 1.2 \\ 796 & 2.9 & 1.4 \\ 824 & 1.8 & 1.8 \\ 844 & -1.4 . & .4\end{array}$

$a=\operatorname{slope}(x, y) \quad a=-0.0028$

$b=$ intercept $(x, y) b=4.1121$

$\operatorname{corr}(x . y)=-0.7357$

Note: Ground water elevations have been adjusted to fit the graph. 0 feet $=102.25$ feet $/ 2$

$\operatorname{corr}(x . y)^{2}=0.5412$

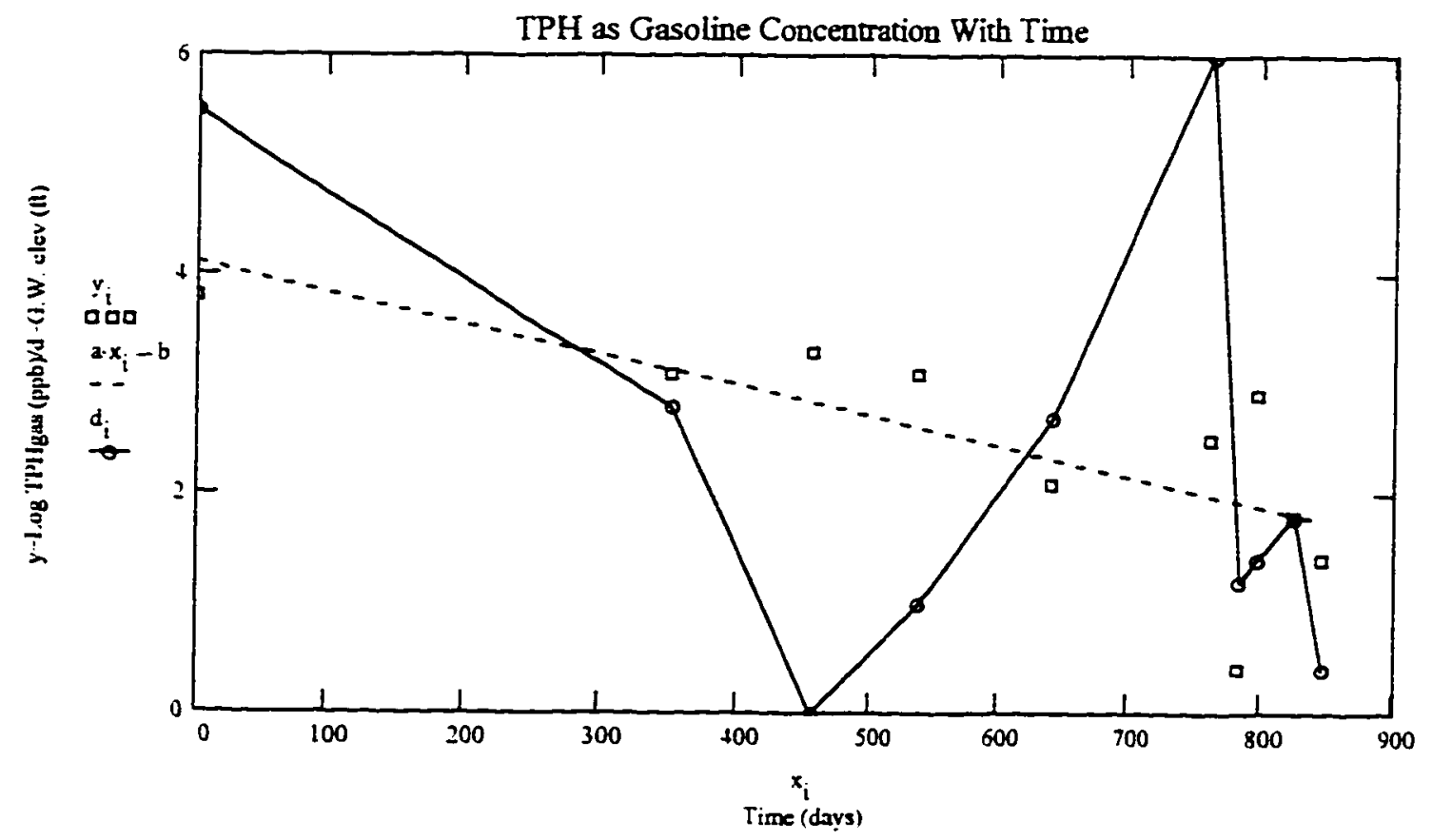


SCWWD Site Number : 08S1W03F01F Site Address: 700 Hacienda Ave.

Site Name: Exxon \#7-0201

City: Campbell

\begin{tabular}{|c|c|c|}
\hline Days & $\log C$ & $\begin{array}{l}\text { G.W. } \\
\text { Elev }\end{array}$ \\
\hline 0 & $3.1^{\circ}$ & 1.21 \\
\hline$=135$ & 2.3 & $d=1.13$ \\
\hline 193 & $\begin{array}{ll}y & 1.8\end{array}$ & 1.51 \\
\hline 286 & 1.4. & 1.0 \\
\hline
\end{tabular}

Note: The ground water elevations have been adjusted to fit the graph. $1.0 \mathrm{ft}=209.99 \mathrm{ft}$

$a=\operatorname{slope}(x . y) \quad a=-0.0061$

$b=$ intercept( $x, y) \quad b=3.0841$

$\operatorname{corr}(x, y)=-0.9948$

$\operatorname{corr}(x, y)^{2}=0.9895$

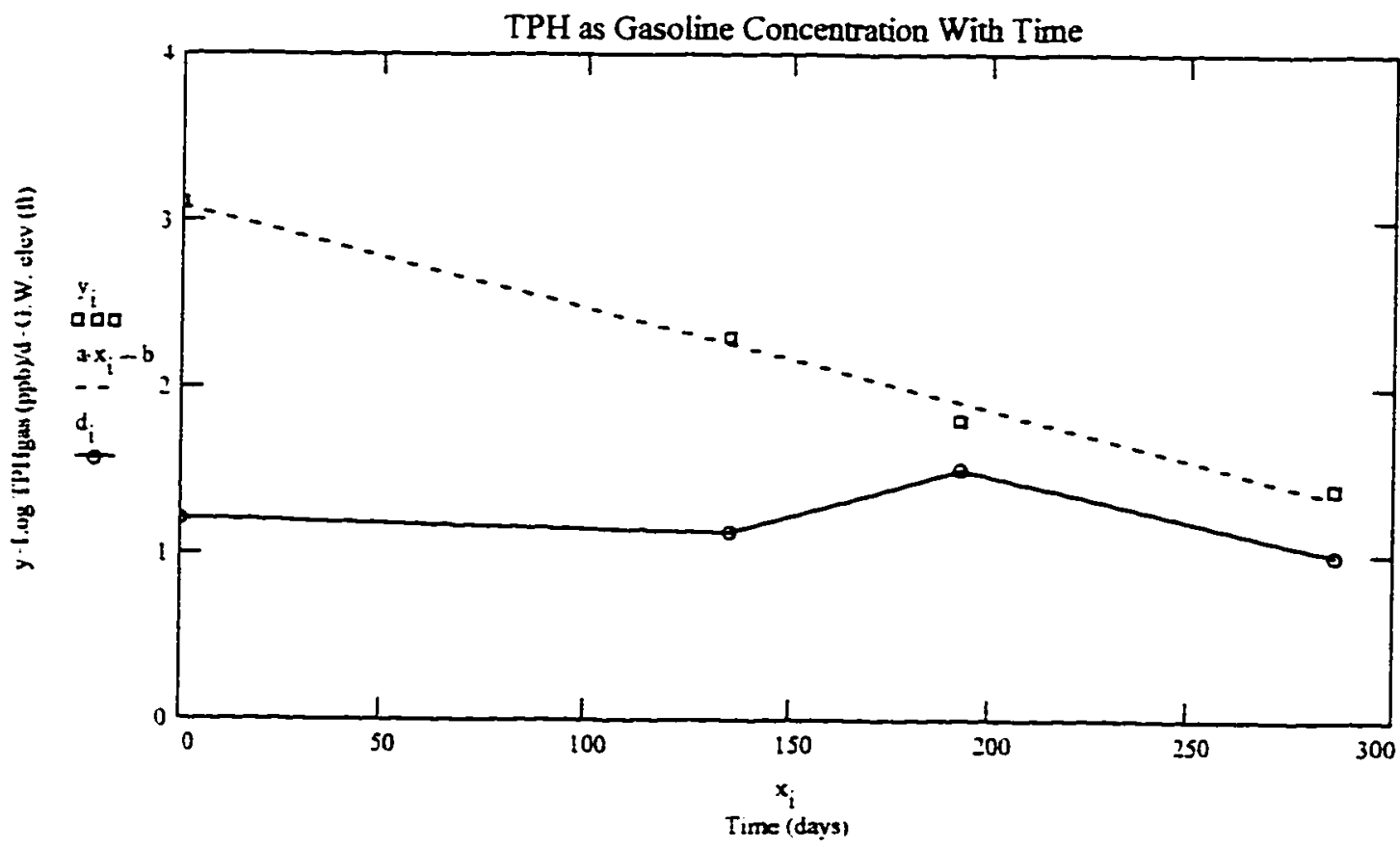


SCVWD Site Number : 08S1W03F015

Site Address: 700 Hacienda Ave.

Site Name: Exxon \#7-0201

City: Campbell

Contaminant: Benzene

$$
i=0 . .4
$$

$\begin{array}{ccc}\text { Days } & \text { LogC } & \begin{array}{c}\text { G.W. } \\ \text { Elev }\end{array} \\ 0 & 2.2 & - \\ 91 & 1.25 \\ \mathrm{x}= & \mathrm{y}=1.3 & 1.0 \\ 273 & .8 & \mathrm{~d}=1.08 \\ .331 . & -0.3 . & 1.0 \\ & & -1.38 .\end{array}$

$\mathrm{a}=\operatorname{slope}(\mathrm{x} . \mathrm{y}) \mathrm{a}=-0.0066$

Note: The ground water elevations have been adjusted

$b=$ intercept $(x, y) \quad b=2.2355$ to fit the graph. $1.0 \mathrm{ft}=210.12 \mathrm{ft}$.

$\operatorname{corr}(x . y)=-0.9273$

$\operatorname{corr}(x . y)^{2}=0.86$

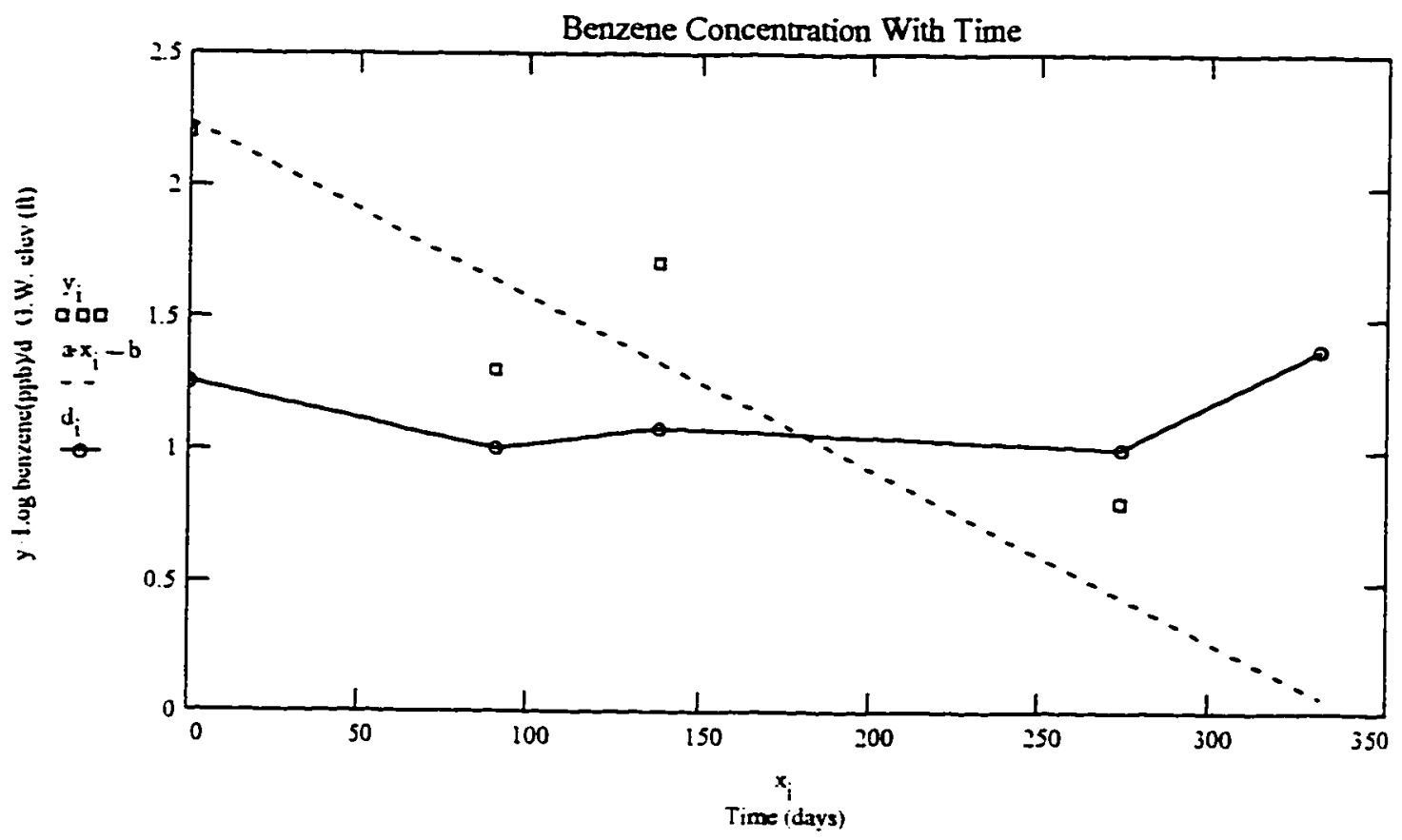


SCVWD Site Number : 07S1W35P01F

Site Address: 420 McGlincey Lane

Site Name: Cushman Construction

City: Campbell

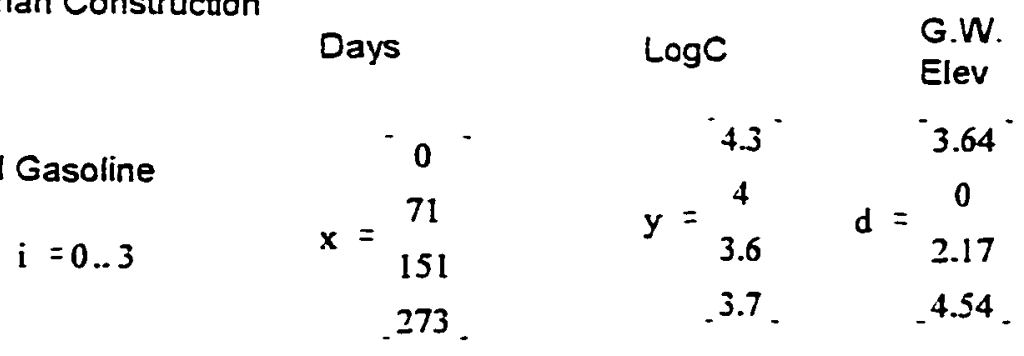

Contaminant: TPH Gasoline

Note: Ground water elevations were adjusted to fit

$a=\operatorname{slope}(x \cdot y) \quad a=-0.0023$ the graph. $0 \mathrm{ft}=196.74 \mathrm{ft}$.

$b=$ intercept $(x, y) \quad b=4.1793$

$\operatorname{corr}(x . y)=-0.8356$

$\operatorname{corr}(x, y)^{2}=0.6982$

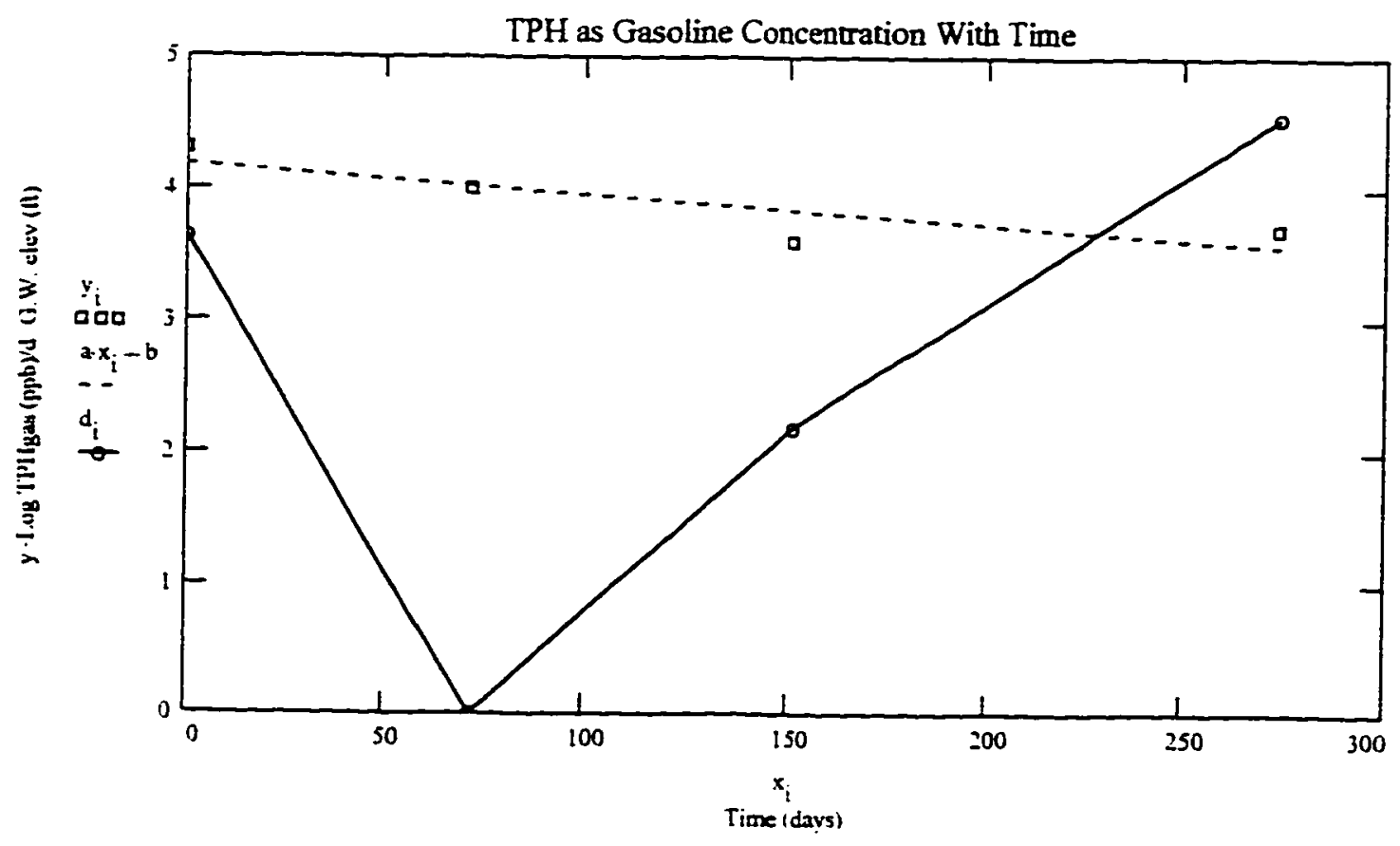


SCWWD Site Number : 07S1W35P01F

Site Address: 420 McGlincey Lane

Site Name: Cushman Construction

City: Campbell

Days

Contaminant: Benzene

$i=0 . .3$

$a=\operatorname{siope}(x . y) \quad a=-5.7035 \cdot 10^{-t}$

$b=$ intercept $(x, y) b=0.5206$

$\operatorname{corr}(x, y)=-0.2148$

$\operatorname{corr}(x, y)^{2}=0.0461$

Note: Ground water elevations were adjusted to fit the graph. $O \mathrm{ft}=196.74 \mathrm{ft}$.

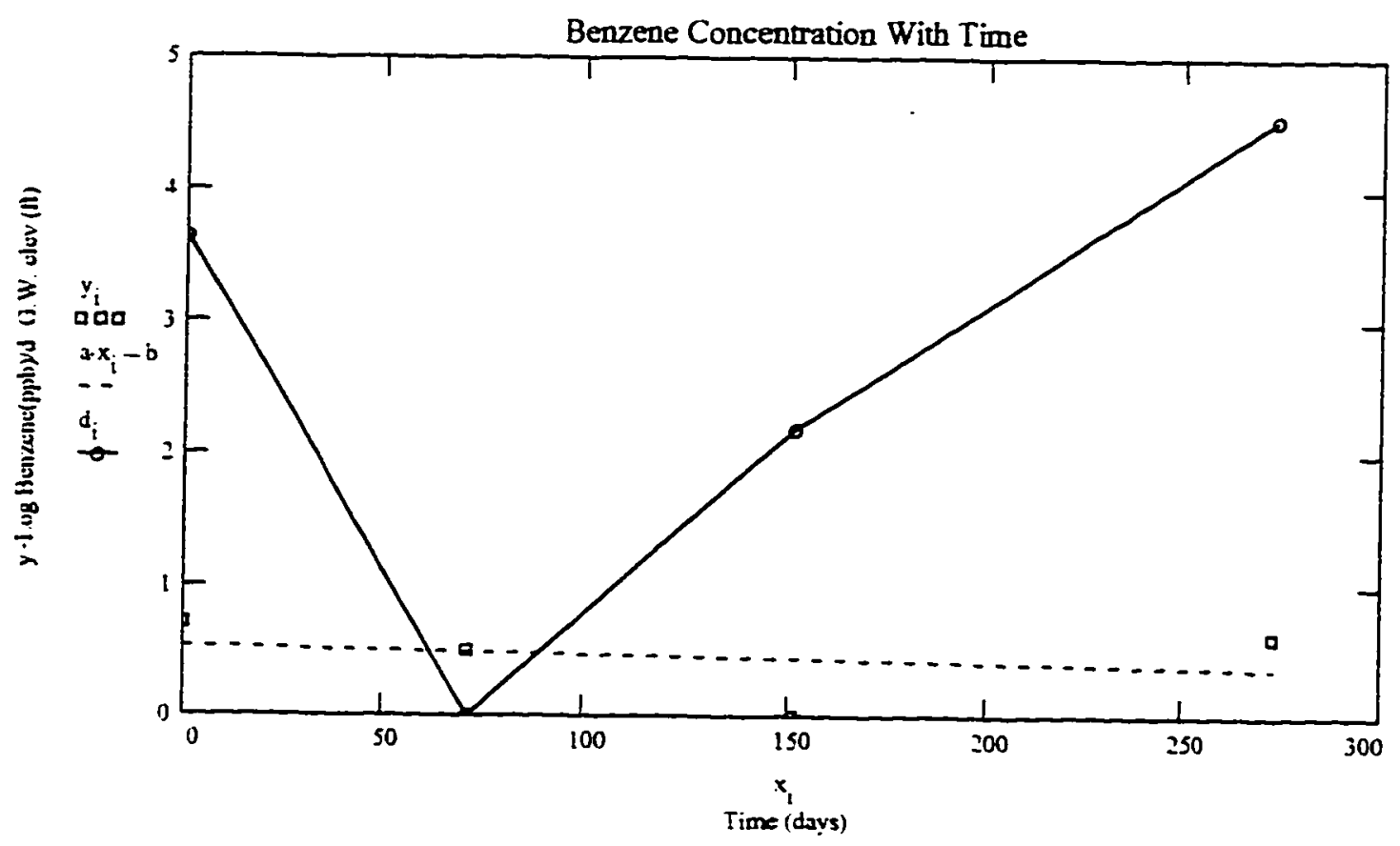


SCWWD Site Number : 075135802F

Site Address: 790 E. CAMPBELL AVE.

Site Name: COAST OIL \#51

City: CAMPBELL

Days

0

Contaminant: Benzene

$i=0 . .5$

$x=\begin{aligned} & 281 \\ & 360\end{aligned}$

360

452

.554 .
G.W.
Elev

$y=\begin{array}{cc}2 & -1.1 \\ .8 & 2.2 \\ .3 & \mathrm{~d}=3.14 \\ .08 & 2.1 \\ .6 & 0 \\ .0 .6 & -3.2\end{array}$

$a=\operatorname{slope}(x, y) \quad a=-0.004$

$b=$ intercept $(x, y) b=1.7516$

Note: Ground water elevations were adjusted to fit the $\operatorname{corr}(x, y)=-0.9016$ graph. Oft $=2.42 \mathrm{ft} / 4$

$\operatorname{corr}(x, y)^{2}=0.8129$

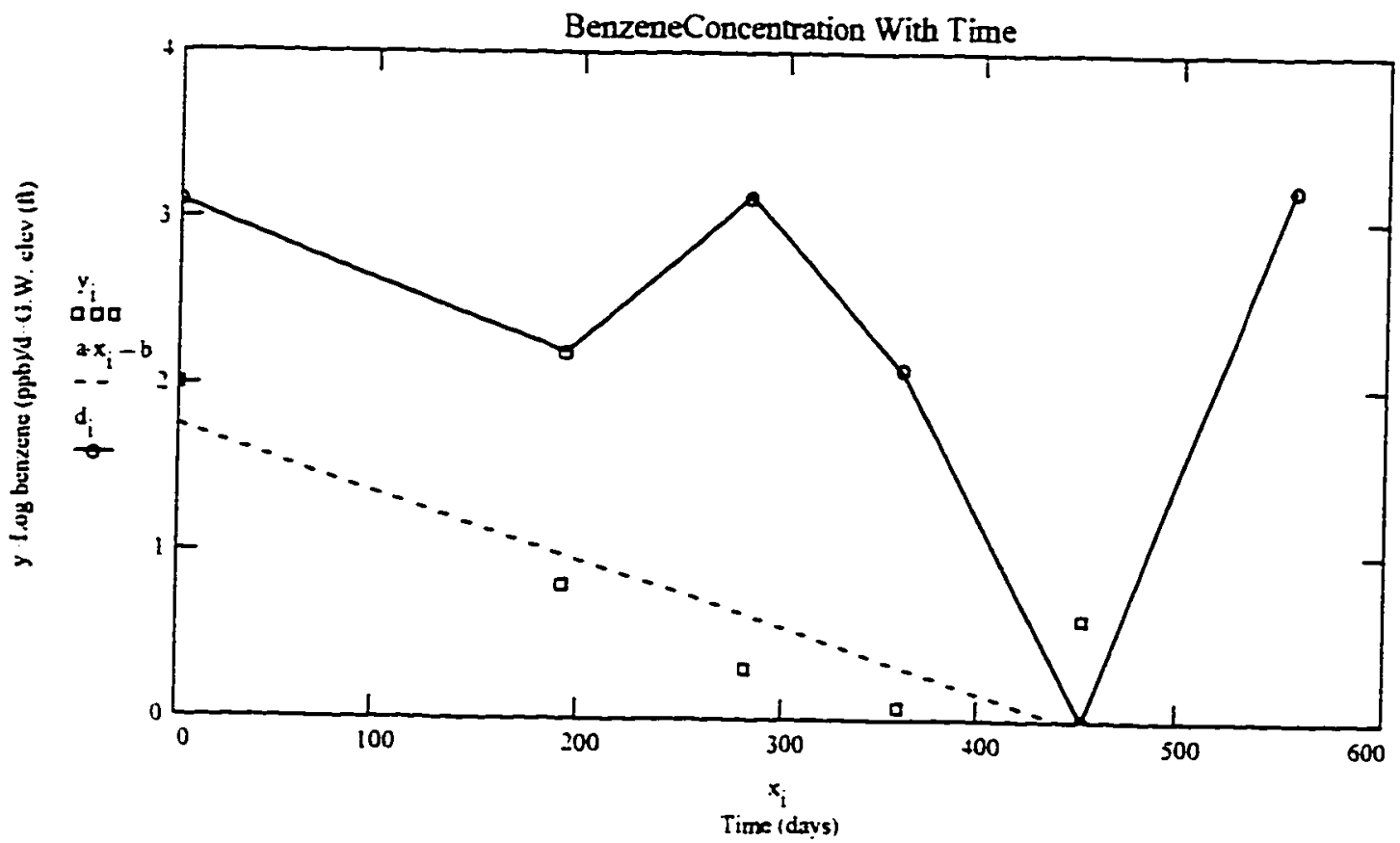


SCVWD Site Number : 07S135B02F

Site fodress: 790 E. CAMPBELL AVE

Site Name: COAST OIL \#51

City: CAMPBELL

$\begin{array}{ccc}\text { Days } & \log C & \begin{array}{c}\text { G.W. } \\ \text { Elev }\end{array} \\ 0 & -4.2^{-} & -3.1 \\ 192 & 2.9 & 2.2 \\ 281 & 2.6 & 3.1 \\ x=360 & y=2.2 & \mathrm{~d}=2.1 \\ 452 & 2.7 & 0 \\ 554 & 1.9 & 3.2 \\ 632 . & .2 .2 . & .5 .2 .\end{array}$

$a=\operatorname{slope}(x . y) \quad a=-0.003$

$b=$ intercepl( $x, y) \quad b=3.739$

Note: Ground water elevations were adjusted to fit the

$\operatorname{corr}(x, y)=-0.8694$ graph. $\mathrm{Oft}=12.42 \mathrm{ft} / 4$

$\operatorname{corr}(x . y)^{2}=0.7558$

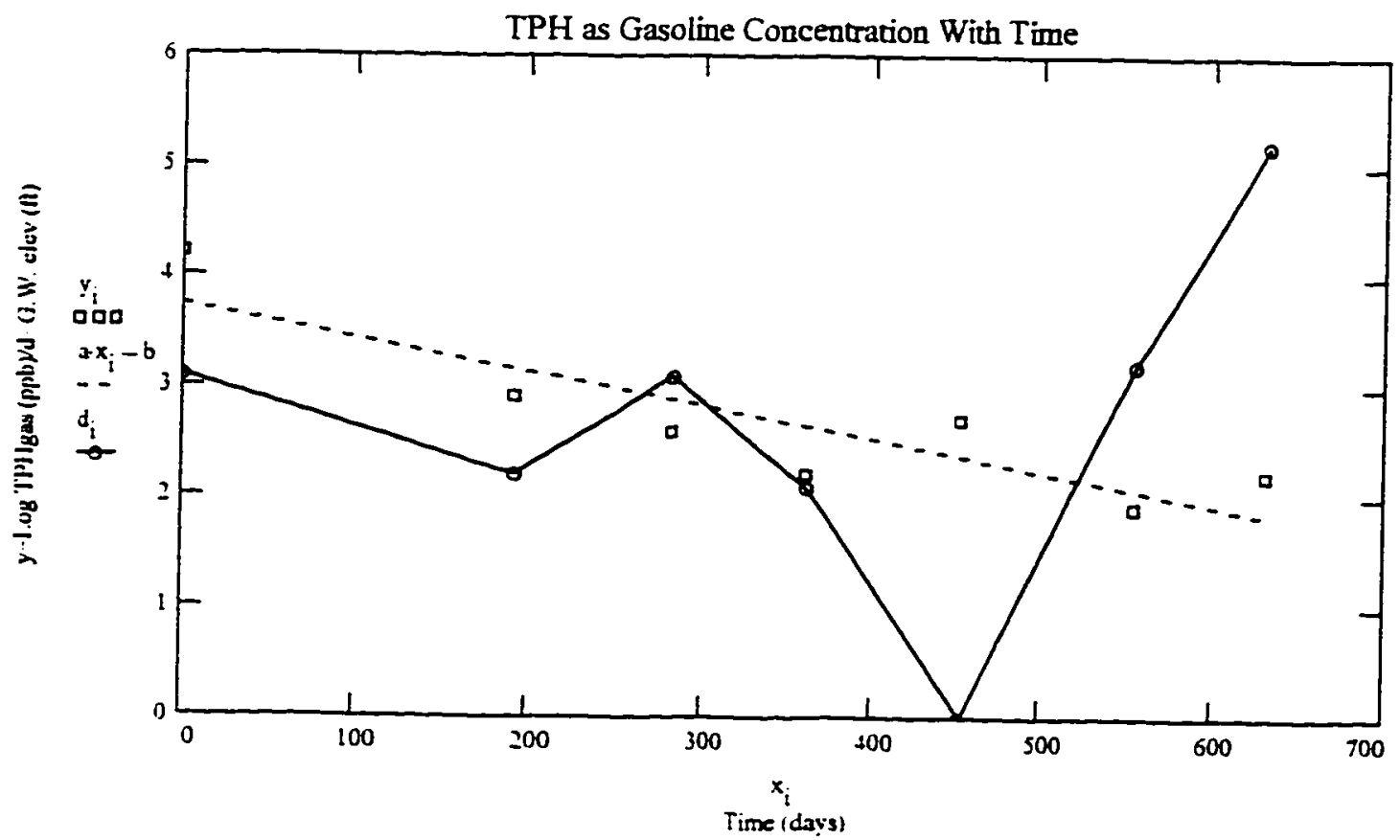


SCWWD Site Number : 0652W30R01F

Site Address: 330 South San Antonio Rd.

Site Name: Unocal \#5957

City: Los Altos

Contaminant: TPH Gasoline

$$
i=0 . .5
$$

$\begin{array}{ccc}\text { Days } & \text { LogC } & \begin{array}{c}\text { G.W. } \\ \text { Elev }\end{array} \\ 0 & -4.08 & 0 \\ 110 & 3.58 & 0 \\ 208 & y=3.28 & \mathrm{~d}=4.2 \\ 281 & 2.56 & 3.6 \\ 377 & 2.08 & 3.3 \\ .468 & .1 .4 & .4 .6\end{array}$

$a=\operatorname{slope}(x, y) \quad a=-0.0058$

$b=$ intercept $(x, y) \quad b=4.2155$

$\operatorname{corr}(x, y)=-0.9895$

Note: The ground water elevations have been

$\operatorname{corr}(x, y)^{2}=0.9792$

modified to fit the graph. $O$ feet $=45.15 / 4$

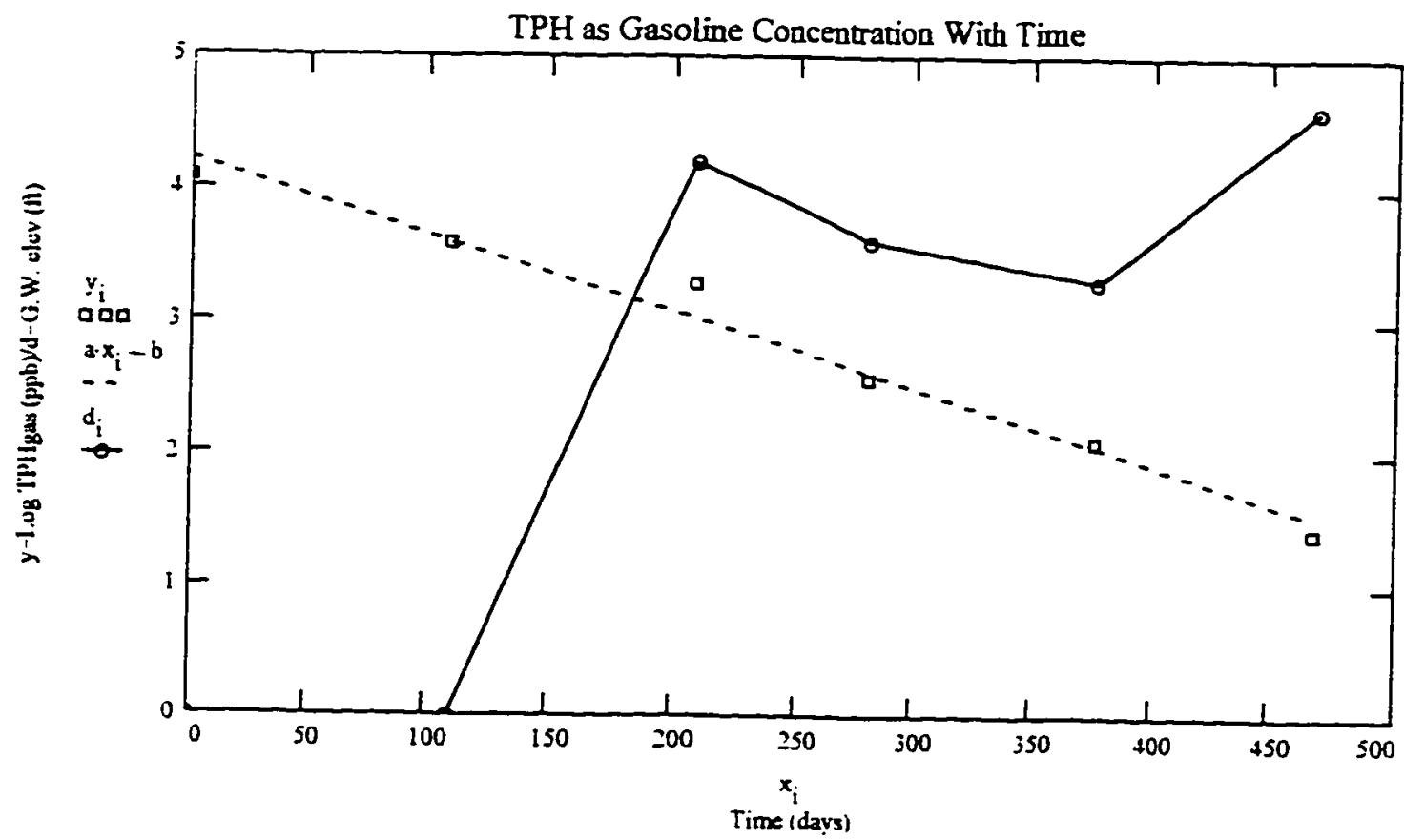


SCYND Site Number : 0652W30R01F

Site Address: 330 South San Antonio Rd.

Site Name: Unocal \#5957

City: Los Aitos

Contaminant: Benzene

$\mathrm{i}=0 . .7$

$\mathrm{a}=\operatorname{slope}(\mathrm{x} . \mathrm{y}) \mathrm{a}=-0.0056$

$b=\operatorname{intercept}(x . y) \quad b=3.4885$

Note: The ground water elevations have been

$\operatorname{corr}(x . y)=-0.8085$

modified to fit the graph. 0 feet $=45.15: 4$

$\operatorname{corr}(x . y)^{2}=0.6536$

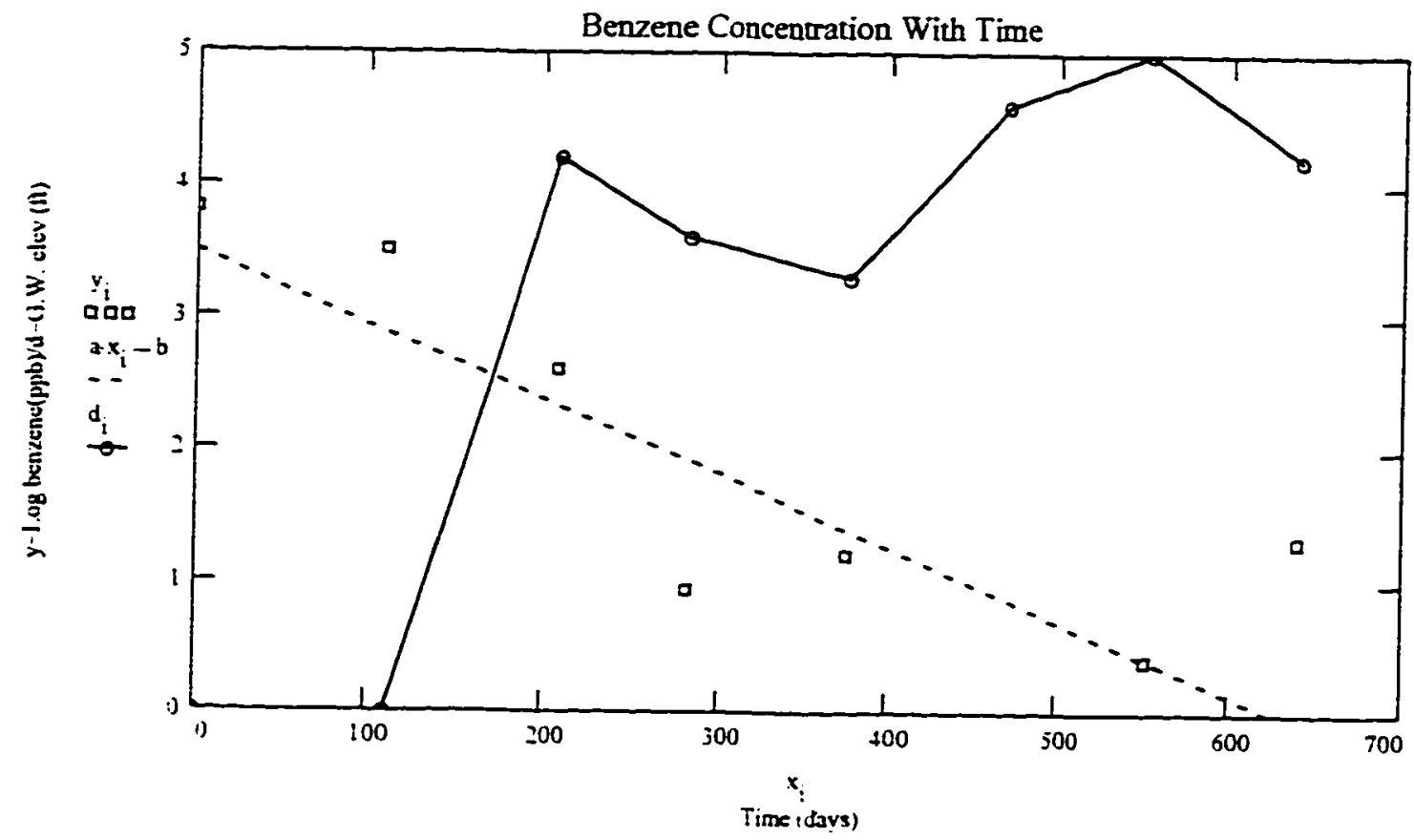


SCWWD Site Number: 06s2w19a0 if

Site Address: 988 N. San Antonio Rd.

Site Name: Arco \#0707

City: Los Altos

Contaminant: TPH Gasoline

Monitoring well A-1

$i=0 . .6$

$\begin{array}{rcc}\text { Days } & \text { LogC } & \begin{array}{c}\text { G.W. } \\ \text { Elev }\end{array} \\ 0 & -3.8 & -36 \\ 86 & 3.6 & 0 \\ 176 & 3.7 & 2.17 \\ x=267 & y=2.4 & \mathrm{~d}=7.7 \\ 389 & 1.7 & 8.11 \\ 449 & 2.3 & 7.31 \\ 567 . & -1.4 . & 0\end{array}$

$a=\operatorname{slope}(x . y) \quad a=-0.0045$

$b=\operatorname{intercept}(x, y) \quad b=3.9528$

Note: The ground water elevations have been

$\operatorname{corr}(x, y)=-0.9282$

$\operatorname{corr}(x . y)^{2}=0.8615$

modified to fit the graph. 0 feet $=30.65$ feet. The last date did not have a ground water elevation so 0 was input.

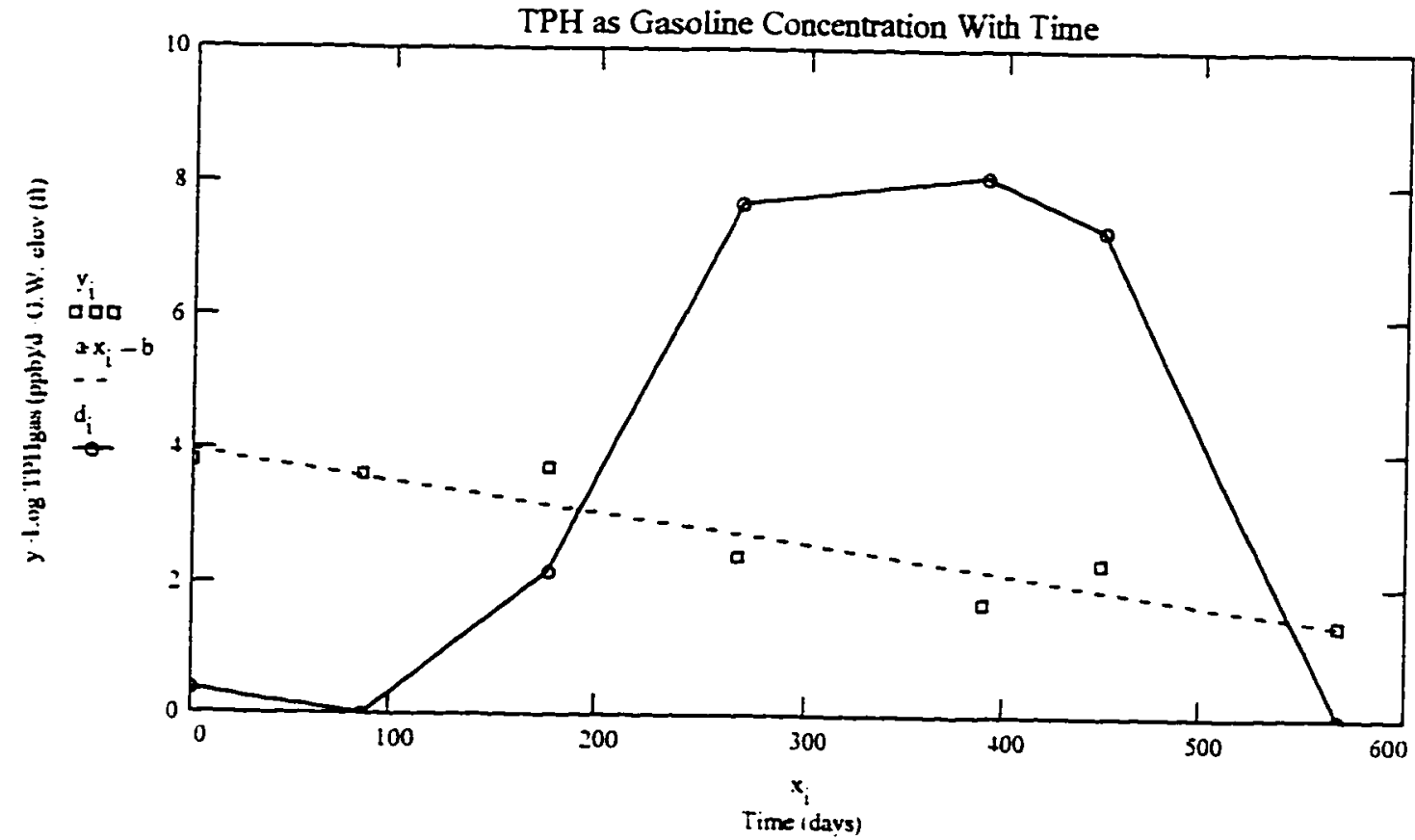


SCVWD Site Number : 06s2w19a0 if

Site Address: 988 N. San Antonio Rd.

Site Name: Arco \#0707

City: Los Altos

Contaminant: TPH Gasoline

Monitoring well A-2

Days
0
60
179
253
356
447
546
636

$\log C$
4
3.5
2.8
2.1
2.1
2
1.4
.2 .4

G.W

Elev

4

1.81

1.02

$i=0 . .7$

79

2.8

0

356

47

546

636.

.2 .4 .

.69

.63

0

3.79

.7 .87

$a=\operatorname{slope}(x, y) \quad a=-0.003 l$

$b=$ intercept $(x . y) \quad b=3.4877$

$\operatorname{corr}(x . y)=-0.8159$

$\operatorname{corr}(x . y)^{2}=0.6658$

Note: The ground water elevations have been modified to fit the graph. 0 feet $=36.99$ feet. The third date did not have a ground water elevation so 0 was input.

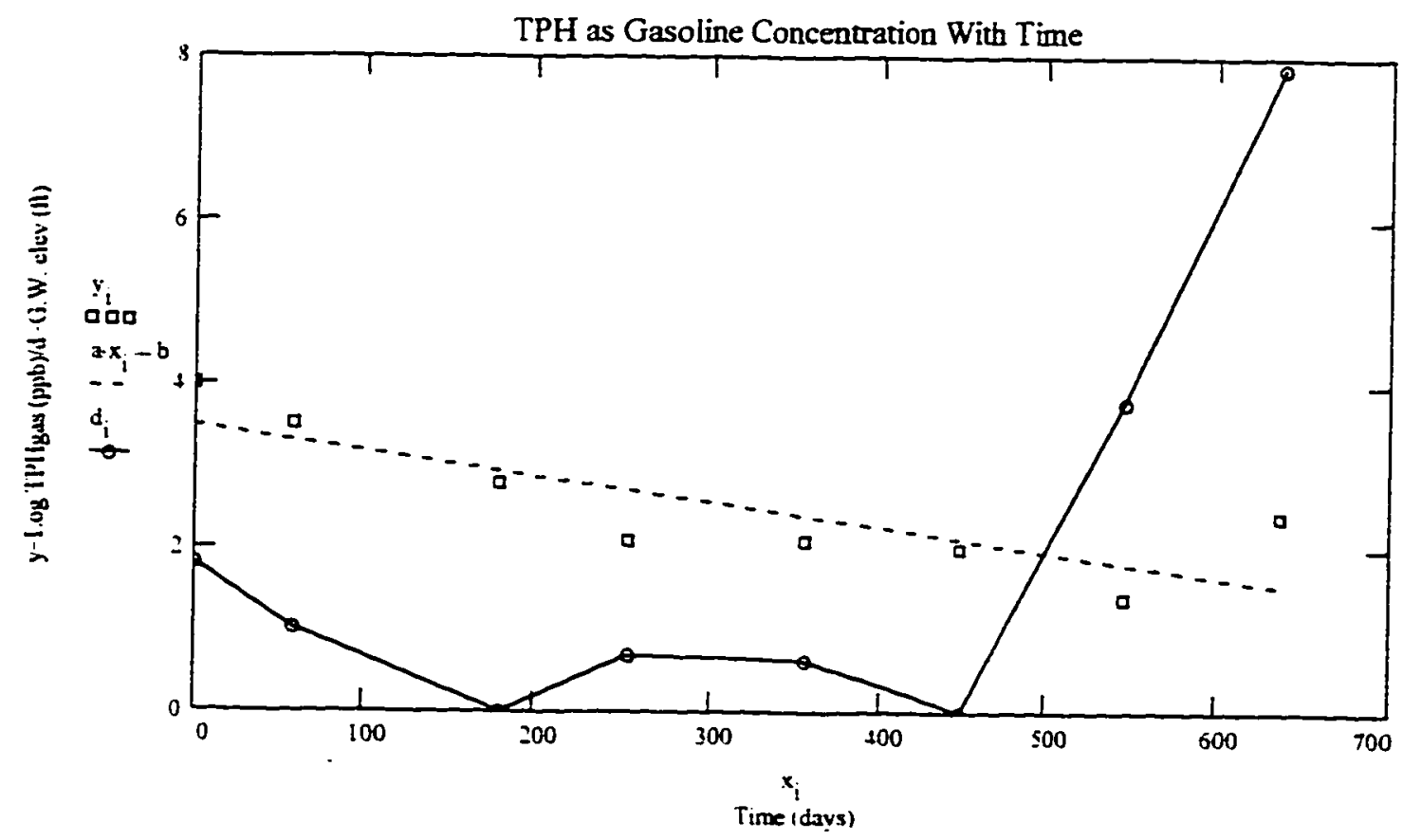


SCWWD Site Number: 06s2w19a01f

Site Address: 988 N. San Antonio Rd.

Site Name: Arco $\# 0707$

City: Los Altos

$\begin{array}{ccc}\text { Days } & \text { LogC } & \begin{array}{c}\text { G.W. } \\ \text { Elev }\end{array} \\ 0 & -4.7^{-} & - \\ 86 & 4.1 & 0 \\ 177 & 3.5 & 3.49 \\ 268 & \mathrm{y}=2.9 & \mathrm{~d}=26 \\ 390 & 3.5 & 5.21 \\ 450 & 3.2 & 10.87 \\ 568 & -1.4 . & 11.21 \\ -50.44\end{array}$

$a=\operatorname{slope}(x . y) \quad a=-0.0044$

$b=$ intercept $(x . y) \quad b=4.5492$

$\operatorname{com}(x . y)=-0.8684$

$\operatorname{corr}(x . y)^{2}=0.7542$

Note: The ground water elevations have been modified to fit the graph. 0 feet $=27.44$ feet. The last date did not have a ground water elevation so 0 was input.

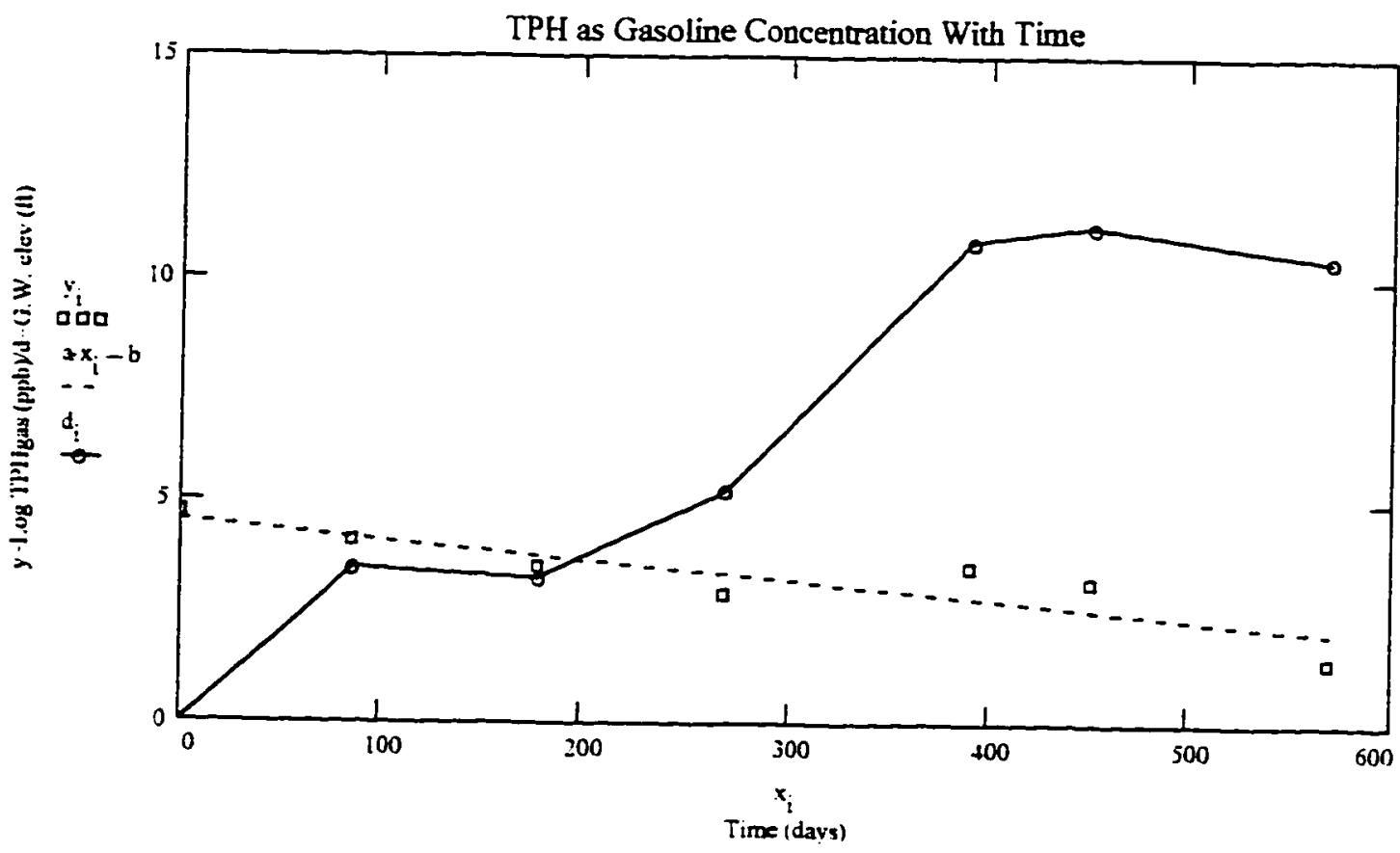


SCWWD Site Number : 08S 1 W1MO3

Site fiddress: 700 Blossom Hill Road Site Name: Exxon \#7-0223

City: Los Gatos

$\begin{array}{ccc}\text { Days } & \text { LogC } & \begin{array}{c}\text { G.W. } \\ \text { Elev }\end{array} \\ -0 & 4.4 & .76 \\ 80 & 3.8 & 3.65 \\ 159 & \mathrm{y}=3.5 & \mathrm{~d}=.48 \\ 257 & 3.1 & 0 \\ 329 & 3 & .48 \\ .432 & .4 .3 & .8 .9\end{array}$

$a=\operatorname{slope}(x . y) \quad a=-9.9146 \cdot 10^{-4}$

$b=$ intercept $(x . y) b=3.891$

$\operatorname{corr}(x, y)=-0.2696$

Note: Ground water elevations have been modified $\operatorname{corr}(x . y)^{2}=0.0727$ to fit the graph. $O \mathrm{ft}=310.14$

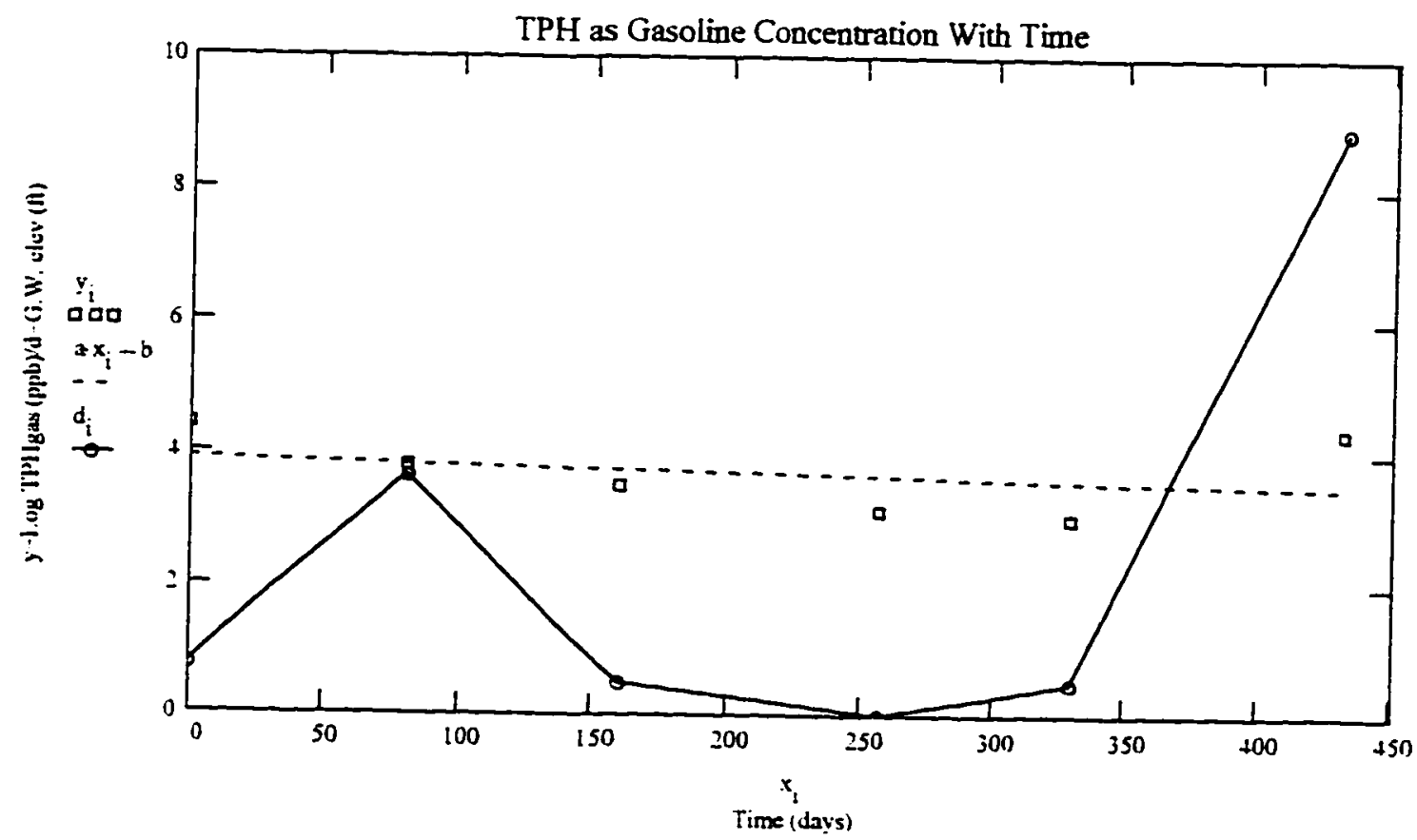


SCVWD Site Number : 0851W21D01F Site Address: 155 North Santa Cruz Ave Site Name: Mobil

City: Los Gatos

Contaminant: TPH Gasoline

$$
\begin{aligned}
& i=0 . .11 \\
& m \cup-C
\end{aligned}
$$

$a=\operatorname{slope}(x . y) \quad a=-1.3354 \cdot 10^{-1}$

$b=$ intercept $(x, y) \quad b=3.0272$

$\operatorname{corr}(x, y)=-0.1218$

$\operatorname{corr}(x, y)^{2}=0.0148$

$\begin{array}{ccc}\text { Days } & \text { LogC } & \begin{array}{l}\text { G.W. } \\ \text { Elev }\end{array} \\ 0 & 3.6 & 2.74 \\ 111 & 3.2 & 2.43 \\ 216 & 2.7 & 1.19 \\ 299 & 2.1 & .93 \\ 384 & 3.2 & 6.75 \\ 475 & 3 & \mathrm{~d}=3.28 \\ 563 & =2.9 & .6 \\ 654 & 2.8 & 2.12 \\ 734 & 2.9 & 2.06 \\ 830 & 3.1 & 2.81 \\ 918 & 3 & 2.29 \\ 1007 & .3 & 1.65\end{array}$

Note: Ground water elevations have been adjusted to fit the graph. $O f t=379.57$ it

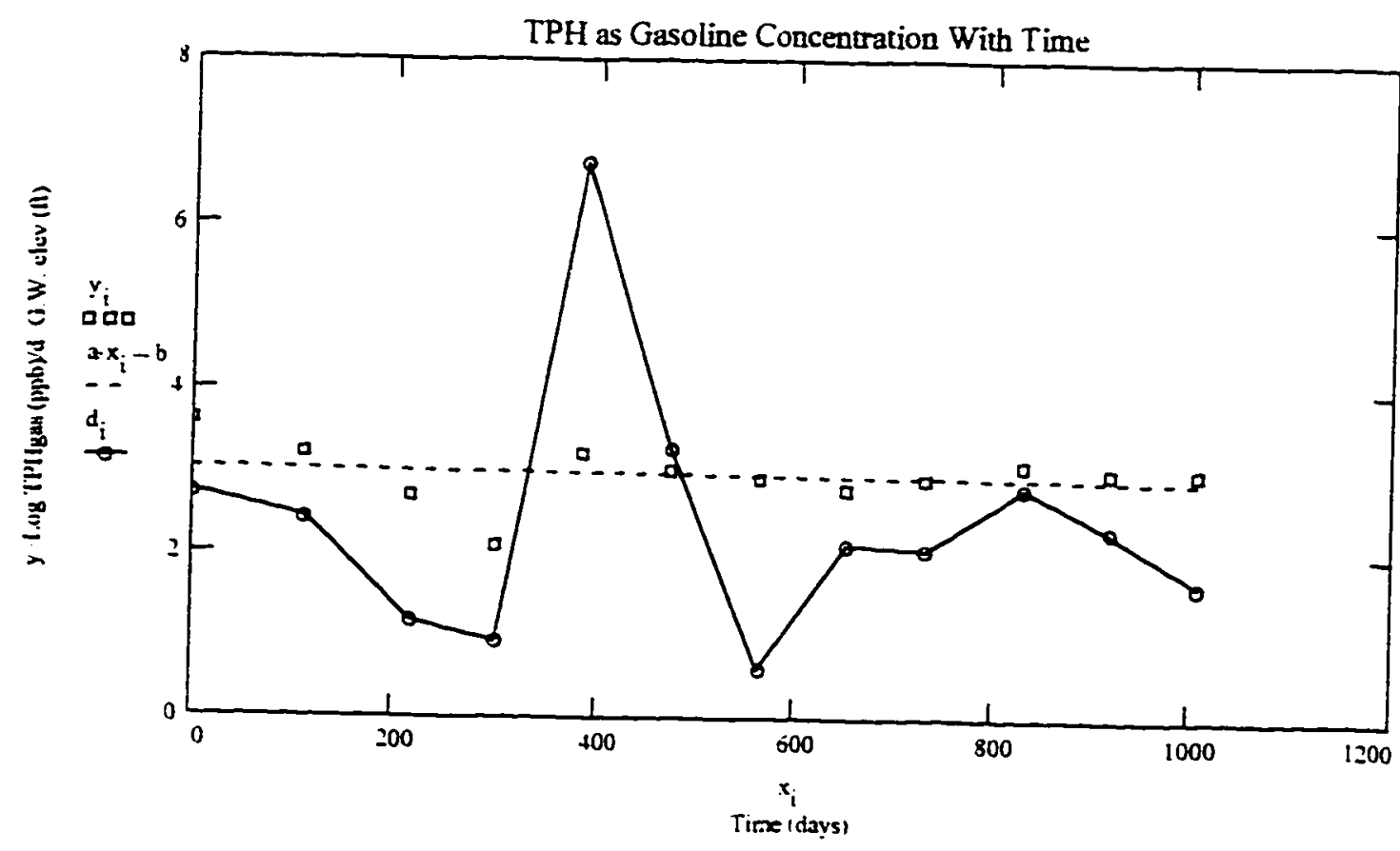


SCWWD Site Number : 0851W21D01F Site Address: 155 North Santa Cruz Ave Site Name: Mobil City: Los Gatos

\begin{tabular}{|c|c|c|}
\hline Days & $\log C$ & $\begin{array}{l}\text { G.W. } \\
\text { Elev }\end{array}$ \\
\hline 0 & $2.2^{\circ}$ & 6.75 \\
\hline 91 & 1.9 & 3.28 \\
\hline 179 & 2.1 & .6 \\
\hline$=270$ & 1.8 & 2.12 \\
\hline 350 & 1.6 & 2.06 \\
\hline 446 & 1.8 & 2.81 \\
\hline 534 & 1.8 & 2.24 \\
\hline 623 & 1.8 & 1.65 \\
\hline
\end{tabular}

$a=\operatorname{slope}(x, y) \quad a=-5.8656 \cdot 10^{-\downarrow}$

$b=$ intercepl( $x . y) b=2.0578$

$\operatorname{corr}(x, y)=-0.6683$

$\operatorname{com}(x . y)^{2}=0.4466$

Note: Ground water elevations have been adjusted to fit the graph. Oft $=379.57 \mathrm{ft}$

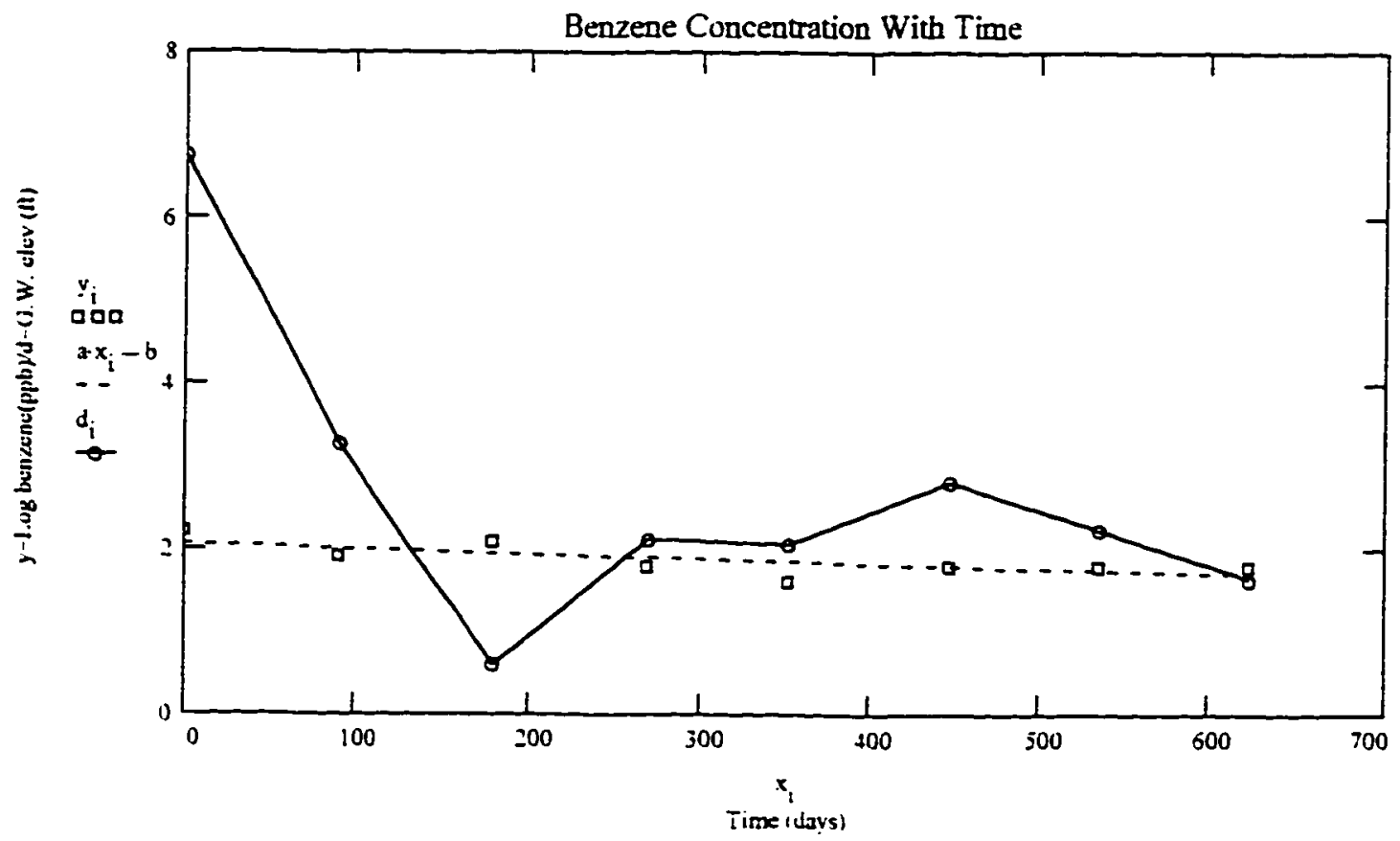


SCWWD Site Number : 08S1W21D01F Site Address: 155 North Santa Cruz Ave Site Name: Mobil

City: Los Gatos

$$
\begin{aligned}
& a=\operatorname{slope}(x, y) \quad a=-6.3506 \cdot 10^{-4} \\
& b=\operatorname{intercept}(x, y) \quad b=2.0425 \\
& \operatorname{corr}(x . y)=-0.3954 \\
& \operatorname{corr}(x . y)^{2}=0.1564
\end{aligned}
$$

$\begin{array}{ccc}\text { Days } & \text { LogC } & \begin{array}{c}\text { G.W. } \\ \text { Elev }\end{array} \\ 0 & -2.6 & -1.41^{-} \\ 14 & 1.7 & .23 \\ 137 & 1 & 0 \\ 272 & 2.4 & 5.3 \\ 366 & 2.1 & 2.19 \\ x=455 & y=2 & \mathrm{~d}=1.57 \\ 545 & 1.5 & 1.15 \\ 625 & 1.5 & 1.17 \\ 715 & 1.6 & 1.57 \\ 806 & 1.9 & 1.39 \\ 896 & -1.1 & .65\end{array}$

Note: Ground water elevations have been adjusted to fit the graph. Oft $=379.57 \mathrm{ft}$

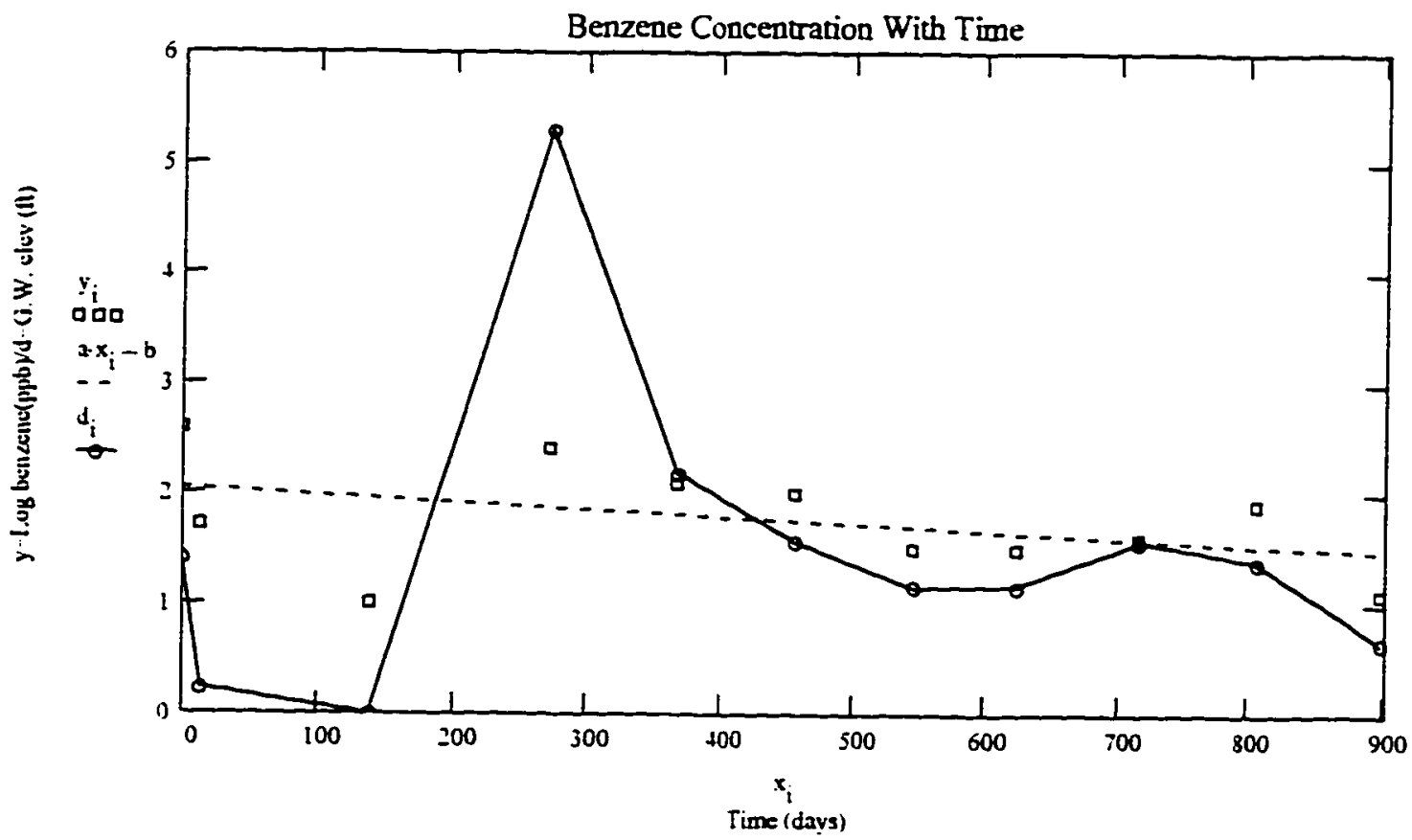


SCWWD Site Number : 08S1W21DO1F Site Address: 155 North Santa Cruz Ave Site Name: Mobil City: Los Gatos

$\begin{array}{ccc}\text { Days } & \text { LogC } & \begin{array}{c}\text { G.W. } \\ \text { Elev }\end{array} \\ -0 & -3.7^{\circ} & 1.41 \\ 14 & 2.8 & .23 \\ 137 & 2.6 & 0 \\ 272 & 3.4 & 5.3 \\ 366 & 3.4 & 2.19 \\ \mathrm{x}=455 & \mathrm{y}=2.9 & \mathrm{~d}=1.57 \\ 545 & 2.6 & 1.15 \\ 625 & 2.8 & 1.17 \\ 715 & 3 & 1.57 \\ 806 & 3.3 & 1.39 \\ 896 . & 2.3 . & .65\end{array}$

$a=\operatorname{slope}(x, y) \quad a=-5.0693 \cdot 10^{-4}$

$b=$ intercept $(x . y) \quad b=3.2045$

$\operatorname{corr}(x, y)=-0.3713$

$\operatorname{corr}(x . y)^{2}=0.1378$

Note: Ground water elevations have been adjusted to fit the graph. Oft $=379.57 \mathrm{ft}$

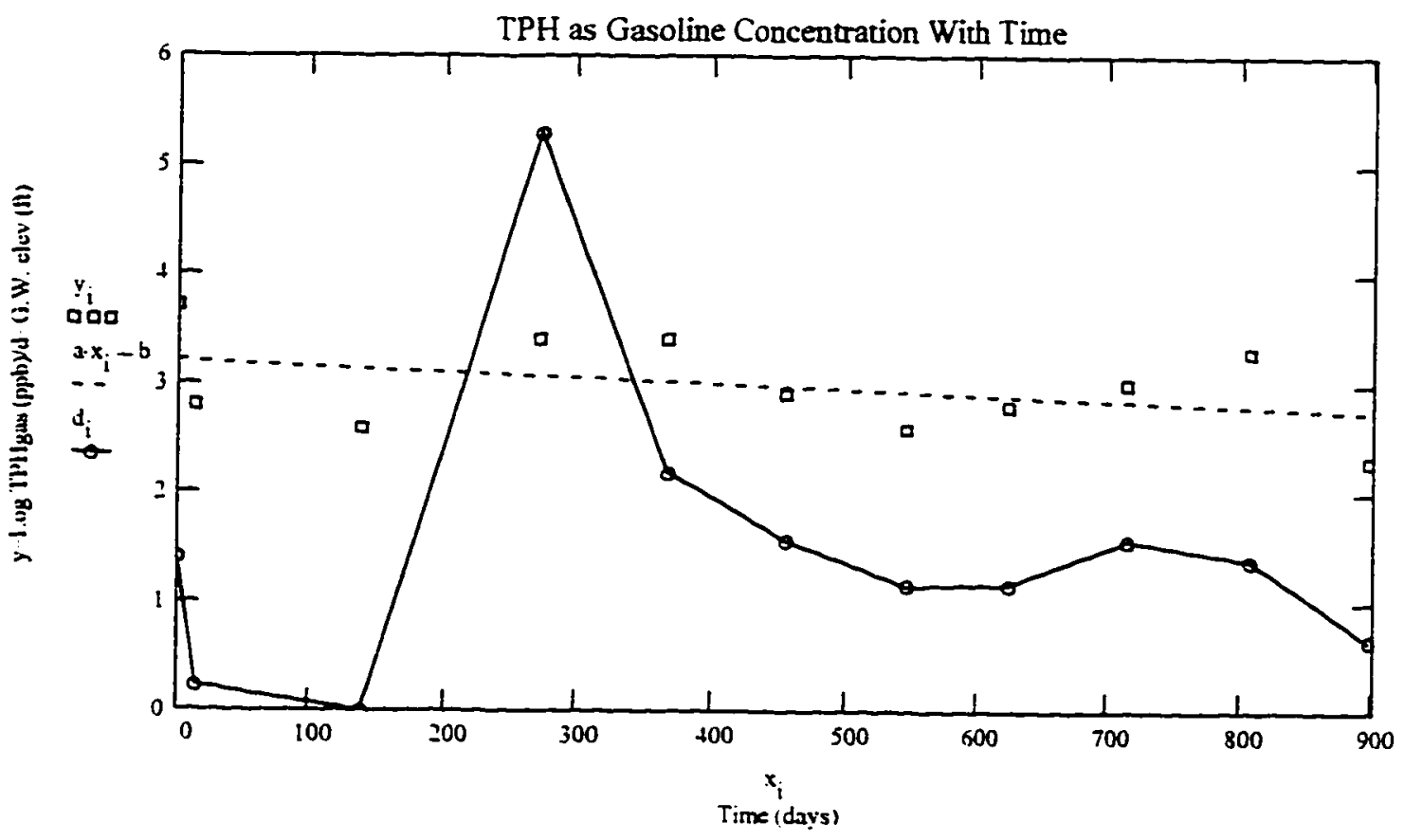


SCWWD Site Number: 08S1W13J01F

Site Address: 13980 Blossom Hill Road Site Name: Chevron \#9-1538

City: Los Gatos

$\begin{array}{ccc}\text { Days } & \text { LogC } & \begin{array}{c}\text { G.W. } \\ \text { Elev }\end{array} \\ 0 & 3.6 & .57 \\ 70 & 3 & 0 \\ 136 & y=1.4 & \mathrm{~d}= \\ 226 & 2.8 & .77 \\ 339 & 3.1 & 2.93 \\ .24 . & .1 .4 . & -2.37\end{array}$

$a=\operatorname{slope}(x . y) \quad a=-0.0028$

$b=$ intercept $(x, y) \quad b=3.1111$

$\operatorname{corr}(x . y)=-0.4912$

$\operatorname{corr}(x . y)^{2}=0.2413$

Note: Ground water elevations have been adjusted to fit the graph. $O A t=247.13$

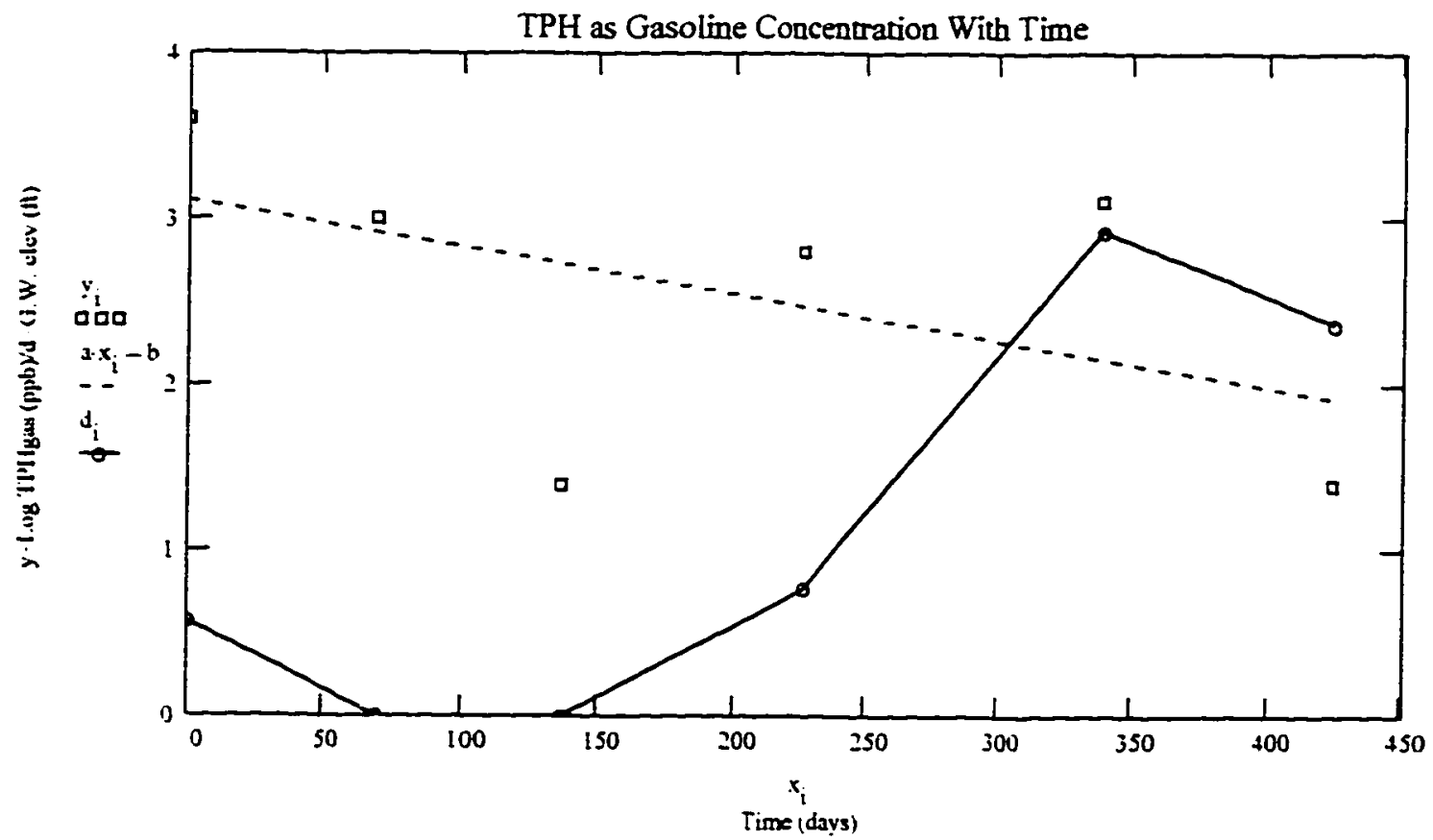


SCVND Site Number: 08S1W16N04F Site Address: 275 Saratoga Ave

Site Name: Chevron \#97162

City: Los Gatos

$\begin{array}{ccc}\text { Days } & \text { LogC } & \begin{array}{c}\text { G.W } \\ \text { Elev }\end{array} \\ -0 & -3.4 & -.38 \\ 92 & 2.7 & 1.68 \\ 181 & 3 & 2.44 \\ 272 & 2.9 & .5 \\ 369 & y= & 0 \\ 454 & 3.5 & .68 \\ 557 & 3.2 & 4.39 \\ 639 & .2 .9 & .97\end{array}$

\footnotetext{
$a=\operatorname{slope}(x . y) \quad a=-6.647 \cdot 10^{-5}$

$b=$ intercept $(x, y) \quad b=3.0088$

$\operatorname{corr}(x . y)=-0.0491$

$\operatorname{corr}(x . y)^{2}=0.0024$
}

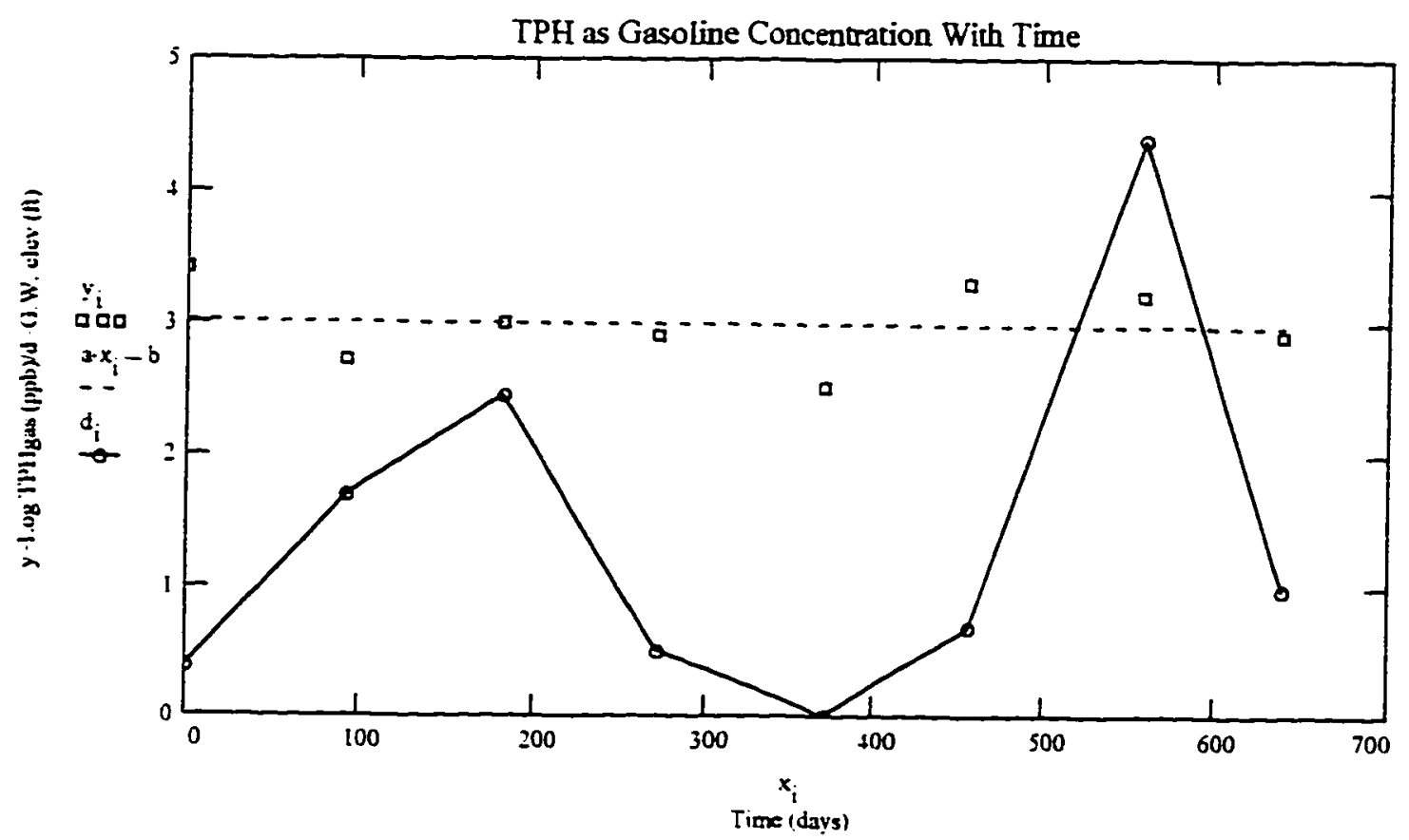


SCWWD Site Number: 08S16N04F

Site Address: 275 Saratoga Ave

Site Name: Chevron \#97162

City: Los Gatos

$\begin{array}{ccc}\text { Days } & \text { LogC } & \begin{array}{c}\text { G.W. } \\ \text { Elev }\end{array} \\ 0 & 2.9^{-} & 3.32 \\ 91 & 1.6 & .61 \\ 188 & \mathrm{y}=1.8 & 0 \\ 274 & 2.4 & \mathrm{~d}= \\ 377 & 2.1 & .36 \\ .459 & .1 .1 . & 7.23 \\ & & .1 .26\end{array}$

$a=\operatorname{slope}(x . y) \quad a=-0.0021$

$b=$ intercept $(x, y) b=2.4722$

$\operatorname{corr}(x . y)=-0.5799$

Note: Ground water elevations have been adjusted to fit the graph. $0 \mathrm{ft}=387.6 \mathrm{ft}$.

$\operatorname{com}(x, y)^{2}=0.3363$

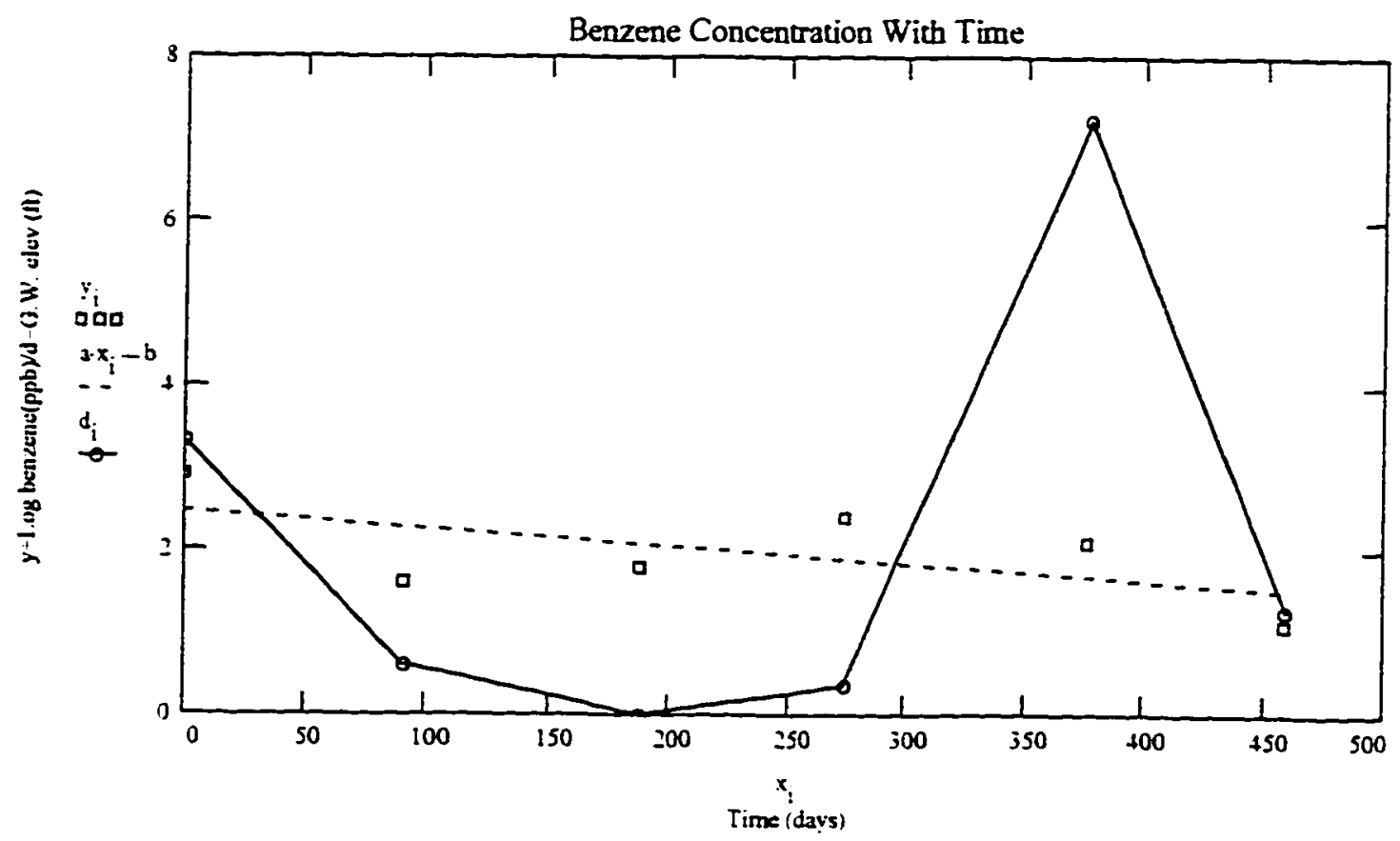


SCWND Site Number: 08S16N04F

Site Address: 275 Saratoga Ave

Site Name: Chevron \#97162

City: Los Gatos

$\begin{array}{ccc}\text { Days } & \text { LogC } & \begin{array}{c}\text { G.W. } \\ \text { Elev }\end{array} \\ -0 & -14 & -3.32 \\ 91 & 2.5 & .61 \\ 188 & \mathrm{y}=2.7 & 0 \\ 274 & 3.3 & \mathrm{~d}= \\ 377 & 3.5 & 7.23 \\ .459 . & .2 .3 . & .1 .26\end{array}$

$a$ =slope(x.y) $a=-0.0015$

Note: Ground water elevations have been adjusted

$b=$ intercept $(x, y) \quad b=3.3926$

to fit the graph. $0 \mathrm{ft}=387.6 \mathrm{ft}$.

$\operatorname{corr}(x . y)=-0.3904$

$\operatorname{cor}(x, y)^{2}=0.1524$

TPH as Gasoline Concentration With Time

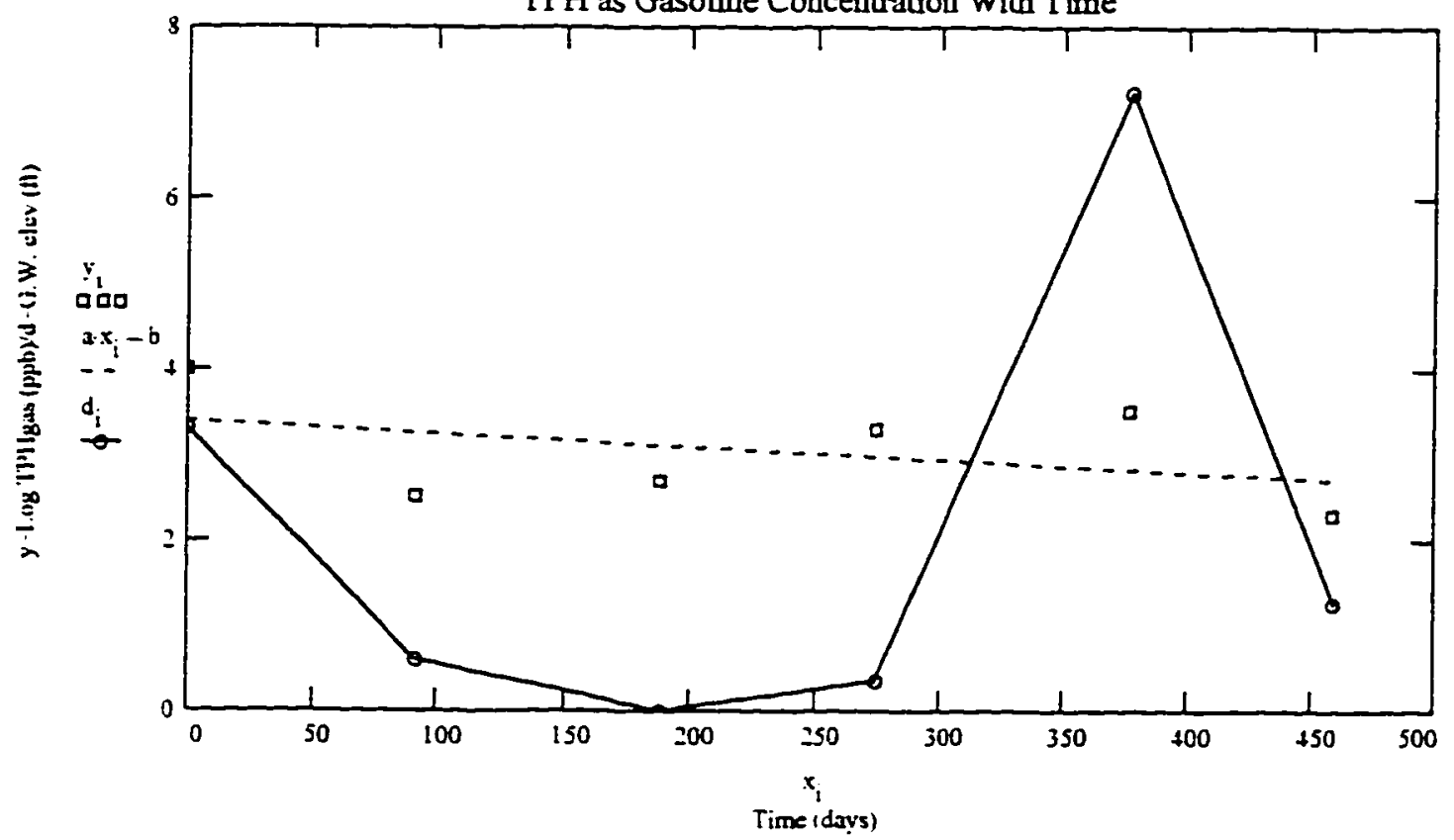




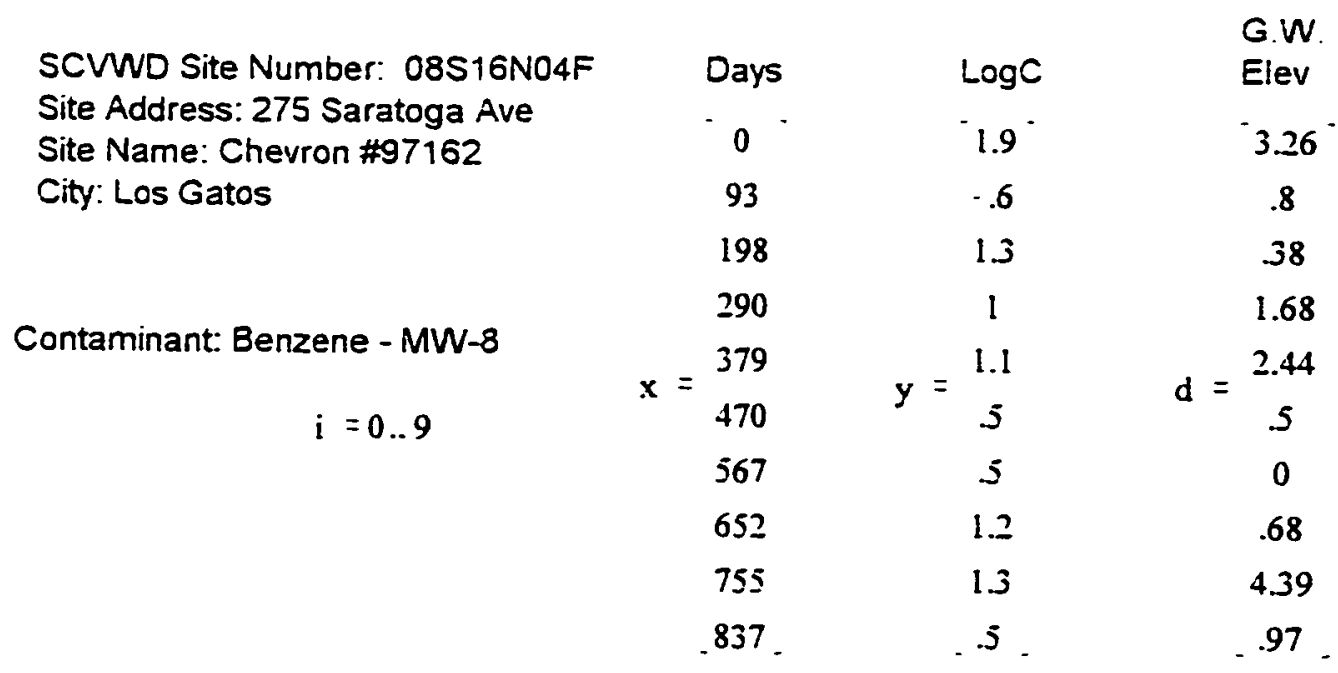

$a=\operatorname{slope}(x . y) \quad a=-1.1225 \cdot 10^{-4}$

$b=$ intercept $(x . y) b=0.9176$

$\operatorname{corr}(x . y)=-0.0464$

Note: Ground water elevations have been adjusted to fit the graph. $0 \mathrm{ft}=386.7 \mathrm{f}$.

$\operatorname{corr}(x . y)^{2}=0.0022$

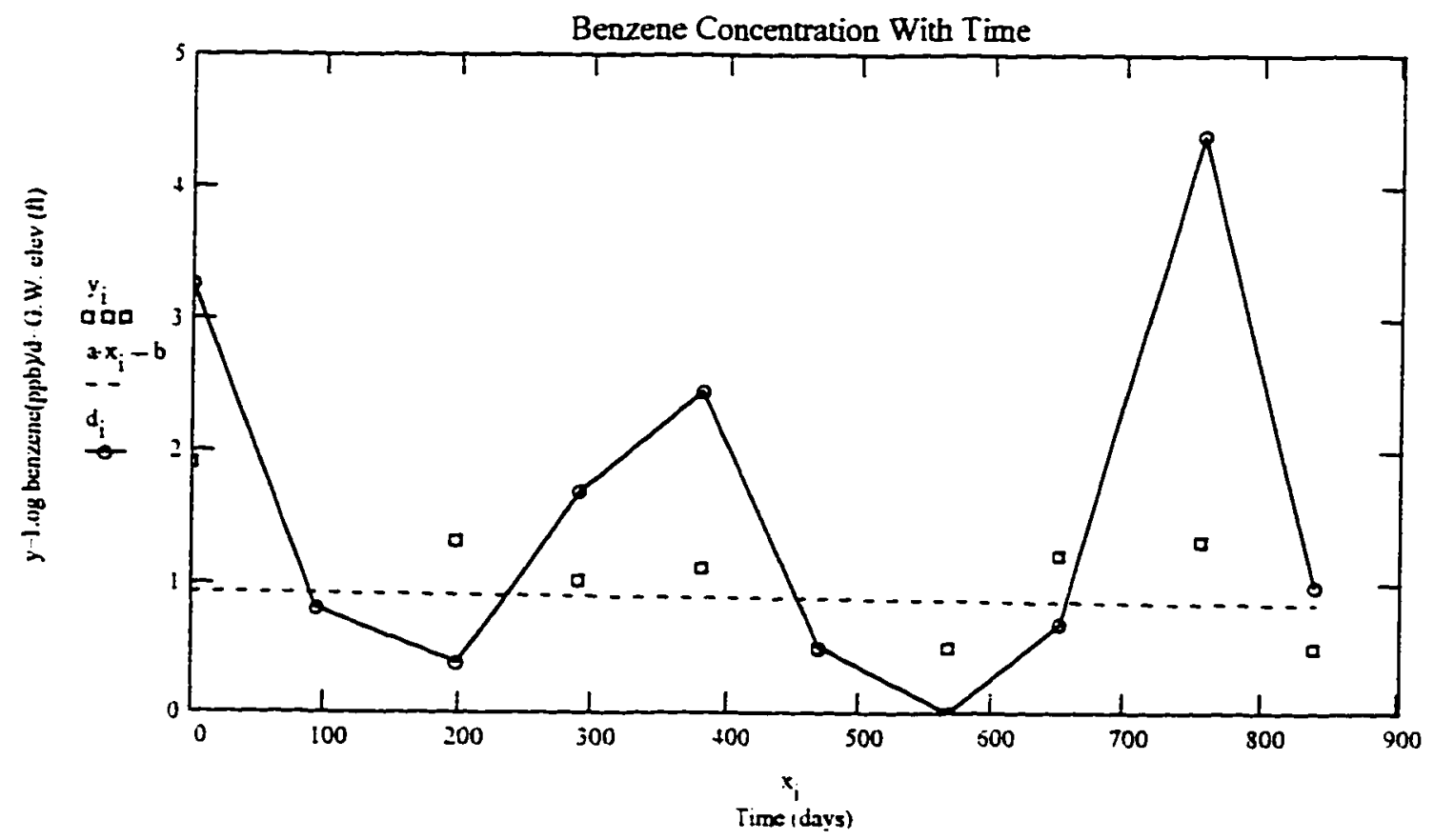


SCWWD Site Number: 08S1W16N03f Site Acdress: 255 Saratoga Avenue Site Name: Shell Service Station City: Los Gatos

Contaminant: TPH Gasoline

$\begin{array}{ccc}\text { Days } & \text { LogC } & \begin{array}{c}\text { G.W. } \\ \text { Elev }\end{array} \\ -0 & -4.7^{-} & 6.9^{-} \\ 79 & 2.9 & 2.3 \\ 184 & 2.7 & 1.4 \\ 274 & 3.3 & 1.4 \\ 364 & y=3.6 & \mathrm{~d}=4.1 \\ 457 & 2.6 & 2.2 \\ 549 & 2 & 1.7 \\ 650 & 2.1 & 0 \\ 739 & 1.7 & 4.1 \\ 830 . & -1.4 . & -1.7\end{array}$

$a=$ slope( $x . y) \quad a=-0.003$

$b=$ intercept $(x, y) \quad b=3.9326$

Note: Ground water elevations have been adjusted $\operatorname{corr}(x, y)=-0.8523$ to fit the graph. $O A t=384.88 \mathrm{ft}$

$\operatorname{corr}(x . y)^{2}=0.7265$

TPH as Gasoline Concentration With Time

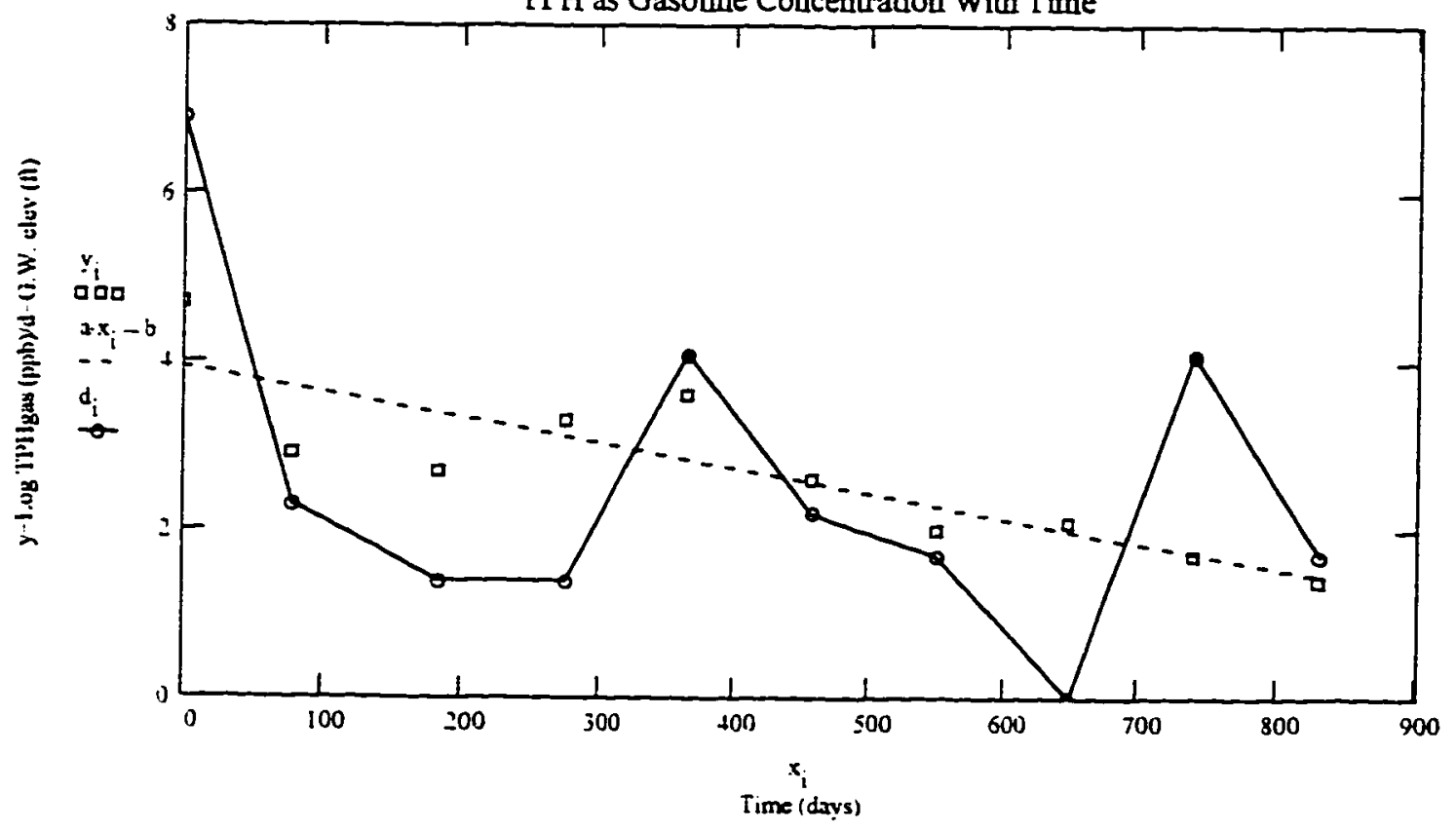


SCWWD Site Number: 08S1W16N03f Site Address: 255 Saratoga Avenue Site Name: Shell Service Station City: Los Gatos

$\begin{array}{ccc}\text { Days } & \text { LogC } & \begin{array}{c}\text { G.W. } \\ \text { Elev }\end{array} \\ 0 & 2.5 & 6.9 \\ 79 & 1 & 2.3 \\ 184 & 1.1 & 1.4 \\ 274 & \mathrm{y}=1.6 & \mathrm{~d}=1.4 \\ 364 & 1.5 & 4.1 \\ 457 & 1.6 & 2.2 \\ 549 & -.2 & 1.7 \\ 650 . & -.6 . & .0\end{array}$

$a=\operatorname{slope}(x, y) \quad a=-0.0034$ Note: Ground water elevation have been adjusted to fit the $b=$ intercept $(x, y) \quad b=2.136$ graph. O ft $=384.88 \mathrm{ft}$

$\operatorname{corr}(x . y)=-0.7543$

$\operatorname{corr}(x . y)^{2}=0.569$

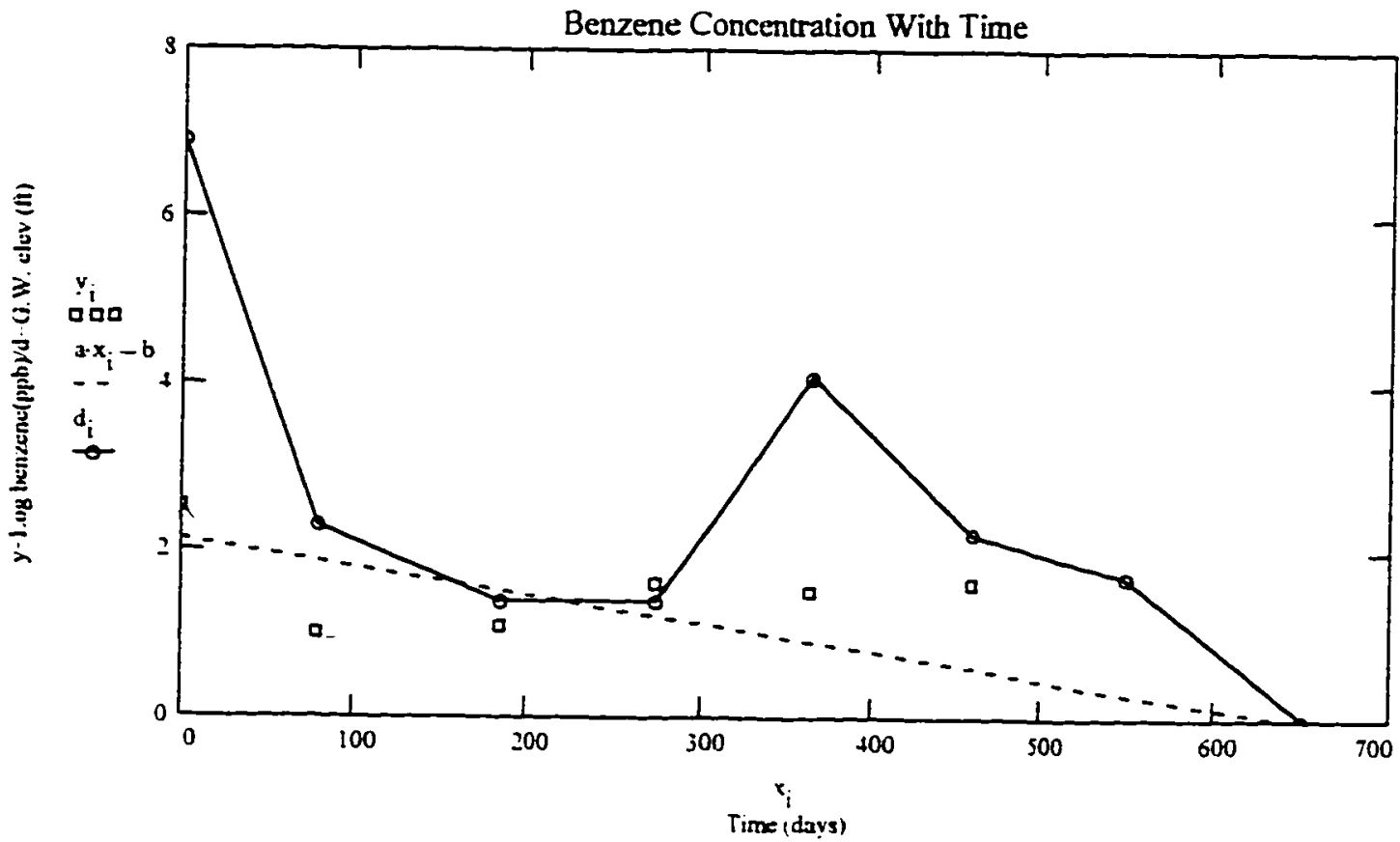




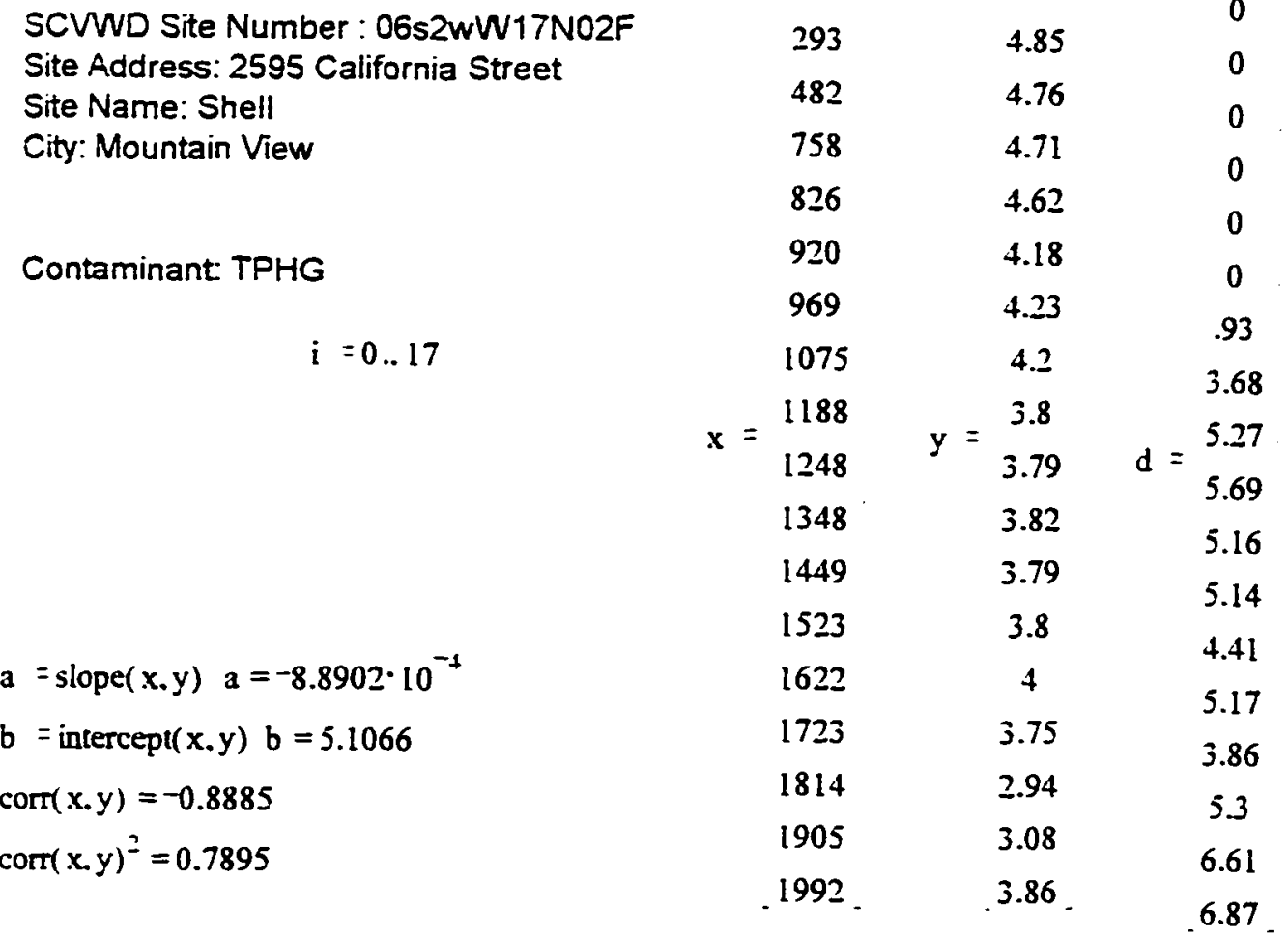

Note: Ground water elevation has been adjusted to fit the graph. 0 feet equals 28.06 feet. Missing data points are noted on graph

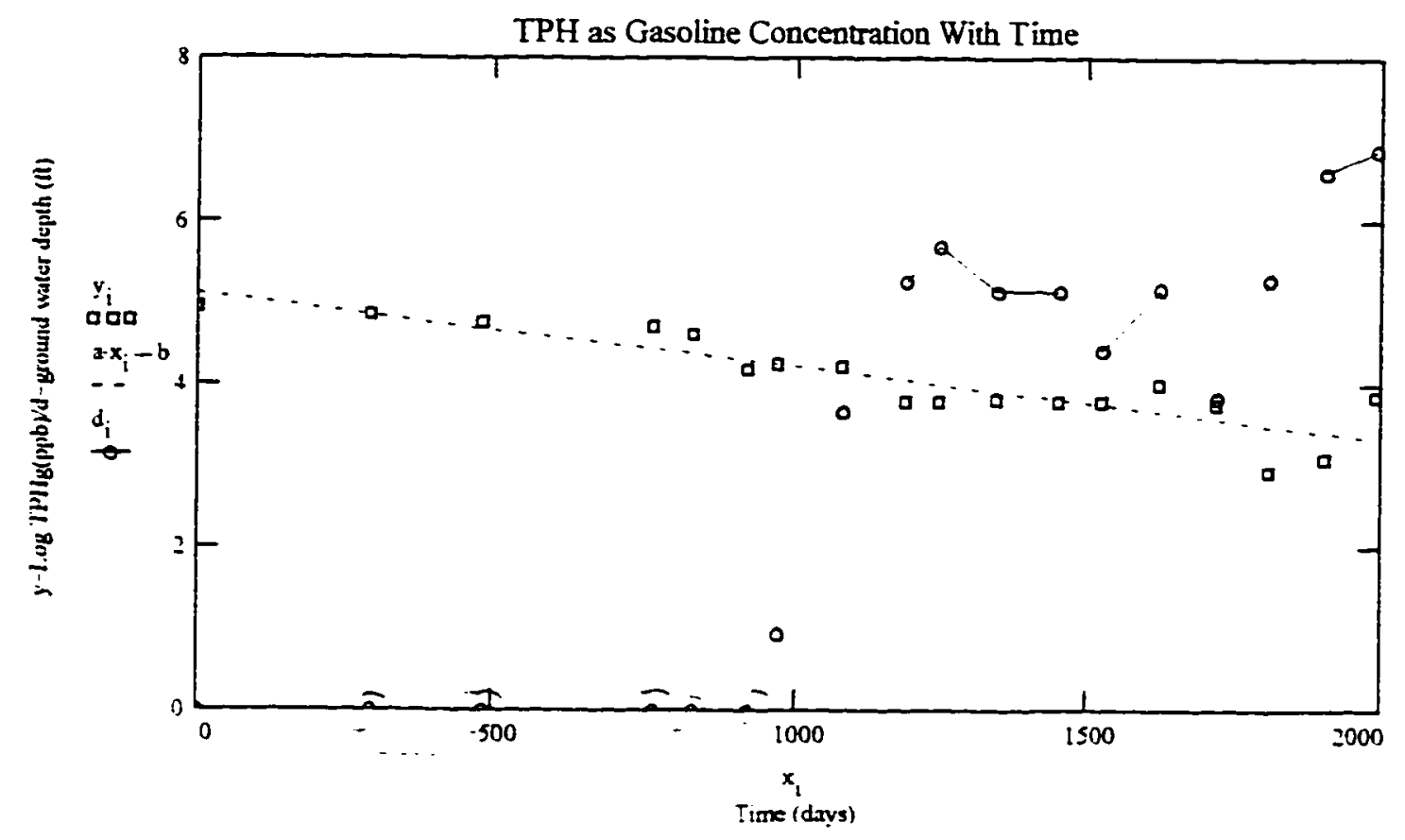




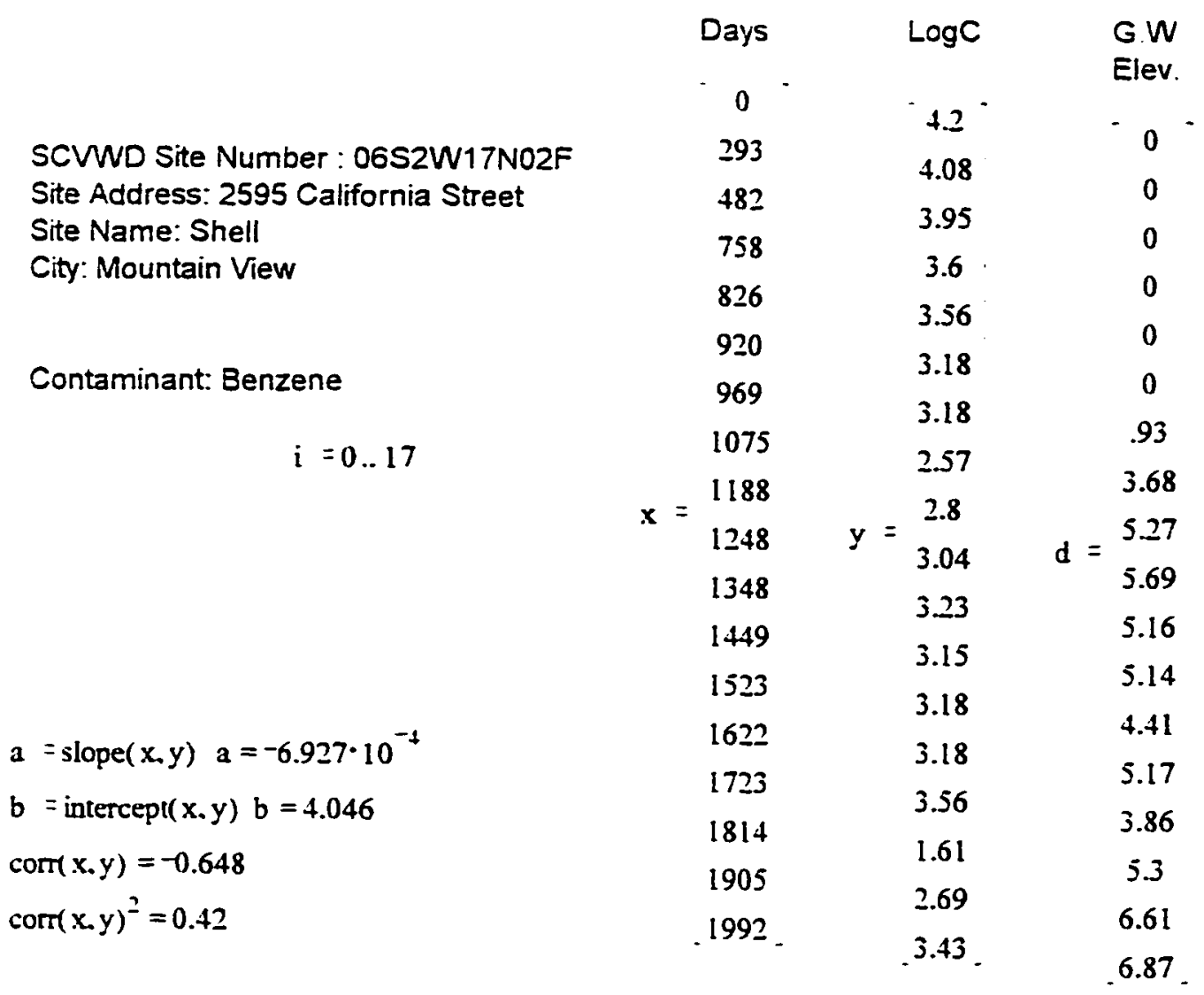

Note: Ground water elevation has been adjusted to it the graph. 0 feet equals 28.06 feet. Missing data points are noted on graph

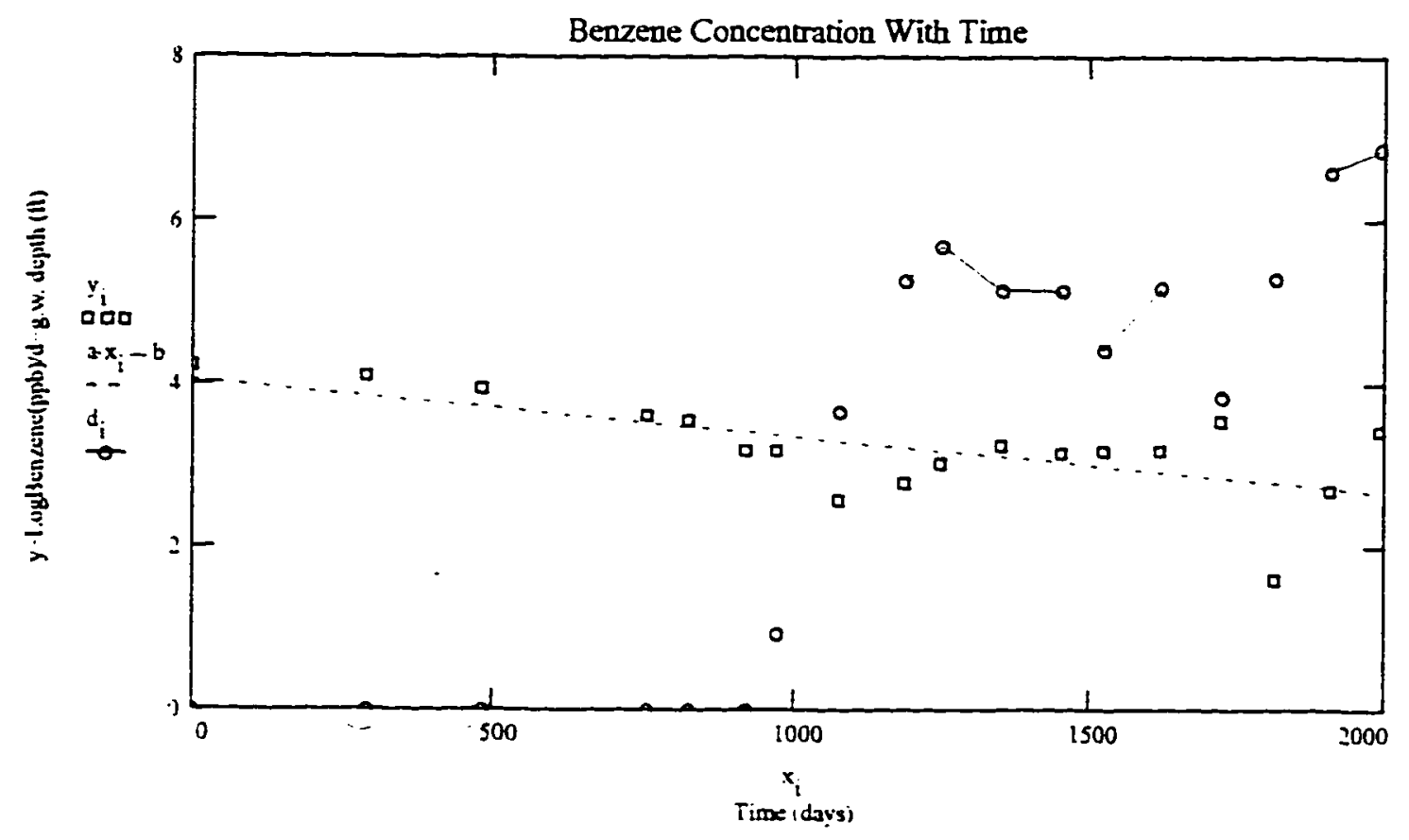


SCWWD Site Number : 0652WOgN01F

Site Address: 1036 N. Rengstorff Ave

Site Name: Texaco

City: Mountain View

Contaminant: TPHg

$$
i=0 . .5
$$

$a=\operatorname{slope}(x, y) \quad a=-0.0029$

$b=\operatorname{intercept}(x, y) \quad b=3.5853$

$\operatorname{corr}(x . y)=-0.873$

$\operatorname{corr}(x . y)^{2}=0.7621$

$x=\begin{array}{cc}\text { Days } & \log C \\ -0 & 3.52 \\ 82 & 3.3 \\ 183 & y=3.32 \\ 516 & 1.4 \\ 605 & 2.57 \\ 695 & -1.4\end{array}$

Note: Data was evaluated up to first two consecutive NDs.

Note: Insufficient ground water elevation data to plot on graph.

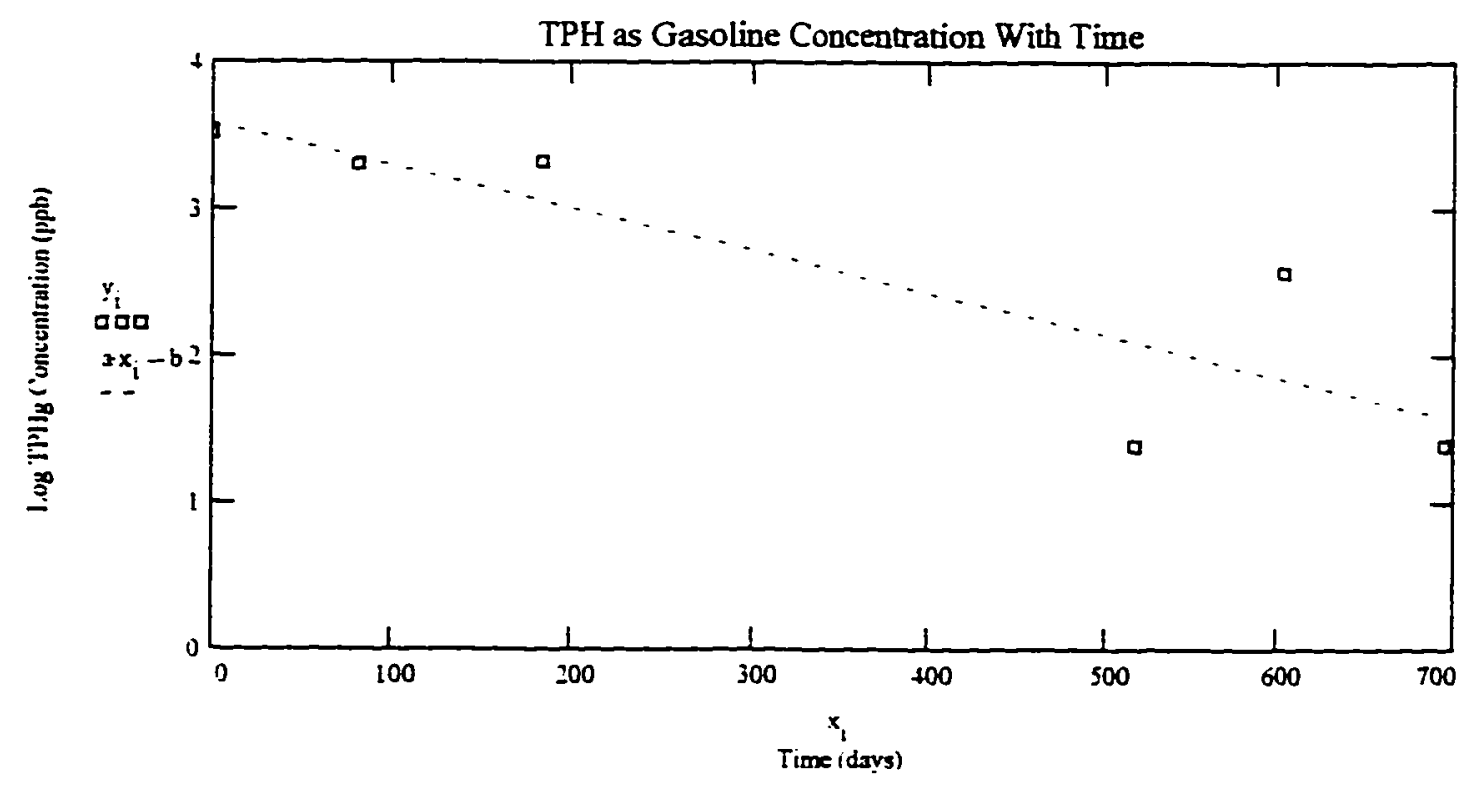


SCWWD Site Number : 06S2W15E02F

Site Address: 1250 L'Avenida Street

Site Name: Rudolph and Sletton

City: Mountain View

Contaminant: TPHg

$$
i=0 . .7
$$

$a=\operatorname{slope}(x . y) \quad a=-0.0015$

$b=$ intercept(x.y) $b=2.7629$

$\operatorname{com}(x . y)=-0.678$

$\operatorname{cort}(x, y)^{2}=0.4597$

$\begin{array}{ccc}\text { Days } & \text { LogC } & \begin{array}{l}\text { GW } \\ \text { Depth } \\ -0\end{array} \\ \mathrm{x}= & 3.4 & 2.0 \\ 96 & 1.85 & 1.23 \\ 176 & 2.77 & 1.8 \\ 224 & \mathrm{y}=2.18 & \mathrm{~d}=1.75 \\ 399 & 2.08 & 1.65 \\ 472 & 2.18 & 1 \\ 584 & 1.9 & 2 \\ 731 & -1.76 . & -1.2\end{array}$

Note: Ground water depth has been adjusted to fit the graph. 1.0 feet equals 8.0 feet.

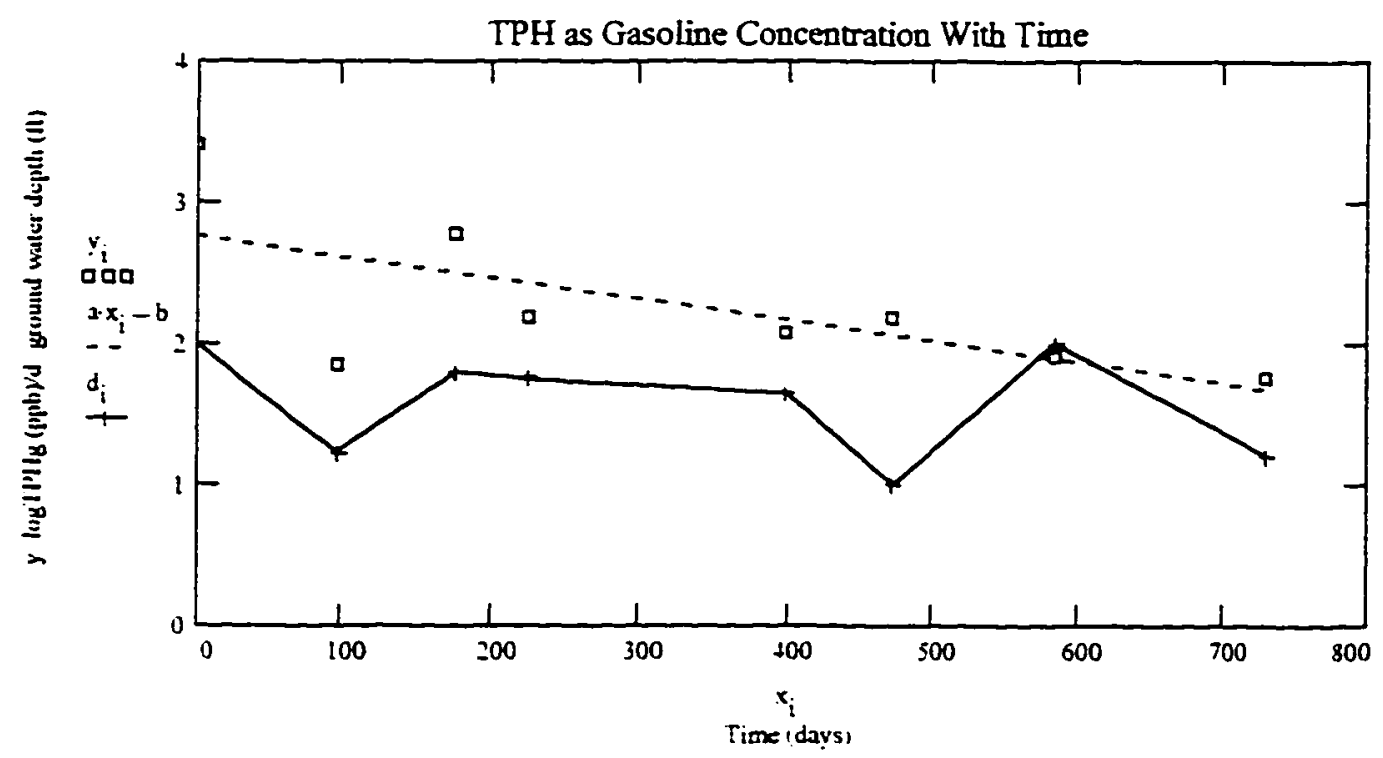


SCWWD Site Number : 06S2W15M01F Site Address: 1080 Linda Vista Ave.

Site Name: Rob-Jack Corp.

City: Mt. View

Contaminant: TPHg

$$
\mathrm{i}=0 . .11
$$

$a=\operatorname{slope}(x, y) \quad a=-2.3495 \cdot 10^{-7}$

$b=$ intercept $(x . y) \quad b=2.6233$

$\operatorname{corr}(x . y)=-0.557$

$\operatorname{corr}(x, y)^{2}=0.3102$

$\begin{array}{ccc}\text { Days } & \text { LogC } & \begin{array}{l}\text { GW } \\ \text { Depth } \\ \text { (ft) }\end{array} \\ 0 & -2.79 & - \\ 101 & 2.54 & 0 \\ 331 & 2.11 & 0 \\ 537 & 2.76 & 5.38 \\ 668 & 2.51 & 2.73 \\ 782 & y .36 & 3.55 \\ 862 & y=2.59 & 3.86 \\ 960 & 2.36 & 1.03 \\ 1095 & 2.34 & .08 \\ 1360 & 2.36 & 0 \\ 1459 & 2.38 & .63 \\ 1635 . & 2.08 . & .43\end{array}$

Note: Ground water depth has been adjusted to fit the graph. 0 feet equais 8.67 feet.

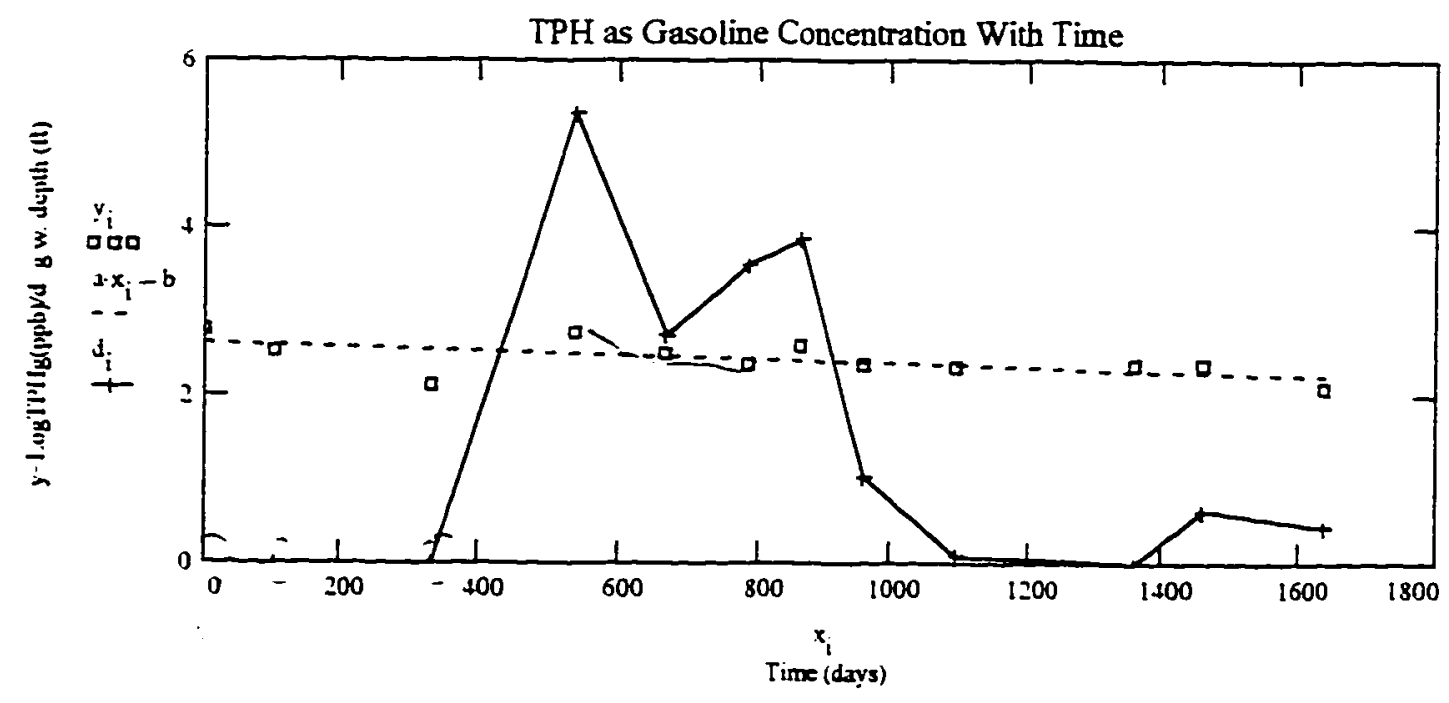


SCVWD Site Number: 06S2W15M01F

Site Address: 1080 Linda Vista Ave.

Site Name: Rob-Jack Corp.

City: Mt. View

Contaminant: Benzene

$$
i=0 . .5
$$

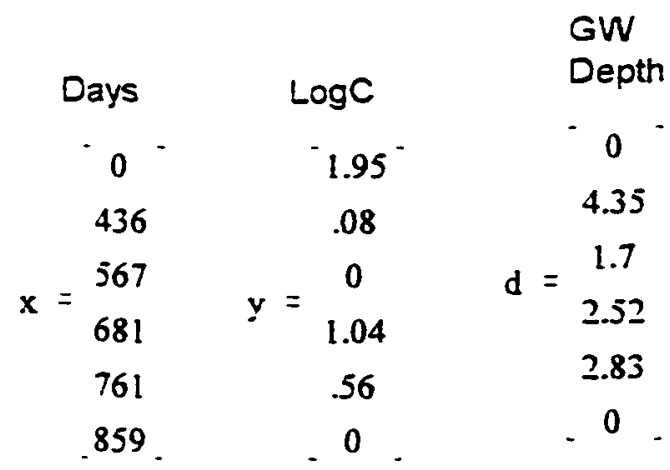

\footnotetext{
$a=\operatorname{slope}(x . y) \quad a=-0.0018$

$b=$ intercept $(x . y) b=1.571$

$\operatorname{corr}(x . y)=-0.6956$

$\operatorname{corr}(x y)^{2}=0.4838$
}

Note: Ground water depth has been adjusted to fit the graph. 0 feet equals 9.7 feet.

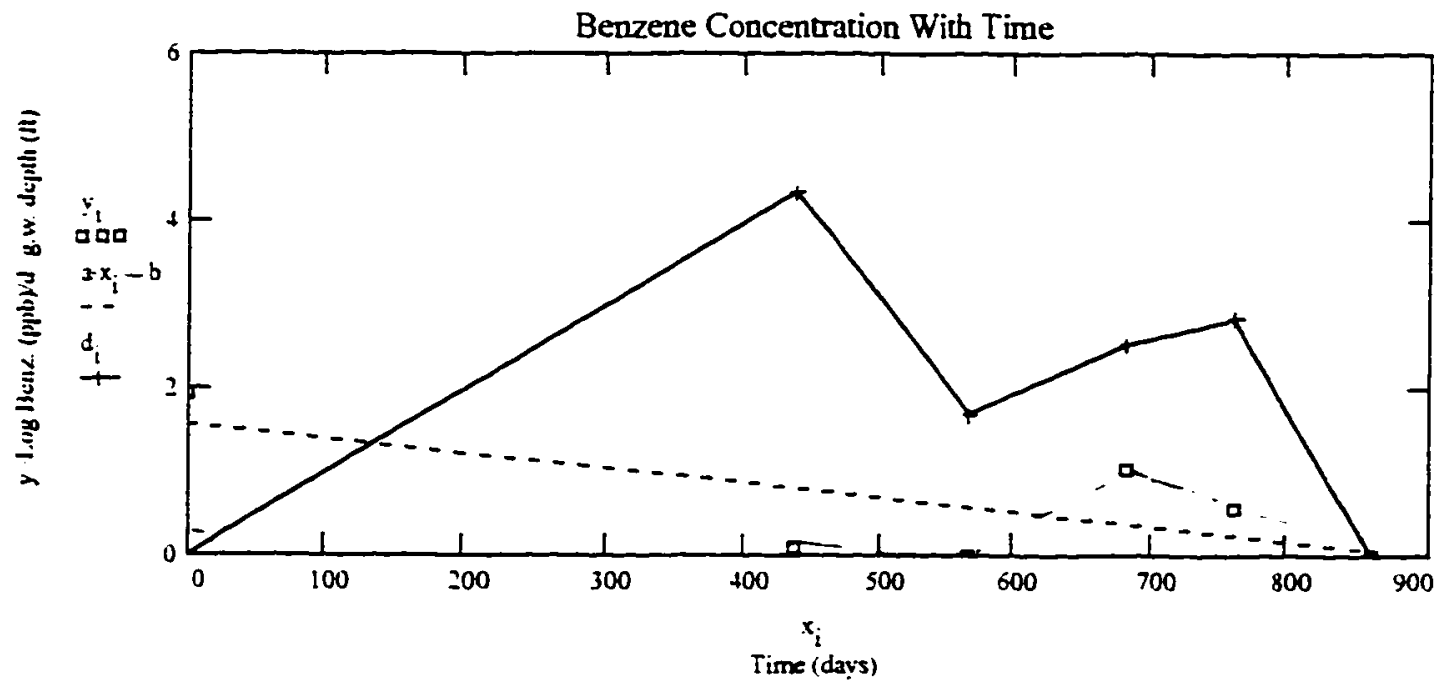


SCVND Site Number : 06S2W2703F

Site Address: 45 West El Camino Real Site Name:Chevron \#9.0699

City: Mountain View

Contaminant: $\mathrm{TPg}$

$\begin{array}{ccc}\text { Days } & \text { LogC } & \begin{array}{c}\text { G.W. } \\ \text { Elev. }\end{array} \\ 0 & -3.69 & -0 \\ 91 & 3.36 & .59 \\ 178 & 2.89 & 2.41 \\ 261 & \mathrm{y}=2.23 & \mathrm{~d}=6.29 \\ 359 & 2.74 & 4.92 \\ 447 & 2.2 & 3.2 \\ 539 & -1.4 & .8 .58\end{array}$

$a=\operatorname{slope}(x . y) \quad a=-0.0037$

$b=$ intercept $(x, y) \quad b=3.6371$

$\operatorname{corr}(x . y)=-0.9277$

$\operatorname{corr}(x . y)^{2}=0.8606$

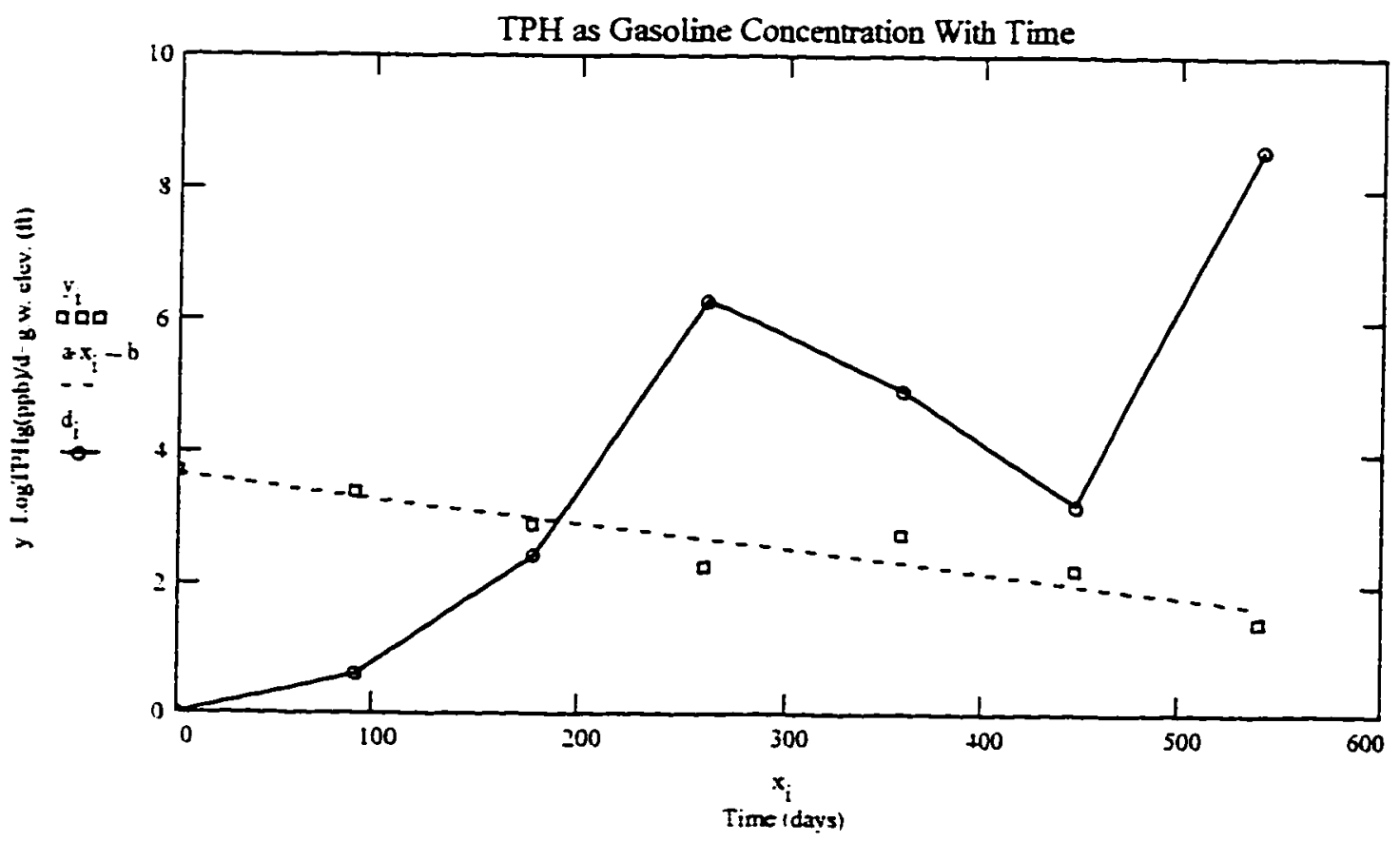


SCWWD Site Number : 06S2W2703F

Site Address: 45 West El Camino Real

Site Name:Chevron \#9.0699

City: Mountain View

Contaminant: Benzene

$$
i=0 . .6
$$

\begin{tabular}{|c|c|c|}
\hline Days & $\log C$ & Elev. \\
\hline 0 & $2.46^{\circ}$ & 0 \\
\hline 91 & 2 & .59 \\
\hline 178 & 1.11 & 2.41 \\
\hline$x=261$ & $y=1.08$ & $d=6.29$ \\
\hline 359 & 1.23 & 4.92 \\
\hline 447 & .65 & 3.2 \\
\hline . 539 & -.6 & .8 .58 \\
\hline
\end{tabular}

G.W.

0

.92

8.58

$a=\operatorname{slope}(x, y) a=-0.0047$

$b=$ intercept $(x, y) \quad b=2.3872$

$\operatorname{corr}(x . y)=-0.9255$

$\operatorname{corr}(x, y)^{2}=0.8565$

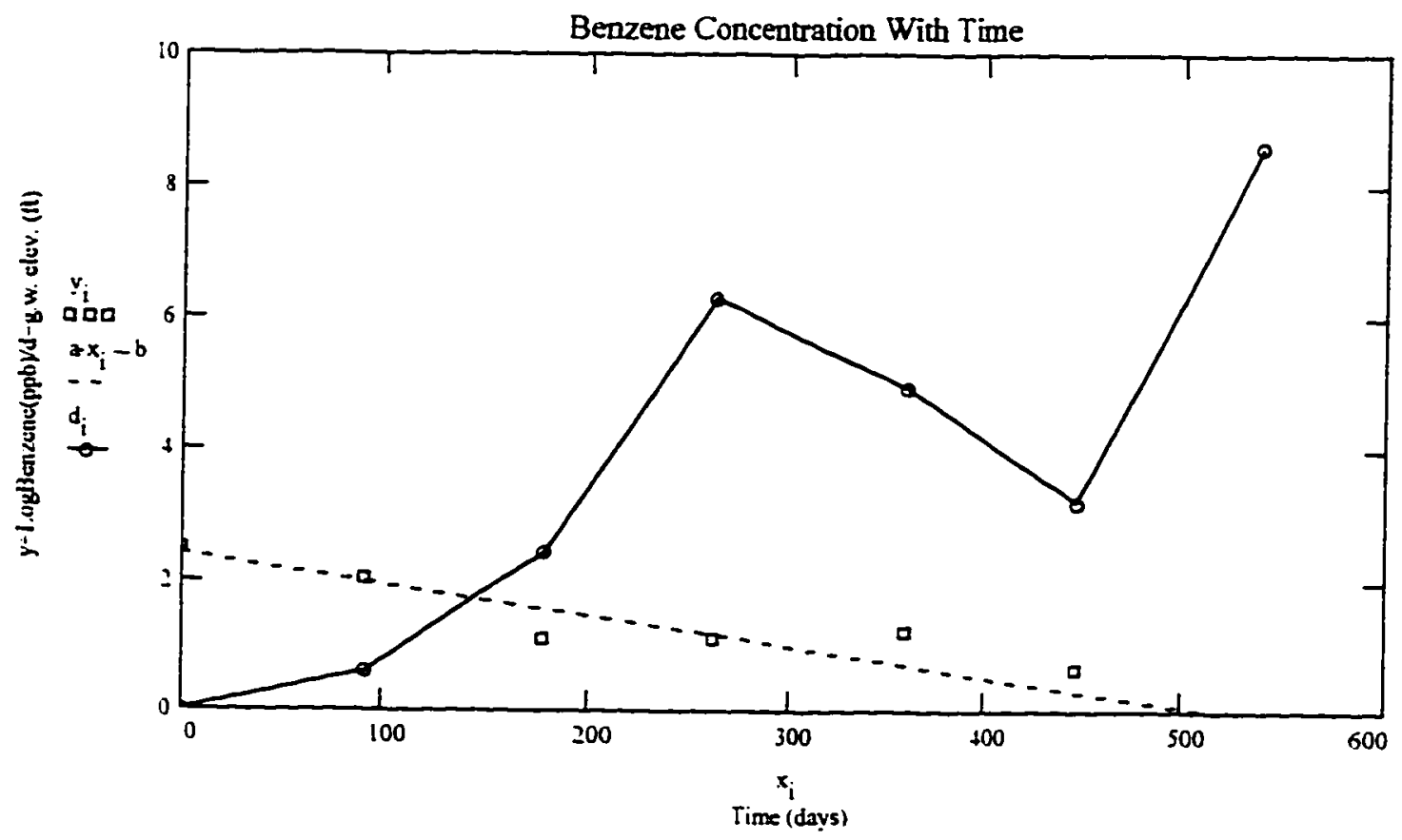




\begin{tabular}{|c|c|c|c|}
\hline & Days & $\log C$ & $\begin{array}{l}\text { G.W. } \\
\text { Elev }\end{array}$ \\
\hline \multirow{4}{*}{$\begin{array}{l}\text { SCWWD Site Number : 06S2W22C02F } \\
\text { Site Address: } 495 \text { MOFFETT BLVD } \\
\text { Site Name: EXXON } \\
\text { City: MT. VIEW }\end{array}$} & 0 & $3.9^{-}$ & 1.69 \\
\hline & 121 & 3.3 & 4.42 \\
\hline & 216 & 3.2 & 2.64 \\
\hline & 286 & 3 & 0 \\
\hline \multirow[t]{8}{*}{ Contaminant: TPH Gasoline } & 397 & 3.7 & 9.15 \\
\hline & 467 & 3.2 & 9.42 \\
\hline & 601 & 3.6 & 7.73 \\
\hline & $x=658$ & $y=2.8$ & $d=7.79$ \\
\hline & 745 & 3.5 & 8.72 \\
\hline & 823 & 2.3 & 8.66 \\
\hline & 919 & 2 & 8.15 \\
\hline & 1012 & 1.9 & 8.06 \\
\hline$a=\operatorname{slope}(x . y) \quad a=-0.0013$ & 1104 & 2.2 & 11.31 \\
\hline$b=$ intercept $(x, y) \quad b=3.7417$ & 1196 & 2.7 & 12.74 \\
\hline $\operatorname{com}(x . y)=-0.7812$ & 1293. & 20. & 9.93 \\
\hline
\end{tabular}

Note: Elevations have been adjusted to fit on the graph. 0 feet $=30.09$ feet

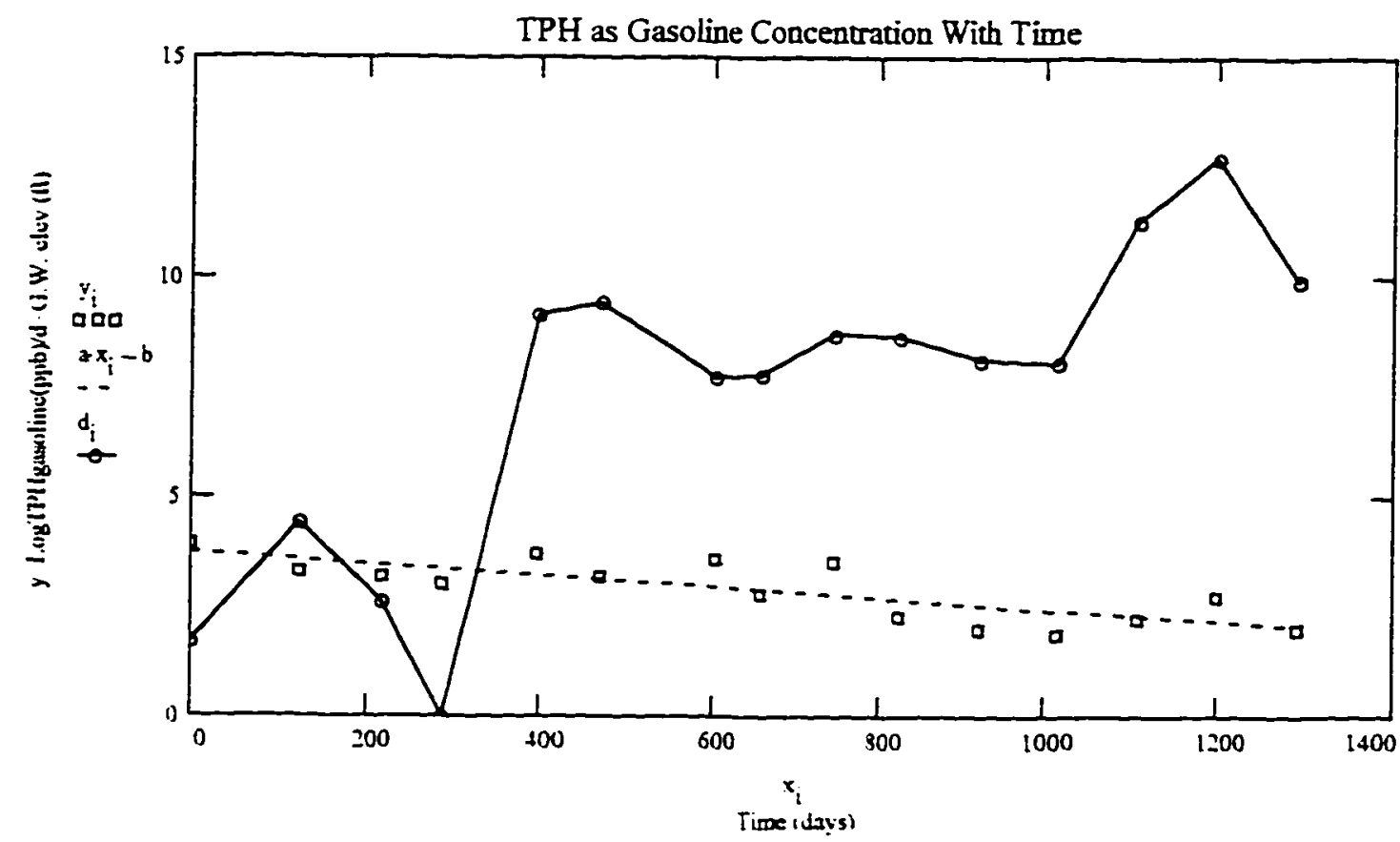


SCVWD Site Number : 06S2W22C02F Site Address: 495 MOFFETT BLVD Site Name: EXXON

City: MT. VIEW

$a=\operatorname{slope}(x . y) \quad a=-0.0013$

$b=$ intercept $(x, y) \quad b=\mathbf{2 . 8 8 4}$

$\operatorname{corr}(x, y)=-0.7019$

$\operatorname{com}(x . y)^{2}=0.4927$

$\begin{array}{ccc}\text { Days } & \text { LogC } & \begin{array}{c}\text { G.W. } \\ \text { Elev }\end{array} \\ 0 & -3 & -1.69 \\ 121 & 2.4 & 4.42 \\ 216 & 2.5 & 2.64 \\ 286 & 2.4 & 0 \\ 397 & 2.7 & 9.15 \\ 467 & 2.7 & 9.42 \\ 601 & 1.9 & 7.73 \\ \mathrm{x}= & \mathrm{d} & 7.79 \\ 758 & \mathrm{y} .1 & 8.72 \\ 745 & 3 & 8.66 \\ 823 & 1.2 & 8.15 \\ 919 & .57 & 8.06 \\ 1012 & 1.1 & 11.31 \\ 1104 & 1.2 & 12.74 \\ 1196 & 2.1 & 9.93 \\ 1293 & .1 .3 . & \end{array}$

Note: Elevations have been adjusted to fit on the graph. 0 feet $=30.09$ feet

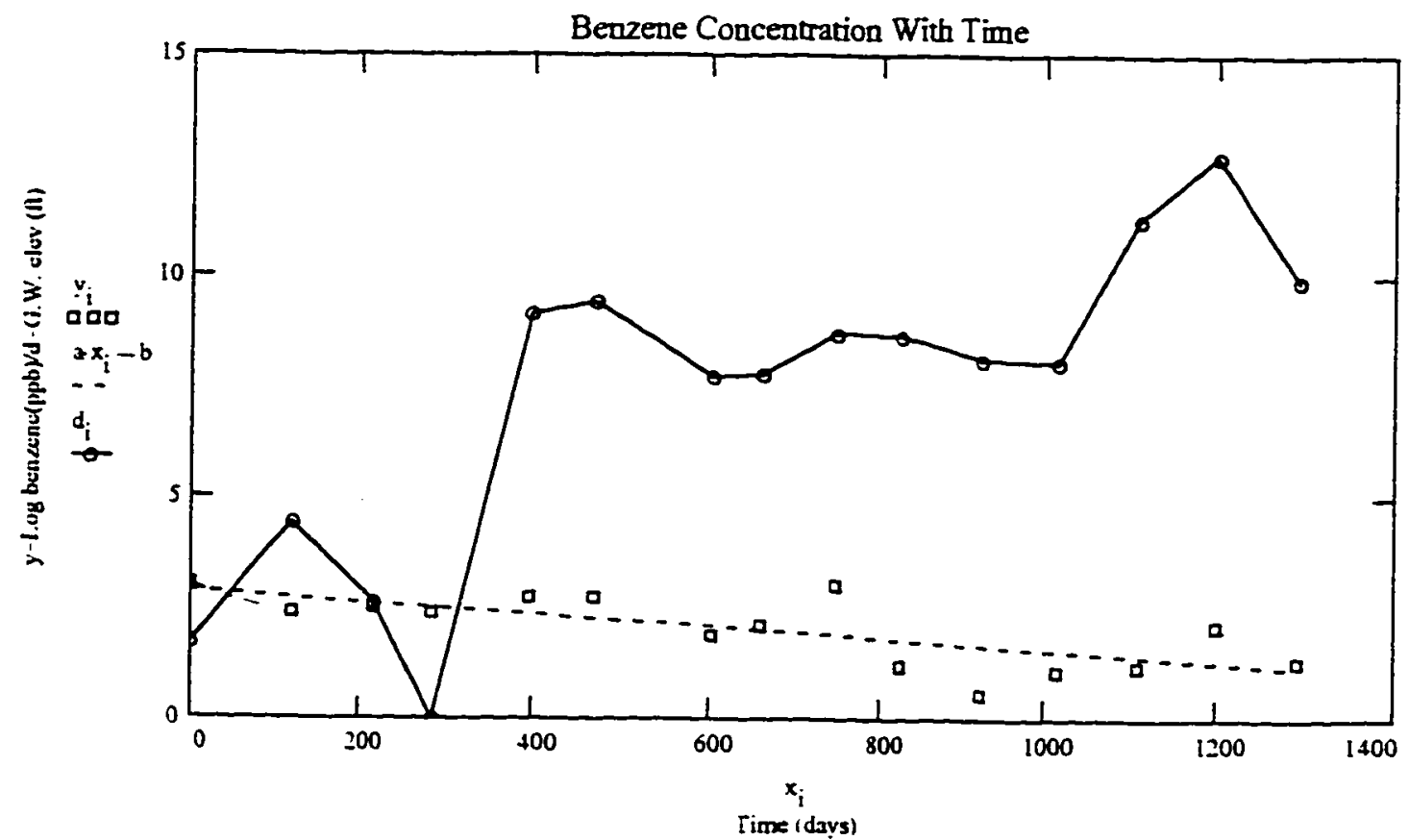


SCWWD Site Number : 0652WSoH02F

Site Address: 789 E. Evelyn Ave

Site Name: H\&M Station

City: Mt. View

Days $\quad$ LogC

Contaminant: TPH Gasoline

0 - $4.4^{-}$

$\mathrm{i}=0 . .3 \quad \mathrm{x}=\begin{array}{r}2089 \\ 2191 \\ 2281\end{array} \quad \mathrm{y}=\begin{gathered}2.9 \\ 3\end{gathered}$

$a=\operatorname{slope}(x, y) \quad a=-9.3364 \cdot 10^{-4}$

$b=\operatorname{intercept}(x, y) \quad b=4.4564$

$\operatorname{corr}(x, y)=-0.835$

Note: No ground water elevation data

$\operatorname{corr}(x . y)^{2}=0.6973$

TPH as Gasoline Concentration With Time

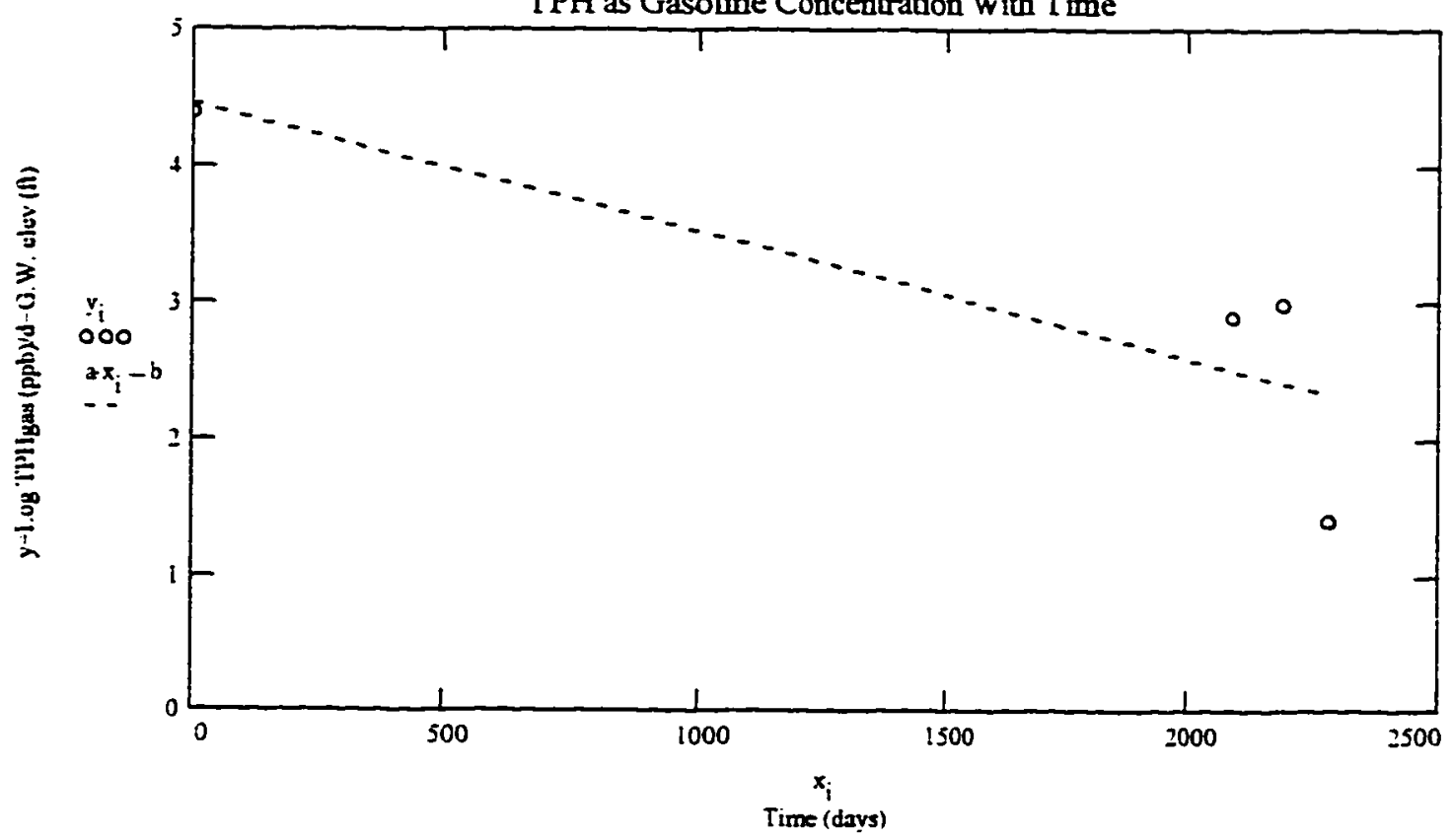


SCVWD Site Number : 06S2WS6H02F

Site Address: 789 E. Evelyn Ave

Site Name: H\&M Station

City: Mtt. View

Contaminant: Benzene

$$
i=0 . .4
$$

Days $\quad \log C$

$\begin{array}{cr}0 & 3.7 \\ 2089 & y=1.3 \\ 2191 & 1.9 \\ 2281 & -.3 \\ .2345 & -1.2\end{array}$

$a=\operatorname{slope}(x, y) \quad a=-0.0012$

$b=$ intercept $(x, y) \quad b=3.7337$

$\operatorname{corr}(x . y)=-0.8449$

Note: No ground water elevation data

$\operatorname{corr}(x . y)^{2}=0.7138$

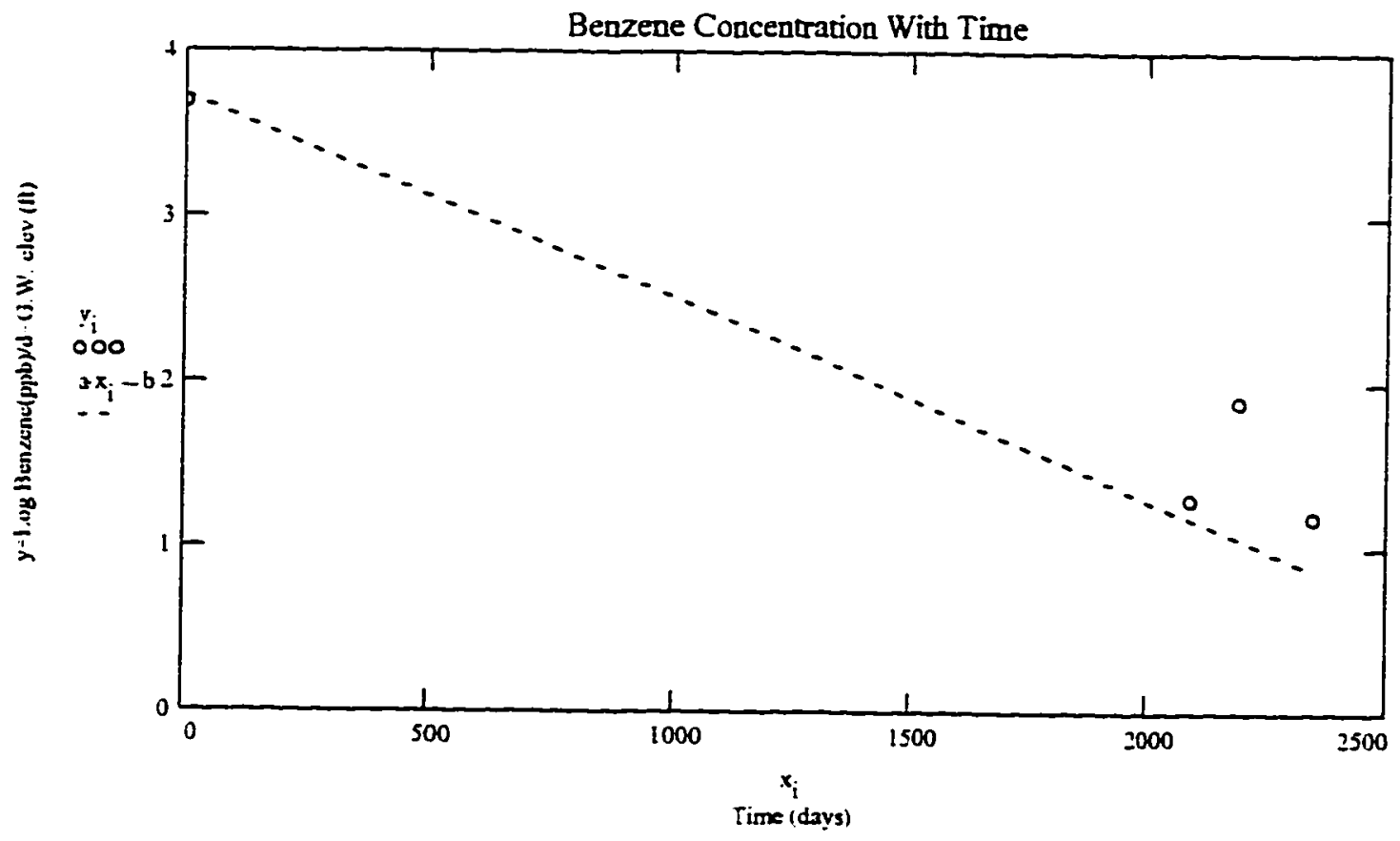




\begin{tabular}{|c|c|c|c|}
\hline \multirow{3}{*}{$\begin{array}{l}\text { SCVWD Site Number: 06S2W08K05F } \\
\text { Site Address: } 840 \text { San Antonio Road } \\
\text { Site Name: Arco } \# 1326 \\
\text { City: Palo Alto }\end{array}$} & Days & $\log C$ & $\begin{array}{l}\text { G.W. } \\
\text { Elev }\end{array}$ \\
\hline & 0 & $4.4^{\circ}$ & 1.5 \\
\hline & 104 & 4.0 & .6 \\
\hline \multirow[b]{2}{*}{ Contaminant: TPH Gasoline - A-2 } & 185 & 3.5 & 1.7 \\
\hline & 291 & 3.2 & 1.1 \\
\hline \multirow{6}{*}{$i=0 . .17$} & 370 & 3.6 & 1.4 \\
\hline & 471 & 4.0 & 2.0 \\
\hline & 558 & 3.5 & 1.3 \\
\hline & 648 & 3.3 & 1.0 \\
\hline & $x=758$ & 3.6 & 1.6 \\
\hline & 821 & 3.1 & 2.2 \\
\hline \multirow{2}{*}{$\begin{array}{l}a=\operatorname{slope}(x, y) \quad a=-6.0731 \cdot 10^{-4} \\
b=\operatorname{intercept}(x, y) \quad b=3.8782\end{array}$} & 933 & 3.2 & 1.1 \\
\hline & 1024 & 3.2 & 1.6 \\
\hline \multirow{2}{*}{$\operatorname{cor}(x, y)=-0.8075$} & 1115 & 3.3 & 3.0 \\
\hline & 1199 & 3.2 & 2.0 \\
\hline \multirow{4}{*}{$\operatorname{cor}(x . y)^{2}=0.652$} & 1319 & 2.9 & 1.3 \\
\hline & 1396 & 3.0 & 1.5 \\
\hline & 1537 & 3.0 & 2.3 \\
\hline & 2104 & .2 .8 & 2.1 \\
\hline
\end{tabular}

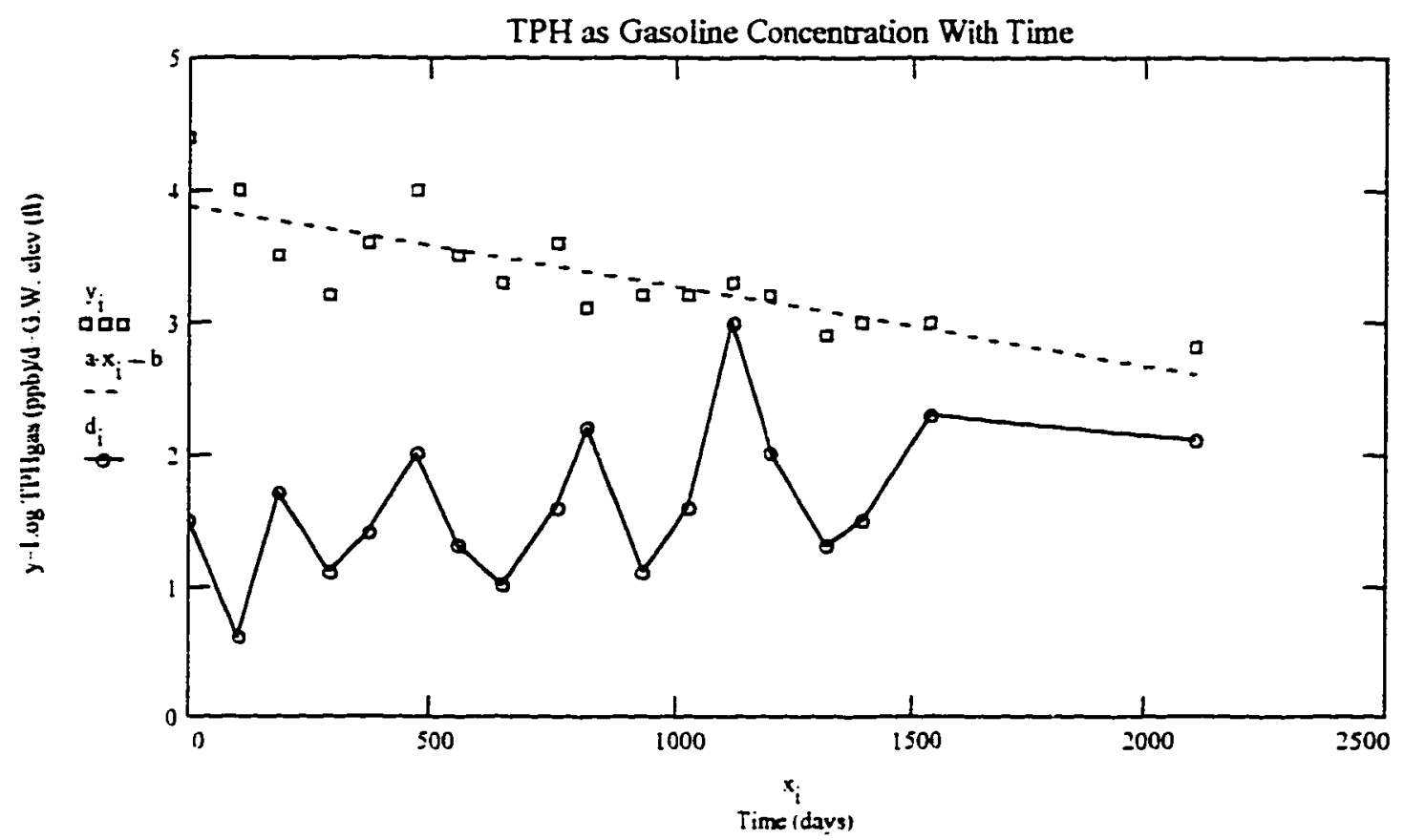

Note Ground water elevations have been adjusted to fit the graph by adding $2 \mathrm{ft}$. 0 it elevation datum (second to last elevation) had no elevation data: 0 was input. 
SCWWD Site Number: 06S2W08K05F Site Address: 840 San Antonio Road Site Name: Arco \#1326

City: Palo Alto

Contaminant: Benzene $-A-2$

$i=0 . .19$

\begin{tabular}{|c|c|c|}
\hline Days & $\log C$ & $\begin{array}{l}\text { G.W. } \\
\text { Elev }\end{array}$ \\
\hline 0 & 3.1 & 1.5 \\
\hline 114 & 2.9 & 1.3 \\
\hline 210 & 2.7 & 1.5 \\
\hline 314 & 2.6 & .6 \\
\hline 395 & 2.5 & 1.7 \\
\hline 501 & 2.1 & 1.1 \\
\hline 580 & 1.8 & 1.4 \\
\hline 681 & 3.1 & 2.0 \\
\hline 768 & 2.2 & 1.3 \\
\hline$k=858$ & $y=2.0$ & -1.0 \\
\hline 968 & 1.9 & $d=1.6$ \\
\hline 1031 & 1.6 & 2.2 \\
\hline 1143 & 2.0 & 1.1 \\
\hline 1234 & 2.0 & 1.6 \\
\hline 1325 & 1.8 & 3.0 \\
\hline 1409 & 1.7 & 2.0 \\
\hline 1529 & 1.5 & 1.3 \\
\hline 1606 & 1.8 & 1.5 \\
\hline 1747 & 1.3 & 2.3 \\
\hline .2104 & .0 & 2.1 \\
\hline
\end{tabular}

Benzene Concentration With Time

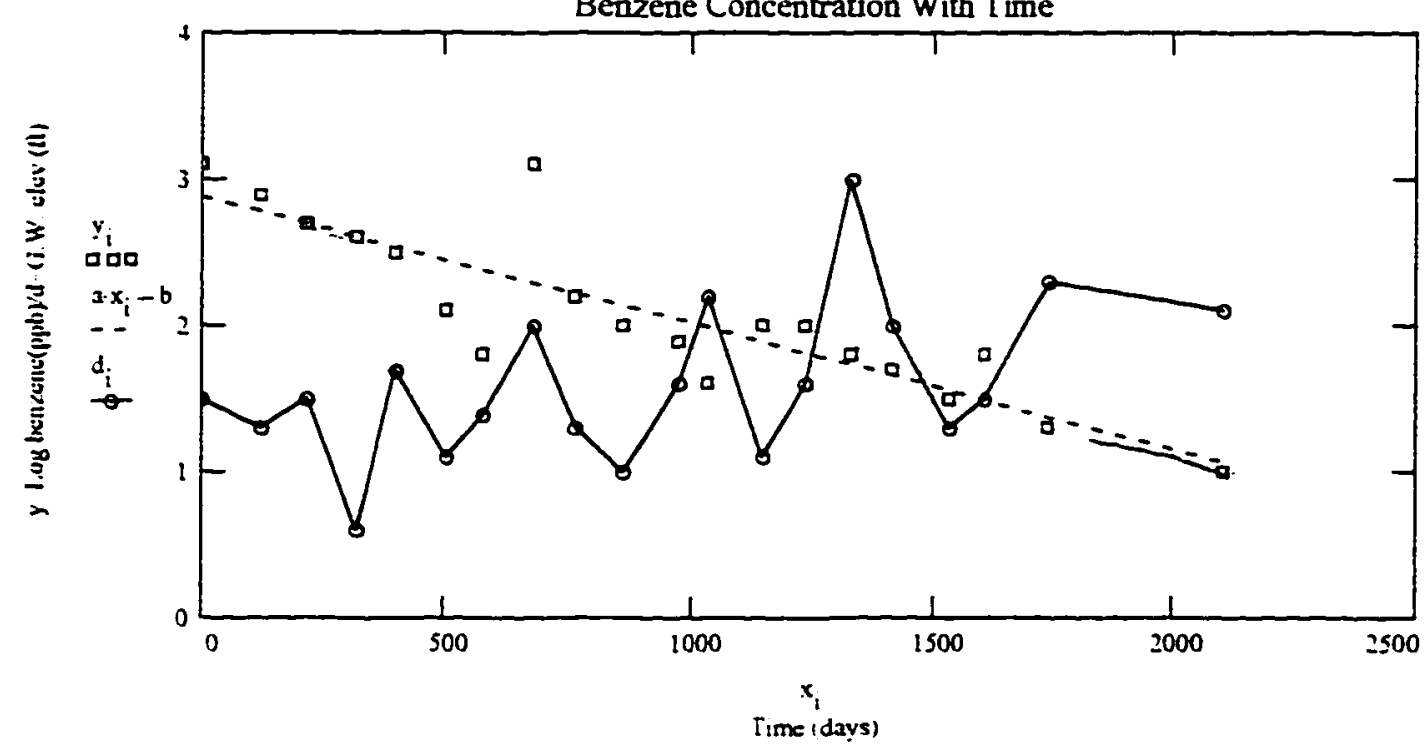

Note: Ground water elevations have been adjusted to fit the graph by adding $2 \mathrm{ft}$. 0 ft elevation aatum (second to last elevation) had no elevation data: 0 was input. 


\begin{tabular}{|c|c|c|c|}
\hline $\begin{array}{l}\text { SCWWD Site Number: 06S2W08K05F } \\
\text { Site Address: } 840 \text { San Antonio Road }\end{array}$ & Days & $\log C$ & $\begin{array}{l}\text { G.W } \\
\text { Elev }\end{array}$ \\
\hline \multirow{2}{*}{$\begin{array}{l}\text { Site Name: Arco \#1326 } \\
\text { City: Palo Alto }\end{array}$} & 0 & $4.2^{-}$ & $1.3^{\circ}$ \\
\hline & 84 & 3.7 & 1.8 \\
\hline \multirow{2}{*}{ Contaminant: TPH Gasoline - A-4 } & 204 & 3.4 & 1.2 \\
\hline & 291 & 2.9 & 1.2 \\
\hline \multirow[t]{6}{*}{$\mathrm{i}=0 . .9$} & $x=430$ & 3.3 & 1.8 \\
\hline & 501 & 3.3 & 1.5 \\
\hline & 597 & 2.8 & 1.0 \\
\hline & 690 & 2.0 & 1.6 \\
\hline & 818 & 3.3 & 1.9 \\
\hline & .910. & 3.3. & 1.4 \\
\hline
\end{tabular}

$a=\operatorname{slope}(x, y) \quad a=-0.0011$

$b=$ intercept $(x, y) \quad b=3.6961$

$\operatorname{corr}(x . y)=-0.5591$

$\operatorname{corr}(\mathrm{x} . \mathrm{y})^{2}=0.3126 \quad$ Note: Ground water elevations have been adjusted to fit the graph by adding $2 \mathrm{ft}$. The fifth elevation data point was input as 0 since no datum for date.

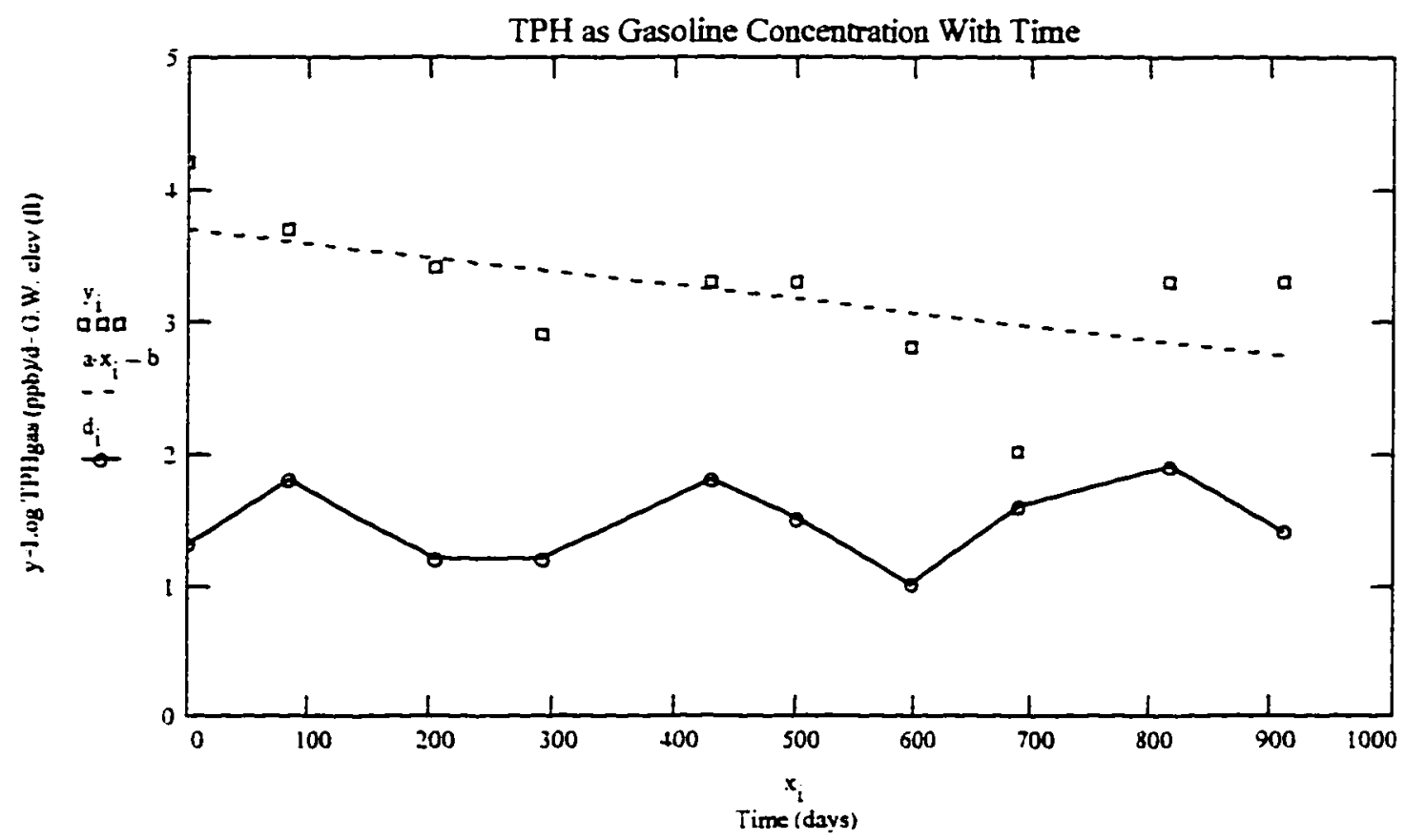


SC'ND Site Number: 06S2W08K05F Site Address: 840 San Antonio Road Site Name: Arco \#1326

City: Palo Alto

Contaminant: Benzene - A-4

$$
i=0 . .13
$$

$a=\operatorname{slope}(x, y) \quad a=-9.5608 \cdot 10^{-4}$

$b=$ intercepl( $x, y) \quad b=\mathbf{2 . 4 7}$

$\operatorname{cort}(x . y)=-0.712$

$\operatorname{cotr}(x . y)^{2}=0.507$

$\begin{array}{ccc}\text { Days } & \text { LogC } & \begin{array}{c}\text { G. } . \\ \text { Elev }\end{array} \\ 0 & 2.7^{-} & 1.6 \\ 62 & 2.6 & 1.1 \\ 93 & 2.3 & 1.0 \\ 184 & 2.2 & 1.3 \\ 275 & 2.5 & 1.3 \\ 359 & 2.3 & 1.8 \\ 479 & \mathrm{y}= & 1.2 \\ 566 & 1.7 & \mathrm{~d}=1.2 \\ 705 & 1.5 & 1.8 \\ 776 & 1.8 & 1.5 \\ 872 & 1.7 & 1.0 \\ 965 & 1.1 & 1.6 \\ 1093 & 1.0 & 1.9 \\ 1185 & 2.2 & 1.4\end{array}$

Note: Ground water elevations nave been adjusted to fit the graph by adding $2 \mathrm{ft}$. The ninth elevation data point was input asio since no datum for date.

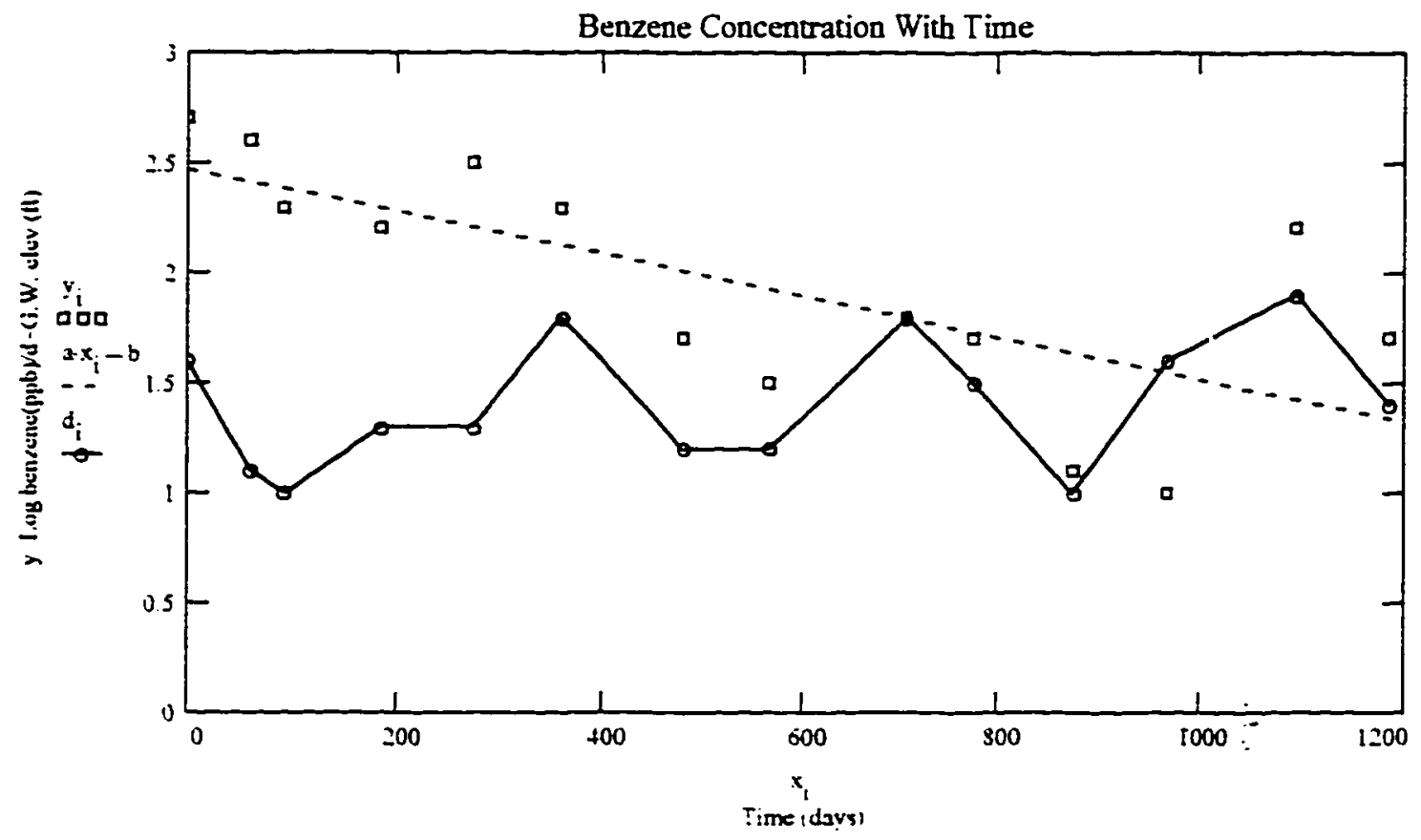




\begin{tabular}{|c|c|c|c|}
\hline \multirow{3}{*}{$\begin{array}{l}\text { SCVWD Site Number: 06S2W08K05F } \\
\text { Site Address: } 840 \text { San Antonio Road } \\
\text { Site Name: Arco \#1326 } \\
\text { City: Palo Alto }\end{array}$} & Days & $\log C$ & $\begin{array}{l}\text { G.W. } \\
\text { Elev }\end{array}$ \\
\hline & 0 & $4.0^{-}$ & $2.4^{-}$ \\
\hline & 85 & 3.7 & 1.8 \\
\hline \multirow{2}{*}{ Contaminant: TPH Gasoline - A-5 } & 144 & 2.7 & 1.3 \\
\hline & 221 & 2.4 & 1.2 \\
\hline \multirow[t]{6}{*}{$\mathrm{i}=0 . .9$} & $x=361$ & 3.3 & $d=2.1$ \\
\hline & 432 & 2.8 & 1.5 \\
\hline & 528 & 1.8 & 1.1 \\
\hline & 621 & 2.8 & 1.4 \\
\hline & 718 & 3.6 & 1.8 \\
\hline & 810 & .3 .2 & 1.4. \\
\hline
\end{tabular}

$a=\operatorname{slope}(x . y) \quad a=-5.4389 \cdot 10^{-4}$

$b=$ intercept $(x, y) \quad b=3.2432$

$\operatorname{corr}(x, y)=-0.2281$

Note: Ground water elevations have been adjusted to fit the graph by adding $2 \mathrm{~A}$.

$\operatorname{corr}(x . y)^{2}=0.052$

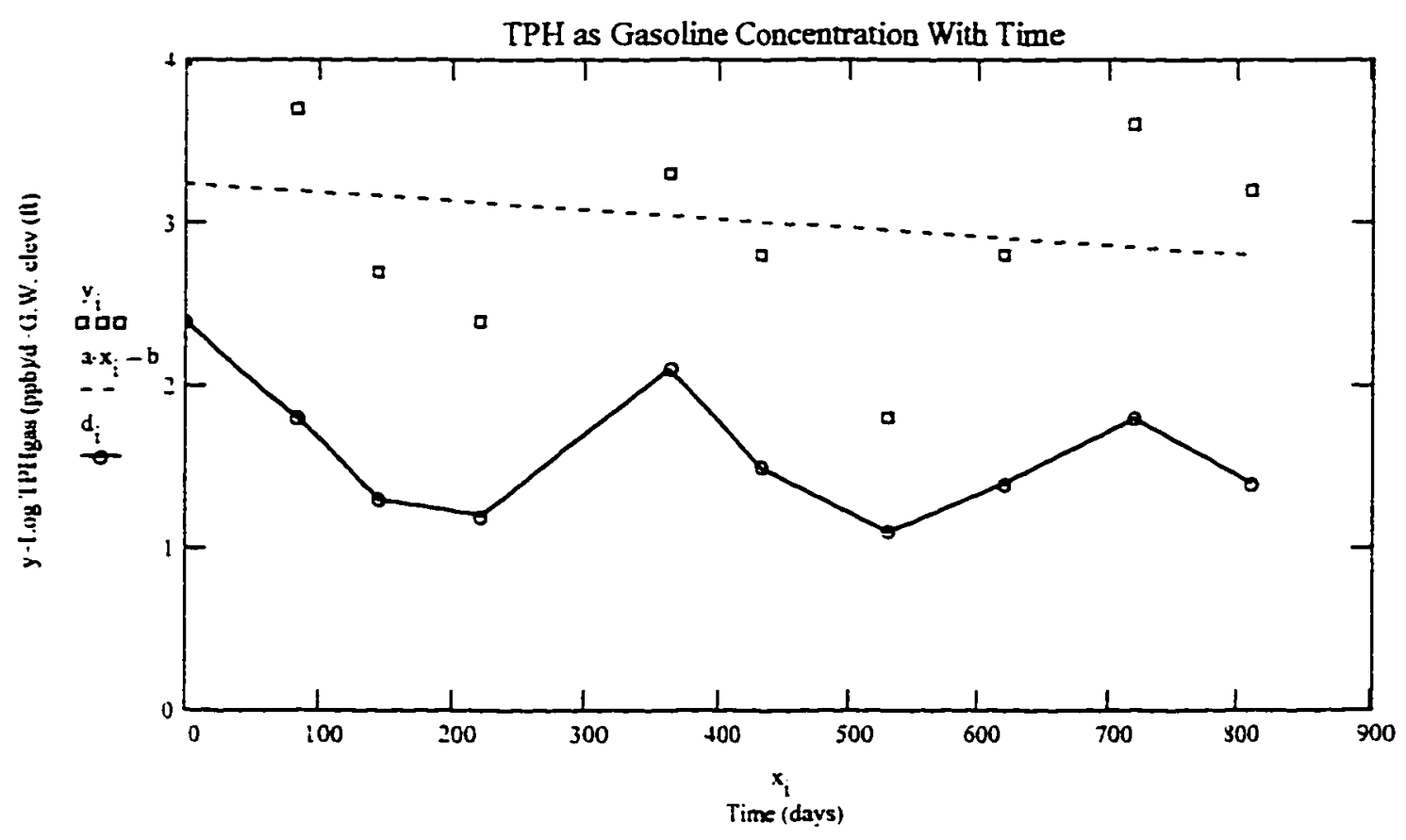


SCVWD Site Number: 0652W08K05F Site Adaress: 840 San Antonio Road Site Name: Arco \#1326

City: Paio Alto

Contaminant: Benzene - A-5

$i=0 . .8$

$\begin{array}{ccc}\text { Days } & \text { LogC } & \begin{array}{c}\text { G.W. } \\ \text { Elev }\end{array} \\ 0 & -3.0 & 1.8 \\ 59 & 1.7 & 1.3 \\ 136 & 1.4 & 1.2 \\ 261 & 2.1 & 2.1 \\ \mathrm{x}=347 & \mathrm{y}=1.7 & \mathrm{~d}=1.5 \\ 443 & .8 & 1.1 \\ 536 & 1.1 & 1.4 \\ 633 & 2.7 & 1.8 \\ .725 . & .2 .3 & -1.4\end{array}$

Note: Ground water elevations have been adjusted to fit the graph oy acding $2 i$.

\footnotetext{
$a=\operatorname{slope}(x, y) \quad a=-2.1346 \cdot 10^{-4}$

$b=$ intercept $(x, y) \quad b=1.9411$

$\operatorname{com}(x, y)=-0.0753$

$\operatorname{corr}(x, y)^{2}=0.0057$
}

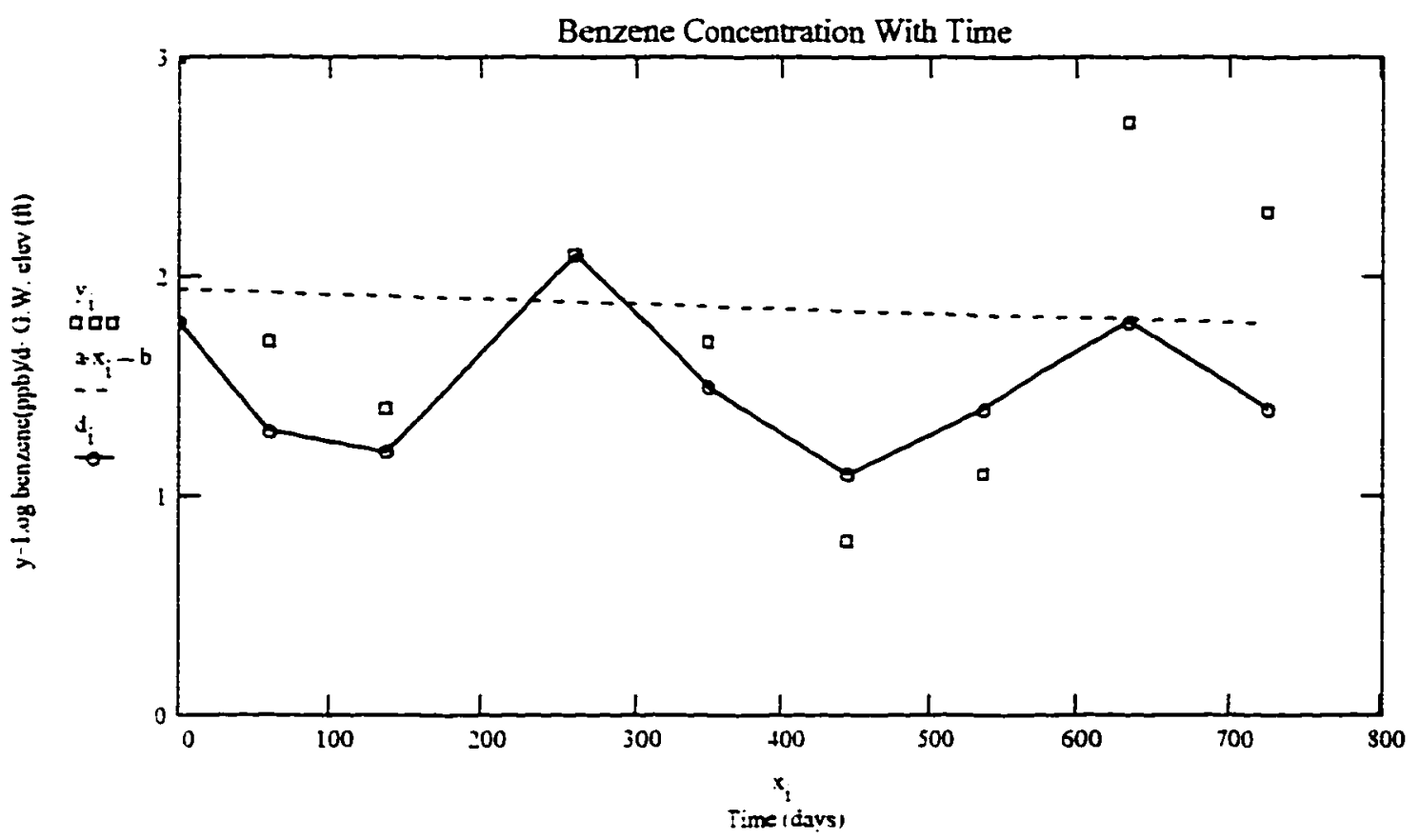


SCWWD Site Number: 06S3W02D05f

Site Address: 355 Alma Street

Site Name:Shel

City: Palo Alto

Contaminant: TPH Gasoline

$$
i=0 . .5
$$

$\begin{array}{ccc}\text { Days } & \text { LogC } & \begin{array}{c}\text { G.W. } \\ \text { Elev }\end{array} \\ 0 & -3.8 & -0 \\ 81 & 2.6 & 1.91 \\ 170 & \mathrm{y}=2.5 & \mathrm{~d}=.74 \\ 267 & 2.4 & .29 \\ 347 & 3 & 3.22 \\ .387 & .1 .4 . & .1 .36 .\end{array}$

$a=\operatorname{slope}(x, y) \quad a=-0.0036$

$b=$ intercept $(x . y) \quad b=3.3686$

Note: Ground water elevations have been modified to fit the $\operatorname{corr}(x, y)=-0.6974$ $\operatorname{corr}(x . y)^{2}=0.4864$ graph. $O \mathrm{ft}=14.94 \mathrm{ft}$. First data point was assigned $\mathrm{O}$ since no elevation data available for date.

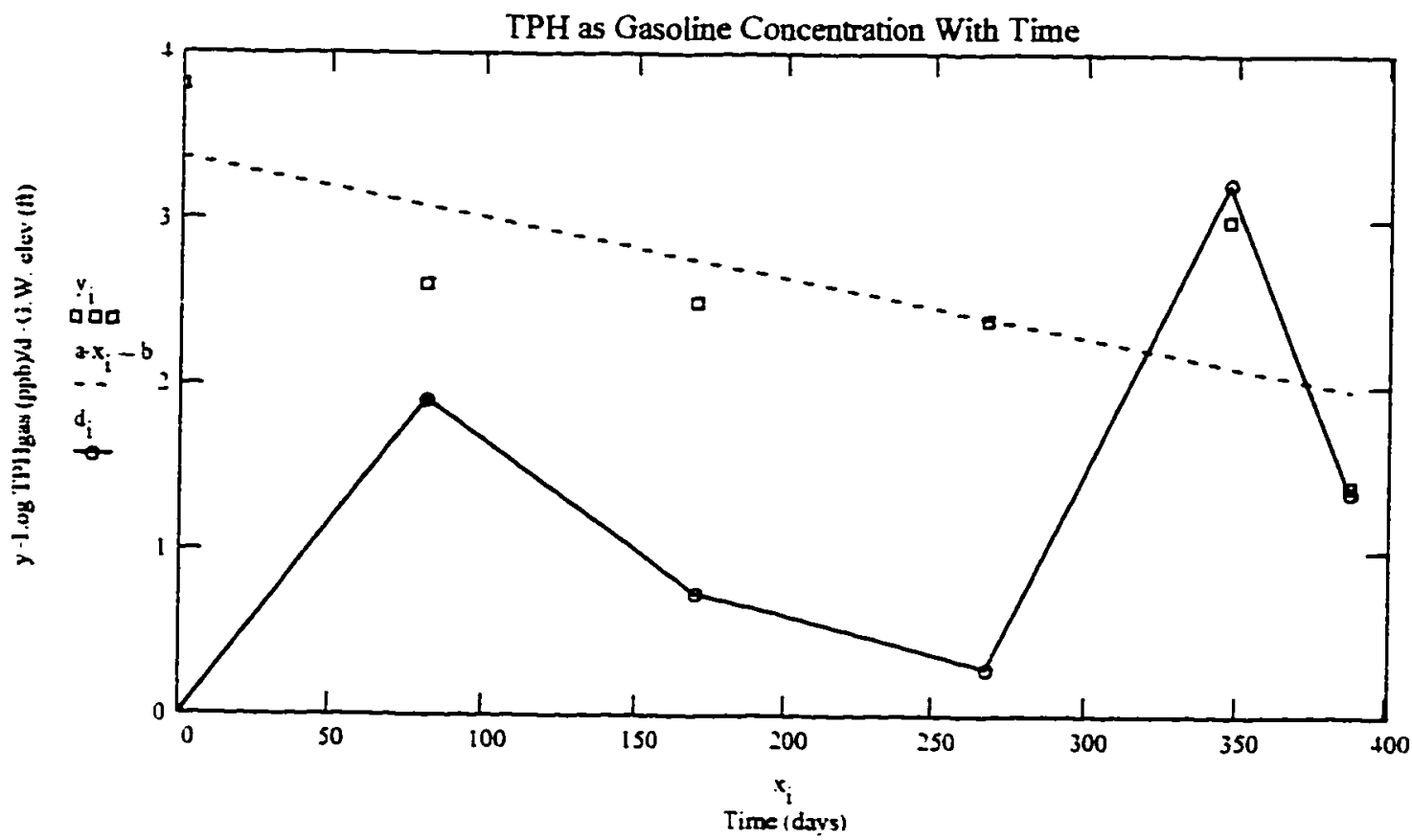


SCIND Site Number: 06S3W02D05f Site Address: 355 Alma Street Site Name:Shel

City: Palo Alto

$\begin{array}{ccc}\text { Days } & \text { LogC } & \begin{array}{c}\text { G.W. } \\ \text { Elev }\end{array} \\ 0 & -3.6 & 0 \\ 81 & 2.4 & 1.91 \\ 170 & 2.4 & .74 \\ 267 & 2.2 & .29 \\ 347 & 2.7 & 3.22 \\ 387 & y & 1.36 \\ 481 & .7 & 0 \\ 587 & .4 & 3.01 \\ 673 & 1.8 & 4.9 \\ 741 & .9 & 3.27 \\ 819 & .7 & 1.78 \\ 939 & .3 & .4 .47\end{array}$

$a=\operatorname{slope}(x, y) \quad a=-0.0036$

$b=$ intercept $(x, y) \quad b=3.0958$

$\operatorname{corr}(x . y)=-0.8721$

$\operatorname{corr}(x . y)^{2}=0.7605$

Note: Ground water elevations have been modified to it the graph. $0 \mathrm{ft}=14.94 \mathrm{it}$. is: is ta pank ossian 1-d o sincs no elov. data for date.

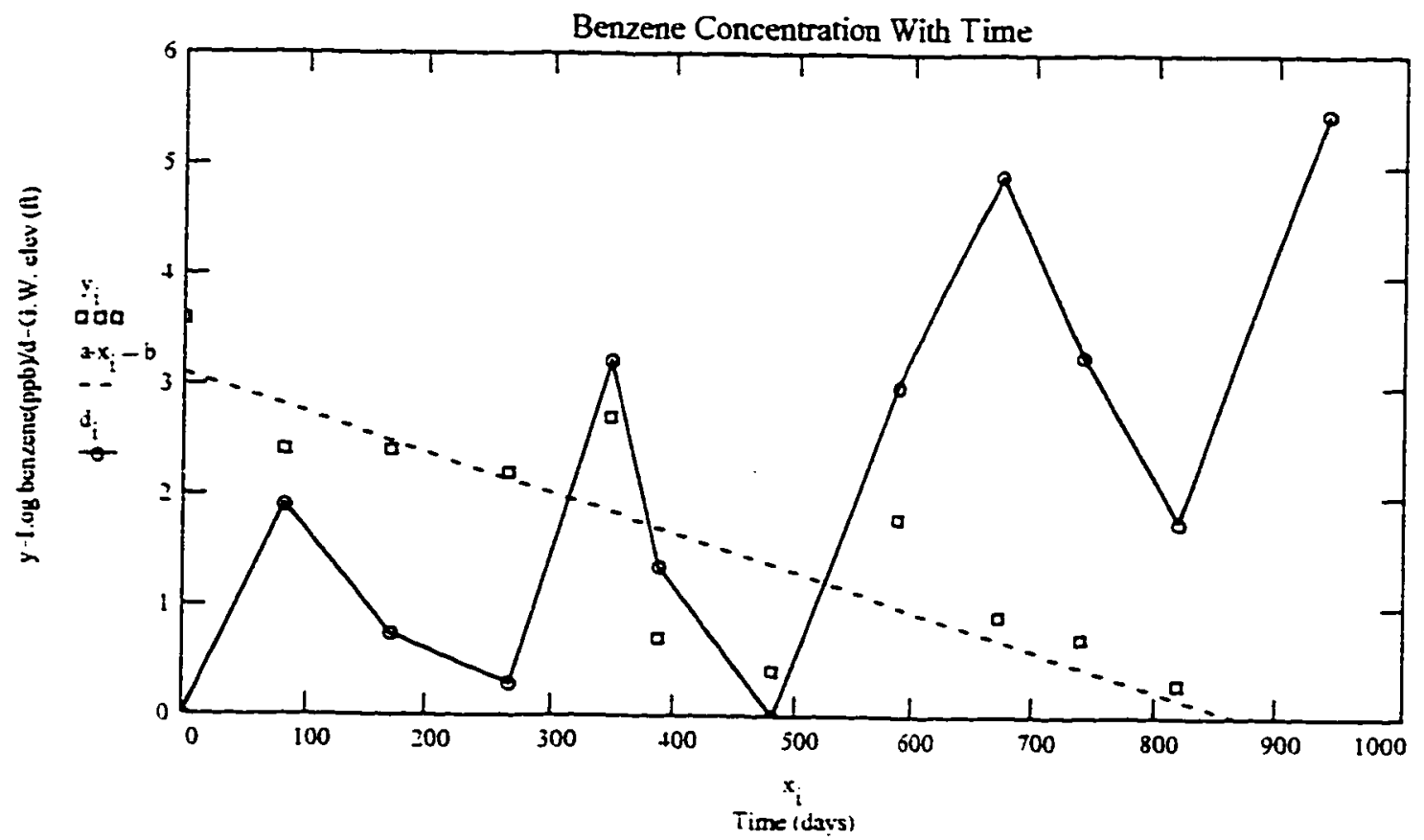


SCVND Site Number: 06S2W07C01f

Site Address: 3011 Middlefield Road

Site Name: Shell

City: Palo Alto

\begin{tabular}{|c|c|c|c|}
\hline \multicolumn{4}{|l|}{ City: Palo Alto } \\
\hline \multirow{2}{*}{ Contaminant: TPH Gasoline } & 0 & $3.8^{-}$ & $2.15^{\circ}$ \\
\hline & 111 & $y=3.6$ & -1.27 \\
\hline$i=0 . .3$ & $x=192$ & 3.4 & $a=1.96$ \\
\hline & 277 & .3 & .3 .5 \\
\hline
\end{tabular}

$a=\operatorname{slope}(x, y) \quad a=-0.0028$

$b=$ intercept( $x . y) \quad b=3.8578$

$\operatorname{corr}(x, y)=-0.9721$

$\operatorname{cor}(x . y)^{2}=0.945$

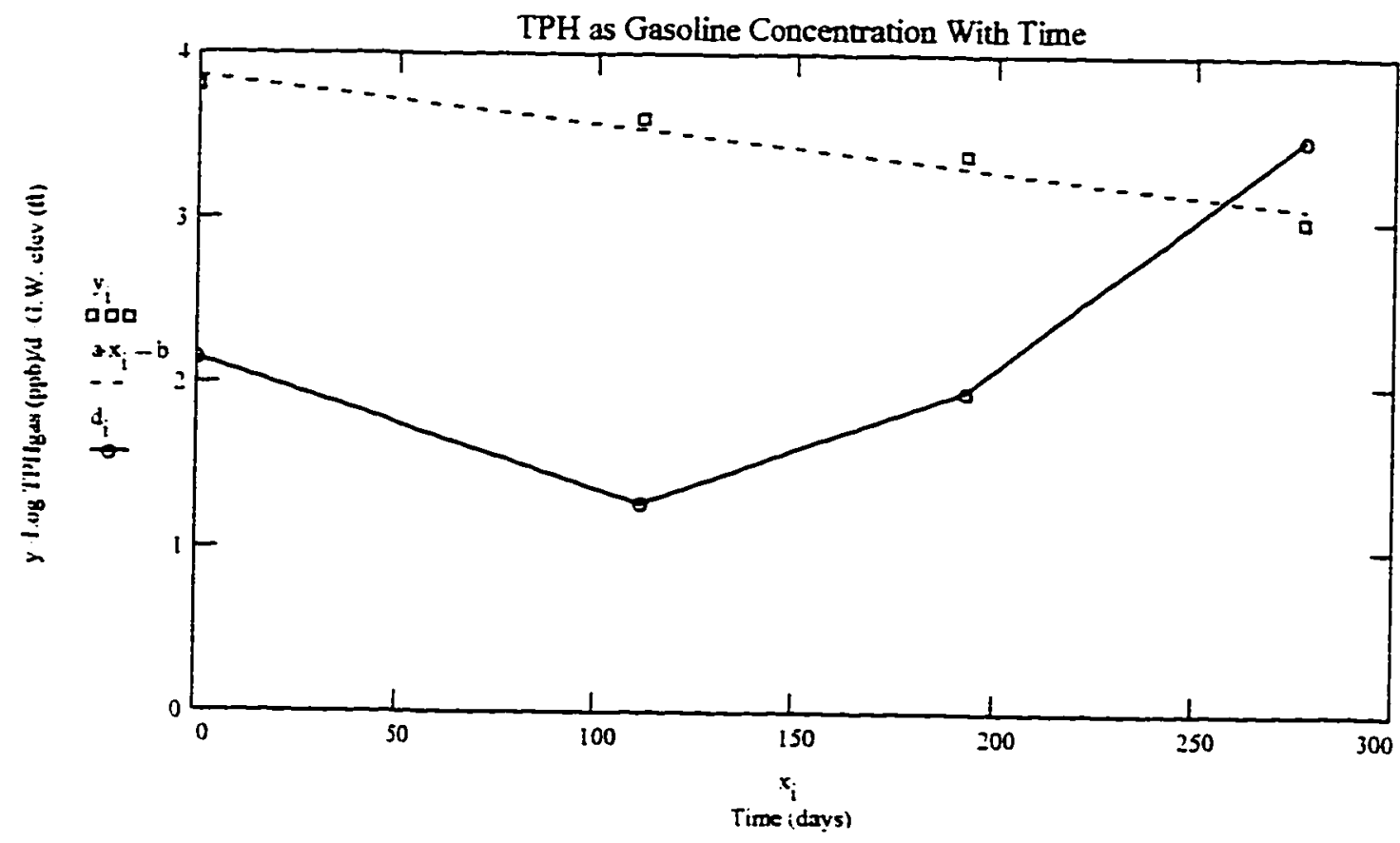


SCVWD Site Number: 06S3W11A02F

Site Address: 1795 El Camino Real

Site Name: Fill'em Fast

City: Palo Alto

Contaminant: TPH Gasoline

$\begin{array}{ccc}\text { Days } & \text { LogC } & \begin{array}{c}\text { G.W. } \\ \text { Elev }\end{array} \\ 0 & 3.9 & 0 \\ 94 & 3.5 & 2.7 \\ 171 & 3.5 & 2.4 \\ 382 & 2.9 & 1.6\end{array}$

$i=0 . .8$

$x=489$

$y=2.9$

$\mathrm{d}=1.8$

582

651

3

1

741

3

1

.846.

3.3

2.6

.2 .6 .

4.2 .

$a=\operatorname{slope}(x . y) \quad a=-0.0011$

$b=$ intercept $(x . y) \quad b=3.6559$

Note: Ground water elevations have been modified to fit the graph. $0 \mathrm{it}=10.14 \mathrm{ft}$

$\operatorname{corr}(x . y)=-0.8061$

$\operatorname{corr}(x, y)^{2}=0.6498$

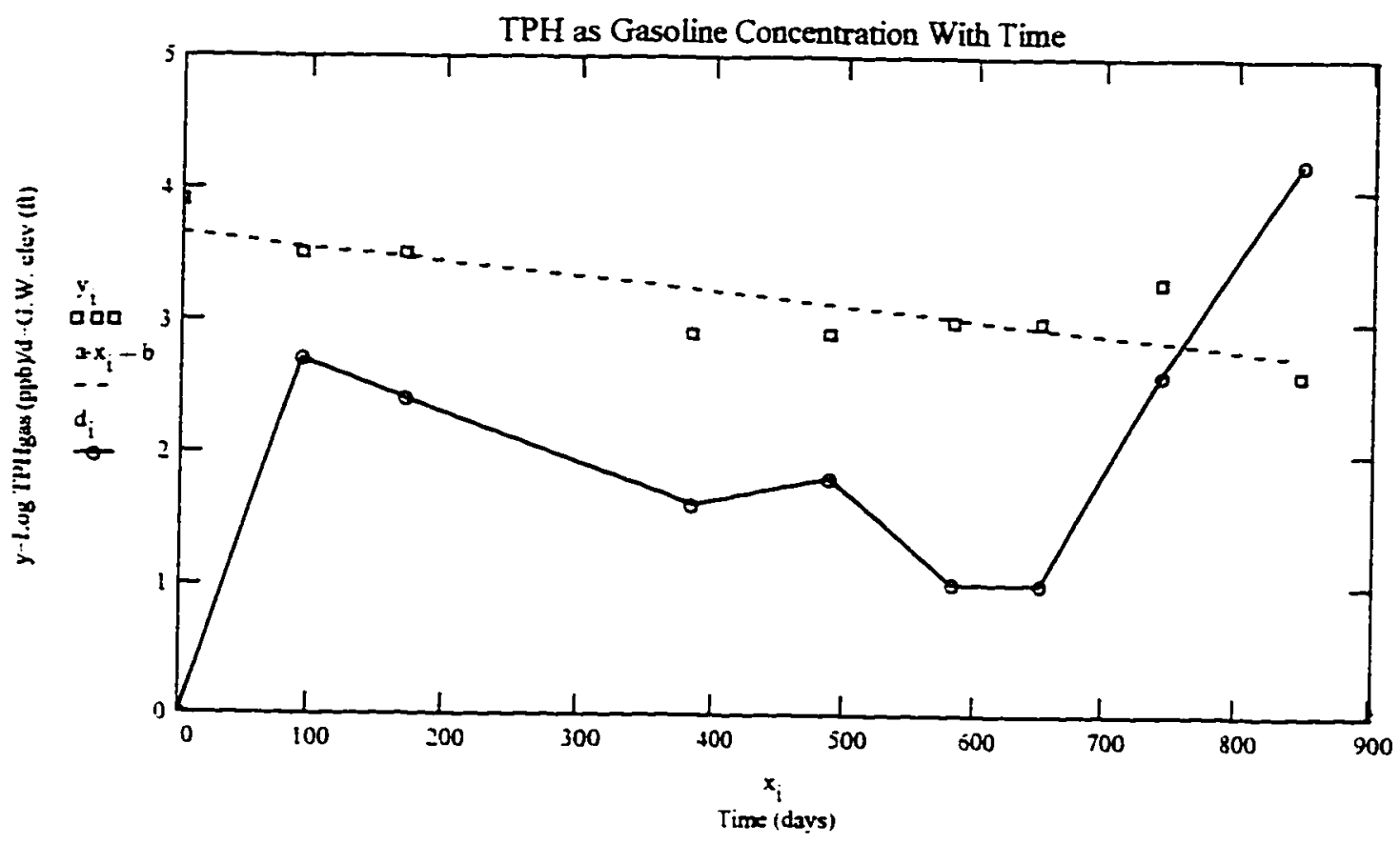


SCVND Site Number: 0653W11A02F

Site Address: 1795 El Camino Real

Site Name: Fill'em Fast

City: Palo Alto

$\begin{array}{cccc} & \text { Days } & \text { LogC } & \text { Elev } \\ \text { Contaminant: Benzene } & 0 & 2.9^{\circ} & 1.4^{-} \\ & 211 & 2.2 & .6 \\ \mathrm{i}=0 . .6 & 318 & 2 & .8 \\ & \mathrm{x}=411 & \mathrm{y}=2.1 & \mathrm{~d}=0 \\ & 480 & 2.1 & 0 \\ & 570 & 2.6 & 1.6 \\ & -675 & -1.6 . & -3.3 .\end{array}$

\footnotetext{
$a=\operatorname{slope}(x, y) \quad a=-0.0012$

$b$ intercept $(x . y) b=\mathbf{2 . 6 6 4 7}$

$\operatorname{corr}(x, y)=-0.6381$

$\operatorname{corr}(x . y)^{2}=0.4071$
}

Note: Ground water elevations have been modified to fit the graph. O ft $=11.09 \mathrm{ft}$.

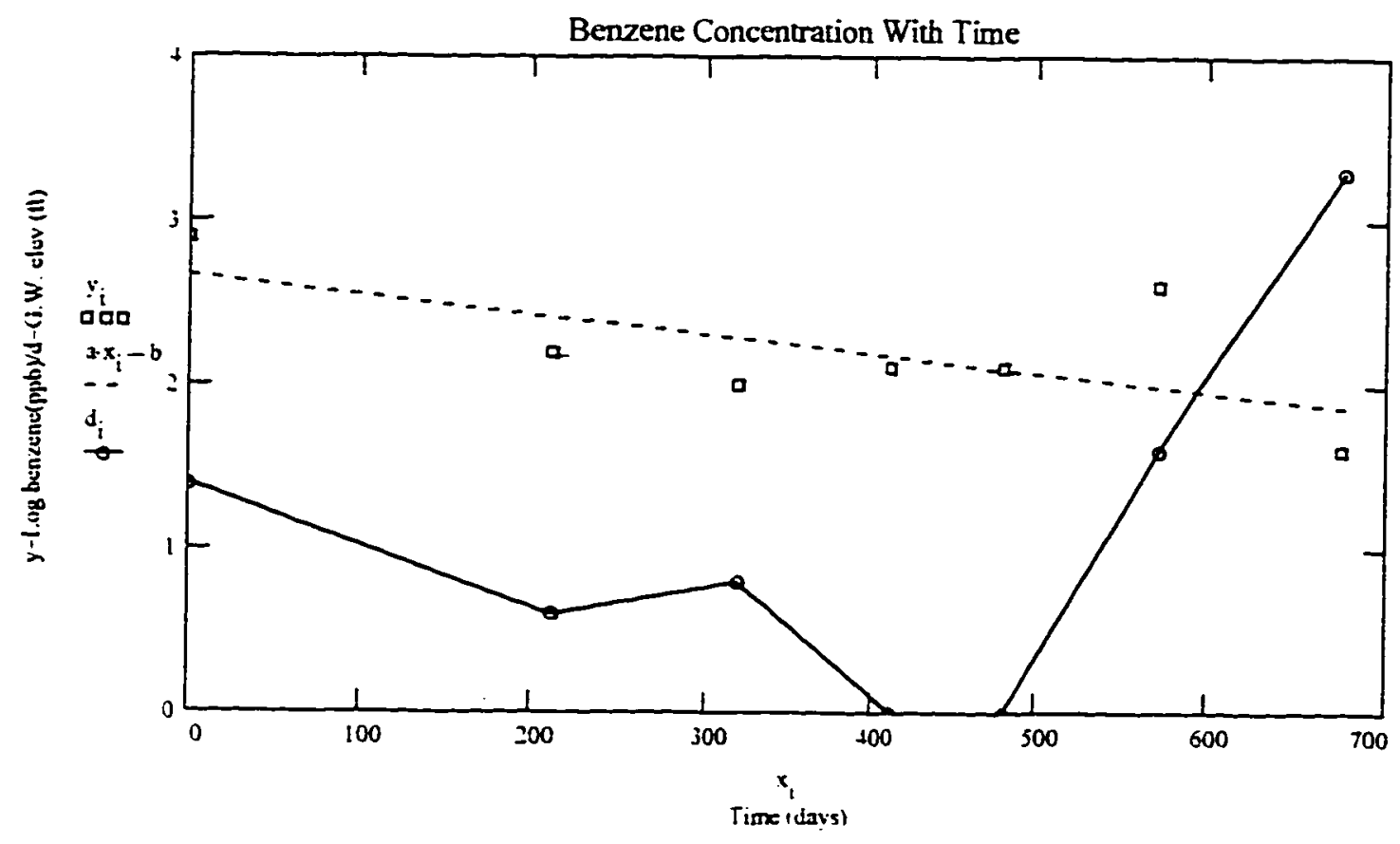




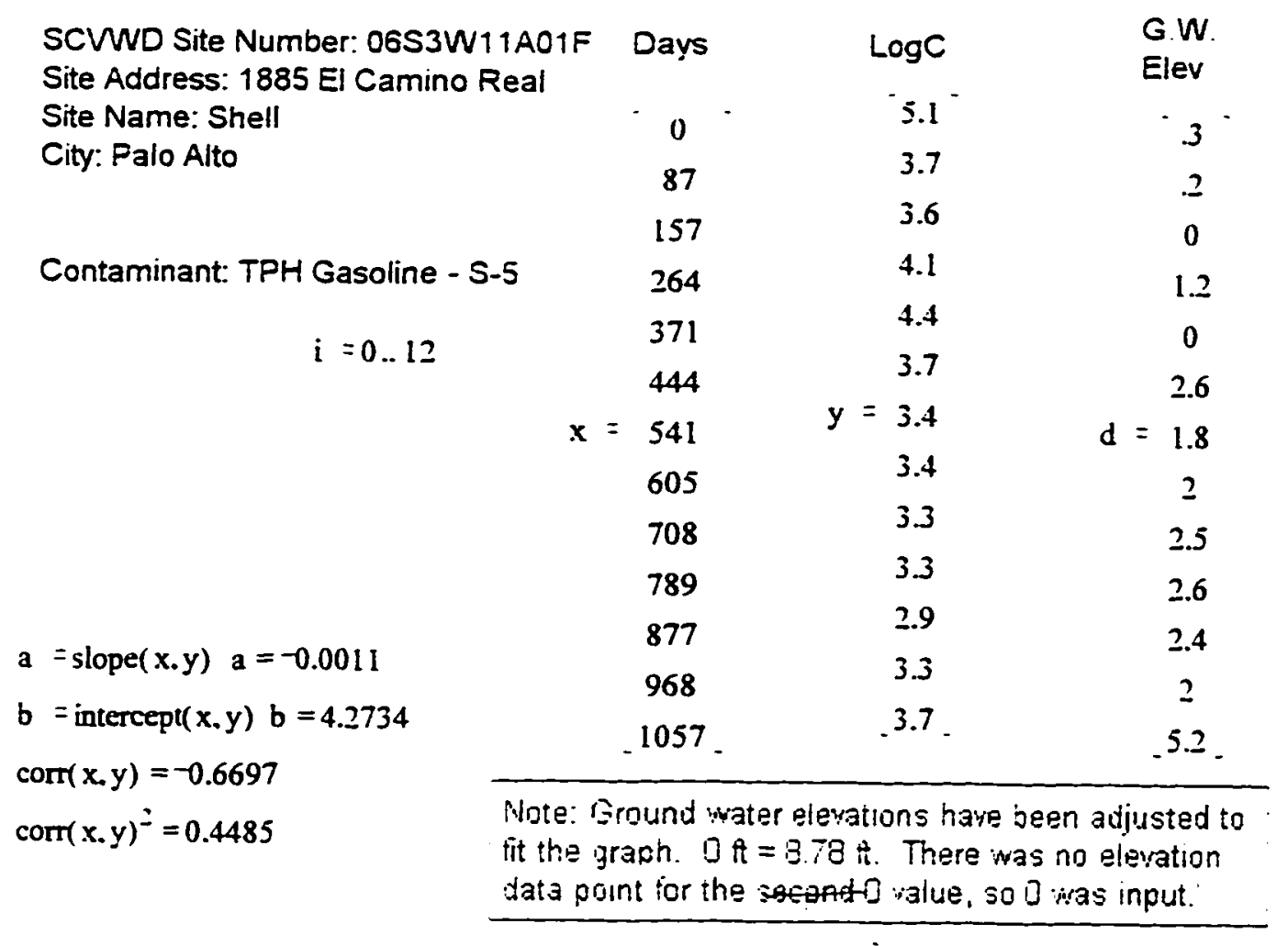

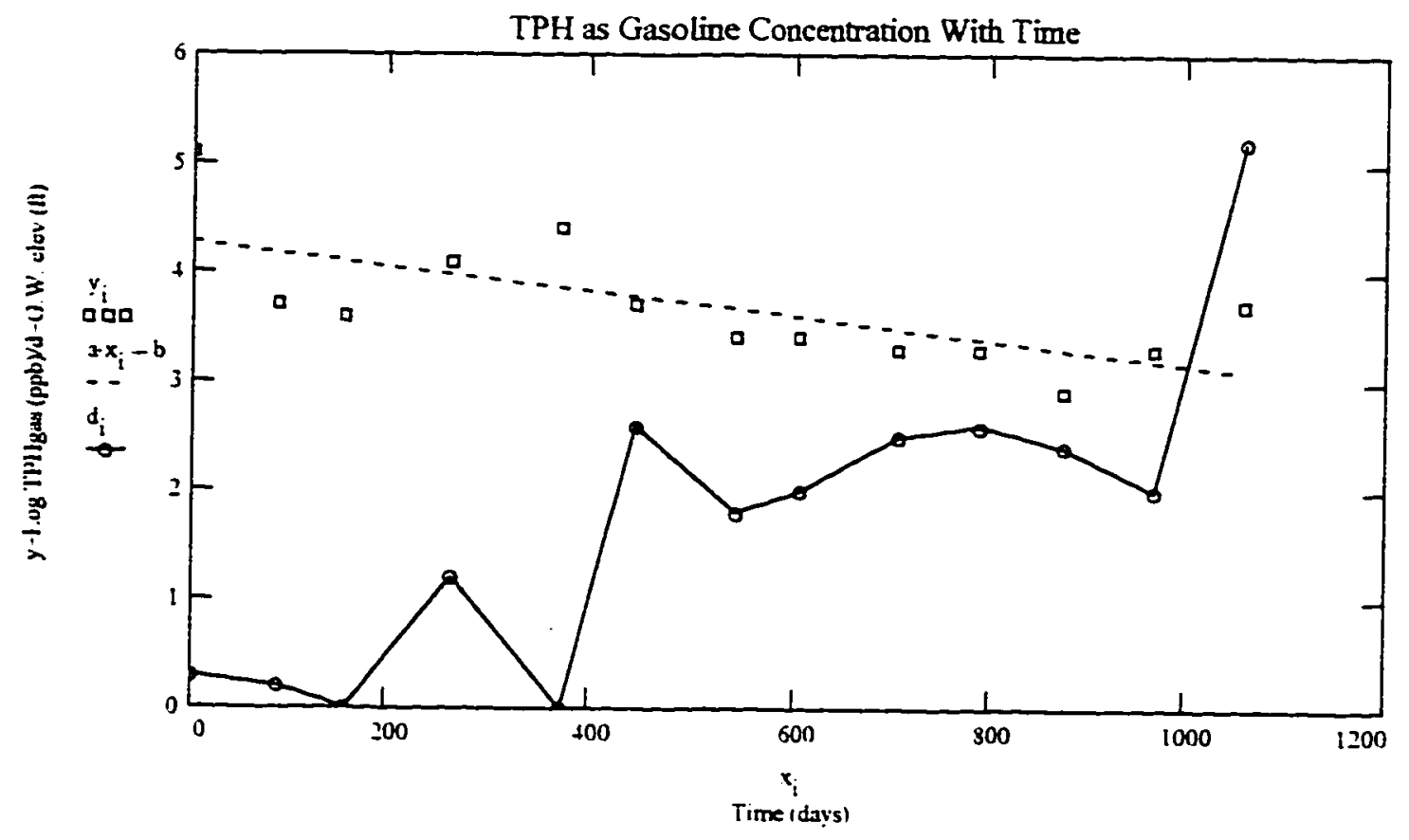


SCWWD Site Number: 06S3W11A01F Site Address: 1885 El Camino Real Site Name: Shell

City: Palo Alto

$\begin{array}{ccc}\text { Days } & \text { LogC } & \begin{array}{c}\text { G.W. } \\ \text { Elev }\end{array} \\ 0 & -4.4 & 0 \\ 107 & 4.2 & .5 \\ 181 & 3.4 & .7 \\ 278 & 3.1 & .8 \\ 342 & 3.2 & 1.4 \\ x=445 & y=3.8 & \mathrm{~d}=1.4 \\ 526 & 3 & 1.3 \\ 614 & 2.2 & .7 \\ 705 & 2.8 & 2 \\ 794 & 2.3 & 3.9 \\ 876 . & -2.5 . & -3.3\end{array}$

Note: Ground water elevations have been adjusted to fit the graph. $0 \mathrm{ft}=9.91: \mathrm{i}$.

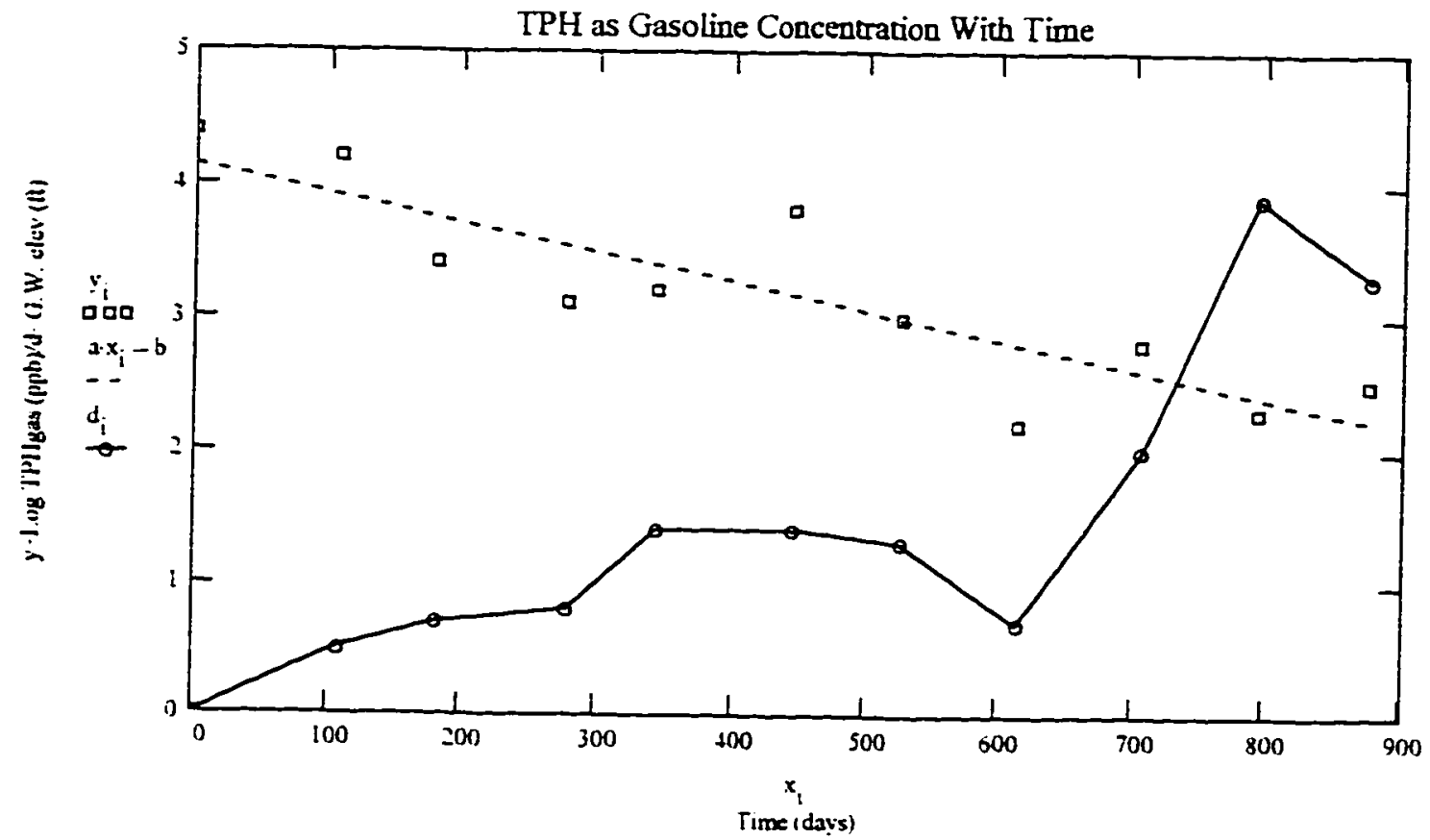


SCVND Site Number: 06S3W11A01F

Site iddress: 1885 El Camino Real

Site Name: Shell

City: Palo Alto

$\begin{array}{ccc}\text { Days } & \text { LogC } & \begin{array}{c}\text { G.W. } \\ \text { Elev }\end{array} \\ 0 & 3.5^{-} & .5 \\ 74 & 2.4 & .7 \\ 171 & 2 & .8 \\ 235 & 1.4 & 1.4 \\ 338 & \mathrm{y}=1.4 & \mathrm{~d}=1.4 \\ 419 & 1 & 1.3 \\ 507 & .08 & .7 \\ 598 & 1 & 2 \\ 687 & -.6 . & .3 .9 .\end{array}$

$a=\operatorname{slope}(x, y) \quad a=-0.0048$

$b=$ intercept $(x, y) b=\mathbf{2 . 9 5 8 8}$

$\operatorname{cort}(x . y)=-0.9279$

$\operatorname{corr}(x . y)^{2}=0.861$

Note: Ground water elevations have been adjusted to fit the graph. $O \mathrm{ft}=9.91 \mathrm{it}$.

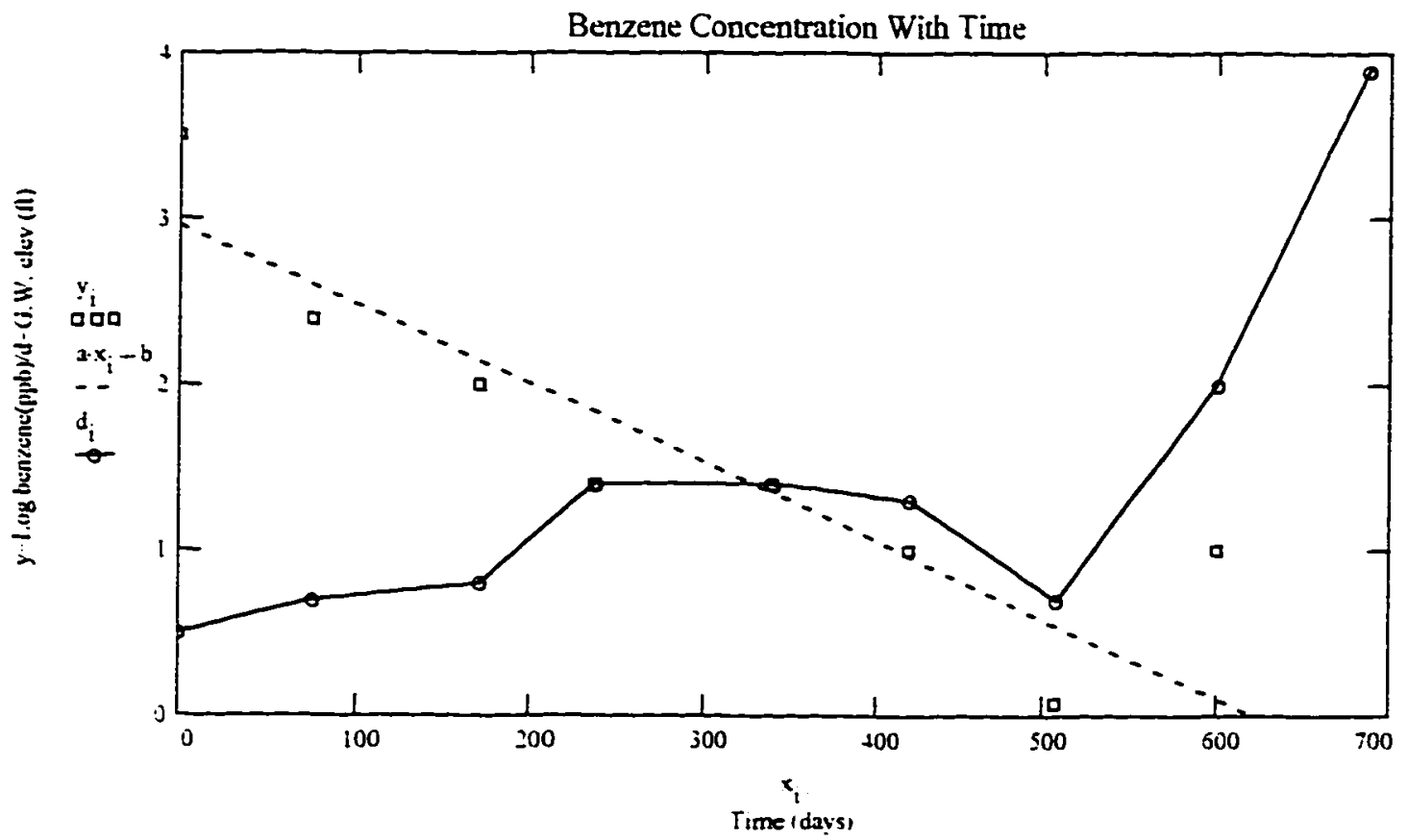


SCWVD Site Number: 06S3W12EOTF

Site Address: 2200 El Camino Real

Site Name: Shell

City: Palo Alto

$\begin{array}{crc}\text { Days } & \text { LogC } & \begin{array}{c}\text { G.W. } \\ \text { Elev }\end{array} \\ 0 & 4.9^{-} & 4.1^{-} \\ 91 & 4.9 & 4.1 \\ 194 & y=4.7 & .3 \\ 277 & 4.6 & .9 \\ 376 & 4.1 & 0 \\ 464 . & 1.4 . & -3.4\end{array}$

$a=\operatorname{slope}(x, y) \quad a=-0.0061$

$b=$ intercepl $(x, y) b=5.5248$

$\operatorname{corr}(x . y)=-0.7839$

Note: Ground water elevations have been adjusted to fit the graph. $O \mathrm{ft}=13.25 \mathrm{ft}$.

$\operatorname{corr}(x . y)^{2}=0.6145$

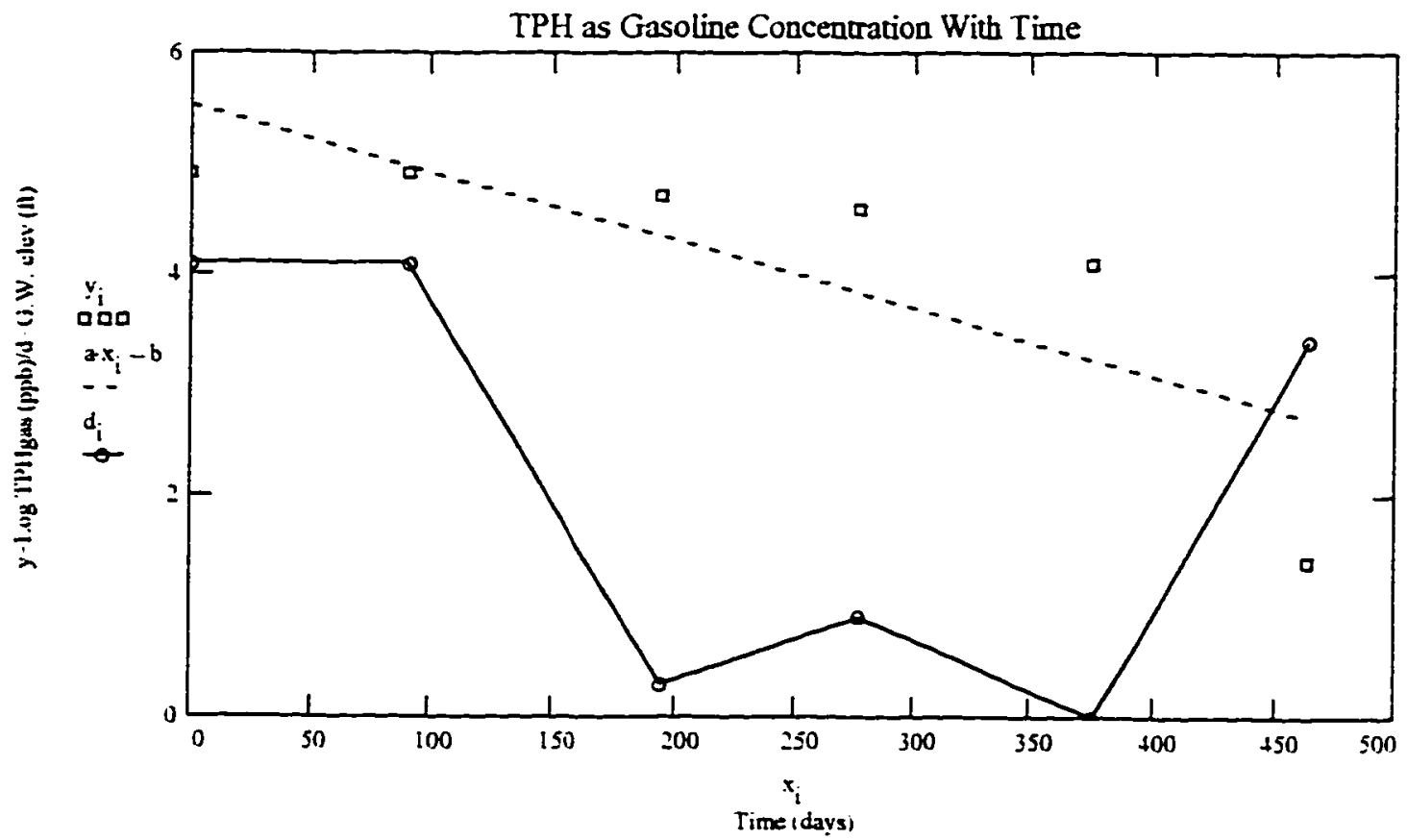




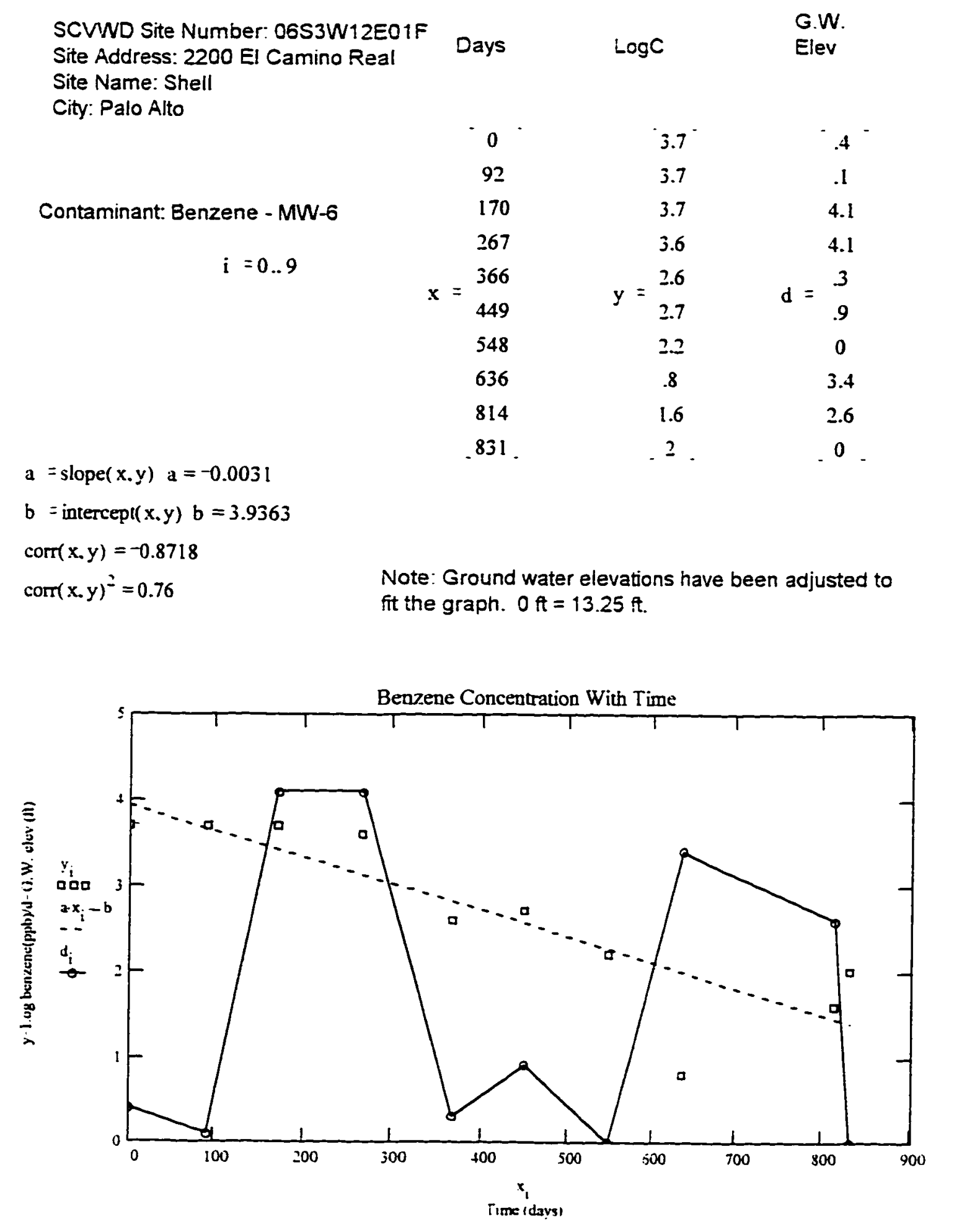




\begin{tabular}{|c|c|c|c|}
\hline \multirow{2}{*}{$\begin{array}{l}\text { SCWWD Site Number: 06S3W12E01F } \\
\text { Site Address: } 2200 \text { El Camino Real } \\
\text { Site Name: Shell } \\
\text { City: Palo Alto }\end{array}$} & \multirow[t]{2}{*}{ Days } & $\log C$ & \multirow{2}{*}{$\begin{array}{l}\text { G.W } \\
\text { Elev }\end{array}$} \\
\hline & & $4.9^{-}$ & \\
\hline \multirow{2}{*}{ Contaminant: TPH Gasoline - MW-8 } & 91 & 4.6 & 3.3 \\
\hline & 194 & 4.5 & .6 \\
\hline \multirow{5}{*}{$i=0 . .7$} & 277 & $y=4.8$ & $d=1.1$ \\
\hline & 376 & 3.3 & .6 \\
\hline & 464 & 3.4 & 3.1 \\
\hline & 558 & 2.4 & 1.3 \\
\hline & 642 & 1.4 & 1.5 \\
\hline
\end{tabular}

Note: Ground water elevations have been adjusted to fit the graph. $0 \mathrm{ft}=13.39 \mathrm{ft}$.

\footnotetext{
$a=\operatorname{slope}(x . y) \quad a=-0.0052$

$b=$ intercepl( $x . y) \quad b=5.3521$

$\operatorname{corr}(x . y)=-0.922$

$\operatorname{corr}(x, y)^{2}=0.8501$
}

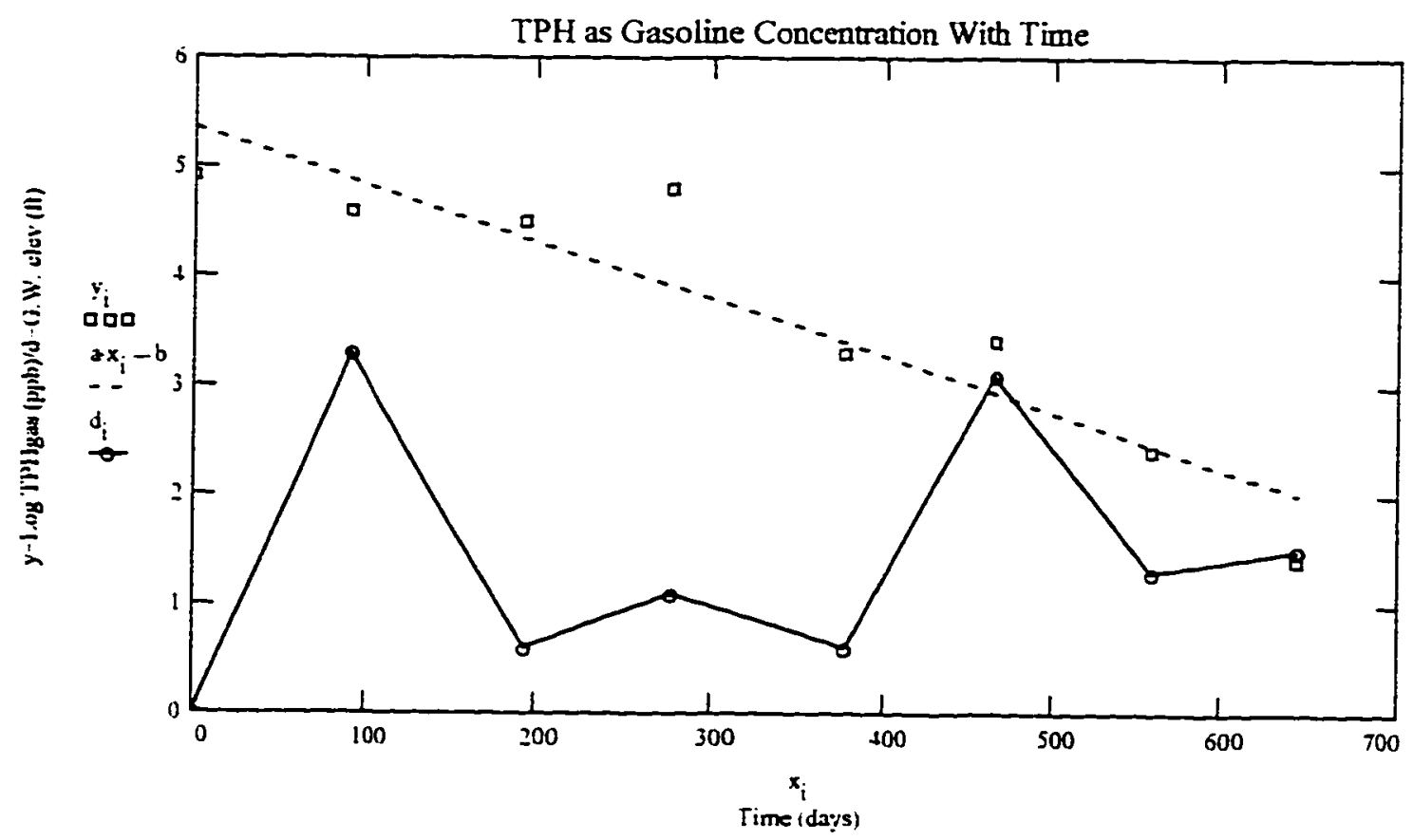


SCVWD Site Number: 06S3W12EOIF

Site Address: 2200 El Camino Real

Site Name: Shell

City: Palo Alto

$\begin{array}{ccc}\text { Days } & \text { LogC } & \begin{array}{c}\text { G.W. } \\ \text { Elev }\end{array} \\ 0 & -2.7^{-} & -.3 \\ 78 & 2.5 & 0 \\ 169 & 2.7 & 3.3 \\ 272 & 2.5 & .6 \\ =355 & y=2.6 & \mathrm{~d}=1.1 \\ 454 & 1 & .6 \\ 542 & 1.6 & 3.1 \\ 636 & .3 & 1.3 \\ 720 . & -0 . & .1 .5\end{array}$

$\mathrm{a}=\operatorname{slope}(\mathrm{x} . \mathrm{y}) \quad \mathrm{a}=-0.0039$

$b=$ intercept( $x . y) \quad b=3.1494$

$\operatorname{corr}(x . y)=-0.8906$

$\operatorname{corr}(x . y)^{2}=0.7932$

Note: Ground water elevations have been adjusted to fit the graph. $0 \mathrm{ft}=13.39 \mathrm{ft}$.

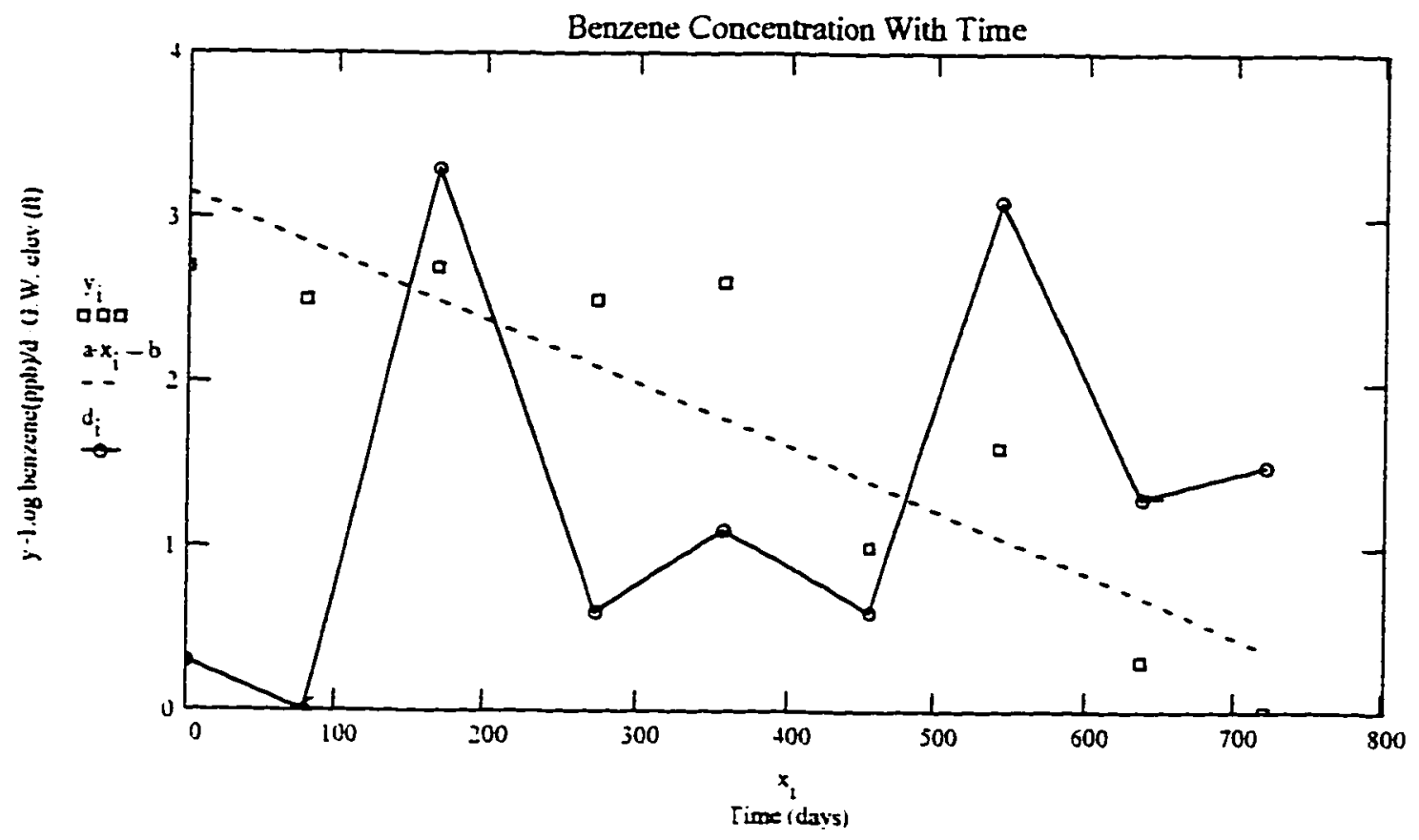




\begin{tabular}{|c|c|c|c|}
\hline $\begin{array}{l}\text { SCWND Site Number: 06S3W12E01F } \\
\text { Site Address: } 2200 \text { El Camino Real }\end{array}$ & Days & $\log C$ & $\begin{array}{l}\text { G.W } \\
\text { Elev }\end{array}$ \\
\hline \multirow{3}{*}{$\begin{array}{l}\text { Site Name: Shell } \\
\text { City: Falo Alto }\end{array}$} & 0 & $4.3^{-}$ & .4 \\
\hline & 86 & 4.2 & 3 \\
\hline & 169 & 4.2 & 1 \\
\hline \multirow[t]{7}{*}{ Contaminant: TPH Gasoline - MW-11 } & 251 & 4 & 1 \\
\hline & 347 & 3.8 & 0 \\
\hline & 458 & 3.8 & 5.3 \\
\hline & 540 & 3.8 & 3.6 \\
\hline & 632 & 3.9 & $d=2.9$ \\
\hline & 710 & 3.7 & 2.6 \\
\hline & 801 & 3.9 & 6.9 \\
\hline$a=\operatorname{slope}(x, y) \quad a=-8.1342 \cdot 10^{-4}$ & 904 & 3.8 & 3.1 \\
\hline \multirow{3}{*}{$\begin{array}{l}b=\text { intercept }(x . y) \quad b=4.3038 \\
\operatorname{corr}(x . y)=-0.8155\end{array}$} & 987 & 3.9 & 3.4 \\
\hline & 1086 & 3.5 & 2.3 \\
\hline & 1176 & 3.7 & 6.4 \\
\hline \multirow{2}{*}{$\operatorname{cotr}(x-y)^{2}=0.665$} & 1270 & 3 & 6.1 \\
\hline & 1353 & 2.6 . & 3.9 \\
\hline
\end{tabular}

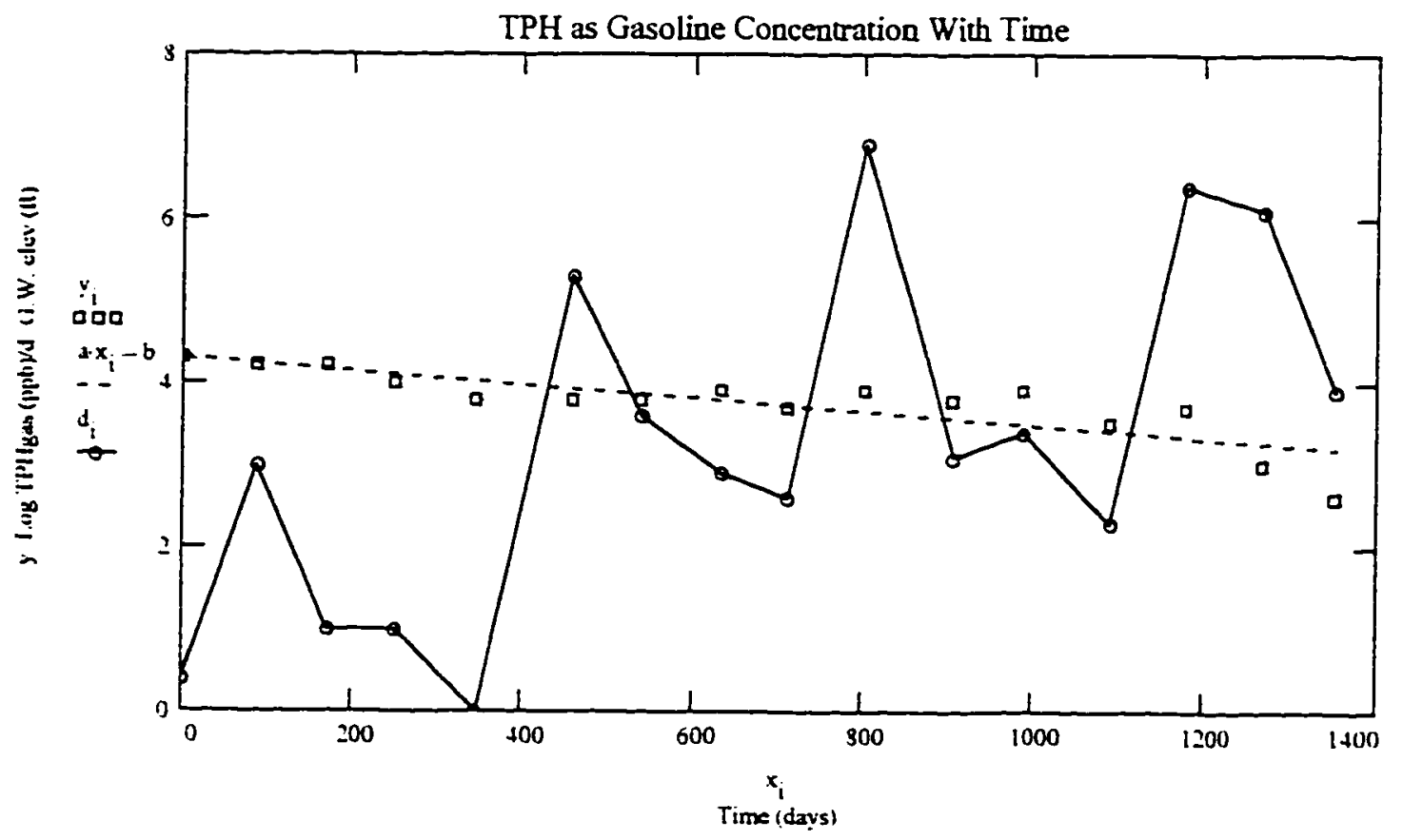

Note: Ground water elevations have been adjusted to fit the graph. $O \mathrm{ft}=10.91 \mathrm{ft}$. 


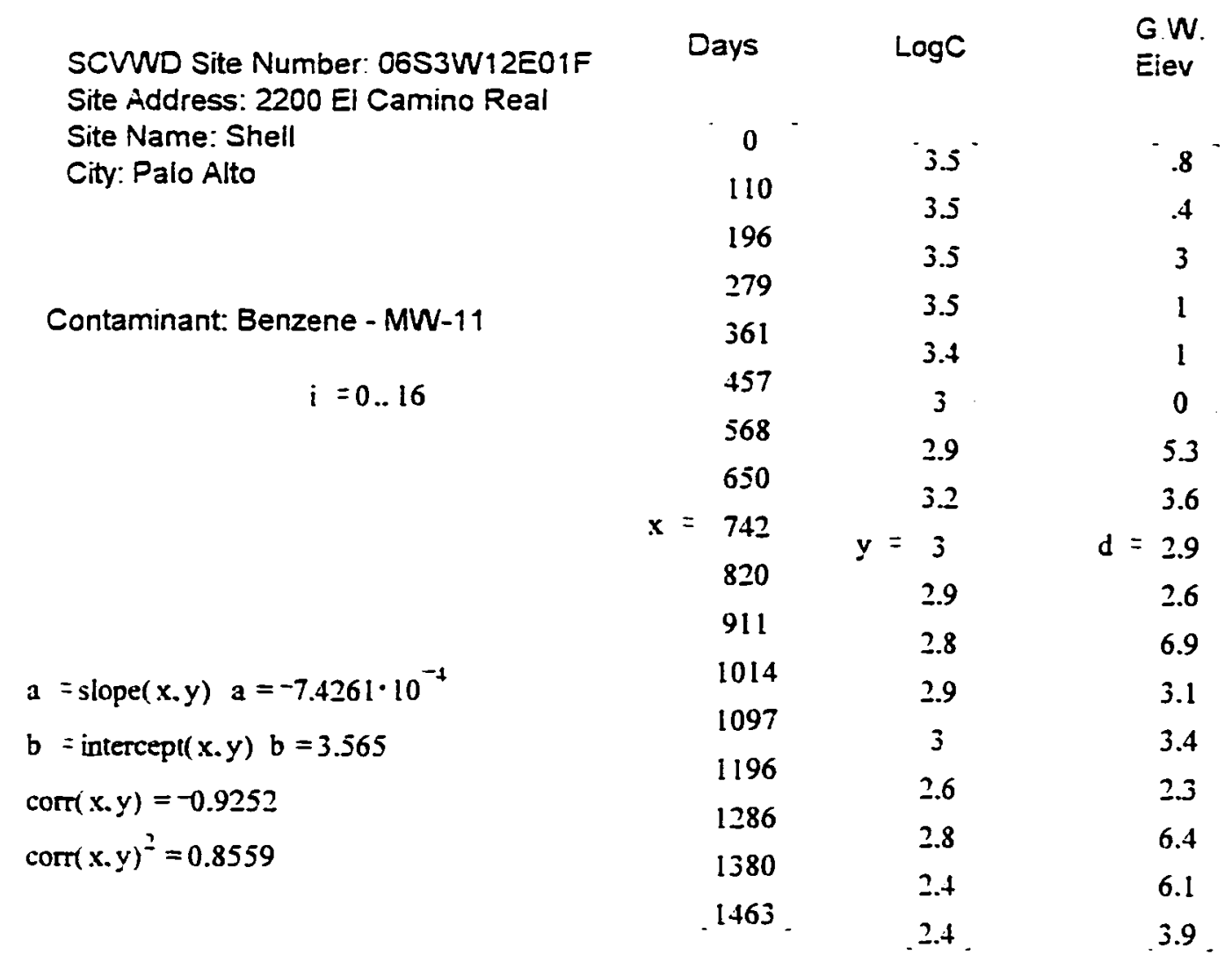

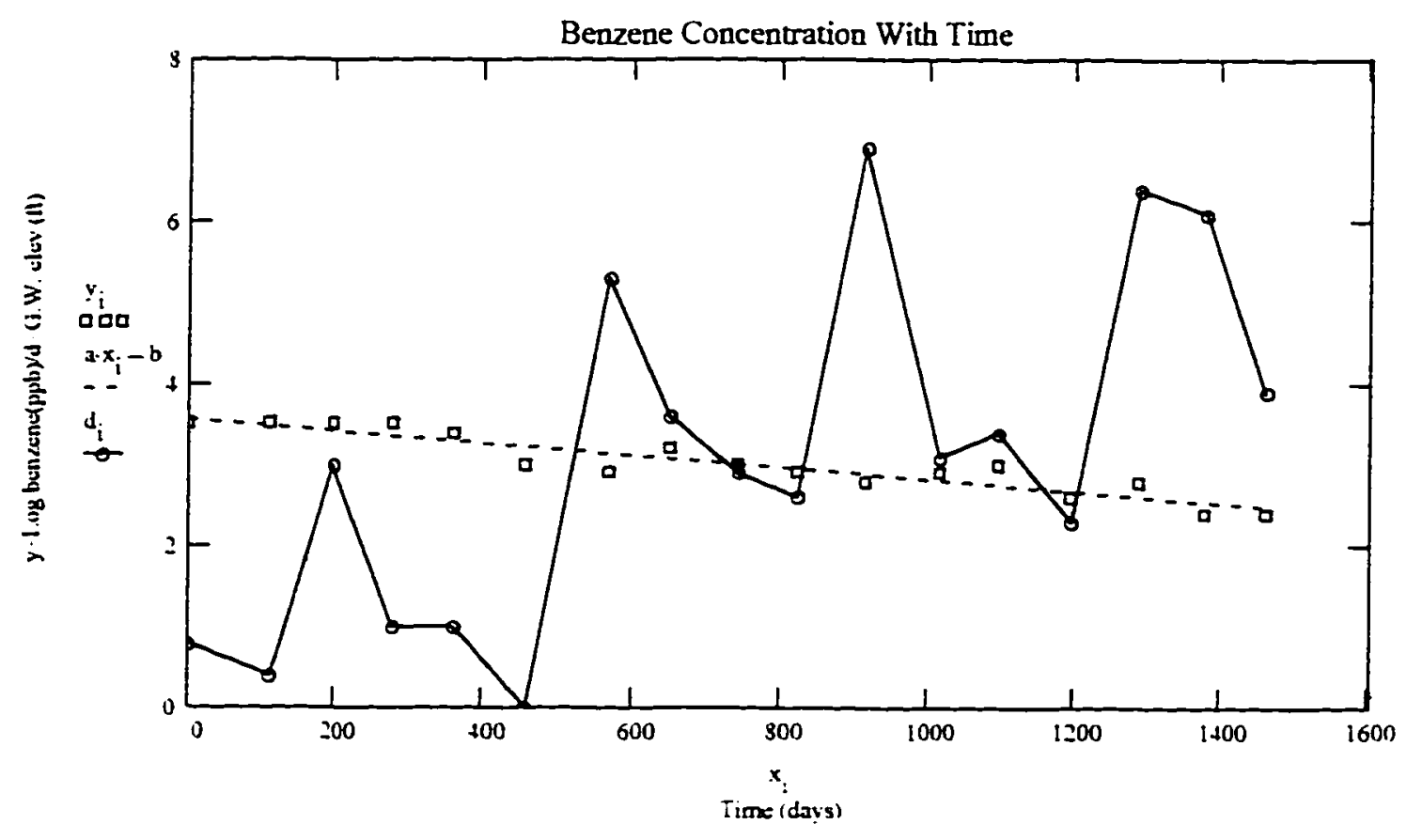

Note: Ground water elevations have been acjusted to fit the graph. $0 \mathrm{ft}=10.91 \mathrm{ft}$. 
SCWWD Site Number: 06S2W08N01F Site Address: 3900 Middlefield Rd.

Site Name: Shell

City: Palo Alto

Contaminant: TPH Gasoline - S-3

$$
i=0 . .9
$$

$$
\text { Days }
$$

0

69

146

271

$x=336$

432

508

597

717

.777 . $\log C$

4.9

4.2

3.8

4.3

$y=\begin{gathered}4 \\ 3.8\end{gathered}$

3.3

3.9

3.2

2.5
G.W.

Elev

.4

2

0

6

.7

$\mathrm{d}=\begin{aligned} & .7 \\ & 0\end{aligned}$

0

1.5

0

.8 .

$a=\operatorname{slope}(x . y) a=-0.0021$

$b=$ intercept $(x . y) \quad b=4.6036$

Note: Ground water elevations have been adjusted to fit the graph. $0 f=6.0 \mathrm{ft}$ (rounded). There was no $\operatorname{corr}(x . y)=-0.8524$ elevation data point for the 9th date. so 0 was input.

$\operatorname{corr}(x, y)^{2}=0.7267$

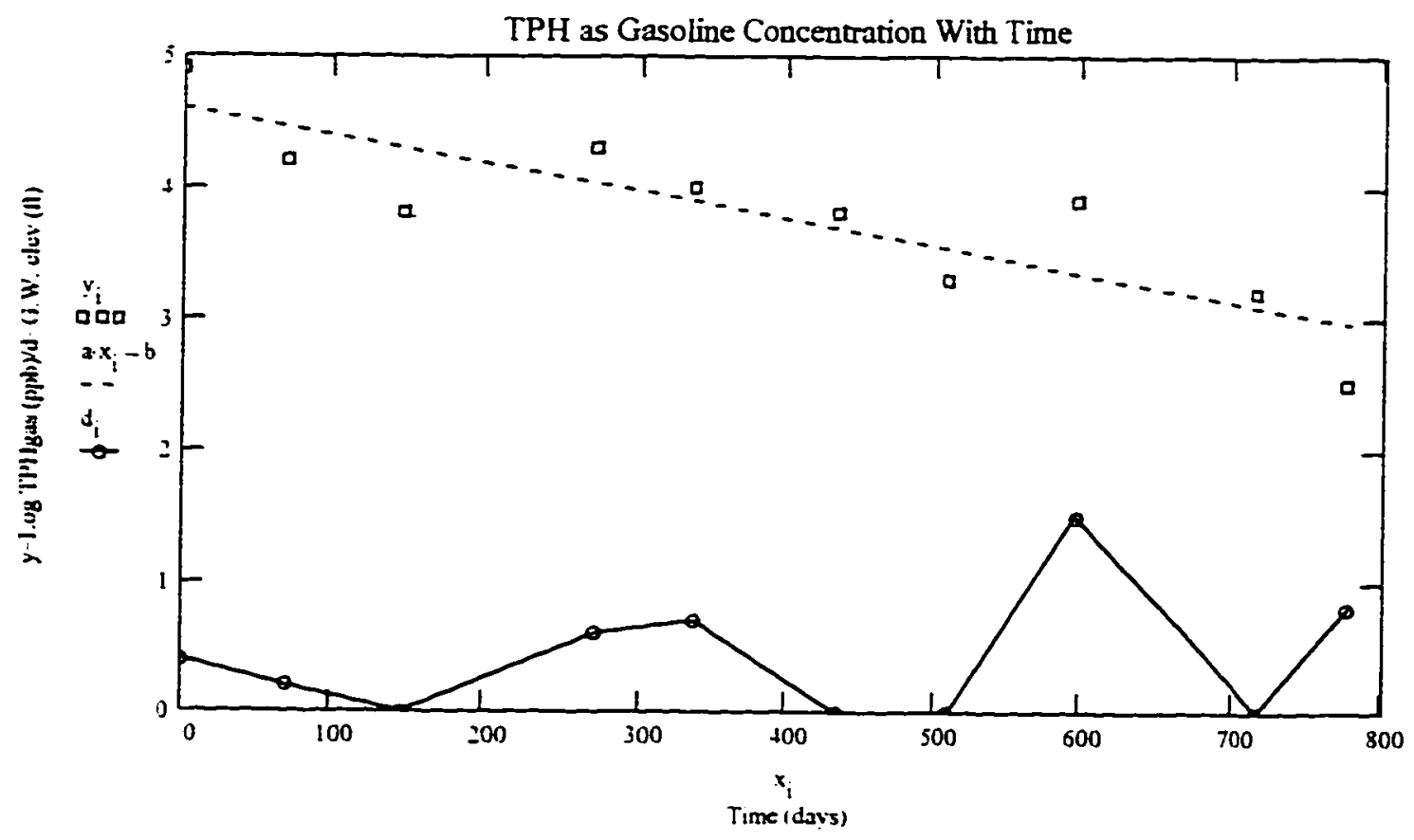


SCWWD Site Number: 06S2W08N01F Site Address: 3900 Middlefield Rd.

Site Name: Shell

City: Palo Alto

$\begin{array}{ccc}\text { Days } & \text { LogC } & \begin{array}{c}\text { G.W. } \\ \text { Elev } \\ 0\end{array} \\ 0 & -4.7 \\ 98 & 3.8 & .7 \\ 173 & 3.8 & 0 \\ 233 & y=3.5 & \mathrm{~d}=1.4 \\ 327 & 3.9 & 1.3 \\ 414 & 3.5 & .8 \\ .514 . & .3 .5 . & .8 .\end{array}$

$a=\operatorname{slope}(x . y) \quad a=-8.4818 \cdot 10^{-4}$

$b=$ intercept $(x, y) b=3.9274$

$\operatorname{cor}(x . y)=-0.7215$

Note: Ground water elevations have been adjusted to it the graph. $0 \mathrm{ft}=6.0 \mathrm{ft}$ (rounded).

$\operatorname{corr}(x . y)^{2}=0.5205$

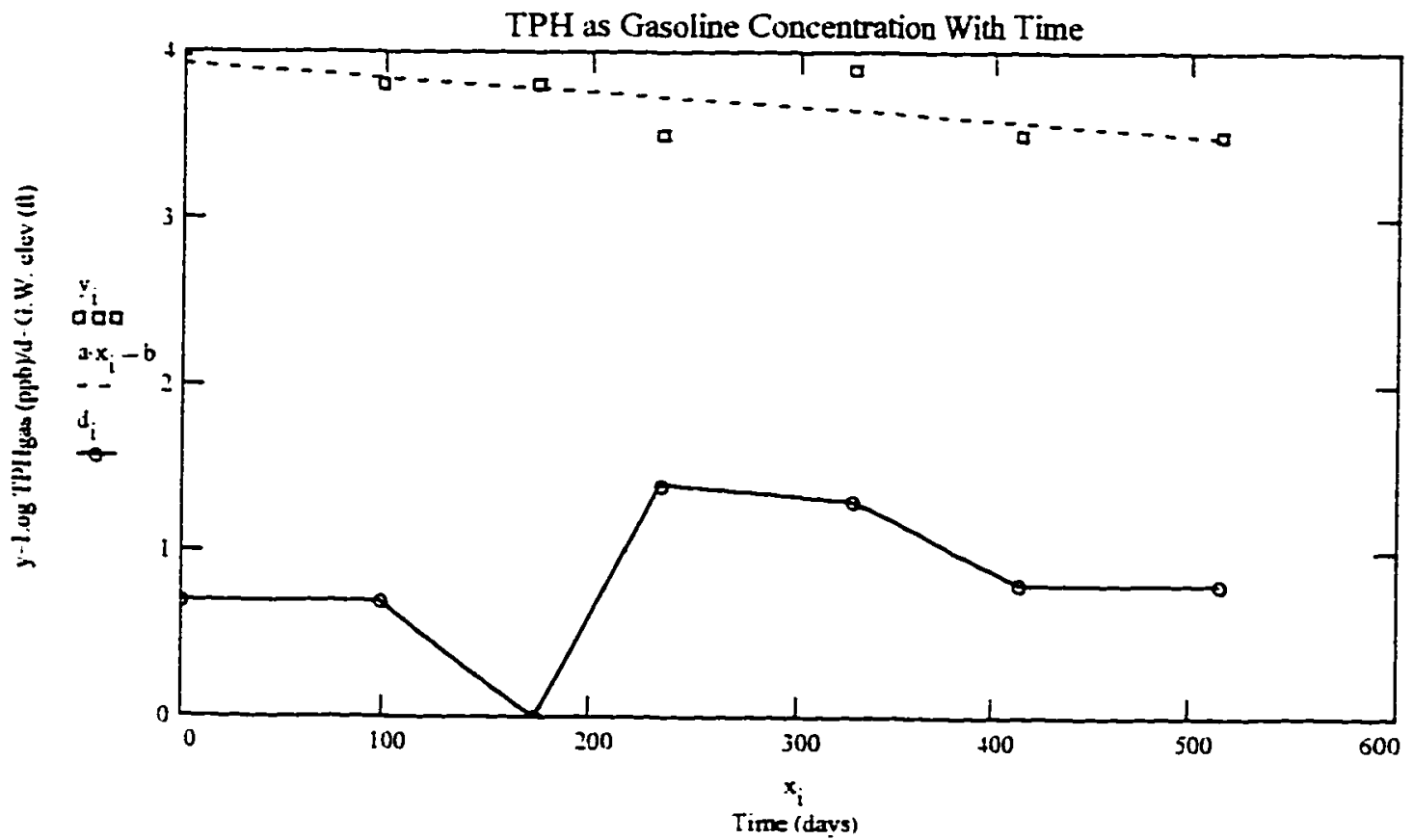


SCVWD Site Number: 06S2W08N01F

Site Address: 3900 Middlefield Rd.

Site Name: Shell

City: Palo Alto

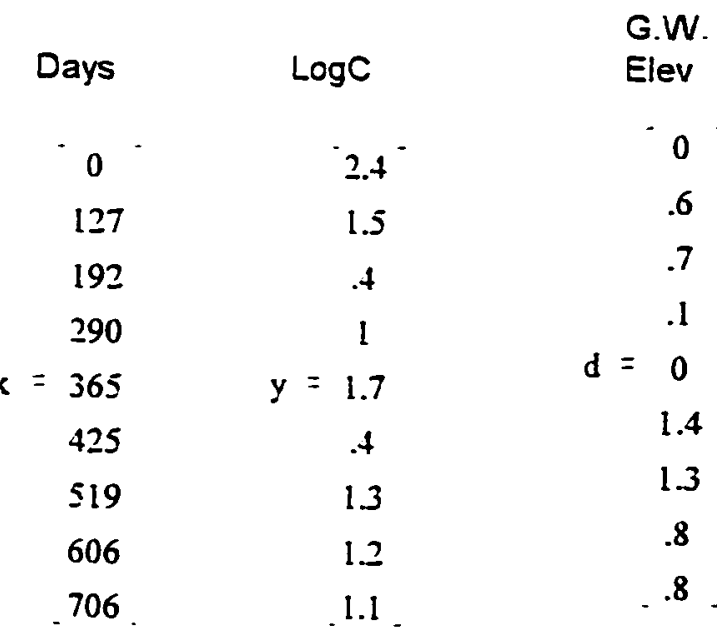

$a=\operatorname{slope}(x, y) \quad a=-9.8761 \cdot 10^{-1}$

$\mathrm{i}=0 . .8$

$b=$ intercept( $x . y) b=1.5767$

$\operatorname{cor}(x . y)=-0.3655$

$\operatorname{corr}(x . y)^{2}=0.1336$

Note: Ground water elevations have been adjusted to it the graph. $O f t=6.0$ ft (rounded).

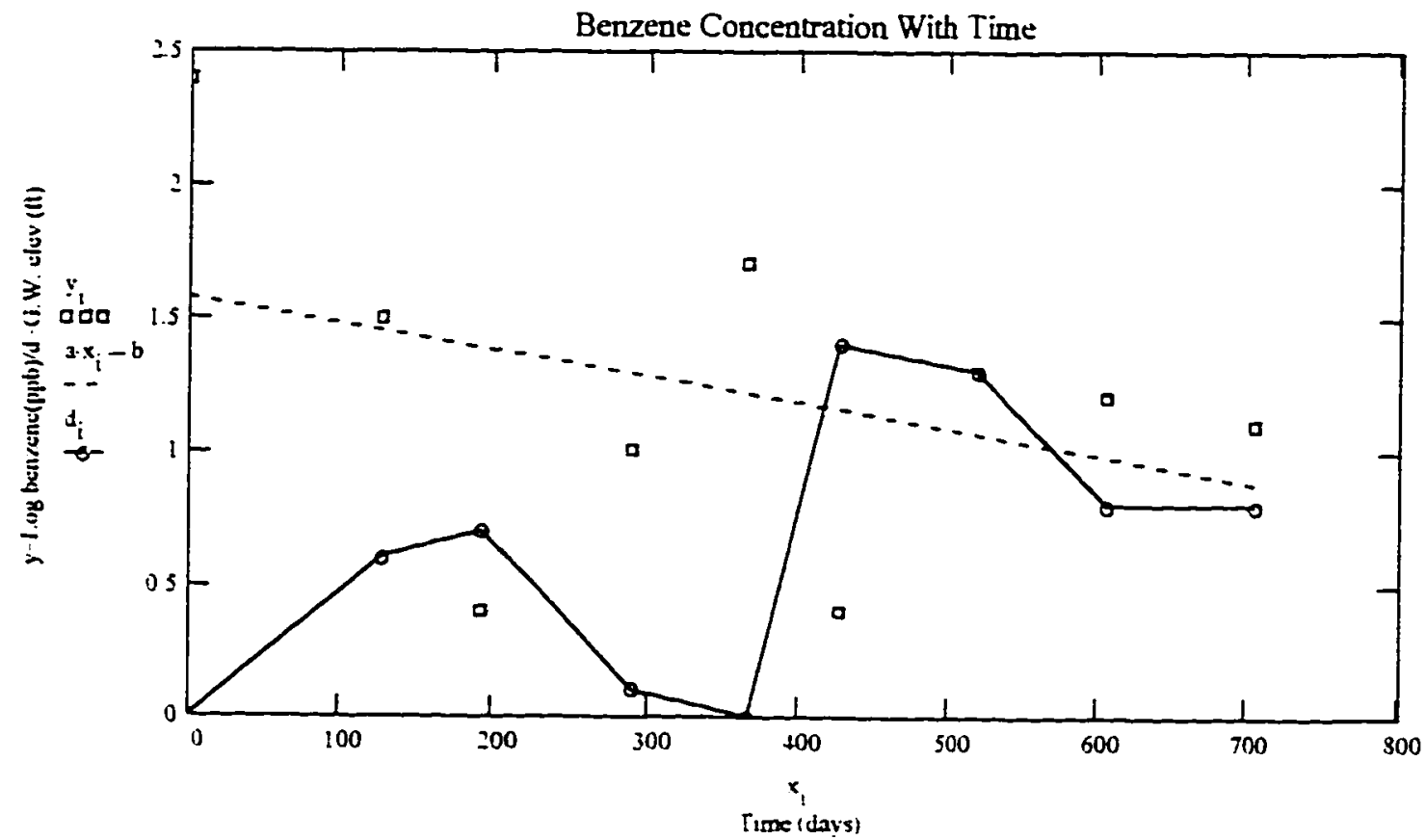


SCWWD Site Number: 06S3W12E02F

Site Address: 1963 El Camino Real

Site Name: Arco Station \#589

Days

City: Palo Alto

Contaminant: TPH Gasoline
\[ i=0 . .8 \]
$=\operatorname{slope}(x . y) \quad a=-0.0015$
$=i n t e r c e p t(x . y) \quad b=3.6048$
$\operatorname{corr}(x . y)=-0.923$
$\operatorname{corr}(x . y)^{2}=0.8519$

$\log C$

G.W.

Elev

$\begin{array}{ccc}0 & 3.8 & 1.4 \\ 124 & 3.3 & .6 \\ 210 & 3.2 & .1 \\ 331 & 3.1 & 0 \\ 402 & \mathrm{y}=2.8 & \mathrm{~d}=.8 \\ 502 & 3 & .3 \\ 604 & 2.5 & 0 \\ 704 & 2.8 & 3.5 \\ 792 . & .2 .3 . & .2 .9 .\end{array}$

Note: Ground water elevations have been adjusted to fit the graph. $\mathrm{O} f \mathrm{t}=10.4 \mathrm{ft}$ (rounded). Elevation datum for fourth date not available: 0 input.

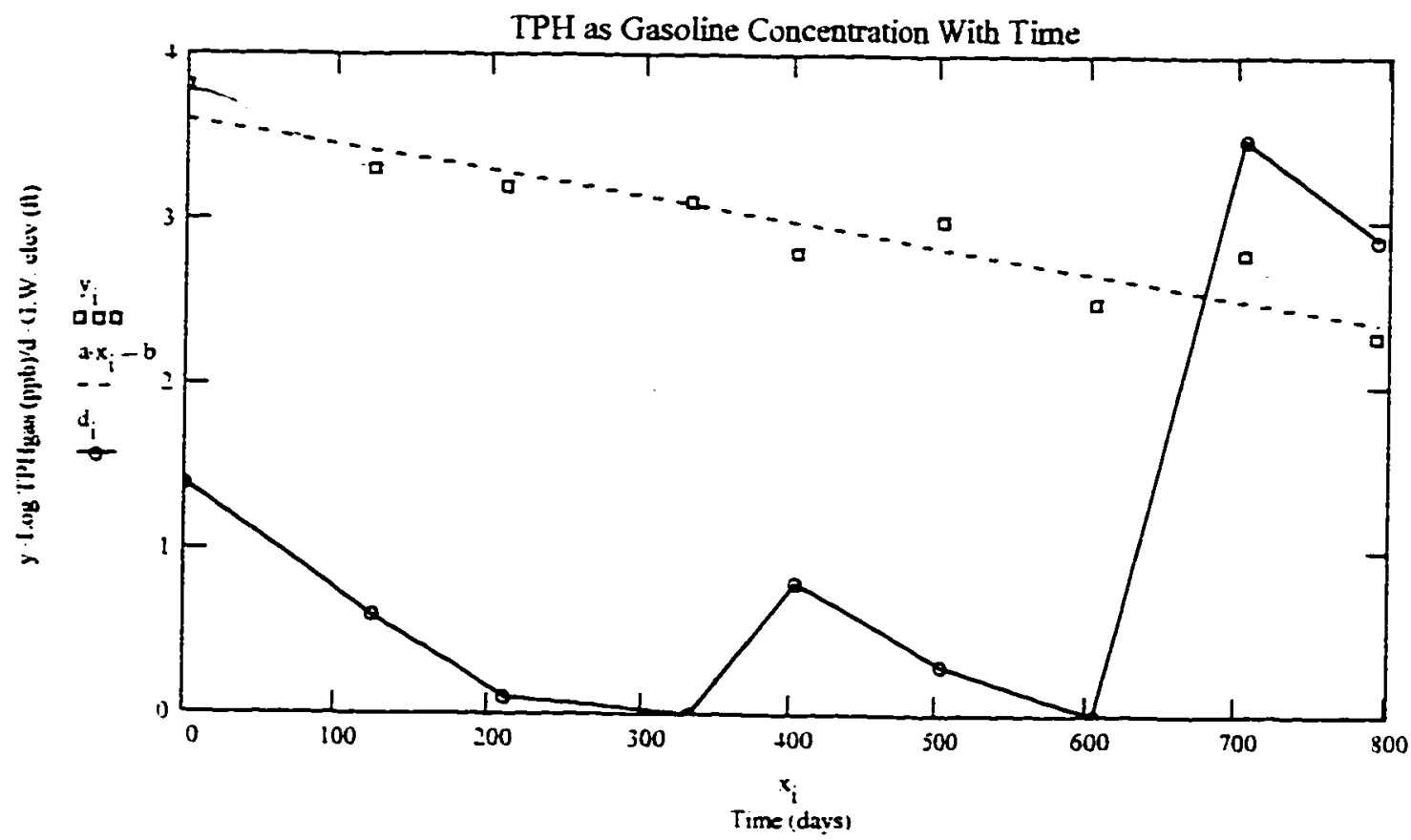


SCVND Site Number: 06S3W12E02F

Site Address: 1963 El Camino Real

Site Name: Arco Station \#589

City: Palo Alto

$\begin{array}{lll}\text { Days } \quad \text { LogC } & \text { G.W. } \\ & \text { Elev }\end{array}$

Contaminant: Benzene - mw- $\frac{7}{8}$

$\begin{array}{ccc}0 & 3 & 1.4 \\ 124 & 2.4 & .6 \\ 210 & 2.1 & .1 \\ 331 & 1.9 & 0 \\ 402 & y=1.6 & \mathrm{~d}=.8 \\ 502 & 1.8 & .3 \\ 604 & 1.6 & 0 \\ 704 & 1.4 & 3.5 \\ 792 & .7 & . .9\end{array}$

$a=\operatorname{slope}(x . y) \quad a=-0.0023$

$i=0 . .8$

$b=$ intercept $(x . y) \quad b=\mathbf{2 . 7 5 9 8}$

$\operatorname{corr}(x, y)=-0.9426$

corr $x . y)^{2}=0.8884$

Note: Ground water elevations have been adjusted to fit the graph. $O A t=10.4$ it (rounded). Elevation datum for fourth date not available: 0 input.

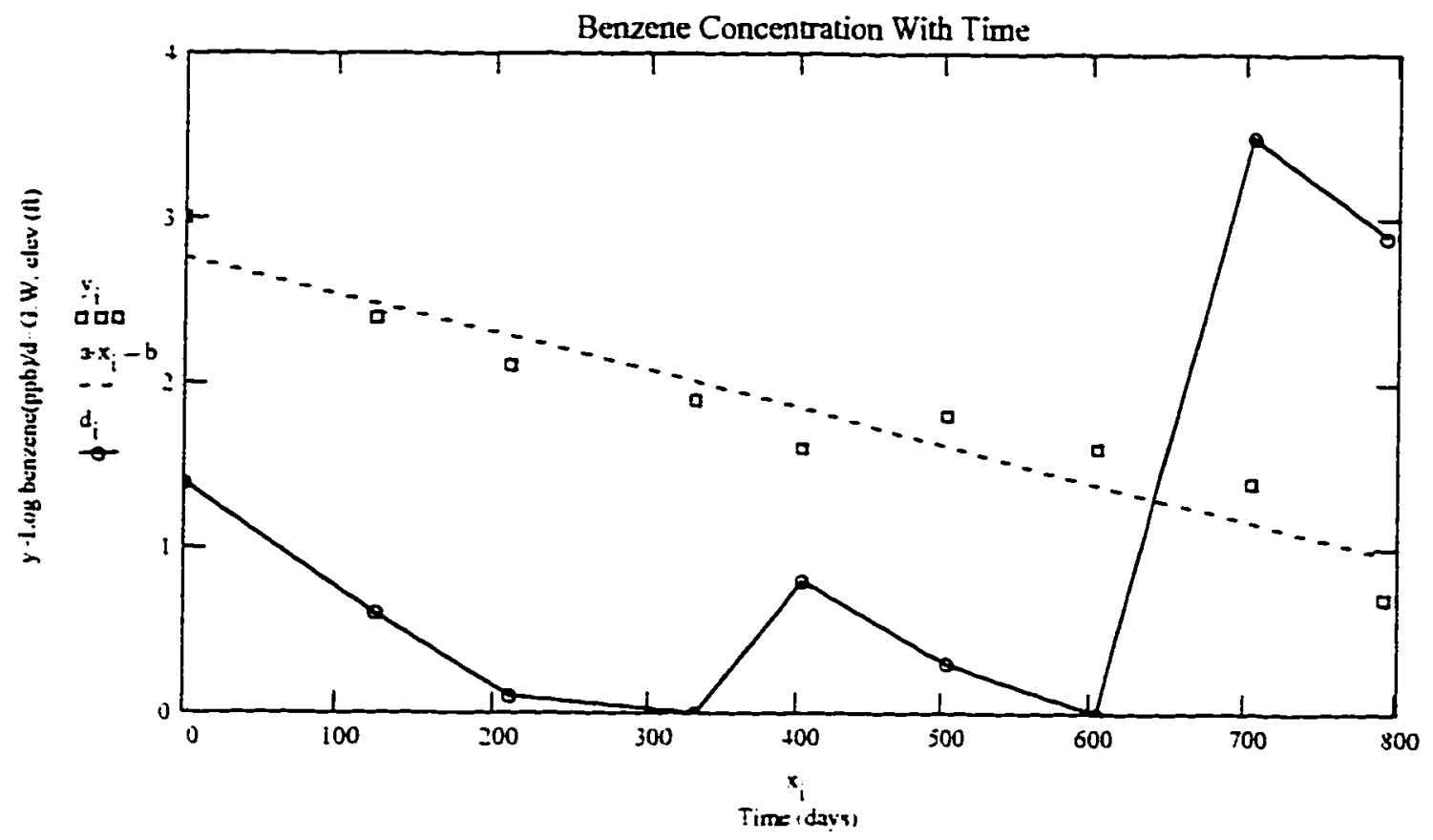


SCVND Site Number: 06S3W12E02F

Site Address: 1963 El Camino Real

Site Name: Arco Station \#589

City: Palo Alto

$\begin{array}{ccc}\text { Days } & \text { LogC } & \begin{array}{c}\text { G.W. } \\ \text { Elev }\end{array} \\ 0 & -4.5 & .2 \\ 97 & 4 & .6 \\ 188 & 4 & .5 \\ 276 & 3.8 & 0 \\ \mathrm{x}= & \mathrm{y} .6 & \mathrm{~d}=2.4 \\ 456 & 3.4 & 3.2 \\ 580 & 3.2 & 2.4 \\ 636 & 2.7 & 2.1 \\ 756 & 2.3 & 0 \\ 924 . & .1 .4 . & .2 .2 .\end{array}$

$a=\operatorname{slope}(x, y) \quad a=-0.003$

$b=$ intercept $(x, y) b=4.5855$

$\operatorname{corr}(x, y)=-0.9713$

Note: Ground water elevations have been adjusted to

$\operatorname{corr}(x . y)^{2}=0.9434$

fit the grapin. $O \mathrm{ft}=8.3 \mathrm{ft}$ (rounded). Elevation datum for ninth date not available: 0 input.

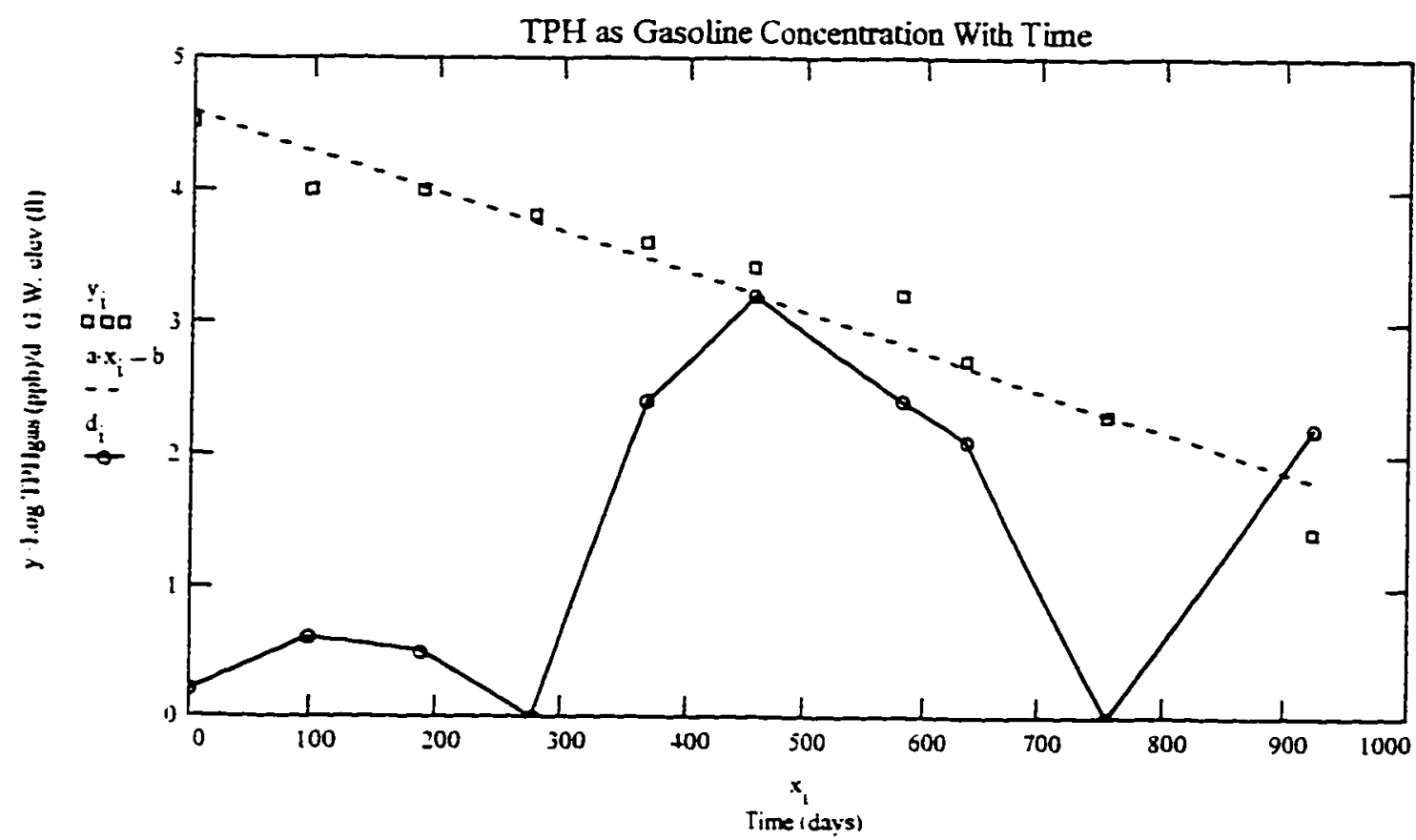




\begin{tabular}{|c|c|c|c|}
\hline \multirow{4}{*}{$\begin{array}{l}\text { SCWWD Site Number: 06S3W12E02F } \\
\text { Site Address: } 1963 \text { El Camino Real } \\
\text { Site Name: Arco Station \#589 } \\
\text { City: Palo Alto }\end{array}$} & Days & $\log C$ & $\begin{array}{l}\text { G.W. } \\
\text { Elev }\end{array}$ \\
\hline & 0 & 2.4 & .2 \\
\hline & 97 & 2.3 & .6 \\
\hline & 188 & 2.4 & .5 \\
\hline \multirow[t]{8}{*}{ Contaminant: Benzene - MW-11 } & 276 & 2.1 & 0 \\
\hline & 367 & 1.8 & 2.4 \\
\hline & 456 & 1 & 3.2 \\
\hline & 580 & $y=12$ & 2.4 \\
\hline & 636 & 1.6 & 2.1 \\
\hline & 756 & .9 & 0 \\
\hline & 924 & $\cdot .05$ & 2.2 \\
\hline & 1026 & .4 & 2 \\
\hline$a=\operatorname{slope}(x, y) \quad a=-0.0016$ & .1125. & 1.7 & 5.3. \\
\hline
\end{tabular}

$\operatorname{corr}(x, y)=-0.7586$

$\operatorname{corr}(x . y)^{2}=0.5755$

Note: Ground water elevations have been adjusted to fit the graph. $O f t=8.3$ it (rounded). Elevation datum for ninth date not available: 0 input.

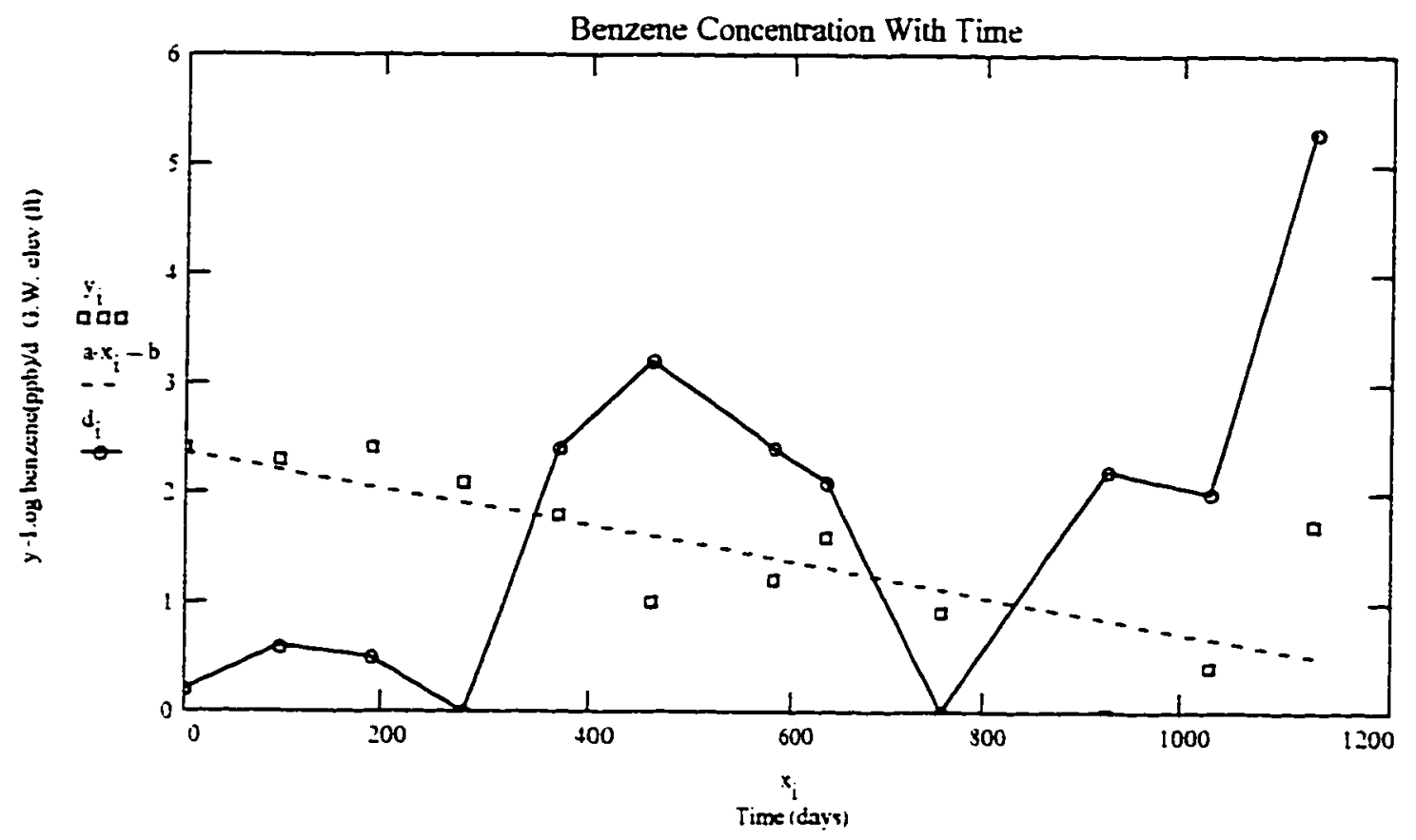


SCVND Site Number: 06S2W17802F

Site Address: 699 San Antonio Rd

Site Name: Arco \#0716

City: Palo Alto

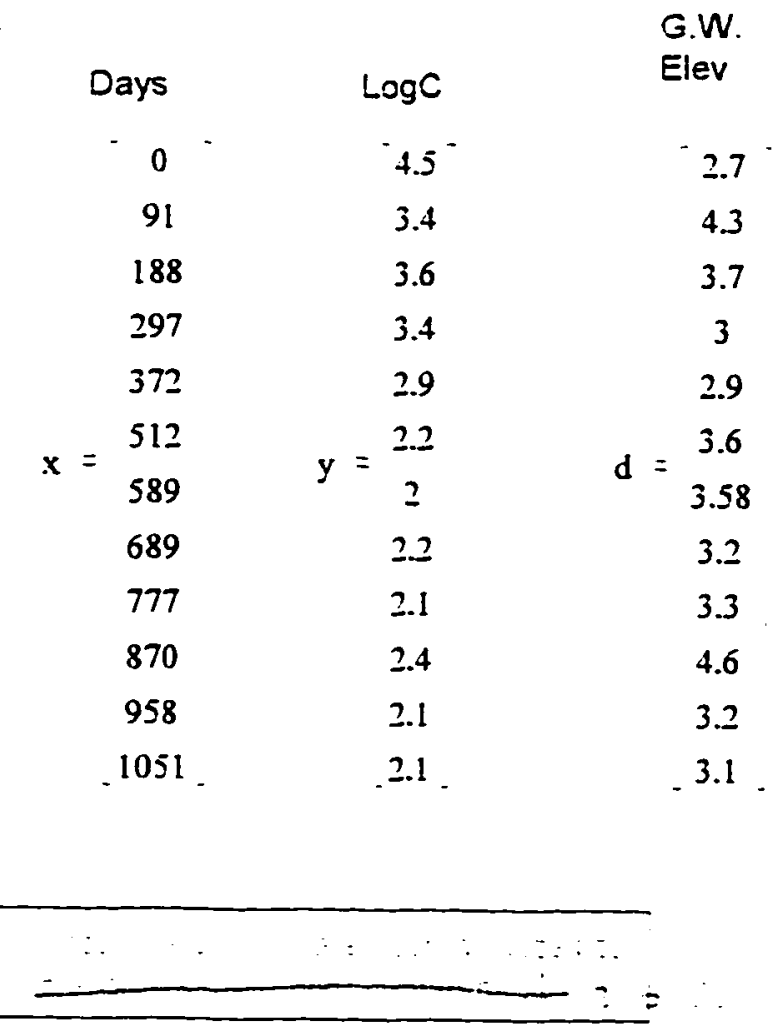

$a=\operatorname{slope}(x \cdot y) \quad a=-0.002$

$i=0 . .11$

$b=$ intercept $(x . y) b=3.822$

$\operatorname{corr}(x . y)=-0.8708$

$\operatorname{corT}(x . y)^{2}=0.7584$

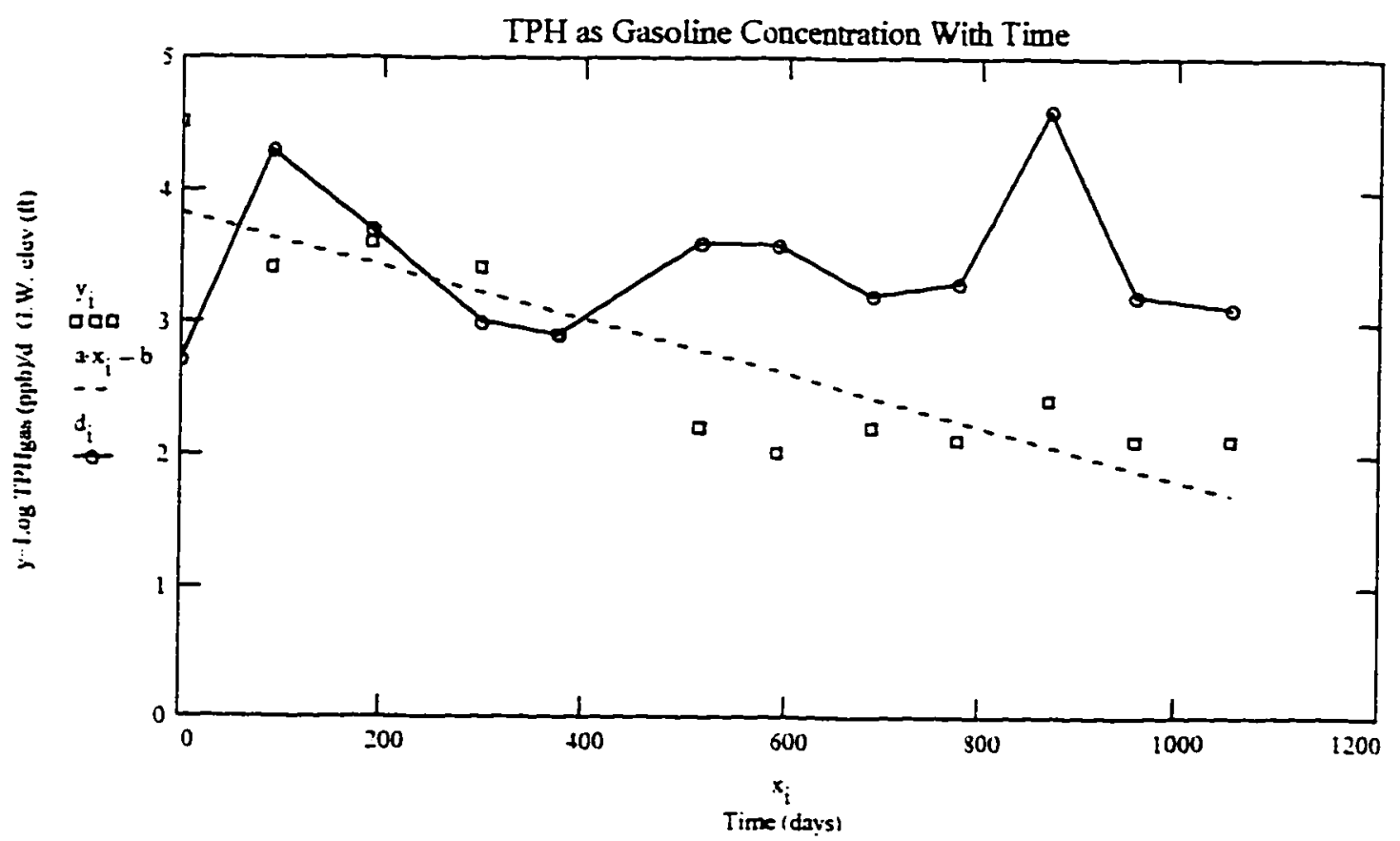


SCWWD Site Number: 06S2W17B02F

Site Address: 699 San Antonio Rd

Site Name: Arco $\# 0716$

City: Palo Alto

$$
\begin{aligned}
& \text { Contaminant: Benzene - A-3 } \\
& i=0 . .4
\end{aligned}
$$

$$
\text { Days }
$$$$
0
$$

109$$
x=184
$$$$
324
$$$$
.401 \text {. }
$$

Note: Ground water elevations have been adjusted to fit the graph. Eievations 2 .
G.W.

Elev

$3.7^{-}$

3

$d=2.9$

3.6

3.5 .

-.6 . 


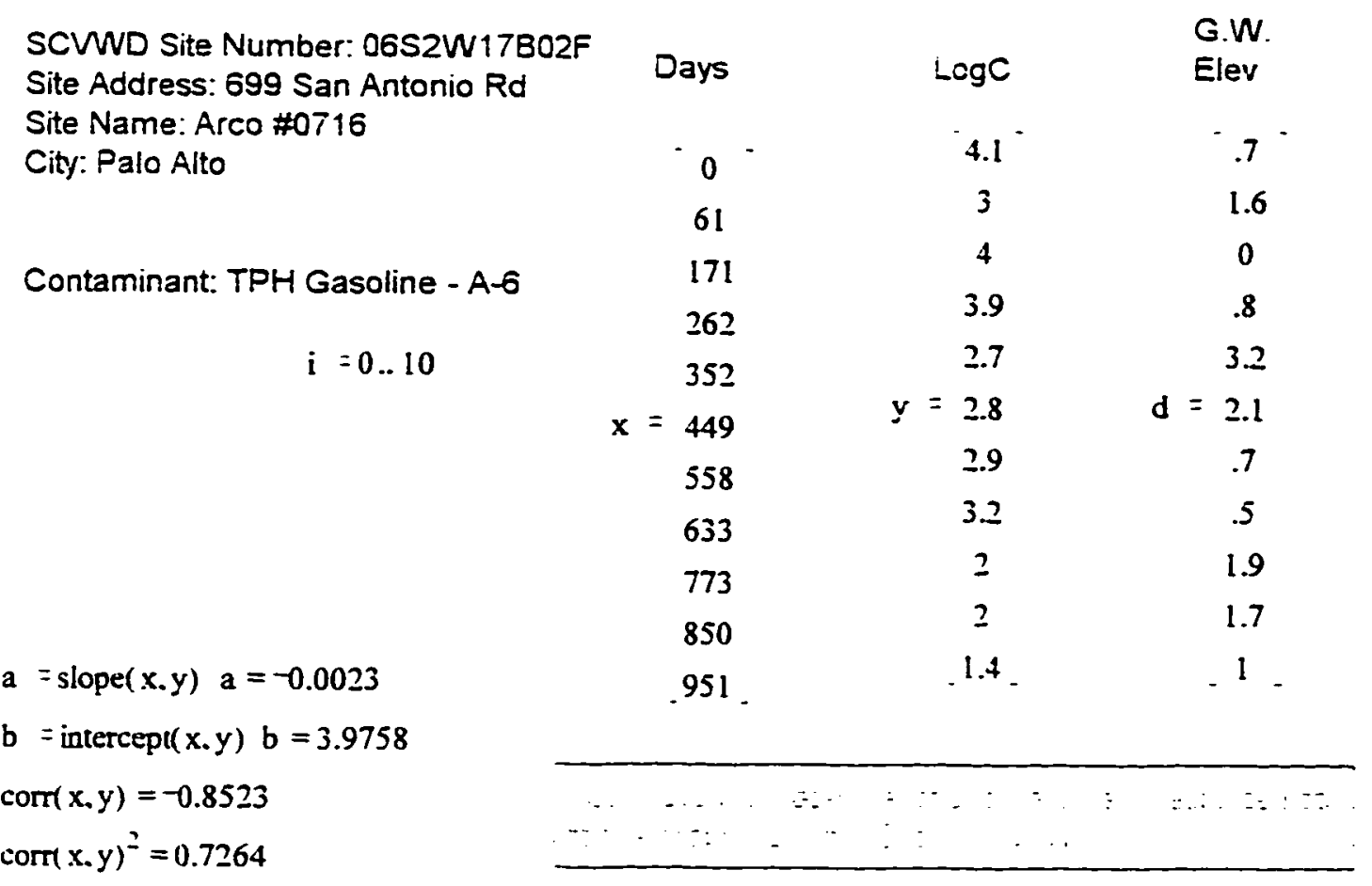

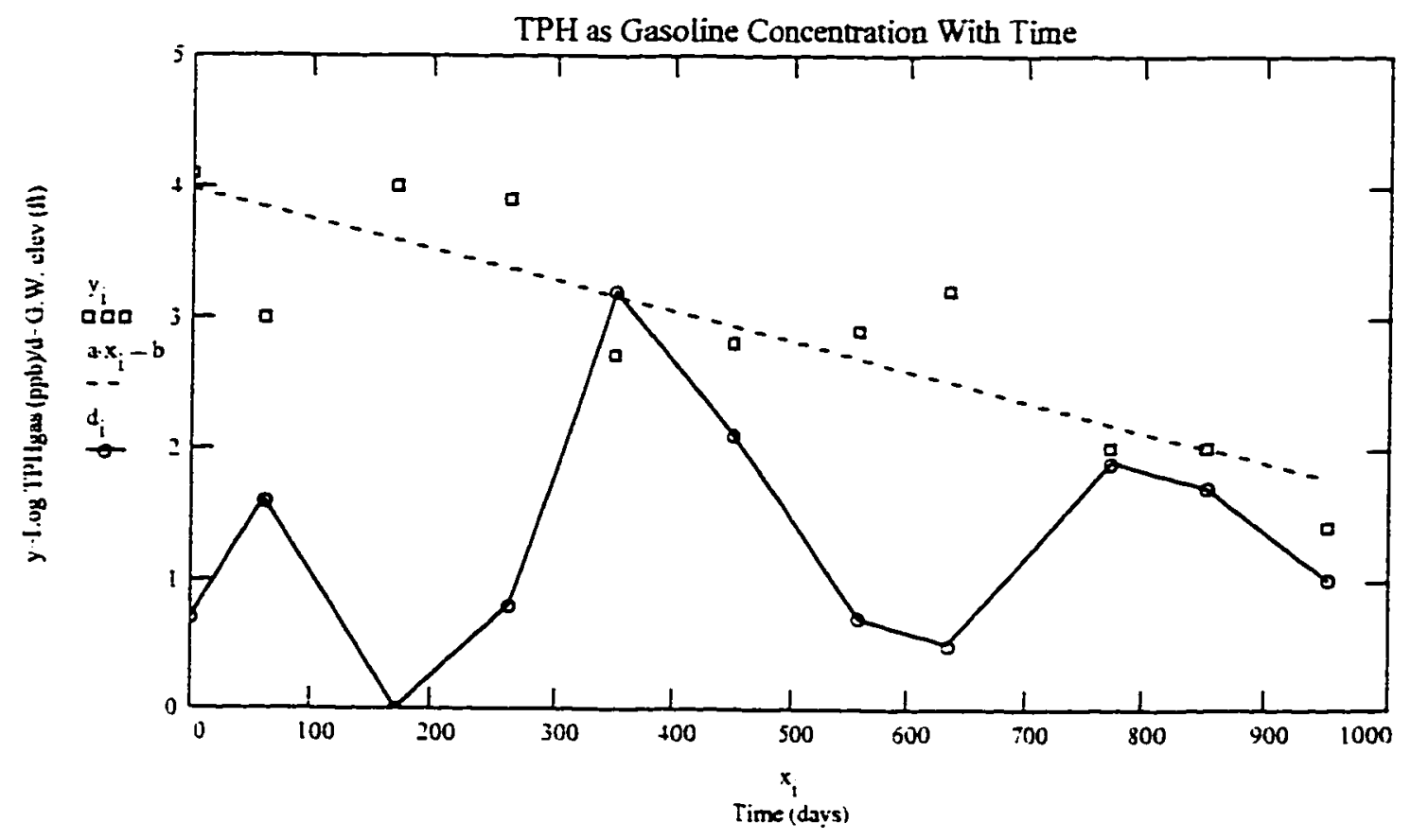


SCWWD Site Number: 06S2W17B02F

Site Address: 699 San Antonio Rd

Site Name: Arco \#0716

City: Palo Alto

Contaminant: Benzene - A-6

$$
\mathrm{i}=0 . .10
$$

$a=\operatorname{slope}(x, y) \quad a=-0.0023$

$b=$ intercepl $(x, y) \quad b=\mathbf{2 . 0 1 6 9}$

$\operatorname{com}(x . y)=-0.9196$

$\operatorname{corr}(x . y)^{2}=0.8456$ $\begin{array}{ll} & \text { G.W. } \\ \text { Days } \quad \log C \quad \text { Elev }\end{array}$

$\begin{array}{ccc}0 & 2.1 & .7 \\ 61 & 1.2 & 1.6 \\ 171 & 2 & 0 \\ 262 & 1.4 & .8 \\ 352 & 1 & 3.2 \\ \mathrm{x}= & \mathrm{y}=1.3 & \mathrm{~d}=1.1 \\ 449 & 1 & .7 \\ 558 & .7 & .5 \\ 633 & .3 & 1.9 \\ 773 & -.05 & 1.7 \\ 850 & -.6 & 1 \\ 951 & & \end{array}$

Note: Ground water elevations have been adjusted to fit the graph. O ft $=4.8 \mathrm{ft}$ (rounded).

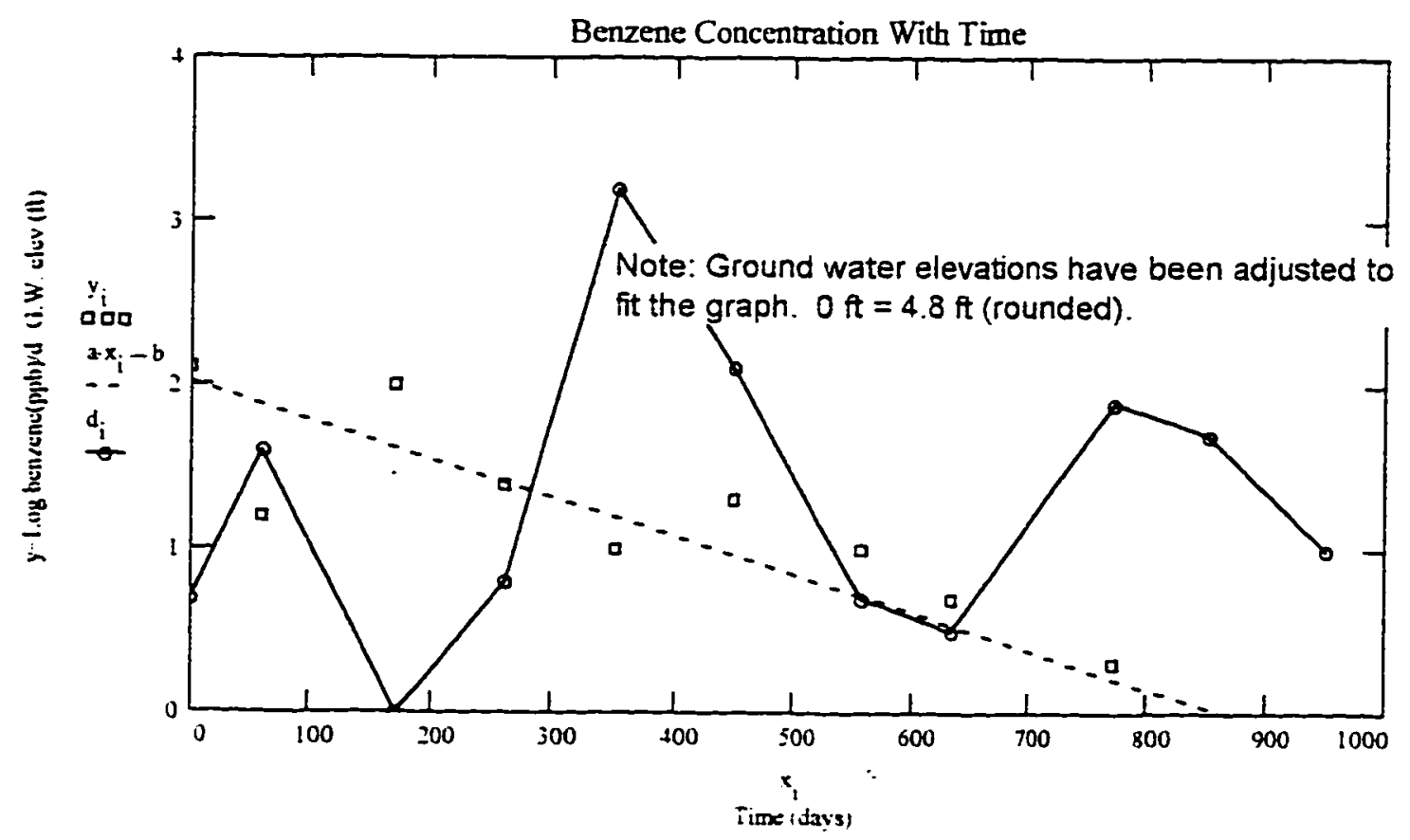


SCWWD Site Number: 06S2W07C02F Site Address: 2995 Middlefield Rd.

Site Name: Arco \#4430

City: Palo Alto

Contaminant: TPH Gasoline - MW-4

$\begin{array}{ccc}\text { Days } & \text { LogC } & \begin{array}{c}\text { G.W. } \\ \text { Elev }\end{array} \\ -0 & -4.8 & -3.4 \\ 110 & 3.9 & 3.3 \\ 199 & 4 & 2.2 \\ 275 & 2.7 & 1.8 \\ 365 & \mathrm{y}=4.2 & 4.8 \\ 457 & 4 & \mathrm{~d}= \\ 554 & 3.6 & 3.4 \\ 637 & 3 & 2.9 \\ 721 & 1.4 & 4.0 \\ 1091 & .3 .2 & 5.2\end{array}$

$a=\operatorname{slope}(x, y) \quad a=-0.0017$

Note: Ground water elevations have been rounded to

$b=\operatorname{intercept}(x, y) \quad b=4.228$

$\operatorname{corr}(x, y)=-0.5757$

$\operatorname{corr}(x . y)^{2}=0.3314$ the nearest $0.1 \mathrm{ft}$

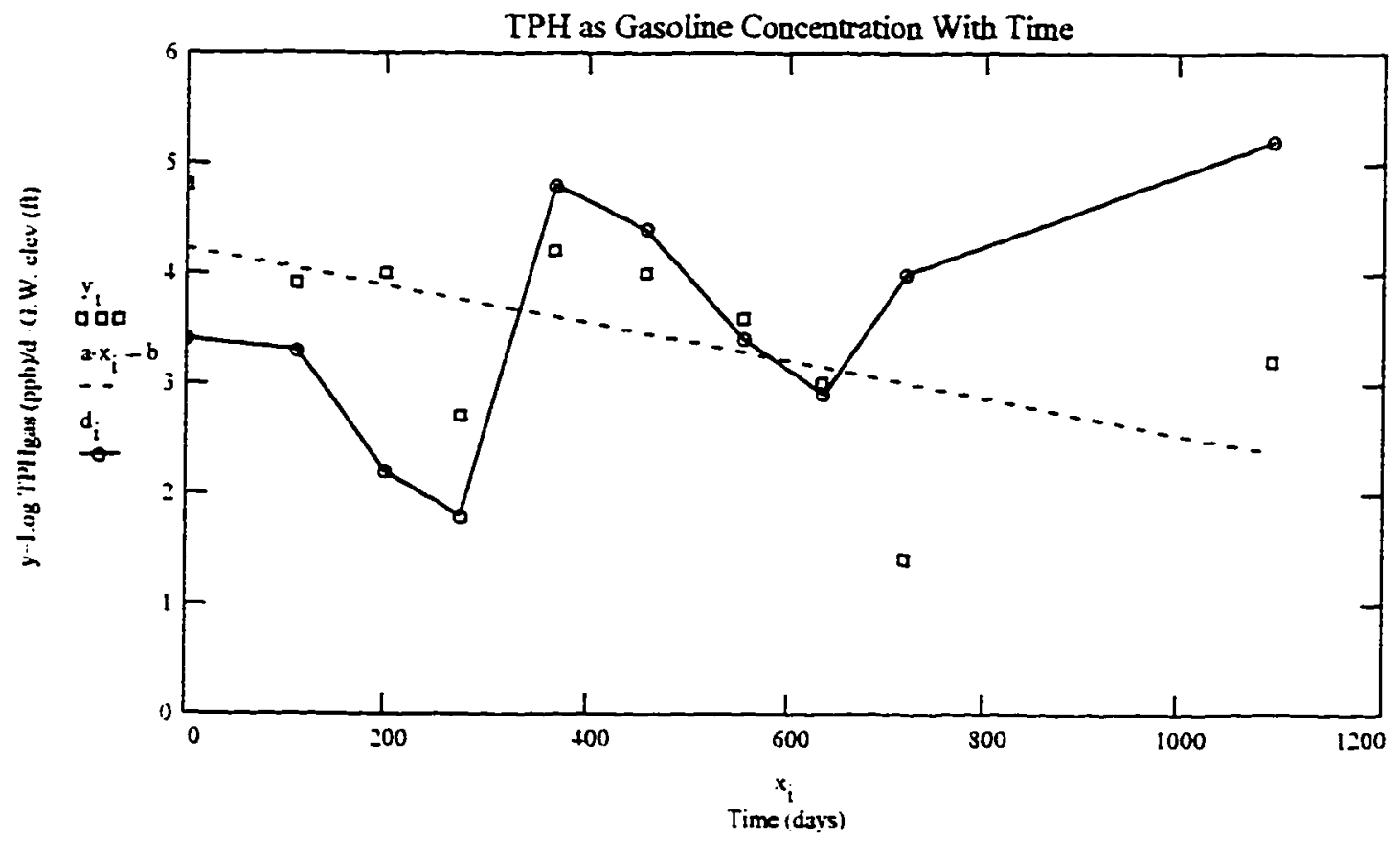


SCWWD Site Number: 06S2W07C02F Site Address: 2995 Middlefield Rd.

Site Name: Arco \#4430

City: Palo Alto

Contaminant: Benzene - MW-4

$$
i=0 . .9
$$

$\begin{array}{ccc}\text { Days } & \text { LogC } & \begin{array}{c}\text { G.W. } \\ \text { Elev }\end{array} \\ 0 & -2.8 & 3.4 \\ 110 & 1.3 & 3.3 \\ 199 & 1.9 & 2.2 \\ 275 & 1.2 & 1.8 \\ \mathrm{x}=365 & \mathrm{y}=2.3 & \mathrm{~d}=4.8 \\ 457 & 1.4 & 4.4 \\ 554 & 1.1 & 3.4 \\ 637 & .5 & 2.9 \\ 721 & .1 & 4.0 \\ 1091 & .1 . & 5.2 .\end{array}$

Note: Ground water elevations have been rounded to the nearest $0.1 \mathrm{ft}$.

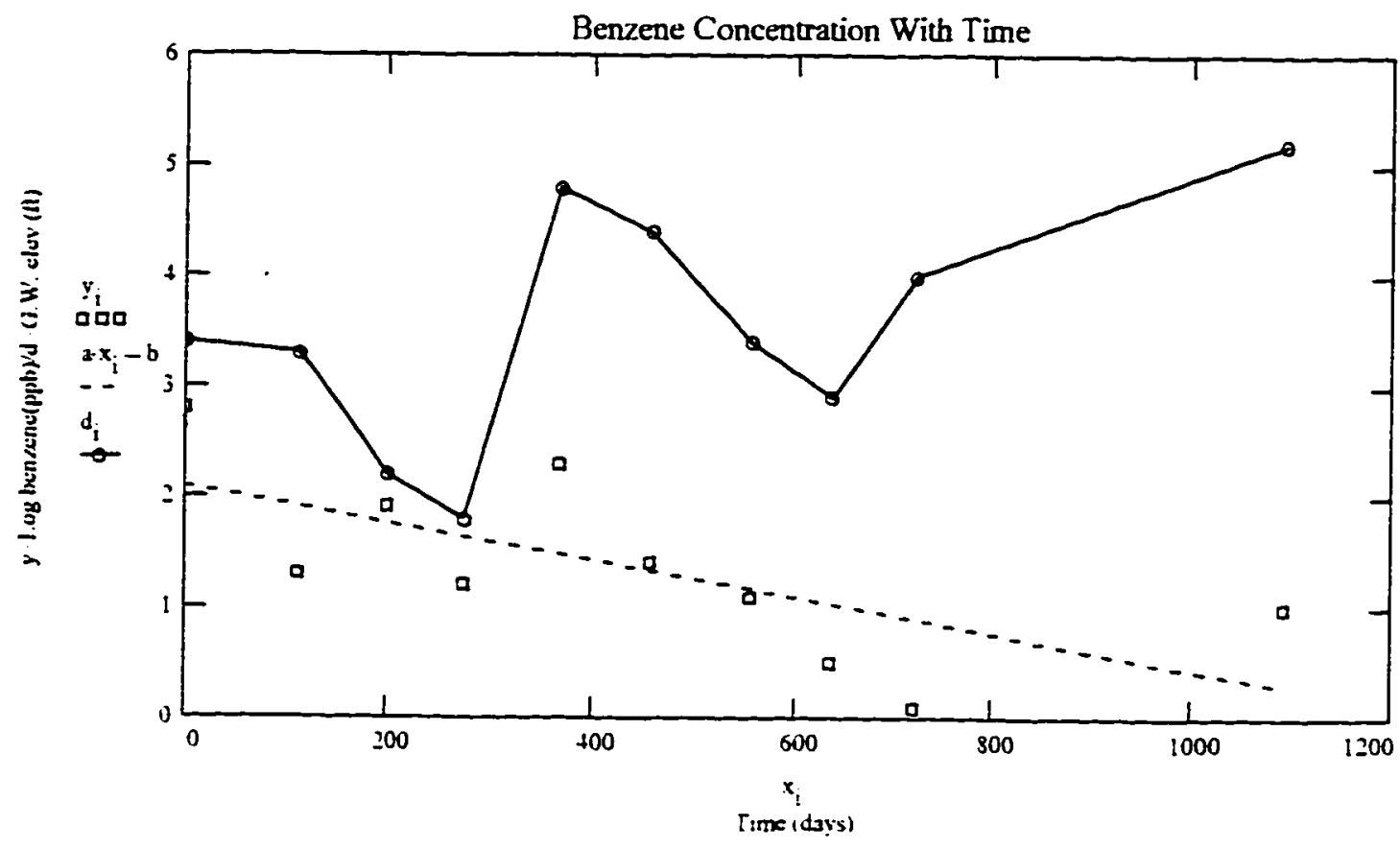


SCVND Site Number: 06S2W07C02F

Site Address: 2995 Middlefieid Rd.

Site Name: Arco \#4430

City: Palo Alto

$\begin{array}{ccc}\text { Days } & \text { LogC } & \begin{array}{c}\text { G.W. } \\ \text { Elev }\end{array} \\ 0 & -3.8^{-} & - \\ 92 & 3.6 & 4.6^{\circ} \\ 188 & \mathrm{y}=3.3 & 4.3 \\ 271 & 2.7 & \mathrm{~d}=3.3 \\ 355 & 2.6 & 2.7 \\ .727 & .3 & 3.9 \\ & & .3 .0\end{array}$

$a=\operatorname{slope}(x \cdot y) \quad a=-0.0012$

$b=$ intercept(x.y) $b=3.4858$

$\operatorname{com}(x . y)=-0.6194$

$\operatorname{corr}(x, y)^{2}=0.3836$

Note: Ground water elevations have been rounded to the nearest $0.1 \mathrm{ft}$.

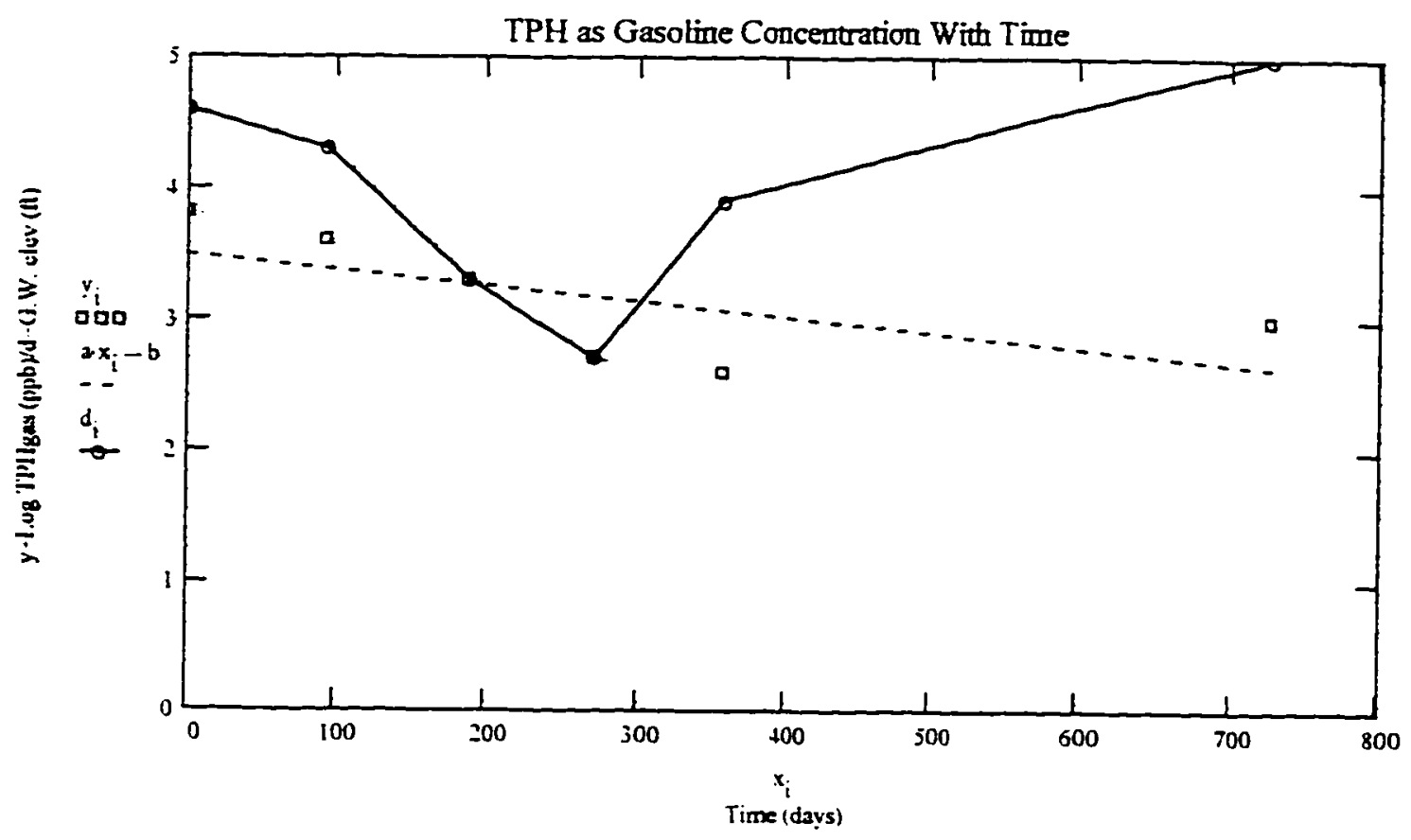


SCWWD Site Number: 06S2W07C02F

Site Address: 2995 Middlefield Rd.

Site Name: Arco $\$ 4430$

City: Palo Alto

Contaminant: Benzene - MW-5

$$
i=0 . .5
$$

$\begin{array}{lll} & \text { GW } \\ \text { Days } \quad \text { LogC } & \text { Elev }\end{array}$

$\mathrm{x}=\begin{array}{ccr}0 & 2.5^{-} & 4.6 \\ 92 & 2.1 & 4.3 \\ 188 & \mathrm{y}= & 1.7 \\ 271 & .6 & \mathrm{~d}=3.3 \\ 355 & 1.1 & 2.7 \\ 727 & .2 & 3.9 \\ \end{array}$

Note: Ground water elevations have been rounded to the nearest $0.1 \%$.

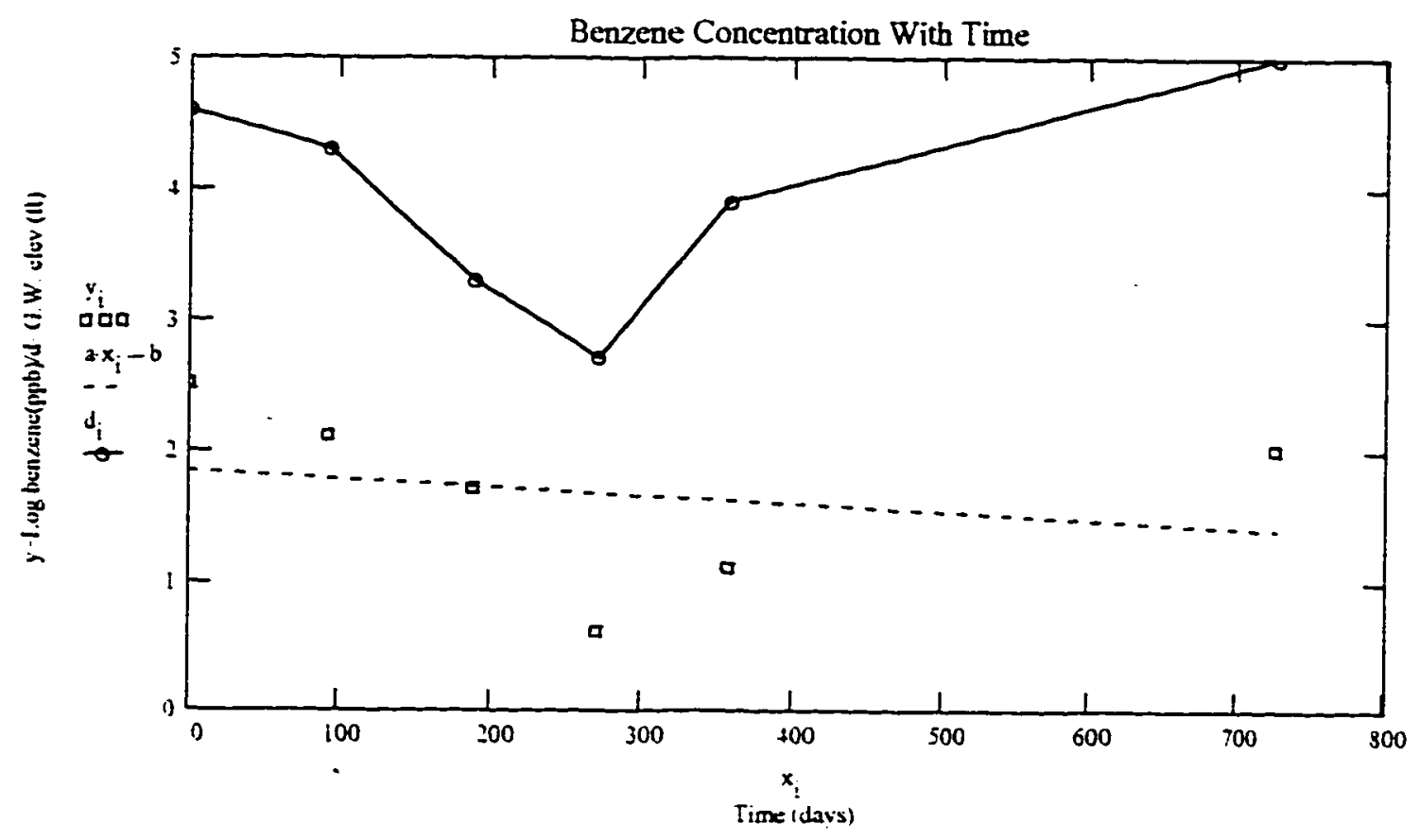


SCWWD Site Number: 06S2W07P01F Site Address: 3401 Alma St

Site Name: Chevron

City: Palo Alto

Contaminant: TPH Gasoline - MW-1

$$
i=0 . .16
$$

Days

$\log C$

G.W.

Elev

$\begin{array}{ccc}0 & & \\ 112 & 4.8 & 2.1 \\ 183 & 4.4 & .8 \\ 274 & 3.6 & 0 \\ 370 & 3.5 & .1 \\ 461 & 3.4 & 2.7 \\ 546 & 3.8 & 1.2 \\ 641 & 2.7 & .5 \\ x=747 & 2.7 & 1.7 \\ 820 & 2.9 & 5.5 \\ 910 & 3.1 & 4.7 \\ 1016 & 2.6 & 3.36 \\ 1117 & 2.7 & 3.4 \\ 1217 & 2.8 & 4.6 \\ 1294 & 2.8 & 3.9 \\ 1384 & 2.7 & 3.0 \\ 1476 & 2.4 & 3.3 \\ & .1 .4 . & 6.7\end{array}$

$b=$ intercept $(x, y) \quad b=4.1623$

$\operatorname{corr}(x, y)=-0.8637$

$\operatorname{corr}(x . y)^{2}=0.746$

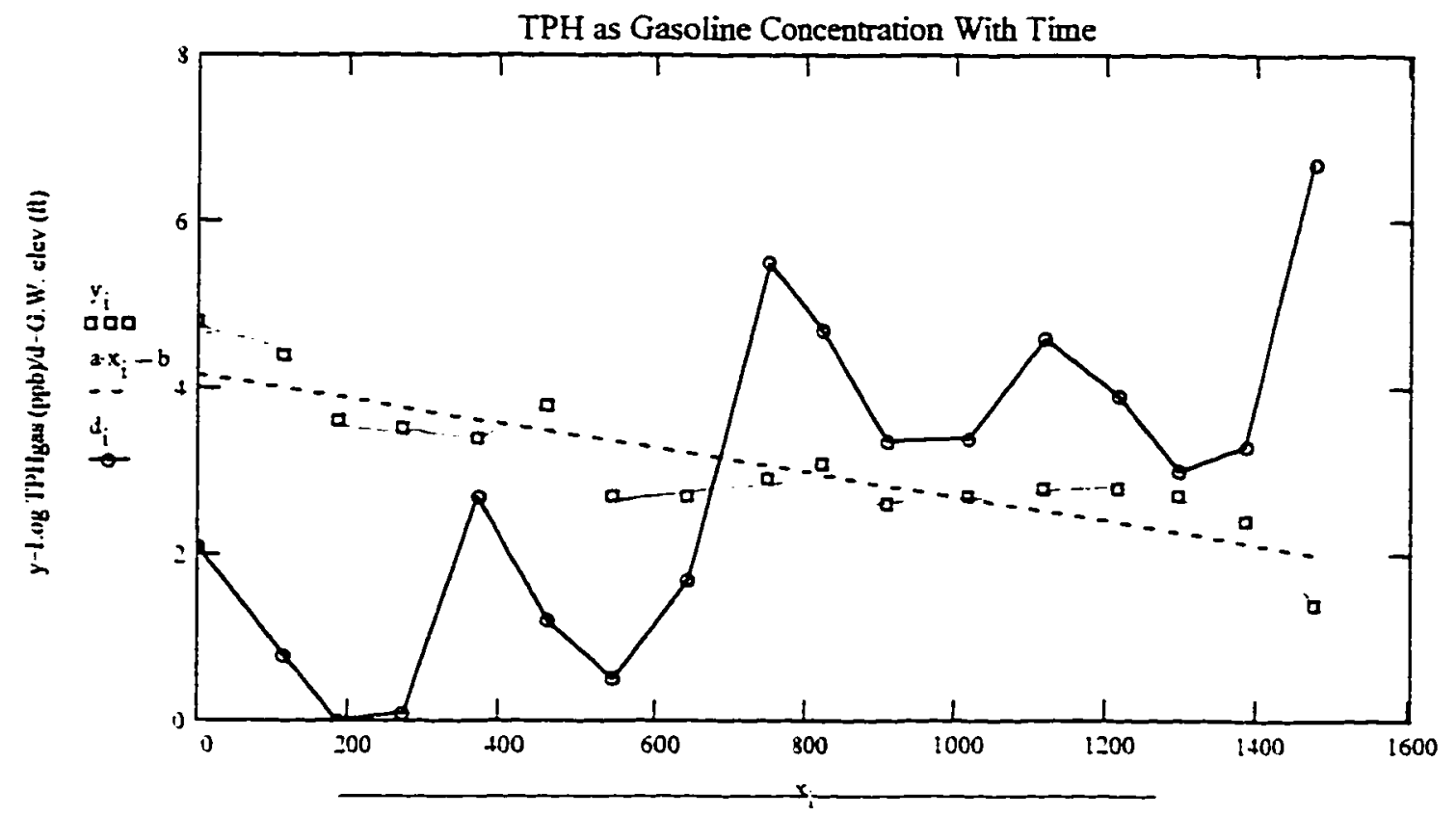


SCWWD Site Number: 06S2W07P01F Site Address: 3401 Alma St

Site Name: Chevron

City: Palo Alto

Contaminant: Benzene - VE-2

$$
i=0 . .9
$$

$\begin{array}{ccc}\text { Days } & \text { LogC } & \begin{array}{c}\text { G.W. } \\ \text { Elev }\end{array} \\ -0 & -3.6 & 1.7^{-} \\ 112 & 3.6 & .4 \\ 274 & 2.0 & .2 \\ 370 & 2.0 & 2.3 \\ 461 & y=1.4 & \mathrm{~d}=.9 \\ 546 & 1.1 & 0 \\ 644 & 0.5 & 1.2 \\ 720 & -0.6 & 5.0 \\ 793 & -0.1 & 4.1 \\ .882 . & -0.6 & .2 .8\end{array}$

Note: Ground water elevations have been adjusted to fit the graph. $O \mathrm{ft}=9.01 \mathrm{ft}$.

Benzene Concentration With Time

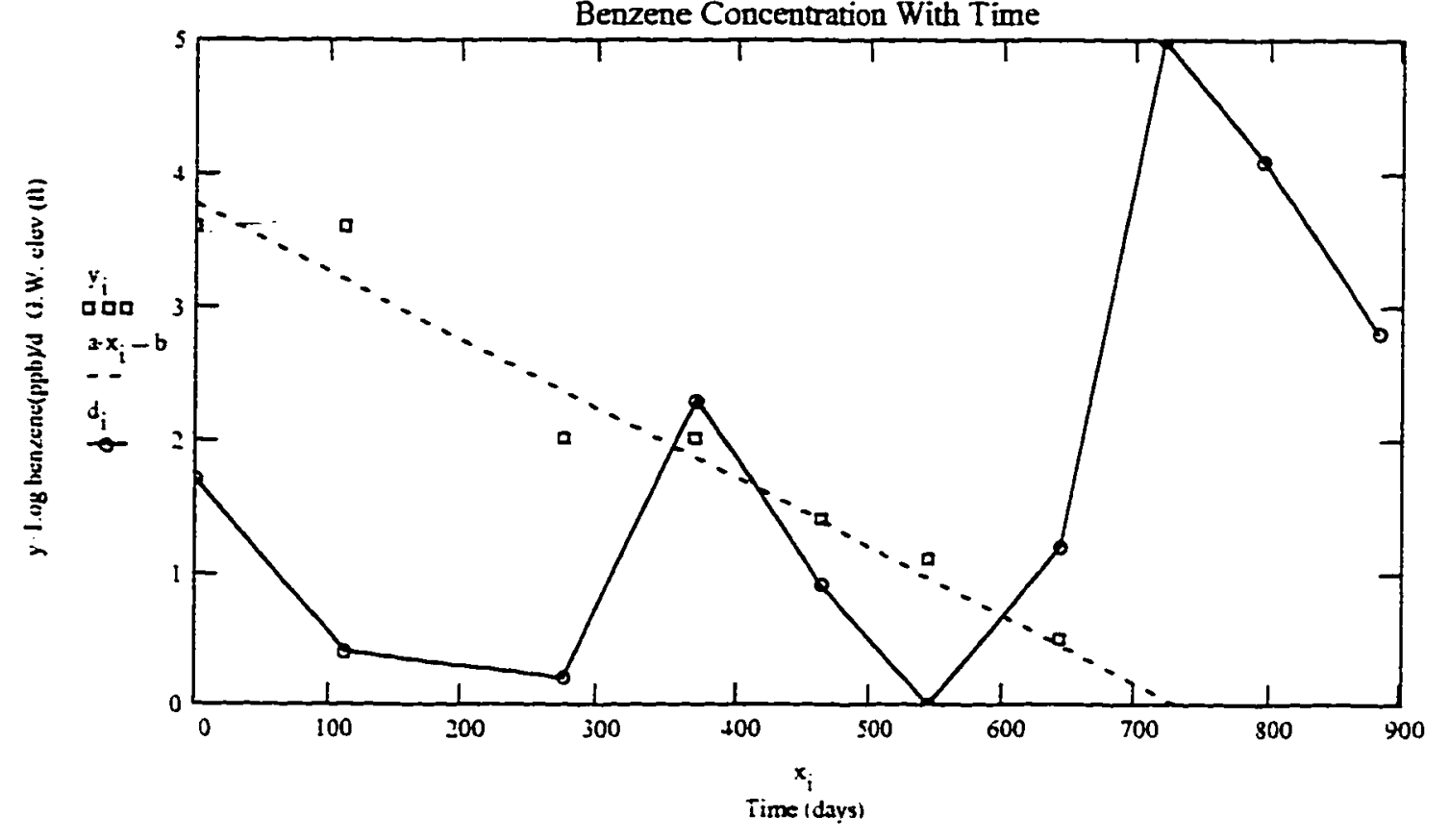




\begin{tabular}{|c|c|c|c|}
\hline $\begin{array}{l}\text { SCVWD Site Number: 06S2W0TP01F } \\
\text { Site Address: } 3401 \text { Alma St }\end{array}$ & Days & $\log C$ & $\begin{array}{l}\text { G.W. } \\
\text { Elev }\end{array}$ \\
\hline \multirow{2}{*}{ City: Palo Alto } & 0 & 5.2 & 1.6 \\
\hline & 625 & 4.7 & 1.7 \\
\hline Contaminant: TPH Gasoline - VE-2 & 737 & 4.6 & .4 \\
\hline \multirow{7}{*}{$i=0 . .16$} & 899 & 3.9 & .2 \\
\hline & 995 & 3.6 & 2.3 \\
\hline & 1086 & 3.1 & .9 \\
\hline & 1171 & 3.4 & 0 \\
\hline & 1269 & 3.3 & 1.2 \\
\hline & $x=1345$ & $y=1.4$ & $d=5.0$ \\
\hline & 1418 & 2.9 & 4.1 \\
\hline \multirow{7}{*}{$\begin{array}{l}a=\operatorname{slope}(x, y) a=-0.0017 \\
b=\operatorname{intercept}(x . y) \quad b=5.2827 \\
\operatorname{com}(x \cdot y)=-0.852 \\
\operatorname{com}(x . y)^{2}=0.7258\end{array}$} & 1507 & 2.2 & 2.8 \\
\hline & 1614 & 2.5 & 2.9 \\
\hline & 1695 & 2.4 & 4.2 \\
\hline & 1795 & 2.7 & 3.4 \\
\hline & 1871 & 2.8 & 2.5 \\
\hline & 1961 & 2.7 & 2.9 \\
\hline & 2053. & 1.4 . & -7.5 \\
\hline
\end{tabular}

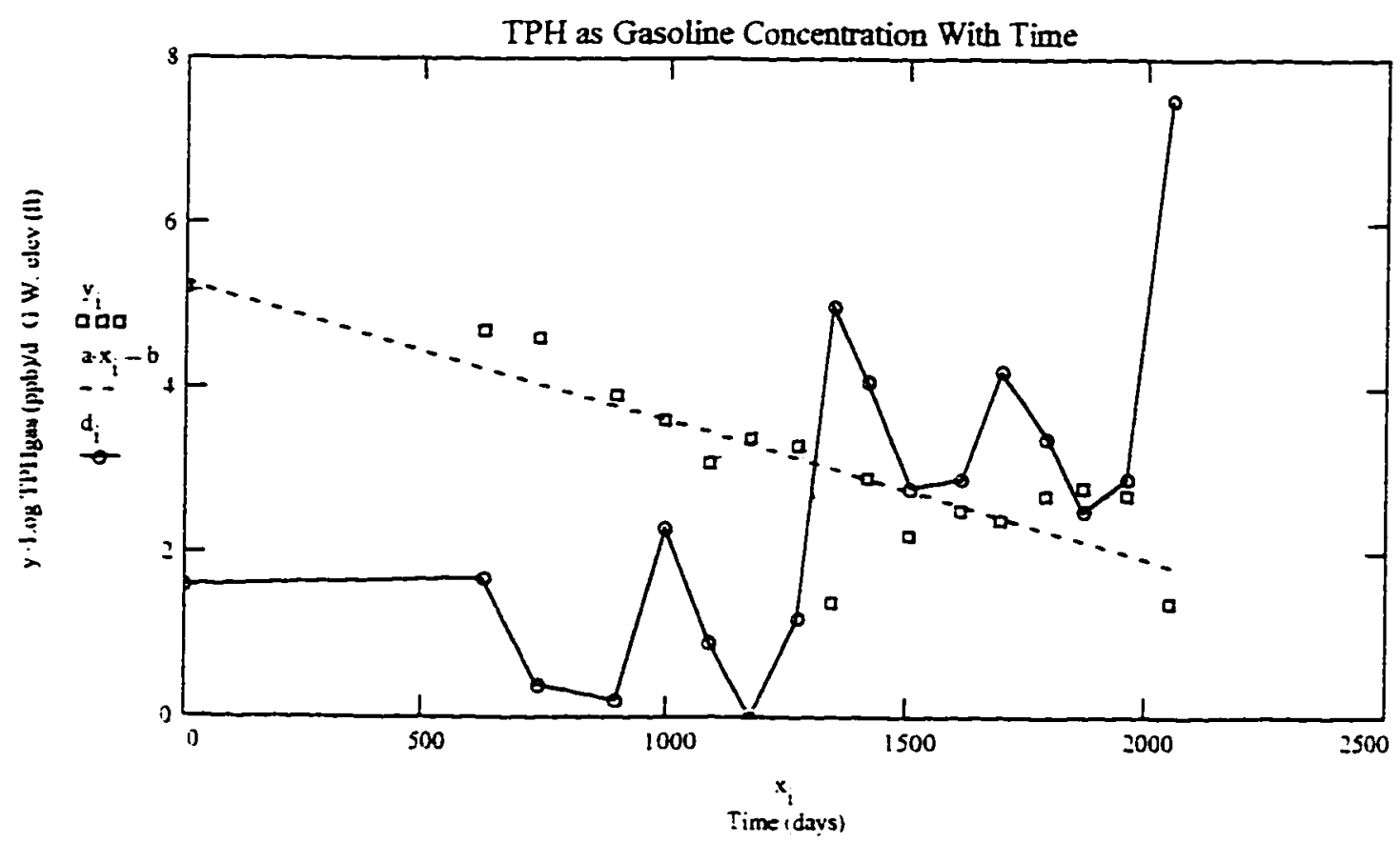

Note: Ground water elevations have been acjusied to it the graoh. $0 \mathrm{ft}=9.01 \mathrm{it}$. 
SCWWD Site Number: 06S2W08Q01F

Site Address: 780 San Antonio Rd.

Site Name: Beacon \#590

City: Palo Alto

$\begin{array}{ccc}\text { Days } & \text { LogC } & \begin{array}{c}\text { G.W. } \\ \text { Elev }\end{array} \\ 0 & -2.9^{-} & 0 \\ 89 & 2.1 & 0.6 \\ 180 & 2.7 & 1.0 \\ \mathrm{x}=306 & \mathrm{y}=2.6 & \mathrm{~d}=0.5 \\ 397 & 1.4 & 0.1 \\ 487 & 1.8 & 0.5 \\ 578 . & -1.4 . & -1.3 .\end{array}$

$a=\operatorname{slope}(x, y) \quad a=-0.0023$

$b=$ intercept $(x . y) b=2.8029$

$\operatorname{corr}(x, y)=-0.7916$

Note: Ground water elevations have been adjusted to fit the graph. $0 \mathrm{ft}=6.92 \mathrm{ft}$.

$\operatorname{corr}(x . y)^{2}=0.6266$

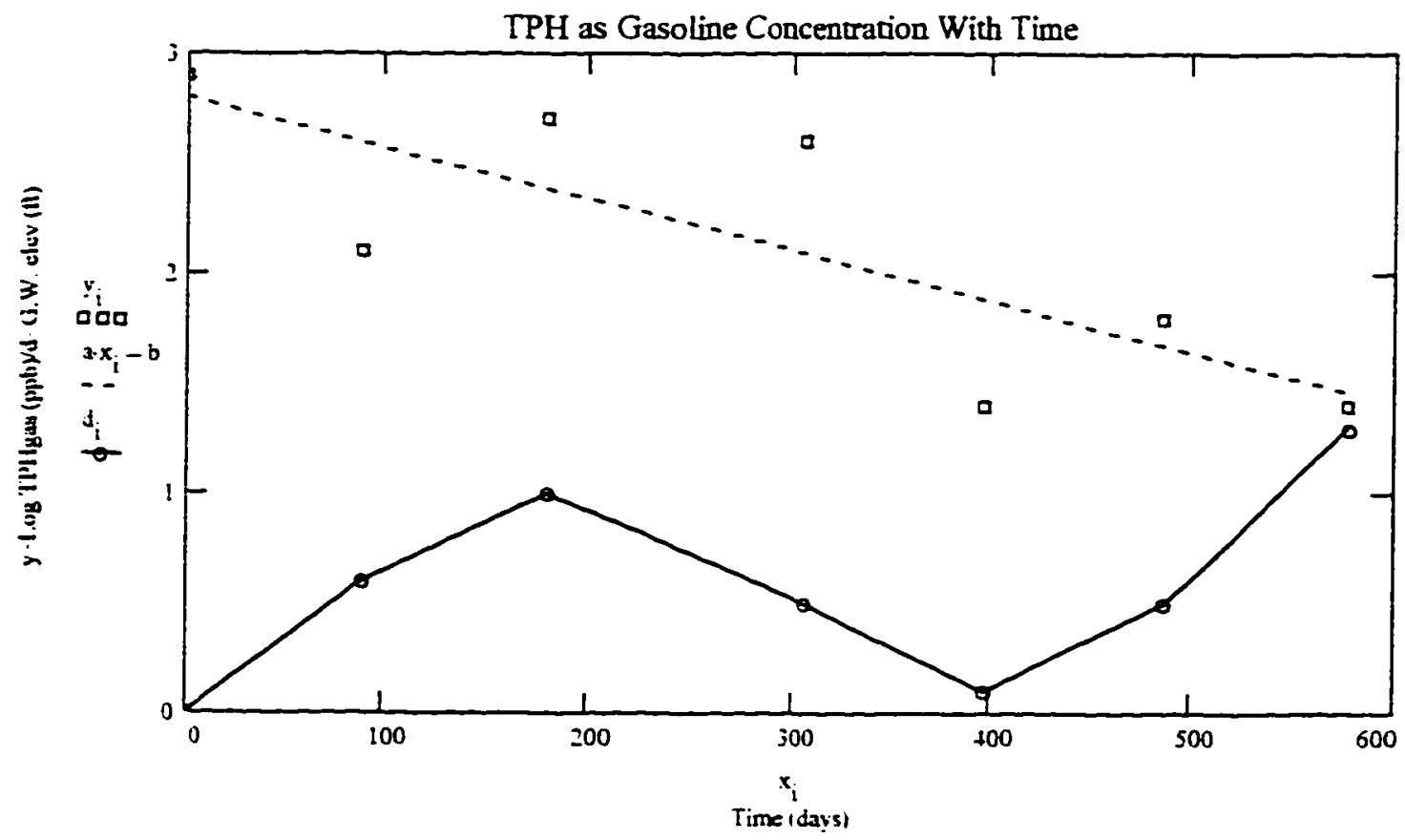


SCWwD Site Number: 06S2W08Q01F Site Address: 780 San Antonio Rd.

Site Name: Beacon \#590

City: Palo Alto

\section{Contaminant: Benzene}

$$
i=0 . .7
$$

$\begin{array}{ccc}\text { Days } & \text { LogC } & \begin{array}{c}\text { G.W. } \\ \text { Elev }\end{array} \\ 0 & 1.2 & 0 \\ 89 & 0.7 & 0.6 \\ 180 & 0.9 & 1.0 \\ 306 & \mathrm{y}=1.3 & \mathrm{~d}=.05 \\ 397 & -0.6 & 0.1 \\ 487 & 0.5 & 0.5 \\ 578 & -0.3 & 1.3 \\ .669 & -0.6 & 0.8\end{array}$

Note: Ground water slevarions have been adjusted to fit the graph. O $\mathrm{ft}=$ it.

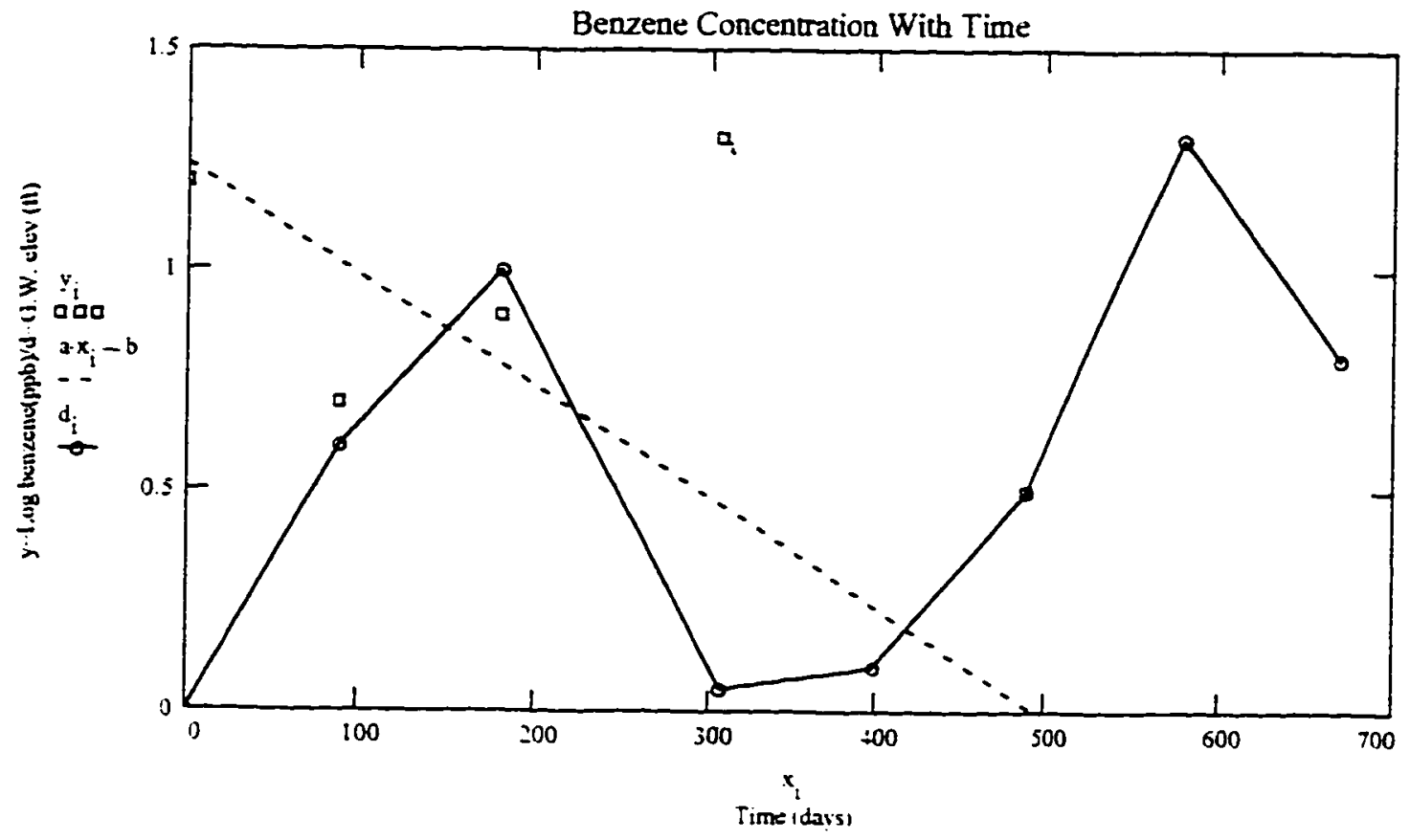


SCWWD Site Number: 06S2W18C01F Site Address: 4073 El Camino Real Site Name: Beacon \#463

City: Palo Alto

$\begin{array}{ccc}\text { Days } & \text { LogC } & \text { G.W. } \\ -0.1 e v \\ 0 & 4.5 & 3.6 \\ 74 & 4.3 & 3.7 \\ 507 & 1.4 & 1.7 \\ 598 & 3.6 & 2.0 \\ 694 & \mathrm{y}=3.9 & \mathrm{~d}=1.9 \\ 790 & 3.2 & 1.8 \\ 882 & 2.9 & 2.7 \\ 917 & 2.6 & 2.6 \\ 1007 & 2.7 & 1.3 \\ 1101 & .2 .7 & -0\end{array}$

$a=\operatorname{slope}(x . y) \quad a=-0.0015$

$b=\operatorname{intercept}(x, y) b=4.1456$

Note: Ground water elevations have been adjusted to $\operatorname{corr}(x, y)=-0.5918$ fit the graph. $0 \mathrm{ft}=14.4 \mathrm{ft} / 2$

$\operatorname{corr}(x . y)^{2}=0.3502$

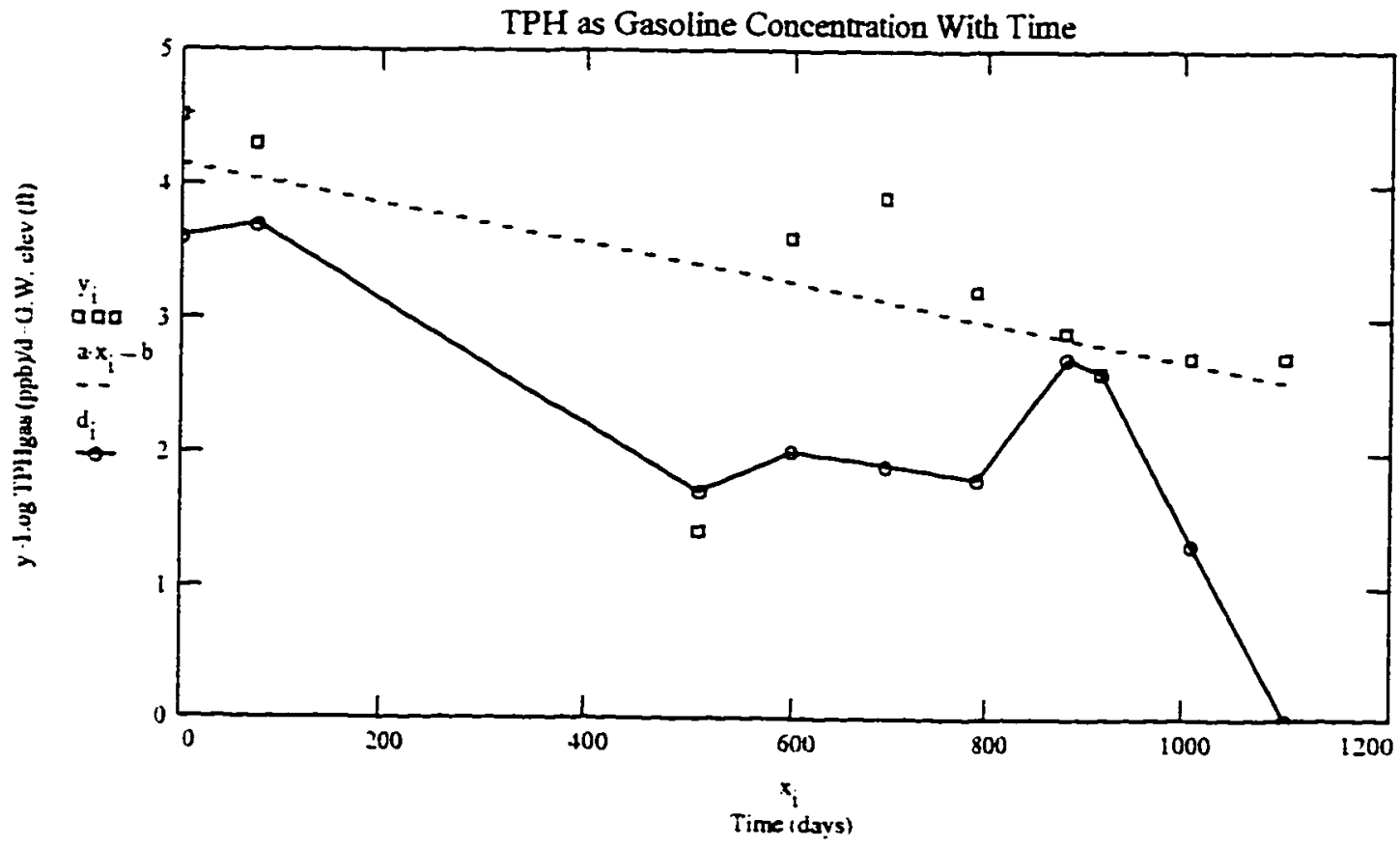


SCWWD Site Number: 06S2W18D01F Days Site Address: 3972 El Camino Real Site Name:Chevron \#3173 City: Palo Alto

0
374

499

Contaminant: TPH Gasoline

$$
i=0 . .29
$$

\begin{tabular}{cc} 
LogC & G.W. \\
Elev \\
4.8 & - \\
4.3 & 0 \\
4.1 & 0 \\
3.8 & 0 \\
3.6 & 3.1 \\
3.9 & 3.1 \\
3.8 & 3.5 \\
3.7 & 3.7 \\
3.5 & 3.8 \\
3.5 & 3.6 \\
3.7 & 4.0 \\
3.7 & 4.4 \\
3.3 & 4.5 \\
3.5 & 4.3 \\
3.6 & 4.1 \\
4.0 & $\mathrm{~d}=4.6$ \\
3.4 & 4.6 \\
3.5 & 3.4 \\
3.5 & 3.9 \\
3.4 & 4.1 \\
3.5 & 1.7 \\
3.6 & 1.4 \\
3.0 & 1.9 \\
3.9 & 2.3 \\
3.4 & 1.8 \\
3.1 & 1.7 \\
3.2 & 2.6 \\
4.0 & 2.6 \\
3.9 & 0 \\
4.2. & 0 \\
& .3 \\
\hline &
\end{tabular}

$a=\operatorname{slope}(x . y) \quad a=-1.8519 \cdot 10^{-4}$

2111

$b=$ intercept $(x, y) b=3.9851$

2201

2278

2383

2479

2572

2668

2760

2848

2922

3013 .

$10 / 6 / 96$
G.W.

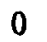

0

0

1

3.5

3.7

3.8

3.6

4.0

4.4

4.5

4.1

4.1 4.6

3.4

3.9

4.1

1.7

1.4

1.9

2.3

1.8

1.7

2.6

2.6

0

3 . 


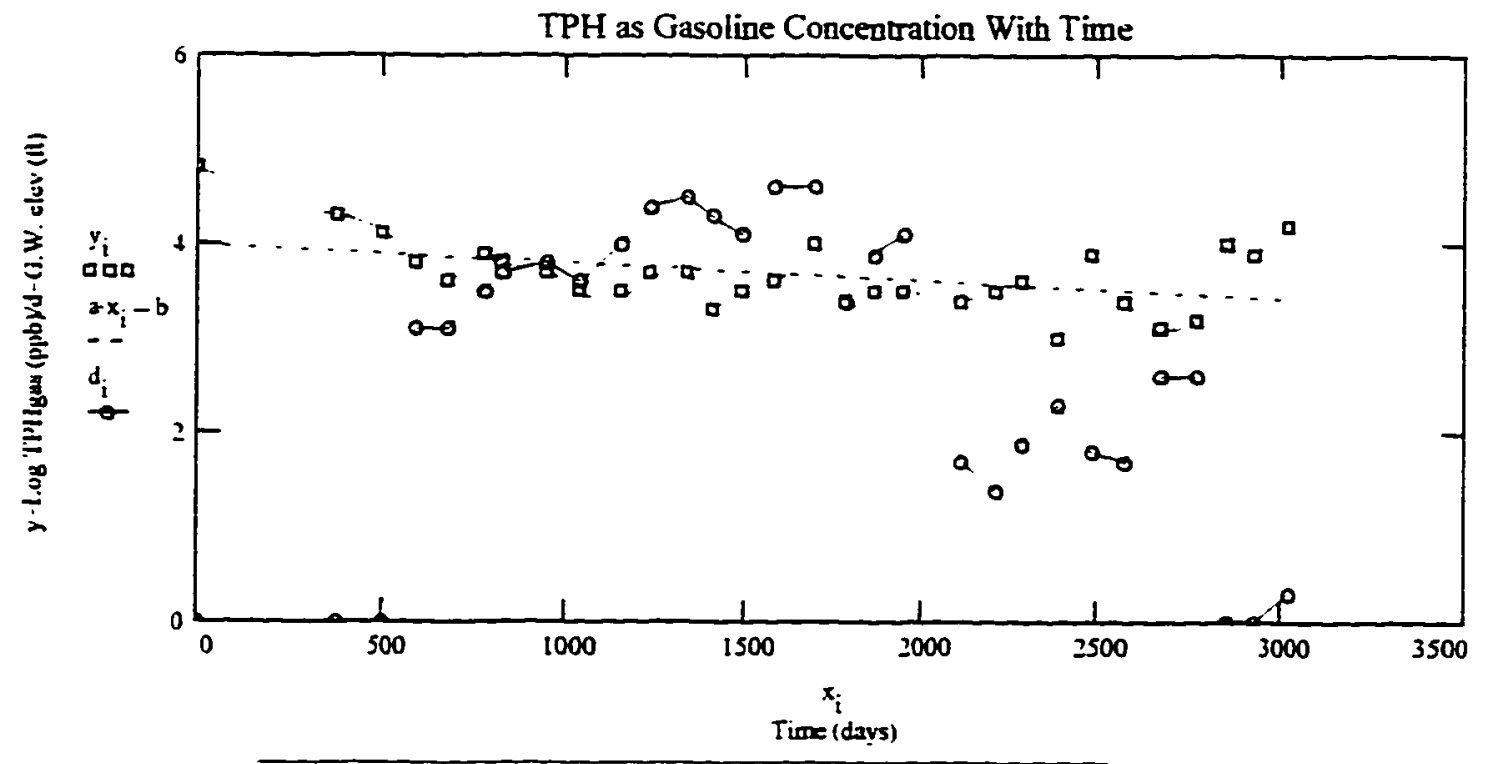

Note: Ground water elevations have been adjusted to fit the graph. $O \mathrm{~A}=14.7 \mathrm{f} / 2$ 


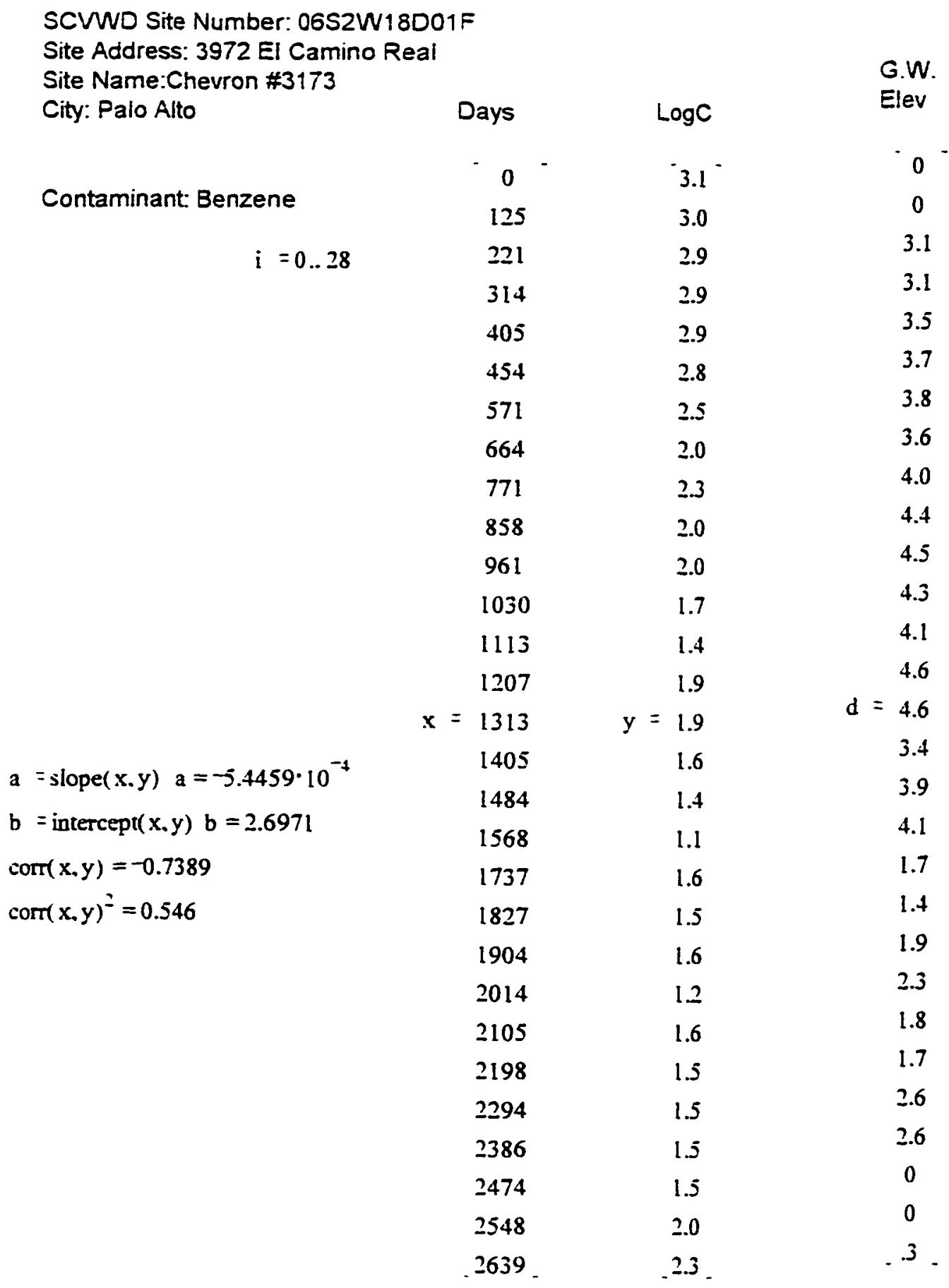




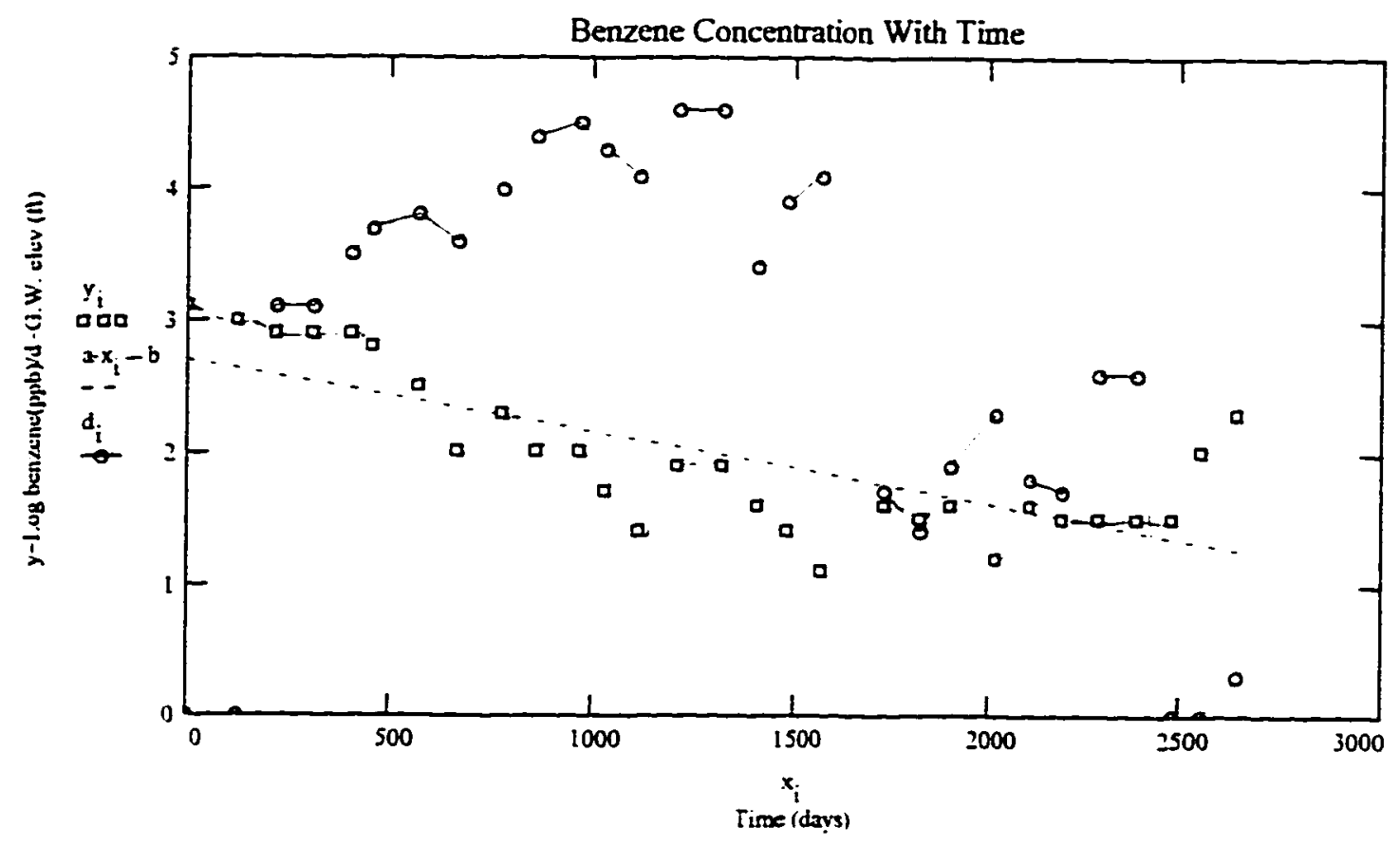

Note: Ground water elevations have been adjusted to it the graph. $O \mathrm{ft}=14.7 \mathrm{ft} / 2$. 
SCWWD Site Number: 0751W03G04

Site Address: 1995 Warburton Ave

Site Name: Arco \#2082

City: Santa Clara

Contaminant: TPH Gasoline. A-1

$\begin{array}{crc}\text { Days } & \text { LogC } & \begin{array}{c}\text { G.W. } \\ \text { Elev }\end{array} \\ 0 & 4.0 & 0 \\ 90 & 3.3 & 3.7 \\ 175 & \mathrm{y}=3.1 & \mathrm{~d}=5.0 \\ 274 & 2.2 & 4.2 \\ .374 & .2 .6 & 4.5 .\end{array}$

$\mathrm{a}=\operatorname{slope}(x . y) \quad a=-0.0041$

$b=\operatorname{intercept}(x . y) b=3.7976$

$\operatorname{cort}(x . y)=-0.8895$

Note: Ground water elevations have been adjusted to fit the graph. $0 \mathrm{ft}=49.15 \mathrm{ft}$.

$\operatorname{corr}(x . y)^{2}=0.7913$

TPH as Gasoline Concentration With Time

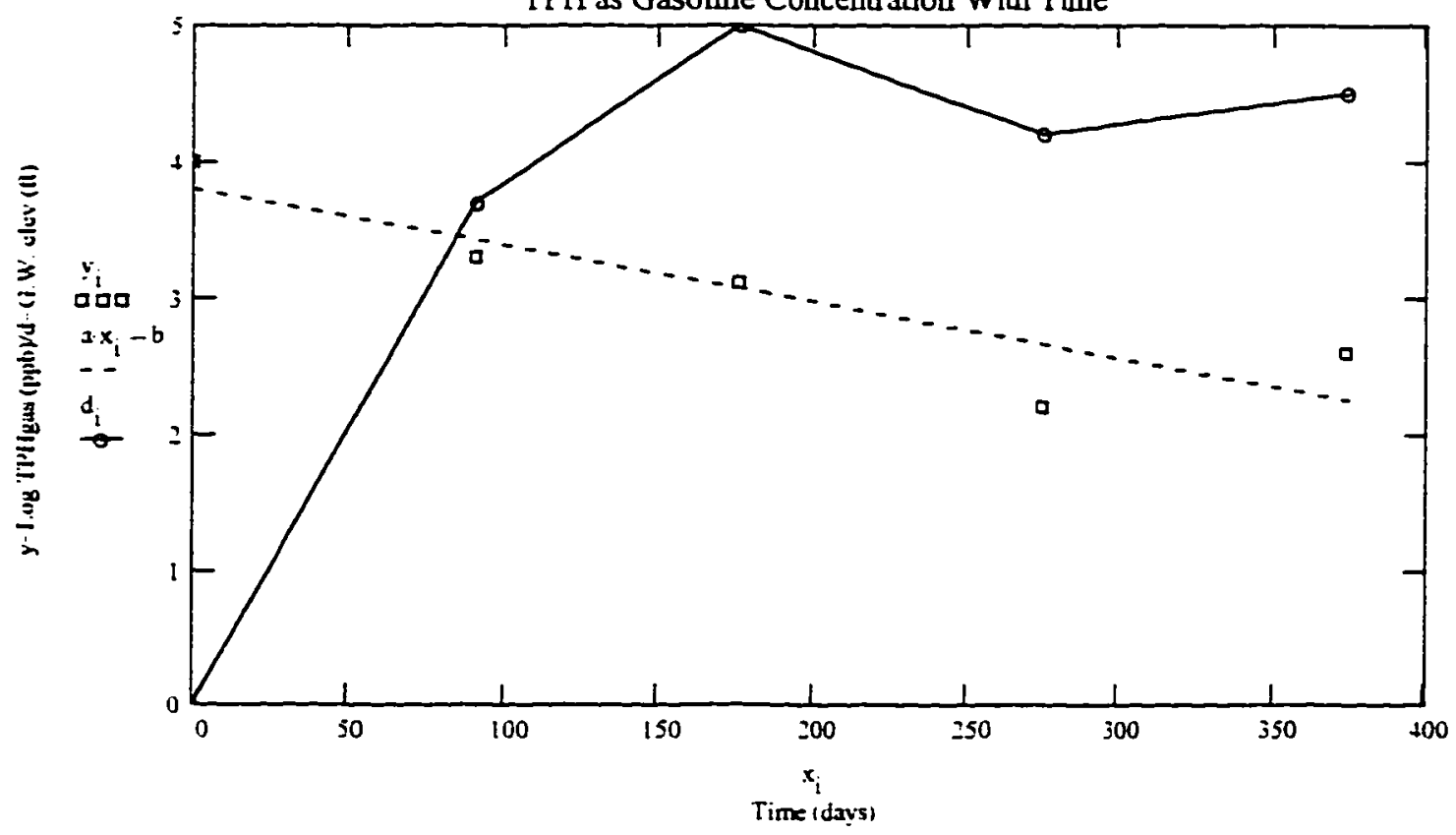


SCVWD Site Number: 0751W03G04 Site Address: 1995 Warburton Ave Site Name: Arco \#2082

City: Santa Clara

Contaminant: Benzene, 4 - 1

$$
i=0 . .4
$$

$\begin{array}{lll} & \text { G.W. } \\ \text { Days } & \text { LogC } & \text { Elev }\end{array}$

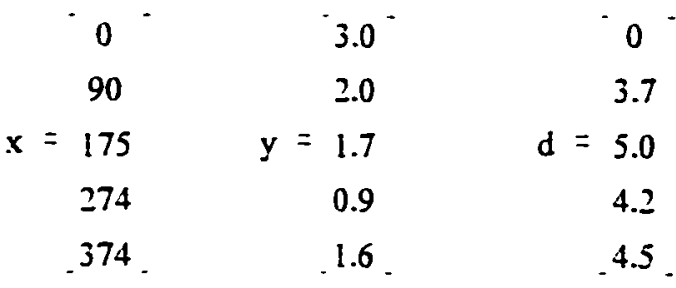

$$
\begin{aligned}
& a=\operatorname{slope}(x . y) \quad a=-0.0041 \\
& b=\operatorname{intercept}(x . y) \quad b=2.5905 \\
& \operatorname{corr}(x . y)=-0.7937 \\
& \operatorname{corr}(x . y)^{2}=0.6299
\end{aligned}
$$

Note: Ground water elevations have been adjusted to fit the graph. $O \mathrm{ft}=49.15 \mathrm{ft}$.

Benzene Concentration With Time

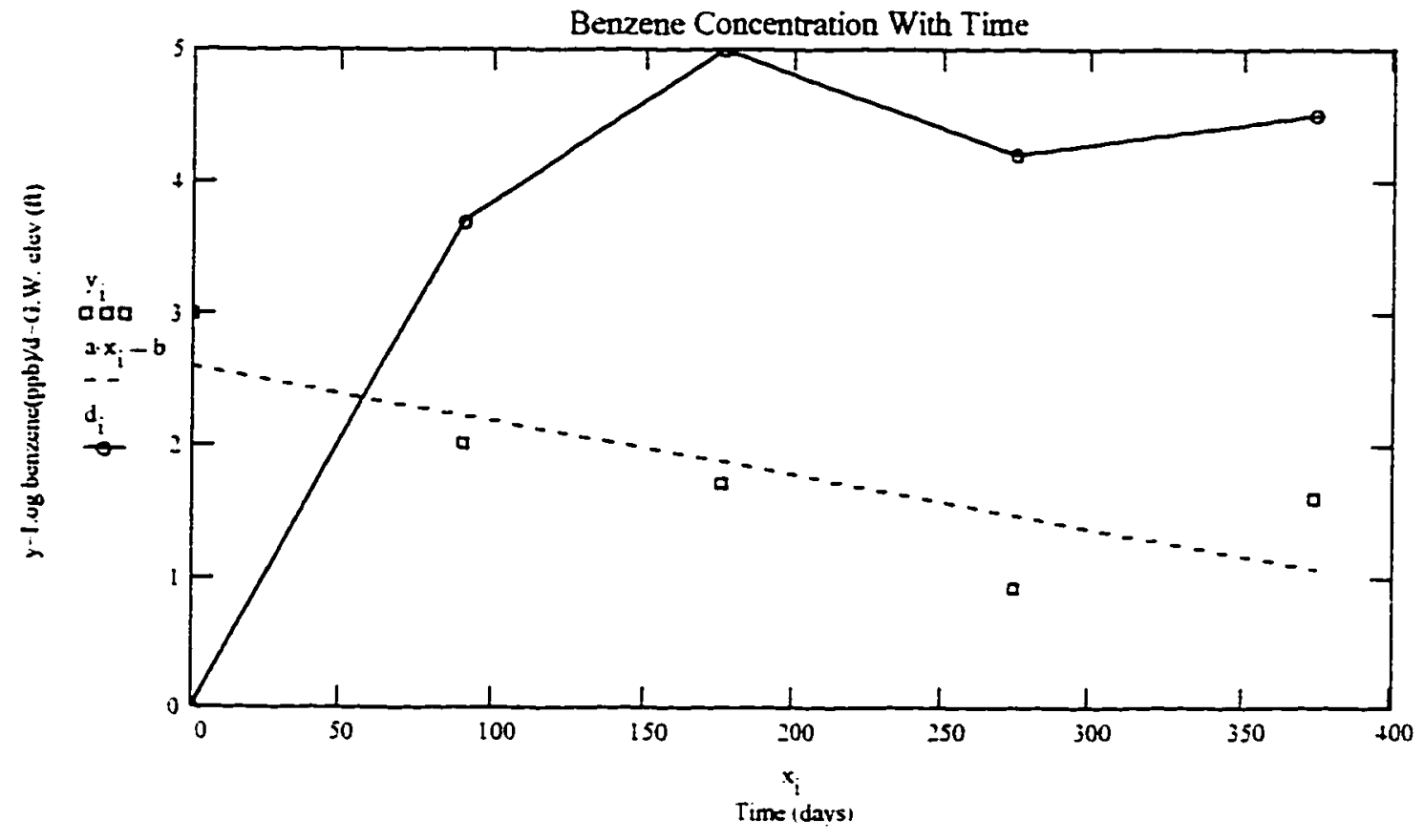


SCVND Site Number: 07S1W03G04

Site Address: 1995 Warburton Ave

Site Name: Arco \#2082

City: Santa Clara

Contaminant: Benzene. A-2

$$
i=0.11
$$

$a=\operatorname{slope}(x, y) \quad a=-0.0016$

$b=$ intercept $(x . y) \quad b=2.3363$

$\operatorname{cotr}(x . y)=-0.8456$

$\operatorname{corr}(x . y)^{2}=0.715$

$\begin{array}{ccc}\text { Days } & \text { LogC } & \begin{array}{c}\text { G.W. } \\ \text { Elev }\end{array} \\ 0 & 2.6 & 0 \\ 88 & 2.2 & 0 \\ 257 & 1.9 & 5.5 \\ 389 & 1.7 & 5.0 \\ 444 & 1.0 & 5.0 \\ 560 & \mathrm{y}=1.1 & 6.7 \\ 578 & 1.4 & 6.8 \\ 672 & 1.6 & 0 \\ 866 & 1.8 & 9.3 \\ 951 & 0.8 & 10.1 \\ 1050 & .0 .3 & 9.4 \\ 1150 & .0 .4 & 9.7\end{array}$

Note: Ground water elevations have been adjusted to fit the graph. $0 \mathrm{ft}=44.0 \mathrm{ft}$. No elevation data was available for the eigth date. so 0 was input.

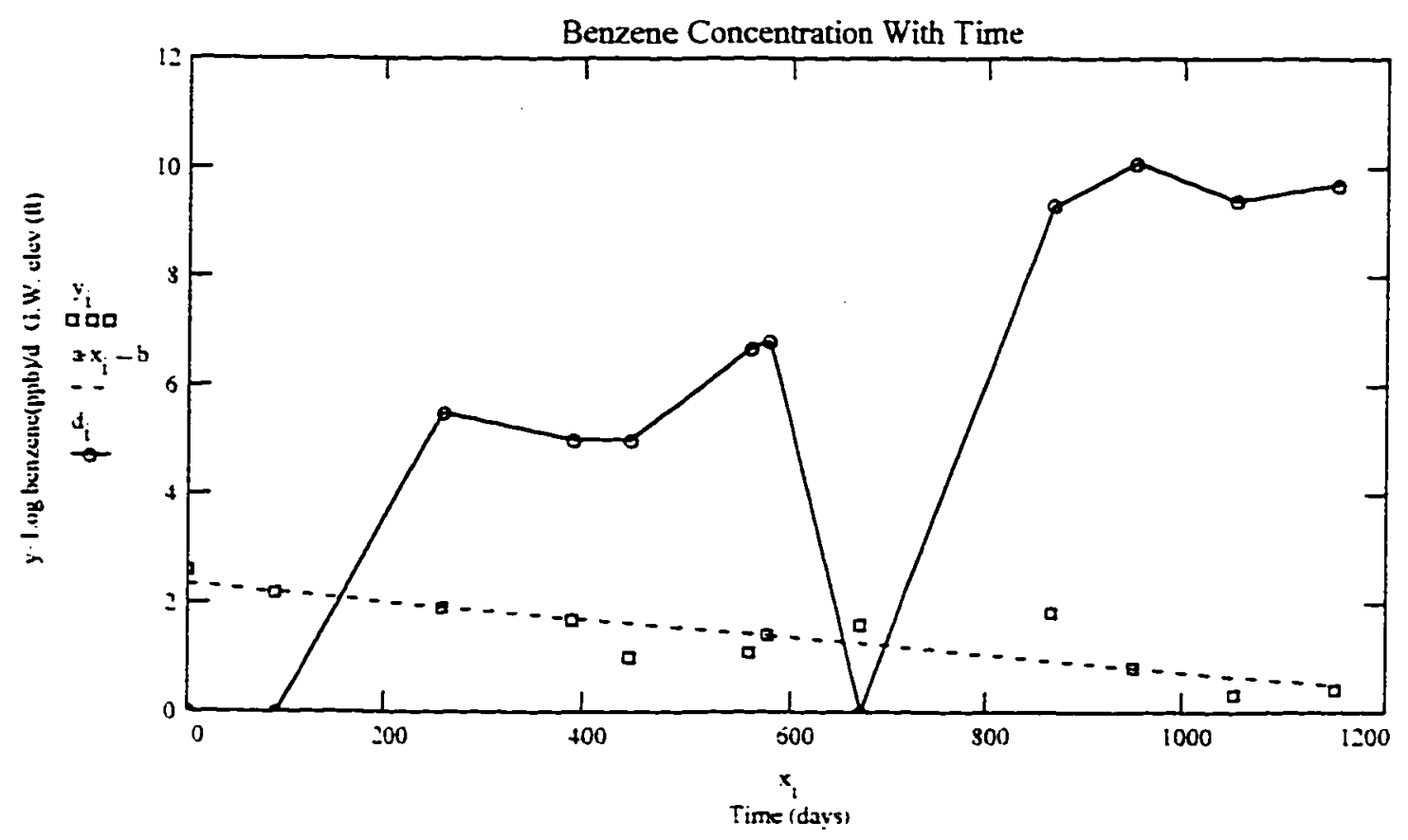


SCWWD Site Number: 0751W03G04

Site Address: 1995 Warburton Ave

Site Name: Arco \#2082

City: Santa Clara

Contaminant: TPH Gasoline. A-2

$$
i=0 . .11
$$

$a=\operatorname{slope}(x, y) \quad a=-0.0014$

$b=$ intercept( $x . y) b=4.3946$

$\operatorname{com}(x, y)=-0.851$

$\operatorname{corr}(x . y)^{2}=0.7242$

\begin{tabular}{|c|c|c|}
\hline Days & $\log C$ & $\begin{array}{l}\text { G.W. } \\
\text { Elev }\end{array}$ \\
\hline-0 & $4.4^{\circ}$ & 0 \\
\hline 88 & 4.2 & 0 \\
\hline 257 & 4.1 & 5.5 \\
\hline 389 & 4.0 & 5.0 \\
\hline 444 & 3.5 & 5.0 \\
\hline 560 & $y=3.2$ & 6.7 \\
\hline 578 & 3.6 & 6.8 \\
\hline 672 & 3.8 & 0 \\
\hline 866 & 3.9 & 9.3 \\
\hline 951 & 3.2 & 10.1 \\
\hline 1050 & 2.8 & 9.4 \\
\hline .1150 & .2 .4 & .9 .7 \\
\hline
\end{tabular}

Note: Ground water elevations have been adjusted to iit the graph. O ft $=44.0 \mathrm{ft}$. No elevation data was avallable for the eigth date. so 0 was input.

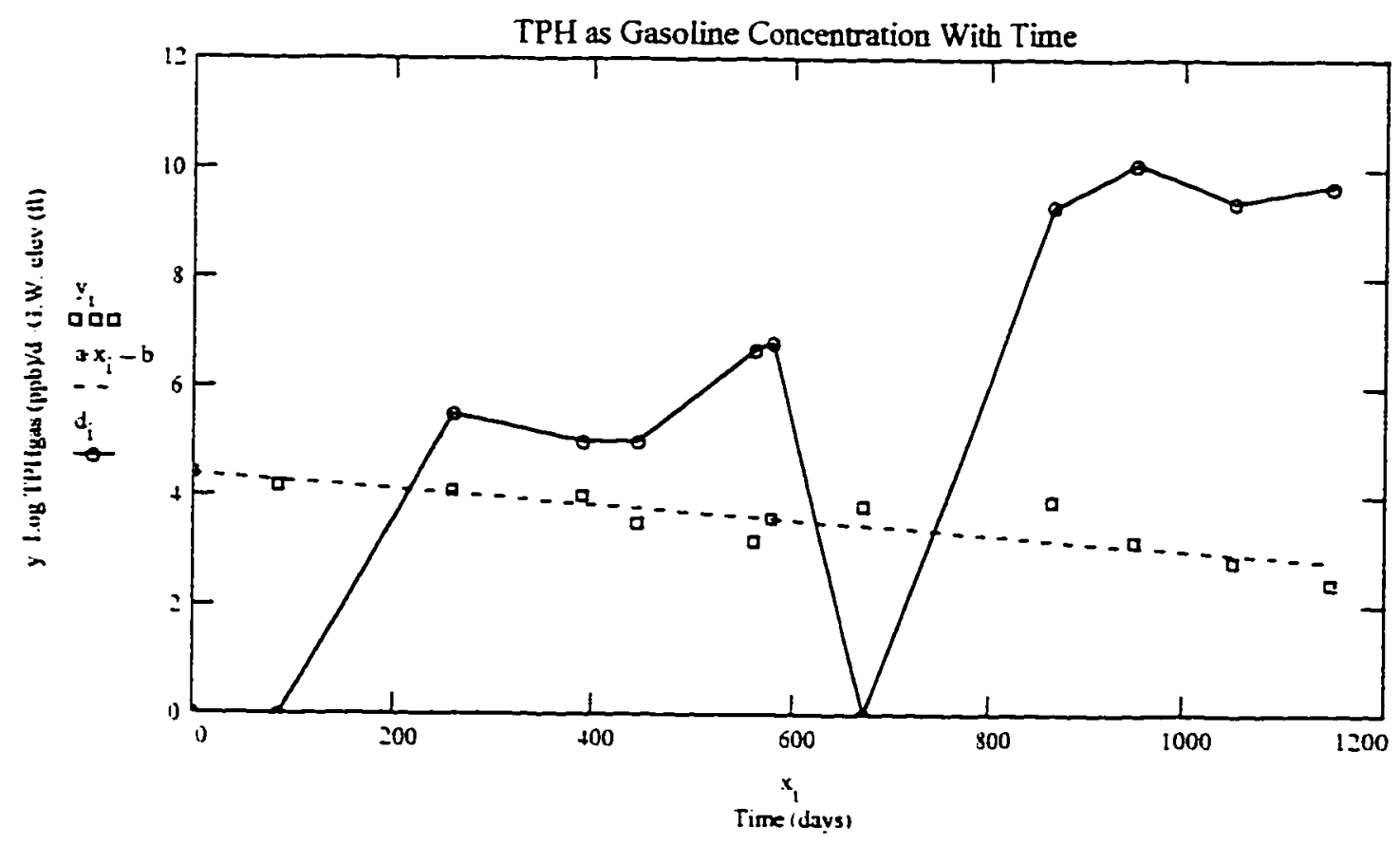


SCWWD Site Number: 0751W03M01F Site Address: 2320 El Camino Real Site Name: Arco \#0606

City: Santa Clara

Contaminant: TPH Gasoline

$$
i=0 . .8
$$

$\begin{array}{ccc}\text { Days } & \log C & \begin{array}{c}\text { G.W. } \\ \text { Elev }\end{array} \\ 0 & -3.9^{-} & -0^{-} \\ 128 & 3.6 & 0 \\ 201 & 3.7 & 1.8 \\ 295 & 3.6 & 1.3 \\ 399 & y=3.2 & \mathrm{~d}=.8 \\ 502 & 2.5 & 7.2 \\ 594 & 2.4 & 6.3 \\ 682 & 2.1 & 5.7 \\ 768 & -1.8 & 5.2 .\end{array}$

\footnotetext{
$a=\operatorname{slope}(x, y) \quad a=-0.0029$

$b=$ intercept $(x . y) \quad b=4.1288$

$\operatorname{corr}(x, y)=-0.9687$

$\operatorname{corr}(x . y)^{2}=0.9384$
}

Note: Ground water elevations have been adjusted to fit the graph. $0 \mathrm{ft}=53.55 \mathrm{ft}$. No elevation data was availabie for the second data point. so 0 was input.

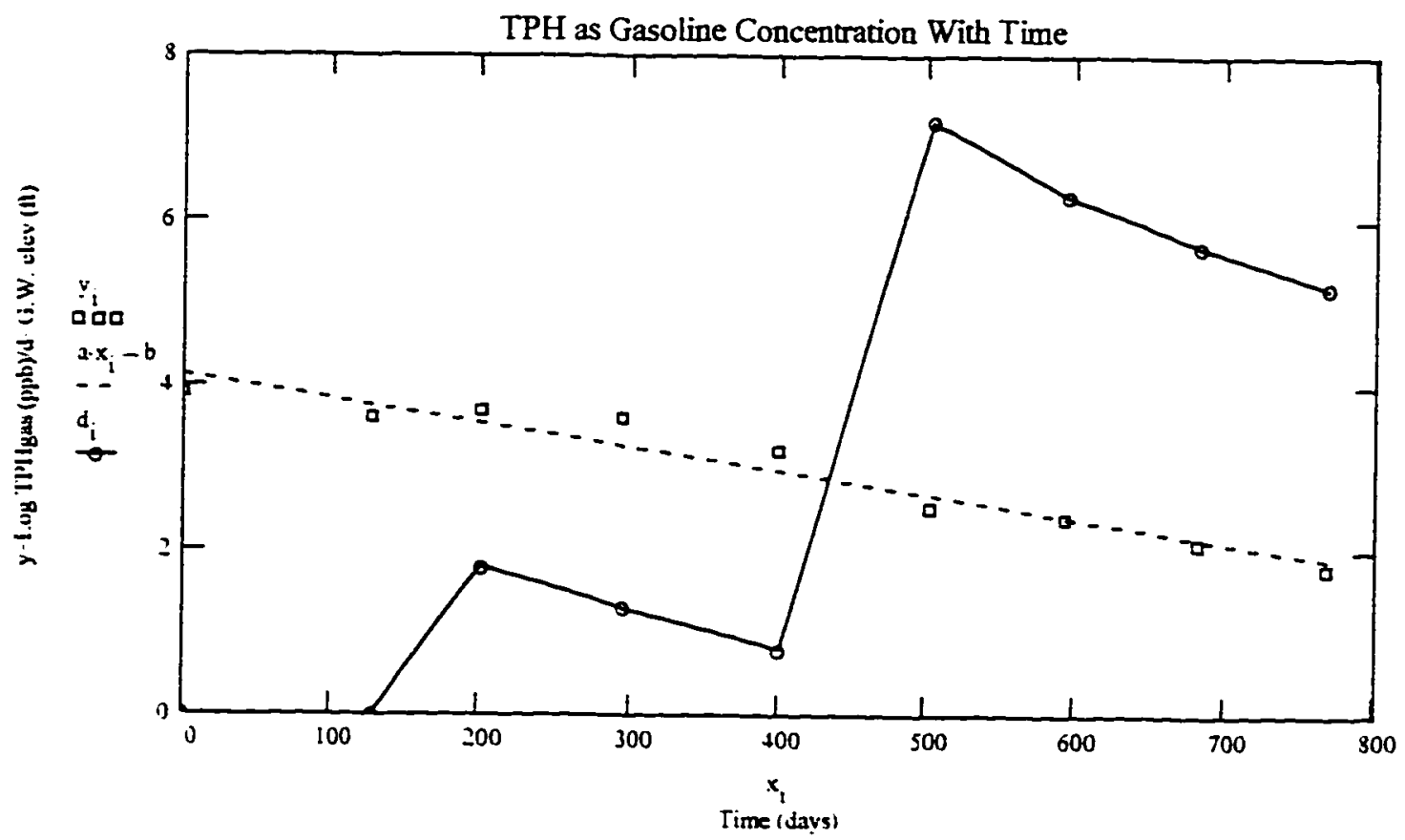


SCVND Site Number: 07S1W03M01F Site Address: 2320 El Camino Real Site Name: Arco $\# 0606$

City: Santa Clara

Contaminant: Benzene

$$
\mathrm{i}=0 . .9
$$

$\begin{array}{ccc}\text { Days } & \text { LogC } & \begin{array}{c}\text { G.W } \\ \text { Elev }\end{array} \\ 0 & -1.5 & 0.1 \\ 35 & 1.4 & 0 \\ 163 & 1.0 & 0 \\ 236 & 0.9 & 1.8 \\ \mathrm{x}= & 0.6 & \mathrm{~d}=1.3 \\ 430 & \mathrm{y}=.3 & 0.8 \\ 537 & -0.2 & 7.2 \\ 629 & 0.4 & 6.3 \\ 717 & -0.1 & 5.7 \\ 803 & -0.6 & 5.2\end{array}$

$a=\operatorname{slope}(x . y) \quad a=-0.0023$

$b=\operatorname{intercept}(x . y) \quad b=1.4305$

$\operatorname{corr}(x . y)=-0.952$

$\operatorname{corr}(x, y)^{2}=0.9063$

Note: Ground water elevations have been adjusted to fit the graph. $O f t=53.55 \mathrm{ft}$. There was no elevation data for the third date so 0 was input.

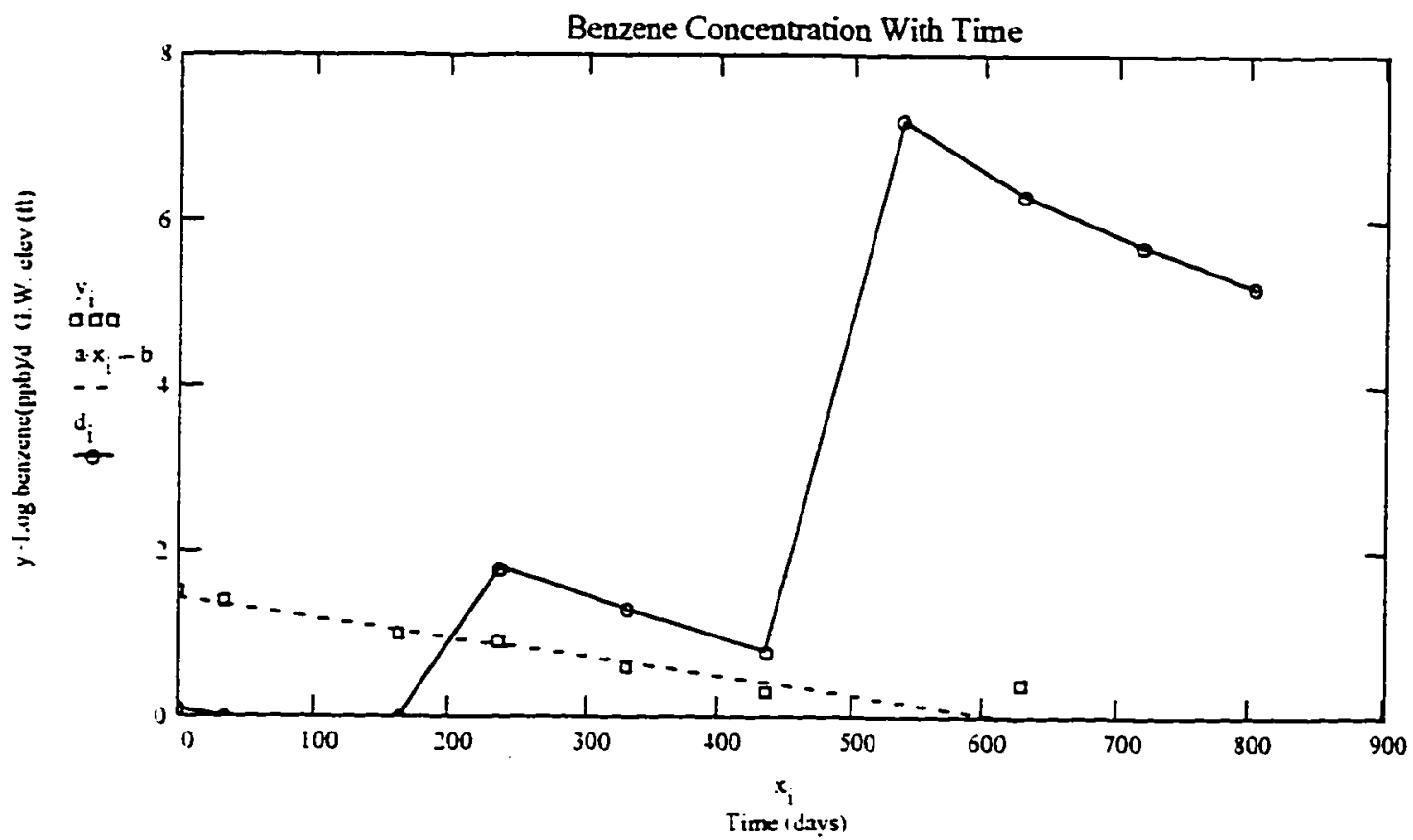


SCVWD Site Number: 07S1W09G02F Site Address: 2800 Homestead

Site Name: Arco \#2153

City: Santa Clara

\begin{tabular}{|c|c|c|}
\hline Days & $\log C$ & $\begin{array}{l}\text { G.W } \\
\text { Elev }\end{array}$ \\
\hline 0 & $4.0^{\circ}$ & 0.2 \\
\hline 68 & 3.9 & 0 \\
\hline 186 & 2.8 & 0 \\
\hline 282 & 3.2 & 1.5 \\
\hline$x=358$ & $y=3.3$ & $d=0.8$ \\
\hline 458 & 3.5 & 0.4 \\
\hline 555 & 3.1 & 4.5 \\
\hline 651 & 3.3 & 6.6 \\
\hline 724 & 3.2 & 6.0 \\
\hline .820 & 2.2 & .4 .7 \\
\hline $\begin{array}{ll}\cdot & \\
. & \end{array}$ & $\because$ & $\begin{array}{c} \\
\therefore \quad: \\
\therefore \quad\end{array}$ \\
\hline
\end{tabular}

$a=\operatorname{slope}(x . y) \quad a=-0.0012$

$b=$ intercept $(x, y) \quad b=3.7575$

$\operatorname{corr}(x, y)=-0.6715$

$\operatorname{cor}(x . y)^{=}=0.4509$

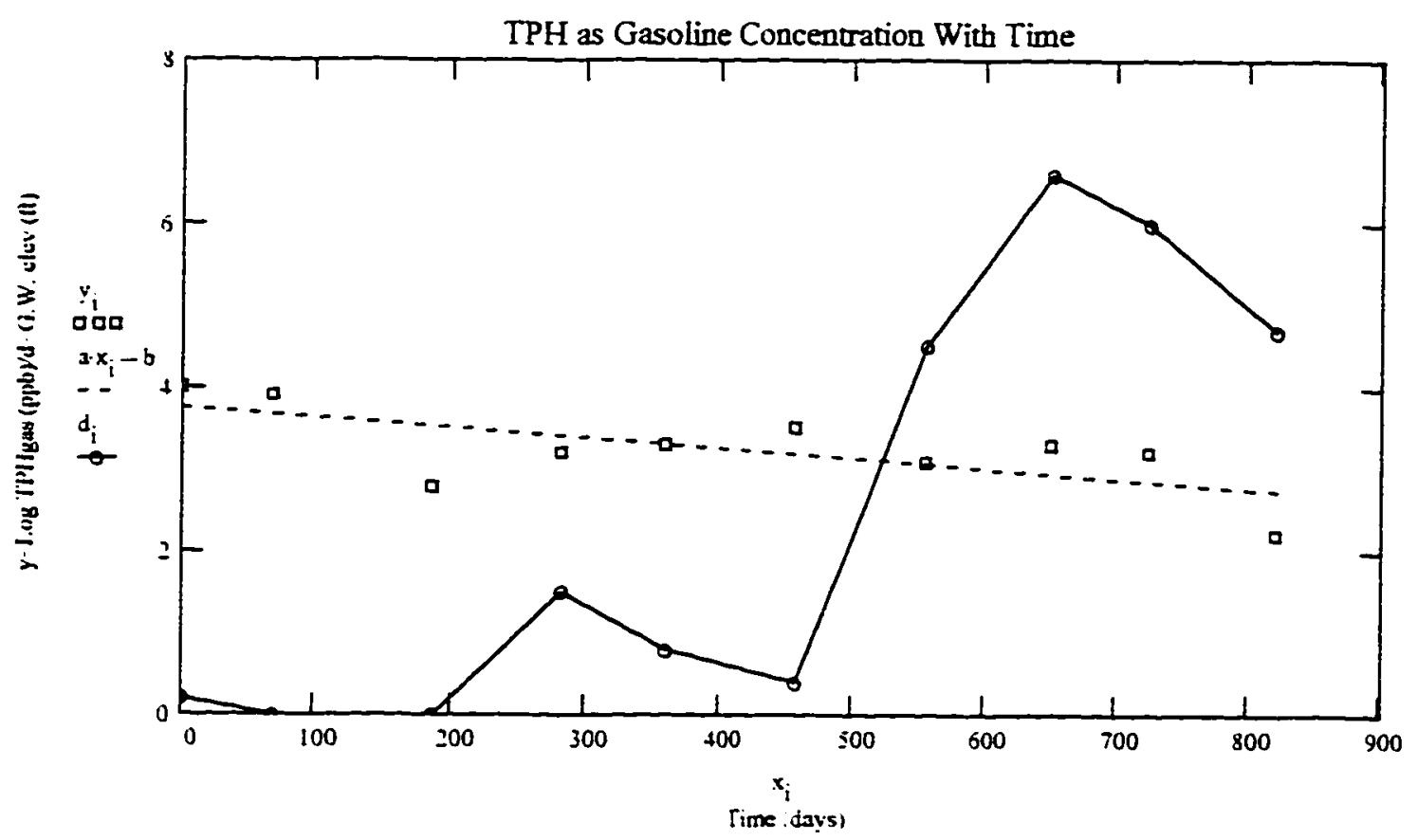


SCVWD Site Number: 07S1W09G02F

Site Address: 2800 Homestead

Site Name: Arco \#2153

City: Santa Clara

Contaminant: Benzene

$$
i=0 . .9
$$

Days

0

68

186

282

$x=\begin{aligned} & 358 \\ & 458\end{aligned}$

555

651

724

820 $\log C$

2.8

2.7

1.0

1.8

$y=\begin{aligned} & 2.0 \\ & 1.8\end{aligned}$

0.7

1.0

0.7

-0.6 .
G.W.

Elev<smiles></smiles>

0

0

1.5

$d=\begin{aligned} & 0.8 \\ & 0.4\end{aligned}$

4.5

6.6

6.0

4.7 .

$a=\operatorname{slope}(x . y) \quad a=-0.0032$

$b=$ intercept( $x . y) \quad b=2.6922$

$\operatorname{corr}(x . y)=-0.8574$

$\operatorname{corr}(x, y)^{2}=0.7352$

Note: Ground water elevations have been adjusted to fit the graph. $0 \mathrm{ft}=64.97 \mathrm{ft}$. There was no elevation data for the third date. so 0 was input.

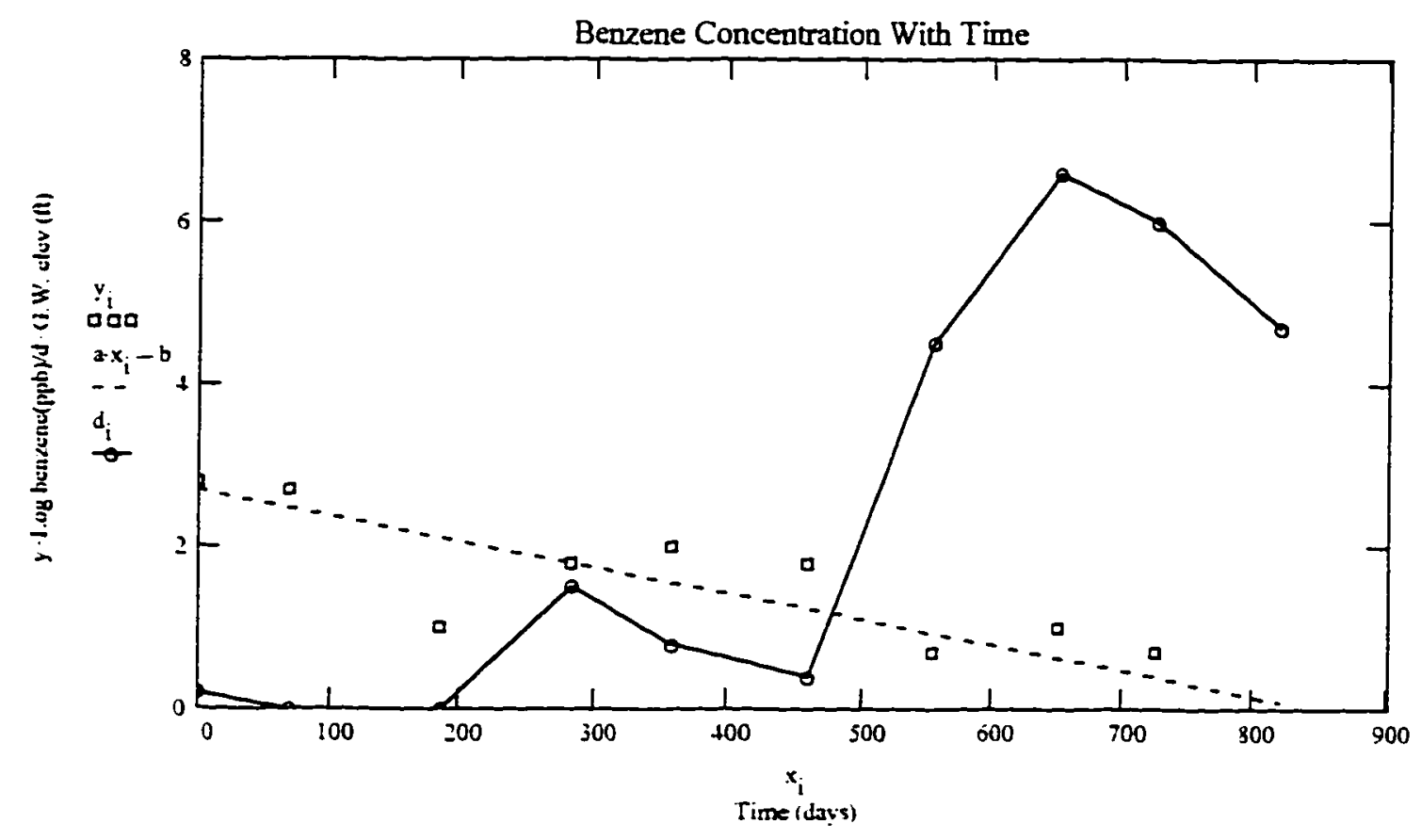


SCWWD Site Number: 07SiW03G01F Site Address: 1795 Scott Blvd Site Name: Chevron \#97116 City: Santa Clara

\section{Contaminant: TPH Gasoline}

$$
i=0 . .14
$$$$
a=\operatorname{slope}(x, y) \quad a=-0.0026
$$$$
b=\operatorname{intercept}(x, y) \quad b=5.649
$$$$
\operatorname{corr}(x . y)=-0.8547
$$$$
\operatorname{com}(x . y)^{2}=0.7305
$$

$\begin{array}{ccc}\text { Days } & \text { LogC } & \begin{array}{c}\text { G.W. } \\ \text { Elev }\end{array} \\ 0 & -5.1^{-} & .2 \\ 89 & 5.0 & .4 \\ 178 & 5.0 & 0 \\ 275 & 5.1 & 2.7 \\ 379 & 4.7 & 6.1 \\ 451 & 4.4 & 5.9 \\ 529 & 4.5 & 5.6 \\ x=606 & y=4.6 & \mathrm{~d}=6.0 \\ 695 & 4.5 & 7.1 \\ 795 & 4.2 & 7.1 \\ 877 & 4.2 & 6.0 \\ 975 & 3.7 & 9.7 \\ 1057 & 1.4 & 11.0 \\ 1175 & 2.5 & 10.6 \\ 1241 & 1.8 & 10.1\end{array}$

Note: Ground water elevations have been adjusted to fit the graph. $0 \mathrm{ft}=43.42 \mathrm{f}$.

TPH as Gasoline Concentration With Time

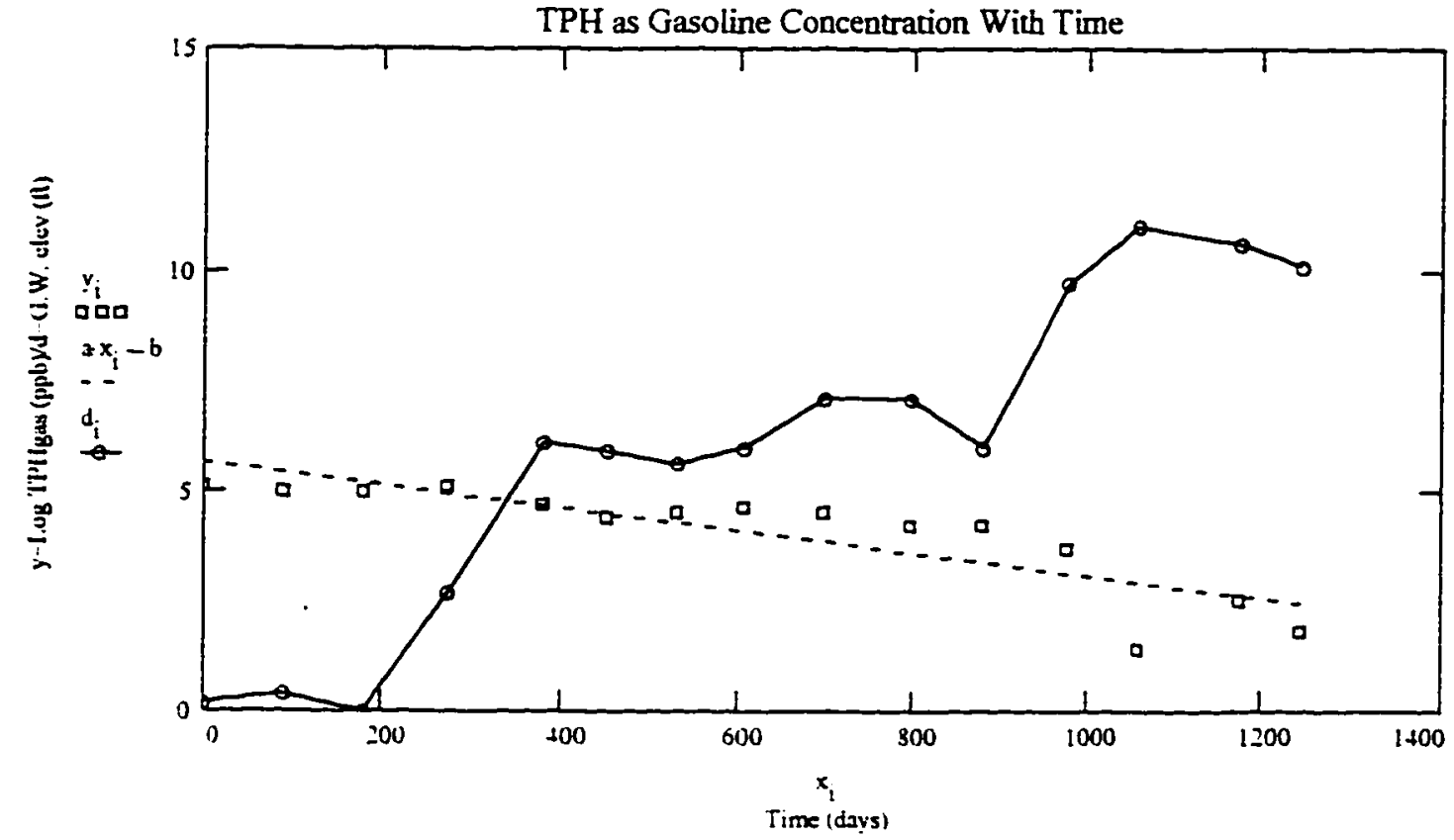


SCWWD Site Number: 07S1W03G01F Site Address: 1795 Scott Blvd Site Name: Chevron \#97116 City: Santa Clara

\section{Contaminant: Benzene}

$$
i=0.12
$$

\begin{tabular}{|c|c|c|}
\hline Days & $\log C$ & $\begin{array}{l}\text { G.W. } \\
\text { Elev }\end{array}$ \\
\hline 0 & $3.3^{-}$ & 0.2 \\
\hline 89 & 3.2 & 0.4 \\
\hline 178 & 3.2 & 0 \\
\hline 275 & 3.0 & 2.7 \\
\hline 379 & 2.9 & 6.1 \\
\hline 451 & 2.7 & 5.9 \\
\hline$x=529$ & $y=2.6$ & $d=5.6$ \\
\hline 606 & 2.6 & 6.0 \\
\hline 695 & 2.4 & 7.1 \\
\hline 795 & 2.0 & 7.1 \\
\hline 877 & 1.6 & 6.0 \\
\hline 975 & 1.3 & 9.7 \\
\hline 1057. & -0.6. & .11 .0 \\
\hline
\end{tabular}

Note: Ground water elevations irave been adjusted to fit the graph. $0 \mathrm{ft}=43.42 \mathrm{ft}$.

Benzene Concentration With Time

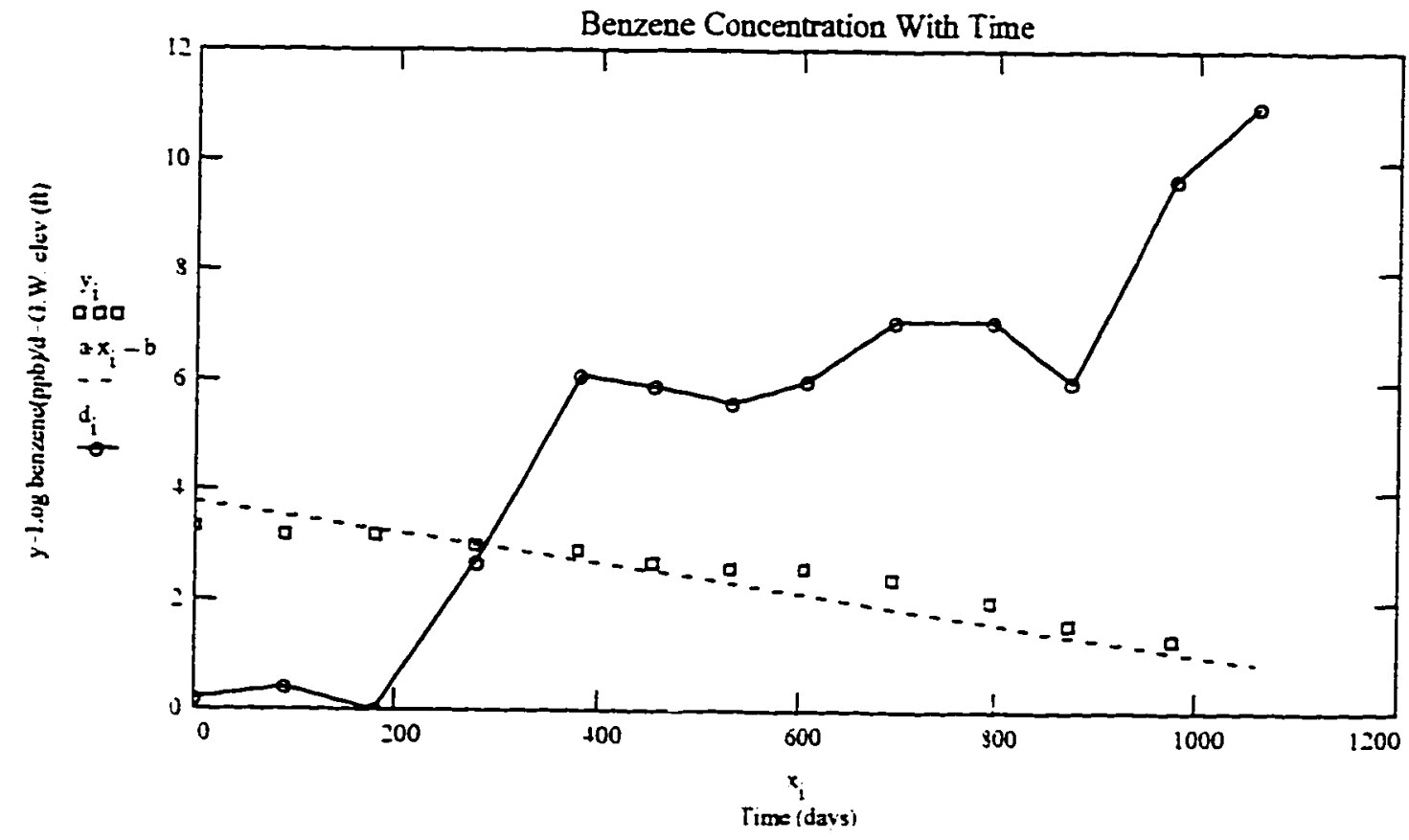


SCWWD Site Number: 06S1W35F01F

Site Address: 2600 De La Cruz Blvd

Site Name: Container Corp

City: Santa Clara

\section{Contaminant: TPH Gasoline}

$$
i=0 . .7
$$

$a=\operatorname{slope}(x, y) \quad a=-2.0002 \cdot 10^{-1}$

$b=\operatorname{intercept}(x, y) b=4.8949$

$\operatorname{corr}(x . y)=-0.3931$

$\operatorname{corr}(x . y)^{2}=0.1546$

Note: Ground water elevations have been adjusted to fit the graph. $O \mathrm{ft}=24.05 \mathrm{ft}$. There was no elevation data available for the first two dates. so 0 was input.

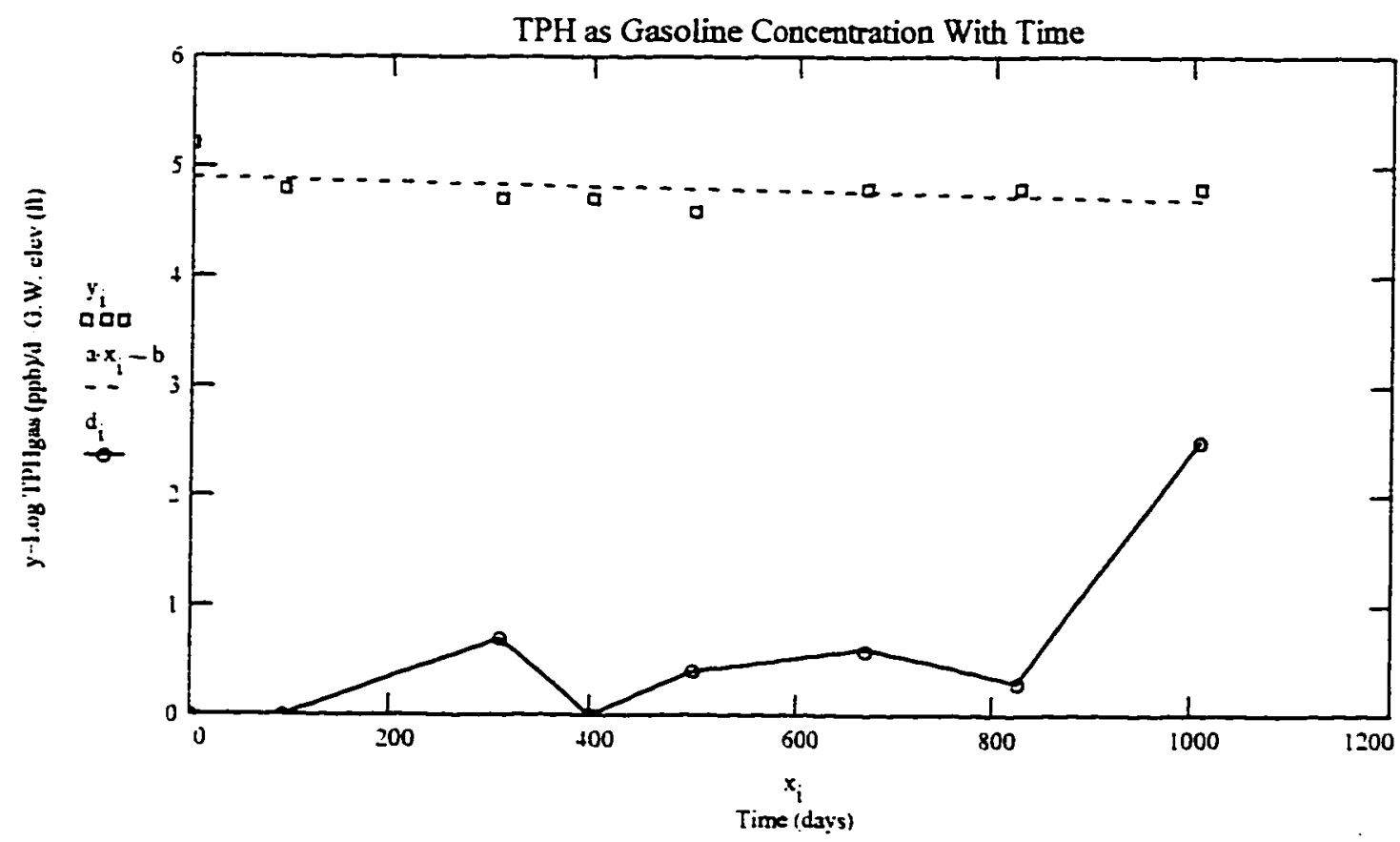


SCUWD Site Number: 06SiW35F01F Site Address: 2600 De La Cruz Blvd Site Name: Container Corp City: Santa Clara

Contaminant: Benzene

$i=0 . .10$

$\begin{array}{ccc}\text { Days } & \text { LogC } & \begin{array}{c}\text { G.W. } \\ \text { Elev }\end{array} \\ 0 & 3.9 & 0 \\ 92 & 3.7 & 0 \\ 245 & 3.6 & 0 \\ 337 & 3.6 & 0 \\ 459 & 3.4 & 0.7 \\ x=549 & y & \mathrm{~d}=0.7 \\ 641 & 3.4 & 0 \\ 733 & 3.3 & 0.4 \\ 976 & 3.2 & 0.6 \\ 1068 & 3.2 & 0.3 \\ 1250 & .3 .1 . & 2.5\end{array}$

Note: Ground water elevations have been adjusted to fit the graph. $O \mathrm{ft}=24.05 \mathrm{ft}$. There was no elevation data available for the first four dates, so 0 was input.

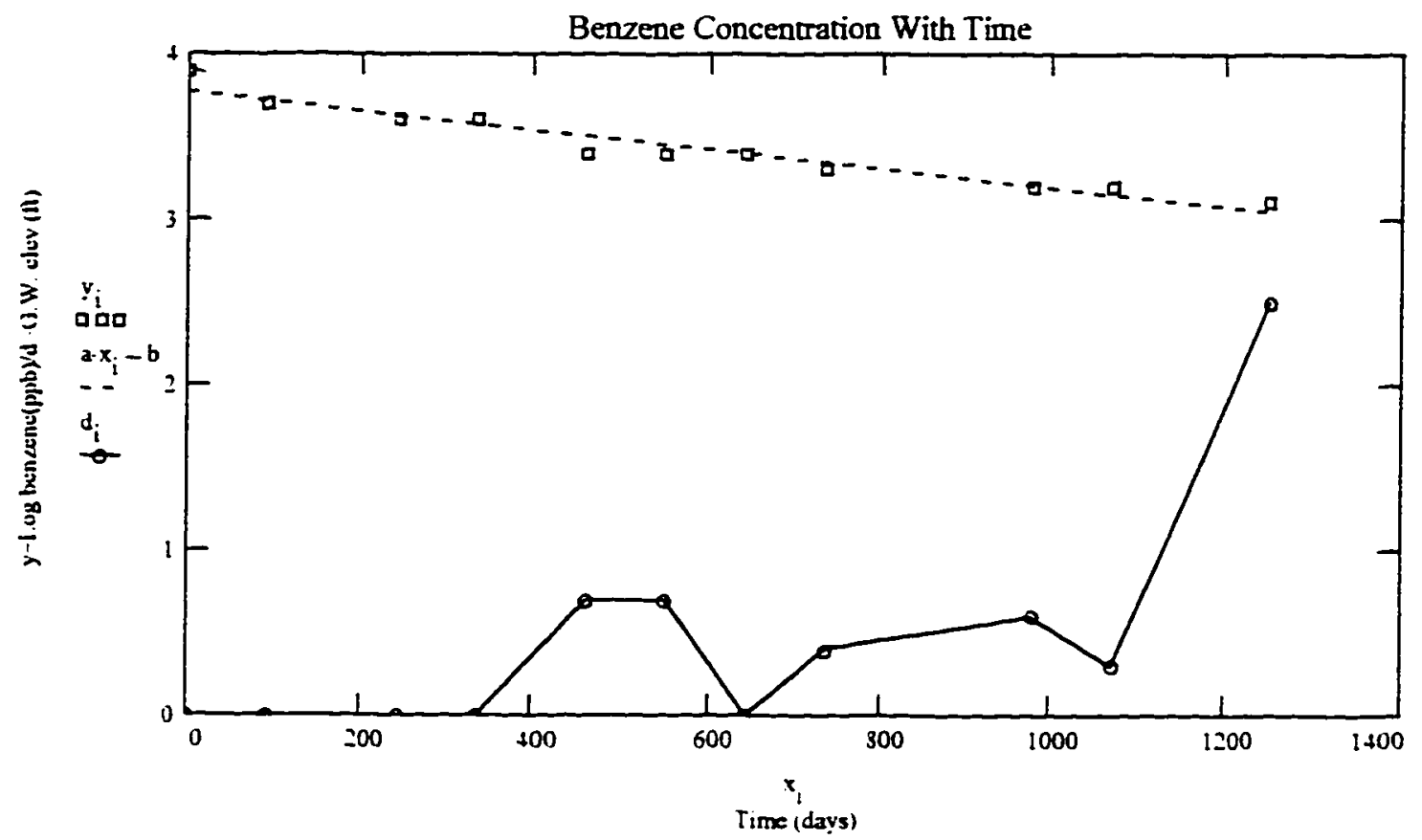


SCWWD Site Number: 07S1W15F01F

Site Address: 375 El Camino Real

Site Name: Exxon \#7-3850

City: Santa Clara

Contaminant: TPH Gasoline

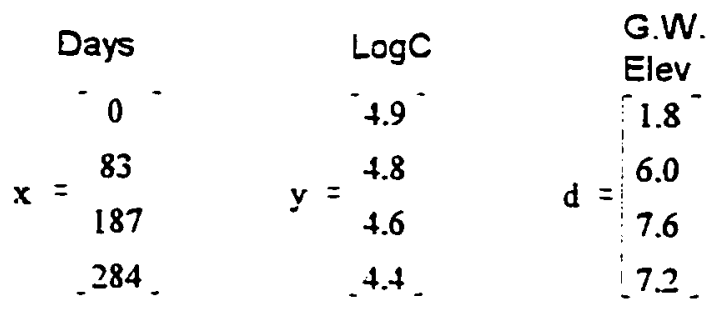

$a=\operatorname{slope}(x, y) \quad a=-0.0018$

$b=$ intercept $(x . y) b=4.9223$

$\operatorname{corr}(x, y)=-0.9948$

Note: Ground water elevations have been adjusted to fit the graph. $1.8 \mathrm{ft}=56.87 \mathrm{ft}$.

$\operatorname{corr}(x . y)^{2}=0.9896$

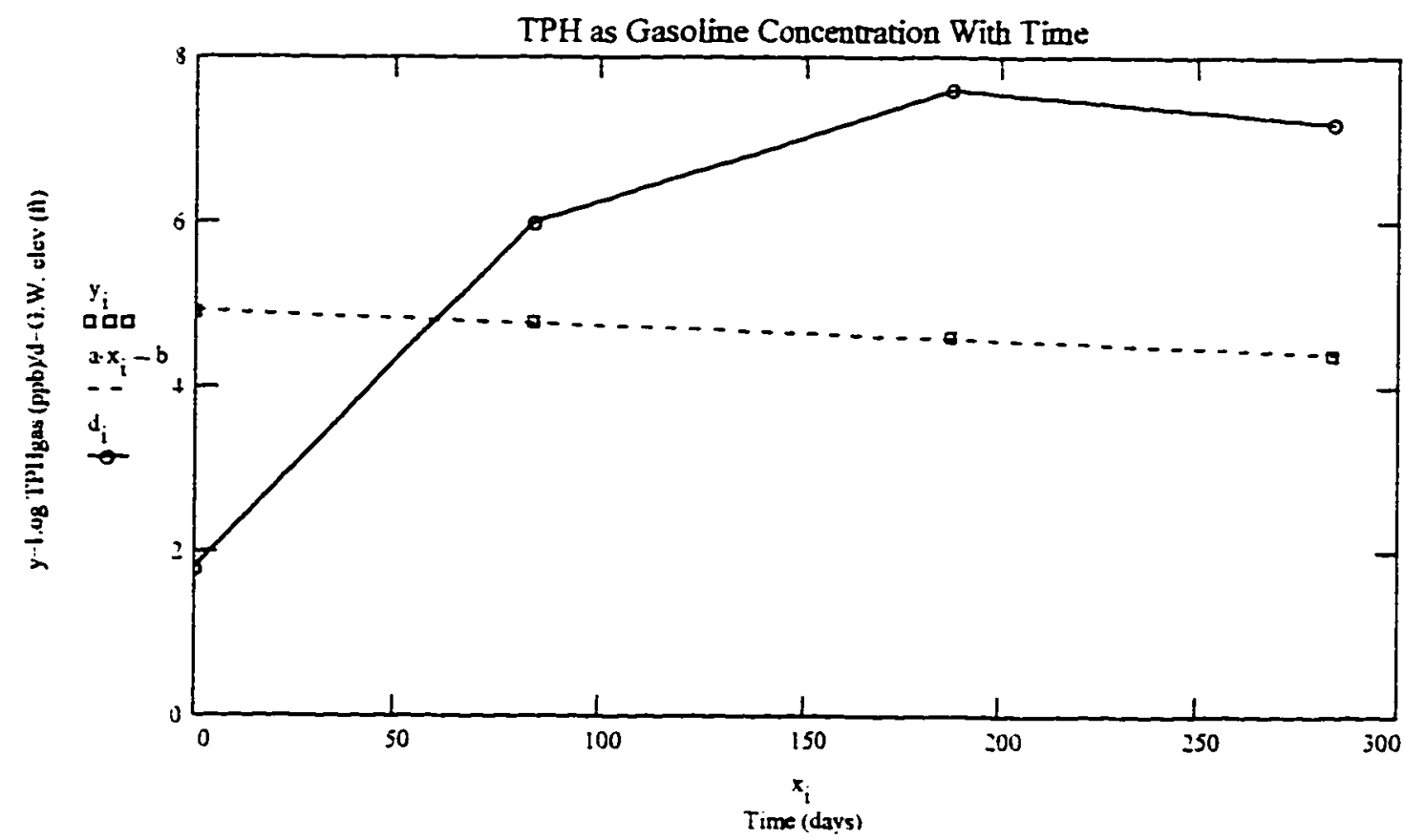


SCWWC Site Number: 07S1W15F01F

Site Address: 375 El Camino Real

Site Name: Exxon \#7-3850

City: Santa Clara

\begin{tabular}{|c|c|c|}
\hline Days & $\log C$ & $\begin{array}{l}\text { G.W. } \\
\text { Elev }\end{array}$ \\
\hline 0 & 3.5 & $0.6^{-}$ \\
\hline 111 & 3.4 & 0 \\
\hline$=189$ & 3.1 & 1.8 \\
\hline 272 & $y-3.1$ & 6.0 \\
\hline 376 & 2.9 & 7.6 \\
\hline .474 & 2.8 & .7 .2$. \\
\hline
\end{tabular}

Contaminant: Benzene

$$
i=0 . .5
$$

$a=\operatorname{slope}(x . y) \quad a=-0.0015$

$b=$ intercepl $(x . y) \quad b=3.4965$

$\operatorname{corr}(x, y)=-0.9748$

$\operatorname{corr}(x, y)^{2}=0.9503$

Note: Ground water elevations have been adjusted to fit the graph. $O \mathrm{ft}=55.11 \mathrm{f}$.

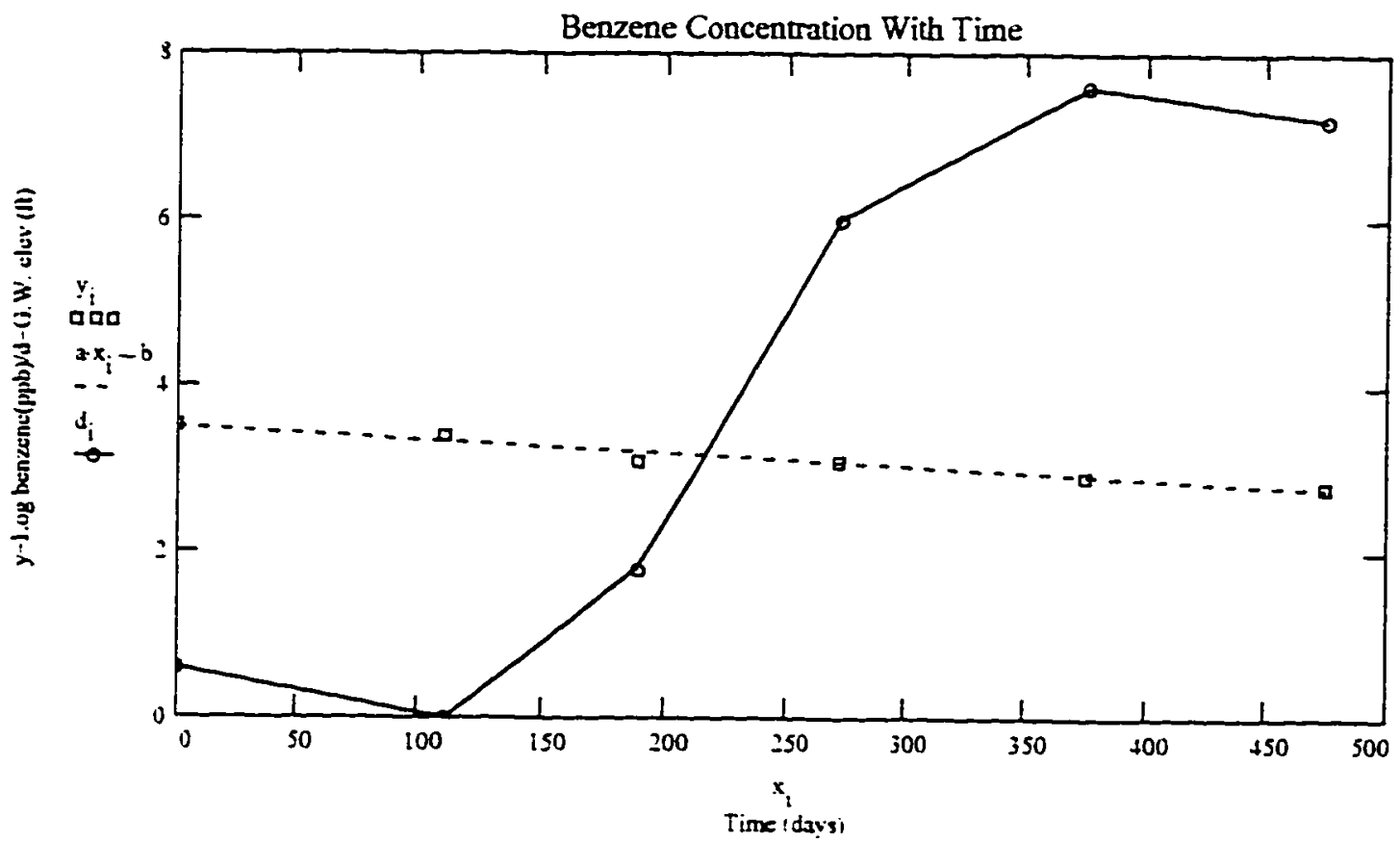


SCWWD Site Number: 07S1W03K01F Site Address: 1810 El Camino Real Site Name: Gangi Investments

City: Santa Clara

$\begin{array}{ccc}\text { Days } & \text { LogC } & \begin{array}{c}\text { G.W. } \\ \text { Elev }\end{array} \\ 0 & -4.4 & - \\ 91 & 3.9 & 0 \\ 197 & 3.3 & 0 \\ 291 & 2.9 & 0 \\ \mathrm{x}= & \mathrm{y}=2.2 & \mathrm{~d}=0.6 \\ 468 & 2.2 & 0.4 \\ 463 & 2.1 & 0.6 \\ 564 & 2.7 & 4.5 \\ 635 & -1.4 . & -8.6 \\ 748 . & \end{array}$

$a=\operatorname{slope}(x . y) \quad a=-0.0034$

$b=$ intercept $(x . y) \quad b=4.0603$

$\operatorname{corr}(x . y)=-0.9068$

$\operatorname{corr}(x, y)^{2}=0.8223$

$$
i=0 . .8
$$
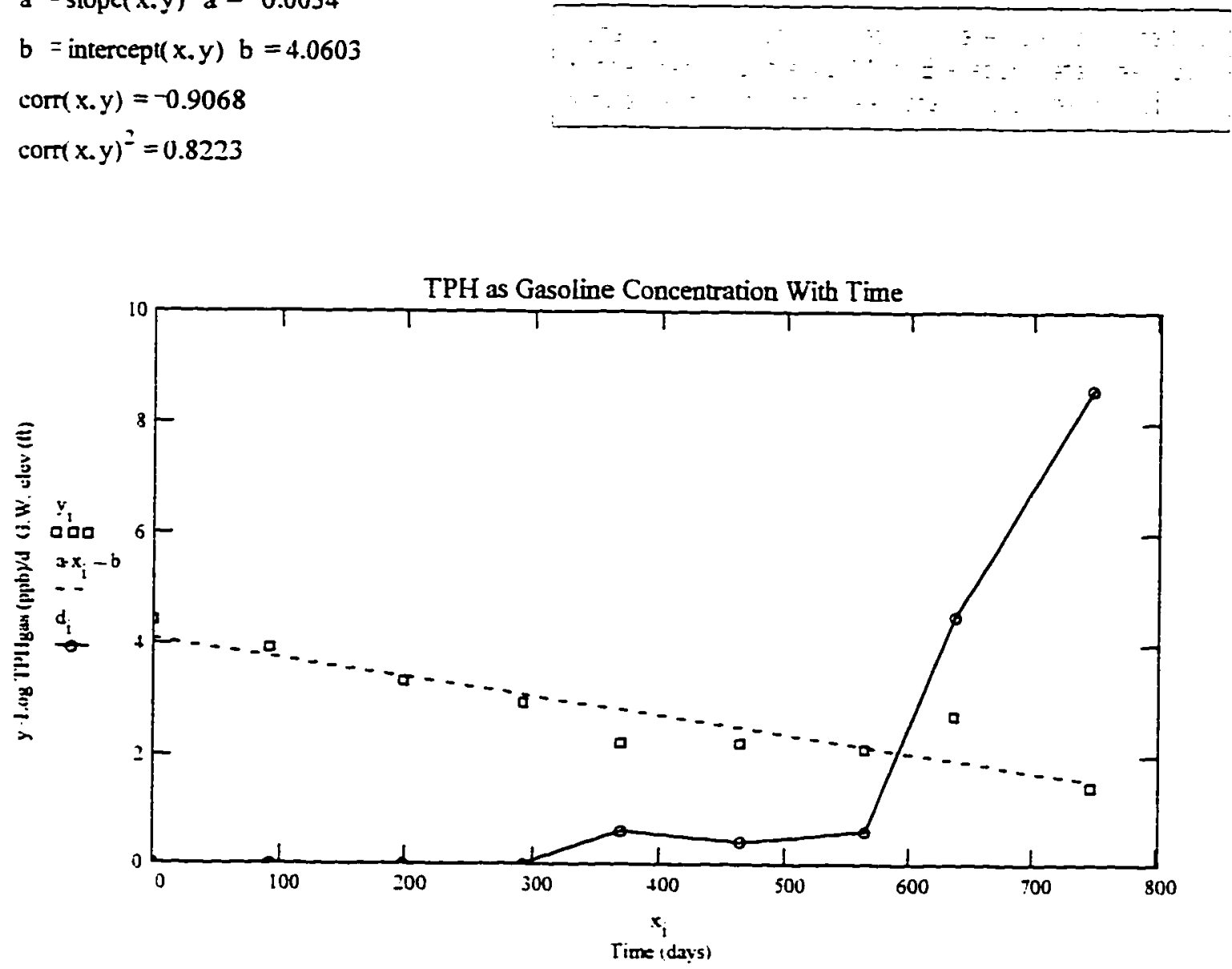
SCWWD Site Number: 0751W03K01F Site Address: 1810 El Camino Real Site Name: Gangi Investments City: Santa Clara

Contaminant: Benzene - $m w-5$

$$
i=0 . .8
$$

$\begin{array}{crc}\text { Days } & \text { LogC } & \begin{array}{l}\text { G.W. } \\ \text { Elev }\end{array} \\ -0 & -3.2 & -0 \\ 91 & 2.3 & 0 \\ 197 & 2.4 & 0 \\ 291 & 0.8 & 0 \\ \mathrm{x}=368 & y=0.4 & \mathrm{~d}=0.6 \\ 463 & 0.2 & 0.4 \\ 564 & 0.4 & 0.6 \\ 635 & 1.3 & 4.5 \\ 748 . & -0.8 . & -8.6 .\end{array}$

Note: Ground water elevations have been adjusted to it the graph. $0 \mathrm{ft}=43.14 \mathrm{ft}$. Elevation data was not available for the first three dates. so 0 was input.

$\operatorname{corr}(x, y)=-0.8512$

$\operatorname{corr}(x . y)^{2}=0.7245$

Benzene Concentration With Time

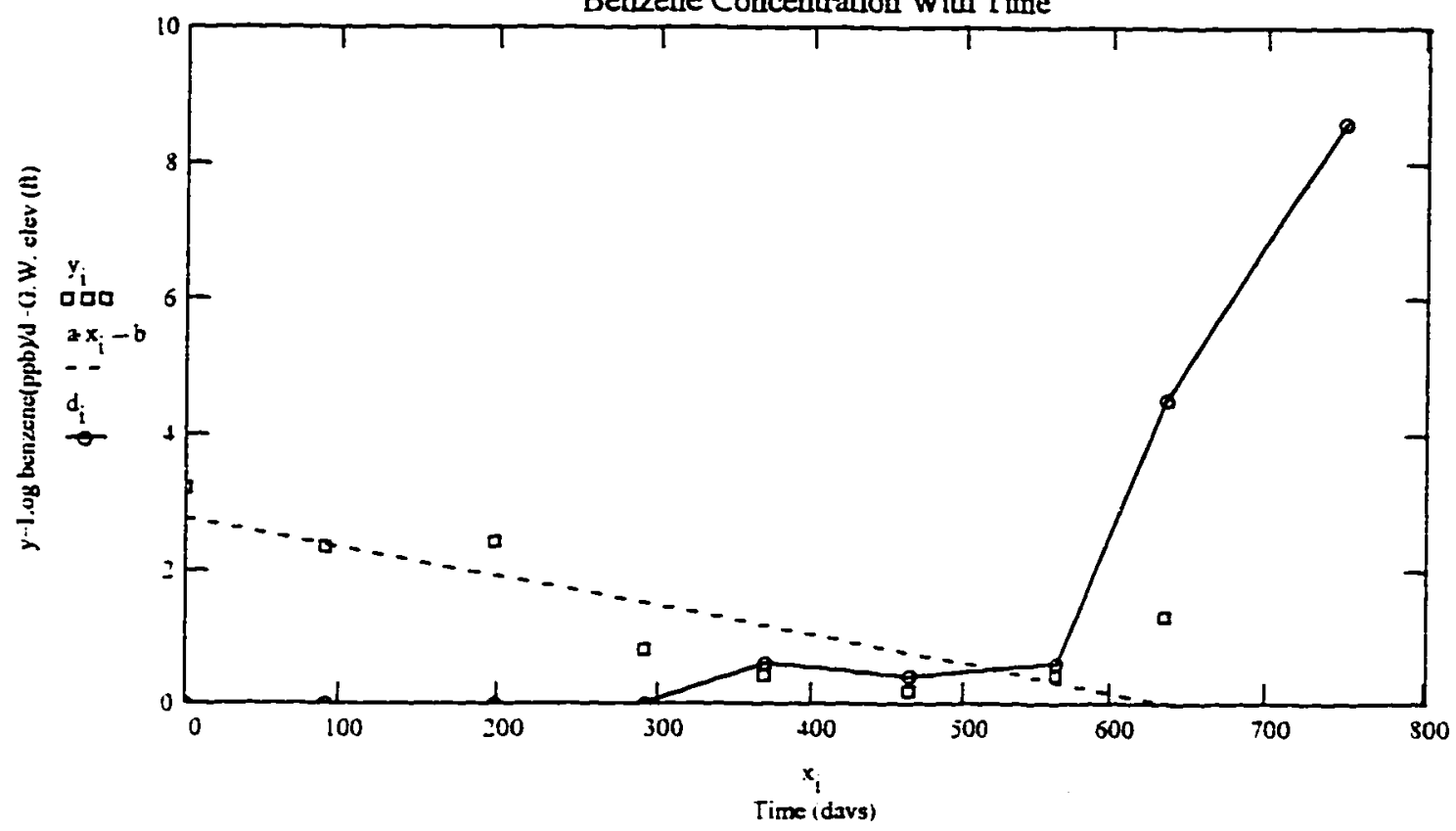


SCYWD Site Number: 07S1W03KO1F

Site Address: 1810 El Camino Real

Site Name: Gangi Investments

City: Santa Clara

Contaminant: TPH Gasoline - MW-6

\begin{tabular}{|c|c|c|}
\hline Days & $\log C$ & $\begin{array}{l}\text { G.W. } \\
\text { Elev }\end{array}$ \\
\hline 0 & 3.7 & 0 \\
\hline 97 & 3.7 & 1.0 \\
\hline 188 & 3.3 & 1.4 \\
\hline$=294$ & 2.7 & 2.0 \\
\hline 388 & 2.2 & 3.7 \\
\hline 465 & 1.4 & 4.0 \\
\hline 560 & 1.8 & 3.9 \\
\hline 661 & 1.4 & 4.0 \\
\hline
\end{tabular}

$a=\operatorname{slope}(x . y) \quad a=-0.004$

$b=$ intercepl( $x, y) \quad b=3.8632$

$\operatorname{corr}(x, y)=-0.957$

Note: Ground water elevations have been adjusted to fit the graph. $0 \mathrm{ft}=35.84 \mathrm{~A} / 2$.

$\operatorname{corr}(x . y)^{2}=0.9159$

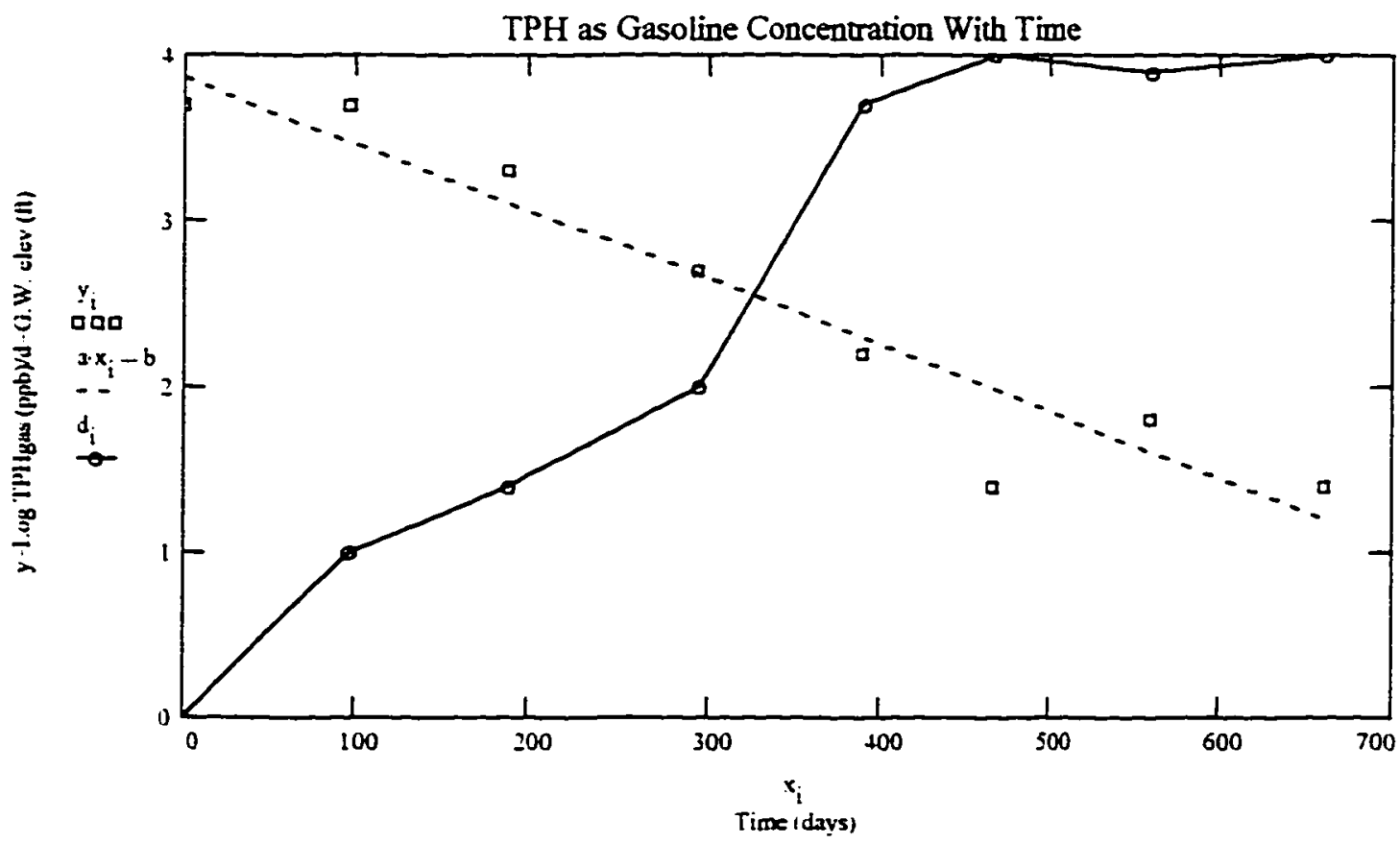


SCWWD Site Number: 07S1W03K01F

Site Address: 1810 El Camino Real

Site Name: Gangi Investments

City: Santa Clara

$\begin{array}{ccc}\text { Days } & \text { LogC } & \begin{array}{c}\text { G.W. } \\ \text { Elev }\end{array} \\ 0 & -1.7 & -1.0 \\ 91 & 0.7 & 1.4 \\ 197 & 0.2 & 2.0 \\ \mathrm{x}=291 & \mathrm{y}=-0.2 & \mathrm{~d}=3.7 \\ 368 & -0.5 & 4.0 \\ 463 & -0.5 & 3.9 \\ .564 & -0.8 . & -4.0\end{array}$

\footnotetext{
$a=\operatorname{slope}(x . y) \quad a=-0.0041$

$b=$ intercept $(x . y) \quad b=1.2358$
}

Note: Ground water elevations have been adjusted to fit the graph. $\mathrm{oft}=35.84 \mathrm{ft} 2$.

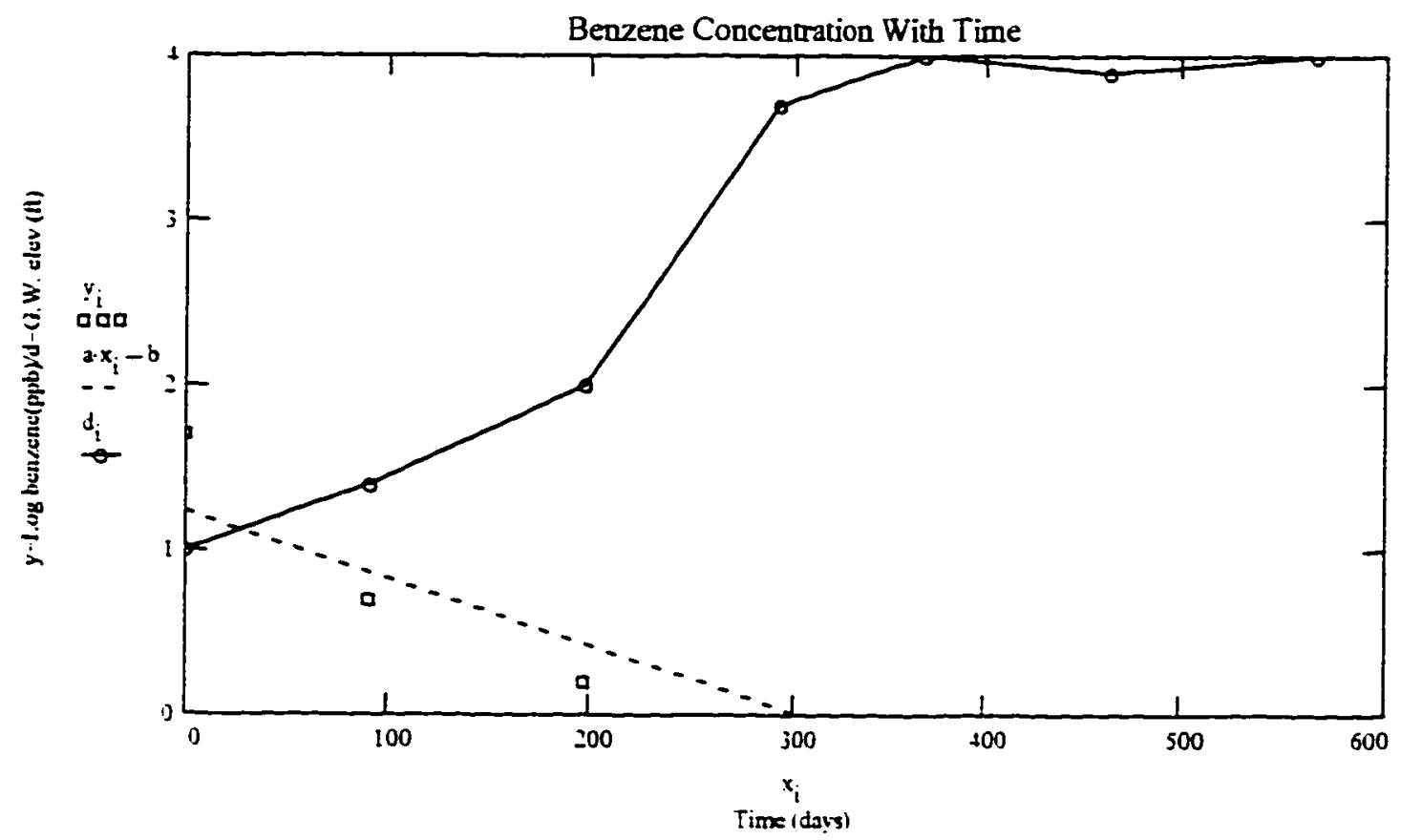


SCWND Site Number: 06S1W27F01F Site Address: 2181 Laurelwood Road Site Name: Exxon \#7-3624

City: Santa Clara

Contaminant: TPHg

$$
i=0 . .7
$$

$\begin{array}{ccc}\text { Days } & \text { LogC } & \begin{array}{c}\text { G.W. } \\ \text { Elev }\end{array} \\ 0 & -3.5 & 2.3 \\ 127 & 3.5 & 2.0 \\ 183 & 3.2 & 2.8 \\ 274 & \mathrm{y}= & 2.5 \\ 352 & 2.8 & \mathrm{~d}=2.4 \\ 4.2 \\ 448 & 3.0 & 1.8 \\ 538 & 2.9 & 2.1 \\ 630 & .1 .4 . & -0\end{array}$

$a=\operatorname{slope}(x . y) \quad a=-0.0024$

$b$ =intercept(x.y) b=3.63

Note: Ground water elevations have been adjusted to fit the graph. $0 \mathrm{ft}=14.93 \mathrm{ft}$.

$\operatorname{corr}(x, y)=-0.7727$

$\operatorname{corr}(x . y)^{2}=0.5971$

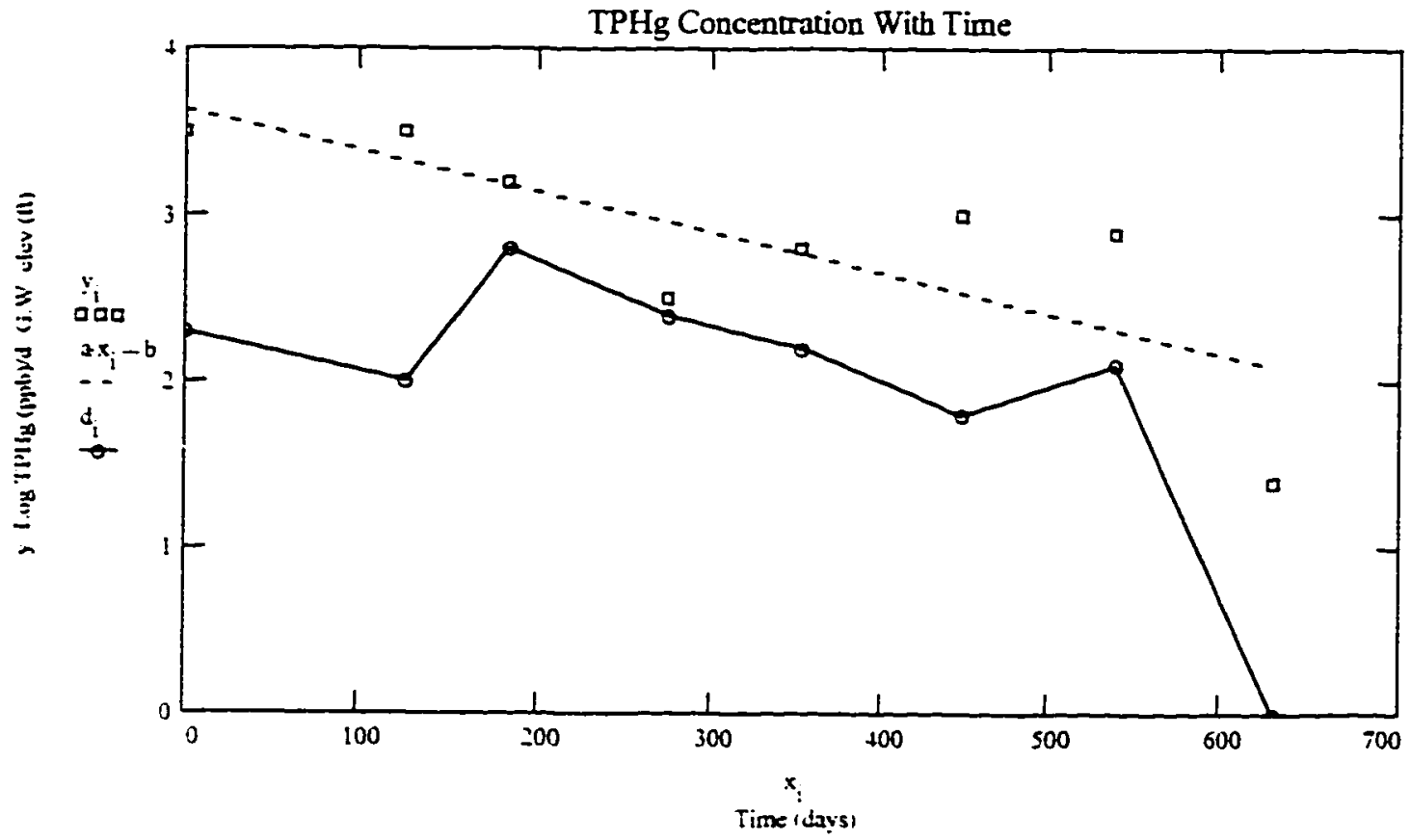


SCWWD Site Number: 06S1W27F01F Site Address: 2181 Laurelwood Road Site Name: Exxon \#7-3624

City: Santa Clara

\section{Contaminant: Benzene}

$a=\operatorname{slope}(x, y) \quad a=-0.002$

$$
i=0 . .11
$$

$\begin{array}{ccc}\text { Days } & \text { LogC } & \text { Elev } \\ 0 & 2.2 & 3.1 \\ 91 & 1.8 & 1.4 \\ 183 & 1.6 & 1.3 \\ 356 & 1.6 & 2.9 \\ 445 & 1.6 & 2.3 \\ 572 & \mathrm{y}=1.6 & 2.0 \\ 628 & 1.0 & \mathrm{~d}=2.8 \\ 719 & 0.4 & 2.4 \\ 797 & 0.6 & 2.2 \\ 893 & 0.7 & 1.8 \\ 983 & 0.7 & 2.1 \\ 1075 & -0.6 & .0\end{array}$

Note: Ground water elevations have been adjusted to fit the graph. $O \mathrm{ft}=14.93 \mathrm{ft}$.

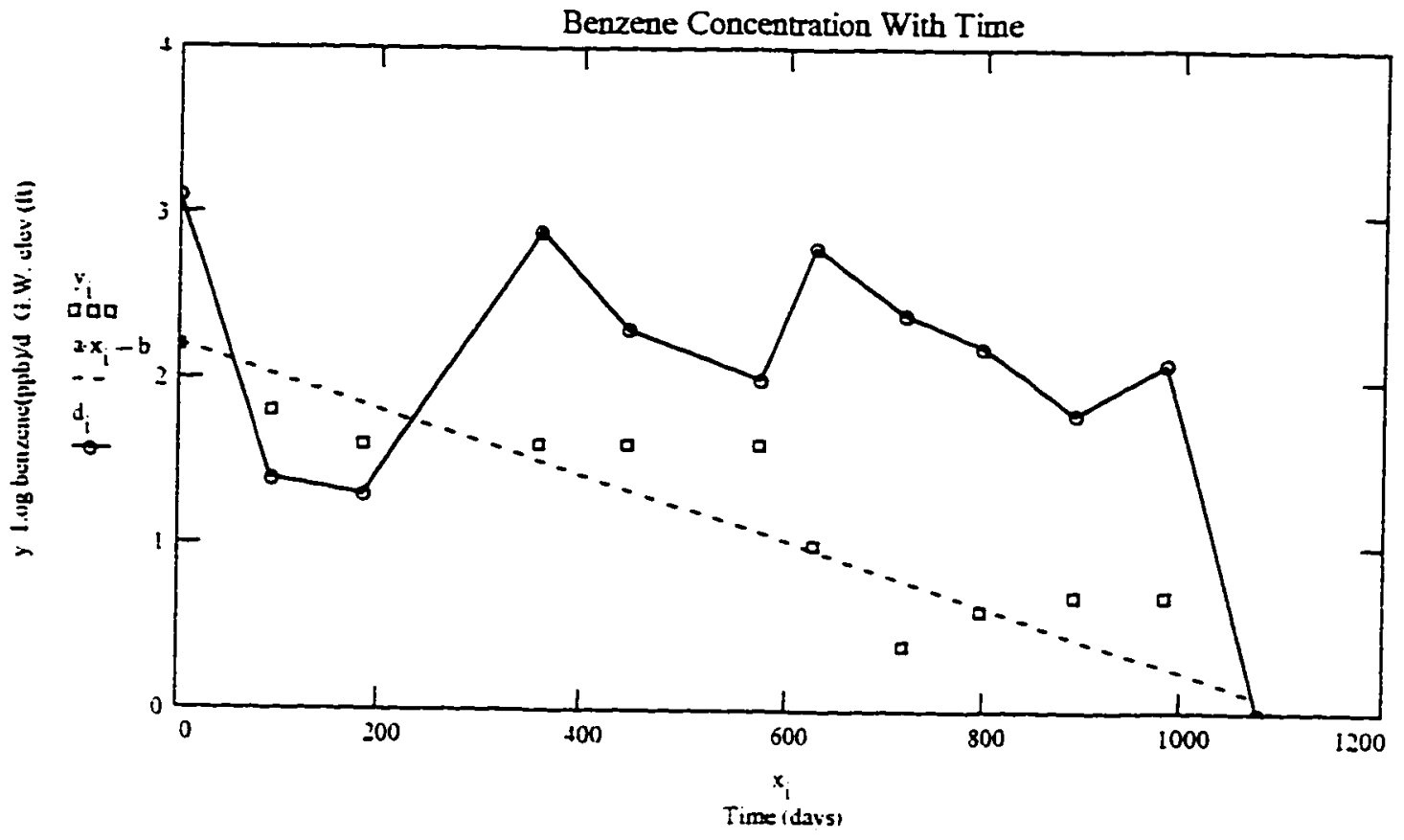


SCVWD Site Number: 07S1W11G02F

Site Address: 36 Washington Street

Site Name: Exxon \#7-0960

City: Santa Clara

Contaminant: TPH Gasoline

$\begin{array}{ccc}\text { Days } & \text { LogC } & \begin{array}{c}\text { G.W. } \\ \text { Elev }\end{array} \\ 0 & -3.2^{-} & 0 \\ 95 & 2.6 & 3.8 \\ 183 & 2.0 & 4.9 \\ 274 & \mathrm{y}=2.1 & \mathrm{~d}=\mathrm{5.4} \\ 357 & 2.7 & 10.0 \\ 449 & 2.9 & 9.8 \\ 546 & 1.8 & 9.3 \\ .637 & 1.4 . & -9.1\end{array}$

$a=\operatorname{slope}(x . y) \quad a=-0.0018$

$b=$ intercept $(x, y) \quad b=2.9022$

$\operatorname{corr}(x . y)=-0.6463$

Note: Ground water elevations have been adjusted to fit the graph. $O \mathrm{ft}=49.45 \mathrm{ft}$.

$\operatorname{corr}(x . y)^{2}=0.4177$

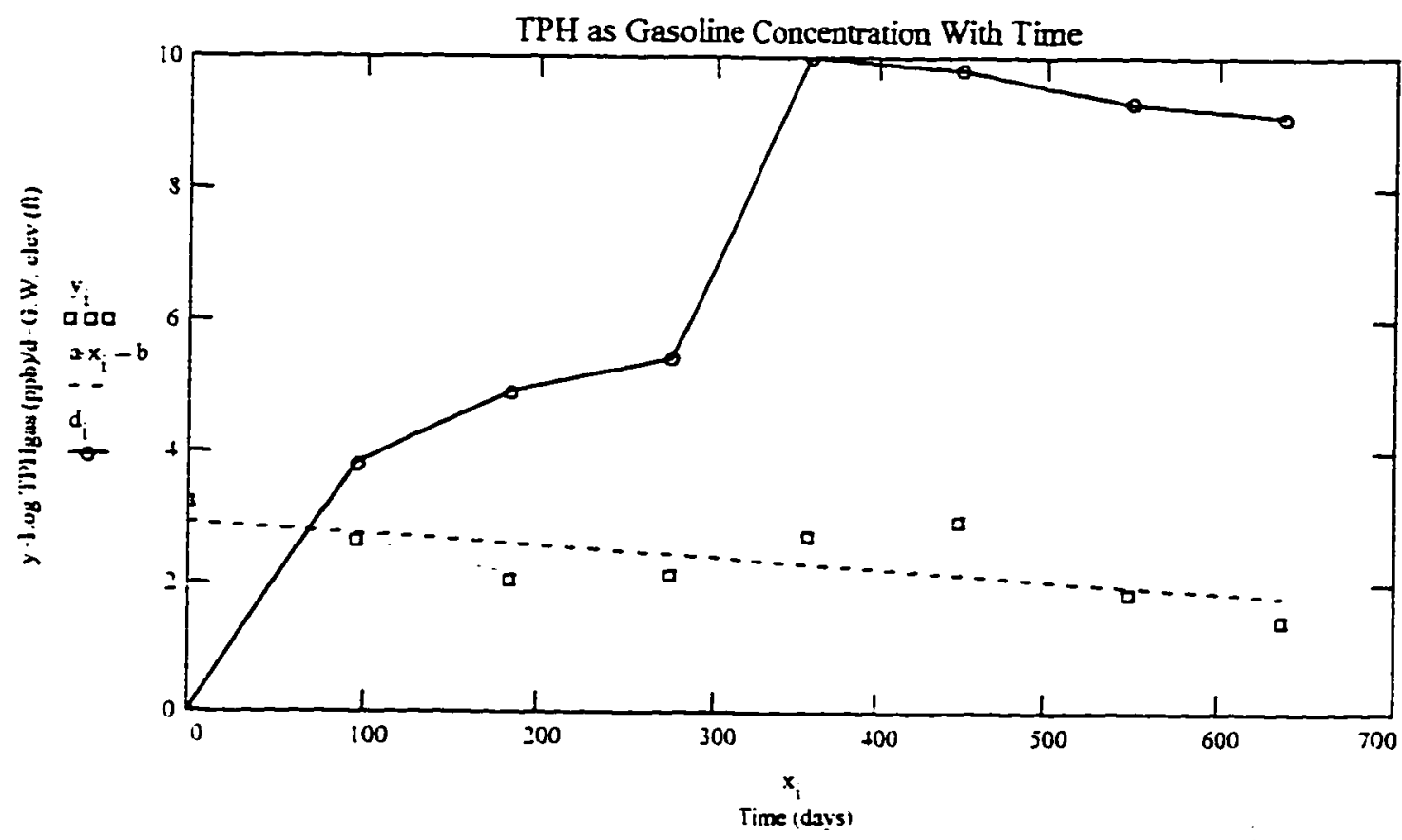


SC:WD Site Number: 07S1W11G02F Site Address: 36 Washington Street Site Name: Exxon \#7-0960 City: Santa Clara

\begin{tabular}{|c|c|c|}
\hline Days & $\log C$ & $\begin{array}{l}\text { G.W. } \\
\text { Elev }\end{array}$ \\
\hline 0 & 1.7 & 0 \\
\hline 95 & 0.8 & 3.8 \\
\hline 183 & 0.5 & 4.9 \\
\hline 274 & 1.0 & 5.4 \\
\hline$=357$ & $y=1.7$ & $d=10.0$ \\
\hline 449 & 0.7 & 9.8 \\
\hline 546 & 0.5 & 9.3 \\
\hline 637 & -0.1 & 9.1 \\
\hline .733. & .0 .6 & .13 .5 \\
\hline
\end{tabular}

$a=\operatorname{slope}(x . y) \quad a=-0.0023$

$b=$ intercept( $x . y) \quad b=1.5114$

$\operatorname{corr}(x, y)=-0.7505$

$\operatorname{corr}(x . y)^{2}=0.5632$

Note: Ground water elevations have been adjusted to fit the graph. O ft $=49.45 \mathrm{ft}$.

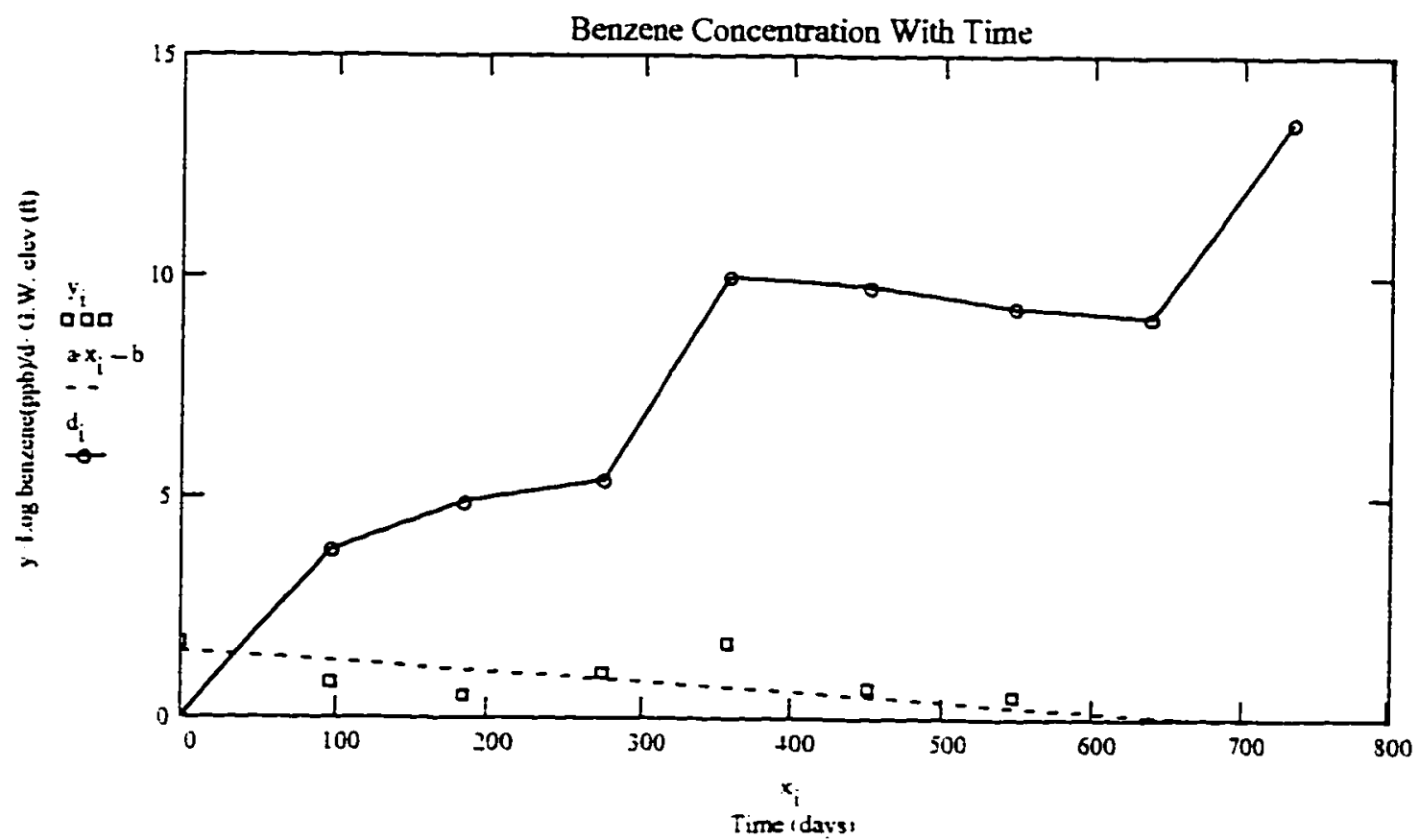


$a=\operatorname{slope}(x, y) \quad a=-8.4274 \cdot 10^{-4}$

$b=$ intercept $(x, y) b=4.0904$

$\operatorname{corr}(x . y)=-0.5169$

$\operatorname{corr}(x . y)^{2}=0.2672$
SCVWD Site Number: 06S1W26L01F Site Address: 565 Laurelwood Road Site Name: E.A. Hathaway \& Co.

City: Santa Clara

\section{Days}

0

98

129

Contaminant: TPH Gasoline - MW-1

$i=0 . .19$
161

220

310

393

492

586

$=675$

777

870

961

1040

1075

1137

1224

1318

1401

1501 .

\begin{tabular}{cc} 
LogC & G.W. \\
4.4 & Elev \\
4.4 & 0.8 \\
4.2 & 1.6 \\
4.3 & 0.2 \\
4.4 & 0.9 \\
4.2 & 0.6 \\
4.0 & 0 \\
4.0 & 1.2 \\
1.4 & 1.3 \\
3.4 & 1.2 \\
3.9 & 1.3 \\
$y=2.8$ & 1.5 \\
3.6 & 1.2 \\
3.4 & 0.4 \\
2.6 & 0.9 \\
3.3 & 1.0 \\
3.3 & 2.0 \\
3.3 & 2.2 \\
2.2 & 1.7 \\
3.3 & 1.1 \\
3.7 & 2.1 \\
\hline
\end{tabular}

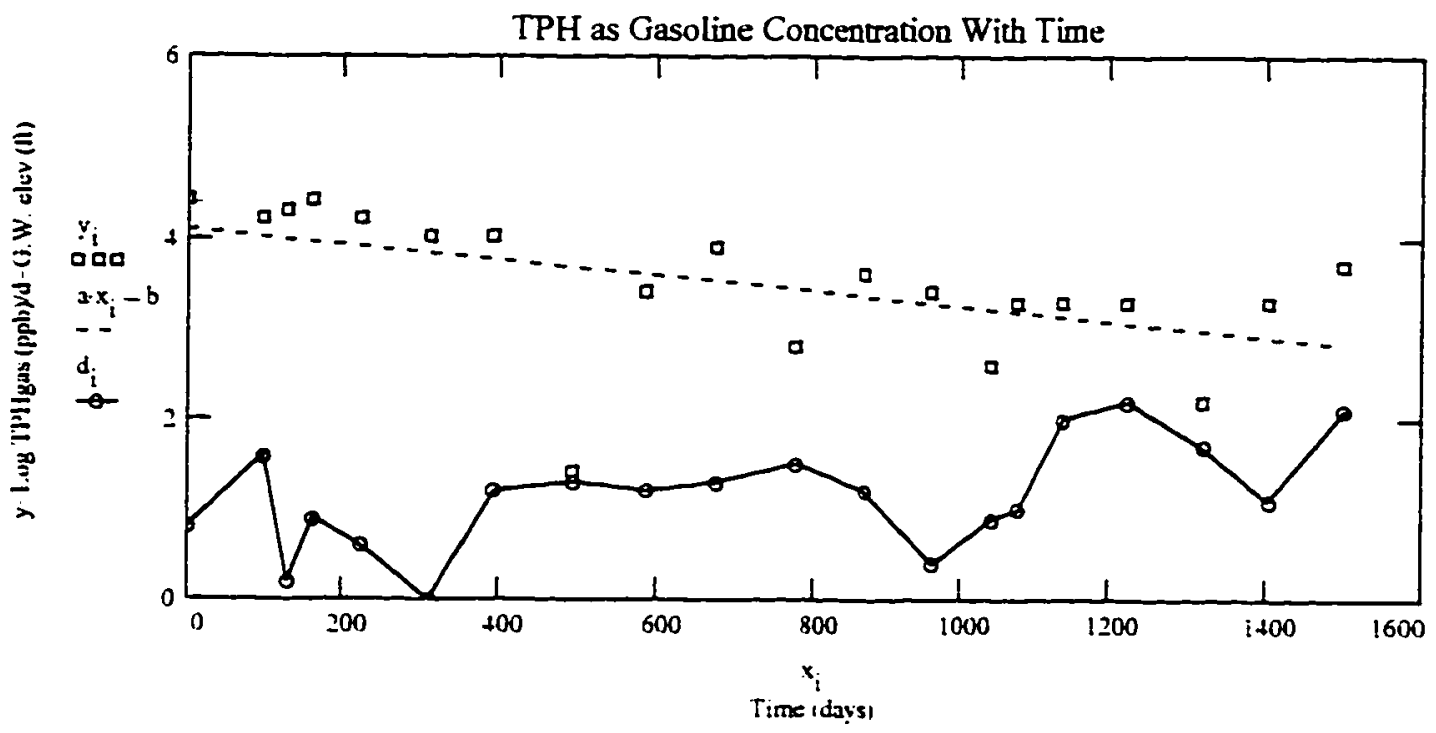

Note. Ground water elevations have been adjusted to it the graph. $0 \mathrm{ft}=1443 \mathrm{ft}$. 


\begin{tabular}{|c|c|c|c|}
\hline \multirow{3}{*}{$\begin{array}{l}\text { SCWWD Site Number: 06S1W26L01F } \\
\text { Site Address: } 565 \text { Laurelwood Road } \\
\text { Site Name: E.A. Hathaway \& Co. } \\
\text { City: Santa Clara }\end{array}$} & Days & $\log C$ & $\begin{array}{l}\text { G.W. } \\
\text { Elev }\end{array}$ \\
\hline & 0 & 2.3 & 0.8 \\
\hline & 98 & 1.9 & 1.6 \\
\hline & 129 & 1.9 & 0.2 \\
\hline & 161 & 2.0 & 0.9 \\
\hline Contaminant: Benzene - MW-1 & 220 & 1.8 & 0.6 \\
\hline$i=0 . .13$ & 310 & 2.0 & 0 \\
\hline & $x=393$ & $y=1.8$ & $d=1.2$ \\
\hline & 492 & -0.6 & -1.3 \\
\hline & 586 & 0.7 & 1.2 \\
\hline & 675 & 1.6 & 1.3 \\
\hline & 777 & 0.7 & 1.5 \\
\hline$=\operatorname{slope}(x . y) \quad a=-0.002$ & 870 & 0.7 & 1.2 \\
\hline$=$ intercept $(x, y) b=2.1815$ & 961 & 0.7 & 0.4 \\
\hline $\operatorname{orr}(x . y)=-0.7495$ & .1040 & -0.3 & 0.9 \\
\hline
\end{tabular}

Note: Ground water elevations have been adjusted to fit the graph. $O \mathrm{ft}=14.43 \mathrm{ft}$.

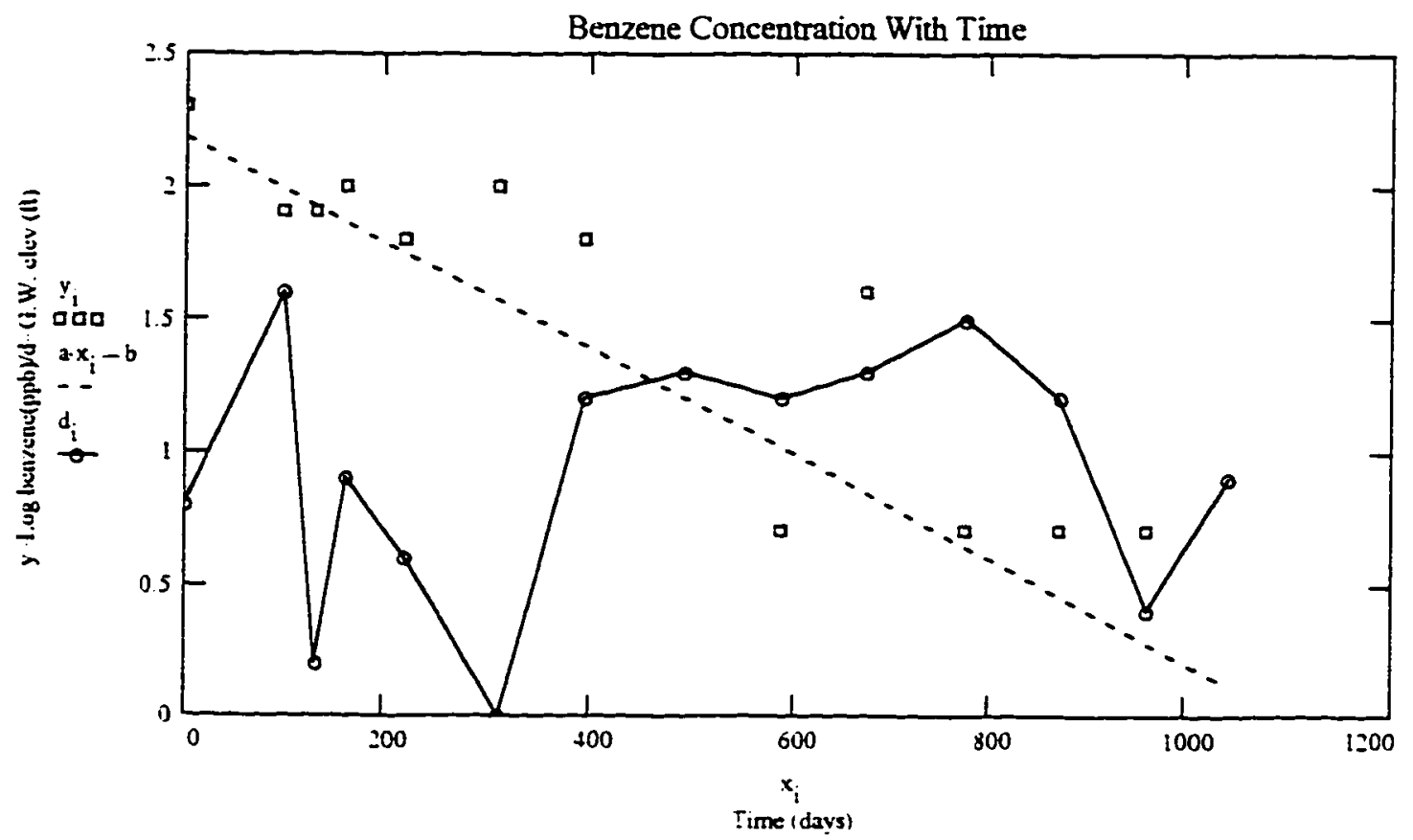


SCWWD Site Number: 06S1W26LO1F

$$
\text { Days } \quad \log C
$$

G.W.

Site Address: 565 Laurelwood Road

Site Name: E.A. Hathaway \& Co.

City: Santa Clara

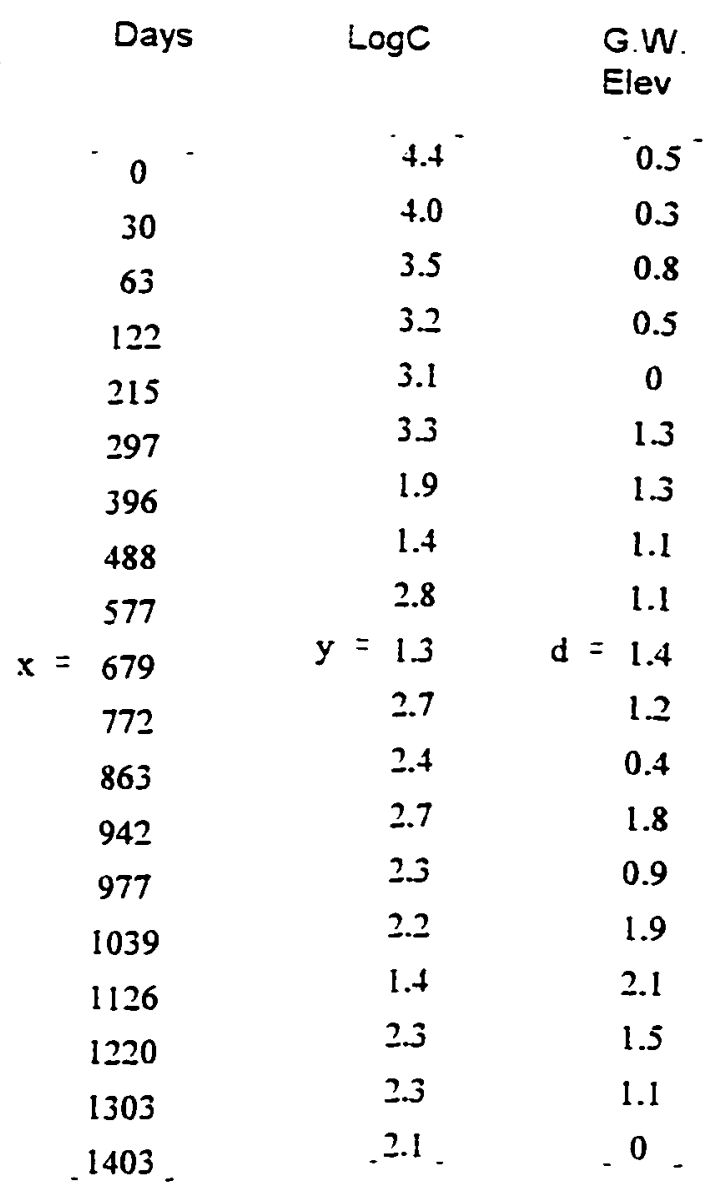
$a=\operatorname{slope}(x . y) \quad a=-0.0012$
$b=$ intercept $(x, y) \quad b=3.3937$
$\operatorname{corr}(x . y)=-0.6563$
$\operatorname{corr}(x . y)^{2}=0.4307$

$i=0 . .18$

Note: Ground water elevations have been adjusted to fit the graph. $O f t=14.53 \mathrm{it}$.

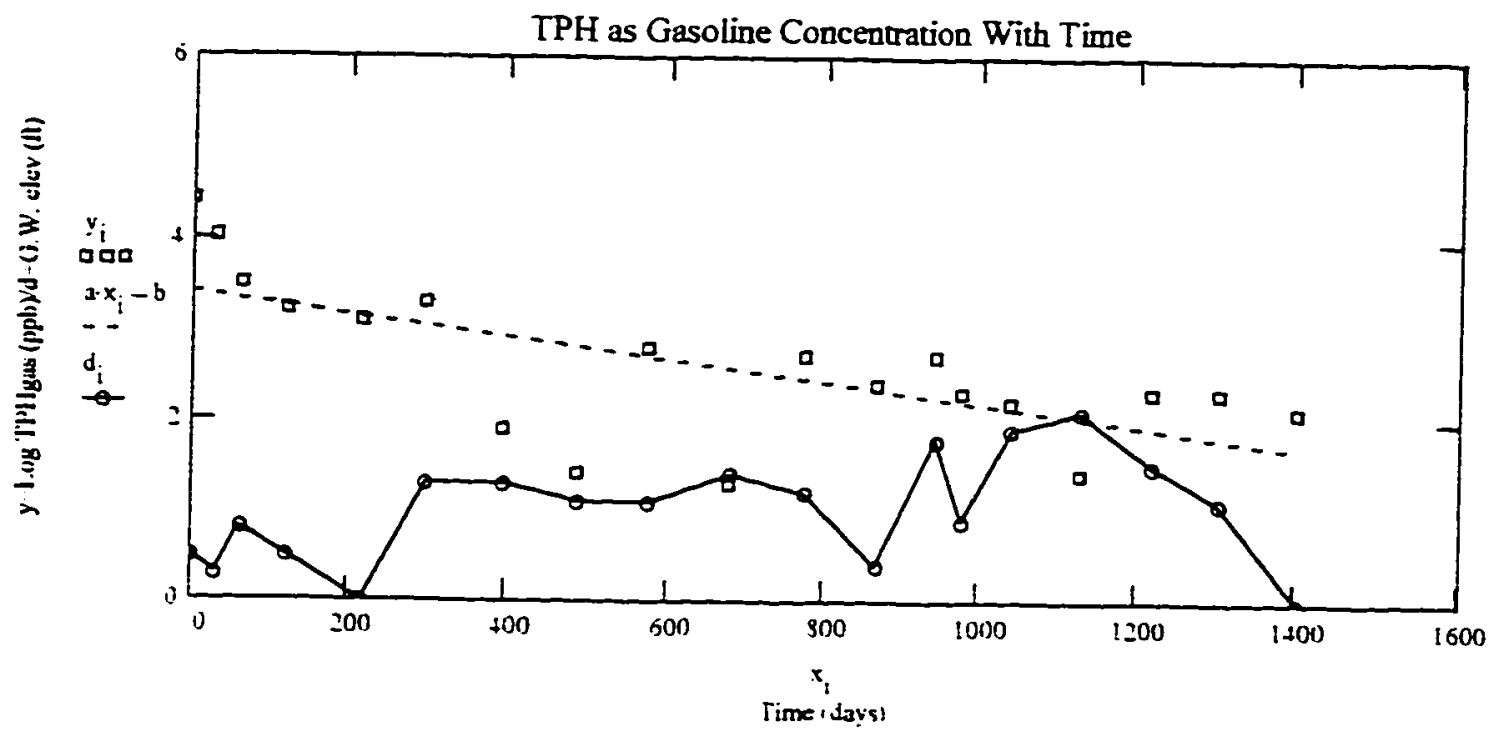

Note: Grounc water elevations have jeen adjusted to fit the graph. 0 it $=$ i.t. 
SCVWD Site Number: 07S1W03K02F

Site Address: 1702 El Camino Real

Site Name: Jones Automotive

City: Santa Clara

\begin{tabular}{|c|c|c|}
\hline Days & $\log C$ & $\begin{array}{l}\text { G.W. } \\
\text { Elev }\end{array}$ \\
\hline 0 & $2.5^{\circ}$ & 0 \\
\hline 41 & 2.0 & 0 \\
\hline$=132$ & $y=1.9$ & $d=2.7$ \\
\hline 217 & 1.8 & 2.5 \\
\hline .294. & .2 .2 . & 4.2 \\
\hline
\end{tabular}

Contaminant: Benzene MWS1-1

$$
i=0 . .4
$$

4.2 .

$a=\operatorname{slope}(x, y) \quad a=-8.8928 \cdot 10^{-4}$

$b=$ intercept $(x . y) \quad b=2.2017$

$\operatorname{corr}(x . y)=-0.3894$

$\operatorname{corr}(x . y)^{2}=0.1516$

Note: Ground water elevations have been adjusted to fit the graph. $0 \mathrm{ft}=53.61 \mathrm{ft}$. Elevation data was not available for the first date. so 0 was input.

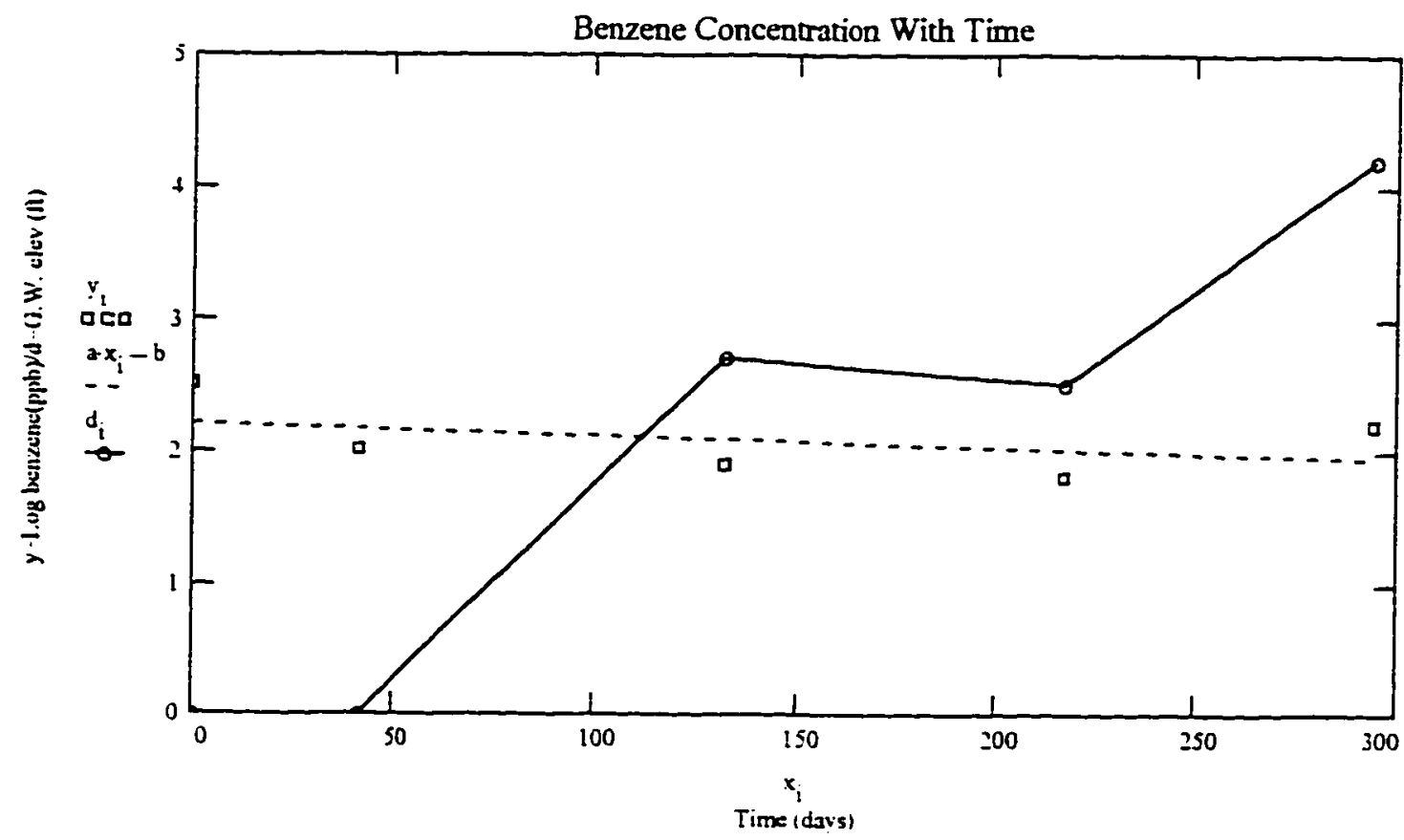


SCUND Site Number: 07S1W03K02F

Site Address: 1702 El Camino Real

Site Name: Jones Automotive

City: Santa Clara

Contaminant: TPH Gasoline - MW-5

$\begin{array}{ccc}\text { Days } & \text { LogC } & \begin{array}{l}\text { G.W. } \\ \text { Elev }\end{array} \\ -0 & -4.2^{-} & -0.5^{-} \\ 126 & \mathrm{y}=4.0 & 0.8 \\ 241 & 3.5 & \mathrm{~d}= \\ 319 & -3.4 & -1.8 .\end{array}$

$a=\operatorname{slope}(x, y) a=-0.0027$

$b=$ intercept $(x, y) \quad b=4.2403$

$\operatorname{corr}(x, y)=-0.9773$

Note: Ground water elevations have been adjusted to fit the graph. $0 \mathrm{ft}=56.22 \mathrm{ft}$.

$\operatorname{corr}(x . y)^{2}=0.9552$

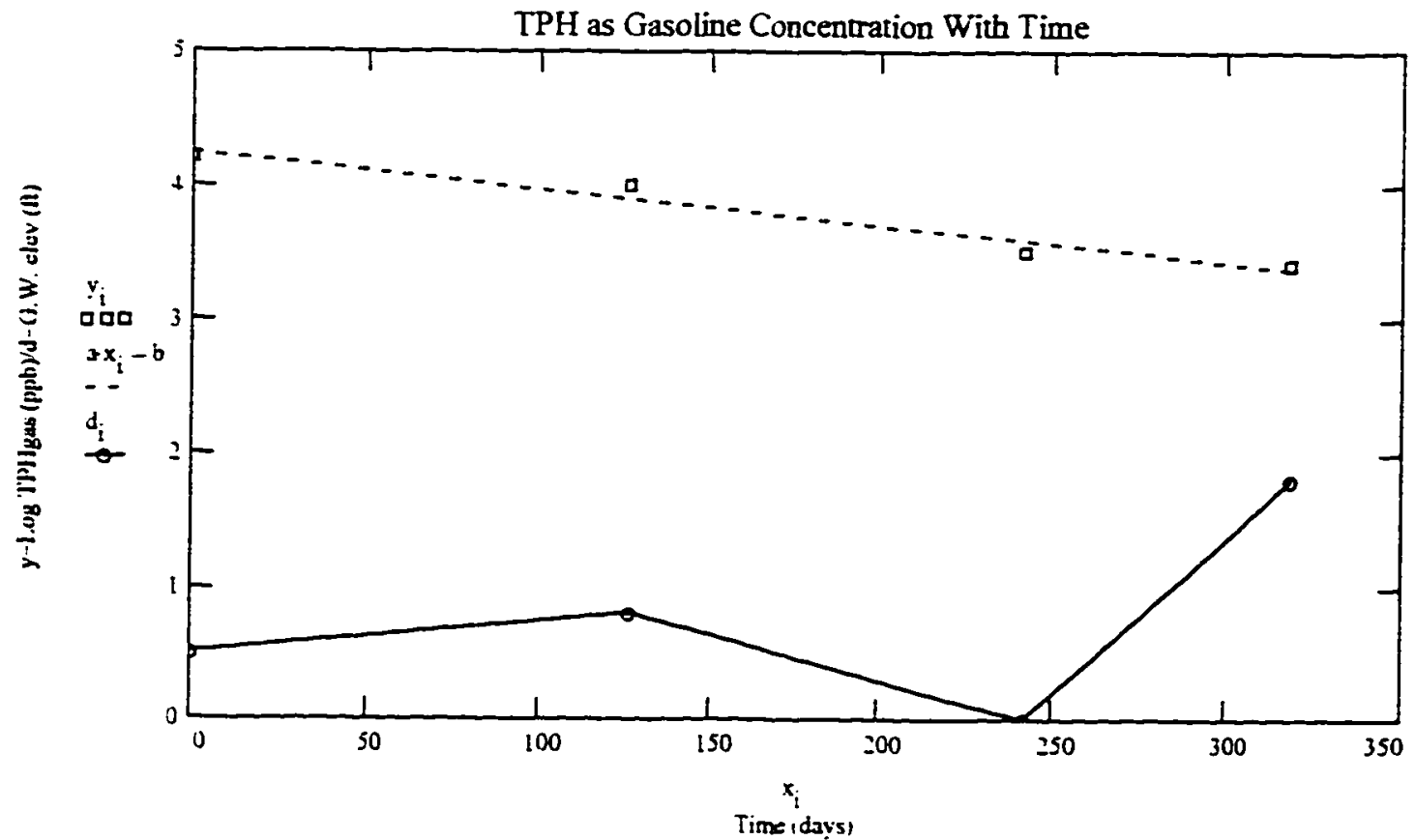




\begin{tabular}{|c|c|c|}
\hline $\begin{array}{l}\text { SCVND Site Number: 07S1W03K02F } \\
\text { Site Address: } 1702 \text { El Camino Real } \\
\text { Site Name: Jones Automotive } \\
\text { City: Santa Clara }\end{array}$ & Days & $\log C$ \\
\hline
\end{tabular}

\section{Contaminant: Benzene - MW-5}

$$
i=0 . .3
$$

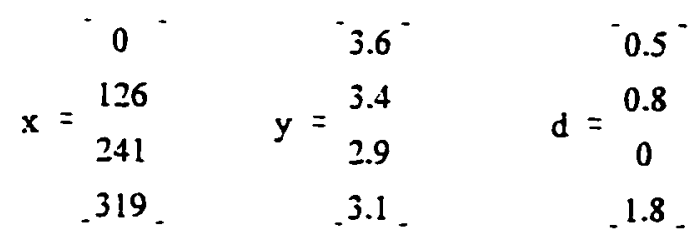

\footnotetext{
$a=\operatorname{slope}(x . y) \quad a=-0.002$

$b=$ intercept $(x, y) \quad b=3.5846$

$\operatorname{cotr}(x, y)=-0.8731$

$\operatorname{corr}(x, y)^{2}=0.7623$
}

Note: Ground water elevations have been adjusted to fit the graph. $0 \mathrm{ft}=56.22 \mathrm{ft}$.

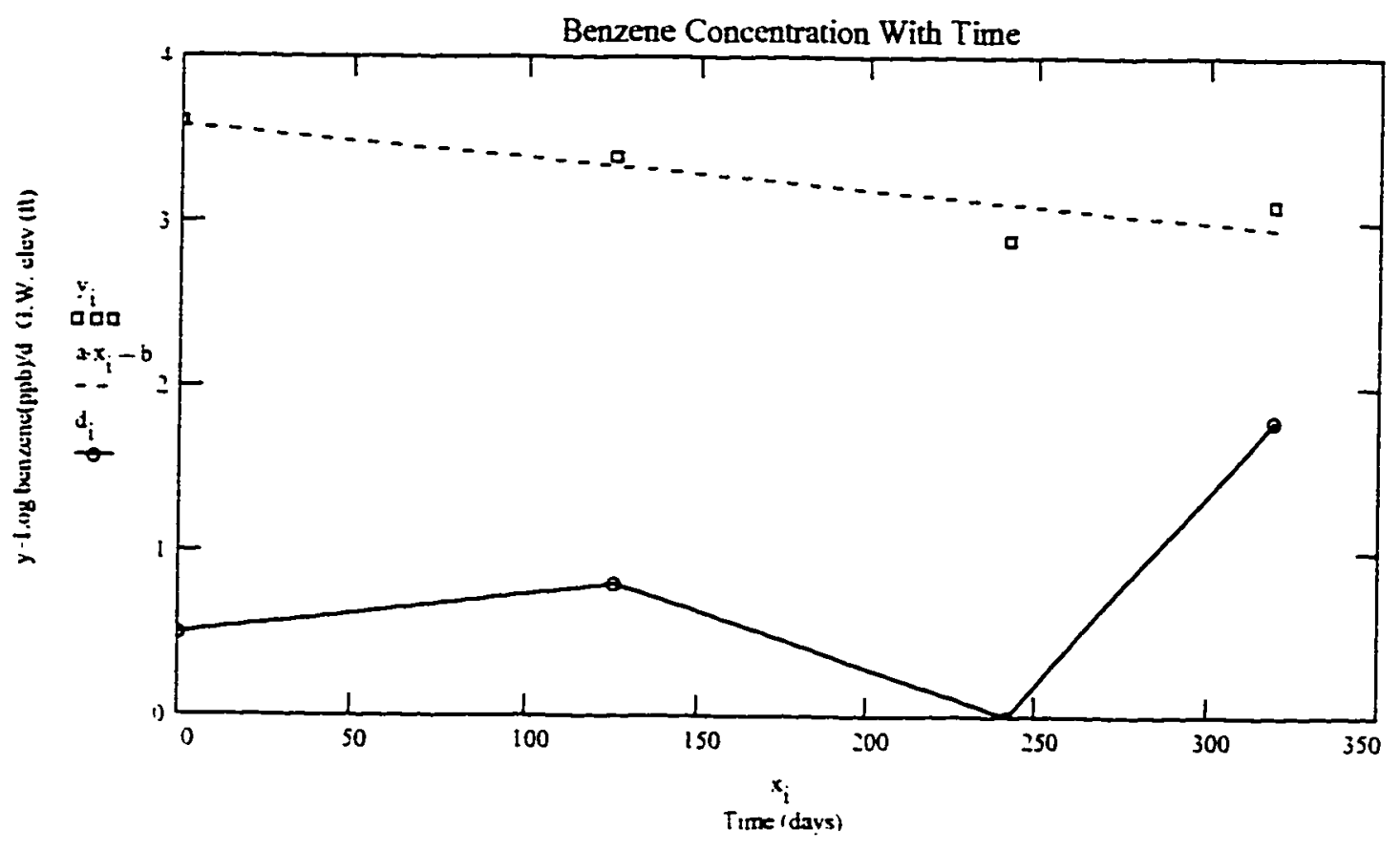


SCWWD Site Number: 07S1W15A02F

Site Address: $230 \mathrm{~N}$. Winchester Blvd.

Site Name: Mobile

City: Santa Clara

$\begin{array}{ccc}\text { Days } & \text { LogC } & \begin{array}{c}\text { G.W. } \\ \text { Elev }\end{array} \\ 0 & 3.6 & 2.2 \\ 53 & 2.6 & 2.1 \\ 228 & 2.3 & 2.0 \\ 320 & 2.0 & 2.3 \\ \mathrm{x}=411 & \mathrm{v}=2.8 & \mathrm{~d}=0 \\ 501 & 2.9 & 2.4 \\ 612 & 2.1 & 2.4 \\ 683 & 2.7 & 2.3 \\ .777 . & .1 .4 . & .2 .2 .\end{array}$

$a=\operatorname{slope}(x . y) a=-0.0013$

$b=$ intercept $(x, y) b=3.0253$

Note: Ground water elevations have been adjusted to $\operatorname{corr}(x, y)=-0.5829$

$\operatorname{corr}(x, y)^{2}=0.3398$ fit the graph. $2.0 \mathrm{ft}=87.86 \mathrm{ft}$. No elevation data was available for the fifth date. so 0 was input.

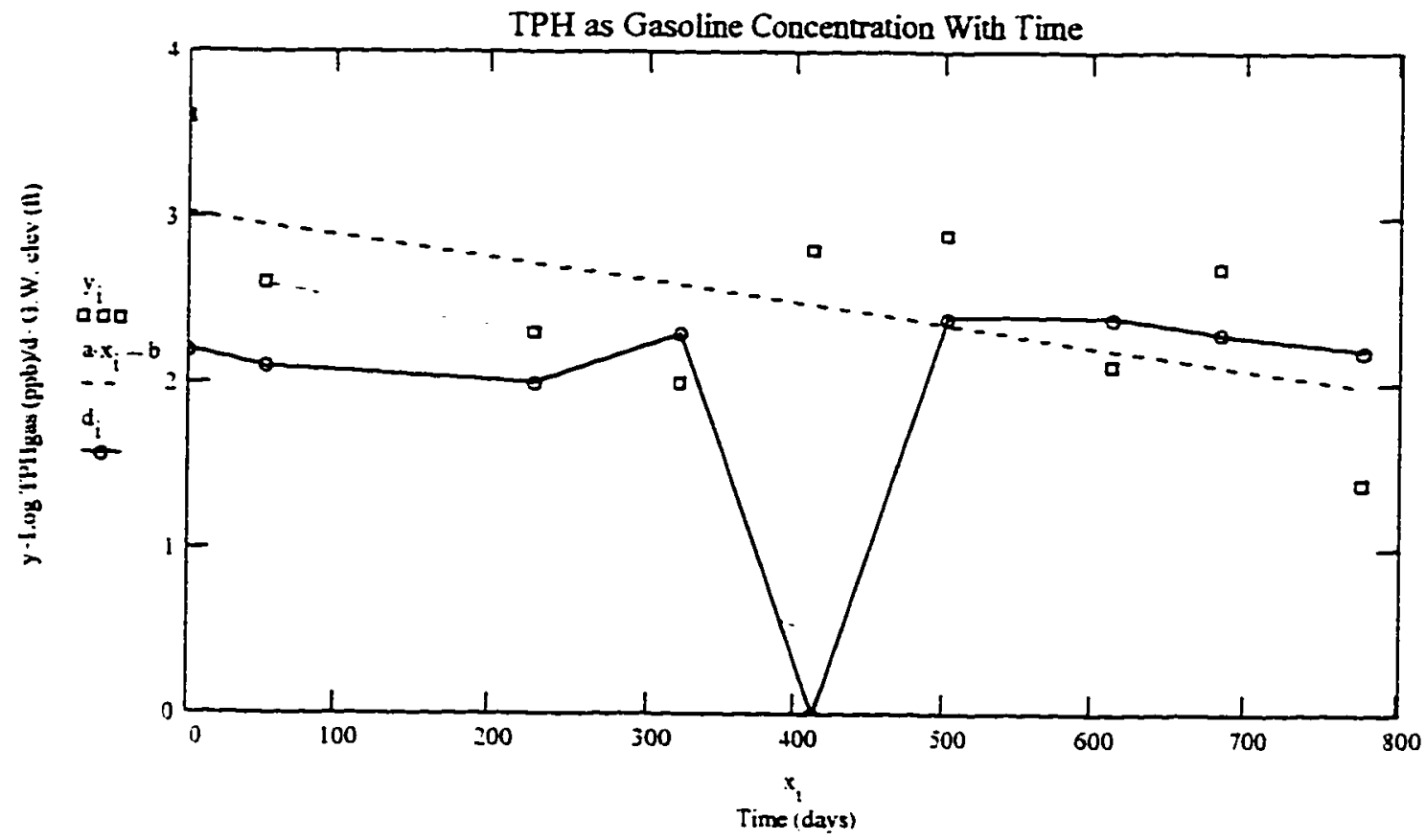


SCWWD Site Number: 07S1W15A02F

Site Address: $230 \mathrm{~N}$. Winchester Bivd.

Site Name: Mobile

City: Santa Clara

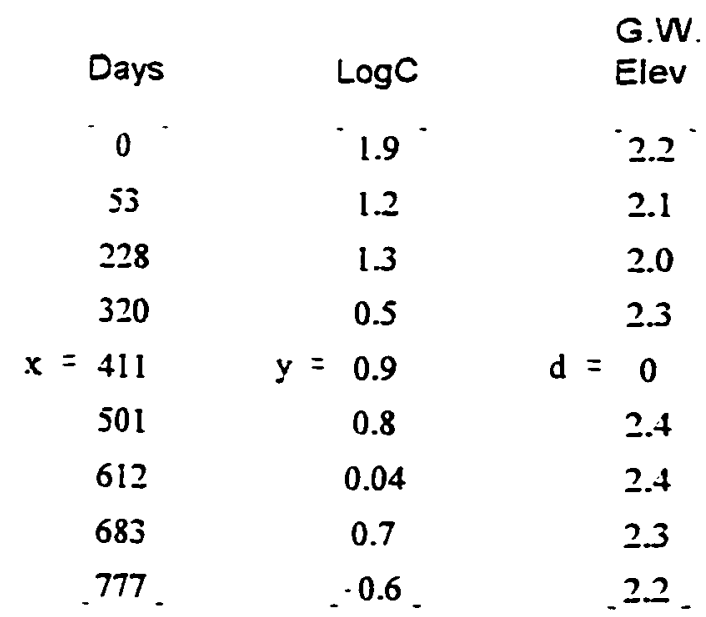

$a=\operatorname{slope}(x . y) a=-0.0023$

$b=$ intercept $(x, y) b=1.6596$

$\operatorname{corr}(x, y)=-0.8552$

$\operatorname{corr}(x, y)^{2}=0.7314$

Note: Ground water elevations have been adjusted to fit the graph. $2.0 \mathrm{ft}=37.86 \mathrm{ft}$. No elevation data was available for the fifth date. so 0 was input

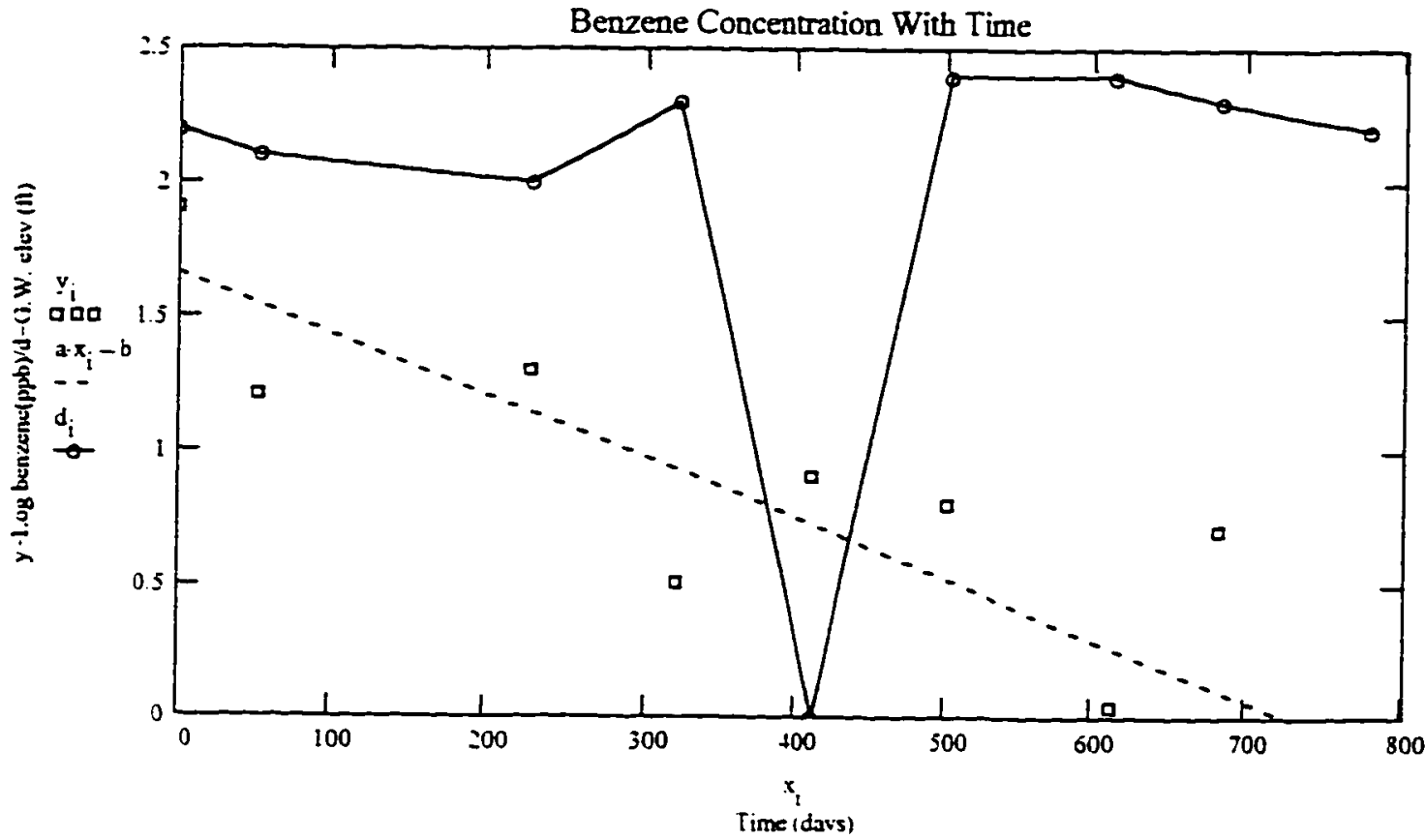


SCWWD Site Number: 0651W34K03F

Site Address: 1810 Richard Avenue

Site Name: Roman Sausae Co.

City: Santa Clara

Contaminant: TPH Gasoline - MW-1

$\begin{array}{ccc}\text { Days } & \text { LogC } & \begin{array}{c}\text { G.W. } \\ \text { Elev }\end{array} \\ 0 & 2.9^{-} & 2.0^{\circ} \\ 211 & 2.9 & 0 \\ 291 & 2.5 & 0.2 \\ \mathrm{x}=396 & \mathrm{y}=1.7 & \mathrm{~d}=3.7 \\ 481 & 1.7 & 1.7 \\ 584 & 1.8 & 0.9 \\ 662 . & -1.4 . & .1 .4 .\end{array}$

$a=\operatorname{slope}(x . y) \quad a=-0.0025$

$b=$ intercept $(x . y) b=3.0642$

$\operatorname{com}(x, y)=-0.9126$

Note: Ground water elevations have been adjusted to fit the graph. $0 \mathrm{ft}=88.51 \mathrm{ft}$.

$\operatorname{corr}(x . y)^{2}=0.8328$

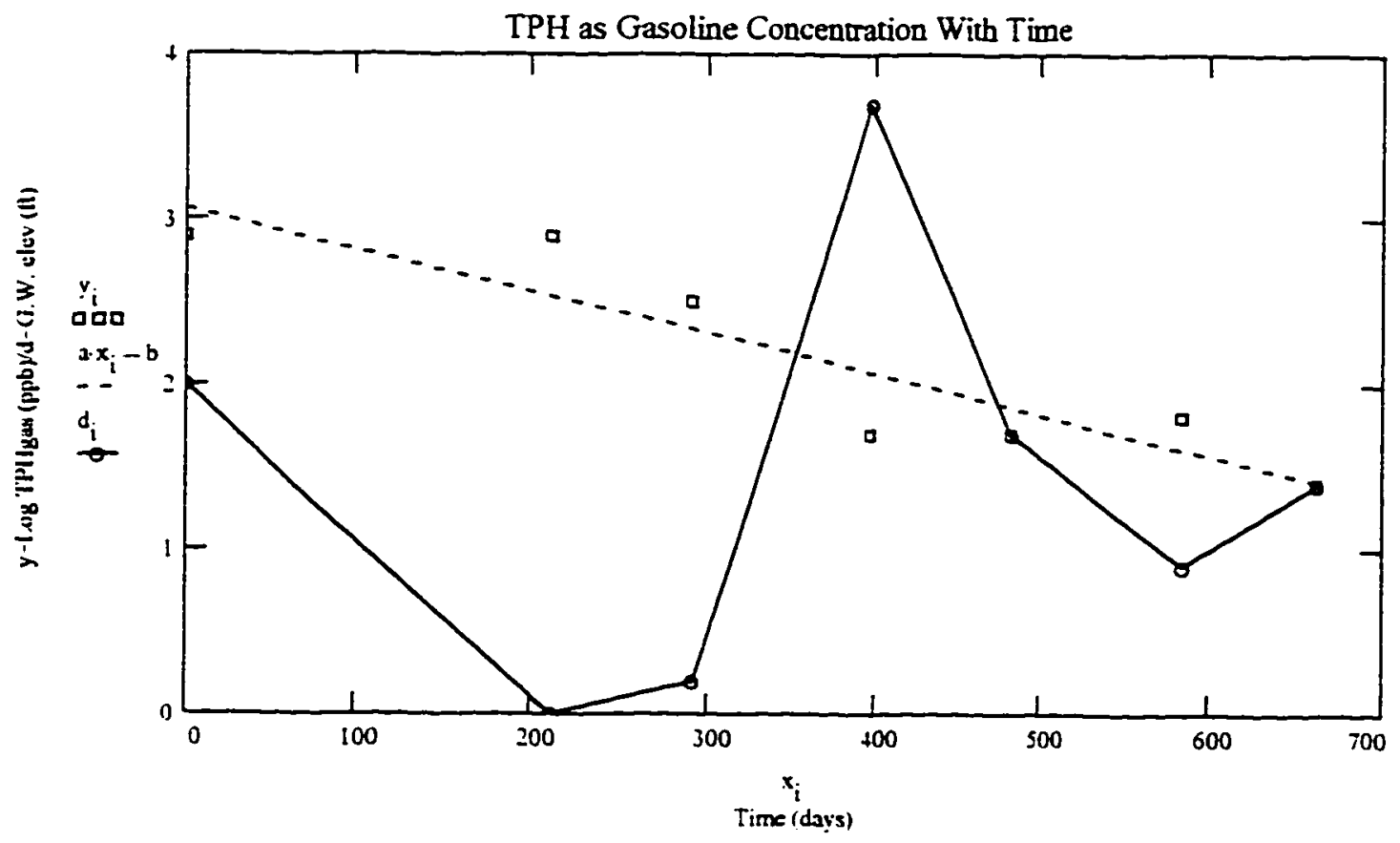


SCWND Site Number: 06S1W34K03F

Site Address: 1810 Richard Avenue

Site Name: Roman Sausae Co.

City: Santa Clara

Contaminant: TPH Gasoline - MW-3

$\begin{array}{ccc}\text { Days } & \text { LogC } & \begin{array}{c}\text { G.W. } \\ \text { Elev }\end{array} \\ 0 & 4.7^{-} & - \\ 211 & 4.6 & 1.9 \\ 291 & 4.4 & 0 \\ 396 & \mathrm{y}=4.3 & \mathrm{~d}=3.5 \\ 481 & 4.2 & 1.6 \\ 584 & 4.4 & 0.7 \\ 662 & 4.0 & 1.3 \\ .757 . & -4.1 & -3.1\end{array}$

$a=\operatorname{slope}(x . y) \quad a=-8.5031 \cdot 10^{-4}$

$b=$ intercept $(x . y) \quad b=4.697$

$\operatorname{corr}(x, y)=-0.8932$

Note: Ground water elevations have been adjusted to $\operatorname{corr}(x . y)^{2}=0.7978$

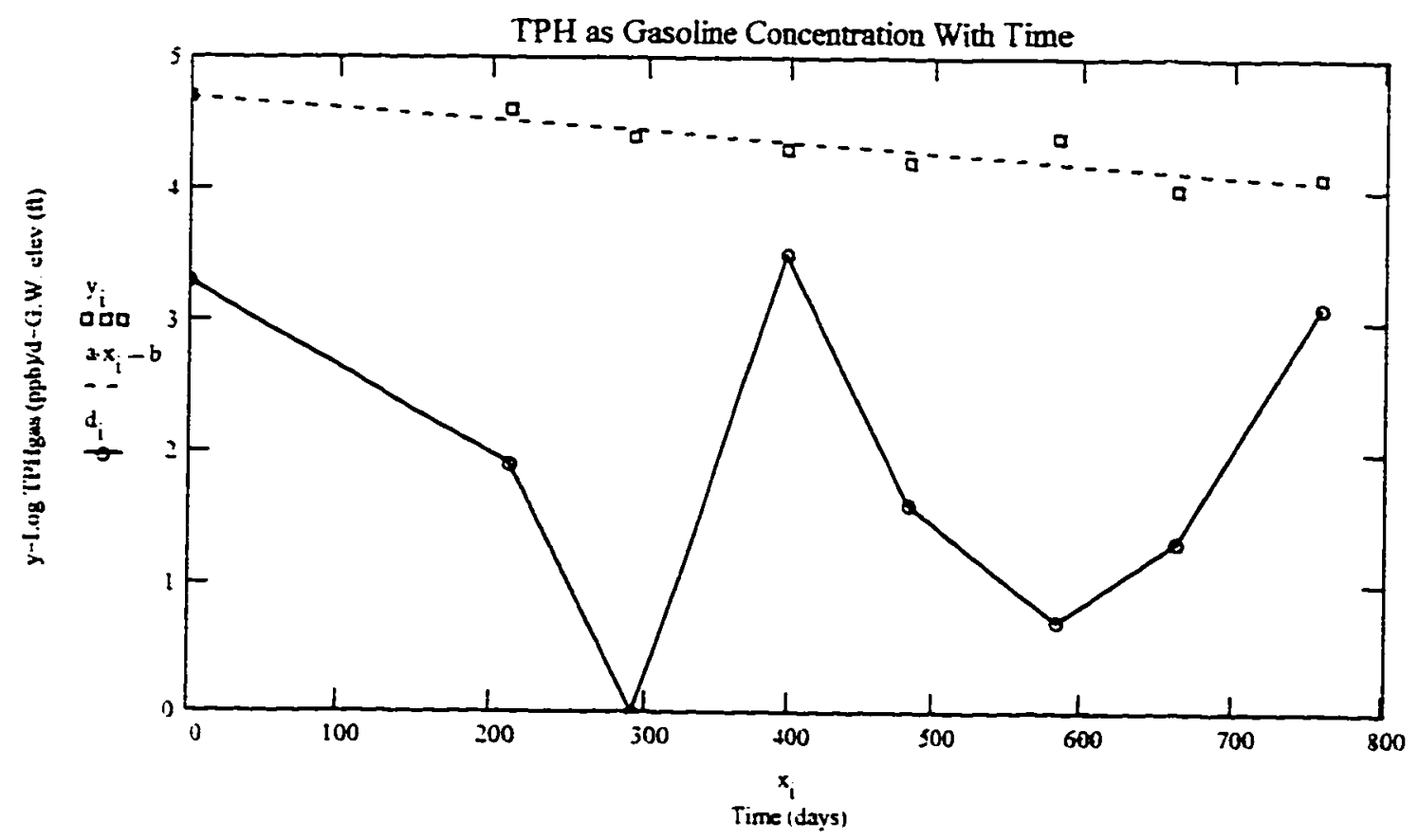


SCWWD Site Number: 06S1W32G01

Site Address: 2455 Lawrence Epwy

Site Name: Shell

City: Santa Clara

Contaminant: TPH Gasoline - MW-2

$$
i=0 . .6
$$

$\begin{array}{ccc}\text { Days } & \text { LogC } & \begin{array}{c}\text { G.W. } \\ \text { Elev }\end{array} \\ -0 & 3.7^{-} & -0.8^{-} \\ 92 & 3.3 & 0.7 \\ 176 & 3.3 & 0 \\ \mathrm{x}=262 & \mathrm{y}=3.4 & \mathrm{~d}=0.4 \\ 360 & 3.3 & 1.1 \\ 647 & 1.9 & 3.9 \\ -729 & -1.4 . & -3.8 .\end{array}$

Note: Ground water elevations have been adjusted to fit the graph. $O \mathrm{ft}=39.71 \mathrm{ft}$.

\footnotetext{
$a=\operatorname{slope}(x . y) \quad a=-0.003$

$b=$ intercept $(x, y) \quad b=3.8681$

$\operatorname{corr}(x . y)=-0.9377$

$\operatorname{cor}(x, y)^{2}=0.8792$
}

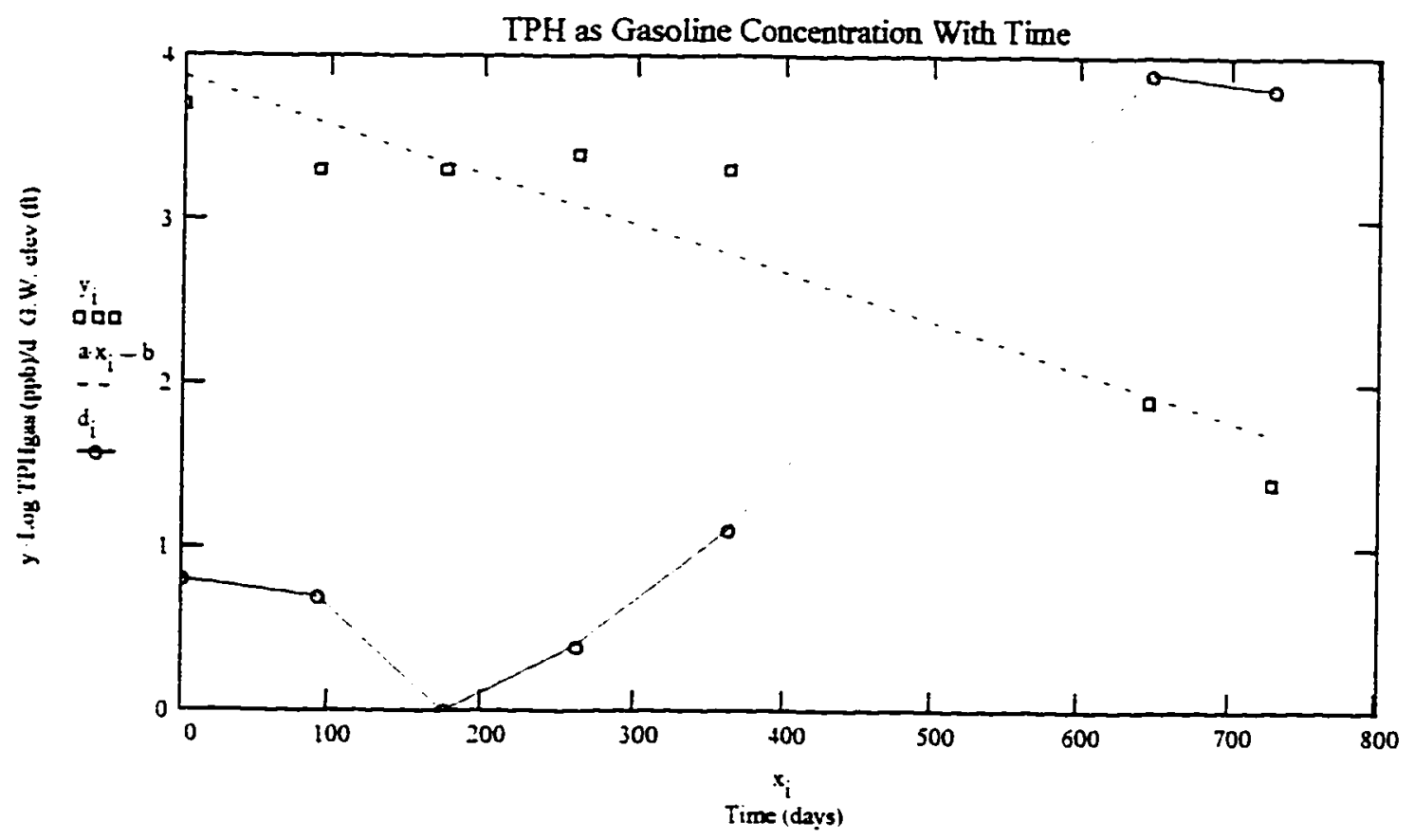




\begin{tabular}{|c|c|c|c|}
\hline SCWWD Site Number: 0651W32G01 & & $\log C$ & $\begin{array}{l}\text { G.W. } \\
\text { Elev }\end{array}$ \\
\hline $\begin{array}{l}\text { Site Address: } 2455 \text { Lawrence Epwy } \\
\text { Site Name: Shell }\end{array}$ & Days & $3.0^{\circ}$ & 0.8 \\
\hline City: Santa Clara & 97 & 2.1 & 0.7 \\
\hline & 176 & 2.8 & 0 \\
\hline Contaminant: Benzene $\quad \therefore$ & 262 & 2.4 & 0.4 \\
\hline & 360 & 2.3 & 1.1 \\
\hline \multirow[t]{6}{*}{$i=0.10$} & $x=647$ & $y=1$ & $d=3.9$ \\
\hline & 729 & -0.6 & 3.8 \\
\hline & 834 & -0.2 & 3.4 \\
\hline & 907 & 0.4 & 3.1 \\
\hline & 1034 & 1.3 & 7.5 \\
\hline & 1133. & -0.6. & -7.8 \\
\hline
\end{tabular}

$a=\operatorname{slope}(x, y) \quad a=-0.0029$

$b=\operatorname{intercept}(x . y) \quad b=\mathbf{2 . 8 8}$

$\operatorname{corr}(x . y)=-0.8487$

$\operatorname{cotr}(x . y)^{2}=0.7203$

Note: Ground water elevations have been adjusted to it the graph. O ft $=39.71 \mathrm{ft}$.

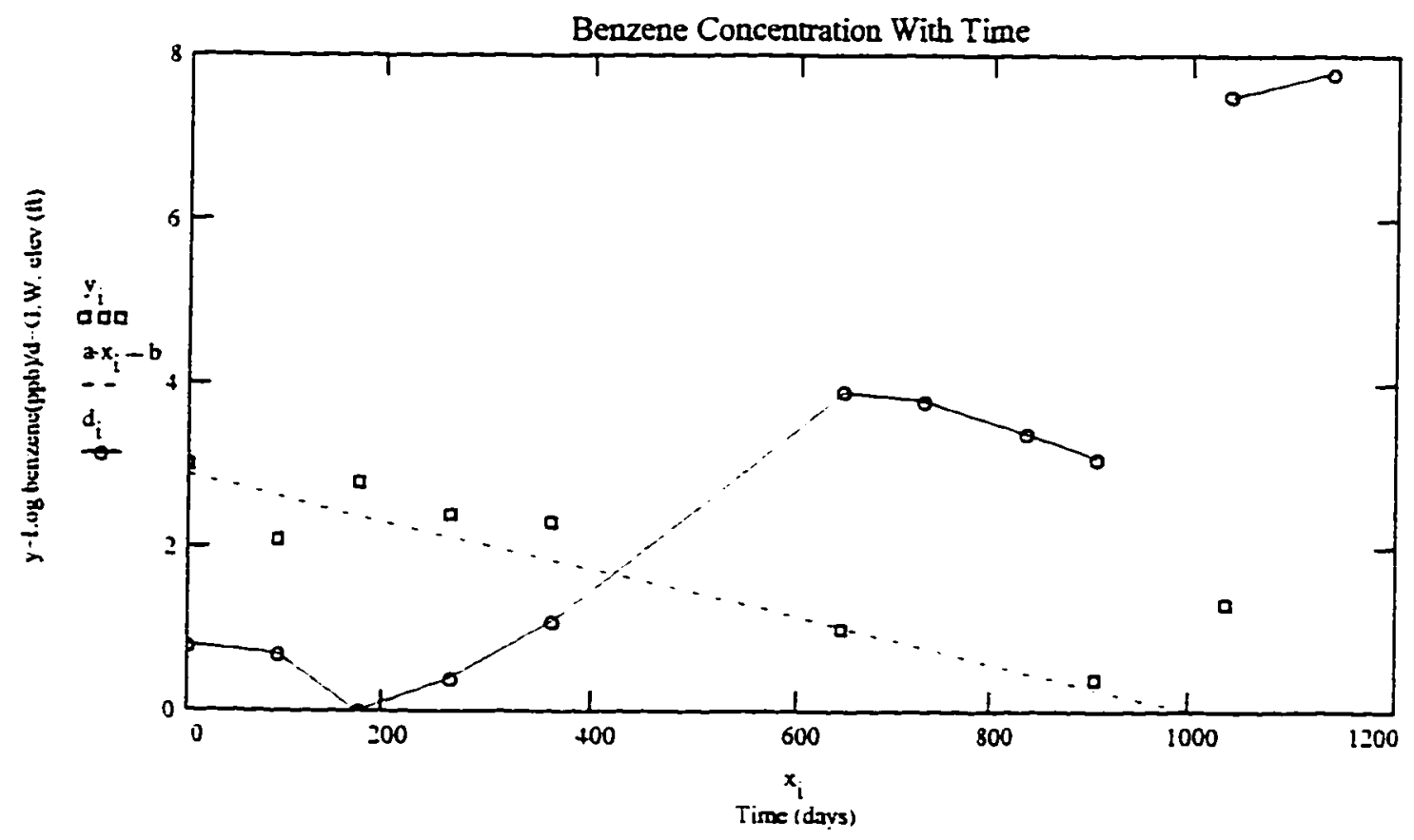


SCVWD Site Number: 06S1W32G01

Site Address: 2455 Lawrence Epwy

Site Name: Shell

City: Santa Clara

Contaminant: TPH Gasoline - MW-4

$\begin{array}{ccc}\text { Days } & \text { LogC } & \begin{array}{c}\text { G.W. } \\ \text { Elev }\end{array} \\ -0 & -3.0^{-} & 0.4 \\ 94 & 3.0 & 0 \\ 196 & \mathrm{y}=1.9 & \mathrm{~d}=2.4 \\ 279 & 1.8 & 2.8 \\ 362 & 2.0 & 4.6 \\ 458 . & -1.4 . & -3.9\end{array}$

$a=\operatorname{slope}(x . y) \quad a=-0.0035$

$b=\operatorname{intercept}(x . y) \quad b=3.0026$

$\operatorname{corr}(x . y)=-0.9048$

Note: Ground water elevations have been adjusted to

$\operatorname{corr}(x, y)^{2}=0.8187$

fit the graph. $O \mathrm{ft}=47.33 \mathrm{ft}$.

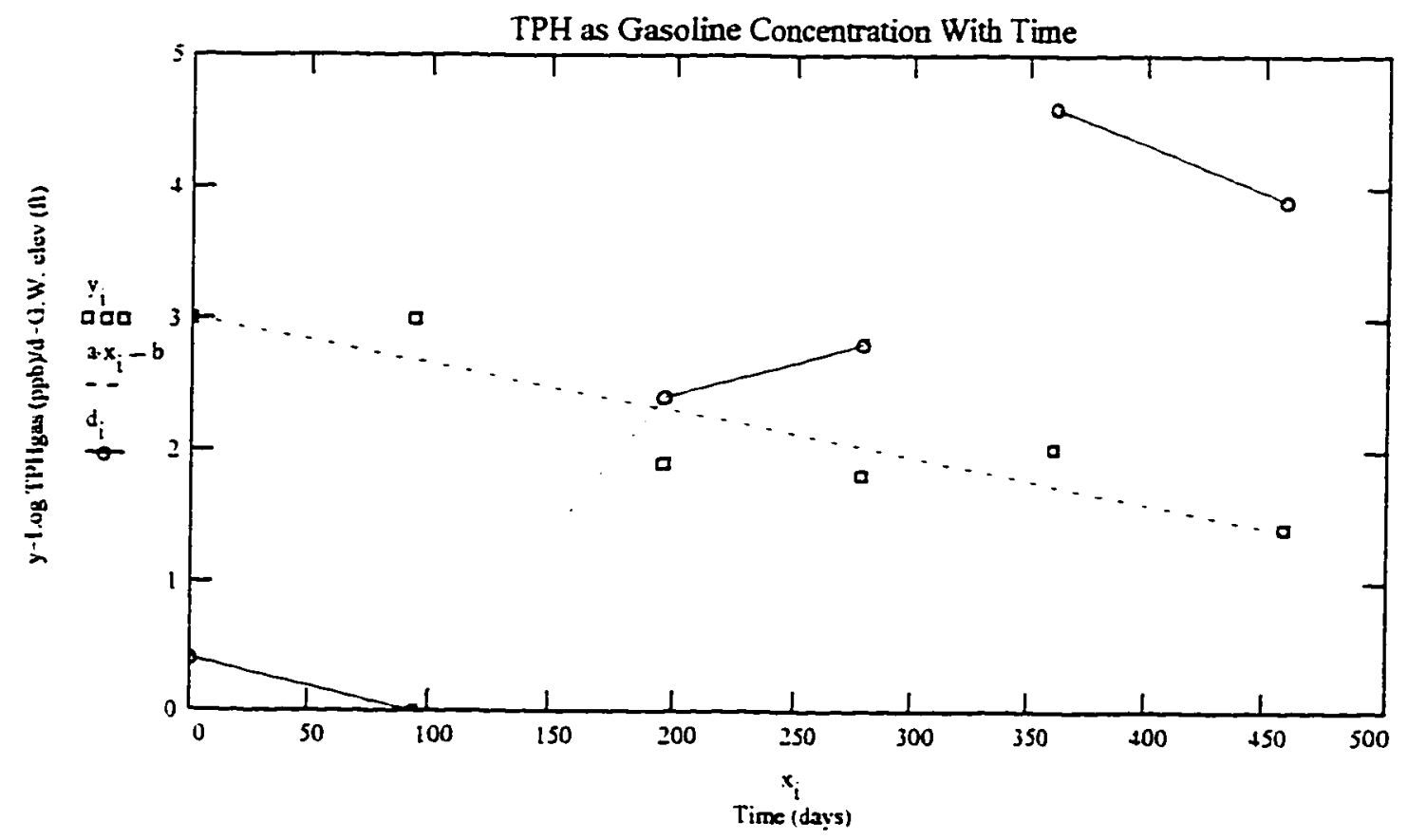


SCWWD Site Number: 06S1W32G01

Site Address: 2455 Lawrence Epwy

Site Name: Shell

City: Santa Clara

Contaminant: Benzene - MW-4

$$
i=0 . .6
$$

$\begin{array}{ccc}\text { Days } & \text { LogC } & \begin{array}{c}\text { G.W. } \\ \text { Elev }\end{array} \\ 0 & 2.5 & 0.4 \\ 94 & 2.2 & 0 \\ 196 & 0.5 & 2.4 \\ \mathrm{x}= & \mathrm{y}=1.0 & \mathrm{~d}=2.8 \\ 362 & 1.2 & 4.6 \\ 458 & 0 & 3.9 \\ .539 . & -0.6 . & -5.0 .\end{array}$

Note: Ground water elevations have been adjusted to fit the graph. $0 \mathrm{ft}=47.33 \mathrm{ft}$.

Benzene Concentration With Time

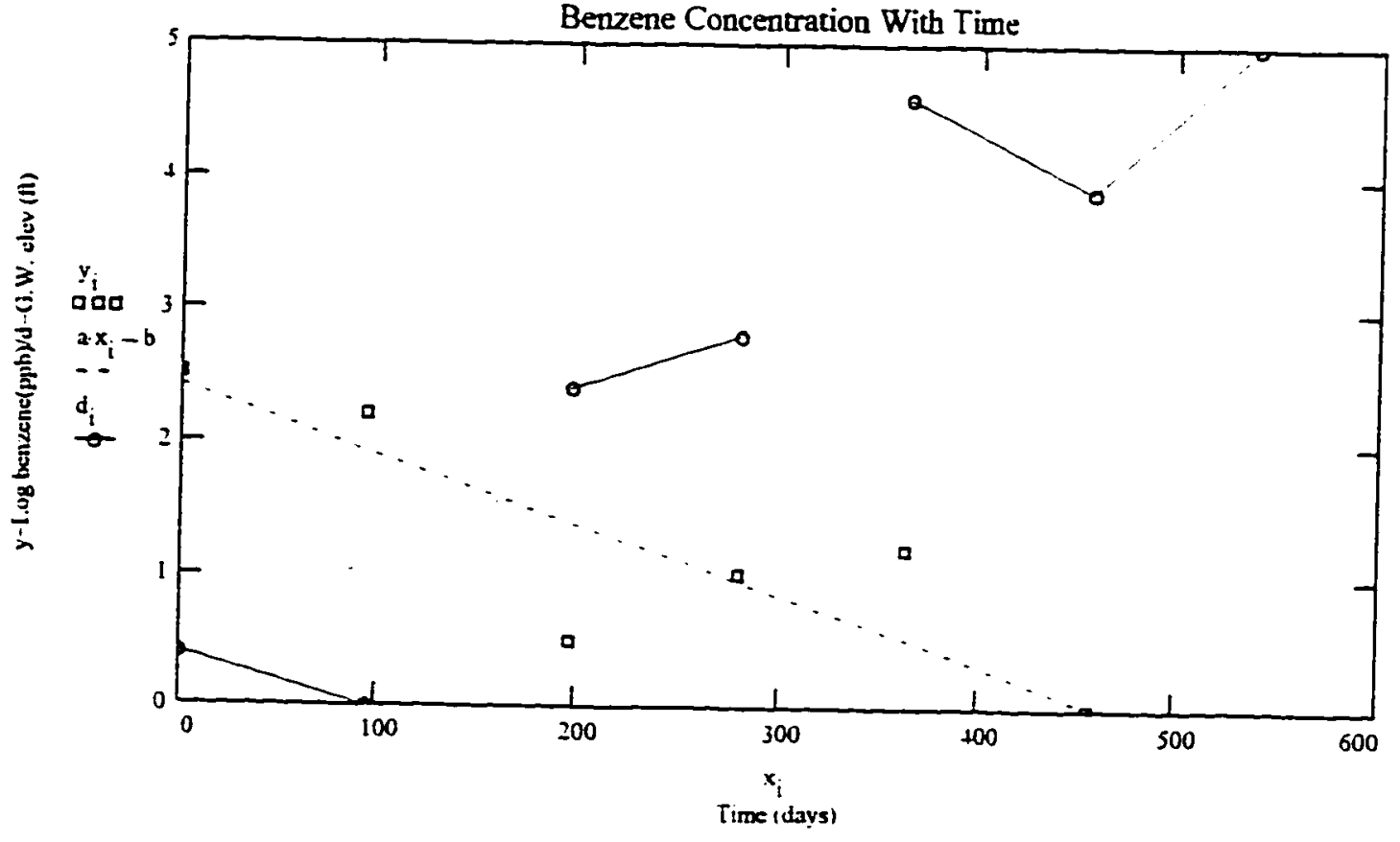


SCWWD Site Number: 07S1W04J01 Site Address: 2540 El Camino Real Site Name: Shell

City: Santa Clara

Contaminant: TPH Gasoline - MW-2

$$
i=0 . .10
$$

$\begin{array}{ccc}\text { Days } & \text { LogC } & \begin{array}{c}\text { G.W } \\ \text { Elev }\end{array} \\ 0 & -3.3 & -0.1 \\ 89 & 2.9 & 0 \\ 186 & 2.4 & 1.1 \\ 273 & 2.6 & 1.0 \\ 327 & 2.9 & 2.7 \\ \mathrm{x}=510 & \mathrm{y}=1.4 & \mathrm{~d}=2.2 \\ 599 & 1.8 & 2.7 \\ 693 & 1.0 & 2.4 \\ 758 & 1.4 & 2.3 \\ 872 & 2.1 & 4.0 \\ 986 . & -1.4 & 4.7\end{array}$

Note: Ground water elevations have been adjusted to fit the graph. $0 \mathrm{ft}=68.04 \mathrm{f} / 3$.

$\operatorname{corr}(x, y)=-0.8129$

$\operatorname{cor}(x, y)^{2}=0.6608$

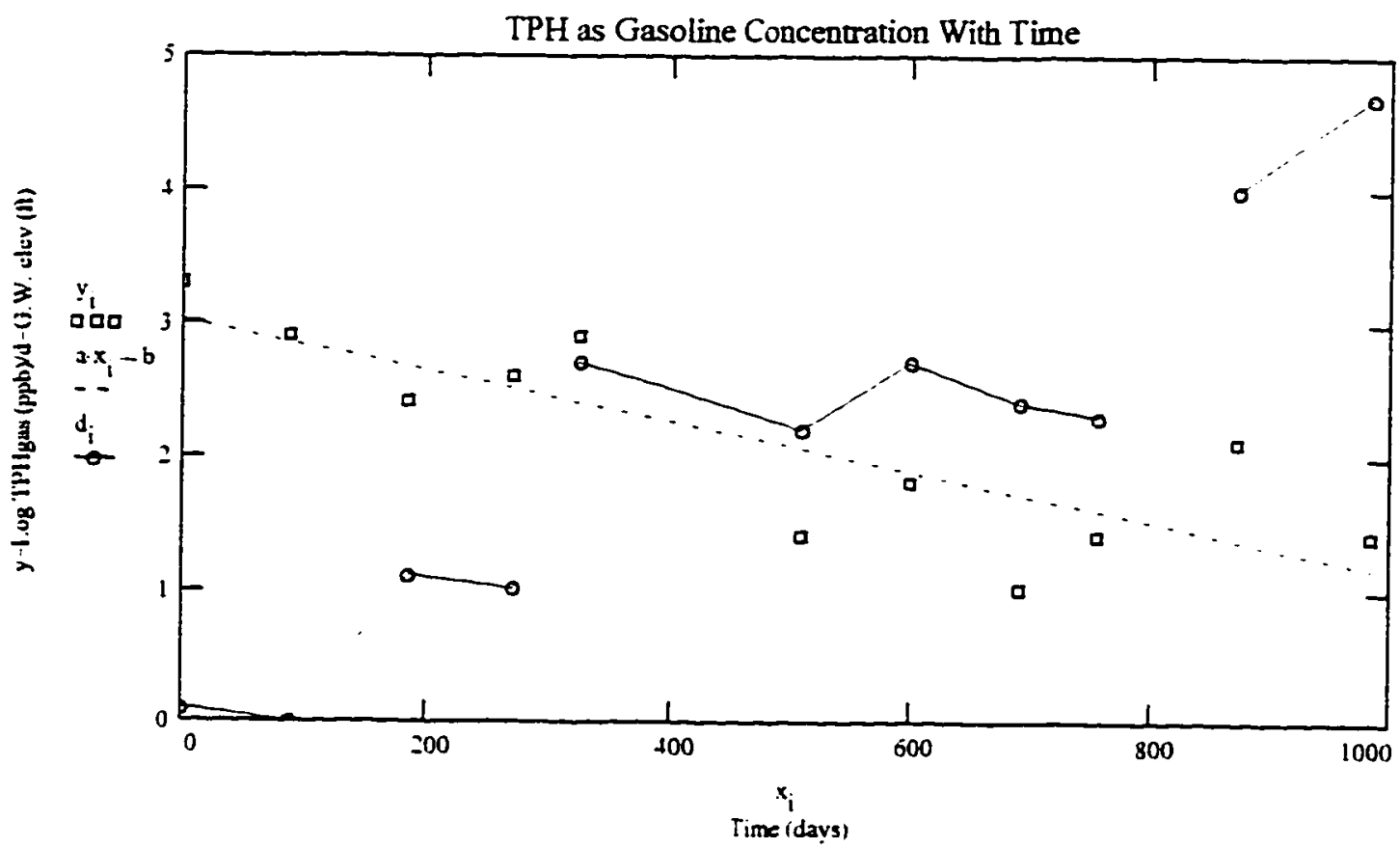


SCWWD Site Number: 07S1W04J01

Site Address: 2540 El Camino Real

Site Name: Shell

City: Santa Clara

Contaminant: Benzene - MW-2

$$
i=0.10
$$

\footnotetext{
$a=\operatorname{slope}(x, y) \quad a=-0.0027$

$b=$ intercept $(x . y) \quad b=2.1844$

$\operatorname{corr}(x, y)=-0.9081$

$\operatorname{corr}(x, y)^{2}=0.8246$
}

$\begin{array}{crc}\text { Days } & \text { LogC } & \begin{array}{c}\text { G.W. } \\ \text { Elev }\end{array} \\ 0 & 2.1 & 0.1 \\ 89 & 1.8 & 0 \\ 186 & 1.7 & 1.1 \\ 273 & 1.6 & 1.0 \\ 327 & 1.5 & 2.7 \\ \mathrm{x}=510 & \mathrm{y}=1.3 & \mathrm{~d}=2.2 \\ 599 & 0.2 & 2.7 \\ 693 & 0.4 & 2.4 \\ 758 & -0.6 & 2.3 \\ 872 & 0.6 & 4.0 \\ 986 & -0.6 & -4.7\end{array}$

Note: Ground water elevations have been adjusted to fit the graph. $0 \mathrm{ft}=68.04 \mathrm{ft} / 3$.

Benzene Concentration With Time

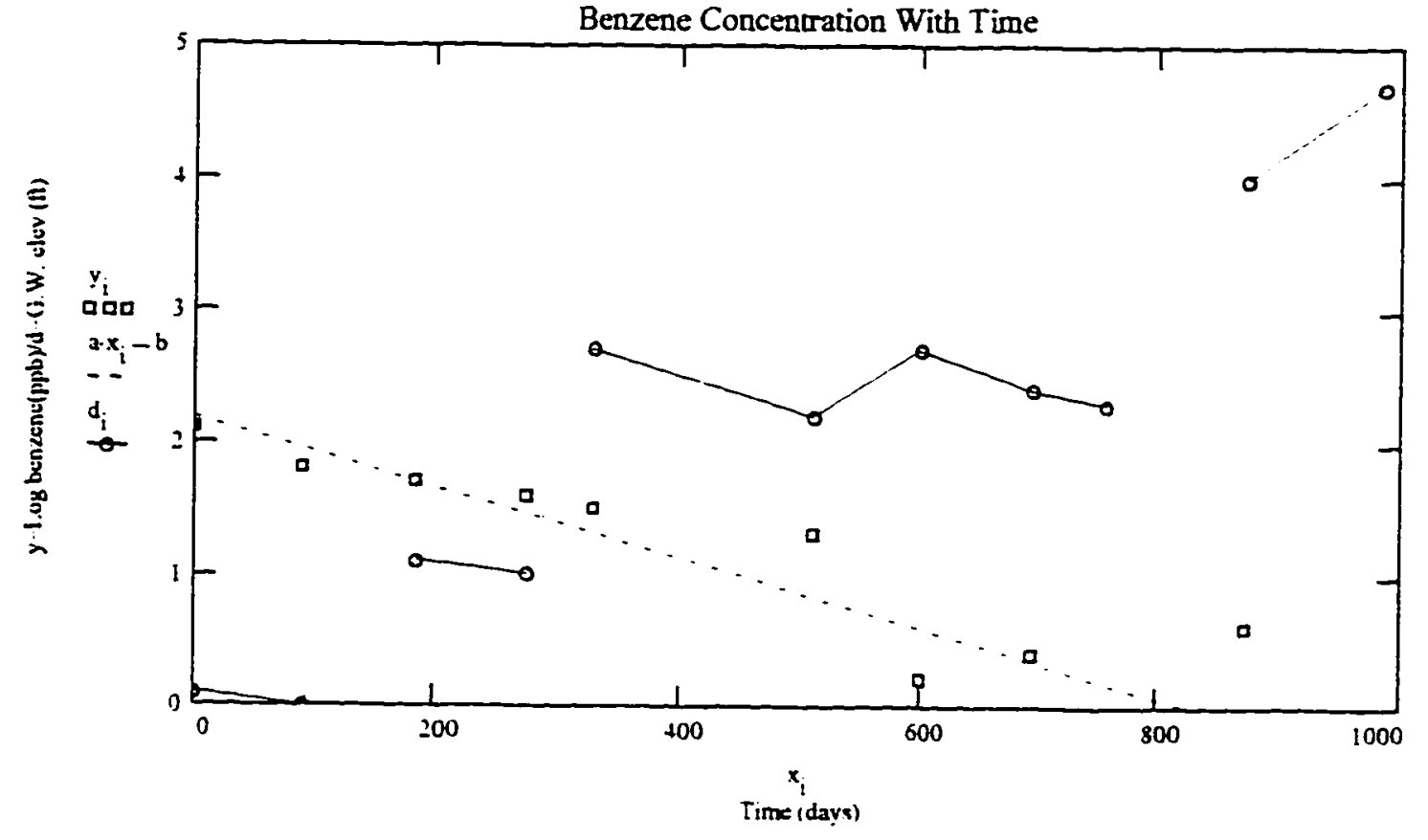




\begin{tabular}{|c|c|c|c|}
\hline \multirow{2}{*}{$\begin{array}{l}\text { SCWWD Site Number: 07S1W04J01 } \\
\text { Site Address: } 2540 \text { El Camino Real } \\
\text { Site Name: Sheil } \\
\text { City: Santa Clara }\end{array}$} & \multirow[t]{2}{*}{ Days } & $\log C$ & $\begin{array}{l}\text { GW } \\
\text { Elev }\end{array}$ \\
\hline & & $4.0^{\circ}$ & $0.2^{-}$ \\
\hline \multirow{3}{*}{ Contaminant: TPH Gasoline - MW-1 } & 87 & 3.9 & 0.2 \\
\hline & 141 & 3.8 & 0 \\
\hline & 332 & 3.7 & 1.3 \\
\hline \multirow{18}{*}{$\begin{array}{l}b=\operatorname{intercept}(x . y) b=3.9389 \\
\operatorname{com}(x . y)=-0.9277\end{array}$} & 422 & 3.3 & 1.9 \\
\hline & 517 & 3.2 & 1.5 \\
\hline & 582 & 3.2 & 1.4 \\
\hline & 692 & 3.2 & 3.1 \\
\hline & 806 & 3.2 & 3.8 \\
\hline & 867 & 3.1 & 3.5 \\
\hline & $x=965$ & $y=2.9$ & $d=3.4$ \\
\hline & 1044 & 2.8 & 3.6 \\
\hline & 1133 & 2.7 & 4.0 \\
\hline & 1228 & 3.3 & 3.7 \\
\hline & 1317 & 2.5 & 3.5 \\
\hline & 1422 & 2.7 & 4.7 \\
\hline & 1501 & 2.9 & 4.9 \\
\hline & 1591 & 2.5 & 4.9 \\
\hline & 1684 & 2.5 & 4.7 \\
\hline & 1769 & 2.0 & 5.0 \\
\hline & 1867 & 2.0 & 5.3 \\
\hline & .1966. & 1.4 & .5 .2$. \\
\hline
\end{tabular}

Note: Ground water elevations have been adjusted to fit the graph. $\mathrm{Oft}=70.7 \mathrm{t} / 3$. 


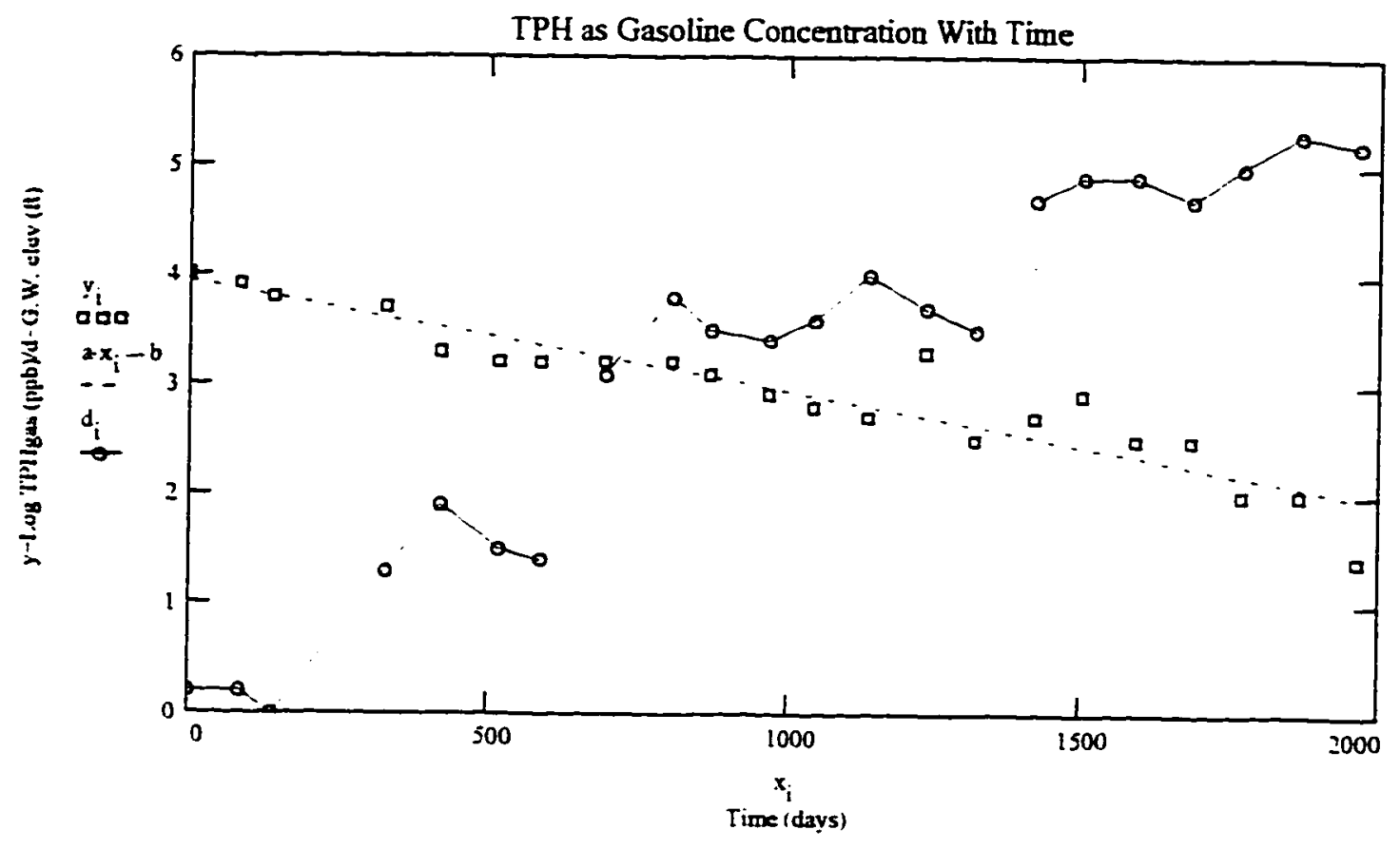




\section{SCVND Site Number: 07S1W04J01}

Site Address: 2540 El Camino Real

Site Name: Shell

City: Santa Clara

$\begin{array}{ccc}\text { Days } & \text { LogC } & \begin{array}{c}\text { G.W. } \\ \text { Elev }\end{array} \\ 0 & 3.5 & 0.2 \\ 87 & 3.1 & 0.2 \\ 141 & 3.2 & 0 \\ 332 & 2.9 & 1.3 \\ 422 & 2.3 & 1.9 \\ 517 & 2.3 & 1.5 \\ 582 & 2.2 & 1.4 \\ 692 & 2.2 & 3.1 \\ 806 & 2.4 & 3.8 \\ 867 & 2.2 & 3.5 \\ 965 & 1.9 & \mathrm{~d}=3.4 \\ \mathrm{x}=4.6 & 3.6 \\ 1133 & 2.0 & 4.0 \\ 1228 & 1.8 & 3.7 \\ 1317 & 2.5 & 3.5 \\ 1422 & 1.6 & 4.7 \\ 1501 & 1.8 & 4.9 \\ 1591 & 2.1 & 4.9 \\ 1684 & 1.8 & 4.7 \\ 1769 & 1.5 & 5.0 \\ 1867 & 0.9 & 5.3 \\ 1966 . & 2.2 & 5.2 .\end{array}$

$\mathrm{i}=0 . .21$

Contaminant: Benzene - MW-1

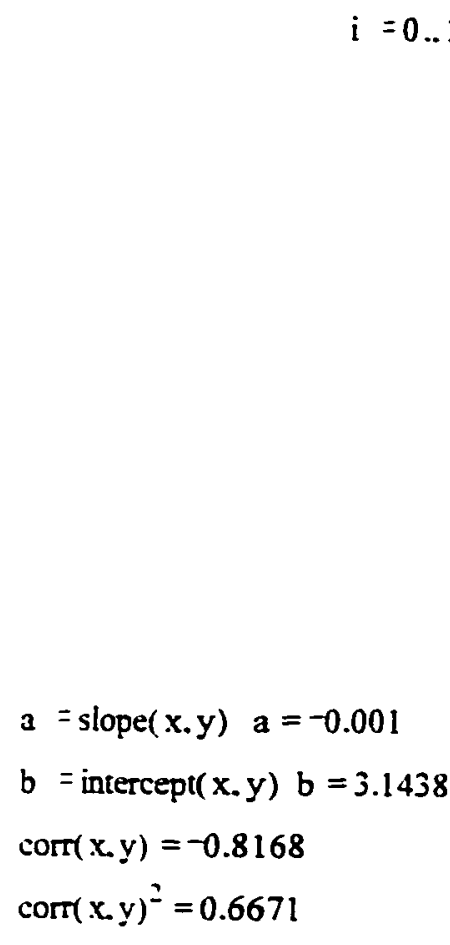

$a=\operatorname{slope}(x, y) \quad a=-0.001$

$b=$ intercept( $x . y) \quad b=3.1438$

$\operatorname{corr}(x, y)=-0.8168$

$\operatorname{corr}(x, y)^{2}=0.6671$

(n)




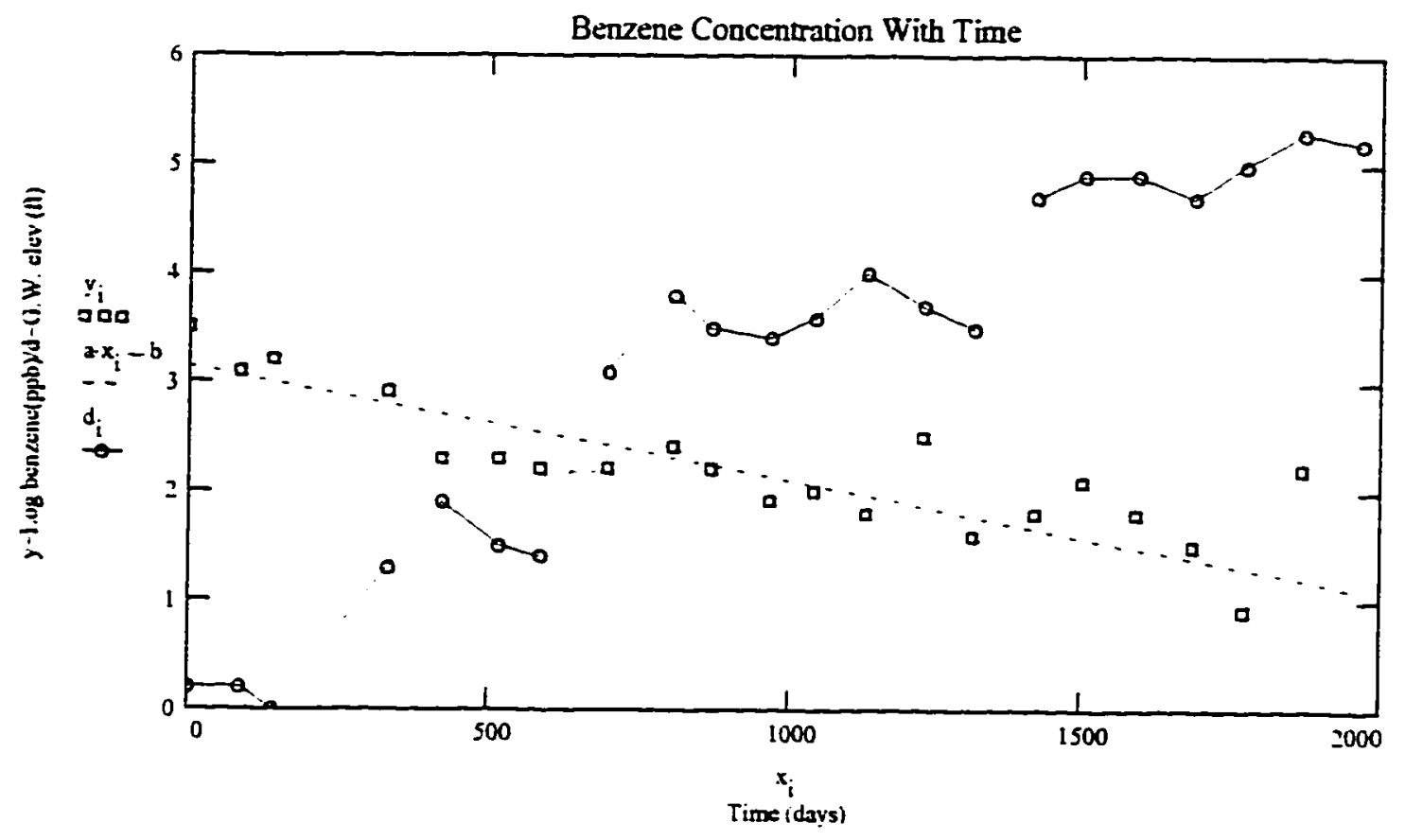


SCWND Site Number: 07S1W05G01

Site Address: 3499 El Camino Real

Site Name: Unocal \#4425

City: Santa Clara

Contaminant: TPH Gasoline

$i=0 . .10$

$\begin{array}{cr}\text { Days } & \log C \\ -0 & -4.7^{-} \\ 92 & 4.7 \\ 183 & 4.0 \\ 275 & 4.2 \\ 365 & 4.0 \\ x=457 & y=4.3 \\ 548 & 3.8 \\ 822 & 3.2 \\ 913 & 2.9 \\ 1005 & 3.8 \\ 1095 & 2.1 .\end{array}$

Note: No ground water elevations were available $\operatorname{corr}(x, y)=-0.8619$ $\operatorname{com}(x . y)^{2}=0.7429$

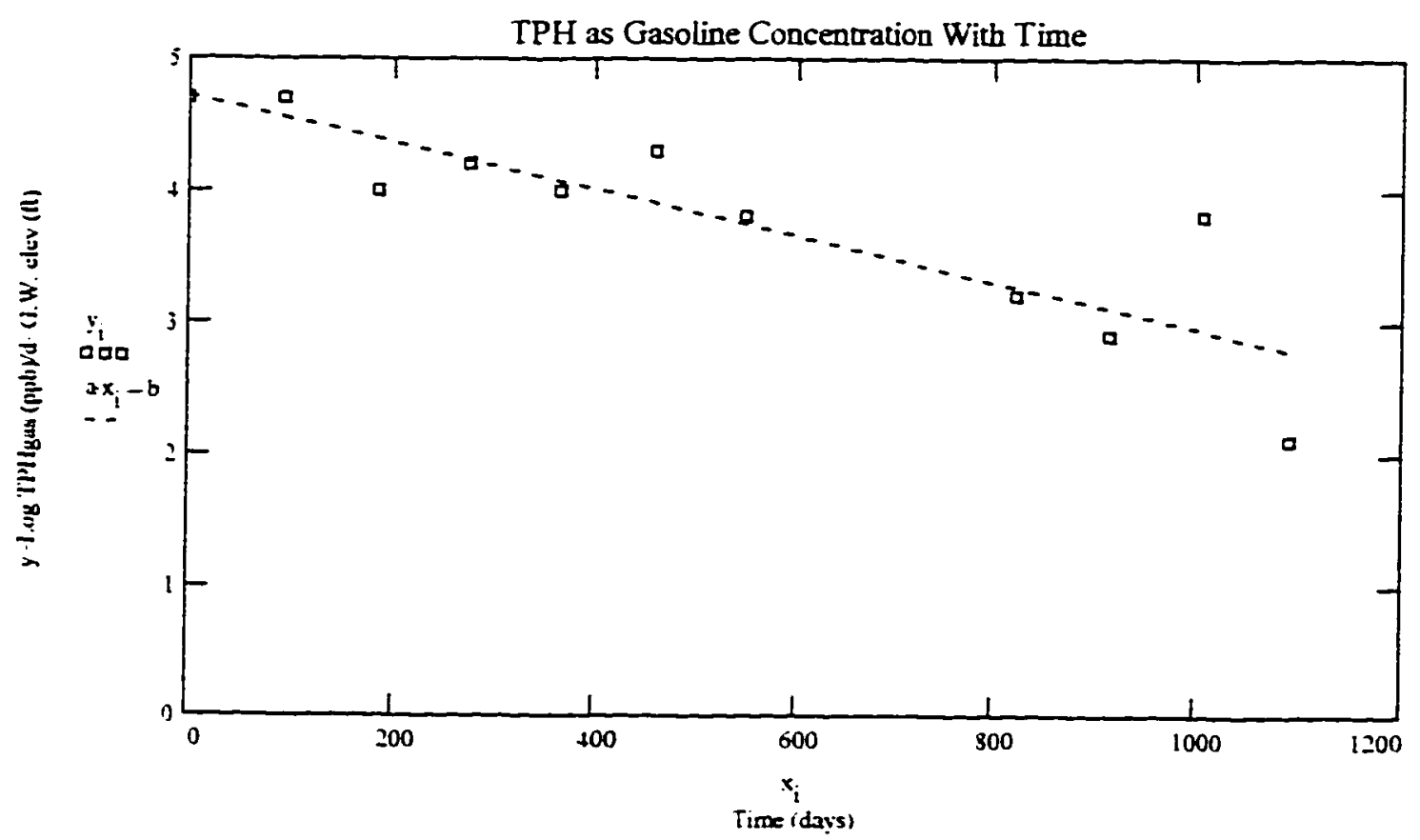


SCVND Site Number: 0651W22L01 Site Address: 2017 Agnew Road Site Name: Wolco Oil Co. City: Sunnyvale

Contaminant: TPH Gasoline

$$
\begin{aligned}
& a=\operatorname{slope}(x, y) \quad a=-0.0014 \\
& b=\operatorname{intercept}(x, y) \quad b=5.0383 \\
& \operatorname{corr}(x, y)=-0.8672 \\
& \operatorname{corr}(x, y)^{2}=0.7521
\end{aligned}
$$

\begin{tabular}{cr} 
Days & LogC \\
-0 & 5.4 \\
127 & 4.8 \\
254 & 4.8 \\
334 & 4.4 \\
428 & 4.2 \\
578 & 3.6 \\
697 & 4.4 \\
806 & 3.6 \\
892 & 4.1 \\
$x=985$ & $y .8$ \\
1069 & 3.4 \\
1166 & 3.0 \\
1257 & 3.7 \\
1347 & 4.3 \\
1460 & 3.4 \\
1529 & 2.9 \\
1621 & 3.2 \\
1712 & 2.2 \\
1801 & 2.0 \\
\hline
\end{tabular}

\section{Note: No ground water} elevation data was available.

TPH as Gasoline Concentration With Time

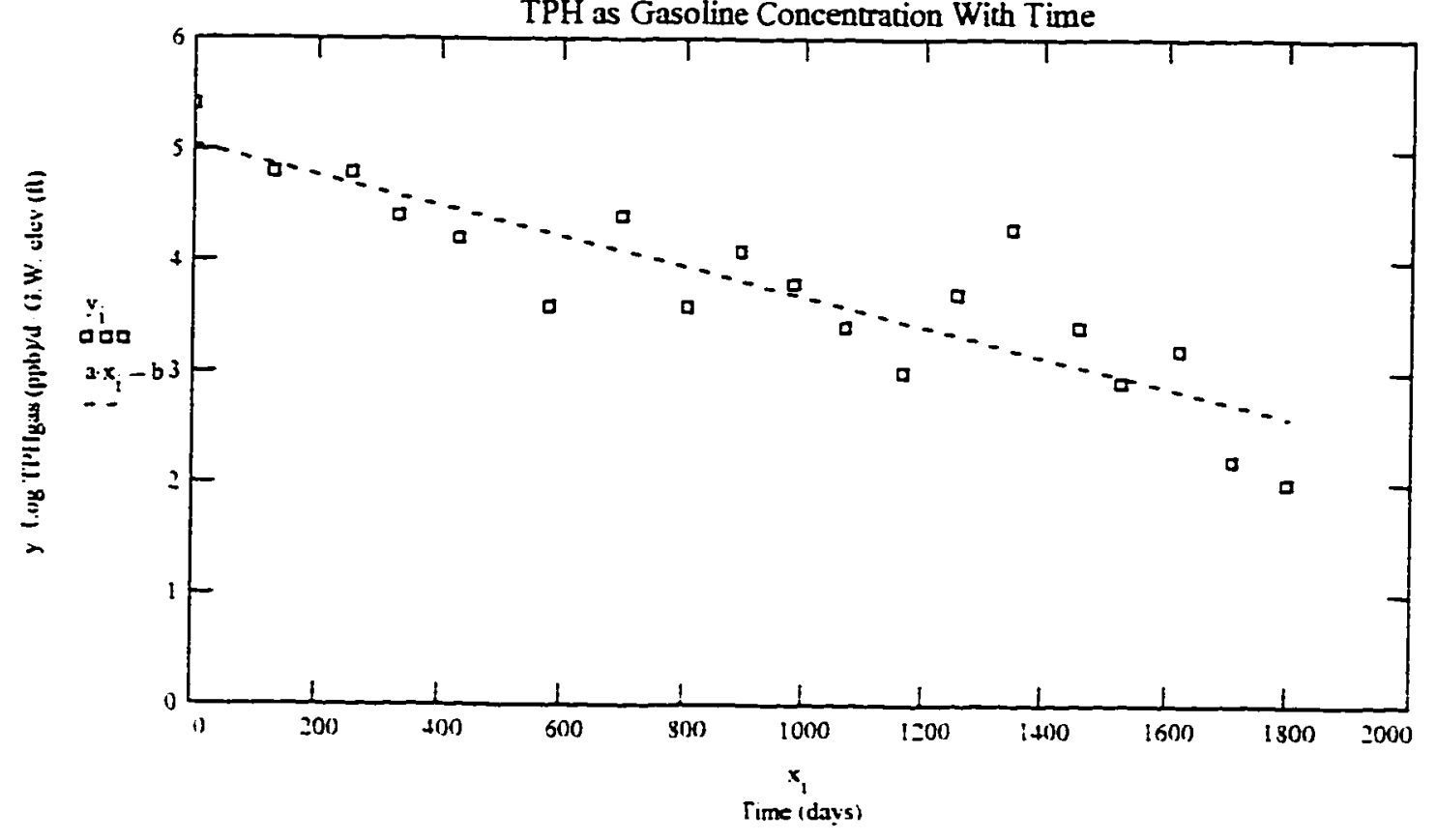




\begin{tabular}{|c|c|c|c|}
\hline \multirow{5}{*}{$\begin{array}{l}\text { SCWWD Site Number: 06S1W22L01 } \\
\text { Site Address: } 2017 \text { Agnew Road } \\
\text { Site Name: Wolco Oil Co. } \\
\text { City: Sunnyvale }\end{array}$} & Days & $\log C$ & \\
\hline & 0 & 40 & \\
\hline & 127 & 2.8 & \\
\hline & 254 & 3.0 & \\
\hline & 334 & 2.5 & \\
\hline Contaminant: Benzene & 428 & 3.0 & \\
\hline$i=0.15$ & 578 & 2.4 & \\
\hline $1-0 . .13$ & 697 & 2.1 & \\
\hline & 806 & 2.2 & $\begin{array}{l}\text { Note: No ground } \\
\text { water elevation data }\end{array}$ \\
\hline & $89 ?$ & $y=2.2$ & was available. \\
\hline & 985 & 1.6 & \\
\hline & 1069 & 1.4 & \\
\hline$=\operatorname{slope}(x . y) \quad a=-0.0017$ & 1166 & 0.8 & \\
\hline$-\operatorname{siope}(x, y) a=0.0017$ & 1257 & 2.5 & \\
\hline$=$ intercept $(x . y) b=3.4617$ & 1347 & 1.9 & \\
\hline $\operatorname{orr}(x, y)=-0.7934$ & 1460 & 1.7 & \\
\hline orr $(x . y)^{2}=0.6295$ & 1529 & 0.6 & \\
\hline
\end{tabular}

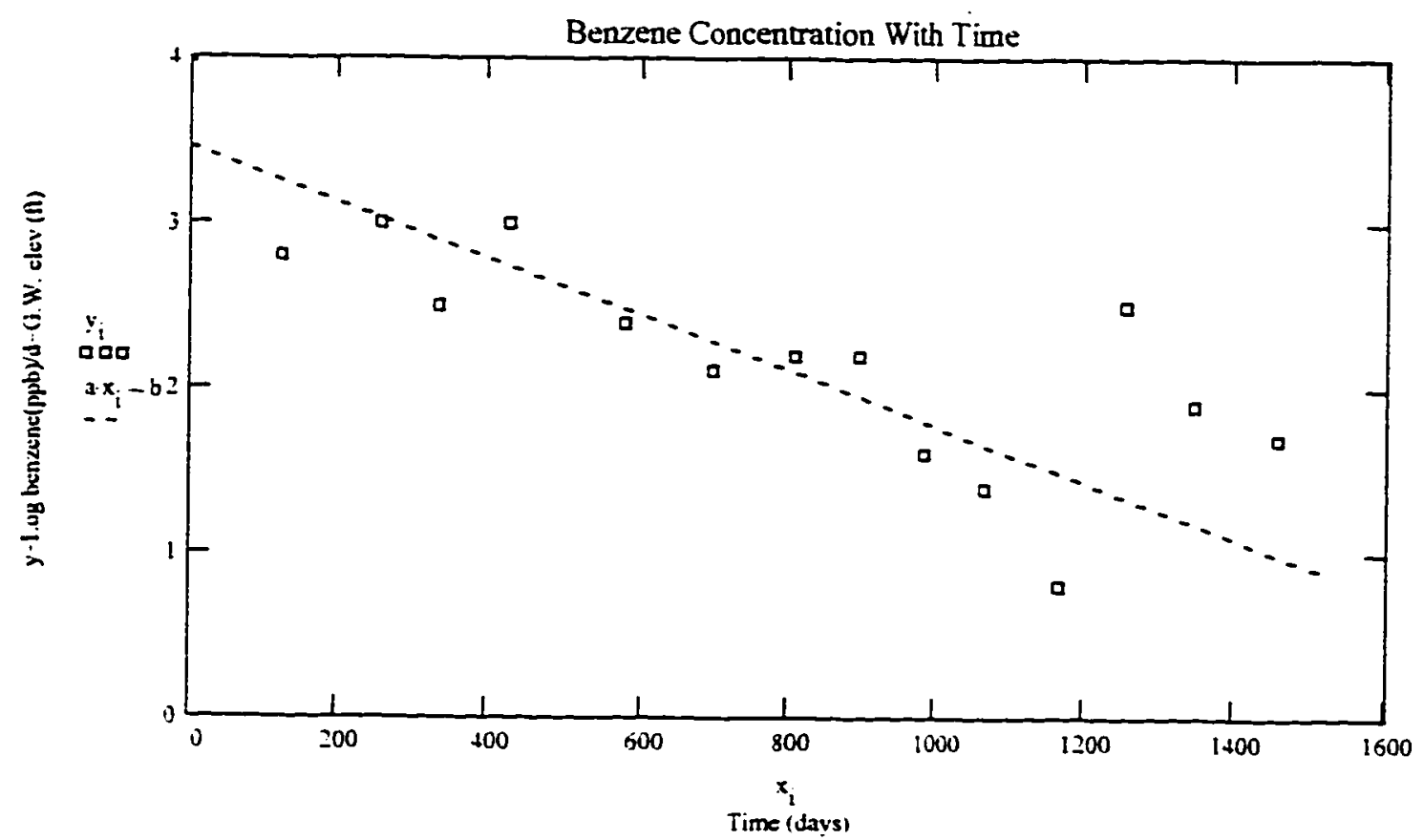


SCWWD Site Number: 0652W36F01

Site Address: 707 S. Mathilda

Site Name: Arco \#5334

City: Sunnyvale

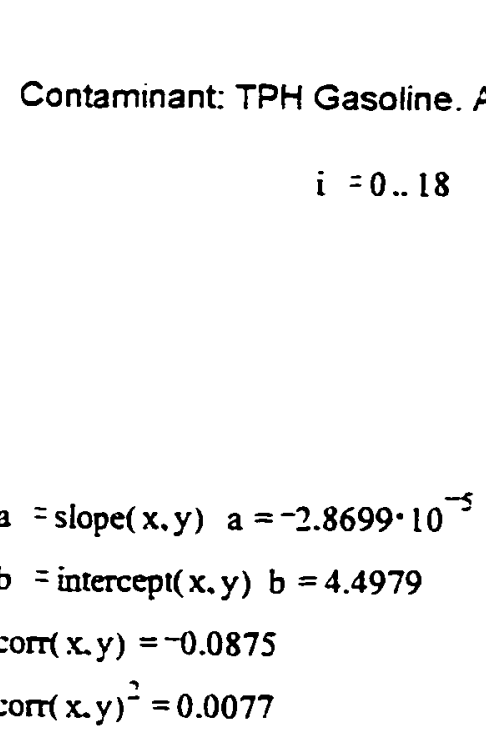

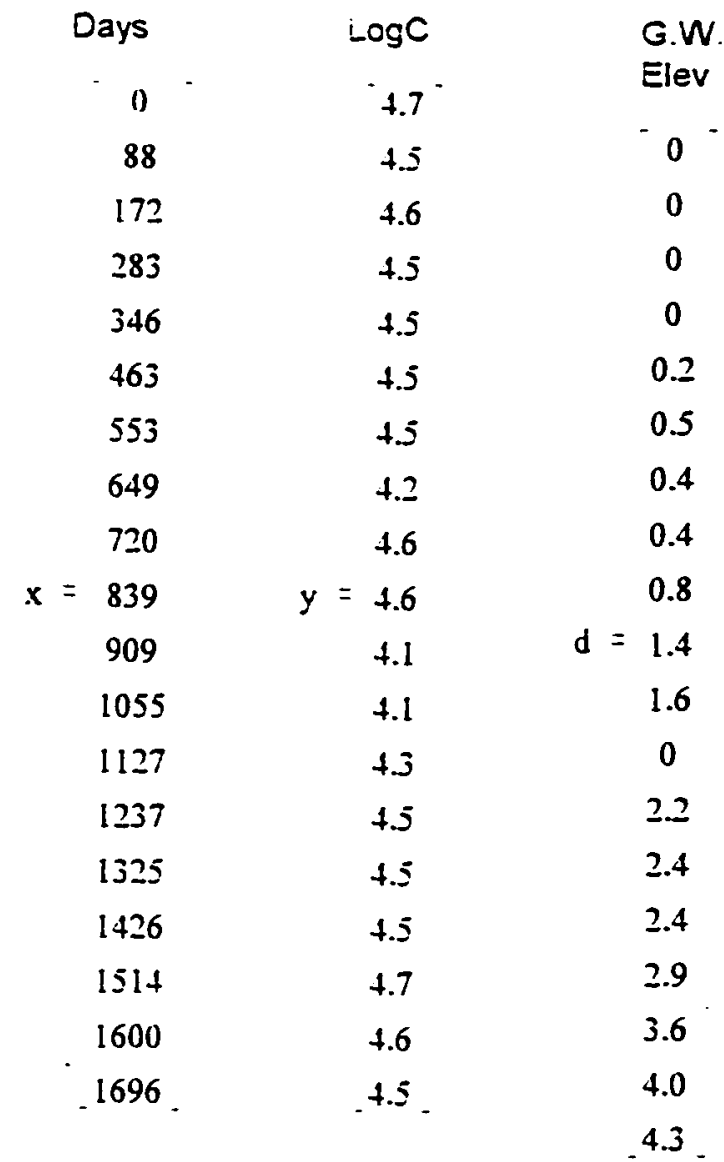

TPH as Gasoline Concentration With Time

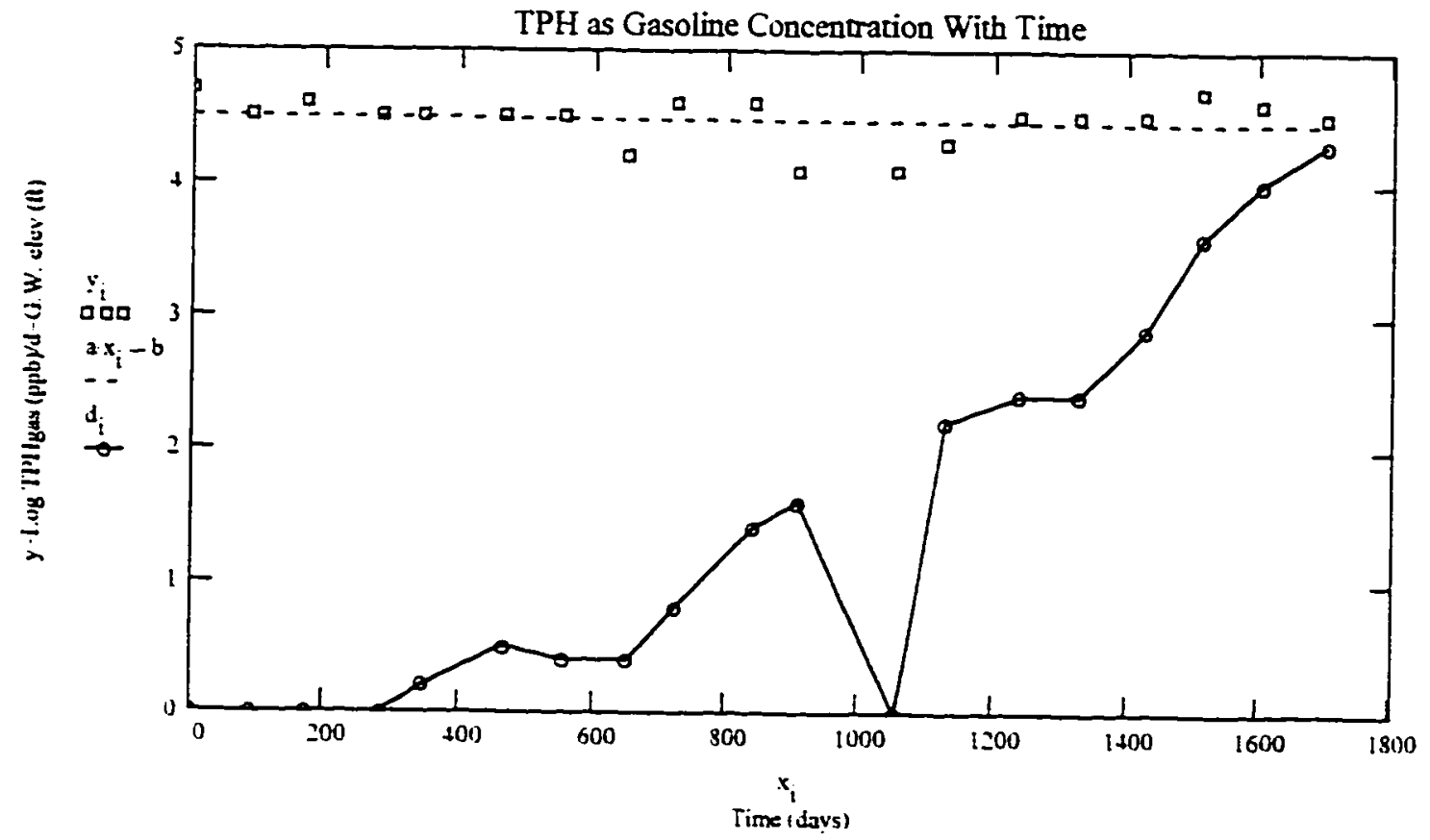

Note: Ground water elevations have been adjusted to fit the graph. 0 feet $=39.9$ feet/5. No elevation data was avallable for the 12th date. so 0 was input. 
SCWND Site Number: 0652W36F01

Site Address: 707 S. Mathilda

Site Name: Arco \#5334

City: Sunnyvale

Contaminant: Benzene. A-2

$$
i=0.19
$$

$a=\operatorname{slope}(x . y) \quad a=-9.1298 \cdot 10^{-t}$

$b=$ intercept $(x, y) b=3.2893$

$\operatorname{corr}(x . y)=-0.8941$

$\operatorname{corr}(x . y)^{2}=0.7995$

Note: Ground water elevations have been adjusted to fit the graph. O feet $=39.9$ feet $/ 5$. No elevation data was available for the 10 th date. so 0 was input.

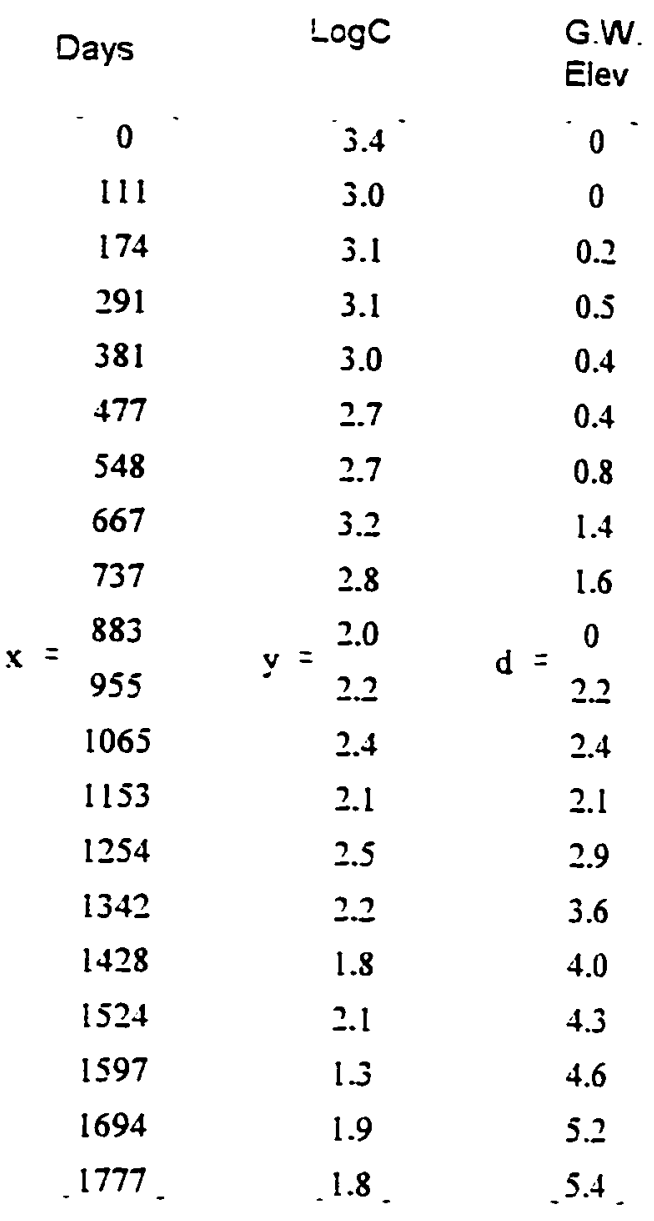

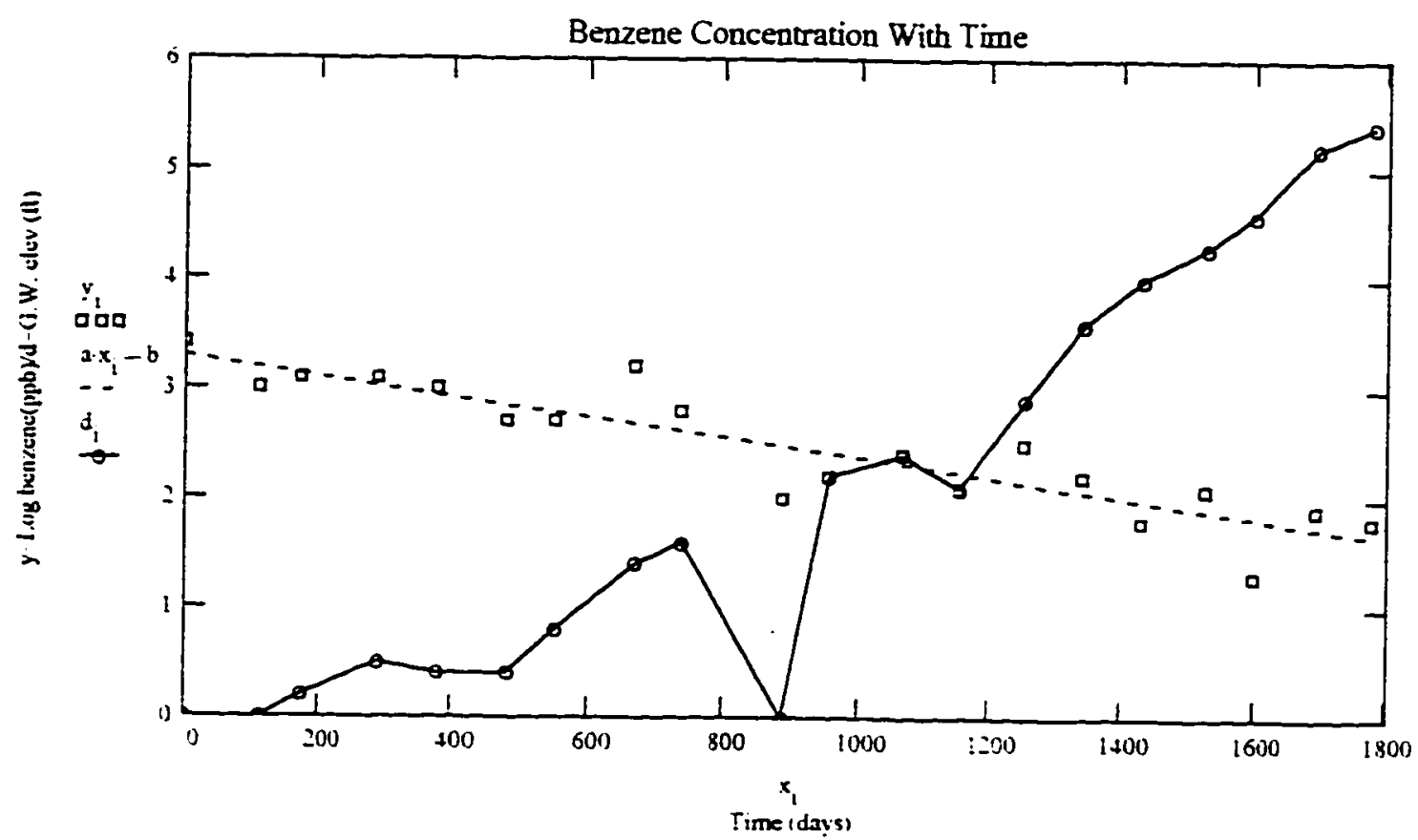


SCVND Site Number: 06S2W36F01

Site Address: 707 S. Mathilda

Site Name: Arco \#5334

City: Sunnyvale

Contaminant: TPH Gasoline. A-3

$\begin{array}{ccc}\text { Days } & \text { LogC } & \begin{array}{c}\text { G.W. } \\ \text { Elev }\end{array} \\ 0 & 3.7^{-} & - \\ 116 & 3.3 & 1.3 \\ 207 & 3.3 & 1.4 \\ 303 & \mathrm{y}=3.0 & \mathrm{~d}=1.1 \\ 375 & 3.7 & 3.9 \\ 494 & 2.6 & 6.0 \\ 564 & 2.2 & 7.1 \\ .710 & -1.4 & -0\end{array}$

$a=\operatorname{slope}(x, y) \quad a=-0.0029$

$b=\operatorname{intercep} t(x, y) b=3.9025$

Note: Ground water elevations have been adjusted to $\operatorname{corr}(x . y)=-0.8655$ fit the graph. $O$ it $=40.7 \mathrm{ft}$. No elevation data was available for the last date, so 0 was input.

$\operatorname{corr}(x, y)^{2}=0.7492$

TPH as Gasoline Concentration With Time

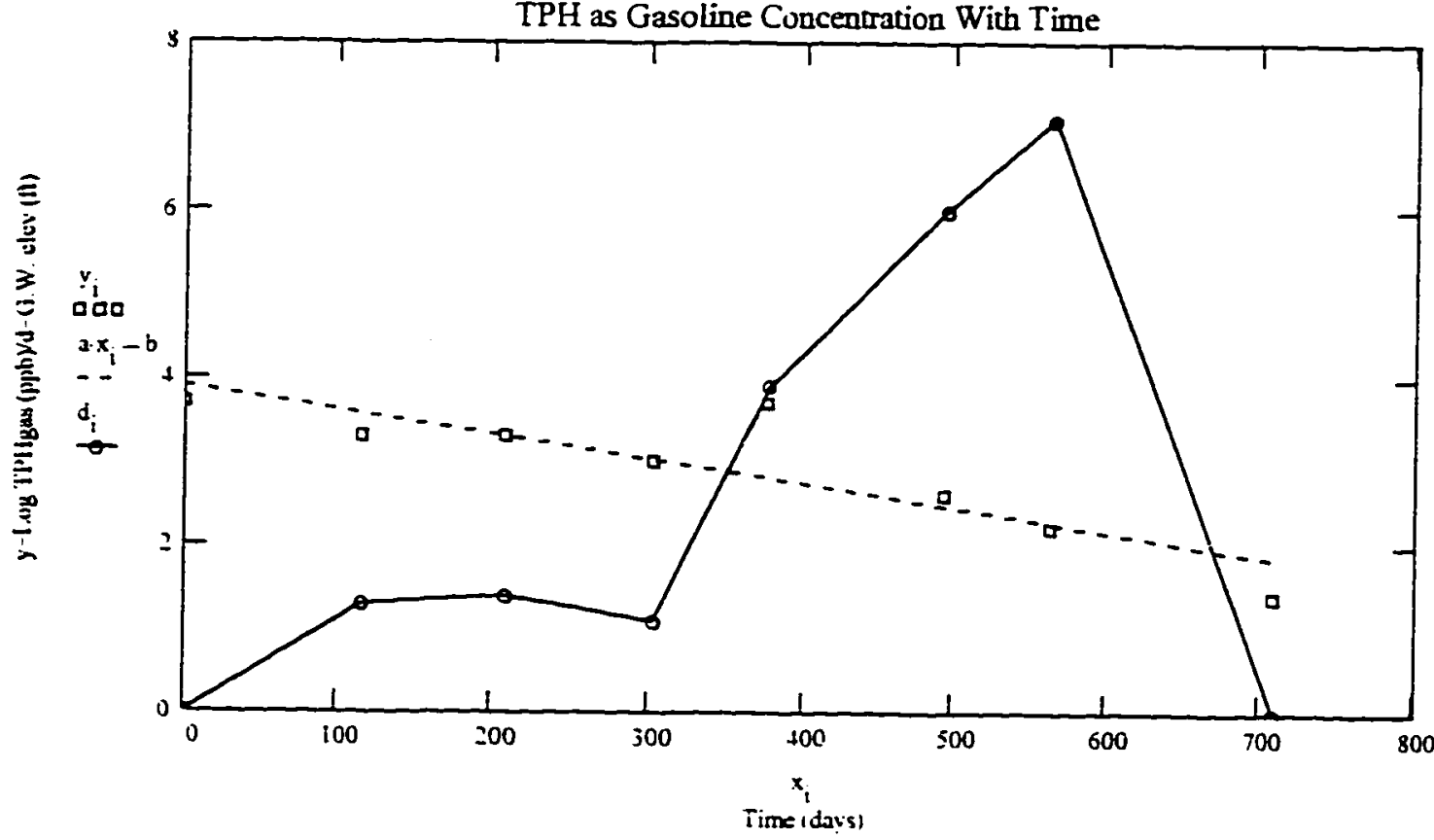


SCVND Site Number: 06S2W36F01

Site Address: 707 S. Mathilda

Site Name: Arco $\$ 5334$

City: Sunnyvale

Contaminant: Benzene. A-3

$$
i=0 . .7
$$

$\begin{array}{ccc}\text { Days } & \text { LogC } & \begin{array}{c}\text { G.W. } \\ \text { Elev }\end{array} \\ 0 & 2.4 & 0 \\ 116 & 1.6 & 1.3 \\ 207 & 1.7 & 1.4 \\ 303 & y=1.8 \\ 375 & 1.7 & \mathrm{~d}=\begin{array}{c}1.1 \\ 3.9 \\ 494\end{array} \\ 564 & 1.0 & 6.0 \\ 710 & 0.9 & 7.1 \\ -710 & -0.6 & -0\end{array}$

$a=\operatorname{slope}(x \cdot y) \quad a=-0.0034$

$b=$ intercept( $x . y) \quad b=2.4806$

Note: Ground water elevations have been adjusted to

$\operatorname{corr}(x . y)=-0.8879$

$\operatorname{corr}\left(x_{.} y\right)^{2}=0.7884$

fit the graph. $O \mathrm{ft}=40.7 \mathrm{ft}$. No elevation data was

available for the last date. so 0 was input.

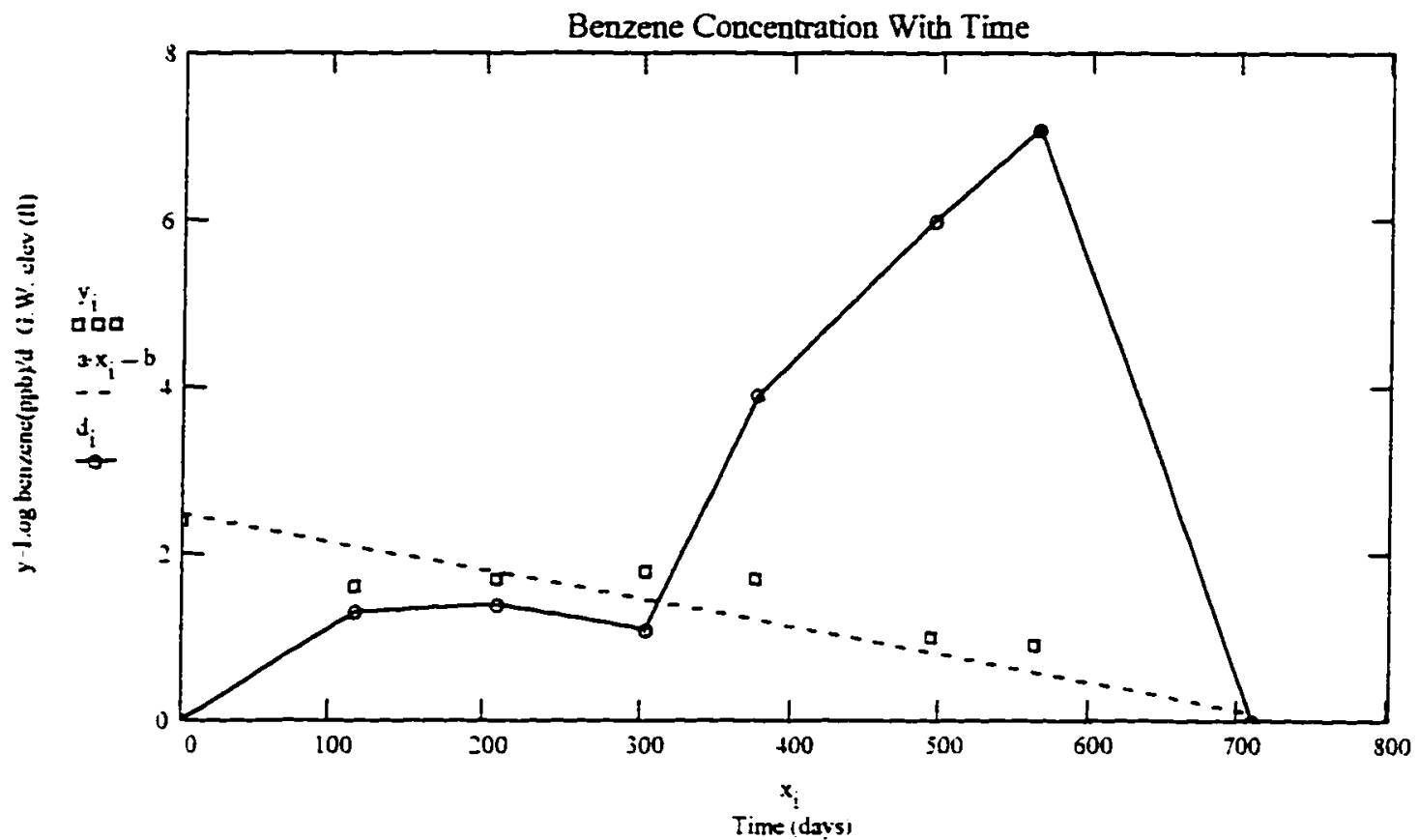


SCWWD Site Number: 06S1W31C01

Site Address: 848 E. Evelyn Ave

Site Name: Beacon \#543

City: Sunnyvale

Contaminant: TPH Gasoline

$$
i=0 . .8
$$

$=\operatorname{slope}(x, y) \quad a=-0.0016$

$b=$ intercept( $x, y) \quad b=3.7233$

$\operatorname{corr}(x, y)=-0.9647$

$\operatorname{corr}(x . y)^{2}=0.9307$

$\begin{array}{ccc}\text { Days } & \text { LogC } & \begin{array}{c}\text { G.W. } \\ \text { Elev }\end{array} \\ 0 & -3.7^{-} & -0.5^{-} \\ 92 & 3.6 & 0 \\ 190 & 3.4 & 1.2 \\ 273 & 3.5 & 2.8 \\ \mathrm{x} & \mathrm{y} & \mathrm{d}=5.9 \\ 357 & 2.0 & 4.9 \\ 473 & 2.9 & 4.3 \\ 552 & 2.8 & 6.5 \\ 590 & 2.7 & 7.1 . \\ 679 & -.9 & \end{array}$

Note: Ground water elevations have been adjusted to fit the graph. $O \mathrm{ft}=52.87 \mathrm{ft}$.

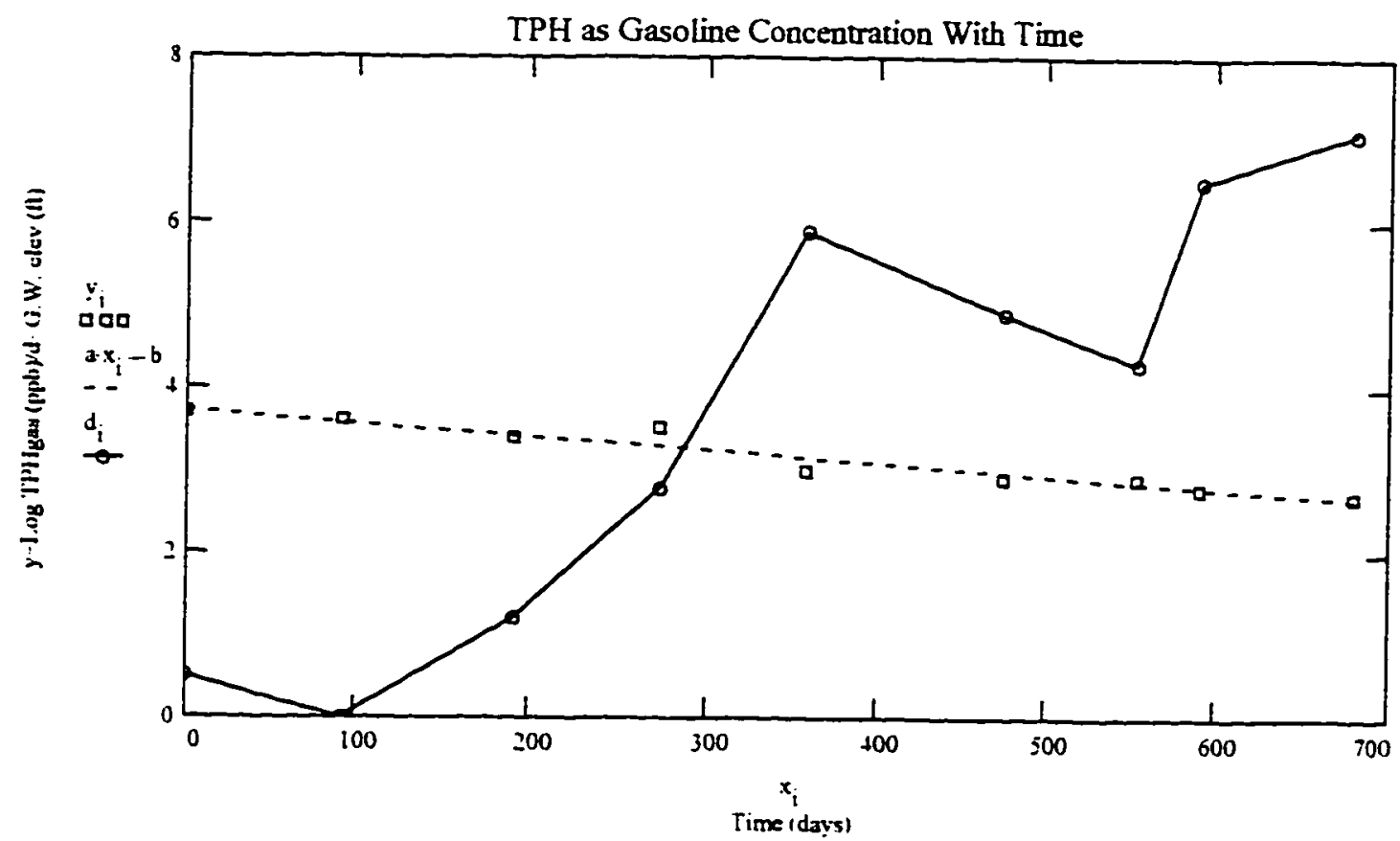


SCWWD Site Number: 06S 1W31C01 Site Address: 848 E. Evelyn Ave Site Name: Beacon \#543

City: Sunnyvale

Contaminant: Benzene

$$
i=0 . .8
$$

\begin{tabular}{|c|c|c|}
\hline Days & $\log C$ & $\begin{array}{l}\text { G.W. } \\
\text { Elev }\end{array}$ \\
\hline 0 & $2.6^{\circ}$ & $0.5^{\circ}$ \\
\hline 92 & 2.7 & 0 \\
\hline 190 & 2.6 & 1.2 \\
\hline 273 & 2.6 & 2.8 \\
\hline$x=357$ & $y=2.0$ & $d=5.9$ \\
\hline 473 & 1.9 & 4.9 \\
\hline 552 & 2.0 & 4.3 \\
\hline 590 & 1.4 & 6.5 \\
\hline 679 & 0.7 & -7.1 \\
\hline
\end{tabular}

Note: Ground water elevations have been adjusted to it the graph. $O \mathrm{ft}=52.8 \mathrm{i} \mathrm{f}$.

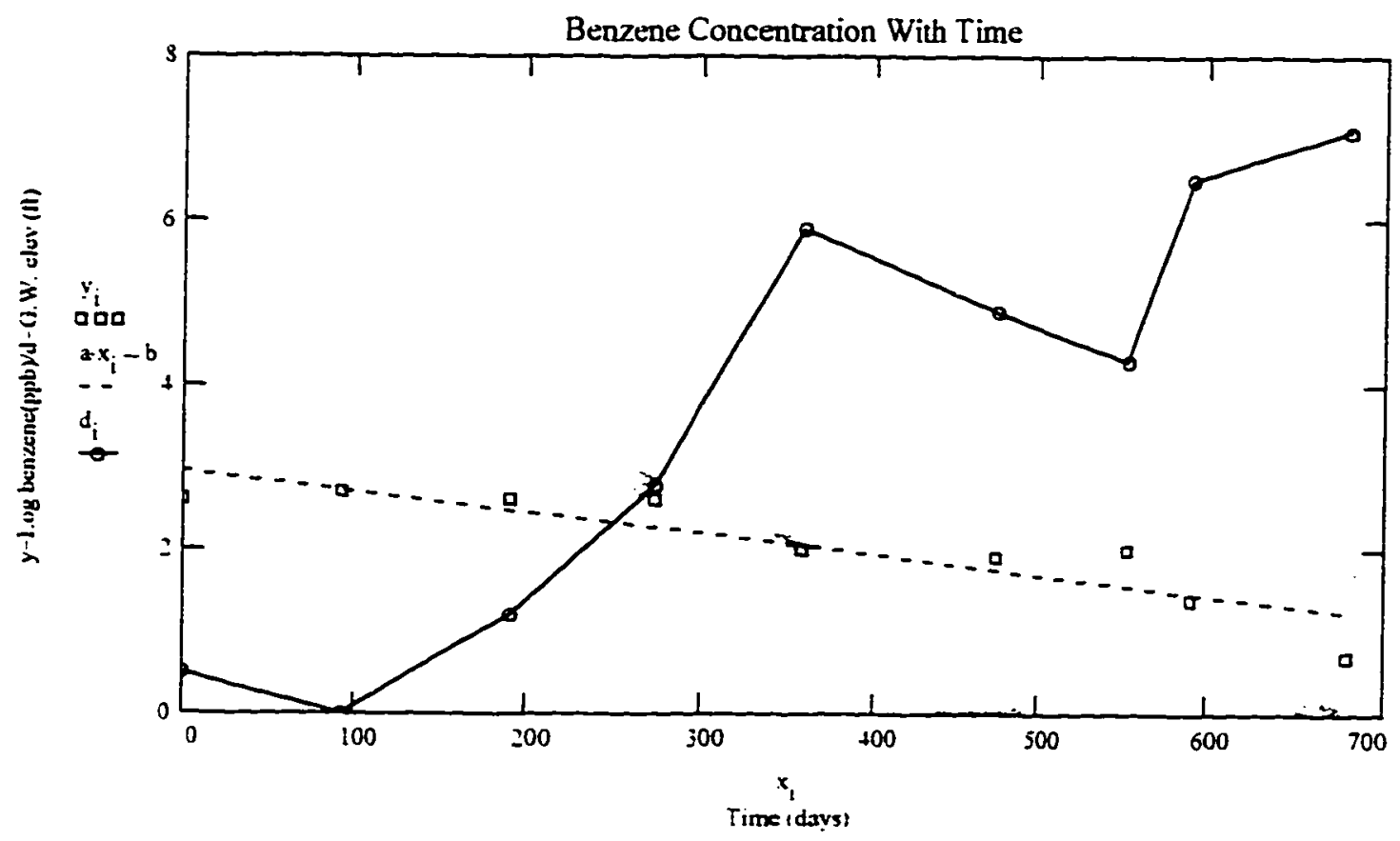

IW31C01B.MCD 
SCWWD Site Number: 06S2W35B01F Site Address: 1005 W. El Camino Real Site Name: Exxon \#7-3326

City: Sunnyvale

Contaminant: TPH Gasoline

$$
i=0 . .14
$$

$a=\operatorname{slope}(x, y) \quad a=-0.0011$

$b=$ intercept $(x, y) \quad b=5.3265$

$\operatorname{corr}(x, y)=-0.8992$

$\operatorname{corr}(x, y)^{2}=0.8086$
Days

0

91

184

273

344

470

560

$x=644$

738

834

931

1016

1115

1197

1283. $\log C$

5.8

4.9

4.7

5.1

5.0

4.7

4.9

$y=4.6$

4.5

4.4

4.2

4.2

4.3

4.1

3.6
G.W.

Elev

0

0

0.2

1.3

1.8

2.1

2.6

$d=2.9$

3.1

3.1

3.4

4.6

5.2

5.4

5.8 .

Note: Ground water elevations have been adjusted to fit the graph. $0 \mathrm{ft}=40.9 / 4 \mathrm{ft}$.

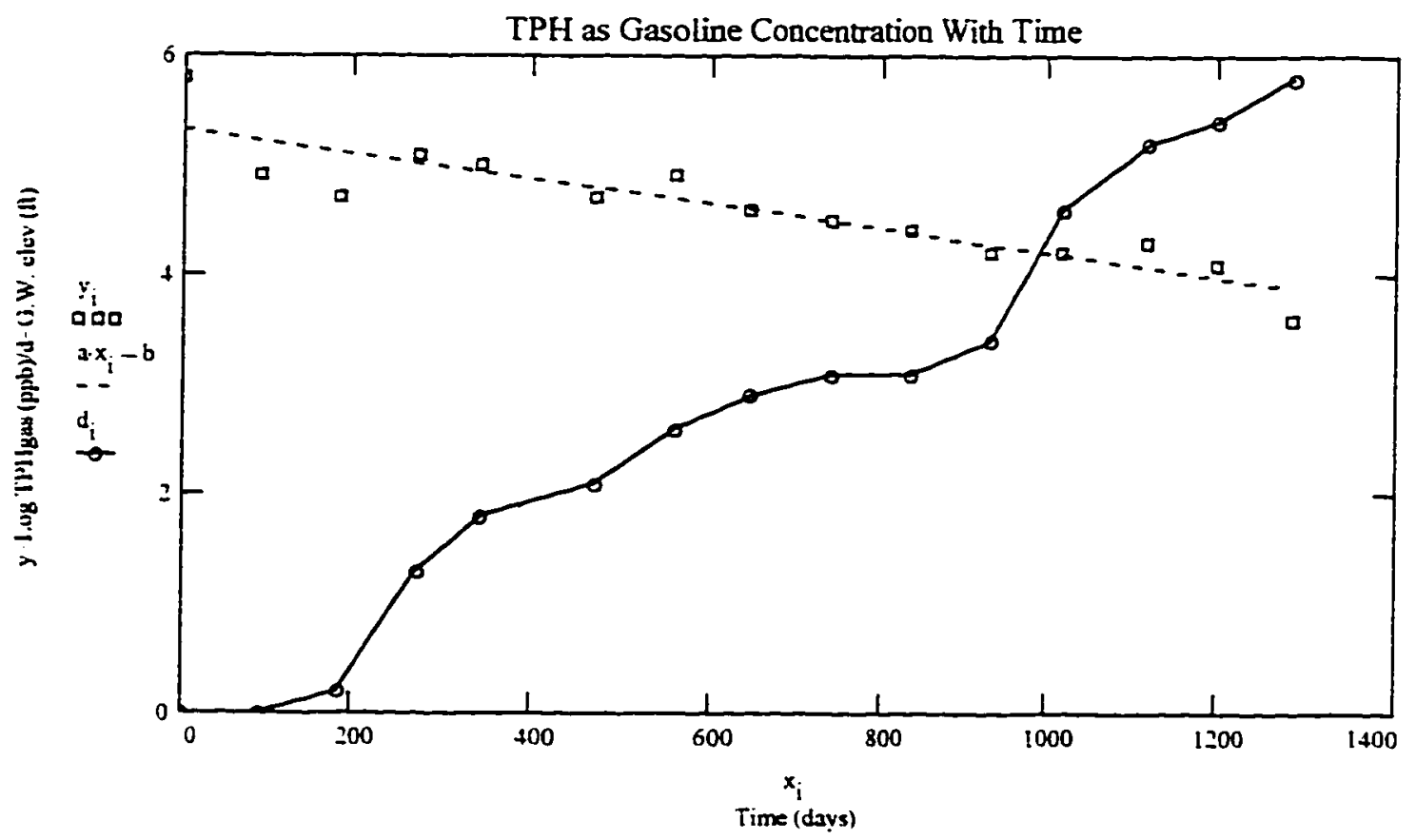


SCVWD Site Number: 06S2W35B01F Site Address: 1005 W. El Camino Real Site Name: Exxon \#7-3326

City: Sunnyvale

$a=\operatorname{slope}(x, y) \quad a=-0.0023$

$b=$ intercept $(x, y) b=4.7149$

$\operatorname{corr}(x . y)=-0.9628$

$\operatorname{corr}(x . y)^{2}=0.9269$

$$
\mathrm{i}=0 . .15
$$

Note: Ground water elevations have been adjusted to it the graph. $O \mathrm{ft}=40.9 / 2 \mathrm{f}$.

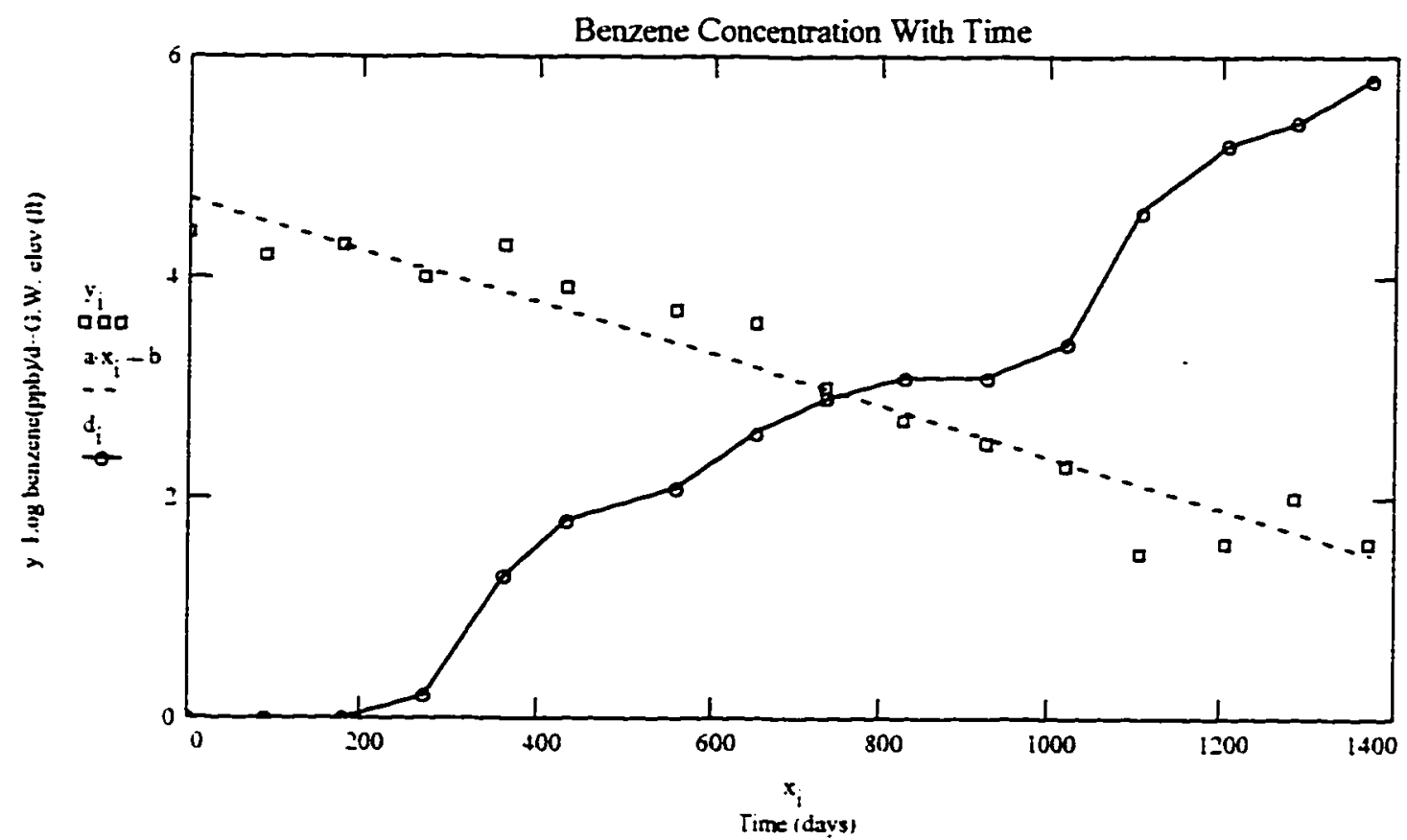


SCWWD Site Number: 06S1W32E01F Site Address: 1045 Reed Lane

Site Name: Exxon \#7-0286

City: Sunnyvale

$$
\begin{aligned}
& a=\operatorname{slope}(x . y) \quad a=-0.0017 \\
& b=\text { intercept }(x . y) \quad b=3.9396 \\
& \operatorname{corr}(x . y)=-0.7302 \\
& \operatorname{corr}(x . y)^{2}=0.5332
\end{aligned}
$$$$
\mathrm{i}=0 . .13
$$

$\begin{array}{ccc}\text { Days } & \text { LogC } & \begin{array}{c}\text { G.W } \\ \text { Elev }\end{array} \\ 0 & -3.3 & 0 \\ 154 & 3.9 & 0 \\ 205 & 3.3 & 1.0 \\ 280 & 3.2 & 0.2 \\ 336 & 3.2 & 0 \\ 456 & 2.6 & 2.5 \\ 556 & y .4 & \mathrm{~d}=1.6 \\ 643 & \mathrm{y} & 1.3 \\ 745 & 3.5 & 2.1 \\ 854 & 3.4 & 5.1 \\ 943 & 2.0 & 4.6 \\ 1045 & 1.4 & 1.0 \\ 1138 & 3.2 & 4.9 \\ 1227 & .1 .4 . & 6.9\end{array}$

Note: Ground water elevations have been adjusted to fit the graph. $O \mathrm{ft}=43.62 \mathrm{ft}$. No elevation data was availabe for first two dates. so 0 was input.

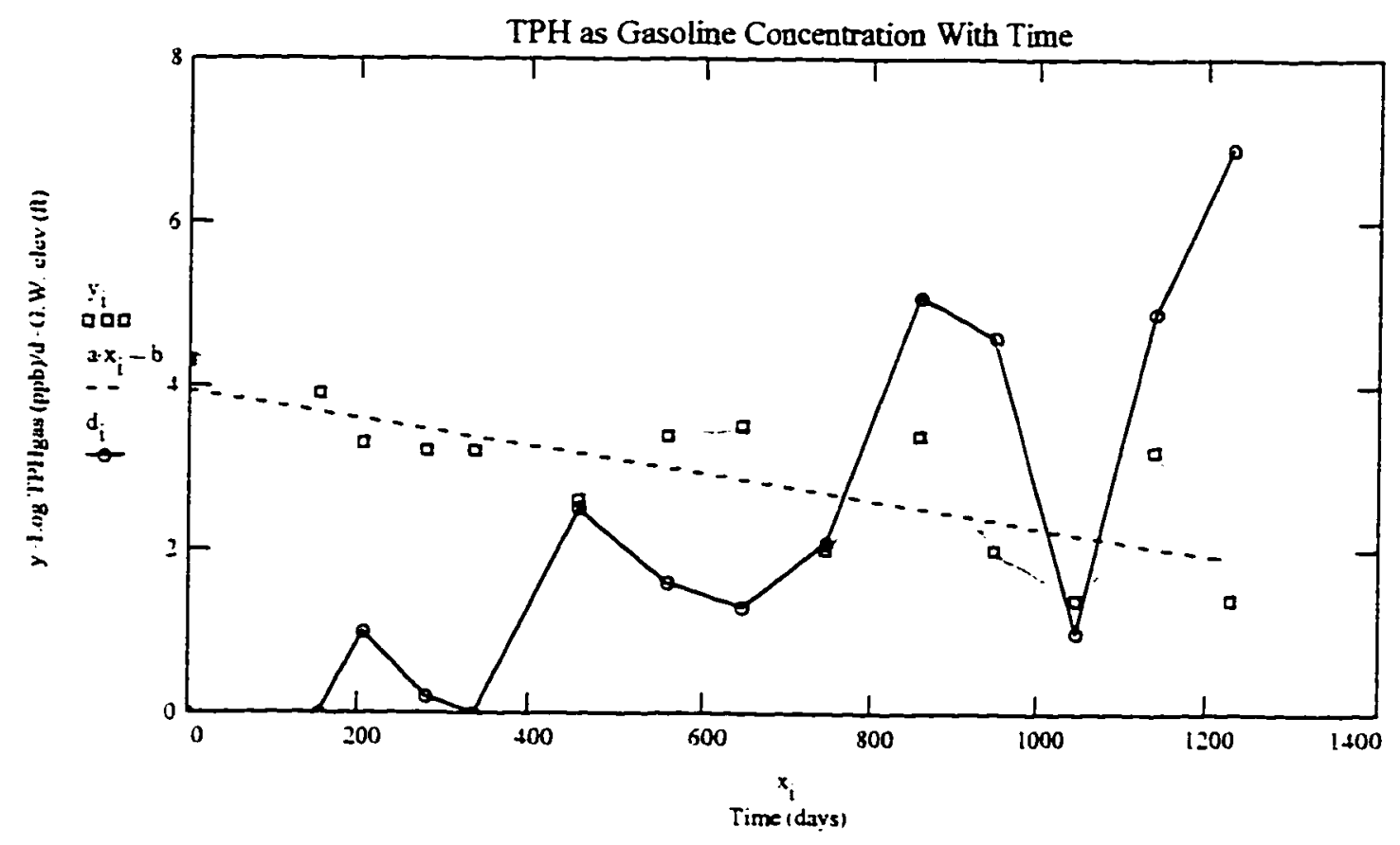


SCIND Site Number: 06S1W32E01F Site Acdress: 1045 Reed Lane

Site Name: Exxon \#7-0286

City: Sunnyvale

\begin{tabular}{|c|c|c|}
\hline Days & $\log C$ & $\begin{array}{l}\text { G.W. } \\
\text { Elev }\end{array}$ \\
\hline 0 & $2.3^{\circ}$ & $1.6^{\circ}$ \\
\hline 87 & 2.0 & 1.3 \\
\hline 189 & 0.6 & 2.1 \\
\hline$=298$ & 2.3 & $d=5.1$ \\
\hline 387 & 1.1 & 4.6 \\
\hline 489 & -0.6 & 1.0 \\
\hline 582 & 0.7 & 4.9 \\
\hline 671. & -0.6 & 6.9. \\
\hline
\end{tabular}

\footnotetext{
$a=\operatorname{slope}(x . y) \quad a=-0.0038$

$b=$ intercept $(x, y) \quad b=\mathbf{2 . 2 7 4 4}$

$\operatorname{corr}(x . y)=-0.7755$

$\operatorname{com}(x, y)^{2}=0.6014$
}

Note: Ground water elevations have been adjusted to fit the graph. $0 \mathrm{ft}=43.52 \mathrm{ft}$.

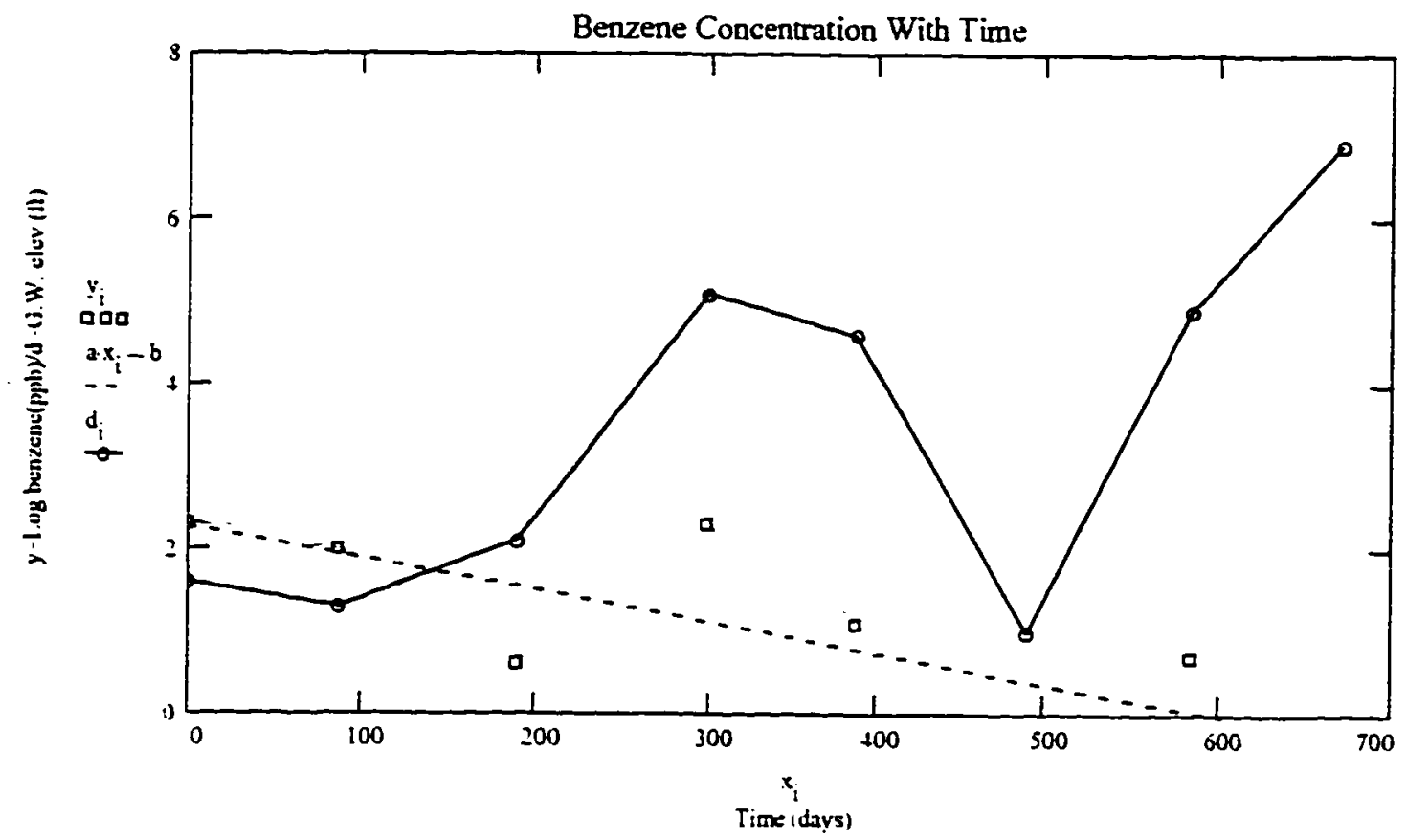


SCVWD Site Number: 06S1W20G01F Site Address: 1101 N. Lawrence Expwy Site Name: Shell

City: Sunnyvale

Contaminant: TPH Gasoline, OP-4

$$
i=0 . .9
$$

$a=\operatorname{slope}(x . y) a=-0.0015$

$b=$ intercept $(x . y) b=3.5826$

$\operatorname{corr}(x . y)=-0.6187$

$\operatorname{corr}(x . y)^{2}=0.3828$

$\begin{array}{ccc}\text { Days } & \text { LogC } & \begin{array}{c}\text { G.W. } \\ \text { Elev }\end{array} \\ 0 & 3.8 & 2.1 \\ 91 & 3.6 & 1.0 \\ 182 & 3.0 & 0 \\ 285 & 2.6 & 3.3 \\ 362 & \mathrm{y}=2.9 & \mathrm{~d}=2.4 \\ 463 & 3.0 & 1.2 \\ 546 & 3.1 & 0.7 \\ 636 & 3.2 & 2.9 \\ 727 & 3.2 & 2.6 \\ 819 . & 1.4 . & -0.4\end{array}$

Note: Ground water elevations have been adjusted to fit the graph. $0 \mathrm{ft}=3.92 \mathrm{ft}$.

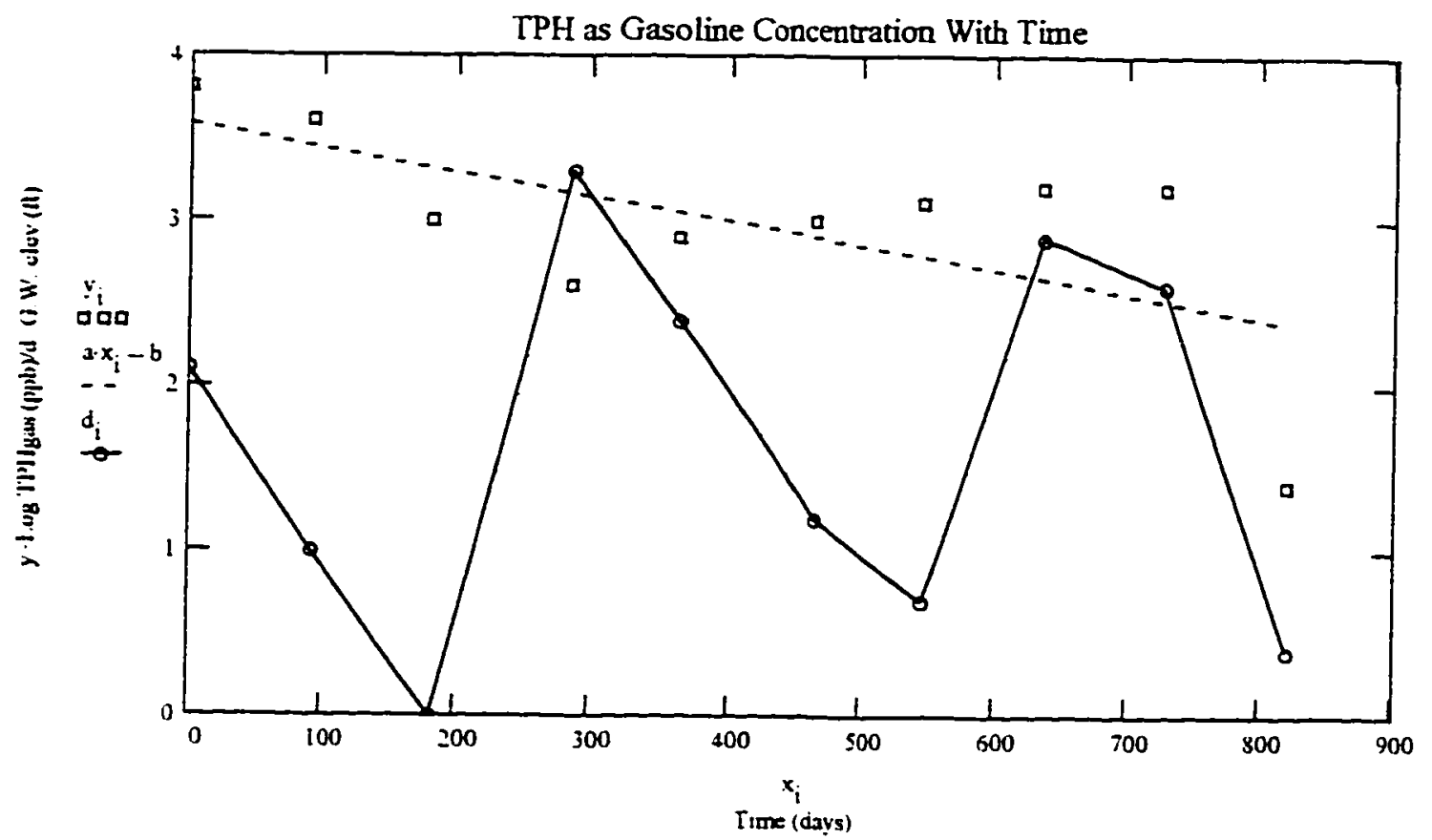


SCWWD Site Number: 06S1W20G01F Site Address: 1101 N. Lawrence Expwy Site Name: Shell

City: Sunnyale

$\begin{array}{ccc}\text { Days } & \text { LogC } & \begin{array}{c}\text { G.W. } \\ \text { Elev }\end{array} \\ 0 & 3.1 & 2.1 \\ 91 & 2.7 & 1.0 \\ 182 & 2.0 & 0 \\ 285 & 1.1 & 3.3 \\ 362 & 2.4 & 2.4 \\ 463 & 2.0 & 1.2 \\ \mathrm{x}=546 & \mathrm{y}=2.1 & \mathrm{~d}=0.7 \\ 636 & 1.5 & 2.9 \\ 727 & 2.3 & 2.6 \\ 819 & 0.04 & 0.4 \\ 914 & -0.6 & 0.9 \\ 1011 & -0.2 & 3.2 \\ -1102 & -0.6 & 2.6\end{array}$

$a=\operatorname{slope}(x, y) \quad a=-0.0031$

$b=$ intercept $(x, y) \quad b=3.0614$

$\operatorname{corr}(x . y)=-0.8467$

$\operatorname{corr}(x . y)^{2}=0.7169$

Note: Ground water elevations have been adjusted to fit the graph. $0 \mathrm{ft}=3.92 \mathrm{ft}$.

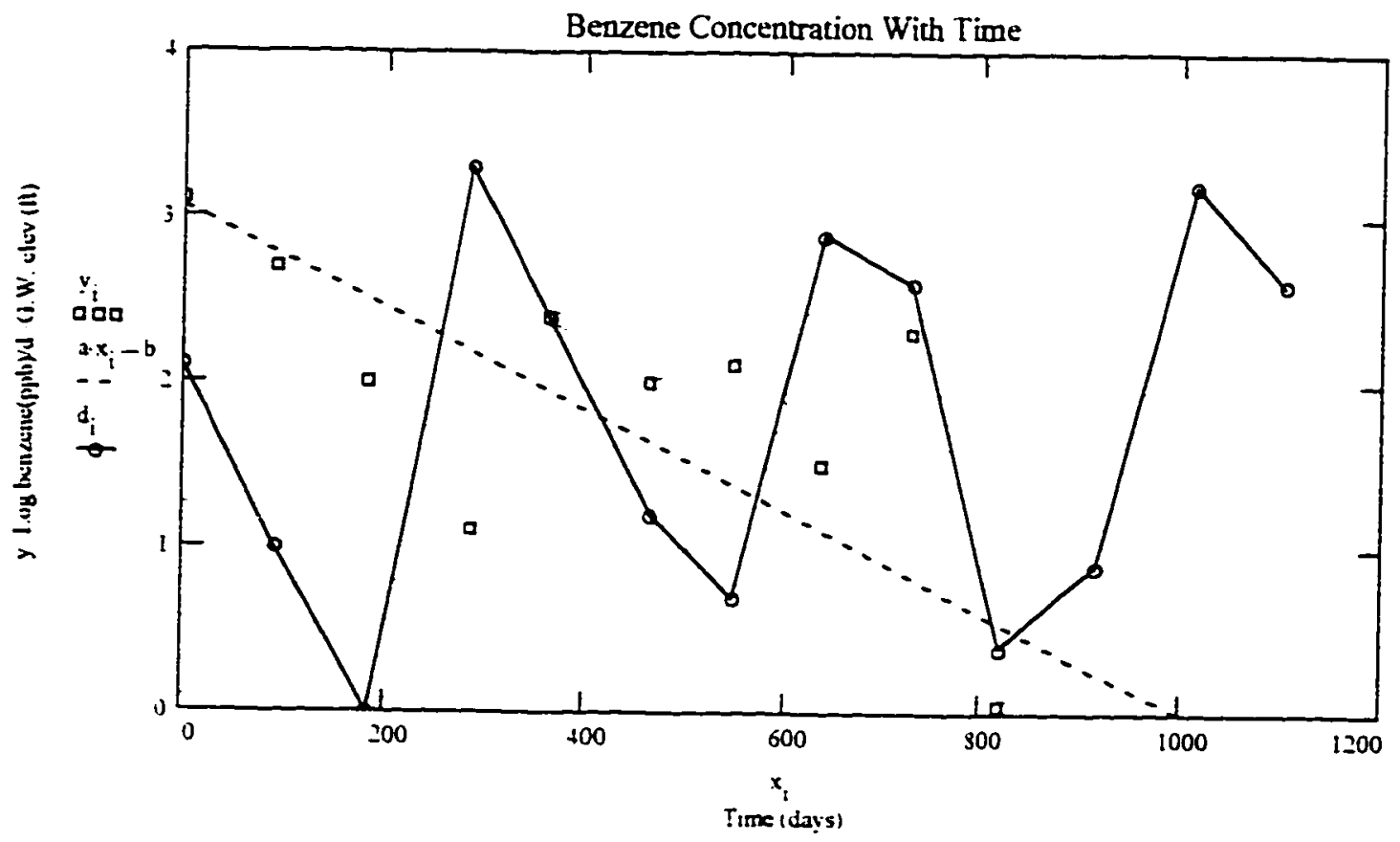




\begin{tabular}{|c|c|c|c|}
\hline \multirow{3}{*}{$\begin{array}{l}\text { SCWWD Site Number: 06S1W20G01F } \\
\text { Site Address: } 1101 \text { N. Lawrence Expwy } \\
\text { Site Name: Shell } \\
\text { City: Sunnyvale }\end{array}$} & Days & $\log C$ & $\begin{array}{l}\text { G.W. } \\
\text { Elev }\end{array}$ \\
\hline & 0 & 3.8 & 3.8 \\
\hline & 79 & 2.8 & 3.5 \\
\hline \multirow{2}{*}{ Contaminant: TPH Gasoline. $\mathrm{mw}-16$} & 170 & 3.0 & 2.2 \\
\hline & 261 & 3.1 & 1.4 \\
\hline \multirow[t]{5}{*}{$\mathrm{i}=0 . .13$} & 364 & 2.8 & 3.1 \\
\hline & 441 & 3.2 & 2.2 \\
\hline & 542 & $y=3.1$ & $d=1.6$ \\
\hline & 625 & 2.9 & 4.4 \\
\hline & 715 & 2.3 & 4.1 \\
\hline$a=\operatorname{slope}(x . y) a=-0.0014$ & 806 & 2.9 & 3.4 \\
\hline$b=\operatorname{intercept}(x, y) b=3.4492$ & 898 & 1.4 & 0 \\
\hline $\operatorname{com}(x, y)=-0.7654$ & 993 & 2.0 & 1.7 \\
\hline \multirow[t]{2}{*}{$\operatorname{corr}(x, y)^{2}=0.5858$} & 1090 & 1.4 & 4.4 \\
\hline & .1181 & 2.4 & .3 .6 \\
\hline
\end{tabular}

Note: Ground water elevations have been adjusted to it the graph. $O \mathrm{ft}=2.76 \mathrm{ft}$.

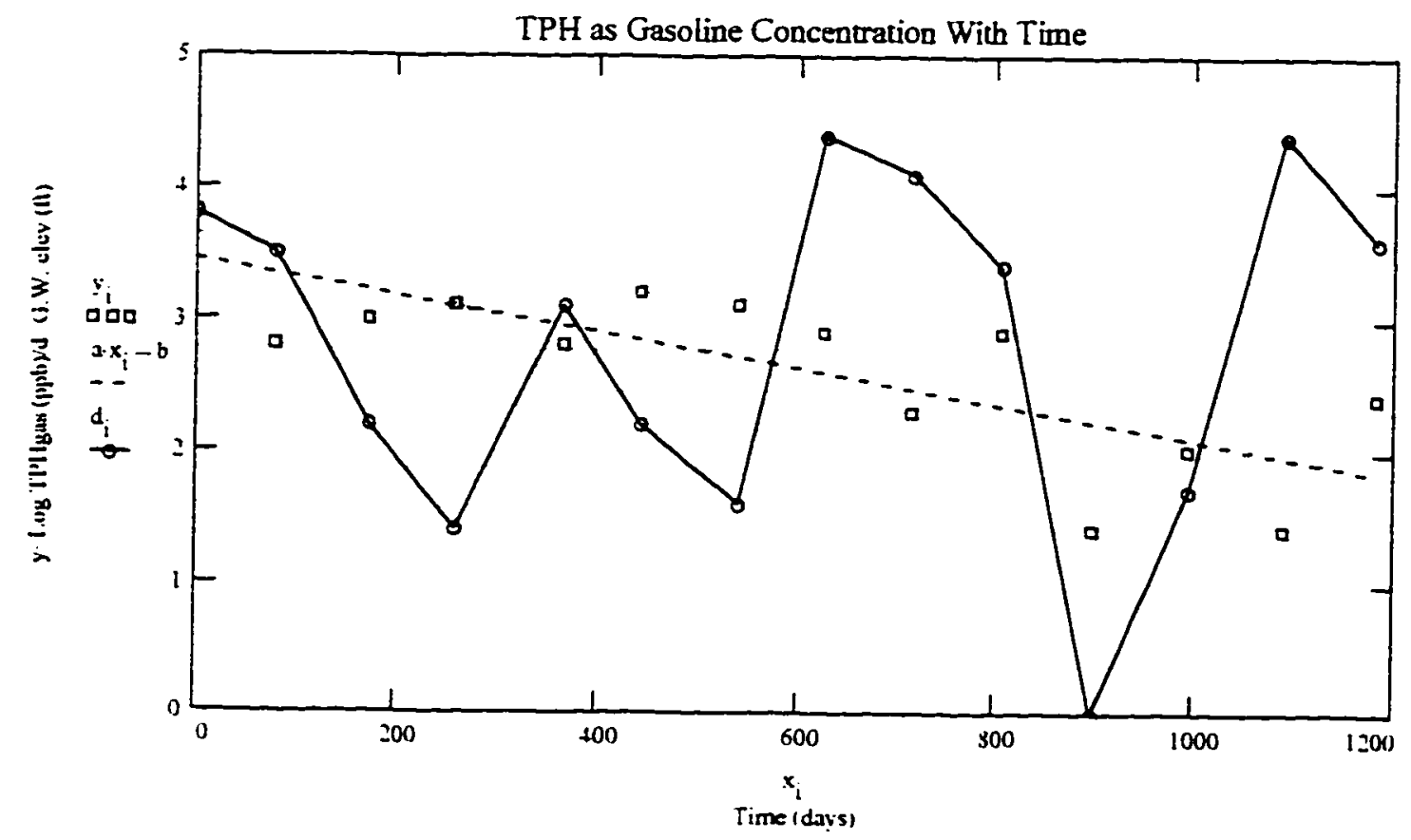




\begin{tabular}{|c|c|c|c|}
\hline \multirow{4}{*}{$\begin{array}{l}\text { SCWWD Site Number: 06SiW20G01F } \\
\text { Site Address: } 1101 \mathrm{~N} \text {. Lawrence Expwy } \\
\text { Site Name: Shell } \\
\text { City: Sunnyvale }\end{array}$} & Days & $\log C$ & $\begin{array}{l}\text { G.W. } \\
\text { Elev }\end{array}$ \\
\hline & 0 & 1.7 & 3.8 \\
\hline & 79 & 0.9 & 3.5 \\
\hline & 170 & 1.0 & 2.2 \\
\hline \multirow[t]{8}{*}{ Contaminant: Benzene. MW-16 } & 261 & 0.6 & 1.4 \\
\hline & 364 & 1.0 & 3.1 \\
\hline & 441 & 1.4 & 2.2 \\
\hline & 542 & 1.3 & $d=1.6$ \\
\hline & 625 & 1.0 & 4.4 \\
\hline & 715 & 0.4 & 4.1 \\
\hline & 806 & 0.8 & 3.4 \\
\hline & 898 & -0.6 & 0 \\
\hline$a=\operatorname{slope}(x \cdot y) \quad a=-0.0011$ & 993 & 0.7 & 1.7 \\
\hline$b=$ intercept $(x, y) b=1.3636$ & 1090 & -0.05 & 4.4 \\
\hline $\operatorname{corr}(x . y)=-0.6743$ & .1181. & 0.3 & 3.6 \\
\hline
\end{tabular}

Note: Ground water elevations have been adjusted to fit the graph. $0 \mathrm{ft}=2.07 \mathrm{ft}$.

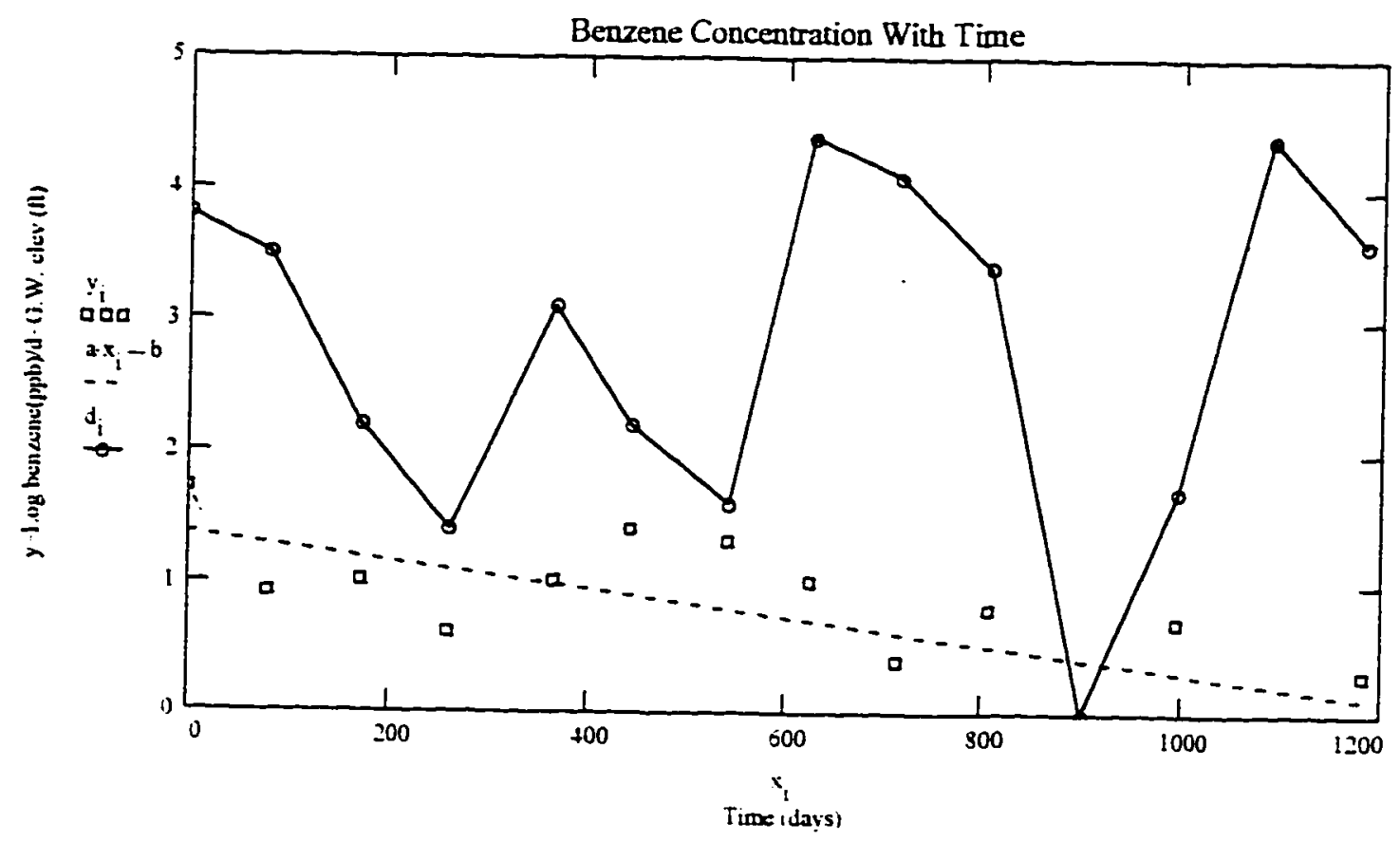




\begin{tabular}{|c|c|c|c|}
\hline \multirow{4}{*}{$\begin{array}{l}\text { SCVND Site Number: 06S2W24Q03F } \\
\text { Site Acidress: } 505 \text { N. Mathilda } \\
\text { Site Name: Shell } \\
\text { City: Sunnyvale }\end{array}$} & Days & $\log C$ & $\begin{array}{l}\text { G.W. } \\
\text { Elev }\end{array}$ \\
\hline & $\mathbf{0}$ & $5.0^{\circ}$ & $-16^{\circ}$ \\
\hline & 78 & 3.3 & \\
\hline & 174 & 2.6 & 2.4 \\
\hline \multirow[t]{8}{*}{ Contaminant: TPH Gasoline } & 239 & 3.0 & 2.4 \\
\hline & 349 & 3.0 & 3.7 \\
\hline & 456 & 3.2 & 4.7 \\
\hline & 547 & 2.5 & 0.3 \\
\hline & 640 & 2.1 & 0 \\
\hline & 731 & 3.1 & 0.8 \\
\hline & $x=826$ & $y=26$ & $d=1.2$ \\
\hline & 918 & 2.6 & 1.2 \\
\hline$a=\operatorname{slope}(x . y) \quad a=-3.0127 \cdot 10^{-1}$ & 1009 & 3.1 & 1.3 \\
\hline$b=$ intercept $(x, y) b=3.248$ & 1114 & 2.8 & 2.0 \\
\hline $\operatorname{corr}(x . y)=-0.2773$ & 1197 & 3.2 & 2.8 \\
\hline \multirow[t]{5}{*}{$\operatorname{corr}(x, y)^{2}=0.0769$} & 1290 & 3.0 & 2.4 \\
\hline & 1381 & 3.0 & 2.6 \\
\hline & $147\rceil$ & 5.0 & 3.4 \\
\hline & 1565 & 3.1 & 3.6 \\
\hline & 1655 & .2 .8 & .4 .4 \\
\hline
\end{tabular}

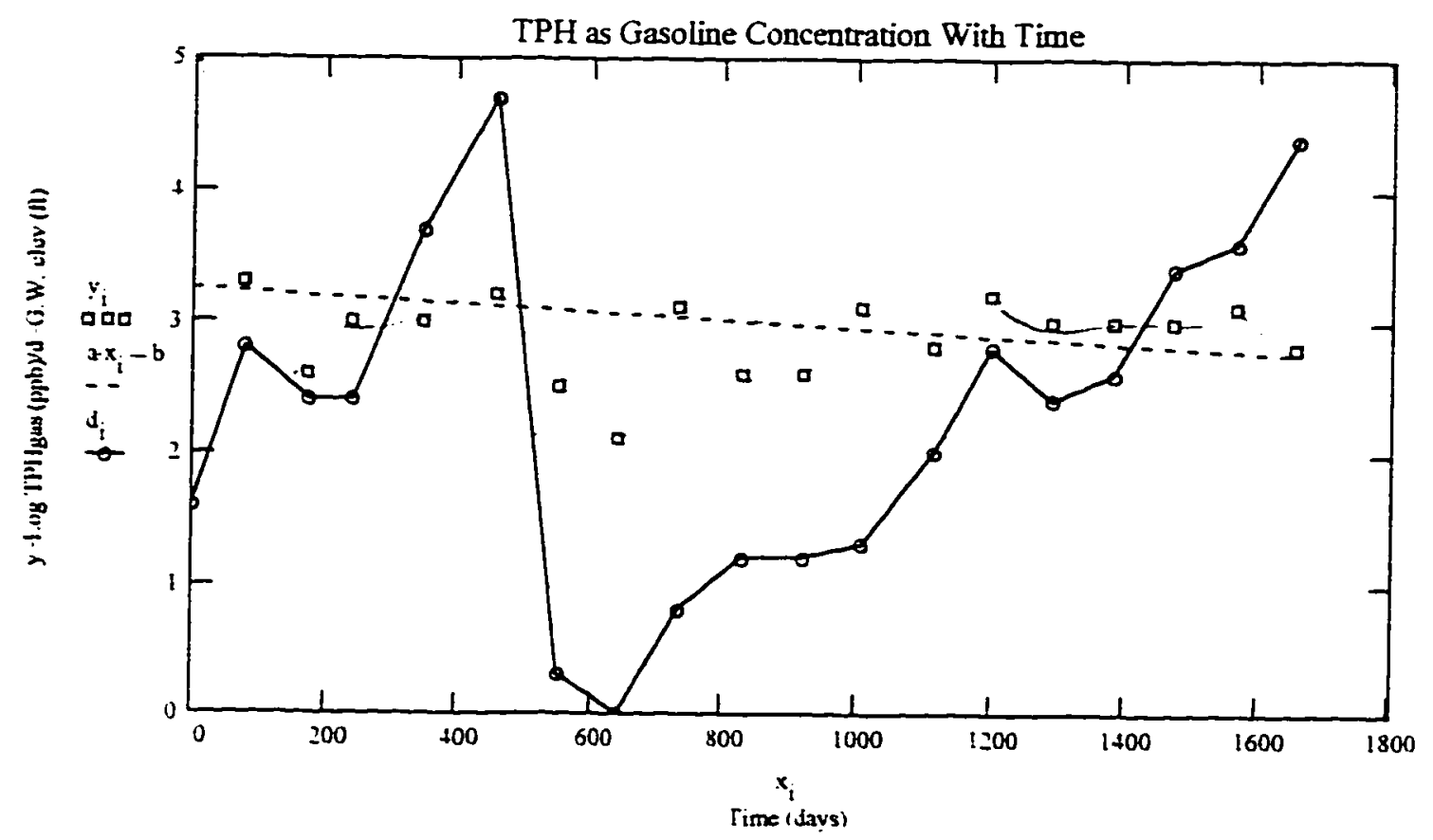

Note: Ground water elevations have been adjusted to fit the graph. $0 \mathrm{ft}=34.62 \mathrm{ft}$. 


\begin{tabular}{|c|c|c|c|}
\hline & Days & $\log C$ & G.W \\
\hline \multirow{4}{*}{$\begin{array}{l}\text { SCVWD Site Number: 06S2W24Q03F } \\
\text { Site Address: } 505 \text { N. Mathilda } \\
\text { Site Name: Shell } \\
\text { City: Sunnwale }\end{array}$} & 0 & $3.6^{-}$ & \\
\hline & 78 & 23 & 1.6 \\
\hline & 174 & 05 & 2.8 \\
\hline & 239 & 0.5 & 2.4 \\
\hline \multirow[b]{2}{*}{ Contaminant: Benzene } & 349 & 1.6 & 2.4 \\
\hline & 456 & 1.6 & 3.7 \\
\hline \multirow{6}{*}{$i=0 . .18$} & 547 & 3.3 & 4.7 \\
\hline & 640 & $\begin{array}{l}1.4 \\
0.9\end{array}$ & 0.3 \\
\hline & 731 & $\begin{array}{l}0.9 \\
1.8\end{array}$ & 0 \\
\hline & $x=826$ & $\begin{array}{r}1.8 \\
y=1.3\end{array}$ & 0.8 \\
\hline & 918 & $y=\begin{array}{r}1.3 \\
1.4\end{array}$ & $d=1.2$ \\
\hline & 1009 & 1.4 & 1.2 \\
\hline$a=\operatorname{slope}(x, y) a=-3.7611 \cdot 10^{-4}$ & 1114 & $\begin{array}{l}2.1 \\
18\end{array}$ & 1.3 \\
\hline$b=$ intercept $(x, y) \quad b=2.0622$ & 1197 & 1.8 & 2.0 \\
\hline $\operatorname{corr}(x . y)=-0.2548$ & 1290 & 2.4 & 2.8 \\
\hline \multirow{4}{*}{$\operatorname{corr}(x . y)^{2}=0.0649$} & 1381 & 1.6 & 2.4 \\
\hline & 1471 & 1.3 & 2.6 \\
\hline & 1565 & 1.2 & 3.4 \\
\hline & 1655 & 2.2 & 3.6 \\
\hline
\end{tabular}

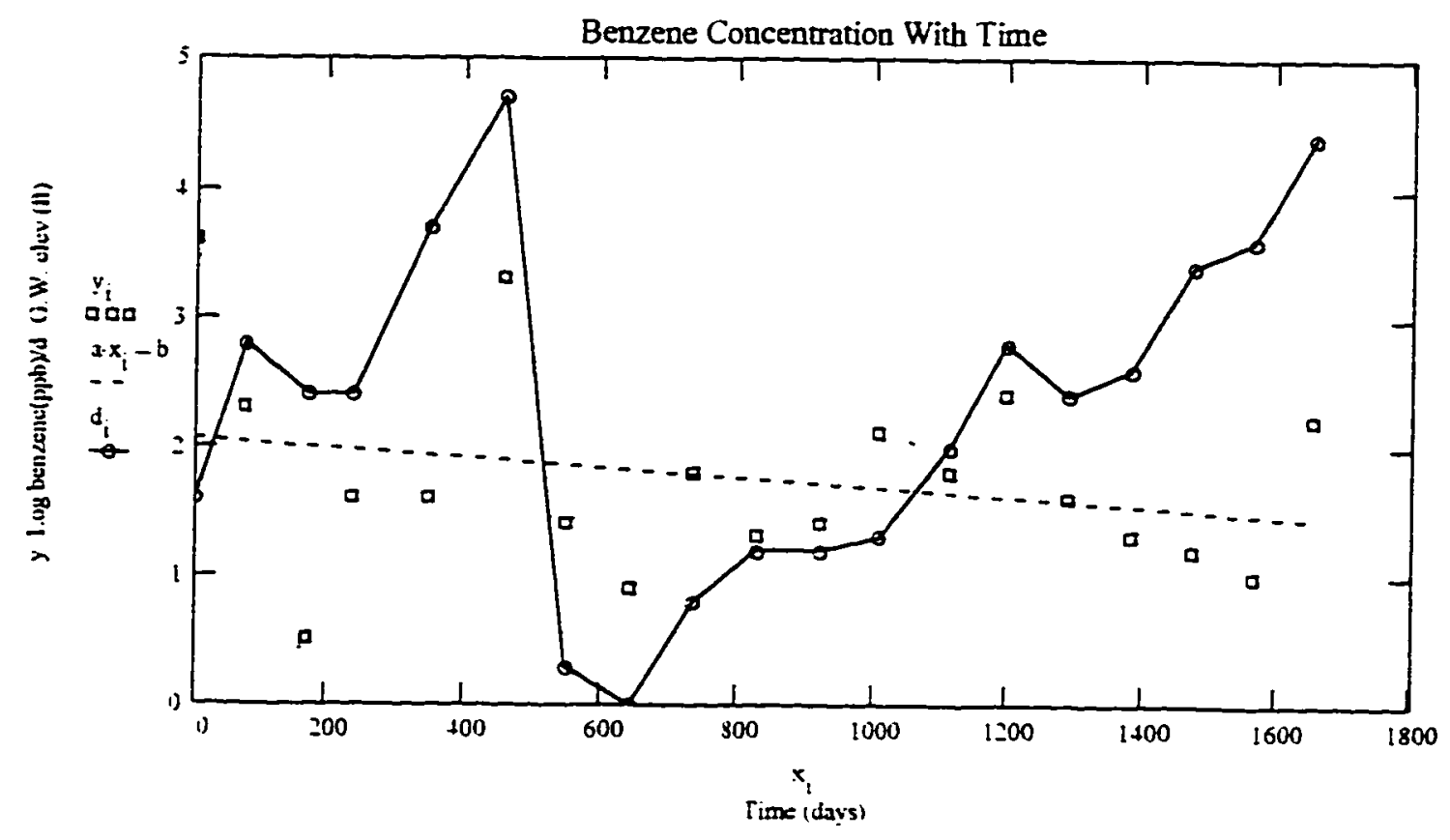

Note: Ground water elevations have been adjusted to fit the graph. $0 \mathrm{ft}=$ it. 
SCWWD Site Number: 06S2W24Q02F Site Address: 499 N. Mathilda Ave Site Name: Unocal \#4315

City: Sunnyvale

$$
\begin{aligned}
& \text { Contaminant: TPH Gasoline, MW-5 } \\
& \qquad i=0 . .26 \\
& \text { a }=\operatorname{siope}(x . y) \quad a=-2.2938 \cdot 10^{-4} \\
& b=\text { intercept }(x . y) b=4.9981 \\
& \text { corr }(x . y)=-0.6155 \\
& \text { corr }(x . y)^{2}=0.3788
\end{aligned}
$$

$$
\text { Days }
$$$$
\log C
$$

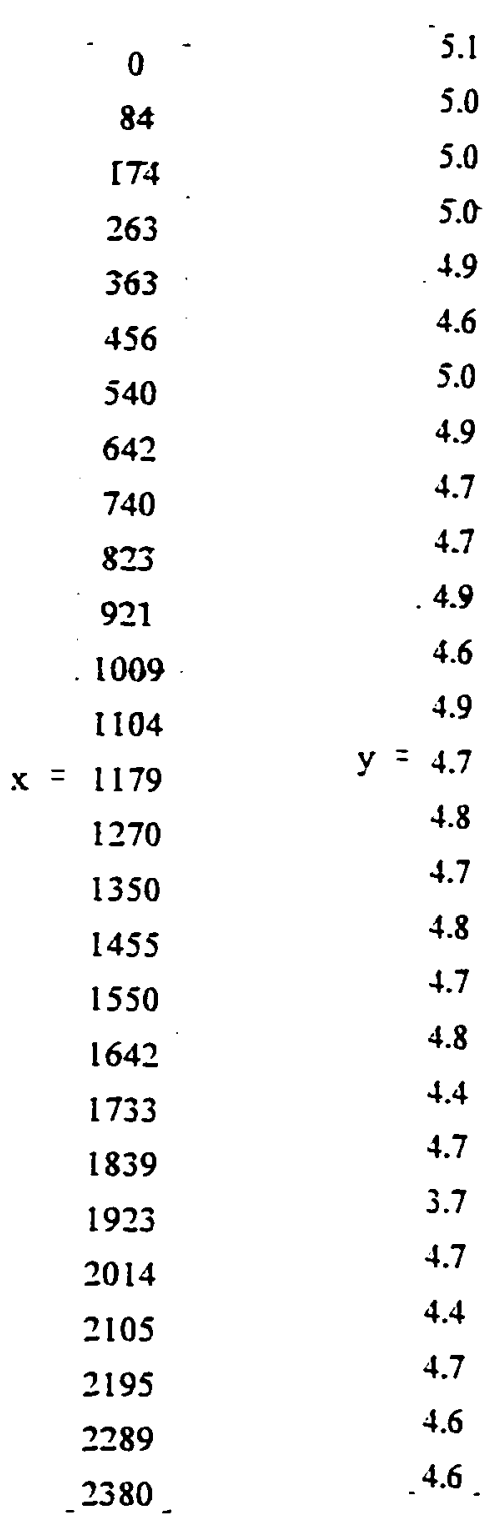




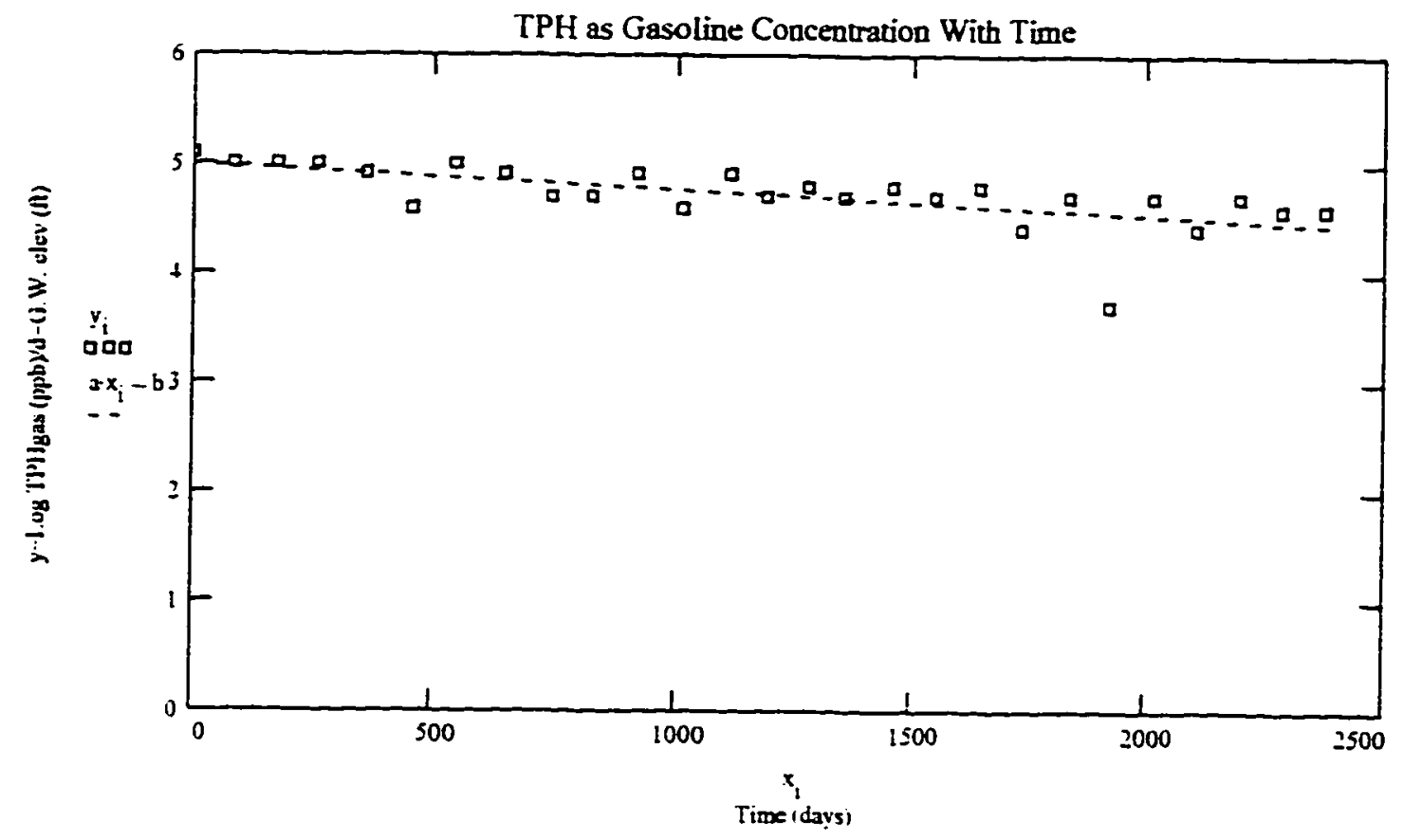




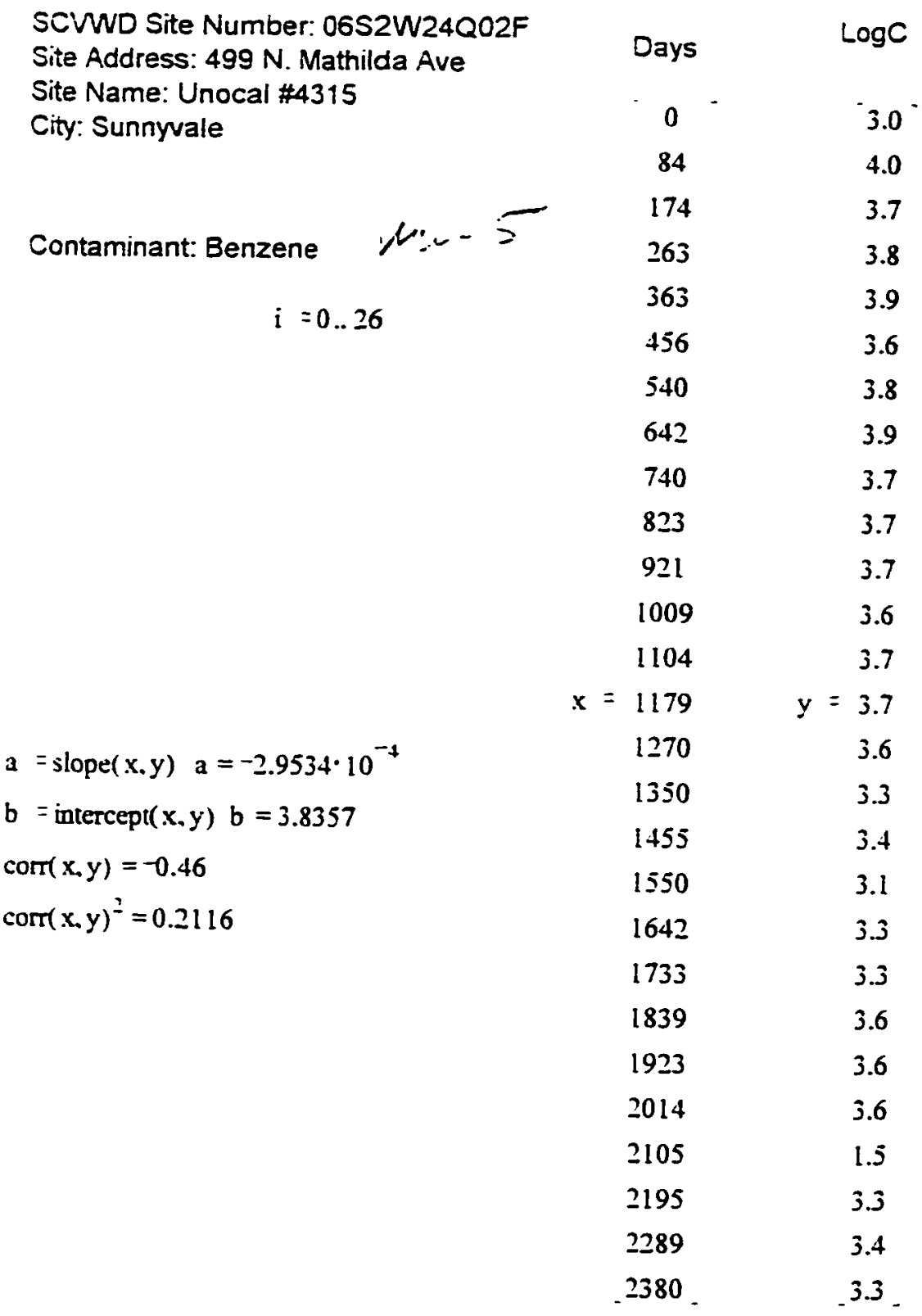

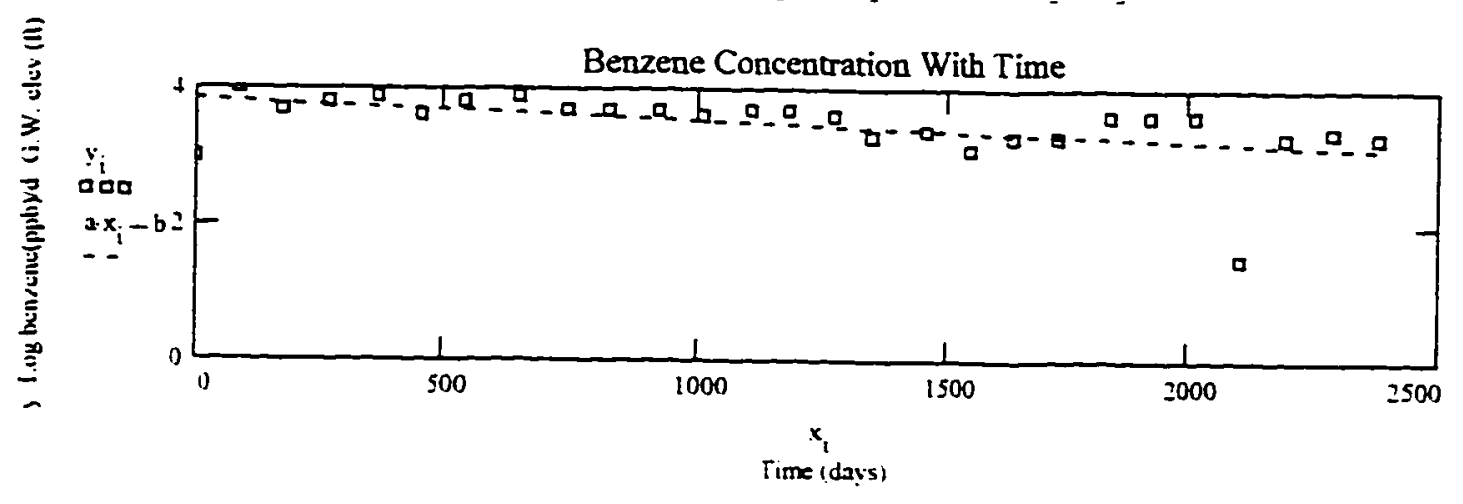




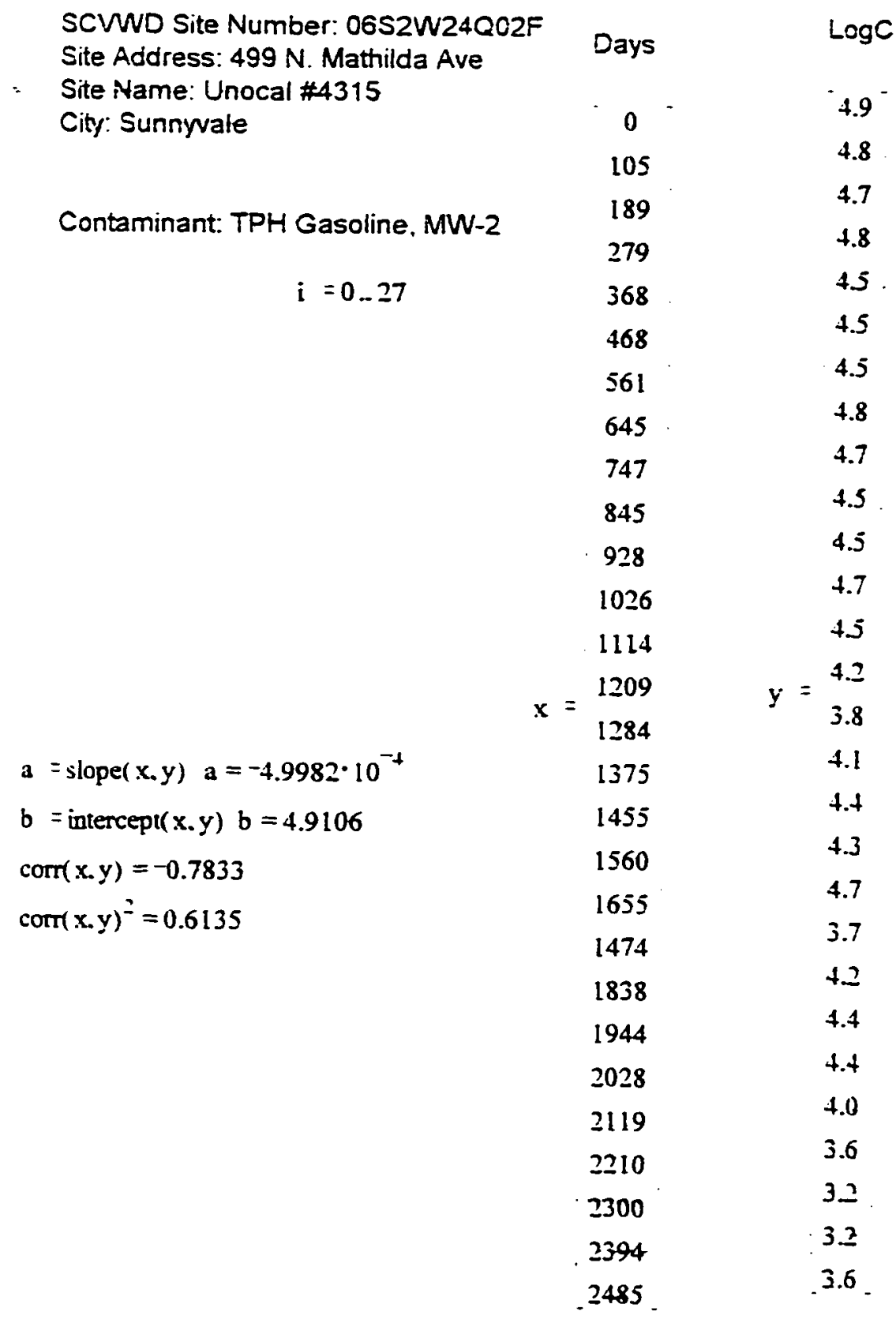




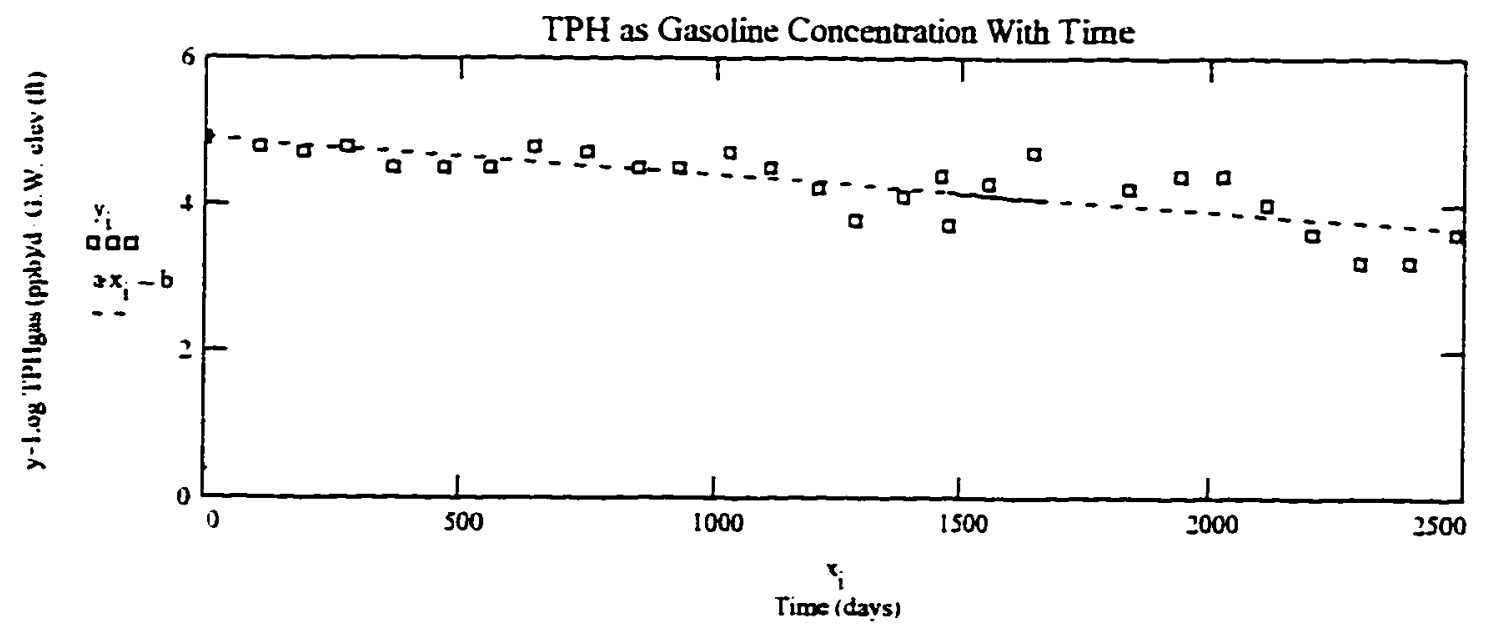

Note: No ground water elevation data availabe except for last four sample dates. 


\begin{tabular}{|c|c|c|}
\hline $\begin{array}{l}\text { SCWWD Site Number: 06S2W24QC2F } \\
\text { Site A.ddress: } 499 \text { N. Mathilda Ave }\end{array}$ & Days & $\operatorname{Lg} C$ \\
\hline $\begin{array}{l}\text { Site Name: Unocal \#4315 } \\
\text { City: Sunnyvale }\end{array}$ & 0 & $3.2^{\circ}$ \\
\hline & 105 & 2.7 \\
\hline & 189 & 2.9 \\
\hline Contaminant: Benzene. MW-2 & 279 & 2.9 \\
\hline$i=0 . .27$ & 368 & 2.7 \\
\hline & 468 & 2.9 \\
\hline & 561 & 2.7 \\
\hline & 645 & 2.6 \\
\hline & 747 & 2.9 \\
\hline & 845 & 2.4 \\
\hline & 928 & 2.4 \\
\hline & 1026 & 2.3 \\
\hline & 1114 & 2.6 \\
\hline & $x=1209$ & $y=2.0$ \\
\hline$=\operatorname{slope}(x . y) \quad a=-4.6889 \cdot 10^{-4}$ & 1284 & 1.3 \\
\hline$=$ intercept $(x, y) b=2.8795$ & 1375 & 1.7 \\
\hline $\operatorname{corr}(x . y)=-0.722$ & 1455 & 2.0 \\
\hline $\operatorname{corr}(x, y)^{2}=0.5212$ & 1560 & 1.8 \\
\hline & 1655 & 2.0 \\
\hline & 1474 & 2.6 \\
\hline & 1838 & 2.1 \\
\hline & 1944 & 2.0 \\
\hline & 2028 & 2.0 \\
\hline & 2119 & 1.6 \\
\hline & $\begin{array}{l}2210 \\
2300\end{array}$ & 1.8 \\
\hline & $\begin{array}{l}2300 \\
2394\end{array}$ & 1.7 \\
\hline & $\begin{array}{l}2394 \\
2485\end{array}$ & -.0 \\
\hline & -2485 & -.00 \\
\hline
\end{tabular}


Note: No ground water elevation data availabe except for last four sample dates.

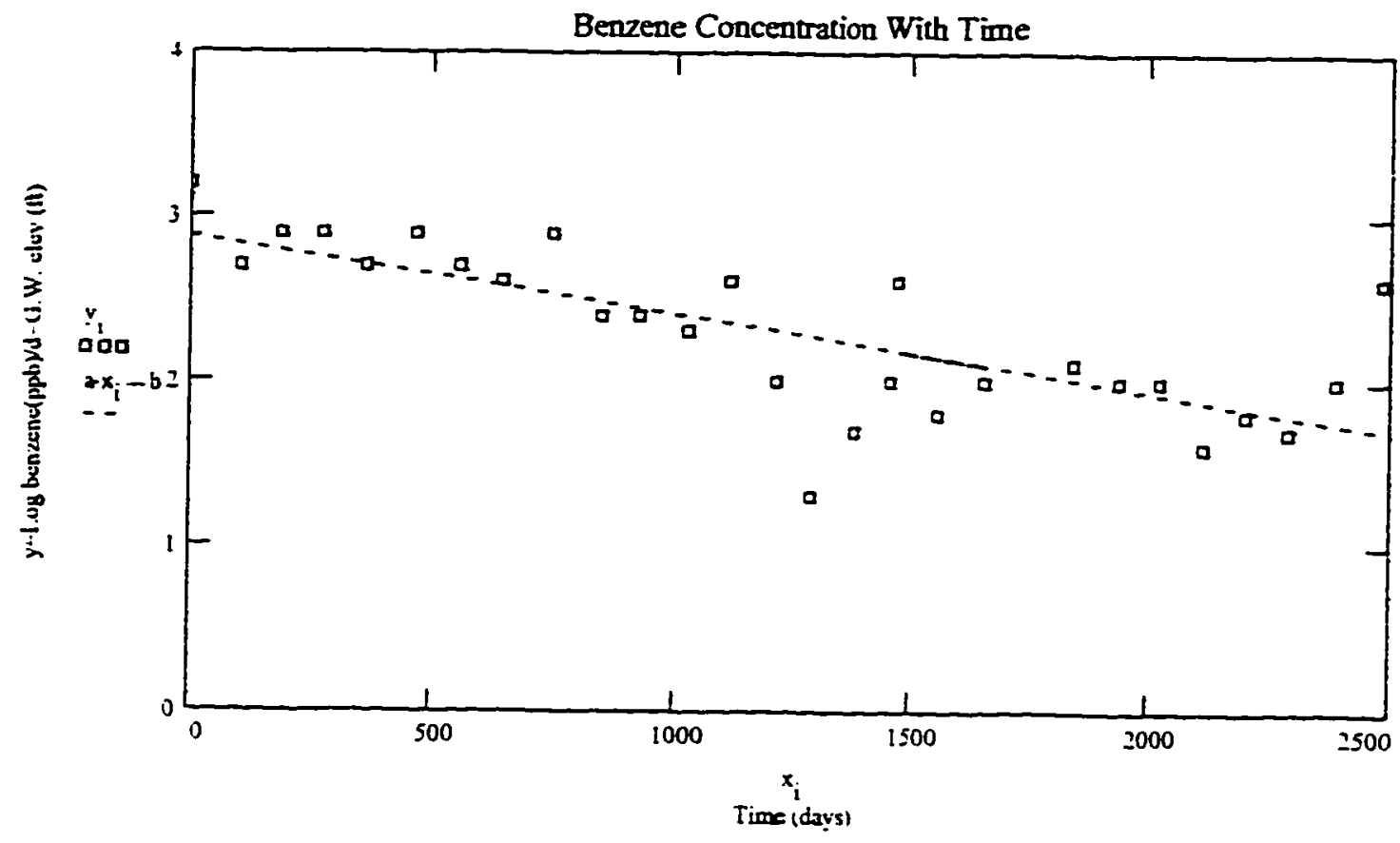


SCWWD Site Number: 06S2W24Q02F Site Address: 499 N. Mathilda Ave

Site Name: Unocal \#4315

City: Sunnyvale

$\begin{array}{cr}\text { Days } & \text { LogC } \\ -0 & 3.5 \\ 95 & 3.4 \\ 136 & 3.0 \\ 278 & 2.7 \\ 383 & 2.5 \\ \mathrm{x}=461 & \mathrm{y}=2.5 \\ 553 & 2.1 \\ 643 & 2.4 \\ 734 & 2.2 \\ 828 & 2.4 \\ 919 . & 1.4\end{array}$

$a=\operatorname{slope}(x . y) \quad a=-0.0017$

b $=$ intercepl( $x . y) \quad b=3.3541$

Note: No ground water elevationd data was available.

$\operatorname{corr}(x . y)=-0.9058$

$\operatorname{corr}(x, y)^{2}=0.8205$

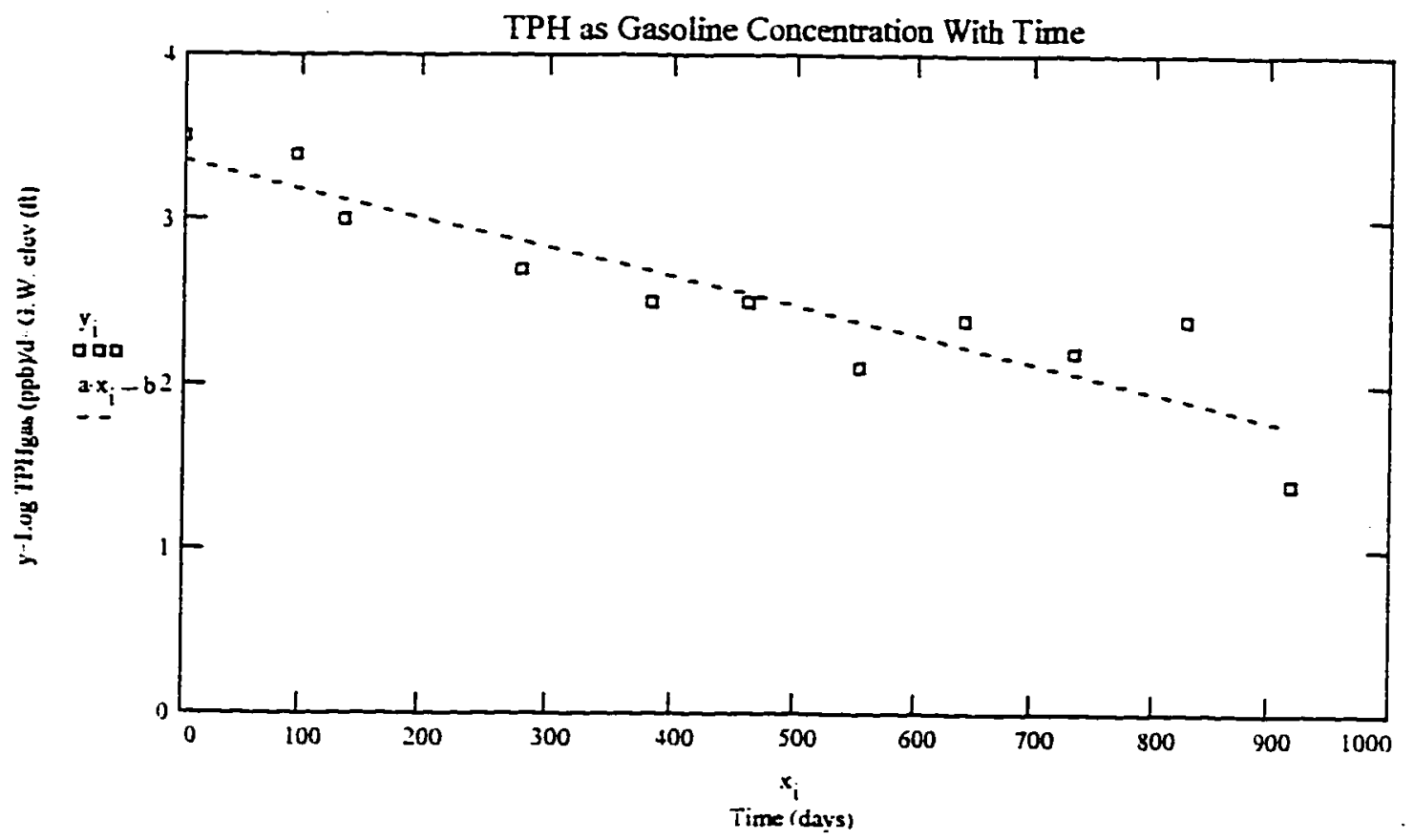




\begin{tabular}{|c|c|c|c|}
\hline $\begin{array}{l}\text { SCWWD Site Number: 06S1W32B01F } \\
\text { Site Address: } 1202 \text { Kifer Road }\end{array}$ & Days & $\log C$ & $\begin{array}{l}\text { G.W. } \\
\text { Elev }\end{array}$ \\
\hline $\begin{array}{l}\text { Site Name: Texaco } \\
\text { City: Sunnywale }\end{array}$ & 0 & $4.1^{-}$ & $5.1^{\circ}$ \\
\hline & 82 & 3.8 & 6.5 \\
\hline Contaminant: TPH Gasoline & 166 & 2.8 & 6.3 \\
\hline Contaminant: IPH Gasoline & 264 & 2.9 & 6.2 \\
\hline$i=0 . .10$ & 344 & 3.1 & 6.0 \\
\hline & $x=433$ & $y=3.3$ & $d=6.2$ \\
\hline & 526 & 2.6 & 6.4 \\
\hline & 612 & 2.5 & 6.2 \\
\hline & 714 & 3.0 & 0 \\
\hline & 795 & 1.8 & 8.4 \\
\hline$=$ slope $(x, y) \quad a=-0.0018$ & 900 & 2.2. & 8.3 \\
\hline
\end{tabular}

Note: Ground water elevations have been adjusted to fit the graph. $O$ it $=33.1$ it.

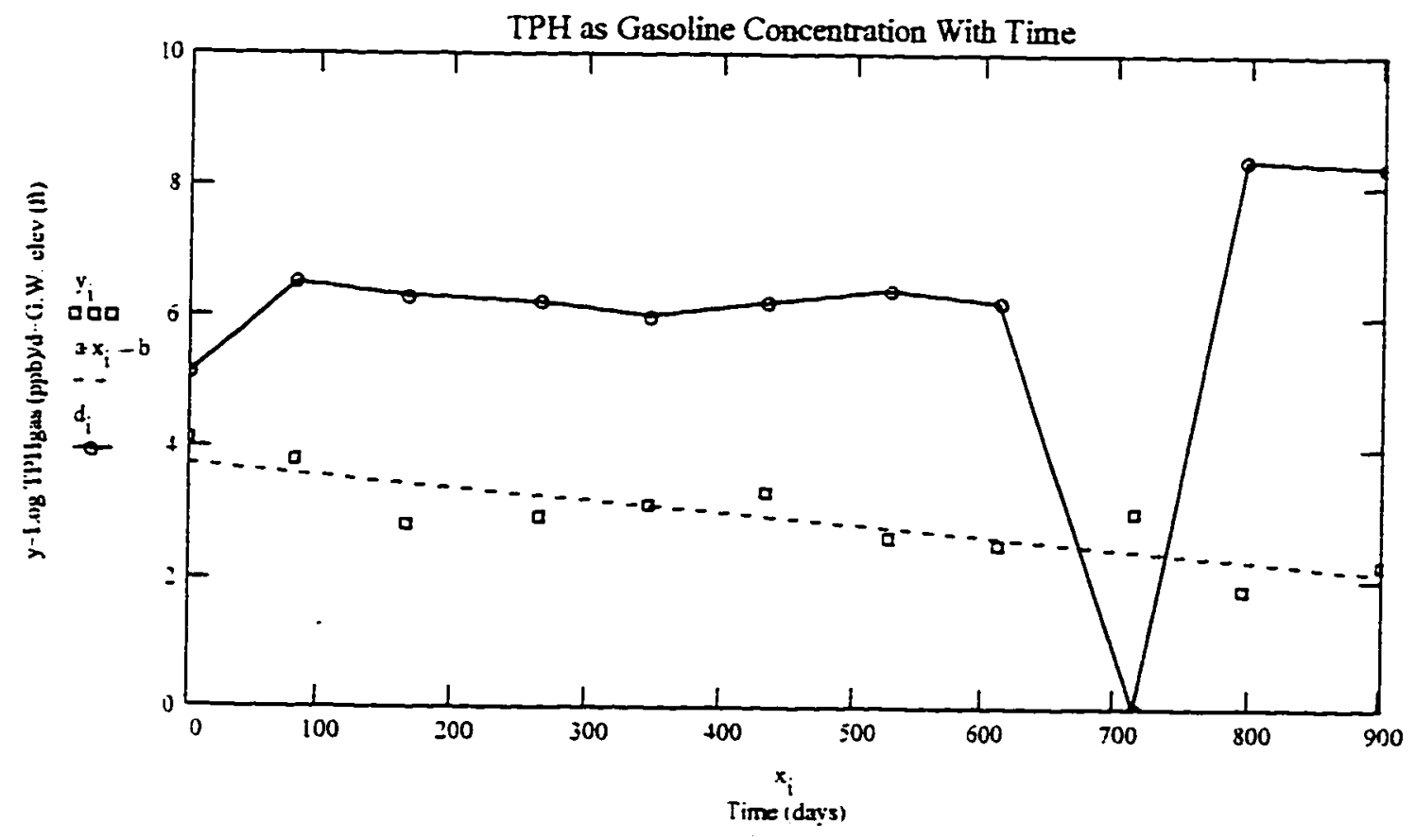


SCNND Site Number: 06S1W32301F

Site Address: 1202 Kifer Road

Site Name: Texaco

City: Sunnyvale

$\begin{array}{ccc}\text { Days } & \text { LogC } & \begin{array}{c}\text { G.W. } \\ \text { Elev }\end{array} \\ 0 & -1.7 & 5.1 \\ 82 & -0.6 & 6.5 \\ 166 & 0.3 & 6.3 \\ 264 & y=0.4 & d=6.2 \\ 344 & 0.7 & 6.0 \\ 433 & 1.1 & 6.2 \\ .526 . & -0.6 & .6 .4\end{array}$

\footnotetext{
$\mathrm{a}=\operatorname{slope}(x . y) \quad a=-0.0013$

$b=$ intercept $(x . y) b=0.7531$

$\operatorname{corr}(x, y)=-0.2812$

$\operatorname{corr}\left(x_{.} y\right)^{2}=0.0791$
}

Note: Ground water elevations have been adjusted to fit the graph. Oft $=33.1 \mathrm{ft}$.

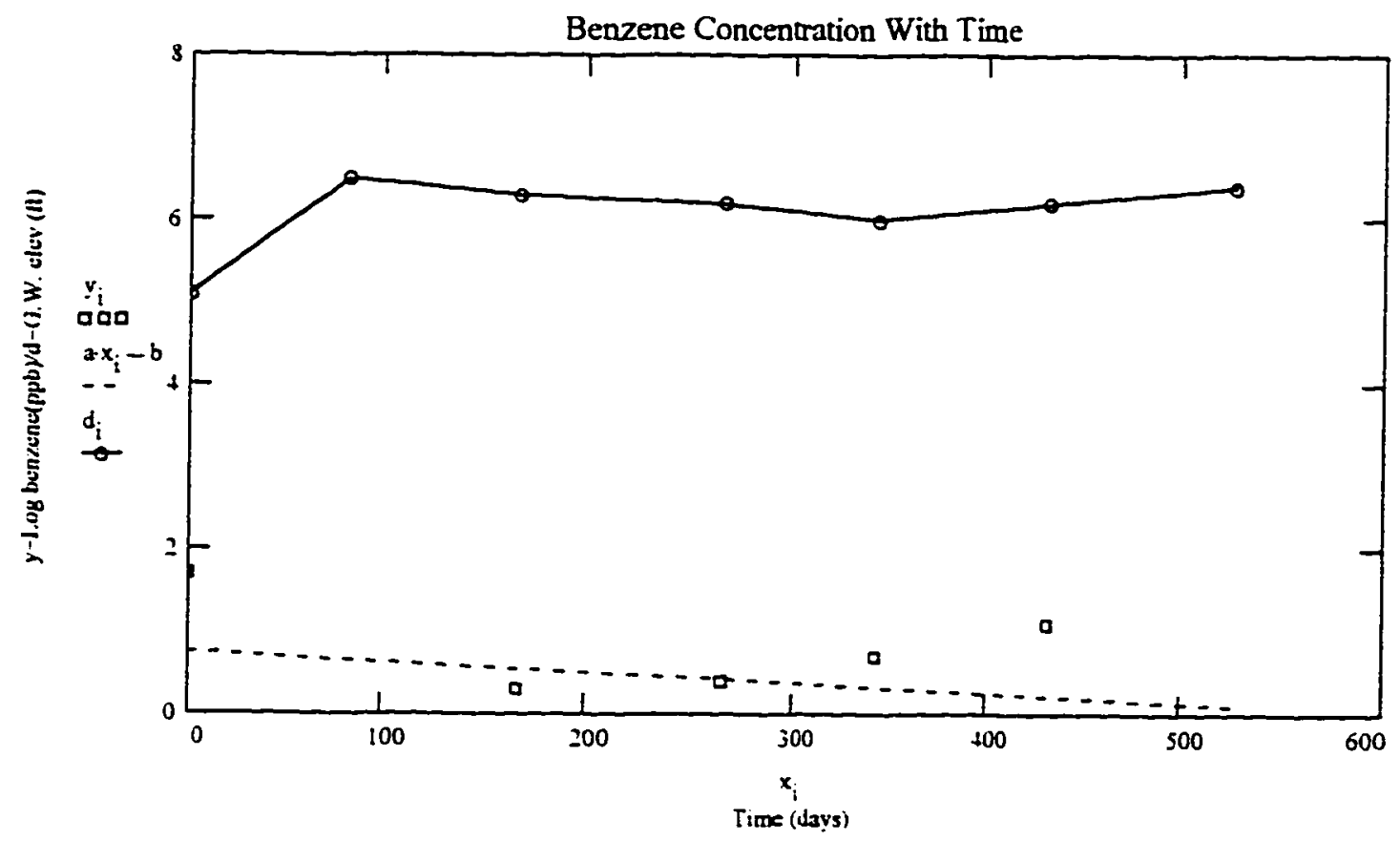




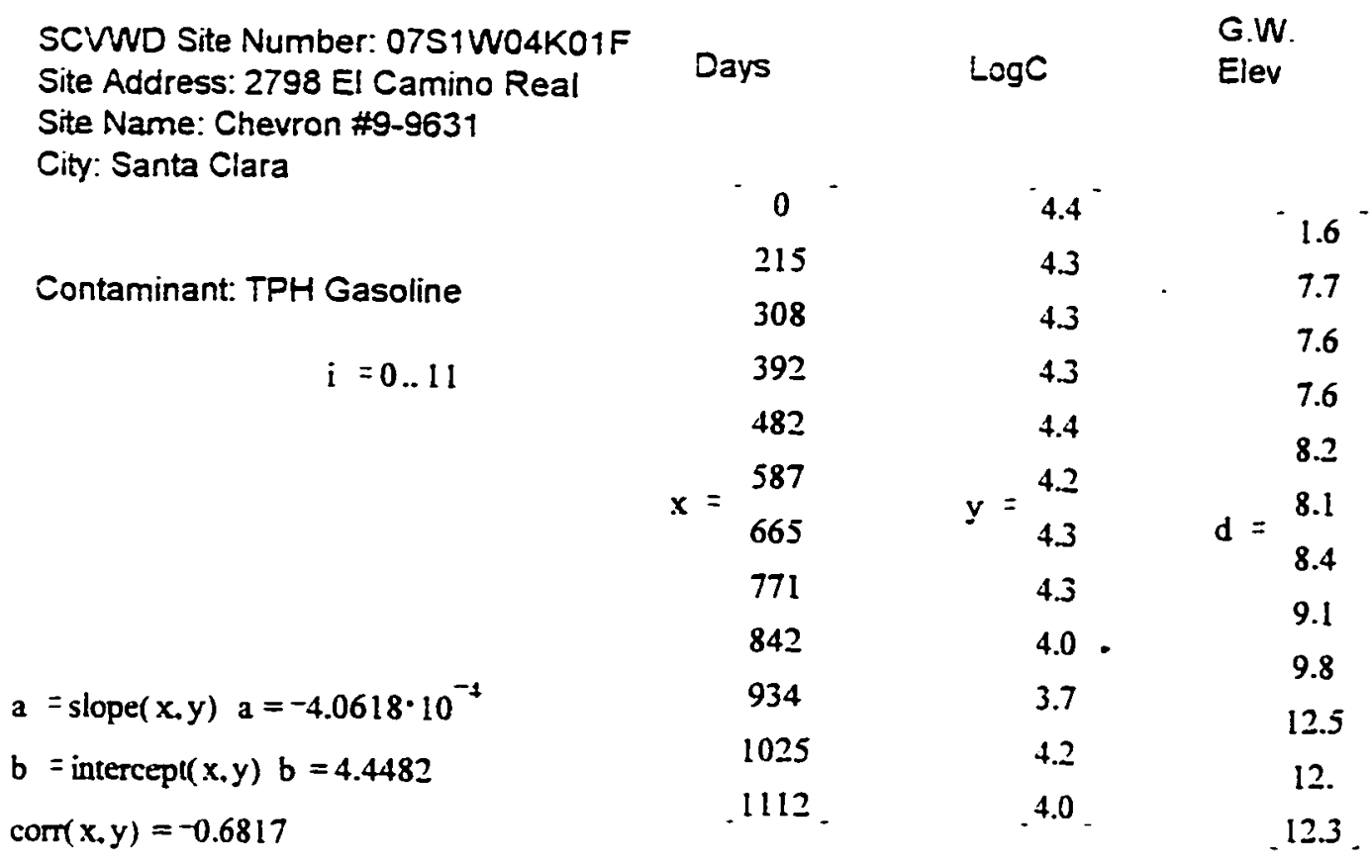

Note: Ground water elevations have been adjusted to fit the graph. $O \mathrm{ft}=49.51 \mathrm{ft}$.

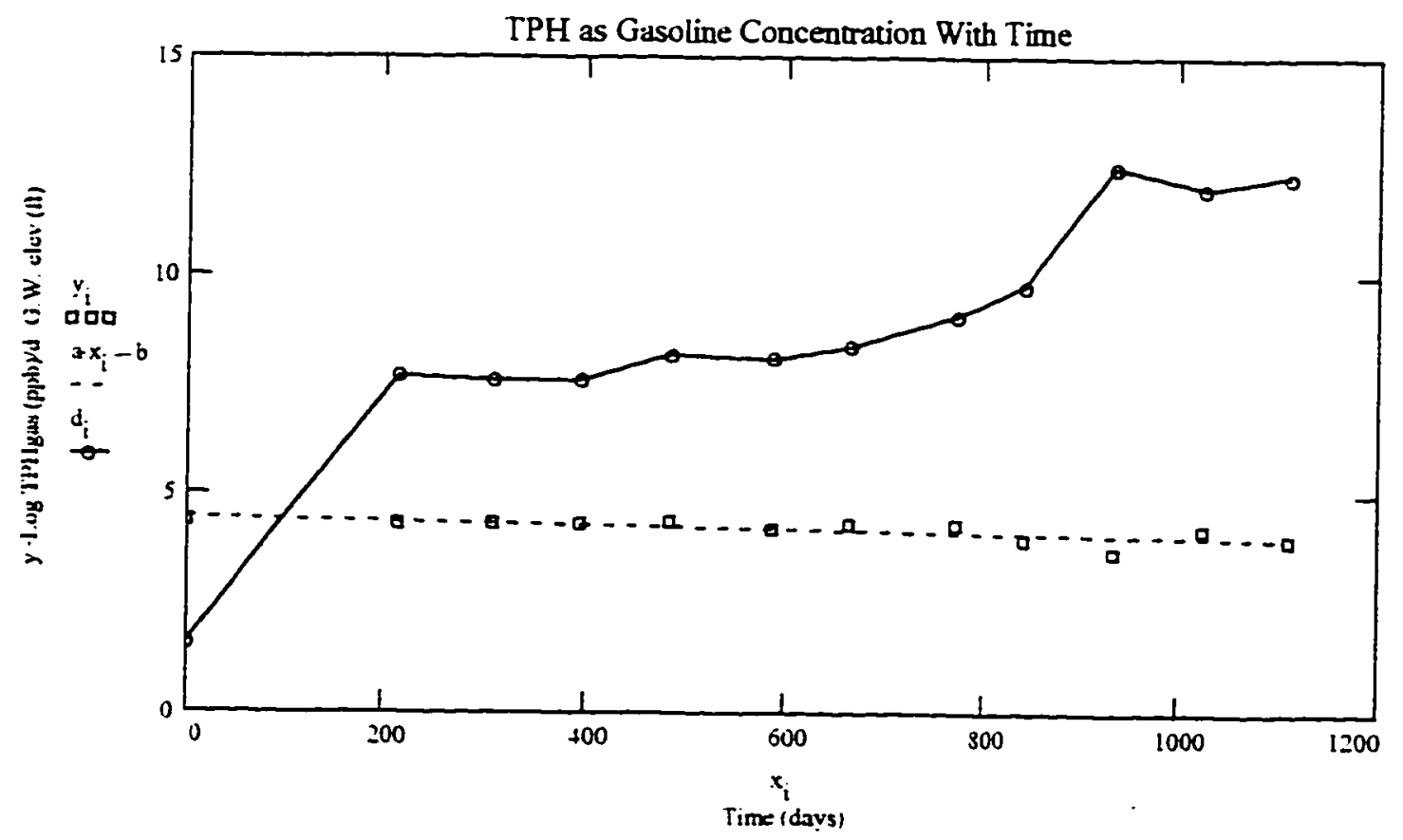


SCWWD Site Number: 07S1W04K01F Site Address: 2798 El Camino Real Site Name: Chevron \#9-9631

City: Santa Clara

$$
\begin{aligned}
& \text { Contaminant: Benzene } \\
& \qquad i=0 . .21 \\
& a=\operatorname{slope}(x, y) \quad a=-3.8726 \cdot 10^{-4} \\
& b=\operatorname{intercept}(x . y) \quad b=3.5174 \\
& \operatorname{corr}(x . y)=-0.7094 \\
& \operatorname{corr}(x . y)^{2}=0.5033
\end{aligned}
$$

\begin{tabular}{|c|c|c|}
\hline Days & $\log C$ & $\begin{array}{l}\text { G.W. } \\
\text { Elev }\end{array}$ \\
\hline 0 & $3.6^{\circ}$ & -0.2 \\
\hline 102 & 3.4 & 0.6 \\
\hline 188 & 3.3 & 0 \\
\hline 265 & 3.2 & 0.2 \\
\hline 356 & 3.4 & 0.3 \\
\hline 448 & 3.3 & 0.5 \\
\hline 535 & 3.2 & 0.9 \\
\hline 627 & 3.1 & 1.0 \\
\hline 729 & 3.3 & 1.7 \\
\hline 799 & 3.1 & 1.9 \\
\hline$x=877$ & $v=3.1$ & 1.6 \\
\hline 1092 & 3.4 & 7.7 \\
\hline 1185 & 3.4 & 7.6 \\
\hline 1269 & 3.4 & 7.6 \\
\hline 1359 & 3.4 & 8.2 \\
\hline 1464 & 3.1 & 8.1 \\
\hline 1542 & 3.1 & 8.4 \\
\hline 1648 & 3.1 & 9.1 \\
\hline 1719 & 2.8 & 9.8 \\
\hline 1811 & 2.3 & 12.5 \\
\hline 1902 & 2.5 & 12.6 \\
\hline 1989. & 2.4. & .12 .3 \\
\hline
\end{tabular}$$
\text { City: Santa Clara }
$$

Benzene Concentration With Time

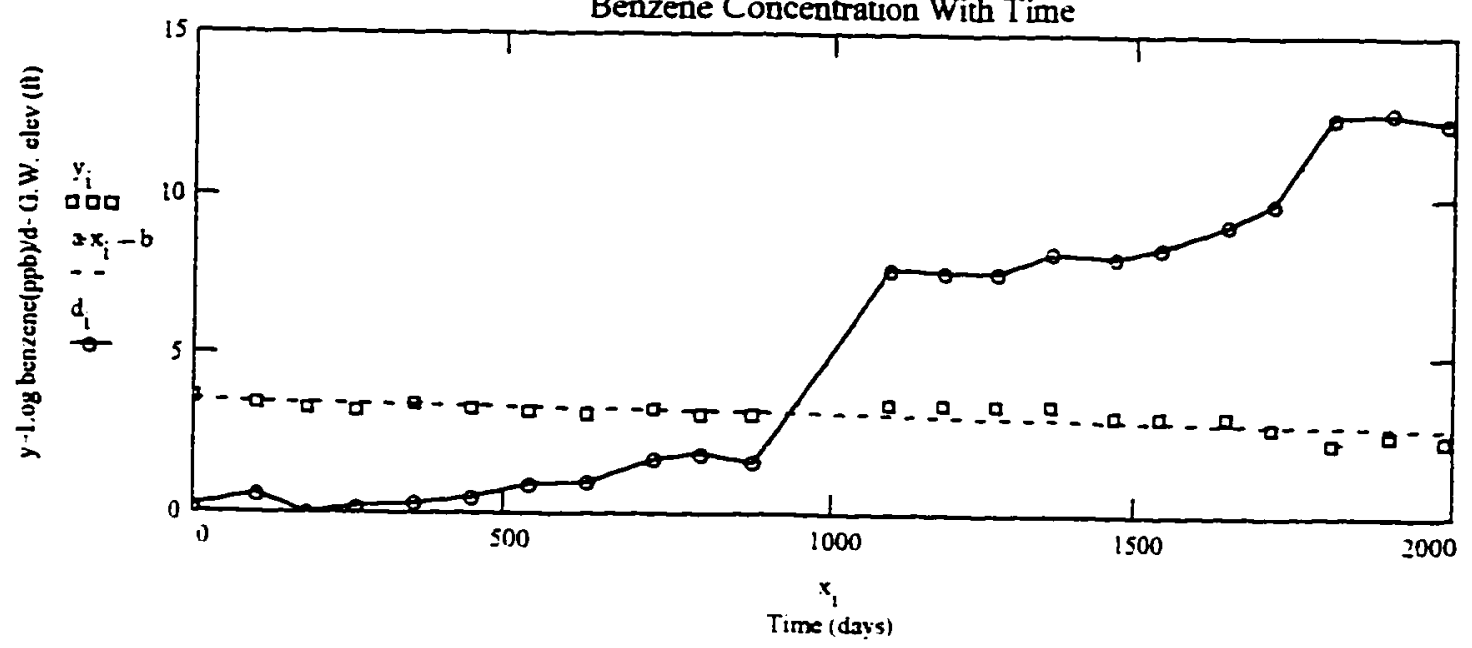

Note: Ground water elevations have been adjusted to it the grach. $0 \mathrm{ft}=49.51 \mathrm{ft}$. 


\begin{tabular}{|c|c|c|c|}
\hline $\begin{array}{l}\text { SCWWD Site Number: 06S 1W32E02F } \\
\text { Site Address: } 1037 \text { Reed Ave }\end{array}$ & Days & $\log C$ & $\begin{array}{l}\text { G.W. } \\
\text { Elev }\end{array}$ \\
\hline Site Name: Chevron $\# 9-6338$ & -0 & $5.2^{\circ}$ & 0 \\
\hline & 80 & 4.8 & 0 \\
\hline & 189 & 4.8 & 0 \\
\hline Contaminant: TPH Gasoline & 279 & 4.4 & 0 \\
\hline $\mathrm{i}=0 . .17$ & 380 & 5.1 & 0 \\
\hline & 455 & 4.8 & 1.7 \\
\hline & 560 & 4.8 & 10.7 \\
\hline & 632 & 4.1 & 5.7 \\
\hline & 720 & $y=3.7$ & 5.0 \\
\hline & 812 & $y-3.7$ & 5.5 \\
\hline$a=\operatorname{slope}(x . y) \quad a=-0.0011$ & 908 & 4.0 & 6.8 \\
\hline$b=$ intercept $(x . y) \quad b=5.0284$ & 996 & 3.6 & 6.9 \\
\hline $\operatorname{corr}(x . y)=-0.8292$ & 1085 & 4.0 & 6.7 \\
\hline $\operatorname{con}(x . y)-0.0292$ & 1175 & 4.0 & 7.0 \\
\hline $\operatorname{corr}(x, y)^{-}=0.6875$ & 1269 & 3.1 & 12.1 \\
\hline & 1369 & 4.0 & 12.9 \\
\hline & 1458 & 3.9 & 11.4 \\
\hline & 1540 & 2.9 & 13.0 \\
\hline
\end{tabular}

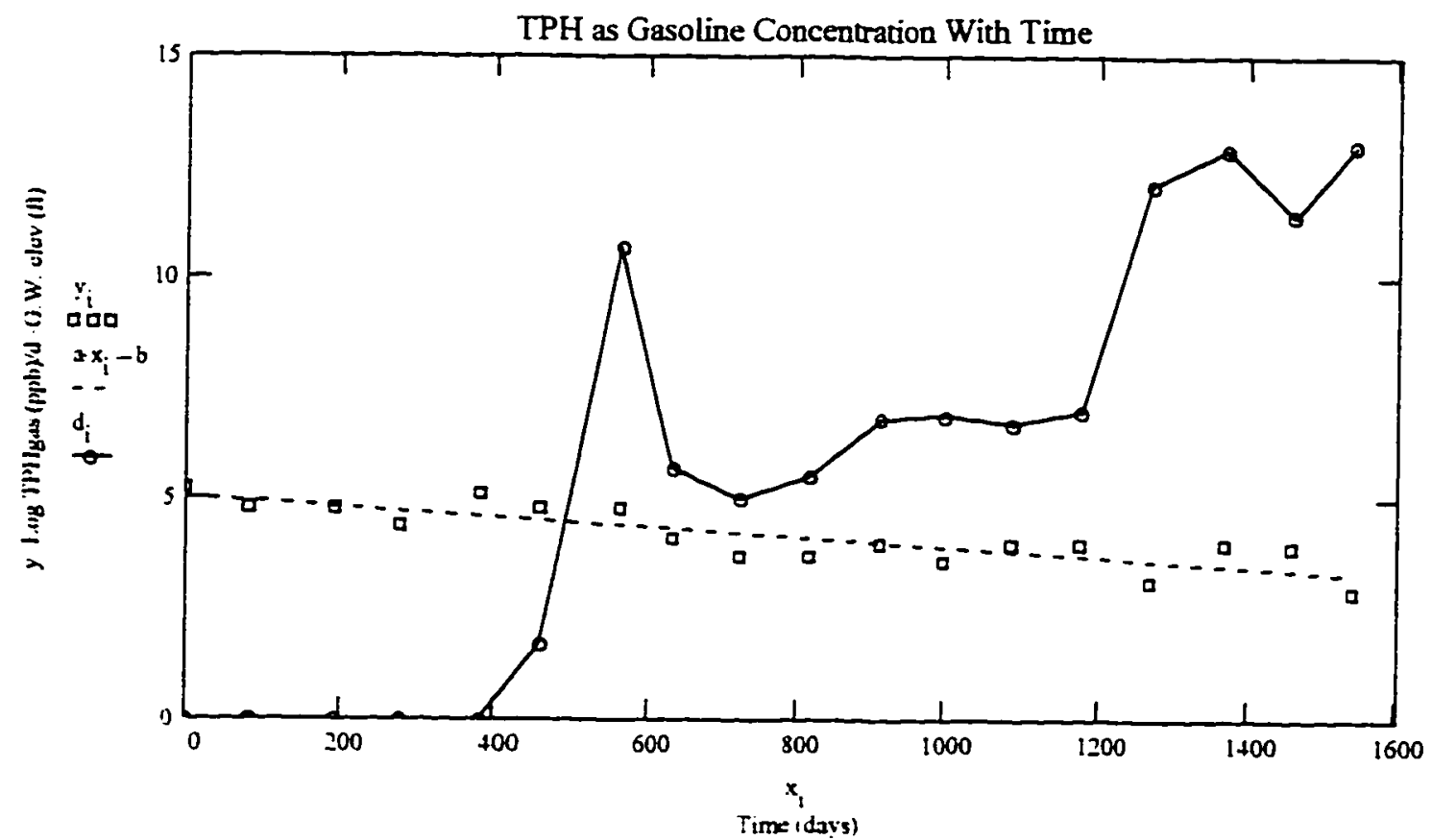

Note: Ground water elevations have been adjusted to fit the graph. $O \mathrm{ft}=43.57$ ft. No elevation data was available for the first four dates. so 0 was input. 
SCVWD Site Number: 06S1W32E02F

Site Address: 1037 Reed Ave

Site Name: Chevron \$9-6338

Citys Sunnyvale:

$\begin{array}{ccc} & & \begin{array}{c}\text { G.W } \\ \text { Elev }\end{array} \\ 0 & \text { LogC } & -10.7 \\ 72 & 4.0 & 5.7 \\ 160 & 2.8 & 5.0 \\ 252 & 2.6 & 5.5 \\ 348 & 2.6 & 6.8 \\ 436 & 3.2 & 6.9 \\ 525 & 2.6 & 6.7 \\ 615 & 3.3 & 7.0 \\ 709 & 2.8 & 12.1 \\ 809 & 2.2 & 12.9 \\ 898 & 3.4 & 11.4 \\ 980 & 3.3 & 13.0\end{array}$

$a=\operatorname{slope}(x . y) a=-5.7217 \cdot 10^{-4}$

$i=0 . .11$

$b=$ intercept $(x . y) b=3.1684$

1.9

$\operatorname{corr}(x, y)=-0.3248$

$\operatorname{corr}(x . y)^{2}=0.1055$

Note: Ground water elevations have been adjusted to it the graph. $O \mathrm{ft}=43.57 \mathrm{f}$.

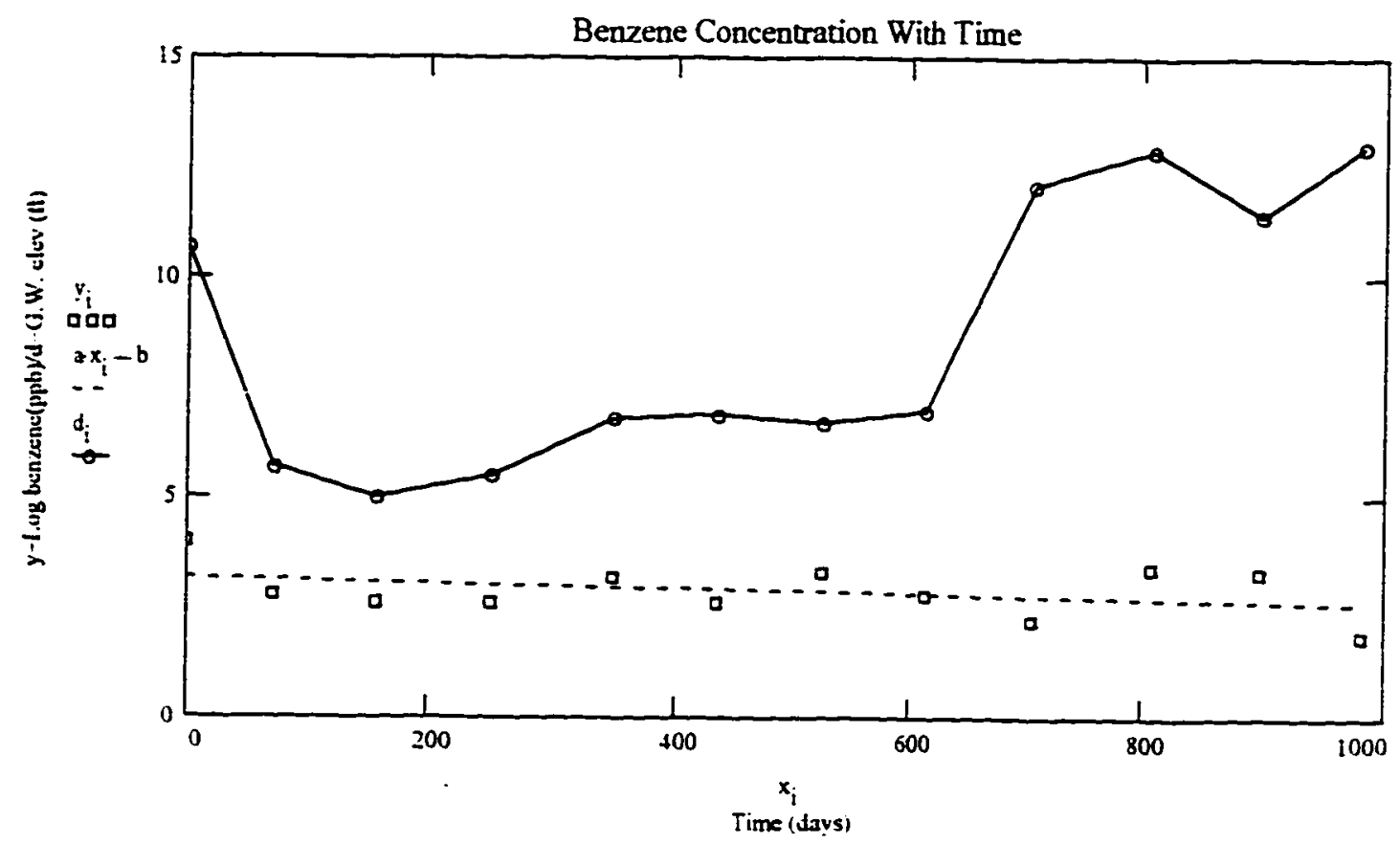


SCVWD Site Number: 06S2W16J01F Site Address: $808 \mathrm{~N}$. Shoreline Site Name: Chevron \#9-6377 City: Mountain View

\section{Contaminant: TPH Gasoline}

$$
i=0 . .10
$$

$a=\operatorname{slope}(x . y) \quad a=-0.003$

$b=$ intercept $(x, y) \quad b=4.488$

$\operatorname{corr}(x, y)=-0.95$

$\operatorname{corr}(x . y)^{2}=0.902$

\begin{tabular}{|c|c|c|}
\hline Days & $\log C$ & $\begin{array}{l}\text { G.W. } \\
\text { Elev }\end{array}$ \\
\hline 0 & $4.3^{\circ}$ & 0.5 \\
\hline 70 & 4.3 & 0.3 \\
\hline 168 & 3.7 & 0 \\
\hline 251 & 4.0 & 0.5 \\
\hline 378 & 3.9 & 1.4 \\
\hline$x=469$ & $y=3.2$ & $d=0.9$ \\
\hline 580 & 2.9 & 0.6 \\
\hline 642 & 2.4 & 2.6 \\
\hline 749 & 1.9 & 2.7 \\
\hline 847 & 1.7 & 3.1 \\
\hline 917. & .2 .2 . & .2 .7 \\
\hline
\end{tabular}

Note: Ground water elevations have been adjusted to fit the graph. O ft $=24.36 \mathrm{ft}$.

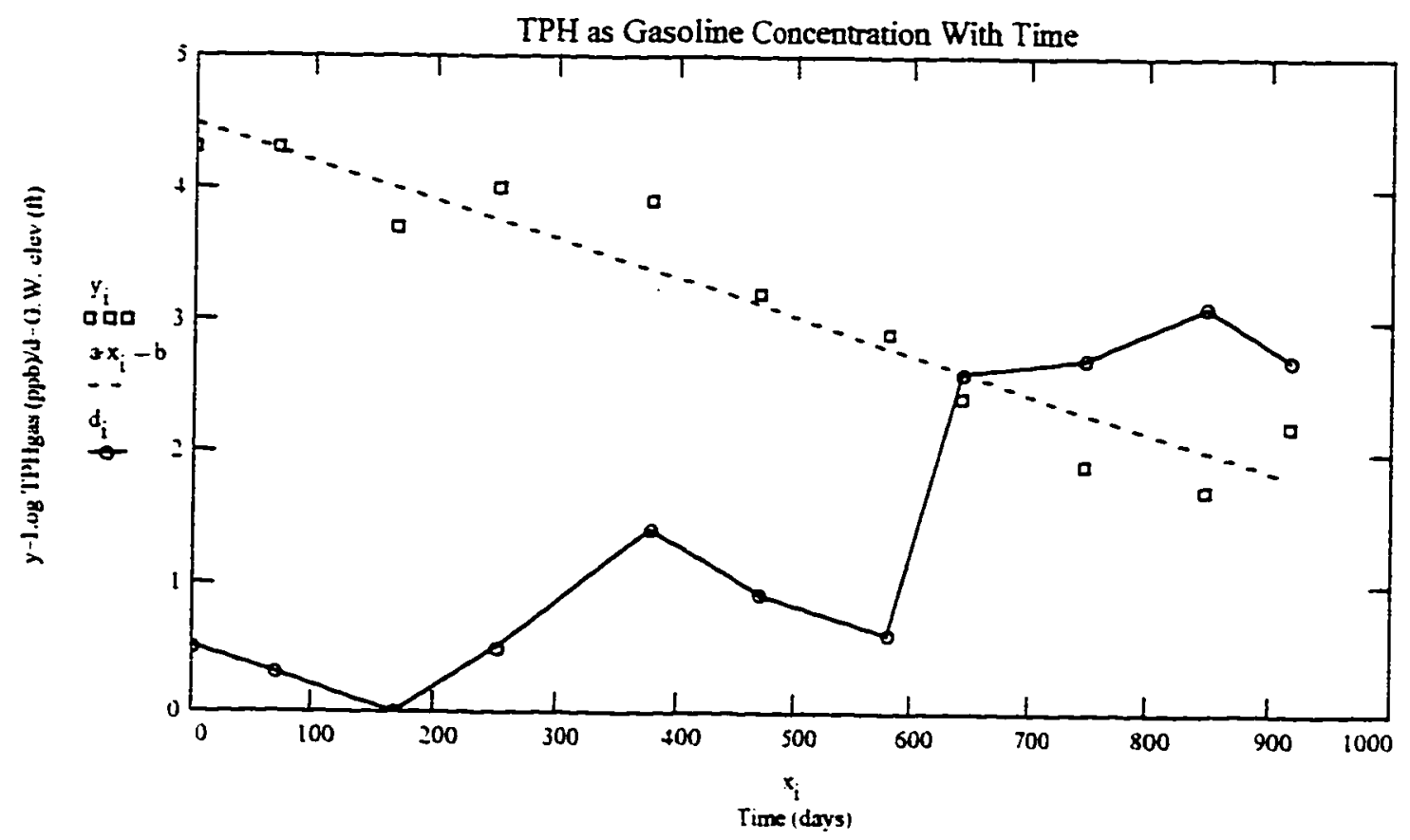


SCWWD Site Number: 06S2W16Jo1F

Site Address: $808 \mathrm{~N}$. Shoreline

Site Name: Chevron \$9-6377

City: Mountain View

$\begin{array}{ccc}\text { Days } & \text { LogC } & \begin{array}{c}\text { G.W. } \\ \text { Elev }\end{array} \\ 0 & 2.4 & -0.5 \\ 70 & 2.3 & 0.3 \\ 168 & 1.6 & 0 \\ \mathbf{x}= & \mathrm{y}=1.6 & \mathrm{~d}=0.5 \\ 378 & 1.2 & 1.4 \\ 469 & 0.9 & 0.9 \\ .580 . & -0 . & -0.6\end{array}$

$a=\operatorname{slope}(x, y) \quad a=-0.0038$

$b=$ intercept $(x . y) \quad b=2.4692$

$\operatorname{corr}(x, y)=-0.9732$

$\operatorname{corr}(x . y)^{2}=0.9472$

Note: Ground water elevations have been adjusted to fit the graph. $O \mathrm{ft}=24.36 \mathrm{ft}$.

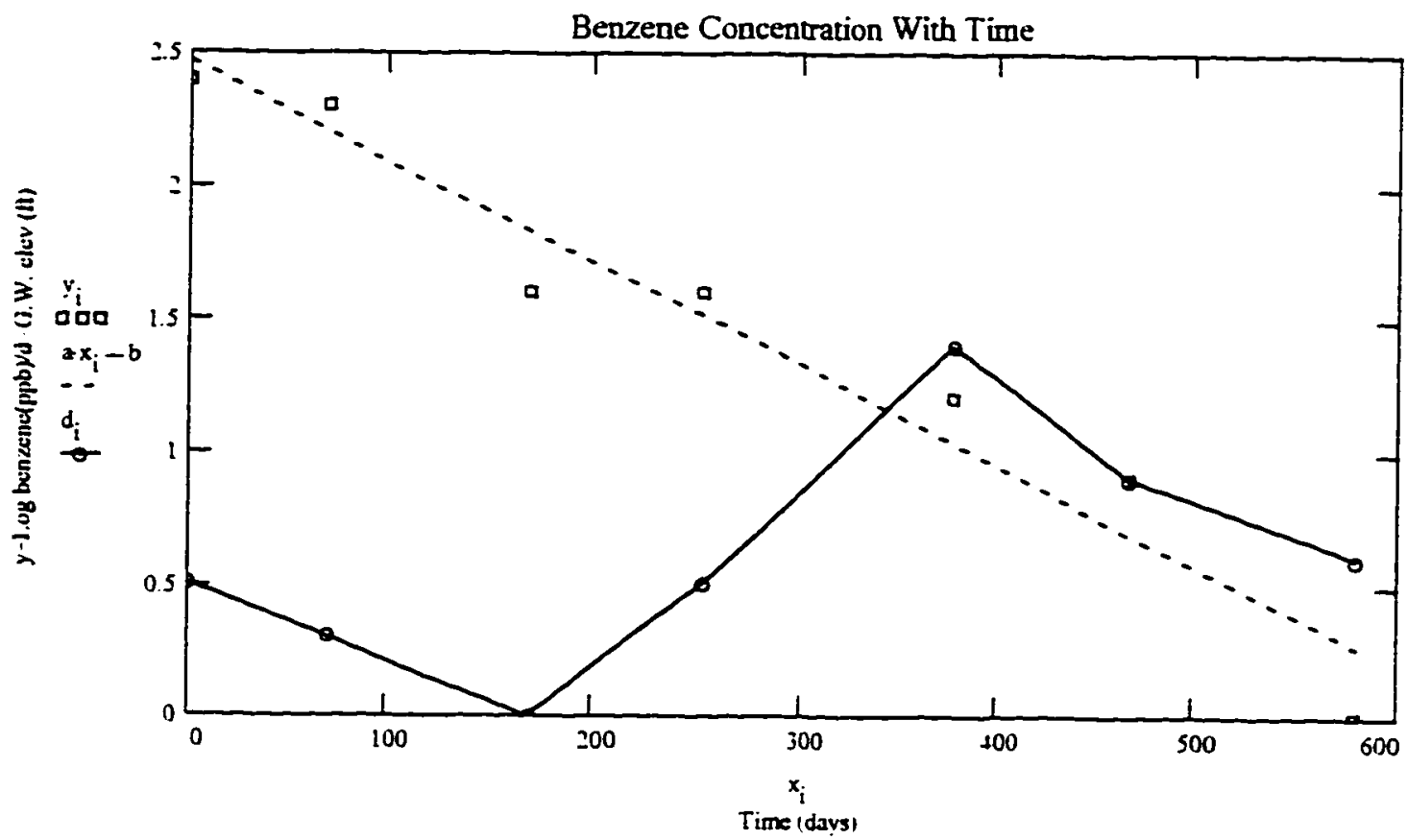


SCWWD Site Number: 07S1W09G01F Site Address: 2790 Homestead Rd.

Site Name: Chevron

City: Santa Clara

$\begin{array}{ccc}\text { Days } & \text { LogC } & \begin{array}{c}\text { G.W } \\ \text { Elev }\end{array} \\ 0 & -4.8 & 0.6 \\ 124 & 4.5 & 0.4 \\ 215 & 4.7 & 0 \\ 343 & 4.0 & 2.1 \\ \mathrm{x}= & \mathrm{y} & 3.8 \\ 530 & 4.5 & \mathrm{~d}=4.1 \\ 628 & 3.9 & 3.7 \\ 739 & 3.0 & 3.1 \\ 814 & 3.7 & 5.2 \\ .906 . & 3.5 & 5.4 \\ 906 & & 4.7 .\end{array}$

$a=\operatorname{slope}(x . y) \quad a=-0.0016$

$b=$ intercept $(x . y) \quad b=4.78$

$\operatorname{cotr}(x, y)=-0.8218$

Note: Ground water elevations have been adjusted to fit the graph. 0 it $=55.71 / 3 \mathrm{ft}$.

$\operatorname{corr}(x . y)^{2}=0.6753$

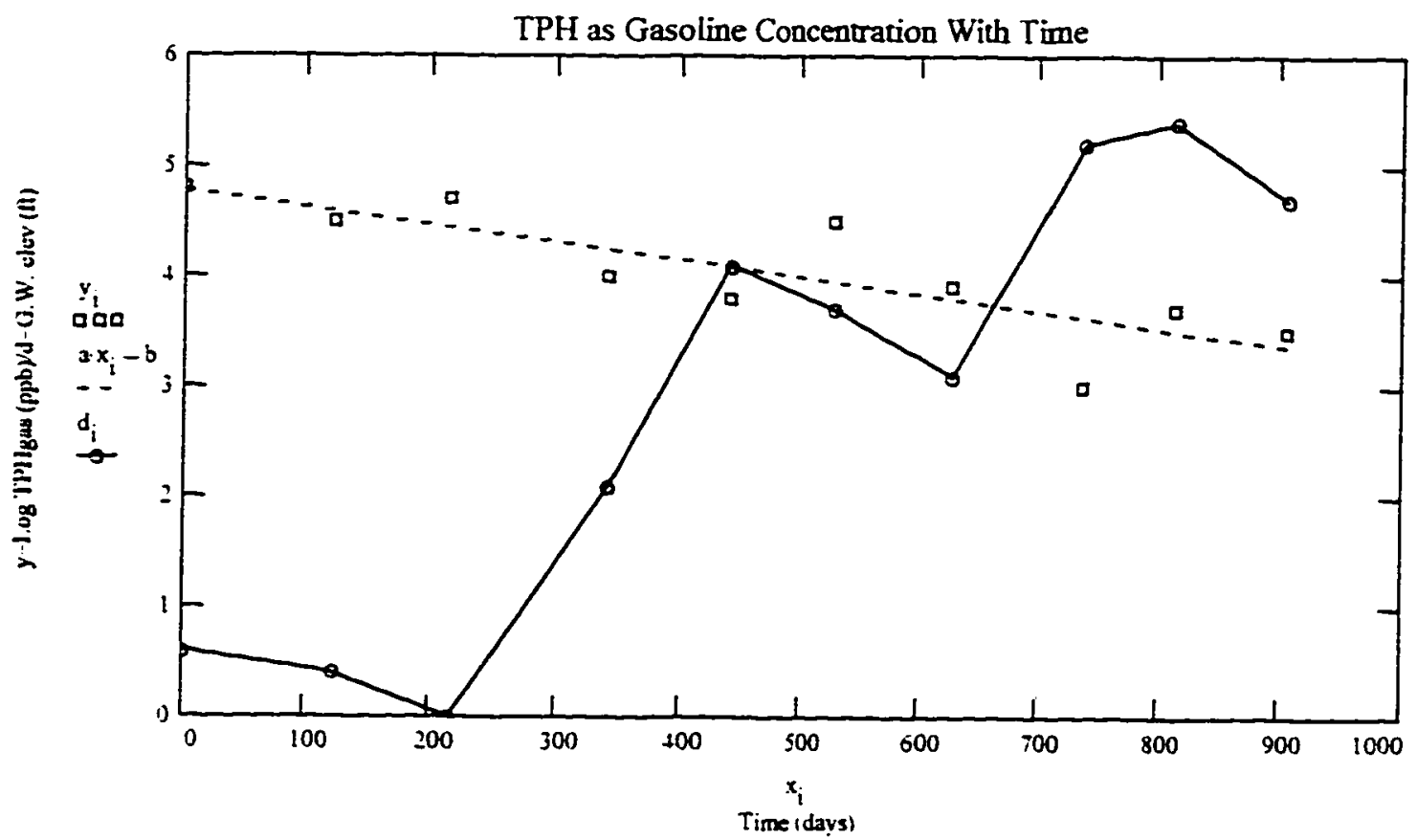




\begin{tabular}{|c|c|c|c|}
\hline \multirow{5}{*}{$\begin{array}{l}\text { SCWWD Site Number: 07S1W09G01F } \\
\text { Site Address: } 2790 \text { Homestead Rd. } \\
\text { Site Name: Chevron } \\
\text { City: Santa Clara }\end{array}$} & Days & $\log C$ & $\begin{array}{l}\text { G.W. } \\
\text { Elev }\end{array}$ \\
\hline & 0 & $4.0^{-}$ & 0 \\
\hline & 193 & 3.6 & $\mathbf{0}$ \\
\hline & 308 & 3.2 & 0 \\
\hline & 478 & 3.8 & 0.6 \\
\hline Contaminant: Benzene & 602 & 3.7 & 0.4 \\
\hline$i=0,12$ & 693 & 3.7 & 0 \\
\hline 0. & $x=821$ & $y=1.9$ & $d=2.1$ \\
\hline & 918 & 1.6 & 4.1 \\
\hline & 1008 & 2.6 & 3.7 \\
\hline & 1106 & 2.5 & 3.1 \\
\hline & 1217 & 1.6 & 5.2 \\
\hline$=\operatorname{slope}(x, y) a=-0,0019$ & 1292 & 2.0 & 5.4 \\
\hline$=$ intercept $(x, y) b=4.1674$ & 1384 & 1.4 & -4.7 \\
\hline
\end{tabular}

$\operatorname{corr}(x, y)=-0.8394$

$\operatorname{corr}(x, y)^{2}=0.7045 \quad$ Note: Ground water elevations have been adjusted to fit the graph. $\mathrm{O} f \mathrm{t}=65.71 / 3 \mathrm{ft}$. No elevation data was available for the first three dates so 0 was input.

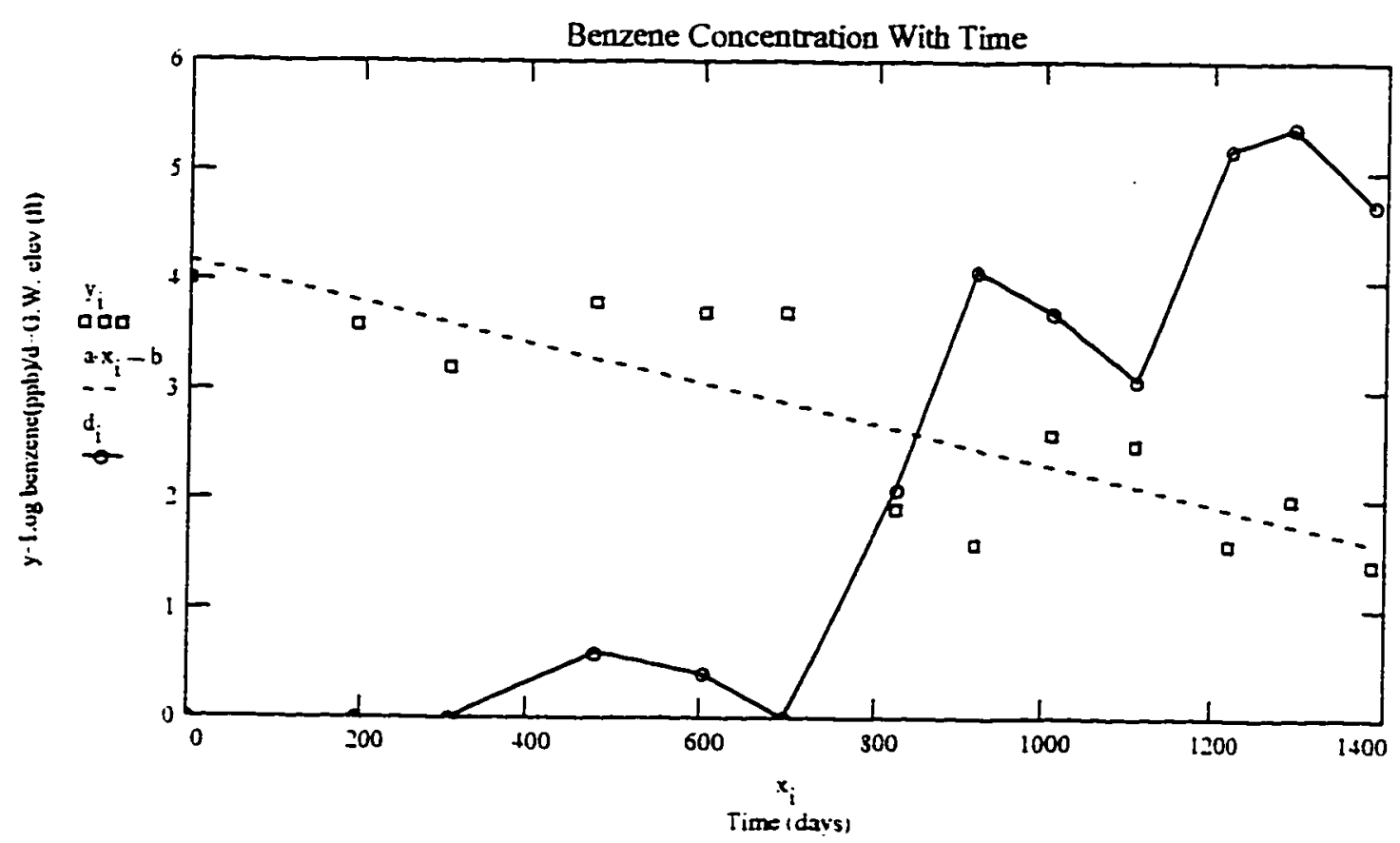


APPENDIX C. TABLE C-1 
Table C-1. Summary of calculated degradation rate constants, cortelations, and site conditions

\begin{tabular}{|c|c|c|c|c|c|c|c|c|c|c|c|c|}
\hline Uecounased & \multirow[b]{2}{*}{ Welli. } & \multirow[b]{2}{*}{$\begin{array}{l}\text { Remed } \\
\text { nonoes- }\end{array}$} & & \multirow[b]{2}{*}{$R \operatorname{Rng}(n)$} & \multirow[b]{2}{*}{ Distruce (n) } & \multirow[b]{2}{*}{ 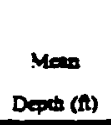 } & \multirow{2}{*}{ 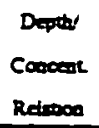 } & \multirow[b]{2}{*}{$\begin{array}{l}\text { TPH ges } \\
\text { Rute (Ld) }\end{array}$} & \multirow[b]{2}{*}{$\begin{array}{l}\text { IPHers } \\
\text { Const }\end{array}$} & \multirow{2}{*}{$\begin{array}{l}\text { Depety } \\
\text { Coecent } \\
\text { Redrioos }\end{array}$} & \multirow[b]{2}{*}{$\begin{array}{l}\text { Bearode } \\
\text { Rese (I/d) }\end{array}$} & \multirow[b]{2}{*}{$\begin{array}{l}\text { Benzede } \\
\text { Cancel }\end{array}$} \\
\hline Sar. & & & $\begin{array}{l}\text { Aeurfe } \\
\text { Type }\end{array}$ & & & & & & & & & \\
\hline OTSIWITEOI & $M W-12$ & phsve & sc & 25 & 0 & 583 & $\boldsymbol{\gamma}$ & 200031 & 0.36 & $v$ & & \\
\hline otsiw3mol & MW & Dose & Guec & 7 & 4 & $i 3.5$ & $N$ & -0.0018 & 0.57 & $\mathbf{s}$ & -0.018 & 0.57 \\
\hline \multirow[t]{3}{*}{ OTSIWZTFOI } & $M W-1$ & swe & SM & $1<2$ & 35 & m & $\mathbf{v}$ & 0.016 & 0.82 & $\mathbf{N}$ & -0.006 & $0.9 x$ \\
\hline & MW-3 & sve & SM & n & is & NA & $\mathbf{x}$ & 0.0028 & $a \pi$ & $\mathbf{Y}$ & -0.0028 & 0.54 \\
\hline & 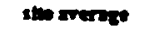 & sve & SM & 126 & & & & 00004 & 0.77 & & -0.002 & 0.74 \\
\hline 205S1W05FOI & MW-2 & soose & $\mathbf{S M}$ & 0.4 & 7 & SA & $\mathbf{N}$ & -0.0061 & 0.99 & $\mathbf{N}$ & -0.0065 & 0.86 \\
\hline OTSIOJSPOI & MW-1 & Dooe & $5 w$ & 4.5 & 5 & $\mathrm{NA}$ & $\mathbf{N}$ & -0.0025 & 0.7 & $\mathrm{~N}$ & 0.00057 & 0.05 \\
\hline 07SIW3580 & E-11 & as se & $S M$ & 30.7 & 0 & NA & $\mathbf{N}$ & -0.000 & 0.76 & $\mathrm{~N}$ & -0.000 & 0.81 \\
\hline 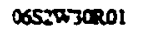 & Les & oose & $\mathbf{S M}$ & 19.9 & 75 & NA & $\boldsymbol{N}$ & -0.0058 & 0.98 & $\mathrm{~s}$ & -0.0056 & 0.65 \\
\hline \multirow[t]{4}{*}{ 0652W19AOII } & A-1 & res ine & $\operatorname{scsin}$ & 7.7 & 35 & 20.8 & $s$ & 0.0045 & 0.86 & & & \\
\hline & A-2 & Phise & SCISM & 7.9 & 3 & 385 & $\mathbf{s}$ & 0.0031 & 0.67 & & & \\
\hline & $A-3$ & ph sve & SCSSM & 112 & 100 & 023 & $\mathbf{s}$ & $0.00 \mathrm{er}$ & 0.75 & & & \\
\hline & sta merate & prise & SCISM & 20333333 & & & & -0.004 & 0.76 & & & \\
\hline 205101900; & $M W-1$ & soose & SM & 3.9 & 50 & 50.2 & & & & & & \\
\hline \multirow[t]{3}{*}{ CesiHzLDOI } & Mw-C & boo & $\operatorname{sess}$ & 6.8 & is & 14 & $\mathbf{Y}$ & -0.00013 & 0.015 & $\mathrm{~N}$ & -0.00059 & 0.45 \\
\hline & MWF & bio & $\operatorname{scs} M$ & 22 & 75 & 14.8 & $\mathbf{Y}$ & -0.00051 & 0.14 & $\mathbf{Y}$ & $-a 0000$ & 0.15 \\
\hline & sthe iverase & bio & $\operatorname{scs} M$ & 4.5 & & ins & & 0.0003 & 0.0775 & & 0.0006 & 0.3 \\
\hline ansiwizol & c-s & noose & GC & 29 & $\leq$ & 182 & $\mathbf{Y}$ & -0.0028 & 0.24 & & & \\
\hline \multirow[t]{3}{*}{ assidianox } & MW-S & sve & SMGCC & 22 & 3 & 172 & $\mathbf{Y}$ & -0.0015 & 0.15 & $\mathbf{N}$ & -0.0021 & 0.33 \\
\hline & MW- & sve & SMEC & 44 & 125 & 14.9 & $\mathbf{Y}$ & 0.000006 & 0.0024 & $\mathbf{Y}$ & -0.00011 & 0.002 \\
\hline & the merse & swe & SAuGC & 13 & & 2605 & & 00000 & 0.0762 & & -0.001 & 0.1661 \\
\hline DesiR:21E02 & $m-2$ & $\alpha$ & SM & 3.6 & 60 & 16.7 & & & & & & \\
\hline CASIWIENOB & s-3 & bian ine & $G C$ & 6.9 & 10 & is.s & $\mathbf{Y}$ & 0.003 & 0.73 & $Y$ & 0.0034 & 0.57 \\
\hline $0652 k 26+102$ & MW-1 & sone & $S M$ & & 15 & & & -0.00093 & 0.7 & & 0.0012 & on \\
\hline ossjwosdos & $5-2$ & ive & SCISM & 55 & 10 & ws & $y$ & -0.0036 & 049 & $Y$ & -0.0036 & 076 \\
\hline OSSTWOTCOI & Mva-6 & $\alpha p t$ & $\mathbf{S P}$ & 3.5 & 10 & 06 & $\mathbf{x}$ & -0.0023 & 0.95 & & & \\
\hline
\end{tabular}


Table C-1. Summary of calculated degradarion rate constants, correlations, and site conditions (continued)

\begin{tabular}{|c|c|c|c|c|c|c|c|c|c|c|c|c|}
\hline \multicolumn{2}{|c|}{ Oecourled (costhend) } & \multirow[b]{2}{*}{$\begin{array}{c}\text { Reoded- } \\
\text { nod }\end{array}$} & \multirow[b]{2}{*}{$\begin{array}{l}\text { Aquiner } \\
\text { Type }\end{array}$} & \multirow[b]{2}{*}{$R \operatorname{mex}(\Omega)$} & \multirow[b]{2}{*}{ Diruace (n) } & \multicolumn{3}{|c|}{ Depth } & \multicolumn{3}{|c|}{ Depthy } & \multirow[b]{2}{*}{$\begin{array}{l}\text { Beacene } \\
\text { Contel }\end{array}$} \\
\hline Sare tio. & Weil No & & & & & $\begin{array}{c}M=\infty \\
D e p e(2)\end{array}$ & $\begin{array}{l}\text { Cosecor } \\
\text { Reinoces }\end{array}$ & $\begin{array}{c}\text { TPH ges } \\
\text { Rue (Ld) }\end{array}$ & $\begin{array}{l}\text { IPH an } \\
\text { Cond }\end{array}$ & $\begin{array}{l}\text { Cosonest } \\
\text { Retemese }\end{array}$ & $\begin{array}{l}\text { Benzene } \\
\text { Rure (Vd) }\end{array}$ & \\
\hline \multirow[t]{3}{*}{ asszwonnol } & $5-3$ & Des se bo & sc & L.S & 5 & 7 & $\mathbf{Y}$ & -0.0021 & $2 \pi 3$ & & & \\
\hline & su & ph we bo bo & sc & 1.4 & 5 & 63 & $\mathbf{N}$ & 0.00005 & $0 . \pi$ & $\mathbf{Y}$ & -0.00099 & 0.14 \\
\hline & Whe werase & Me sve bio & sc & 14 & & cas & & 0.0015 & 0.725 & & 0.001 & 0.14 \\
\hline \multirow[t]{3}{*}{ Cosswlyes } & $\mathbf{n W - 7}$ & $\boldsymbol{p}$ & sc & 3.5 & 90 & 3 & $\mathbf{N}$ & 0.0015 & 0.85 & $N$ & -0.0023 & 0.80 \\
\hline & MW-11 & $x$ & sc & 32 & 25 & 2 & $\mathbf{N}$ & $-0,003$ & 0.96 & $N$ & -20016 & 0.58 \\
\hline & stes eversese & $p$ & sc & 3.35 & & 2065 & & -0.0023 & ases & & 0,002 & 0.73 \\
\hline \multirow[t]{3}{*}{ assewiteces } & $A-3$ & $p$ & unirown & 1.6 & 5 & 7.5 & $\mathbf{N}$ & -0.002 & 0.76 & $\mathbf{x}$ & $-0,00 \mathrm{~m}$ & 0.98 \\
\hline & A-6 & $x$ & & 32 & 76 & $\mathbf{s . 1}$ & $\mathbf{Y}$ & -0.0003 & 0.73 & $\boldsymbol{N}$ & $-0,000$ & 2.85 \\
\hline & stio merase & pr & untrowar & 24 & & .8 & & 0.0022 & 0.745 & & 0.003 & 0.915 \\
\hline \multirow[t]{3}{*}{ osszworcen } & $\mathbf{M W}-\mathbf{A}$ & pt & GC & 3.4 & $s$ & 11.3 & $\mathbf{Y}$ & -0.0017 & 0.33 & $\mathbf{Y}$ & -00017 & 0.45 \\
\hline & MW-S & $\boldsymbol{x}$ & GC & 23 & 90 & 99 & $\mathbf{Y}$ & -0.0012 & 0.38 & $Y$ & 2,00002 & 0.05 \\
\hline & ino morate & $\mathbf{p}$ & $G C$ & 285 & & 106 & & 0.0015 & 0.355 & & -0.001 & 0.25 \\
\hline OTSIWLSAOI & Mow-s & $\alpha$ & $G P$ & 0.4 & s & 24.6 & $x$ & -0.0013 & 0.34 & $\mathbf{x}$ & -0.0023 & 0.73 \\
\hline \multirow[t]{3}{*}{065203601} & $A-2$ & prove & sc & 7 & 25 & 76 & $\mathbf{x}$ & -0.00000 & 0.008 & $\mathbf{N}$ & -0.0009 & 0.8 \\
\hline & $A-j$ & prsve & sc & 7.1 & 10 & $\pi$ & $\mathbf{N}$ & -0.003 & a.s & $\mathbf{N}$ & -0.003 & 0.78 \\
\hline & sthe merate & pts sve & sc & 17.05 & & $\pi$ & & 0.0015 & 0.379 & & -0.002 & 0.79 \\
\hline
\end{tabular}


Table C-1. Summary of calculated degradation rate constants, correlations, and site corditions (continued)

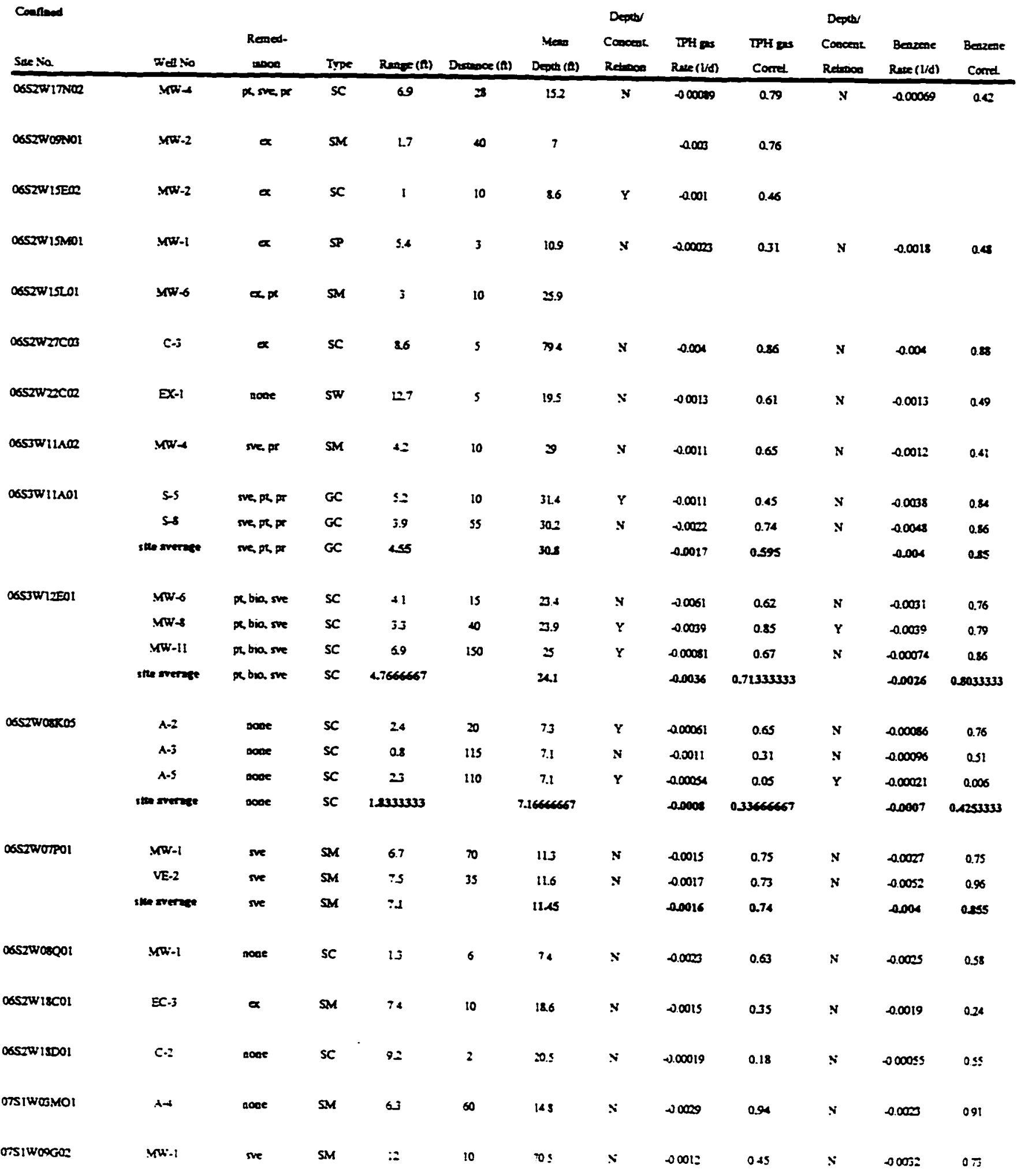


Table C-1. Summary of calculated degradation rate constants. correlations. and site conditions (continued)

\begin{tabular}{|c|c|c|c|c|c|c|c|c|c|c|c|c|}
\hline \multicolumn{2}{|c|}{ Conoued (contand) } & \multirow[b]{2}{*}{$\begin{array}{l}\text { Remed } \\
\text { nos }\end{array}$} & \multirow[b]{2}{*}{ Type } & \multirow[b]{2}{*}{$\operatorname{Ren}=(A)$} & \multirow[b]{2}{*}{ Didenoe (A) } & \multicolumn{3}{|c|}{ Deph } & \multicolumn{3}{|c|}{ Depter } & \multirow[b]{2}{*}{$\begin{array}{l}\text { Benone } \\
\text { Const }\end{array}$} \\
\hline Sine Nia. & WellNo. & & & & & $\begin{array}{c}\text { Men } \\
\text { Deph (a) }\end{array}$ & $\begin{array}{l}\text { Cosocent. } \\
\text { Resoce }\end{array}$ & $\begin{array}{c}\text { IPH gs } \\
\text { Rore(I/d) }\end{array}$ & $\begin{array}{l}\text { PPH pos } \\
\text { Cond }\end{array}$ & $\begin{array}{l}\text { Conceos } \\
\text { Relmion }\end{array}$ & $\begin{array}{l}\text { Benzene } \\
\text { Rese (V/d) }\end{array}$ & \\
\hline 075I woscol & EA- & $\alpha$ & $\mathbf{S P}$ & 11 & 5 & 17.5 & $v$ & -0.0006 & 0.73 & $\mathbf{N}$ & -20027 & 0.75 \\
\hline 0651\%35F01 & $\mathbf{M W - 1}$ & px & SM & 25 & 10 & 103 & $\mathbf{x}$ & -0.0000 & 0.15 & $\mathbf{N}$ & $-0,000 s 9$ & 0.93 \\
\hline O7sIWISFoI & MW-S & Phisve & $5 M$ & .6 & 180 & 364 & $x$ & -0.0018 & 0.99 & $\mathbf{N}$ & -0.0005 & 0.95 \\
\hline \multirow[t]{3}{*}{ OTSIwOsxot } & MW-S & $\alpha$ & $G W$ & 8.6 & 25 & 30.9 & $\mathbf{N}$ & -0.0034 & 0.2 & $\mathbf{N}$ & -0.0013 & 0.2 \\
\hline & $\mathbf{M W}-6$ & $\alpha$ & GW & 8 & so & 353 & $\mathbf{N}$ & -0.004 & 0.92 & $\mathbf{N}$ & -20041 & 0.89 \\
\hline & Itee mesces & $a$ & GW & 23 & & 33.1 & & 0.0037 & 0.87 & & 00004 & 0.205 \\
\hline Orsiwitices & EA-6 & sve & sc & 10 & 20 & $\$ 1.8$ & $x$ & -0.0018 & 0.42 & $\mathbf{x}$ & -0.002 & 0.56 \\
\hline \multirow[t]{3}{*}{ ossiw2sol } & $\mathbf{M W - 1}$ & $\alpha p$ & sw & $=2$ & 0 & 125 & $\mathbf{N}$ & 0.00082 & $a=2$ & $\boldsymbol{x}$ & -0.000 & 0.56 \\
\hline & MW-2 & $\alpha, p t$ & sw & 21 & 25 & 126 & $x$ & 0.0012 & 0.43 & $\mathrm{~N}$ & -0.0036 & 079 \\
\hline & sthe swerase & $\alpha_{p t}$ & sw & 215 & & 1255 & & -0.001 & 0.35 & & 0.003 & 0.675 \\
\hline \multirow[t]{3}{*}{ onsiwesk00 } & MWST-I & $a$ & $\mathbf{S M}$ & $\$ 2$ & is & 19 & $\mathbf{x}$ & -0.0011 & 0.35 & $\mathbf{N}$ & 0.00058 & 0.15 \\
\hline & MW.-S & $\alpha$ & SM & 1.8 & 30 & is & $\mathbf{x}$ & -0.0007 & 0.96 & $\mathbf{N}$ & 0.000 & 0.76 \\
\hline & the werase & $x$ & SM & 3 & & tos & & 00019 & 0.655 & & 0.001 & 0.458 \\
\hline \multirow[t]{3}{*}{ Ossiwaskos } & $\mathbf{M W}-1$ & $\alpha$ & sc & 3.7 & 2 & 10.4 & $\dot{x}$ & -0.0005 & 0.83 & & & \\
\hline & nWw-3 & $\alpha$ & sc & is & 15 & 10.1 & $x$ & -0.00000 & 0.8 & & & \\
\hline & stheremese & $a$ & sc & 36. & & 1025 & & -00017 & osts & & & \\
\hline \multirow[t]{3}{*}{ ossiw32Col } & MW-2 & pts sve & $\mathbf{S P}$ & 7.8 & 22 & 20.4 & $\mathbf{x}$ & -0.003 & 0.88 & $\mathbf{N}$ & -0.003 & 0.72 \\
\hline & MW $-\mathbf{A}$ & prove & $\mathbf{S P}$ & $s$ & 15 & 127 & $\mathbf{x}$ & 0.001 & 0.82 & $\mathrm{~N}$ & -0.000 & 0.82 \\
\hline & stop morate & Ph sue & $\mathbf{S P}$ & 64 & & 16.55 & & 0.0035 & 0.25 & & -0004 & 0.7 \\
\hline \multirow[t]{3}{*}{ otsiweryot } & Mot & soose & $\mathbf{S P}$ & 197 & 2 & 15.5 & $\mathbf{N}$ & -0.001 & 0.86 & $\mathbf{N}$ & $-\infty, \infty$ & 0.67 \\
\hline & $\mathbf{M w - 2}$ & cose & $\mathbf{S P}$ & 29.1 & 30 & 14 & $\mathbf{N}$ & 0.002 & 0.66 & $\mathbf{N}$ & -0.000 & 0.80 \\
\hline & 2llo surease & ocoe & $\mathbf{S P}$ & 241 & & 14.15 & & anois & 0.76 & & $-0,002$ & 0.75 \\
\hline 07siwoscol & $\mathbf{M W H}$ & perbo & ML & & & & $\mathbf{x}$ & -0.002 & 0.74 & & & \\
\hline 06sidiatol & $M O H-1$ & serax $x$ & sc & & 20 & & $\mathbf{v}$ & a)ol & 0.75 & $x$ & 0,000 & 0.63 \\
\hline osinsicol & $\mathbf{M w}-1$ & sooe & $\mathrm{Cl}$ & il & 5 & 21.7 & $\mathbf{v}$ & -0.002 & 0.93 & $\mathbf{N}$ & $-0,003$ & 0.79 \\
\hline C6S:W3SBO1 & Now-s & sve, pt & sw & 3 & 3 & 80 & $s$ & -0.001 & 0.81 & $\mathbf{N}$ & -0.002 & 0.93 \\
\hline $06510,32 E 01$ & $v+x_{-i}$ & Done & sc & 69 & 8 & $=$ & $\mathbf{Y}$ & 0002 & 053 & $\mathbf{Y}$ & $-000 x$ & 06 \\
\hline$x$ stu-acot & OPA & se ph pre bio & SP & $\because z$ & $:$ & $1:$ & $x$ & $-0 \infty 15$ & 0.38 & $\mathbf{N}$ & $-\infty \cos 1$ & $0 \pi$ \\
\hline
\end{tabular}


Table A-1. Summary of Calculated Degradation Rates. Correlations, and Site Conditions (continued)

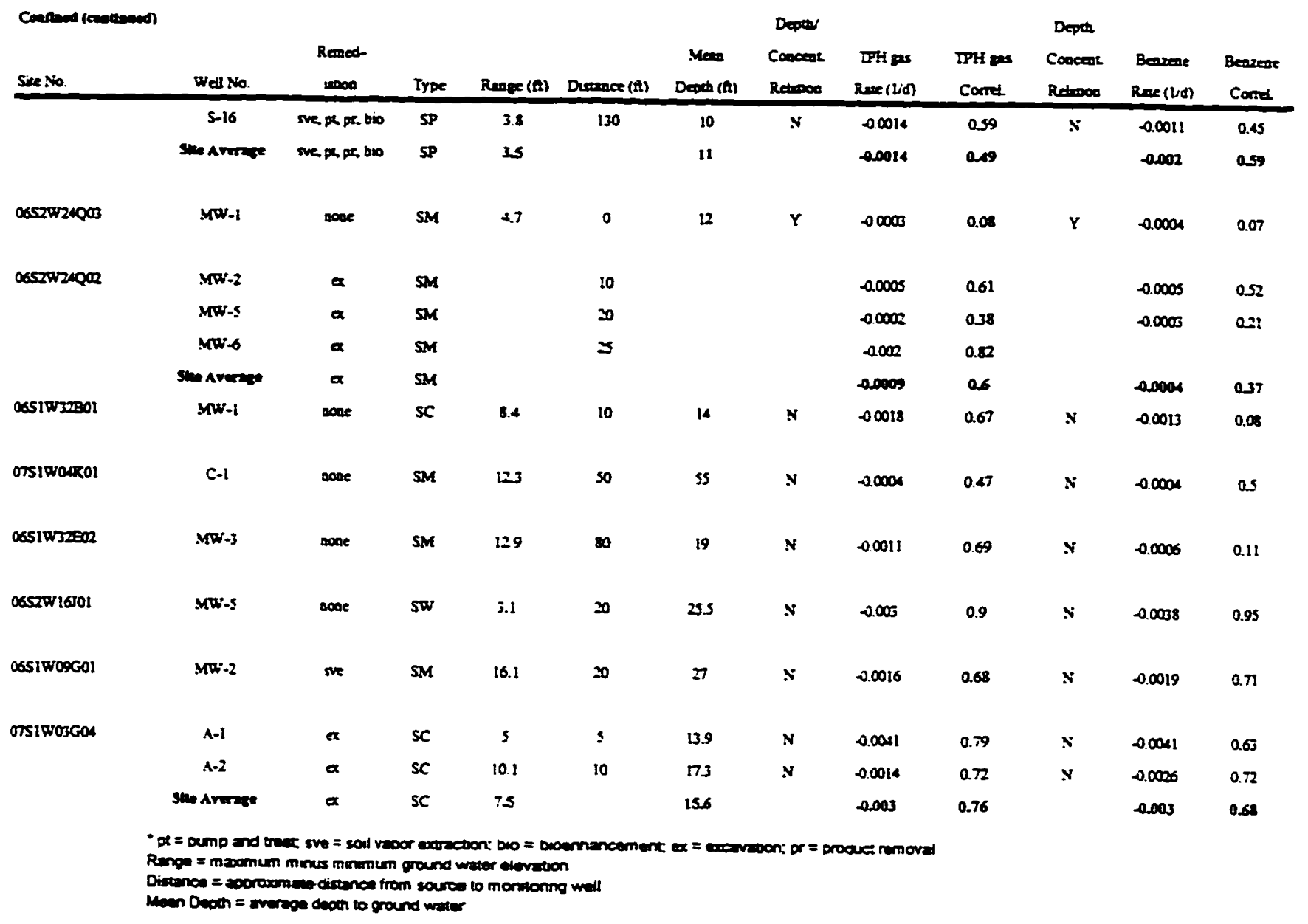

